NREL/TP-550-36754

\title{
International Energy Agency Building Energy Simulation Test and Diagnostic Method for Heating, Ventilating, and Air-Conditioning Equipment Models (HVAC BESTEST)
}

\section{Volume 2: Cases E300-E545}

\author{
J. Neymark \\ J. Neymark \& Associates, Golden, Colorado \\ R. Judkoff \\ National Renewable Energy Laboratory, Golden, Colorado
}

\section{Zipped CD Files}

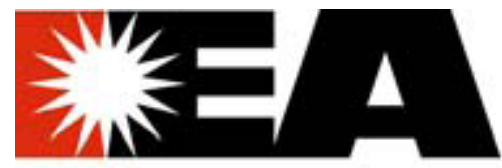

INTERNATIONAL ENERGYAGENCY Solar Heating \& Cooling Programme

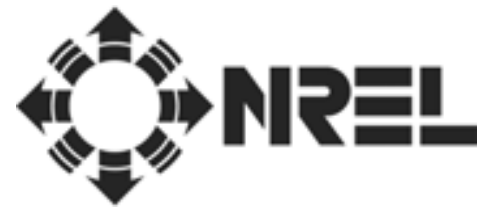

National Renewable Energy Laboratory 1617 Cole Boulevard Golden, Colorado 80401-3393 


\title{
International Energy Agency Building Energy Simulation Test and Diagnostic Method for Heating, Ventilating, and Air-Conditioning Equipment Models (HVAC BESTEST)
}

\section{Volume 2: Cases E300-E545}

\author{
J. Neymark \\ J. Neymark \& Associates, Golden, Colorado
}

R. Judkoff

National Renewable Energy Laboratory, Golden, Colorado

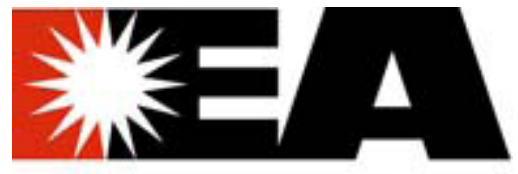

INTERNATIONAL ENERGYAGENCY Solar Heating \& Cooling Programme

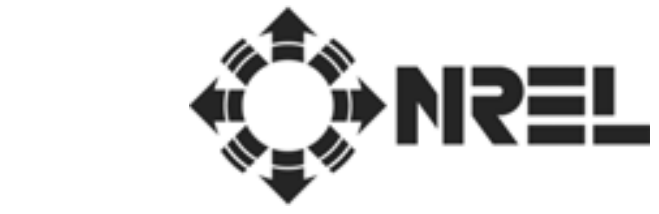

National Renewable Energy Laboratory 1617 Cole Boulevard Golden, Colorado 80401-3393 


\section{NOTICE}

This report was prepared as an account of work sponsored by an agency of the United States government. Neither the United States government nor any agency thereof, nor any of their employees, makes any warranty, express or implied, or assumes any legal liability or responsibility for the accuracy, completeness, or usefulness of any information, apparatus, product, or process disclosed, or represents that its use would not infringe privately owned rights. Reference herein to any specific commercial product, process, or service by trade name, trademark, manufacturer, or otherwise does not necessarily constitute or imply its endorsement, recommendation, or favoring by the United States government or any agency thereof. The views and opinions of authors expressed herein do not necessarily state or reflect those of the United States government or any agency thereof.

Available electronically at http://www.osti.gov/bridge and http://www.iea-shc/task22

Available for a processing fee to U.S. Department of Energy and its contractors, in paper, from:

U.S. Department of Energy

Office of Scientific and Technical Information

P.O. Box 62

Oak Ridge, TN 37831-0062

phone: 865.576 .8401

fax: 865.576 .5728

email: mailto:reports@adonis.osti.gov

Available for sale to the public, in paper, from:

U.S. Department of Commerce

National Technical Information Service

5285 Port Royal Road

Springfield, VA 22161

phone: 800.553 .6847

fax: 703.605 .6900

email: orders@ntis.fedworld.gov

online ordering: http://www.ntis.gov/ordering.htm

Printed on paper containing at least $50 \%$ wastepaper, including $20 \%$ postconsumer waste 


\section{Acknowledgments}

The work described in this report was a cooperative effort involving the members of the International Energy Agency (IEA) Model Evaluation and Improvement Experts Group. The group was composed of experts from the IEA Solar Heating and Cooling (SHC) Programme, Task 22, and was chaired by R. Judkoff of the National Renewable Energy Laboratory (NREL) on behalf of the U.S. Department of Energy (DOE). We gratefully acknowledge the contributions from the modelers and the authors of sections on each of the computer programs used in this effort:

- CODYRUN: T. Mara, E. Fock, and F. Garde; University of Reunion Island, France

- ENERGYPLUS: R. Henninger and M. Witte; GARD Analytics, United States

- HOT3000: K. Haddad; CANMET Energy Technology Centre, Canada

- TRNSYS-TUD 14.2: H.-T. Le and G. Knabe; Technische Universität Dresden, Germany.

For assistance with our work with DOE-2.1E ESTSC (Energy Science and Technology Software Center, Oak Ridge National Laboratory, United States) version and DOE-2.2, we wish to thank F. Buhl of Lawrence Berkeley National Laboratory, United States, and J. Hirsch of James J. Hirsch \& Associates, United States, respectively.

D. Barkley and J. Pegues of Carrier Corporation, United States, were very helpful with providing performance data for, and answering questions about, commercial air-cooled split-system space cooling equipment.

We appreciate the support and guidance of M. Holtz, operating agent for Task 22; and D. Crawley, DOE program manager for Task 22 and DOE representative to the IEA SHC Programme Executive Committee. 


\section{PREFACE}

\section{INTRODUCTION TO THE INTERNATIONAL ENERGY AGENCY}

\section{BACKGROUND}

The International Energy Agency (IEA) was established in 1974 as an autonomous agency within the framework of the Economic Cooperation and Development (OECD) to carry out a comprehensive program of energy cooperation among its 24 member countries and the Commission of the European Communities.

An important part of the Agency's program involves collaboration in the research, development, and demonstration of new energy technologies to reduce excessive reliance on imported oil, increase long-term energy security, and reduce greenhouse gas emissions. The IEA's R\&D activities are headed by the Committee on Energy Research and Technology (CERT) and supported by a small Secretariat staff, headquartered in Paris. In addition, three Working Parties are charged with monitoring the various collaborative energy agreements, identifying new areas for cooperation, and advising the CERT on policy matters.

Collaborative programs in the various energy technology areas are conducted under Implementing Agreements, which are signed by contracting parties (government agencies or entities designated by them). There are currently 40 Implementing Agreements covering fossil fuel technologies, renewable energy technologies, efficient energy end-use technologies, nuclear fusion science and technology, and energy technology information centers.

\section{SOLAR HEATING AND COOLING PROGRAMME}

The Solar Heating and Cooling Programme was one of the first IEA Implementing Agreements to be established. Since 1977, its 20 members have been collaborating to advance active solar, passive solar, and photovoltaic technologies and their application in buildings.

The members are:

\begin{tabular}{|l|l|l|}
\hline Australia & France & Portugal \\
\hline Austria & Germany & Spain \\
\hline Belgium & Italy & Sweden \\
\hline Canada & Mexico & Switzerland \\
\hline Denmark & Netherlands & United Kingdom \\
\hline European Commission & New Zealand & United States \\
\hline Finland & Norway & \\
\hline
\end{tabular}

A total of 34 Tasks have been initiated, 25 of which have been completed. Each Task is managed by an Operating Agent from one of the participating countries. Overall control of the program rests with an Executive Committee comprised of one representative from each contracting party to the Implementing Agreement. In addition, a number of special ad hoc activities - working groups, conferences, and workshops - have been organized. 
The Tasks of the IEA Solar Heating and Cooling Programme, both completed and current, are as follows:

\section{Completed Tasks:}

\begin{tabular}{|l|l|}
\hline Task 1 & Investigation of the Performance of Solar Heating and Cooling Systems \\
\hline Task 2 & Coordination of Solar Heating and Cooling R\&D \\
\hline Task 3 & Performance Testing of Solar Collectors \\
\hline Task 4 & Development of an Insolation Handbook and Instrument Package \\
\hline Task 5 & Use of Existing Meteorological Information for Solar Energy Application \\
\hline Task 6 & Performance of Solar Systems Using Evacuated Collectors \\
\hline Task 7 & Central Solar Heating Plants with Seasonal Storage \\
\hline Task 8 & Passive and Hybrid Solar Low Energy Buildings \\
\hline Task 9 & Solar Radiation and Pyranometry Studies \\
\hline Task 10 & Solar Materials R\&D \\
\hline Task 11 & Passive and Hybrid Solar Commercial Buildings \\
\hline Task 12 & Building Energy Analysis and Design Tools for Solar Applications \\
\hline Task 13 & Advanced Solar Low Energy Buildings \\
\hline Task 14 & Advanced Active Solar Energy Systems \\
\hline Task 16 & Photovoltaics in Buildings \\
\hline Task 17 & Measuring and Modeling Spectral Radiation \\
\hline Task 18 & $\begin{array}{l}\text { Advanced Glazing and Associated Materials for Solar and Building } \\
\text { Applications }\end{array}$ \\
\hline Task 19 & Solar Air Systems \\
\hline Task 20 & Solar Energy in Building Renovation \\
\hline Task 21 & Daylight in Buildings \\
\hline Task 22 & Building Energy Analysis Tools \\
\hline Task 23 & Optimization of Solar Energy Use in Large Buildings \\
\hline Task 24 & Solar Procurement \\
\hline Task 26 & Solar Combisystems Working Group Materials in Solar Thermal Collectors \\
\hline Task 30 & Solar Cities - not initiated \\
\hline
\end{tabular}

\section{Current Tasks:}

\begin{tabular}{|l|l|}
\hline Task 25 & Solar Assisted Cooling Systems for Air Conditioning of Buildings \\
\hline Task 27 & Performance Assessment of Solar Building Envelope Components \\
\hline Task 28 & Solar Sustainable Housing \\
\hline Task 29 & Solar Crop Drying \\
\hline Task 31 & Daylight Buildings in the 21st Century \\
\hline Task 32 & $\begin{array}{l}\text { Advanced Storage Concepts for Solar Thermal Systems in Low Energy } \\
\text { Buildings }\end{array}$ \\
\hline Task 33 & Solar Heat for Industrial Processes \\
\hline Task 34 & Testing and Validation of Building Energy Simulation Tools \\
\hline Task 35 & PV/Thermal Systems \\
\hline
\end{tabular}




\section{TASK 22: BUILDING ENERGY ANALYSIS TOOLS}

\section{Goal and Objectives of the Task}

The overall goal of Task 22 was to establish a sound technical basis for analyzing solar and low-energy buildings with available and emerging building energy analysis tools. This goal was pursued by accomplishing the following objectives:

- Assessing the accuracy of available and emerging building energy analysis tools in predicting the performance of widely used solar and low-energy concepts

- Collecting and documenting engineering models of widely used solar and low-energy concepts for use in the next-generation building energy analysis tools

- Assessing and documenting the impact (value) of improved building analysis tools in analyzing solar and low-energy buildings, and widely disseminate research results and tools to industry and government agencies.

\section{Scope of the Task}

This Task investigated the availability and accuracy of building energy analysis tools and engineering models to evaluate the performance of solar and low-energy buildings. The scope of the Task was limited to whole-building energy analysis tools (including emerging modular type tools), and to widely used solar and low-energy design concepts. Tool evaluation activities included analytical, comparative, and empirical methods, with emphasis given to blind empirical validation using measured data from test rooms of full-scale buildings. Documentation of engineering models used existing standard reporting formats and procedures. The impact of improved building energy analysis was assessed from a building-owner perspective.

The audience for the results of the Task is developers of building energy analysis tools and national organizations that develop building energy standards. However, tool users such as architects, engineers, energy consultants, product manufacturers, and building owners and managers, are the ultimate beneficiaries of the research, and will be informed through targeted reports and articles.

\section{Means}

To accomplish the stated goal and objectives, the Participants carried out research under the framework of four Subtasks:

Subtask A: Tool Evaluation

Subtask B: Model Documentation

Subtask C: Comparative Evaluation

Subtask D: Empirical Evaluation

\section{Participants}

The participants in the Task were Australia, Canada, Finland, France, Germany, Spain, Sweden, Switzerland, the United Kingdom, and the United States. The United States served as Operating Agent for this Task, with Michael J. Holtz of Architectural Energy Corporation providing Operating Agent services on behalf of the U.S. Department of Energy.

This report documents work carried out under Subtask C: Comparative Evaluation. 


\section{Table of Contents}

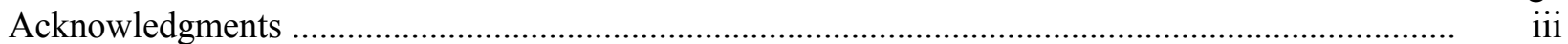

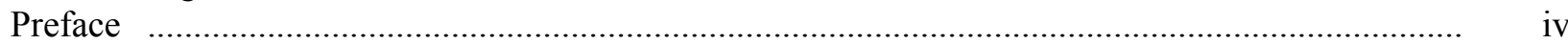

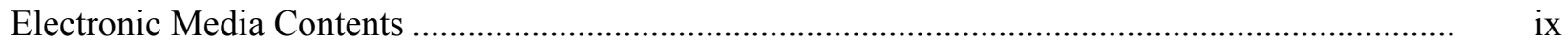

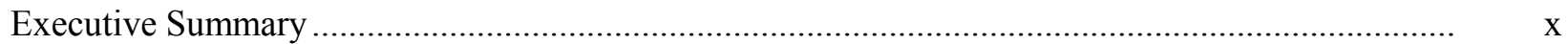

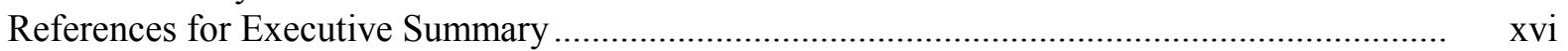

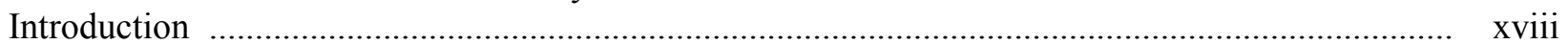

References for Introduction .............................................................................................

1.0 Part I: HVAC BESTEST User's Manual: Procedure and Specification - Cases E300 through E545 1

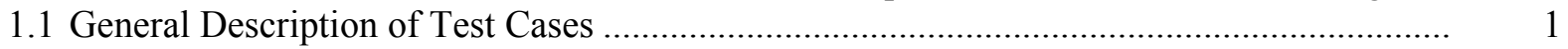

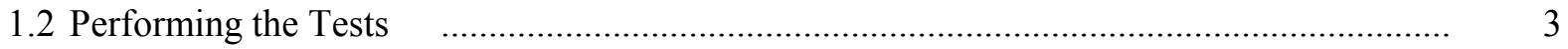

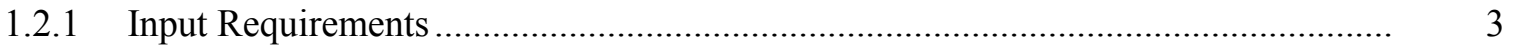

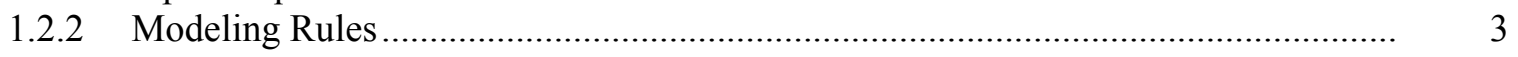

1.2.3 Comparing Your Output to the Example Simulation Results................................... 4

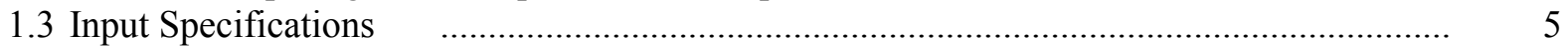

1.3.1 Case E300: Base Case....................................................................

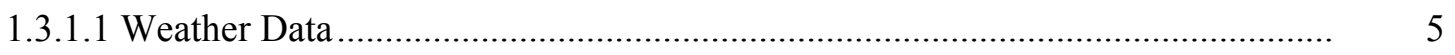

1.3.1.2 Output Requirements................................................................................ 6

1.3.1.3 Building Zone Description ....................................................................... 8

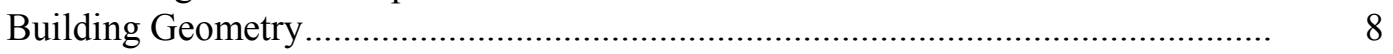

Building Envelope Thermal Properties................................................................. 9

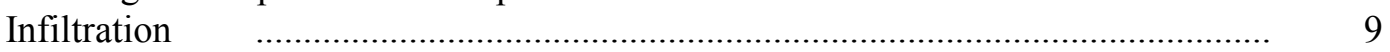

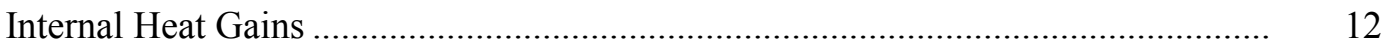

Opaque Surface Radiative Properties ................................................................ 13

Exterior Combined Radiative and Convective

Surface Coefficients............................................................................................. 13

Interior Combined Radiative and Convective

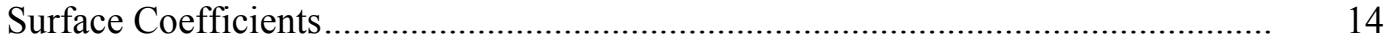

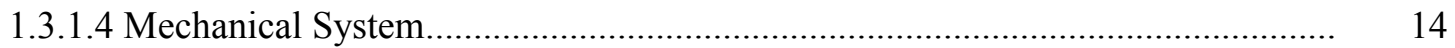

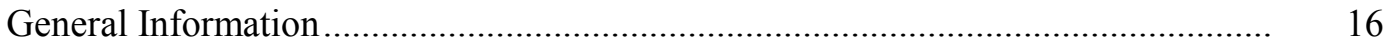

Thermostat Control Strategy ............................................................................. 16

Full-Load Cooling System Performance Data ......................................................... 16

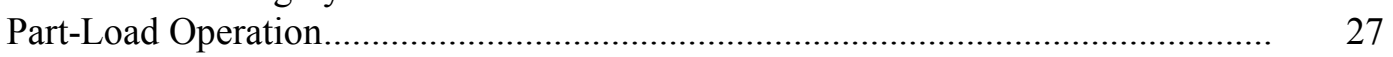

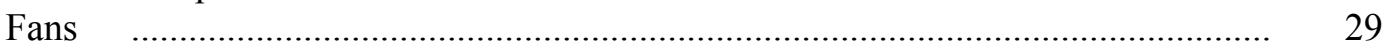

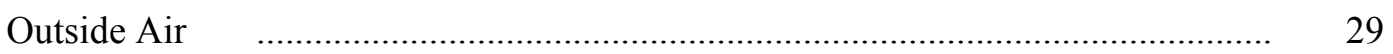

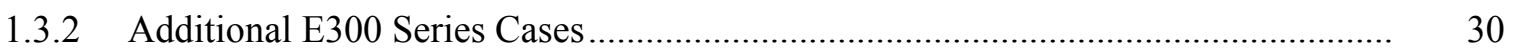

1.3.2.1 Case E310: High Latent Gains .................................................................... $\quad 30$

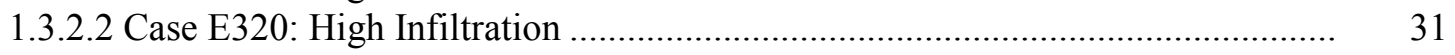

1.3.2.3 Case E330: High Outside Air .......................................................................... 31

1.3.2.4 Case E340: Infiltration and Outside Air Interaction ...................................... $\quad 32$

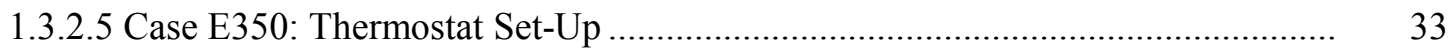

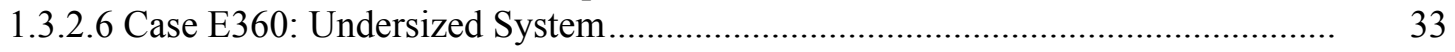

1.3.3 Economizer Series (E400 Series) Cases .................................................................... 35

1.3.3.1 Case E400: Economizer with ODB/IDB Control and Integrated Compressor Control …................................................................................ 35

1.3.3.2 Case E410: Economizer with ODB/IDB Control and Non-Integrated Compressor Control 
1.3.3.3 Case E420: Economizer with ODB Limit Control ........................................... 36

1.3.3.4 Case E430: Enthalpy Economizer with Integrated Compressor Control ............. 37

1.3.3.5 Case E440: Economizer with Enthalpy Limit Control....................................... 37

1.3.4 Cases with No Outside Air - Annual Simulation Context (E500 Series) ...................... 38

1.3.4.1 Case E500: Base Case for Scaling Annual Effect of ODB \& IDB ..................... $\quad 38$

1.3.4.2 Case E510: High Part-Load Ratio ...................................................................... 41

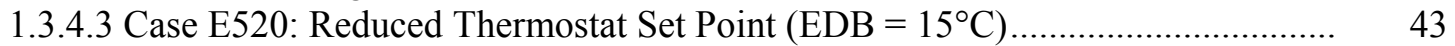

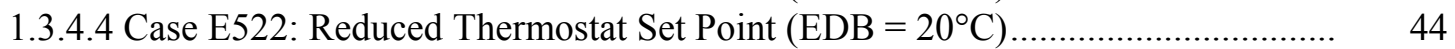

1.3.4.5 Case E525: Increased Thermostat Set Point (EDB Sensitivity) .......................... 44

1.3.4.6 Case E530: Dry Coil....................................................................................... 44

1.3.4.7 Case E540: Dry Coil Reduced Thermostat Set Point (EDB Sensitivity) .............. 45

1.3.4.8 Case E545: Dry Coil Increased Thermostat Set Point (EDB Sensitivity)............ $\quad 45$

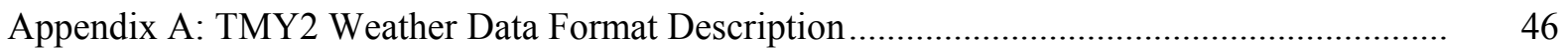

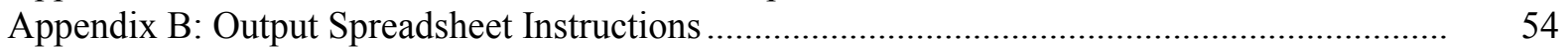

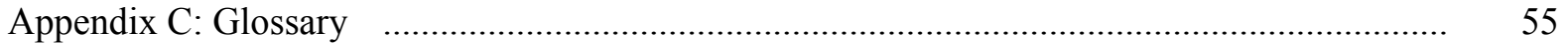

Appendix D: Calculation of Minimum Supply Air Temperature ….......................................... 58

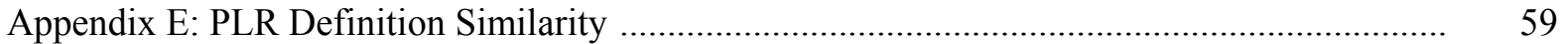

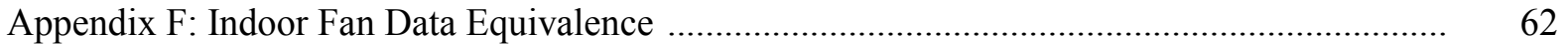

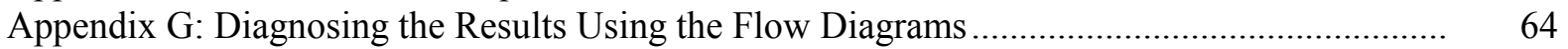

Appendix H: Abbreviations and Acronyms ............................................................................

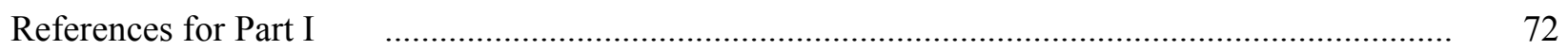

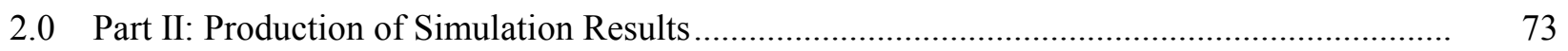

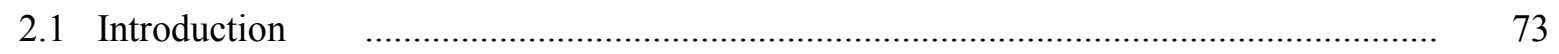

2.2 Selection of Simulation Programs and Modeling Rules for Simulations......................... 74

2.3 Improvements to the Test Specification as a Result of the Field Trials .......................... 74

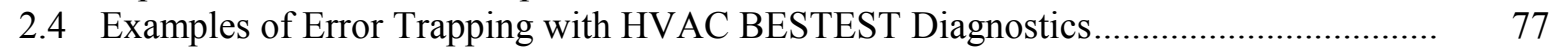

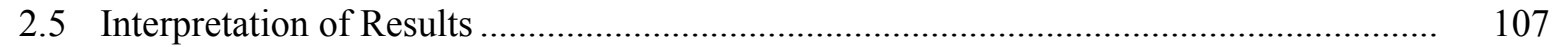

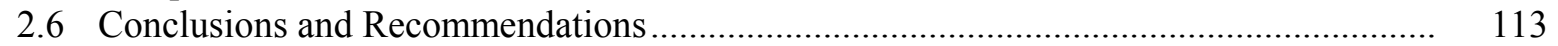

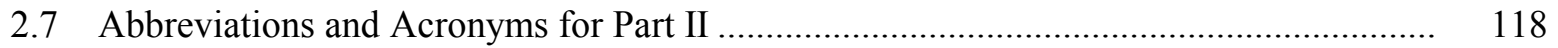

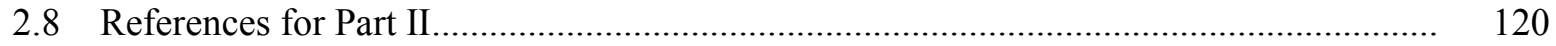

2.9 Appendix II: Simulation Modeler Reports ................................................................. 123

Appendix II-A: EnergyPlus, GARD Analytics, US................................................... 124

Appendix II-B: CODYRUN/LGIMAT, University of Reunion Island, France ............... 151

Appendix II-C: TRNSYS-TUD, Dresden University of Technology, Germany.............. 185

Appendix II-D: HOT3000, CANMET Energy Technology Centre, Canada .................... 194

Appendix II-E: DOE-2.1E ESTSC version, National Renewable Energy Laboratory, US 201

Appendix II-F: DOE-2.2 JJH version, National Renewable Energy Laboratory, US ...... 216

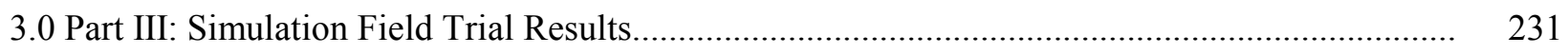

Graphs

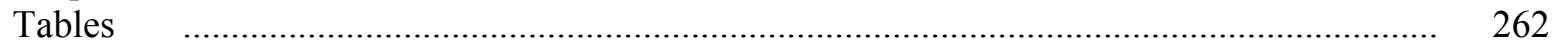




\section{Electronic Media Contents}

Files apply as they are called out in the test procedure.

README.DOC: Electronic media contents

NEW-ORL.TM2: TMY2 weather data for New Orleans, Louisiana, United States

E300MAP.XLS: Performance data (Tables 1-7a, 1-7b)

E300OUT2.XLS: Raw output data spreadsheet used by IEA participants

E300RESULTS.XLS: Results spreadsheet to assist users with plotting their results versus the example simulation results

E300RESULTS.DOC: Documentation for navigating E300RESULTS.XLS

INPDECKS subdirectory (IEA SHC Task 22 participant simulation input decks)

ICODYRUN

$\backslash$ DOE-2.1E ESTSC

IDOE2.2

\ENERGYPLUS

\HOT3000

ITRNSYS-TUD 


\section{Executive Summary}

This report is Volume 2 of the Building Energy Simulation Test for Heating, Ventilating, and AirConditioning Equipment Models (HVAC BESTEST Volume 2). Volume 2 represents an extension of the tests in HVAC BESTEST Volume 1. Volume 1 was limited to steady-state test cases that could be solved with analytical solutions. Volume 2 includes hourly dynamic effects, and other cases that cannot be solved analytically. This work was conducted by the National Renewable Energy Laboratory (NREL), United States in collaboration with the Tool Evaluation and Improvement Experts Group, under the International Energy Agency (IEA) Solar Heating and Cooling (SHC) Programme Task 22. Other tool evaluation projects conducted in Task 22, and reported elsewhere, included work on empirical validation, comparative testing, and analytical verification (see front matter Introduction of this report for a list of references).

\section{Background}

The overall objective of the tool evaluation subtask is to develop a comprehensive and integrated set of tests for quality assurance during development of building energy simulation computer programs. These tests can also be used to certify software used to demonstrate performance-based code compliance in energy standards. Energy simulation tools are essential for evaluating solar energy and advanced energy efficiency technologies that are not normally addressed in prescriptive building energy standards and codes. Greater confidence in the accuracy and validity of predictions from building energy analysis tools can be established by developing these tests.

The development of practical procedures and data for tool evaluation and improvement is part of an overall IEA validation methodology that $\mathrm{NREL}^{2,3}$ has been developing in collaboration with the IEA ${ }^{4,5}$ for many years. The methodology combines empirical validation, analytical verification, and comparative analysis techniques; this is discussed in detail in the Background section of HVAC BESTEST Volume $1 .{ }^{1}$

NREL originally developed the BESTEST method in IEA SHC Task 12 and Energy Conservation in Buildings and Community Systems (ECBCS) Annex 21 to test building thermal fabric (envelope) models, and to diagnose sources of predictive disagreements. ${ }^{6}$ This procedure was adopted with some refinements by the American Society of Heating, Refrigerating, and Air-Conditioning Engineers (ASHRAE) and the American National Standards Institute (ANSI), and now forms the basis for ANSI/ASHRAE Standard 140, Method of Test for the Evaluation of Building Energy Analysis Computer Programs. ${ }^{7}$ HVAC BESTEST extends the original BESTEST by adding the capability to test and diagnose mechanical system models. HVAC BESTEST Volume 1, cases E100-E200, are steady-state analytical verification tests that check the ability of simulation programs to apply basic performance map modeling techniques to simulation of unitary space cooling equipment on the working-fluid side of the cooling coil. These cases have been added to ANSI/ASHRAE Standard $140{ }^{8}$

This report documents an additional set of mechanical system test cases numbered E300-E545. These new cases, which are also planned for inclusion in ANSI/ASHRAE Standard 140, test a program's modeling capabilities on the working-fluid side of the coil, but in an hourly dynamic context over an expanded range of performance conditions. These cases help to scale the significance of disagreements that are less obvious in the steady-state cases. Cases E300-E440 also test the ability to model outside air mixing, infiltration, thermostat set up, overload conditions, and various economizer control schemes. The cases consist of a series of dynamic tests using a carefully specified mechanical cooling system applied to a highly simplified near-adiabatic building envelope. Because the mechanical equipment load is driven almost exclusively by sensible and latent internal gains, the response of the mechanical equipment 
models in simulation programs to a number of equipment performance parameters can be readily explored. Various output values - including energy consumptions, coil loads, and zone conditions - are compared and used in conjunction with a formal diagnostic method to determine the algorithms responsible for predictive differences.

\section{Results}

Field trials of the new HVAC BESTEST cases were conducted with a number of detailed state-of-the-art simulation programs from the United States and Europe as shown in Table ES-1. The process was iterative in that executing the simulations led to the refining of HVAC BESTEST, and the results of the tests led to improving and debugging the mechanical system models in the programs.

Table ES-1. Participating Organizations and Computer Programs

\begin{tabular}{||l|l|l||}
\hline Simulation Program & Authoring Organization & Implemented by \\
\hline \hline CODYRUN/LGIMAT & Université de la Reunion Island, France & $\begin{array}{l}\text { Université de la Reunion Island, } \\
\text { France }\end{array}$ \\
\hline DOE-2.1E-ESTSC version & LANL/LBNL/ESTSC/JJH, ${ }^{\text {a,b,c,d } \text { United States }}$ & NREL/JNA, ${ }^{\text {e United States }}$ \\
\hline DOE-2.2 NT & LBNL/JJH, ${ }^{\text {b,d } \text { United States }}$ & NREL/JNA, ${ }^{\text {e United States }}$ \\
\hline ENERGYPLUS & $\begin{array}{l}\text { LBNL/UIUC/CERL/OSU/GARD } \\
\text { Analytics/FSEC/DOE-BT, },{ }^{,, g, h, i, j} \text { United States }\end{array}$ & GARD Analytics, United States \\
\hline HOT3000 & CETC/ESRU, ${ }^{k, l}$ Canada/United Kingdom & CETC, ${ }^{k}$ Canada \\
\hline $\begin{array}{l}\text { TRNSYS 14.2-TUD } \\
\text { with real controller model }\end{array}$ & $\begin{array}{l}\text { University of Wisconsin, United States; } \\
\text { Technische Universität Dresden, Germany }\end{array}$ & $\begin{array}{l}\text { Technische Universität Dresden, } \\
\text { Germany }\end{array}$ \\
\hline \hline
\end{tabular}

${ }^{a}$ LANL: Los Alamos National Laboratory, United States

bLBNL: Lawrence Berkeley National Laboratory, United States

${ }^{\mathrm{c}}$ ESTSC: Energy Science and Technology Software Center (at Oak Ridge National Laboratory, United States)

dJJH: James J. Hirsch \& Associates, United States

${ }^{\mathrm{e}}$ NREL/JNA: National Renewable Energy Laboratory/J. Neymark \& Associates, United Sates

${ }^{f}$ UIUC: University of Illinois Urbana/Champaign, United States

${ }^{g}$ CERL: U.S. Army Corps of Engineers, Construction Engineering Research Laboratories, United States

hOSU: Oklahoma State University, United States

${ }^{\mathrm{i}}$ FSEC: University of Central Florida, Florida Solar Energy Center, United States

${ }^{j}$ DOE-BT: U.S. Department of Energy, Office of Building Technologies, Energy Efficiency and Renewable Energy, United States

${ }^{k}$ CETC: CANMET Energy Technology Centre, Natural Resources Canada, Canada

'ESRU: Energy Systems Research Unit, University of Strathclyde, Scotland, United Kingdom

The agreement among simulation results improved with each iteration of the field trials. Improvements to the simulation programs are evident when the initial results set in Figure ES-1 is compared to the final results set in Figure ES-2. Improvements to simulation programs or simulation inputs made by participants must have a mathematical and physical basis, and must be applied consistently across tests. Also, all improvements were required to be documented in modeler reports. Arbitrary modification of a simulation program's input or internal code just for the purpose of more closely matching a given set of results is not allowed. 


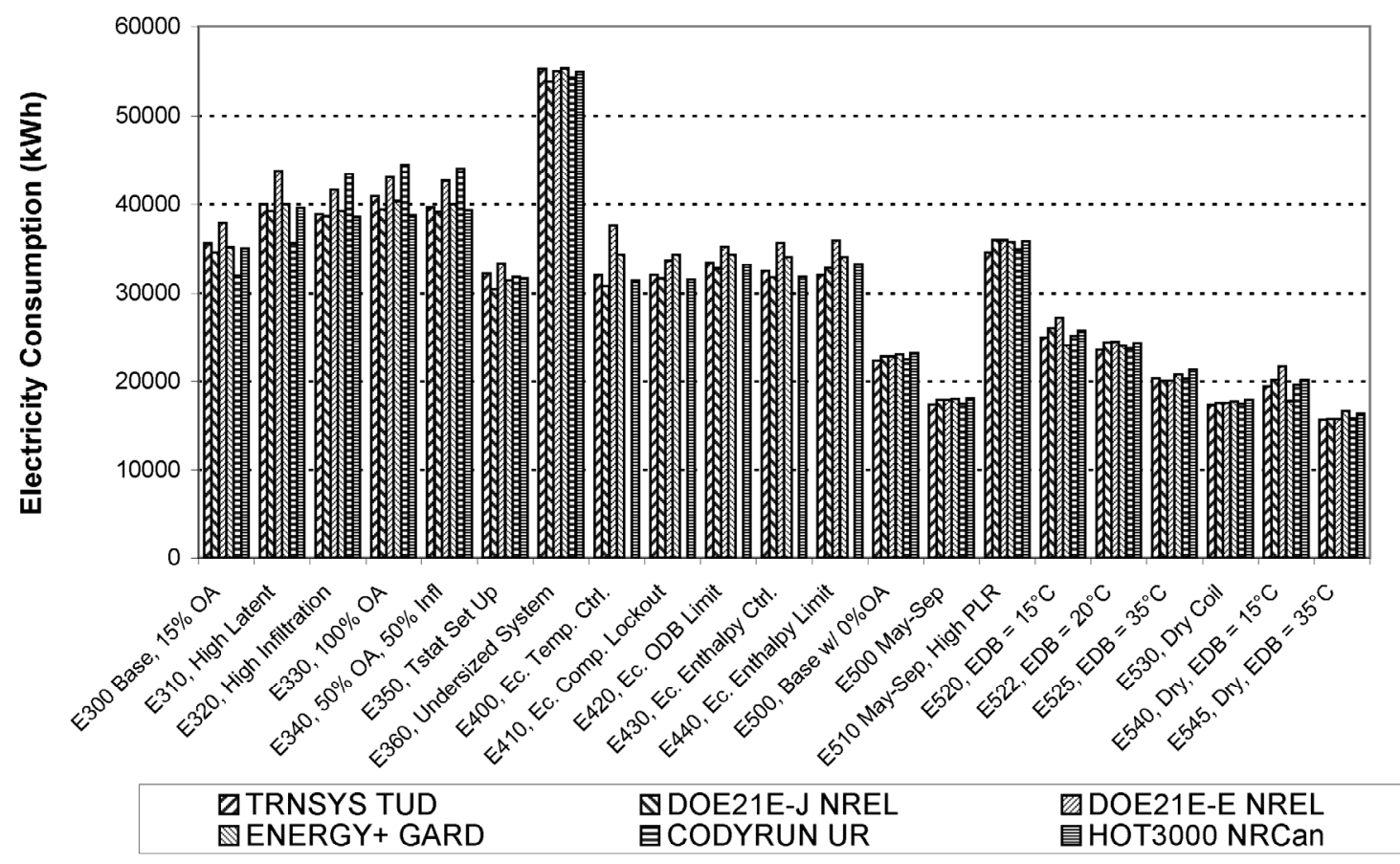

Figure ES-1. HVAC BESTEST E300-E545-total electricity consumption, before "BESTESTing" (Abbreviations along the $\mathrm{x}$-axis are shorthand for the case descriptions; see Part I for full case descriptions.)

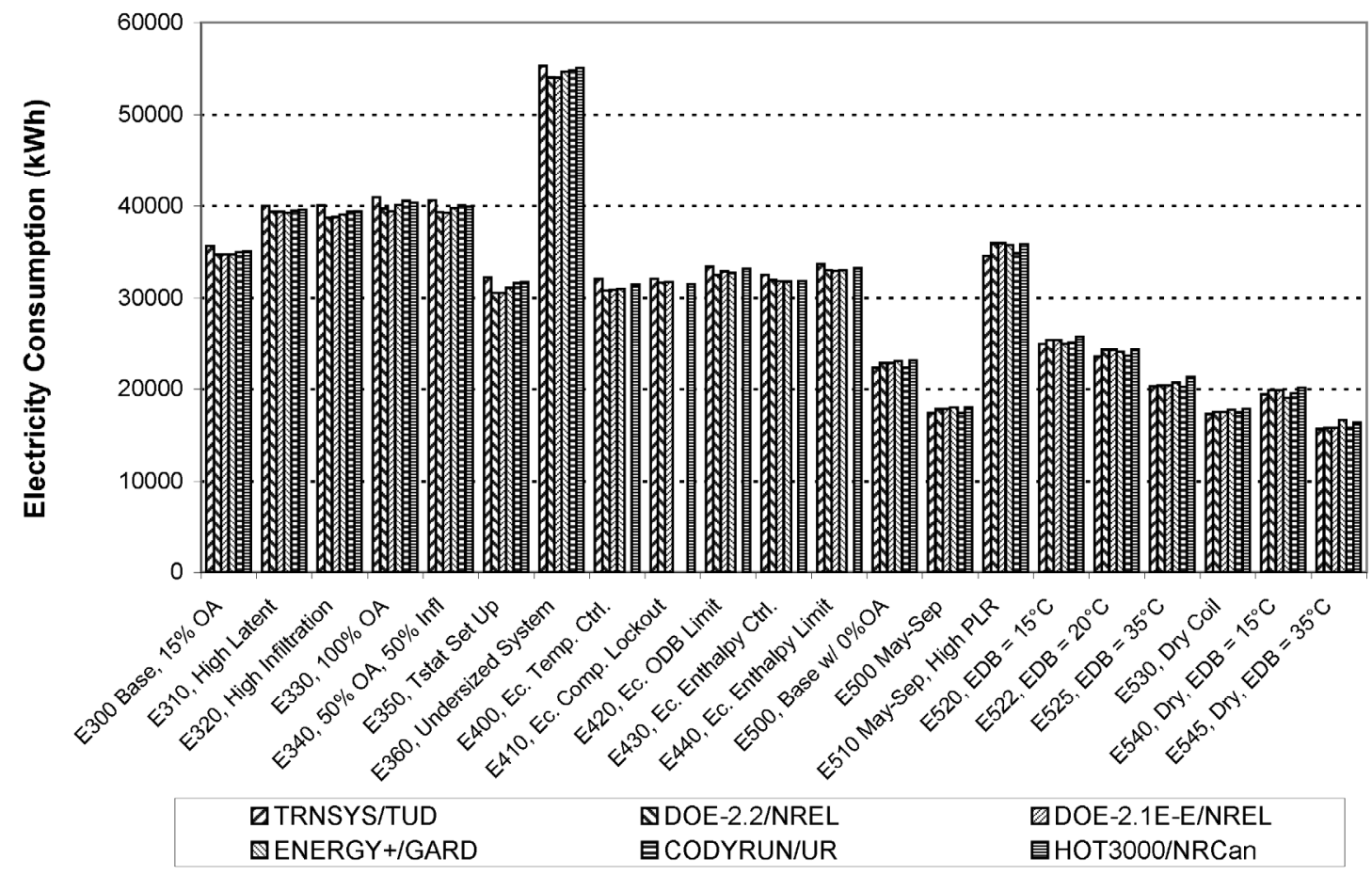

Figure ES-2. HVAC BESTEST E300-E545-total electricity consumption, after BESTESTing (Abbreviations along the $\mathrm{x}$-axis are shorthand for the case descriptions; see Part I for full case descriptions.) 
These results indicate that there was initially a 3\%-21\% disagreement among the cases for the simulated energy consumption results, and that there was a lot of scatter among all the programs. Here disagreement is the difference between the maximum and minimum result for each case, divided by the mean of the results for each case ((max-min)/mean). The initial results disagreements are smaller for these results than for the E100-E200 cases (4\%-40\%) because TRNSYS-TUD, DOE-2.1E, and EnergyPlus were already improved during the earlier field trials of cases E100-E200.

After correcting software errors using HVAC BESTEST diagnostics, the remaining disagreements of results for annual total energy consumption for the programs are $2 \%-6 \%$ with very little scatter among the programs. This shows how the HVAC BESTEST method is used to diagnose and correct faulty algorithms in complex simulation programs.

Based on results after several iterations of HVAC BESTESTing, and on model improvements, the tested programs now appear reliable for performance-map modeling of space cooling equipment over an expanded range of dynamic performance conditions. The programs also appear reliable for modeling outside air mixing, infiltration, thermostat set up, overloaded conditions, and various economizer control schemes. This set of results may therefore be used as a reference or benchmark against which other software can be tested.

In contrast with steady-state cases E100-E200, which were solved analytically, the more realistic nature of cases E300-E545 allows us to gauge the importance of differences in simulation results in terms of annual energy performance, and if desired, annual energy cost (although not done here). This is a good way to understand the importance of the differences in results. For example, a large percentage difference for a given result that has only a very small impact on annual energy use may not be of concern, whereas a small percentage difference with a large impact on annual energy use may be deemed important. The internal gains schedules for cases E300-E545 combine aspects of both building thermal fabric loads and typical internal gains loading. Because there is almost no uncertainty regarding the load to which the mechanical system is responding, all disagreements in simulation results may be attributed to the HVAC system models. It is therefore apparent from the initial results for Case E300 that faulty algorithms in mechanical equipment models can easily account for $10 \%-20 \%$ errors in energy consumption estimates for real buildings. This was after many of the programs had already corrected errors found from running cases E100-E200.

\section{Bugs Found in Simulation Programs}

The results generated with the simulation programs used in this report are intended to be useful for evaluating other detailed or simplified building energy prediction tools. The collective experience of the IEA Experts Group has shown that when a program exhibits major disagreement with the results given in Part III of the report, the underlying cause is usually a bug, a faulty algorithm, or a documentation problem. During the field trials of cases E300-E545, the HVAC BESTEST diagnostic methodology was successful at exposing such problems in all but one of the simulation programs tested. The most notable examples for each program are listed below (in alphabetical order by program name); a listing of 21 problems found among the tested programs appears in Section 2.6 of Part II.

- CODYRUN. Isolation and correction of problems related to both inconsistent accounting of fan heat and neural network performance mapping for dry-coil conditions; this caused underestimated compressor annual consumption estimates of $14 \%$, and underestimated peak-hour total consumption estimates of $9 \%$. (CODYRUN is a detailed hourly simulation program sponsored by University of Reunion Island, France.) 
- DOE-2.1E ESTSC version. Isolation of misleading documentation related to adjustment of bypass factor as a function of part-load ratio (PLR); this caused overestimation of latent coil loads and total energy consumption by $30 \%-115 \%$ and $7 \%-22 \%$, respectively, in cases with continuous fan operation and typical ranges of PLR (Until recently, DOE-2 was the main building energy analysis program sponsored by the U.S. Department of Energy [DOE]; many of its algorithms are being incorporated into EnergyPlus.)

- DOE-2.2. Isolation and correction of an error in DOE-2.2 related to calculation of entering wetbulb temperature; this caused $20 \%-50 \%$ overestimation of peak-hour latent coil loads in cases with high outside air fractions. (DOE-2.2 is based on DOE-2.1E, with further developments by James J. Hirsch \& Associates.)

- ENERGYPLUS. Isolation and correction of an error related to calculating cooling coil outlet temperature and humidity ratio during dry-coil operation that caused the equipment not to operate during certain hours; this affected annual combined compressor and condenser fan annual energy consumption and total peak-hour consumptions by $1 \%-2 \%$ for cases E300-E360. (DOE recently released EnergyPlus as its next-generation building energy simulation program.)

- HOT3000. Isolation and correction of an error related to outside air modeling; this caused 4\% underestimation of total consumption, 5\% underestimation of sensible coil load, and $9 \%$ underestimation of latent coil load in the case with 100\% outside air. (HOT3000 is developed and maintained by CANMET Energy Technology Centre at Natural Resources Canada; it is a modified version of ESP-r - authored by the University of Strathclyde, Scotland, United Kingdom - that retains ESP-r's modeling approach but includes some new models, such as those for unitary space cooling equipment.)

\section{Conclusions}

An advantage of BESTEST is that a program is examined over a broad range of parametric interactions based on a variety of output types, minimizing the possibility for concealment of problems by compensating errors. Performance of the tests resulted in quality improvements to all but one of the building energy simulation programs used in this study. Some of the bugs that were found may well have been present for many years. The fact that they have just now been uncovered shows the power of BESTEST and also suggests the importance of continuing to develop formalized validation and diagnostic methods.

Checking a building energy simulation program for the first time with HVAC BESTEST Volume 2 (cases E300-E545) requires about one person-week for an experienced simulation user, not including improvements to software if necessary. Subsequent program checks are faster because existing input decks may be reused. Because the simulation programs have taken many years to produce, HVAC BESTEST provides a very cost-effective way of testing them. As we continue to develop new test cases, we will adhere to the principle of parsimony so that the entire suite of BESTEST cases may be implemented by users within a reasonable time span.

Software developers, architects, engineers, and researchers can use these new HVAC BESTEST cases in a number of different ways, such as:

- To compare several building energy simulation programs to determine the degree of disagreement among them

- To diagnose the algorithmic sources of prediction differences among several building energy simulation programs 
- To compare predictions from other building energy simulation programs to the simulation results in this report

- To check a program against a previous version of itself after internal code modifications to ensure that only the intended changes actually resulted

- To check a program against itself after a single algorithmic change to understand the sensitivity among algorithms.

\section{Closing Remarks}

The work presented in this report, and the work that has preceded it in IEA SHC Tasks 8, 12 (ECBCS Annex 21), and 22 is significant for two reasons. First, the methods have been extremely successful at correcting software errors in advanced building energy simulation programs throughout the world. Second, the methods are finding their way into industry by being adopted as the theoretical basis for formalized standard methods of test and software certification schemes; in this sense the work may be thought of as pre-normative research.

The previous IEA BESTEST envelope test cases $^{6}$ and the overall validation methodology ${ }^{2,3}$ have been codelanguage adapted and formally approved as a standard method of test (ANSI/ASHRAE Standard 140). ${ }^{7}$ ASHRAE Standard $90.1^{9}$ requires that software used for demonstrating performance compliance with Standard 90.1 be tested using ASHRAE Standard 140. Standard 90.1 is ASHRAE's consensus energy code for commercial buildings and for non-low-rise residential buildings. IEA BESTEST is also being used for simulation certification tests in The Netherlands ${ }^{10}$ and Australia. ${ }^{11,12}$ The HVAC BESTEST Volume 1, cases E100-E200 ${ }^{1}$ have been code-language adapted and formally approved as Addendum $a$ to ASHRAE Standard $140 .^{8}$ HVAC BESTEST Fuel-Fired Furnace Test Cases ${ }^{13}$ are being code-language adapted for Standard 140. We anticipate that HVAC BESTEST Volume 2 cases E300-E545, other work from IEA SHC Task 22, and new work from a collaboration of IEA's SHC and ECBCS programmes (IEA SHC/ECBCS Task 34/Annex 43) will also be added to Standard 140 in the future. In the United States, the National Association of State Energy Officials (NASEO) Residential Energy Services Network (RESNET) has adopted Home Energy Rating System (HERS) BESTEST ${ }^{14}$ as the basis for certifying software to be used for home energy rating systems under the NASEO/RESNET national accreditation standard. ${ }^{15}$ HERS BESTEST is also being code-language adapted for future inclusion with ASHRAE Standard $140 .{ }^{16}$ We hope that as the procedures become better known, developers will automatically run the tests as part of their normal in-house quality control efforts. The large number of requests (more than 1000) that we have received for the various BESTEST reports indicates that this is beginning to happen. For example, we recently learned that Carrier Corporation and Trane, which are among the largest suppliers of HVAC equipment in the world, are testing their respective software HAP and TRACE with Standard 140. Also, EnergyPlus, the United States Department of Energy's most advanced simulation program for building energy analysis, distributes their Standard 140 validation results with their CDs and from their website.

New energy-related technologies are continually being introduced into the buildings market. Thus, there will always be a need for further development of simulation models, combined with a substantial program of testing and validation. Such an effort should contain all the elements of an overall validation methodology (see HVAC BESTEST Volume 1: Background Section), including:

- Analytical verification

- Comparative testing and diagnostics

- Empirical validation. 
Future work should therefore encompass (see Section 2.5.2 for details):

- Continued production of a standard set of analytical tests

- Development of a set of diagnostic comparative tests that emphasize the modeling issues important in large commercial buildings, such as zoning, infiltration airflow rate determination, and more tests for heating, ventilating, and air-conditioning systems

- Development of a sequentially ordered series of high-quality data sets for empirical validation.

Continued support of model development and validation activities is essential because occupied buildings are not amenable to classical controlled, repeatable experiments. The few buildings that are truly useful for empirical validation studies have been designed primarily as test facilities. The energy, comfort, and lighting performance of buildings depend on the interactions among a large number of transfer mechanisms, components, and systems. Simulation is the only practical way to bring a systems integration problem of this magnitude within the grasp of designers. Greatly reducing the energy intensity of buildings through better design is possible with the use of simulation tools. ${ }^{17}$ However, building energy simulation programs will not be widely used unless the design and engineering communities have confidence in these programs. Confidence and quality can best be encouraged by combining a rigorous development and validation effort with user-friendly interfaces.

Finally, the authors wish to acknowledge that the expertise available through IEA and the dedication of the participants were essential to the success of this project. Over the 4-year field trial effort, there were several revisions to the HVAC BESTEST specifications and subsequent re-executions of the computer simulations. This iterative process led to the refining of HVAC BESTEST, and the results of the tests led to improving and debugging of the programs. The process underscores the leveraging of resources for the IEA countries participating in this project. Such extensive field trials, and resulting enhancements to the tests, were much more cost effective with the participation of the IEA SHC Task 22 experts.

\section{References for Executive Summary}

${ }^{1}$ Neymark J.; Judkoff, R. (2002). International Energy Agency Building Energy Simulation Test and Diagnostic Method for Heating Ventilating and Air-Conditioning Equipment Models (HVAC BESTEST), Volume 1: Cases E100-E200. NREL/TP-550-30152. Golden, Colorado, US: National Renewable Energy Laboratory. Available from http://www.nrel.gov/docs/fy02osti/30152.pdf.

${ }^{2}$ Judkoff, R.; Wortman, D.; O'Doherty, B.; Burch, J. (1983). A Methodology for Validating Building Energy Analysis Simulations. SERI/TR-254-1508. Golden, Colorado, US: Solar Energy Research Institute, now National Renewable Energy Laboratory.

${ }^{3}$ Judkoff, R. (1988). "Validation of Building Energy Analysis Simulation Programs at the Solar Energy Research Institute.” Energy and Buildings, Vol. 10, No. 3, p. 235. Lausanne, Switzerland: Elsevier Sequoia.

${ }^{4}$ Bloomfield, D., ed. (November 1989). Design Tool Evaluation: Benchmark Cases. IEA T8B4. Solar Heating and Cooling Programme, Task VIII: Passive and Hybrid Solar Low-Energy Buildings. Building Research Establishment. Garston, Watford, UK: Building Research Establishment.

${ }^{5}$ Lomas, K. (1991). "Dynamic Thermal Simulation Models of Buildings: New Method of Empirical Validation." BSER\&T 12(1):25-37.

${ }^{6}$ Judkoff, R.; Neymark, J. (1995). International Energy Agency Building Energy Simulation Test (IEA BESTEST) and Diagnostic Method. NREL/TP-472-6231. Golden, Colorado, US: National Renewable Energy Laboratory. Available from http://www.nrel.gov/docs/legosti/old/6231.pdf (PDF 13.8 MB). 
${ }^{7}$ ANSI/ASHRAE Standard 140-2001. (2001). Standard Method of Test for the Evaluation of Building Energy Analysis Computer Programs. Atlanta, Georgia, US: American Society of Heating, Refrigerating, and Air-Conditioning Engineers.

${ }^{8}$ ANSI/ASHRAE Addendum $a$ to ANSI/ASHRAE Standard 140-2001. (2004). Standard Method of Test for the Evaluation of Building Energy Analysis Computer Programs. Atlanta, Georgia, US: American Society of Heating, Refrigerating, and Air-Conditioning Engineers.

${ }^{9}$ ANSI/ASHRAE/IESNA (2004). Addendum $p$ to ANSI/ASHRAE/IESNA Standard 90.1-2001, Energy Standard for Buildings Except Low-Rise Residential Buildings. Atlanta, Georgia, US: American Society of Heating, Refrigerating, and Air-Conditioning Engineers.

${ }^{10}$ Instituut Voor Studie En Stimulering Van Onderzoek Op Het Gebied Van Gebouwinstallaties (ISSO). (2003). Energie Diagnose Referentie Versie 3.0. ISSO Publicatie 54. Rotterdam, Netherlands: ISSO (in Dutch).

${ }^{11}$ Sustainable Energy Development Authority (SEDA). (2003). Guidelines for the Use of Simulation in Commitment Agreements. Grosvenor Place, New South Wales, Australia: SEDA.

${ }^{12}$ Pears, A. (1998). Rating Energy Efficiency of Non-Residential Buildings: A Path Forward for New South Wales. Report for the Sustainable Energy Development Authority. Brighton, Victoria, Australia: Sustainable Solutions Pty Ltd. Available from www.abgr.com.au.

${ }^{13}$ Purdy, J.; Beausoleil-Morrison, I. (2003). Building Energy Simulation Test and Diagnostic Method for Heating, Ventilation, and Air-Conditioning Equipment Models (HVAC BESTEST): Fuel-Fired Furnace Test Cases. Ottawa, Ontario, Canada: CANMET Energy Technology Centre, Natural Resources Canada. Available from www.iea-shc.org/task22/deliverables.htm.

${ }^{14}$ Judkoff, R.; Neymark, J. (1995). Home Energy Rating System Building Energy Simulation Test (HERS BESTEST). NREL/TP-472-7332. Golden, Colorado, US: National Renewable Energy Laboratory.

Volume 1: Tier 1 and Tier 2 Tests User's Manual, NREL/TP-472-7332a, available from http://www.nrel.gov/docs/legosti/fy96/7332a.pdf (PDF 5.6 MB); Volume 2: Tier 1 and Tier 2 Tests Reference Results, NREL/TP-472-7332b, available from http://www.nrel.gov/docs/legosti/fy96/7332b.pdf (PDF 1.9 MB).

${ }^{15}$ NASEO/RESNET. (2002). Mortage Industry National Home Energy Rating Systems Accreditation Standards. Oceanside, California, US: Residential Energy Services Network. Available from www.natresnet.com.

${ }^{16}$ SSPC-140. (2004). "Minutes SSPC-140 Standard Method of Test for Building Energy Software." ASHRAE Annual Meeting, Nashville, Tennessee, US. June 26-30, 2004. Atlanta, Georgia, US: American Society of Heating, Refrigerating, and Air-Conditioning Engineers.

${ }^{17}$ Torcellini, P.; Hayter, S.; Judkoff, R. (1999). "Low Energy Building Design: The Process and a Case Study." ASHRAE Transactions 1999 105(2). Atlanta, Georgia, US: American Society of Heating, Refrigerating, and Air-Conditioning Engineers. 


\section{Introduction}

This report is Volume 2 of the Building Energy Simulation Test for Heating, Ventilating, and AirConditioning Equipment Models (HVAC BESTEST Volume 2). Volume 2 represents an extension of the tests in HVAC BESTEST Volume 1 (Neymark and Judkoff 2002). Volume 1 was limited to test cases that could be solved with analytical solutions. Volume 2 includes dynamic effects, and other cases that cannot be solved analytically. This work was conducted by the National Renewable Energy Laboratory (NREL) in collaboration with the Tool Evaluation and Improvement Experts Group under International Energy Agency (IEA) Solar Heating and Cooling (SHC) Programme Task 22. Other tool evaluation projects conducted in Task 22, Subtasks A, C, and D, reported elsewhere, included work on empirical validation (Guyon and Moinard 1999; Maxwell, Loutzenhiser, and Klaassen 2003; Maxwell, Loutzenhiser, and Klaassen 2004; Palomo and Guyon 2002; Travesi et al. 2001); comparative testing (Achermann and Zweifel 2003; Purdy and Beausoleil-Morrison 2003; Deru, Judkoff, and Neymark 2003); and analytical verification (Neymark and Judkoff 2002; Purdy and Beausoleil-Morrison 2003; San Isidro 2000; Tuomaala 1999). In addition, Task 22, Subtask B has produced a report on the application of the Neutral Model Format in building energy simulation programs (Bring, Sahlin, and Vuolle 1999).

\section{Background}

The overall objective of the tool evaluation subtask is to develop a comprehensive and integrated set of tests for quality assurance during development of building energy simulation computer programs. These tests can also be used to certify software used to demonstrate performance-based code compliance in energy standards. Energy simulation tools are essential for evaluating solar energy and advanced energy efficiency technologies that are not normally addressed in prescriptive building energy standards and codes. Greater confidence in the accuracy and validity of predictions from building energy analysis tools can be established by developing these tests.

The development of practical procedures and data for tool evaluation and improvement is part of an overall IEA validation methodology that NREL (Judkoff et al. 1983; Judkoff 1988) and the IEA (e.g., Bloomfield 1989; Lomas 1991) have been developing for many years. The methodology combines empirical validation, analytical verification, and comparative analysis techniques; this is discussed in detail in the Background Section of HVAC BESTEST Volume 1 (Neymark and Judkoff 2002).

The BESTEST method was originally developed by NREL in IEA SHC Task 12 and Energy Conservation in Buildings and Community Systems Annex 21 to test building thermal fabric (envelope) models, and to diagnose sources of predictive disagreements (Judkoff and Neymark 1995a). This method of test was adopted with some refinements by the American Society of Heating, Refrigerating, and AirConditioning Engineers (ASHRAE) in accordance with procedures of the American National Standards Institute (ANSI), and now forms the basis for ANSI/ASHRAE Standard 140, Method of Test for the Evaluation of Building Energy Analysis Computer Programs (ANSI/ASHRAE 2001). HVAC BESTEST extends the original BESTEST by adding the capability to test and diagnose mechanical system models. HVAC BESTEST Volume 1 cases E100-E200 are steady-state analytical verification tests that check the ability of simulation programs to apply basic performance-map modeling techniques to the simulation of unitary space cooling equipment on the working-fluid side of the cooling coil. These cases have been added to ANSI/ASHRAE Standard 140 (ANSI/ASHRAE 2004).

This report documents an additional set of mechanical system test cases numbered E300-E545. These new cases, which are also planned for inclusion in ANSI/ASHRAE Standard 140, test a program's modeling capabilities on the working-fluid side of the coil, but in an hourly dynamic context over an 
expanded range of performance conditions. These cases help to scale the importance of disagreements in simulation results that are less obvious in the steady-state cases. For example, a large percentage difference for a given result that has only a very small impact on annual energy use may not be of concern, whereas a small percentage difference with a large impact on annual energy use may be deemed important. Cases E300-E440 also test the ability to model outside air mixing, infiltration, thermostat set up, overloaded conditions, and various economizer control schemes. The cases consist of a series of dynamic tests using a carefully specified mechanical cooling system applied to a highly simplified near-adiabatic building envelope. Because the mechanical equipment load is driven almost exclusively by sensible and latent internal gains, the response of the mechanical equipment models in simulation programs to a number of equipment performance parameters can be readily explored. Various output values - including energy consumptions, coil loads, and zone conditions - are compared and used in conjunction with a formal diagnostic method to determine the algorithms responsible for predictive differences.

As a BESTEST user, if you have not already tested your software's ability to model envelope loads, we strongly recommend that you run the envelope-load tests in addition to HVAC BESTEST. A set of envelope-load tests is included in ASHRAE Standard 140 (ANSI/ASHRAE 2001); the Standard 140 test cases are based on IEA BESTEST (Judkoff and Neymark 1995a). Another set of envelope-load test cases, which were designed to test simplified tools such as those currently used for home energy rating systems (HERS), is included in HERS BESTEST (Judkoff and Neymark 1995b; Judkoff and Neymark 1997). HERS BESTEST has a more realistic base building than IEA BESTEST; however, its ability to diagnose sources of differences among results is not as detailed (Neymark and Judkoff 1997).

\section{Final Report Structure}

This report is divided into three parts. Part I is a user's manual that furnishes instructions on how to apply the HVAC BESTEST procedure. Part II describes the development, field-testing, and production of results data for the procedure. Part III presents the simulation program example results in tables and graphs along with disagreement statistics that compare the simulation programs to each other; these data can be used to compare results from other programs to Part III results.

An overview of validation methodology and a summary of previous NREL, IEA-related, and other validation work related to software that analyzes energy use in buildings is included in the Background Section of the front matter of Volume 1 (Neymark and Judkoff 2002).

\section{References for Introduction}

Achermann, M.; Zweifel, G. (2003). RADTEST Radiant Heating and Cooling Test Cases. Horw-Lucerne, Switzerland: Lucerne School of Engineering and Architecture, University of Applied Sciences of Central Switzerland. Available from http://www.iea-shc.org/task22/reports/RADTEST_final.pdf.

ANSI/ASHRAE Addendum $a$ to ANSI/ASHRAE Standard 140-2001. (2004). Standard Method of Test for the Evaluation of Building Energy Analysis Computer Programs. Atlanta, Georgia, US: American Society of Heating, Refrigerating, and Air-Conditioning Engineers.

ANSI/ASHRAE Standard 140-2001. (2001). Standard Method of Test for the Evaluation of Building Energy Analysis Computer Programs. Atlanta, Georgia, US: American Society of Heating, Refrigerating, and Air-Conditioning Engineers. 
Bloomfield, D., ed. (November 1989). Design Tool Evaluation: Benchmark Cases. IEA T8B4. Solar Heating and Cooling Programme, Task VIII: Passive and Hybrid Solar Low-Energy Buildings. Building Research Establishment. Garston, Watford, UK: Building Research Establishment.

Bring, A.; Sahlin, P.; Vuolle, M. (September 1999). Models for Building Indoor Climate and Energy Simulation. A report of IEA SHC Task 22, Subtask B, Building Energy Analysis Tools, Model Documentation. Stockholm, Sweden: Kungl Tekniska Hogskolan.

Deru, M.; Judkoff, R.; Neymark, J. (2003). Proposed IEA BESTEST Ground-Coupled Cases. International Energy Agency, Solar Heating and Cooling Programme Task 22, Working Document, September 2003. Golden, Colorado, US: National Renewable Energy Laboratory.

Guyon, G.; Moinard, S. (1999). Empirical Validation of EDF ETNA and GENEC Test-Cell Models. Final Report. IEA SHC Task 22 Building Energy Analysis Tools Project A.3. Moret sur Loing, France: Electricité de France.

Judkoff, R. (1988). "Validation of Building Energy Analysis Simulation Programs at the Solar Energy Research Institute." Energy and Buildings, Vol. 10, No. 3, p. 235. Lausanne, Switzerland: Elsevier Sequoia.

Judkoff, R.; Neymark, J. (1995a). International Energy Agency Building Energy Simulation Test (IEA BESTEST) and Diagnostic Method. NREL/TP-472-6231. Golden, Colorado, US: National Renewable Energy Laboratory. Available from http://www.nrel.gov/docs/legosti/old/6231.pdf (PDF 13.8 MB).

Judkoff, R.; Neymark, J. (1995b). Home Energy Rating System Building Energy Simulation Test (HERS BESTEST). NREL/TP-472-7332. Golden, Colorado, US: National Renewable Energy Laboratory.

Volume 1: Tier 1 and Tier 2 Tests User's Manual, NREL/TP-472-7332a, available from http://www.nrel.gov/docs/legosti/fy96/7332a.pdf (PDF 5.6 MB).

Volume 2: Tier 1 and Tier 2 Tests Reference Results, NREL/TP-472-7332b, available from http://www.nrel.gov/docs/legosti/fy96/7332b.pdf (PDF 1.9 MB).

Judkoff, R.; Neymark, J. (1997). Home Energy Rating System Building Energy Simulation Test for Florida (Florida-HERS BESTEST). NREL/TP-550-23124. Golden, Colorado, US: National Renewable Energy Laboratory.

Judkoff, R.; Wortman, D.; O’Doherty, B.; Burch, J. (1983). A Methodology for Validating Building Energy Analysis Simulations. SERI/TR-254-1508. Golden, Colorado, US: Solar Energy Research Institute, now National Renewable Energy Laboratory.

Lomas, K. (1991). "Dynamic Thermal Simulation Models of Buildings: New Method of Empirical Validation.” BSER\&T 12(1):25-37.

Maxwell G.; Loutzenhiser, P.; Klaassen, C. (2003). Daylighting - HVAC Interaction Tests for the Empirical Validation of Building Energy Analysis Tools. Ankeny, Iowa, US: Iowa Energy Center. Available from http://www.iea-shc.org/task22/deliverables.htm.

Maxwell, G.; Loutzenhiser, P.; Klaassen, C. (2004). Economizer Control Tests for the Empirical Validation of Building Energy Analysis Tools. Ankeny, Iowa, US: Iowa Energy Center. 
Neymark, J.; Judkoff, R. (1997). "A Comparative Validation Based Certification Test for Home Energy Rating System Software.” Proc. Building Simulation '97. September 8-10, Prague, Czech Republic. International Building Performance Simulation Association.

Neymark J.; Judkoff, R. (2002). International Energy Agency Building Energy Simulation Test and Diagnostic Method for Heating Ventilating and Air-Conditioning Equipment Models (HVAC BESTEST), Volume 1: Cases E100-E200. NREL/TP-550-30152. Golden, Colorado, US: National Renewable Energy Laboratory. Available from http://www.nrel.gov/docs/fy02osti/30152.pdf.

Palomo, E.; Guyon, G. (2002). Using Parameters Space Analysis Techniques for Diagnostic Purposes in the Framework of Empirical Model Validation. Theory, Applications and Computer Implementation. Moret sur Loing, France: Electricité de France. Available from http://www.ieashc.org/task22/reports/RapFinal_IEATask22_Diagnostic.pdf.

Purdy, J.; Beausoleil-Morrison, I. (2003). Building Energy Simulation Test and Diagnostic Method for Heating, Ventilation, and Air-Conditioning Equipment Models (HVAC BESTEST): Fuel-Fired Furnace Test Cases. Ottawa, Ontario, Canada: CANMET Energy Technology Centre, Natural Resources Canada. Available from http://www.iea-shc.org/task22/deliverables.htm.

San Isidro, M. (2000). Validating the Solar Shading Test of IEA. Madrid, Spain: Centro de Investigaciones Energeticas Medioambientales y Tecnologicas.

Travesi, J.; Maxwell, G.; Klaassen, C.; Holtz, M.; Knabe, G.; Felsmann, C.; Achermann, M.; Behne, M. (2001). Empirical Validation of Iowa Energy Resource Station Building Energy Analysis Simulation Models. A report of IEA SHC Task 22, Subtask A, Project A.1, Building Energy Analysis Tools, Empirical Validation. Madrid, Spain: Centro de Investigaciones Energeticas, Medioambientales y Technologicas.

Tuomaala, P., ed. (1999). IEA Task 22: A Working Document of Subtask A.1 Analytical Tests. Espoo, Finland: VTT Building Technology. 
This page is intentionally blank.

xxii 


\subsection{Part I: HVAC BESTEST User's Manual: Procedure and Specification Cases E300-E545}

\subsection{General Description of the Test Cases}

There are 20 additional cases as summarized in Table 1-1 beyond those that were specified previously in International Energy Agency Building Energy Simulation Test and Diagnostic Method for Heating, Ventilating, and Air-Conditioning Equipment Models (HVAC BESTEST), Volume 1 (Neymark and Judkoff 2002). These cases (E300-E545) test a program's ability to model mechanical equipment performance using realistic, dynamic, annual hourly weather data for a hot and humid climate.

The configuration of the base case building for these tests (Case E300) is a near-adiabatic rectangular single zone with user-specified internal gains, and outside air to drive dynamic loads. The mechanical system remains as vapor compression cooling equipment, but is a different system than for Cases E100-E200 and includes an expanded performance data set. Also, an air-mixing system has been added so that outside air mixing and economizer control can be included in the tests. As shown in Table 1-1, the following parameters are varied to develop the cases:

- Sensible internal gains

- Latent internal gains

- Infiltration rate

- Outside-air fraction

- Thermostat set points

- Economizer control settings.

The CD included with this document contains the following:

- NEW-ORL.TM2 (weather data for New Orleans, Louisiana, United States; typical meteorological year 2 [TMY2] format)

- E300MAP.XLS (performance data)

- E300OUT2.XLS (spreadsheet for recording output)

- E300RESULTS.XLS (example simulation results)

- E300RESULTS.DOC (navigation instructions for E300RESULTS.XLS)

- README.DOC (electronic media contents)

- IINPDECKS (participant input decks). 
Table 1-1. HVAC BESTEST Case Descriptions (Cases E300-E545)

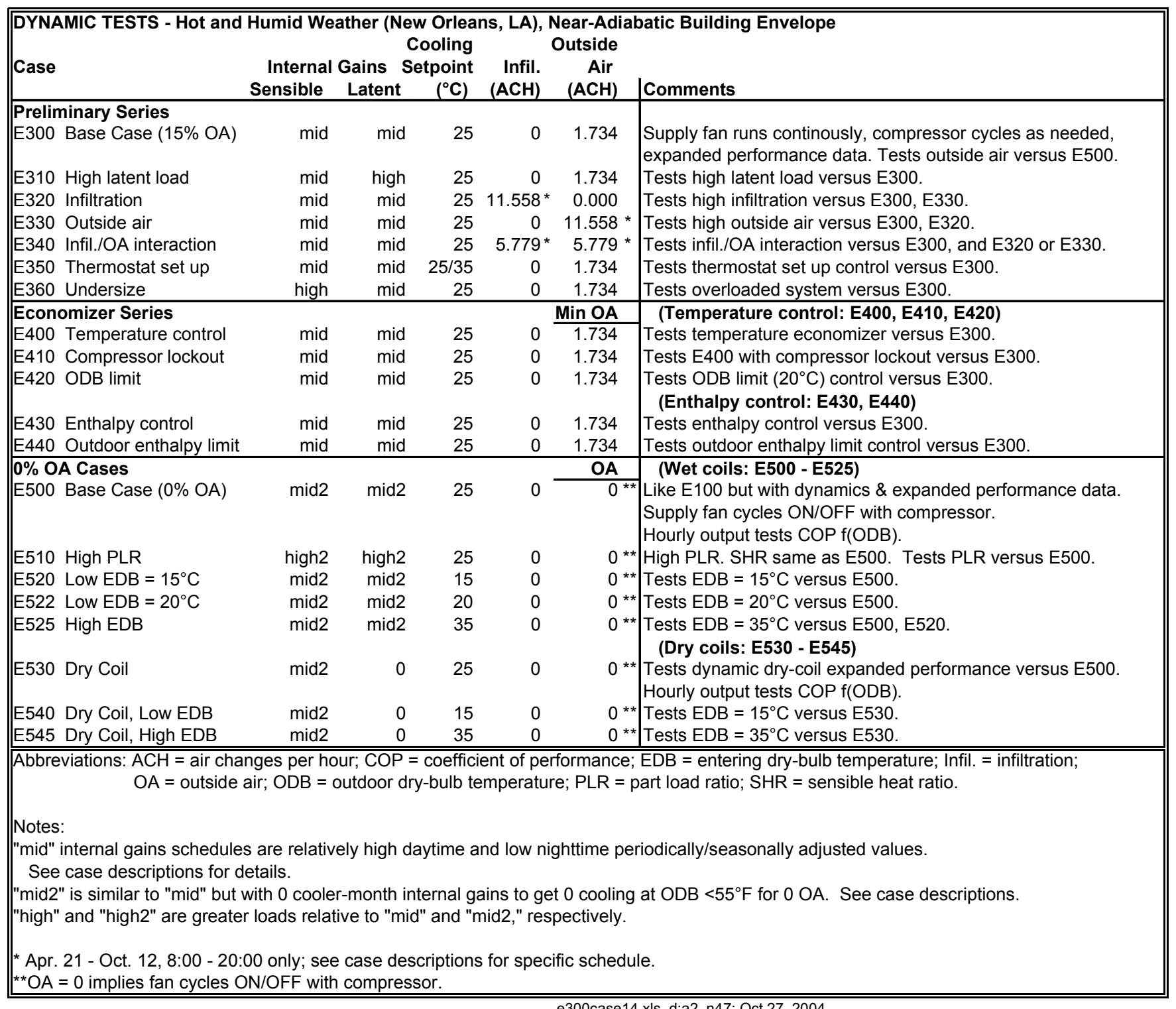

e300case14.xls, d:a2..n47; Oct 27, 2004 


\subsection{Performing the Tests}

\subsubsection{Input Requirements}

Building input data are organized case by case. The base case description (Case E300) is given in Section 1.3.1, with additional cases presented in Sections 1.3.2, 1.3.3, and 1.3.4. The additional cases are organized as modifications to the base case and ordered in a manner that will hopefully facilitate implementing the tests. In some instances (e.g., cases E400 and E500), a case developed from modifications to Case E300 will also serve as the base case for other cases.

Table 1-1 is a summary of the various parametric cases contained herein. These tables are provided only as an overview; use Section 1.3 to generate specific input decks. We recommend a quick look at Table 1-1 now to briefly study the base building and the other cases.

All of the cases utilize the New Orleans weather data; more detail on weather data is in Section 1.3.1.1.

\subsubsection{Modeling Rules}

(Note that these rules are the same as before for Cases E100-E200 except for the time convention, which indicates that weather data are binned into hours corresponding to the usual standard time.)

\subsubsection{Consistent Modeling Methods}

Where options exist within a simulation program for modeling a specific thermal behavior, consistent modeling methods shall be used for all cases. For example, if a software gives the user a choice of methods for modeling indoor air distribution fans, the same indoor fan modeling method shall be used for all cases. For the purpose of generating the example results, the International Energy Agency (IEA) Solar Heating and Cooling (SHC) Programme, Task 22, participants used the most detailed level of modeling that was allowed by their simulation programs and that was consistent with the level of detail provided in this test specification.

\subsubsection{Nonapplicable Inputs}

In some instances the specification will include input values that do not apply to the input structure of your program. For example, your program may not allow the user to specify variation of cooling system sensible capacity with entering dry-bulb temperature, may not use the listed combined convective/radiative film coefficients, and/or may not apply other listed inputs. When nonapplicable input values are found, either use approximation methods suggested in your users manual, or simply disregard the nonapplicable inputs and continue. Such inputs are in the specification for those programs that may need them.

\subsubsection{Time Convention}

References to time in this specification are to local standard time. Assume that hour 1=0:00-1:00 (the interval from midnight to 1 A.M.). Do not use daylight savings time or holidays for scheduling. The required TMY2 data are in hourly bins corresponding to standard time, consistent with all other schedules. 


\subsubsection{Geometry Convention}

If your program includes the thickness of walls in a three-dimensional definition of the building geometry, then the wall, roof, and floor thicknesses should be defined such that the interior air volume of the building remains as specified (e.g., for Case E300, $14 \mathrm{~m} \times 14 \mathrm{~m} \times 3 \mathrm{~m}=588 \mathrm{~m}^{3}$ ). Make the thicknesses extend exterior to the currently defined internal volume.

\subsubsection{Simulation Initialization}

If your software allows, begin the simulation initialization process with zone air conditions that equal the outdoor air conditions.

\subsubsection{Simulation Preconditioning}

If your program allows for preconditioning (iterative simulation of an initial time period until temperatures or fluxes, or both, stabilize at initial values), use that capability.

\subsubsection{Simulation Duration}

Run the full annual simulation using the weather data provided. Give outputs as required per the test case descriptions in Section 1.3.

\subsubsection{Comparing Your Output to the Example Simulation Results}

You should compare your output with the example simulation results located in Part III, or with other results that were generated using this test procedure. Information about how example simulation results were produced is included in Part II. If you wish to plot or tabulate your results along with the example results, we have included for your convenience an electronic version of the example results with the file E300RESULTS.XLS on the accompanying CD.

\subsubsection{Criteria for Determining Agreement between Results}

For the E300 series we provide no formal criteria for when results agree or disagree. Determination of when results agree or disagree is left to the user. In making this determination the user should consider:

- Magnitude of results for individual cases

- Magnitude of difference in results between certain cases (e.g., Case E310-Case E300)

- Same direction of sensitivity (positive or negative) for difference in results between certain cases (e.g., Case E310-Case E300)

- Example results do not represent a truth standard

- Results that are logically counterintuitive with respect to known or expected physical behavior.

\subsubsection{Diagnostic Logic for Determining Causes of Differences among Results}

To help you identify which algorithm in the tested program is causing specific differences between programs, we have included diagnostic flow charts in Appendix G. 


\subsubsection{Rules for Modifying Simulation Programs or Simulation Inputs}

Improvements to simulation programs or simulation inputs must have a mathematical and physical basis, and must be applied consistently across tests. Such improvements must be documented in modeler reports. Arbitrary modification of a simulation program's input or internal code just for the purpose of more closely matching a given set of results is not allowed.

\subsection{Input Specifications}

\subsubsection{Case E300: Base Case}

Begin with Case E300. Case E300 shall be modeled as detailed in this section and its subsections. The bulk of the work for implementing this test is assembling an accurate base building model. We recommend that inputs for Case E300 be double-checked and that results disagreements diagnosed before going on to the other cases.

\subsubsection{Weather Data}

Use the TMY2 format weather data (NEW-ORL.TM2) provided on the CD. Site and weather characteristics are summarized in Table 1-2. The hourly time reference for TMY2 weather data is local standard time. See Appendix A for details about the TMY2 weather data file format.

Note regarding TMY2 data time convention. According to the weather data documentation included in Appendix A, solar radiation data represents energy received during the 60 minutes preceding the hour indicated. For meteorological elements, such as dry-bulb temperature, dew point temperature, relative humidity, and atmospheric pressure, data are spot measurements made at the hour indicated (Marion and Urban 1995). During the field trials, we observed that some simulation tools have adapted the meteorological element data to a preceding hour convention by averaging the listed point measurements for each hour. Other simulation tools have applied the meteorological element data as listed directly to their preceding hour time convention. These different applications give similar annual energy use results, but can cause variations among hourly and peak-hour load and consumption results. We conclude that both of these applications are reasonable interpretations for simulations that use preceding hour time conventions, and that different adaptations of the mixed conventions of TMY2 data cause legitimate disagreement among simulation results. 
Table 1-2. Site and Weather Summary-New Orleans, Louisiana, United States

\begin{tabular}{|l|l||}
\hline Climate Location & New Orleans \\
\hline File name & NEW-ORL.TM2 \\
\hline Weather format & TMY2 \\
\hline Latitude & $30.0^{\circ}$ north \\
\hline Longitude (local site) & $90.3^{\circ}$ west \\
\hline Altitude & $3 \mathrm{~m}$ \\
\hline Time zone (standard meridian longitude) & $6\left(90^{\circ}\right.$ west) \\
\hline Ground reflectivity & 0.2 \\
\hline Site & Flat, unobstructed, located \\
exactly at weather station \\
\hline Mean annual outdoor dry-bulb temperature (ODB) & $19.9^{\circ} \mathrm{C}$ \\
\hline Minimum annual ODB & $-4.4^{\circ} \mathrm{C}$ \\
\hline Maximum annual ODB & $35.0^{\circ} \mathrm{C}$ \\
\hline Mean annual dew point temperature & $14.7^{\circ} \mathrm{C}$ \\
\hline Mean annual humidity ratio & 0.0116 \\
\hline Mean annual wind speed & $3.6 \mathrm{~m} / \mathrm{s}$ \\
\hline Maximum annual wind speed & $13.9 \mathrm{~m} / \mathrm{s}$ \\
\hline Global horizontal solar radiation annual total & $1680 \mathrm{kWh} / \mathrm{m}^{2}$ \\
\hline Direct normal solar radiation annual total & $1498 \mathrm{kWh} / \mathrm{m}^{2}$ \\
\hline
\end{tabular}

\subsubsection{Output Requirements}

Enter all your output data into the preformatted spreadsheet with the file name E300OUT2.XLS on the enclosed CD. Instructions for using the spreadsheet are included at the top of the spreadsheet and in Appendix B. Terms not defined directly below are defined in Appendix C (Glossary).

1.3.1.2.1 Annual Summations. The outputs listed immediately below are to include summed loads or consumptions (as appropriate) for the full annual simulation (full year).

- Cooling energy consumptions (kilowatt-hours [kWh] for annual sums, watt-hours [Wh] for hourly maxima)

- Total consumption (compressor + outdoor condenser fan + indoor air distribution fan)

- Disaggregated compressor consumption

- Disaggregated outdoor condenser fan consumption

- Disaggregated indoor air distribution fan consumption 
- Evaporator coil loads (kWh for annual sums, Wh for hourly maxima)

○ Total evaporator coil load (sensible + latent)

- Disaggregated sensible evaporator coil load

- Disaggregated latent evaporator coil load.

1.3.1.2.2 Annual Hourly Maximum Values Only. The outputs listed immediately below are to include the hourly integrated maximum values for the full annual simulation. Maximum values are to include date and hour of occurrence; if there are multiple hours of occurrence for the maximum value, give the time and date for the first hour of the maximum value occurrence.

- Cooling energy consumptions (Wh)

- Total consumption (compressor and both fans)

- Evaporator coil loads (Wh)

○ Total evaporator coil load (sensible + latent)

- Disaggregated sensible evaporator coil load

- Disaggregated latent evaporator coil load.

1.3.1.2.3 Annual Means, Maxima, and Minima. The outputs listed immediately below are to include the mean value for the full annual simulation and the hourly integrated maximum and minimum values for the full annual simulation. Maximum and minimum values are to include date and hour of occurrence. If there are multiple hours of occurrence for the maximum and/or minimum values, give the time and date for the first hour of the occurrence.

- Zone indoor dry-bulb temperature (IDB; $\left.{ }^{\circ} \mathrm{C}\right)$

- Zone humidity ratio (kg moisture/kg dry air)

- Zone relative humidity (\%)

- Coefficient of performance excluding indoor fan energy consumption ( $\mathrm{COP}_{2}$, as defined below).

Relative humidity is the ratio of the mole fraction of water vapor in a given moist air sample to the mole fraction in an air sample that is saturated and at the same temperature and pressure. This is equivalent to the ratio of the partial pressure of the water vapor in a sample to the saturation pressure at the same temperature.

$\mathrm{COP}_{2}$ is different from COP defined for cases E100-E200. Hourly $\mathrm{COP}_{2}$ is calculated for each hour as

$$
\mathrm{COP}_{2}=(\text { total coil load }) /((\text { compressor energy })+(\text { outdoor fan energy })),
$$

and is calculated for hours only when compressor energy $>0$.

The mean value for $\mathrm{COP}_{2}$ is calculated as

$$
\mathrm{COP}_{2, \text { mean }}=\Sigma(\text { total coil load }) /(\Sigma(\text { compressor energy })+\Sigma(\text { outdoor fan energy })),
$$

where: $\quad \Sigma$ indicates annual summation of the given value

Total coil load is the sensible + latent evaporator coil load.

For example, if for an annual simulation

Total coil load $($ sensible + latent $)=28500 \mathrm{kWh}$ thermal, and 
Combined compressor and outdoor-fan energy is $6240 \mathrm{kWh}$ electric, then

$$
\mathrm{COP}_{2, \text { mean }}=28500 \mathrm{kWh} / 6240 \mathrm{kWh}=4.567 .
$$

Note that if your software does not output enough significant digits, maximum and minimum values for $\mathrm{COP}_{2}$ can be generated by rounding uncertainty. If this is the case, when determining maximum and minimum $\mathrm{COP}_{2}$ it will be necessary to filter out lower part-load ratio (PLR) outputs (e.g., for PLR $<0.01)$.

\subsection{Additional Outputs for Case E300 Only.}

- Annual means and maximum values (weather data checks)

The outputs listed immediately below are to include the mean value for the full annual simulation and the hourly integrated maximum values for the full annual simulation. Maximum values are to include date and hour of occurrence. If there are multiple hours of occurrence for the maximum value, give the time and date for the first hour of the occurrence.

$\circ \operatorname{ODB}\left({ }^{\circ} \mathrm{C}\right)$

○ Outdoor humidity ratio $(\mathrm{kg} / \mathrm{kg})$

- The following hourly outputs are for June 28 (all 24 hours):

- Compressor electric consumption (Wh)

- Outdoor condenser fan electric consumption (Wh)

- Total evaporator coil load (Wh)

- Sensible evaporator coil load (Wh)

$\circ \quad$ Latent evaporator coil load (Wh)

- $\mathrm{COP}_{2}$

- Zone humidity ratio $(\mathrm{kg} / \mathrm{kg})$

○ ODB $\left({ }^{\circ} \mathrm{C}\right)$

○ Entering dry-bulb temperature (EDB), same as mixed air dry-bulb temperature $\left({ }^{\circ} \mathrm{C}\right)$

- Entering wet-bulb temperature (EWB), same as mixed air wet-bulb temperature $\left({ }^{\circ} \mathrm{C}\right)$

- Outdoor Humidity Ratio $(\mathrm{kg} / \mathrm{kg})$

The hourly data are to consist of 24 values for each day. The first hour (hour 1) is defined to run from 00:00 to 01:00. To produce this output, run the program for a normal annual run. Do not run only the required days because the results could contain temperature history errors.

The June 28 hourly outputs are required only for Case E300. June 28 was chosen because of the relatively wide range of conditions occurring on that day. The purpose of including EDB, EWB, and ODB is to be able to check your model's use of the performance map when it is evaluating these hours.

\subsubsection{Building Zone Description}

1.3.1.3.1 Building Geometry. The base building is a $196-\mathrm{m}^{2}$ floor area, single-story building with rectangular-prism geometry as shown in Figure 1-1. Zone air volume is $588 \mathrm{~m}^{3}$. 


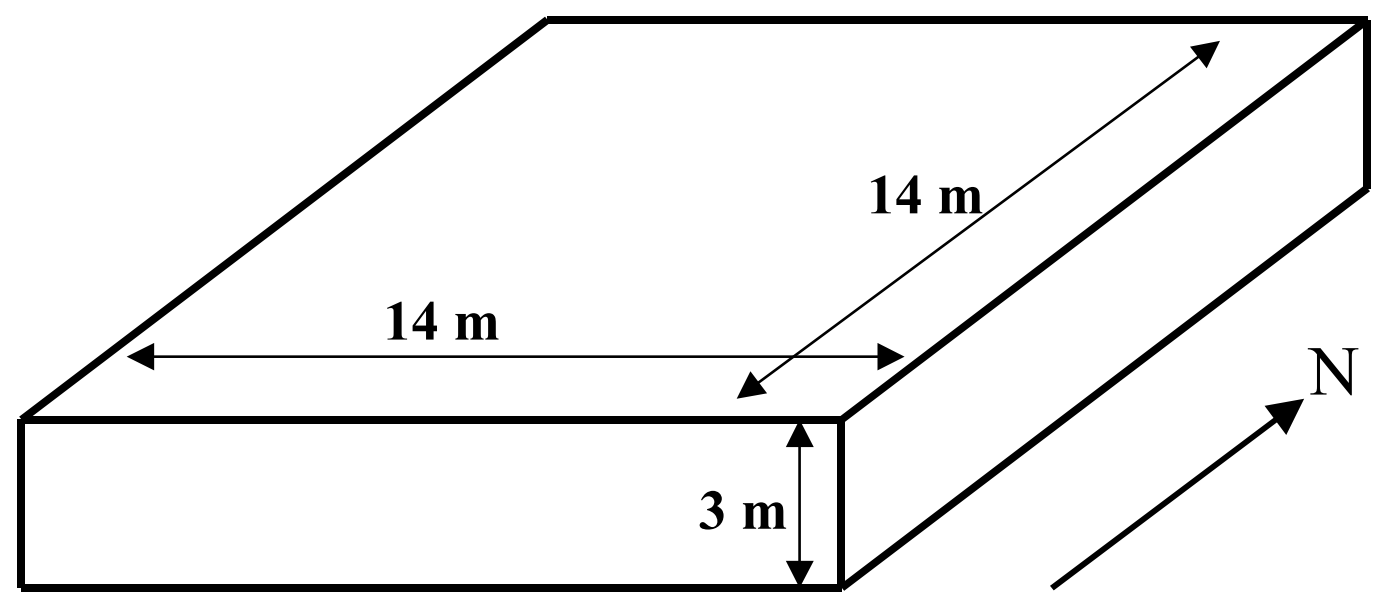

Figure 1-1. HVAC BESTEST Case E300: near-adiabatic envelope geometry

1.3.1.3.2 Building Envelope Thermal Properties. The base building zone is intended as a nearadiabatic test cell with cooling load driven by user-specified scheduled internal gains. Tables 1-3a and 1-3b list material properties in Système Internationale (SI) and English (IP) units, respectively; abbreviations used in these tables are listed in Appendix H. The building insulation has been made very thick to effectively thermally decouple the zone from ambient conditions. Materials of the space have no thermal or moisture capacitance and there is no moisture diffusion through them. If your software requires inputs for thermal capacitance, moisture capacitance, or moisture diffusion, use the minimum values your software allows.

If your software does not allow this much insulation, use the thickest insulation your program will permit and reduce the floor, roof, and wall areas to achieve the thermal conductance (UA) values listed in Table 1-3a (SI) or 1-3b (IP). The zone air volume, however, must remain at $588 \mathrm{~m}^{3}$.

Air density at sea level is $1.201 \mathrm{~kg} / \mathrm{m}^{3}$.

The floor has the same exterior film coefficient as the other walls, as if the entire zone were suspended above the ground.

1.3.1.3.3 Infiltration. Infiltration rate $=0.0$ air changes per hour $(\mathrm{ACH})$, for the entire simulation period. 
Table 1-3a. Material Specifications Base Case (SI Units)

\begin{tabular}{|c|c|c|c|c|}
\hline \multicolumn{5}{|c|}{ EXTERIOR WALL (inside to outside) } \\
\hline \multirow[b]{2}{*}{ ELEMENT } & k & \multirow{2}{*}{$\begin{array}{c}\text { Thickness } \\
\text { (m) }\end{array}$} & \multirow{2}{*}{$\begin{array}{c}U \\
\left(W /\left(m^{2 \star} K\right)\right)\end{array}$} & \multirow{2}{*}{$\begin{array}{c}R \\
\left(m^{2 *} K / W\right)\end{array}$} \\
\hline & $\left(\mathbf{W} /\left(m^{*} K\right)\right)$ & & & \\
\hline Int Surf Coef & & & 8.290 & 0.121 \\
\hline Insulation (Note 1) & 0.00308 & 1.000 & 0.00308 & 325.000 \\
\hline Ext Surf Coef & & & 29.300 & 0.034 \\
\hline Total air - air & & & 0.00308 & 325.155 \\
\hline Total surf - surf & & & 0.00308 & 325.000 \\
\hline \multicolumn{5}{|c|}{ FLOOR (inside to outside) } \\
\hline & k & Thickness & $\mathbf{U}$ & $\mathbf{R}$ \\
\hline ELEMENT & $\left(\mathbf{W} /\left(\mathbf{m}^{*} \mathrm{~K}\right)\right)$ & $(\mathrm{m})$ & $\left(W /\left(m^{2 *} K\right)\right)$ & $\left(m^{2 *} K / W\right)$ \\
\hline Int Surf Coef (Note 2) & & & 8.290 & 0.121 \\
\hline Insulation (Note 1) & 0.00308 & 1.000 & 0.00308 & 325.000 \\
\hline Ext Surf Coef & & & 29.300 & 0.034 \\
\hline Total air - air & & & 0.00308 & 325.155 \\
\hline Total surf - surf & & & 0.00308 & 325.000 \\
\hline \multicolumn{5}{|c|}{ ROOF (inside to outside) } \\
\hline & k & Thickness & $\mathbf{U}$ & $\mathbf{R}$ \\
\hline ELEMENT & $\left(W /\left(m^{*} K\right)\right)$ & (m) & $\left(W /\left(m^{2 *} K\right)\right)$ & $\left(\mathrm{m}^{2 *} \mathrm{~K} / \mathrm{W}\right)$ \\
\hline Int Surf Coef (Note 2) & & & 8.290 & 0.121 \\
\hline Insulation (Note 1) & 0.00308 & 1.000 & 0.00308 & 325.000 \\
\hline Ext Surf Coef & & & 29.300 & 0.034 \\
\hline Total air - air & & & 0.00308 & 325.155 \\
\hline Total surf - surf & & & 0.00308 & 325.000 \\
\hline \multicolumn{5}{|l|}{ SUMMARY } \\
\hline & AREA & UA & & \\
\hline COMPONENT & $\left(m^{2}\right)$ & $(\mathrm{W} / \mathrm{K})$ & & \\
\hline Wall & 168.000 & 0.517 & & \\
\hline Floor & 196.000 & 0.603 & & \\
\hline Roof & 196.000 & 0.603 & & \\
\hline Infiltration (Note 3) & & 0.000 & & \\
\hline \multirow[t]{3}{*}{ Total UA } & & 1.722 & & \\
\hline & $\overline{\mathrm{ACH}}$ & $\begin{array}{c}\text { VOLUME } \\
\left(\mathrm{m}^{3}\right)\end{array}$ & $\begin{array}{c}\text { ALTITUDE } \\
(\mathrm{m}) \\
\end{array}$ & \\
\hline & 0.00 & 588.0 & 3.0 & \\
\hline \multicolumn{5}{|c|}{$\begin{array}{l}\text { Note 1: This level of insulation defines a near-adiabatic condition such that conduction gains } \\
\text { are }<1 \% \text { of the total cooling load. If your software does not allow this much insulation, then } \\
\text { reduce the floor, roof and wall areas to achieve the listed UA values, but keep volume as listed. } \\
\text { Note 2: The interior film coefficient for floors and ceilings is a compromise between upward } \\
\text { and downward heat flow for summer and winter. } \\
\text { Note } 3: \text { Infiltration derived from: } \\
\text { ACH*Volume* (specific heat of air)*(density of air at specified altitude). }\end{array}$} \\
\hline
\end{tabular}

e300env1.xls 
Table 1-3b. Material Specifications Base Case (IP Units)

\begin{tabular}{|c|c|c|c|c|}
\hline \multicolumn{5}{|c|}{$\mid$ EXTERIOR WALL (inside to outside) } \\
\hline \multirow[b]{2}{*}{ ELEMENT } & \multirow{2}{*}{$\begin{array}{c}k \\
\left(B t u /\left(h^{*} f t^{*} F\right)\right)\end{array}$} & \multirow{2}{*}{$\begin{array}{c}\text { Thickness } \\
\text { (ft) }\end{array}$} & \multirow{2}{*}{$\begin{array}{c}U \\
\left(B t u /\left(h^{*} \mathrm{ft}^{2 *} F\right)\right)\end{array}$} & \multirow{2}{*}{$\begin{array}{c}R \\
\left(h^{*} \mathrm{ft}^{2 \star} \mathrm{F} / \mathrm{Btu}\right) \\
\end{array}$} \\
\hline & & & & \\
\hline Int Surf Coef & & & 1.461 & 0.684 \\
\hline Insulation (Note 1) & 0.00178 & 3.281 & 0.000542 & 1844.202 \\
\hline Ext Surf Coef & & & 5.163 & 0.194 \\
\hline Total air - air & & & 0.000542 & 1845.080 \\
\hline Total surf - surf & & & 0.000542 & 1844.202 \\
\hline \multicolumn{5}{|c|}{ FLOOR (inside to outside) } \\
\hline & $\mathbf{k}$ & Thickness & $\mathbf{U}$ & $\mathbf{R}$ \\
\hline ELEMENT & $\left(B t u /\left(h^{*} \mathrm{ft}^{\star} F\right)\right)$ & (ft) & $\left(B t u /\left(h^{*} f^{2 *} F\right)\right)$ & $\left(h * \mathrm{ft}^{2 *} \mathrm{~F} / \mathrm{Btu}\right)$ \\
\hline Int Surf Coef (Note 2) & & & 1.461 & 0.684 \\
\hline Insulation (Note 1) & 0.00178 & 3.281 & 0.000542 & 1844.202 \\
\hline Ext Surf Coef & & & 5.163 & 0.194 \\
\hline Total air - air & & & 0.000542 & 1845.080 \\
\hline Total surf - surf & & & 0.000542 & 1844.202 \\
\hline \multicolumn{5}{|c|}{ ROOF (inside to outside) } \\
\hline & $\mathbf{k}$ & Thickness & $\mathbf{U}$ & $\mathbf{R}$ \\
\hline ELEMENT & $\left(B t u /\left(h^{*} \mathrm{ft}^{*} \mathrm{~F}\right)\right)$ & (ft) & $\left(B t u /\left(h{ }^{*} t^{2 *} F\right)\right)$ & $\left(h^{*} \mathrm{ft}^{2 *} \mathrm{~F} / \mathrm{Btu}\right)$ \\
\hline Int Surf Coef (Note 2) & & & 1.461 & 0.684 \\
\hline Insulation (Note 1) & 0.00178 & 3.281 & 0.000542 & 1844.202 \\
\hline Ext Surf Coef & & & 5.163 & 0.194 \\
\hline Total air - air & & & 0.000542 & 1845.080 \\
\hline Total surf - surf & & & 0.000542 & 1844.202 \\
\hline \multicolumn{5}{|l|}{ SUMMARY } \\
\hline & AREA & UA & & \\
\hline COMPONENT & $\left(\mathrm{ft}^{2}\right)$ & $\left(B t u /\left(h^{*} F\right)\right)$ & & \\
\hline Wall & 1808.337 & 0.980 & & \\
\hline Floor & 2109.726 & 1.143 & & \\
\hline Roof & 2109.726 & 1.143 & & \\
\hline Infiltration & & 0.000 & & \\
\hline \multirow[t]{4}{*}{ Total UA } & & 3.267 & & \\
\hline & $\overline{\mathrm{ACH}}$ & VOLUME & ALTITUDE & UAinf (Note 3) \\
\hline & & $\left(\mathrm{ft}^{3}\right)$ & $(\mathbf{f t})$ & $\left(B t u /\left(h^{*} F\right)\right)$ \\
\hline & 0.000 & 20765 & 9.84 & 0.000 \\
\hline \multirow{2}{*}{\multicolumn{5}{|c|}{$\begin{array}{l}\text { Note 1: This level of insulation defines a near-adiabatic condition such that conduction gains } \\
\text { are }<1 \% \text { of the total cooling load. If your software does not allow this much insulation, then } \\
\text { reduce the floor, roof and wall areas to achieve the listed UA values, but keep volume as listed } \\
\text { Note } 2 \text { : The interior film coefficient for floors and ceilings is a compromise between upward } \\
\text { and downward heat flow for summer and winter. }\end{array}$}} \\
\hline & & & & \\
\hline \multicolumn{5}{|c|}{ Note 3: Infiltration derived from: } \\
\hline $\mathrm{ACH}^{*}$ Volume* (spec & $c$ heat of air $)^{*}(d$ & dents & ispe & \\
\hline
\end{tabular}


1.3.1.3.4 Internal Heat Gains. Sensible and latent internal heat gains are as indicated in Table 1-4.

Table 1-4. Case E300 Hourly Internal Gains Schedule (IP and SI Units)

\begin{tabular}{|c|c|c|c|c|c|c|c|}
\hline & & & $\overline{\text { SEN S I }}$ & I B LE & & - ATE & \\
\hline Period & Hours & Watts & Btu/h & frac v. $\max ^{*}$ & Watts & Btu/h & frac v. $\max ^{*}$ \\
\hline Jan. 1 thru Mar. 10 & 0:00 - 8:00 & 2931 & 10000 & 0.15625 & 0 & 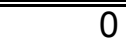 & 0.00 \\
\hline & $8: 00-20: 00$ & 2931 & 10000 & 0.15625 & 366 & 1250 & 0.25 \\
\hline & $20: 00-24: 00$ & 2931 & 10000 & 0.15625 & 0 & 0 & 0.00 \\
\hline Mar. 11 thru Apr. 10 & $0: 00-9: 00$ & 2931 & 10000 & 0.15625 & 0 & 0 & 0.00 \\
\hline & $9: 00$ - 18:00 & 7034 & 24000 & 0.37500 & 1466 & 5000 & 1.00 \\
\hline & $18: 00-24: 00$ & 2931 & 10000 & 0.15625 & 0 & 0 & 0.00 \\
\hline Apr. 11** & $0: 00-8: 00$ & 2931 & 10000 & 0.15625 & 0 & 0 & 0.00 \\
\hline & $8: 00-20: 00$ & 2931 & 10000 & 0.15625 & 366 & 1250 & 0.25 \\
\hline & $20: 00-24: 00$ & 2931 & 10000 & 0.15625 & 0 & 0 & 0.00 \\
\hline Apr. 12 thru Apr. 20 & $0: 00-8: 00$ & 2931 & 10000 & 0.15625 & 0 & 0 & 0.00 \\
\hline & $8: 00-19: 00$ & 9379 & 32000 & 0.50000 & 1466 & 5000 & 1.00 \\
\hline & $19: 00-24: 00$ & 2931 & 10000 & 0.15625 & 0 & 0 & 0.00 \\
\hline Apr. 21 thru Oct. 12 & $0: 00-8: 00$ & 7034 & 24000 & 0.37500 & 0 & 0 & 0.00 \\
\hline & $8: 00-12: 00$ & 9379 & 32000 & 0.50000 & 1466 & 5000 & 1.00 \\
\hline & $12: 00-14: 00$ & 14069 & 48000 & 0.75000 & 1466 & 5000 & 1.00 \\
\hline & $14: 00-16: 00$ & 18758 & 64000 & 1.00000 & 1466 & 5000 & 1.00 \\
\hline & $16: 00-20: 00$ & 9379 & 32000 & 0.50000 & 1466 & 5000 & 1.00 \\
\hline & $20: 00-24: 00$ & 7034 & 24000 & 0.37500 & 0 & 0 & 0.00 \\
\hline Oct. 13 thru Oct. 18 & $0: 00-8: 00$ & 2931 & 10000 & 0.15625 & 0 & 0 & 0.00 \\
\hline & $8: 00-16: 00$ & 9379 & 32000 & 0.50000 & 1466 & 5000 & 1.00 \\
\hline & $16: 00-24: 00$ & 2931 & 10000 & 0.15625 & 0 & 0 & 0.00 \\
\hline Oct. 19 thru Nov. 05 & $0: 00-8: 00$ & 2931 & 10000 & 0.15625 & 0 & 0 & 0.00 \\
\hline & $8: 00-12: 00$ & 9379 & 32000 & 0.50000 & 1466 & 5000 & 1.00 \\
\hline & $12: 00-14: 00$ & 14069 & 48000 & 0.75000 & 1466 & 5000 & 1.00 \\
\hline & $14: 00-16: 00$ & 18758 & 64000 & 1.00000 & 1466 & 5000 & 1.00 \\
\hline & $16: 00-20: 00$ & 9379 & 32000 & 0.50000 & 1466 & 5000 & 1.00 \\
\hline & $20: 00-24: 00$ & 7034 & 24000 & 0.37500 & 0 & 0 & 0.00 \\
\hline Nov. 06 thru Dec. $31^{* \star}$ & $0: 00-8: 00$ & 2931 & 10000 & 0.15625 & 0 & 0 & 0.00 \\
\hline & $8: 00-20: 00$ & 2931 & 10000 & 0.15625 & 366 & 1250 & 0.25 \\
\hline & $20: 00-24: 00$ & 2931 & 10000 & 0.15625 & 0 & 0 & 0.00 \\
\hline $\begin{array}{l}\text { * "frac v. max" is the } \\
\text { value for the year. } \\
\text { * Same schedule as }\end{array}$ & $\begin{array}{l}\text { sponding } \mathrm{f} \\
\text { is included } \\
\text { Jan. } 1 \text { throu }\end{array}$ & conv & (10 & $\begin{array}{l}\text { urly valu } \\
\text { ers who }\end{array}$ & $\operatorname{siv}$ & $\pi$ & $\begin{array}{l}\text { um input. } \\
\text { s inp }\end{array}$ \\
\hline
\end{tabular}

e300intgains.xls e300sch! 
Table 1-4 lists hourly values for a given period. In the first row of values, for example, the $2931 \mathrm{~W}$ of sensible gains and $0 \mathrm{~W}$ of latent gains are applied for each hour from 12 A.M. until 8 A.M. for the entire period from January 1 through March 10. Similarly, the second row of values indicates $2931 \mathrm{~W}$ of sensible gains and $366 \mathrm{~W}$ of latent gains for each hour from 8 A.M until 8 P.M for the same period. Values are provided in both SI and IP units. Additionally, the corresponding fraction of a given hourly value relative to the maximum hourly value for the year is given for the convenience of users who may need to provide input in such a format. In the first row of values for sensible gains, for example, the "frac v. max" value of 0.15625 comes from: (10,000 British thermal units [Btu]/h) / $(64,000 \mathrm{Btu} / \mathrm{h})$. Note that $64,000 \mathrm{Btu} / \mathrm{h}$, which is the hourly sensible heat gain for the period from 14:00 until 16:00 for the period beginning April 21 and ending October 12, is also the maximum hourly sensible internal gain input for the year.

Sensible gains are $100 \%$ convective.

Zone sensible and latent internal gains are assumed to be distributed evenly throughout the zone air. These are internally generated sources of heat that are not related to the operation of the mechanical cooling system or its air distribution fan.

If your software requires input of water vapor mass flow rate rather than latent internal gains, use the heat of vaporization that your software assumes for condensation at the coil to convert the latent gains to water vapor mass flow rate for each listed time period.

If your software requires input of total internal gains, use the sum of sensible + latent internal gains for each listed time period.

The internal gains schedule for E300 was developed to serve the following purposes:

- To avoid extrapolations of performance data, the compressor is intended to be off when $\mathrm{ODB}<12.78^{\circ} \mathrm{C}\left(55.0^{\circ} \mathrm{F}\right)$.

- The resulting E400 series (economizer) sensitivity tests are robust.

- Sensible internal gains variations are intended to correspond with additional building shell and solar loads toward midday when possible (this may allow for additional analysis that scales the significance of disagreements in software found here for real buildings); such shell loads would not otherwise be included in a near-adiabatic building model.

1.3.1.3.5 Opaque Surface Radiative Properties. Interior and exterior opaque surface solar (visible and ultraviolet wavelengths) absorptances and infrared emittances are included in Table 1-5.

Table 1-5. Opaque Surface Radiative Properties

\begin{tabular}{||l||c|c||}
\hline \multicolumn{1}{|c||}{} & Interior Surface & Exterior Surface \\
\hline \hline Solar absorptance & 0.6 & 0.1 \\
\hline Infrared emittance & 0.9 & 0.9 \\
\hline \hline
\end{tabular}

1.3.1.3.6 Exterior Combined Radiative and Convective Surface Coefficients. If your program calculates exterior surface radiation and convection automatically, you may disregard this section. If your program does not calculate this effect, use $29.3 \mathrm{~W} / \mathrm{m}^{2} \mathrm{~K}$ for all exterior surfaces. This value is based on a mean annual wind speed of $4.02 \mathrm{~m} / \mathrm{s}$ for a surface with roughness equivalent to rough plaster or brick. 
1.3.1.3.7 Interior Combined Radiative and Convective Surface Coefficients. If your program calculates interior surface radiation and convection automatically, you may disregard this section. If your program does not calculate these effects, use the American Society of Heating, Refrigerating, and AirConditioning Engineers (ASHRAE) constant combined radiative and convective coefficients given in Table 1-6 (ASHRAE 2001: Chapter 24). (Note that the ASHRAE values are not exactly the same as the Chartered Institution of Building Services Engineers [CIBSE] values.)

Table 1-6. Interior Combined Surface Coefficient versus Surface Orientation

\begin{tabular}{||l|l||}
\hline \multicolumn{1}{|c|}{ Orientation of Surface and Heat Flow } & \multicolumn{1}{c|}{$\begin{array}{c}\text { Interior Combined Surface } \\
\text { Coefficient }\end{array}$} \\
\hline Horizontal heat transfer on vertical surfaces & $8.29 \mathrm{~W} /\left(\mathrm{m}^{2} \cdot \mathrm{K}\right)\left(1.46 \mathrm{Btu} /\left(\mathrm{h} \cdot \mathrm{ft}^{2} \cdot{ }^{\circ} \mathrm{F}\right)\right)$ \\
\hline Upward heat transfer on horizontal surfaces & $9.26 \mathrm{~W} /\left(\mathrm{m}^{2} \cdot \mathrm{K}\right)\left(1.63 \mathrm{Btu} /\left(\mathrm{h} \cdot \mathrm{ft}^{2} \cdot{ }^{\circ} \mathrm{F}\right)\right)$ \\
\hline Downward heat transfer on horizontal surfaces & $6.13 \mathrm{~W} /\left(\mathrm{m}^{2} \cdot \mathrm{K}\right)\left(1.08 \mathrm{Btu} /\left(\mathrm{h} \cdot \mathrm{ft}^{2} \cdot{ }^{\circ} \mathrm{F}\right)\right)$ \\
\hline
\end{tabular}

The radiative portion of these combined coefficients may be taken as $5.13 \mathrm{~W} /\left(\mathrm{m}^{2} \cdot \mathrm{K}\right)\left(0.90 \mathrm{Btu} /\left(\mathrm{h} \cdot \mathrm{ft}^{2} \cdot{ }^{\circ} \mathrm{F}\right)\right)$ for an interior infrared emissivity of 0.9 .

If your program does not allow scheduling of these coefficients, use $8.29 \mathrm{~W} / \mathrm{m}^{2} \mathrm{~K}\left(1.46 \mathrm{Btu} /\left(\mathrm{h} \cdot \mathrm{ft}^{2} \cdot{ }^{\circ} \mathrm{F}\right)\right)$ for all horizontal surfaces. If you can justify using different values, go ahead and use them.

\subsubsection{Mechanical System}

The mechanical system represents a simple unitary vapor compression cooling system, or more precisely a split-system, air-cooled condensing unit with an indoor evaporator coil. Figure 1-2 is a schematic diagram of this system. See the Glossary (Appendix C) for definitions of some terminology used in this section. 


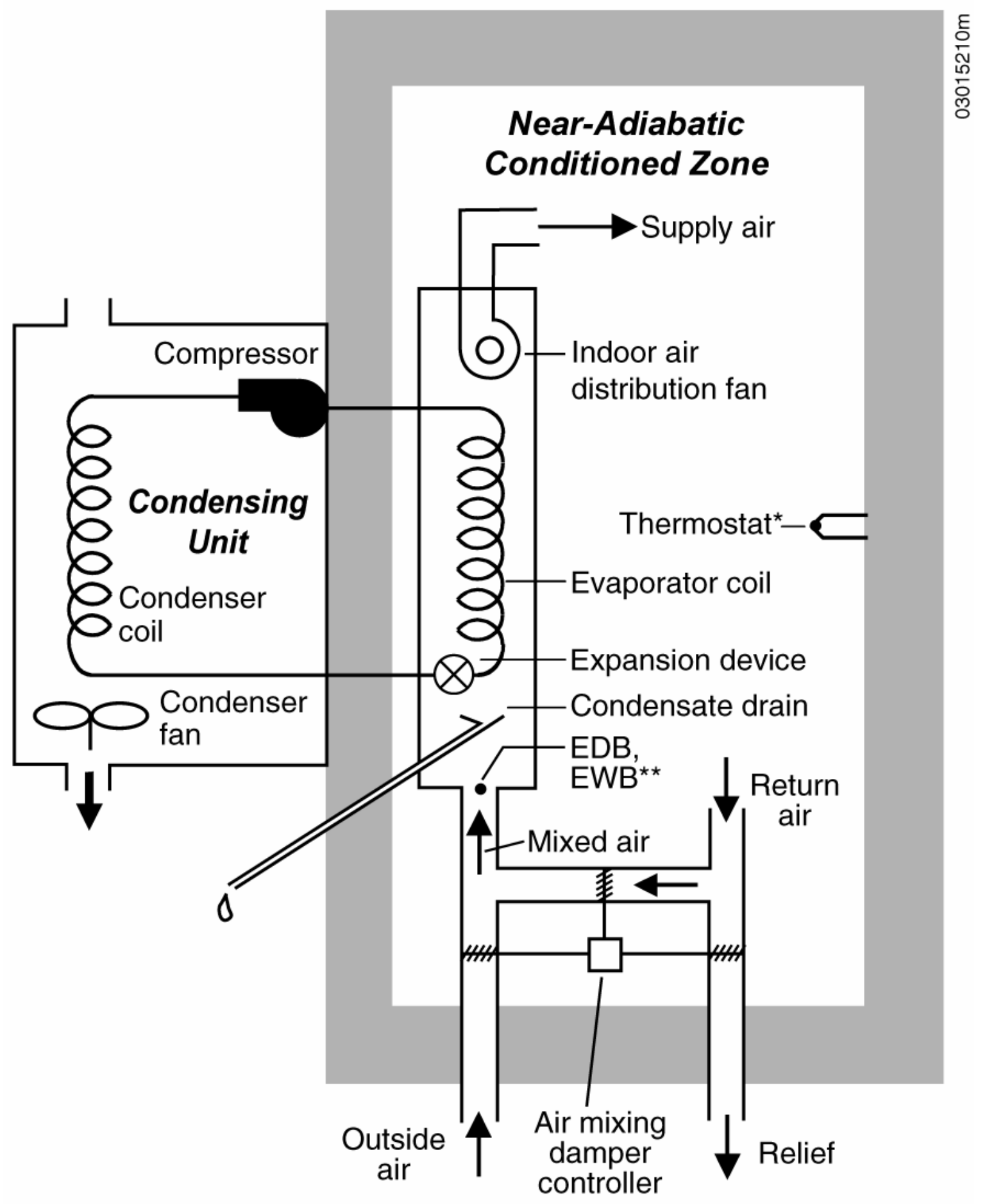

* The thermostat senses only the zone air temperature (IDB).

** Entering dry-bulb and wet-bulb temperatures.

Figure 1-2. Unitary split-system, air-cooled condensing unit with indoor evaporator coil, and with outside-air mixing system 


\subsection{General Information.}

- $100 \%$ convective air system

- Zone air perfectly mixed

- An outside-air mixing system included (as shown in Figure 1-2)

- Single-speed draw-through indoor-air distribution fan, continuous operation

- Outdoor condenser fan, cycling on and off together with compressor

- Air-cooled condenser

- Single-speed reciprocating compressor, R-22 refrigerant, no cylinder unloading

- No system hot-gas bypass

- The compressor, condenser, and condenser fan are located outside the conditioned zone

- All moisture that condenses on the evaporator coil (latent load) leaves the system through a condensate drain

- $\quad$ Crankcase heater and other auxiliary energy $=0$.

\subsection{Thermostat Control Strategy.}

$$
\begin{aligned}
& \text { Heat }=\text { off } \\
& \text { Cool }=\text { on if temperature }>25.0^{\circ} \mathrm{C}\left(77.0^{\circ} \mathrm{F}\right) \text {; otherwise } \mathrm{Cool}=\text { off. }
\end{aligned}
$$

There is no zone humidity control. This means that the zone humidity level will float in accordance with zone latent loads and moisture removal by the mechanical system.

The thermostat senses only the zone air temperature; the thermostat itself does not sense any radiative heat transfer exchange with the interior surfaces.

The controls for this system are ideal in that the equipment is assumed to maintain the set point exactly, when it is operating and not overloaded. There are no minimum on or off time duration requirements for the unit, and no hysteresis control band (e.g., there is no $\mathrm{ON}$ at set point $+\mathrm{x}^{\circ} \mathrm{C}$, or $\mathrm{OFF}$ at set point $\mathrm{y}^{\circ} \mathrm{C}$ ). If your software requires input for these, use the minimum values your software allows.

The thermostat is nonproportional in the sense that when the conditioned zone air temperature exceeds the thermostat cooling set point, the heat extraction rate is assumed to equal the maximum capacity of the cooling equipment corresponding to environmental conditions at the time of operation. A proportional thermostat model can be made to approximate a nonproportional thermostat model by setting a very small throttling range (the minimum allowed by your program). A COP $=\mathrm{f}(\mathrm{PLR})$ curve is given in Section 1.3.1.4.4 to account for equipment cycling.

1.3.1.4.3 Full-Load Cooling System Performance Data. Tables 1-7a and 1-7b give an expanded set of data for equipment full-load capacity and full-load performance data (Carrier Corporation 2001-2002). The tables contain gross capacity data, which are the full capacities of the unit without any fan heat subtracted out. Table 1-7a is in SI units; Table 1-7b is in IP units. Notes that also include specific units for various quantities presented in the tables are given on the last page of each table. Data are included for $2.78^{\circ} \mathrm{C}\left(5^{\circ} \mathrm{F}\right)$ increments of EDB and $\mathrm{EWB}$, and $5.56^{\circ} \mathrm{C}\left(10^{\circ} \mathrm{F}\right)$ increments of ODB. Data are also included for typical rating conditions of $\mathrm{ODB} / \mathrm{EDB} / \mathrm{EWB}=35.00^{\circ} \mathrm{C} / 26.67^{\circ} \mathrm{C} / 19.44^{\circ} \mathrm{C}\left(95^{\circ} \mathrm{F} / 80^{\circ} \mathrm{F} / 67^{\circ} \mathrm{F}\right)$.

For your convenience, an electronic file (E300MAP.XLS) containing Tables 1-7a and 1-7b is included on the accompanying $\mathrm{CD}$. 
Table 1-7a. Equipment Full-Load Performance with Gross Capacities (SI Units)

\begin{tabular}{|c|c|c|c|c|c|c|c|c|c|c|}
\hline $\mathrm{ODB}\left({ }^{\circ} \mathrm{C}\right)$ & 12.78 & & & & & & & & & \\
\hline EWB & & & & & & $\operatorname{EDB}\left({ }^{\circ} \mathrm{C}\right.$ & & & & \\
\hline$\left({ }^{\circ} \mathrm{C}\right)$ & & 12.78 & 15.56 & 18.33 & 21.11 & 23.89 & 26.67 & 29.44 & 32.22 & 35.00 \\
\hline 4.44 & $\begin{array}{c}\mathrm{TC} \\
\mathrm{SHC} \\
\mathrm{kW}\end{array}$ & $\begin{array}{c}27.05 \\
27.05 \\
6.0\end{array}$ & & & & & & & & \\
\hline 7.22 & $\begin{array}{c}\text { TC } \\
\mathrm{SHC} \\
\mathrm{kW}\end{array}$ & $\begin{array}{c}27.46 \\
26.15 \\
6.0\end{array}$ & $\begin{array}{c}28.81 \\
28.81 \\
6.1\end{array}$ & $\begin{array}{c}30.60 \\
30.60 \\
6.3\end{array}$ & & & & & & \\
\hline 10.00 & $\begin{array}{c}\mathrm{TC} \\
\mathrm{SHC} \\
\mathrm{kW}\end{array}$ & $\begin{array}{c}29.81 \\
20.54 \\
6.2\end{array}$ & $\begin{array}{c}29.86 \\
26.27 \\
6.2\end{array}$ & $\begin{array}{c}30.60 \\
30.60 \\
6.3\end{array}$ & $\begin{array}{c}32.41 \\
32.41 \\
6.4\end{array}$ & & & & & \\
\hline 12.78 & $\begin{array}{c}\mathrm{TC} \\
\mathrm{SHC} \\
\mathrm{kW}\end{array}$ & $\begin{array}{c}32.50 \\
14.62 \\
6.4\end{array}$ & $\begin{array}{c}32.52 \\
20.42 \\
6.4\end{array}$ & $\begin{array}{c}32.56 \\
26.18 \\
6.4\end{array}$ & $\begin{array}{c}32.86 \\
31.43 \\
6.4\end{array}$ & $\begin{array}{c}34.23 \\
34.23 \\
6.6\end{array}$ & & & & \\
\hline 15.56 & $\begin{array}{c}\mathrm{TC} \\
\mathrm{SHC} \\
\mathrm{kW}\end{array}$ & & $\begin{array}{c}35.31 \\
14.41 \\
6.6\end{array}$ & $\begin{array}{c}35.44 \\
20.20 \\
6.6\end{array}$ & $\begin{array}{c}35.42 \\
25.86 \\
6.6\end{array}$ & $\begin{array}{c}35.58 \\
31.38 \\
6.7\end{array}$ & $\begin{array}{c}36.25 \\
35.94 \\
6.7\end{array}$ & $\begin{array}{c}37.99 \\
37.99 \\
6.8\end{array}$ & & \\
\hline 18.33 & $\begin{array}{c}\text { TC } \\
\text { SHC } \\
\mathrm{kW}\end{array}$ & & & $\begin{array}{c}38.43 \\
14.14 \\
6.9\end{array}$ & $\begin{array}{c}38.48 \\
19.83 \\
6.9\end{array}$ & $\begin{array}{c}38.54 \\
25.49 \\
6.9\end{array}$ & $\begin{array}{c}38.59 \\
31.04 \\
6.9\end{array}$ & $\begin{array}{c}38.92 \\
36.18 \\
6.9\end{array}$ & $\begin{array}{c}39.91 \\
39.91 \\
7.0\end{array}$ & $\begin{array}{c}41.83 \\
41.83 \\
7.1\end{array}$ \\
\hline 21.11 & $\begin{array}{c}\mathrm{TC} \\
\mathrm{SHC} \\
\mathrm{kW}\end{array}$ & & & & $\begin{array}{c}41.65 \\
13.74 \\
7.1\end{array}$ & $\begin{array}{c}41.77 \\
19.40 \\
7.1\end{array}$ & $\begin{array}{c}41.84 \\
25.00 \\
7.1\end{array}$ & $\begin{array}{c}41.88 \\
30.53 \\
7.1\end{array}$ & $\begin{array}{c}42.02 \\
35.85 \\
7.2\end{array}$ & $\begin{array}{c}42.53 \\
36.36 \\
7.2\end{array}$ \\
\hline 23.89 & $\begin{array}{c}\mathrm{TC} \\
\mathrm{SHC} \\
\mathrm{kW}\end{array}$ & & & & & $\begin{array}{c}45.02 \\
13.27 \\
7.4\end{array}$ & $\begin{array}{c}45.20 \\
18.87 \\
7.4\end{array}$ & $\begin{array}{c}45.31 \\
24.42 \\
7.4\end{array}$ & $\begin{array}{c}45.37 \\
29.91 \\
7.4\end{array}$ & $\begin{array}{c}45.43 \\
35.26 \\
7.4\end{array}$ \\
\hline 26.67 & $\begin{array}{c}\mathrm{TC} \\
\mathrm{SHC} \\
\mathrm{kW}\end{array}$ & & & & & & $\begin{array}{c}48.65 \\
12.73 \\
7.7\end{array}$ & $\begin{array}{c}48.89 \\
18.29 \\
7.7\end{array}$ & $\begin{array}{c}48.99 \\
23.79 \\
7.7\end{array}$ & $\begin{array}{c}49.04 \\
29.20 \\
7.7\end{array}$ \\
\hline 29.44 & $\begin{array}{c}\mathrm{TC} \\
\mathrm{SHC} \\
\mathrm{kW}\end{array}$ & & & & & & & $\begin{array}{c}52.35 \\
12.13 \\
8.0\end{array}$ & $\begin{array}{c}52.66 \\
17.63 \\
8.0\end{array}$ & $\begin{array}{c}52.85 \\
23.09 \\
8.0\end{array}$ \\
\hline 32.22 & $\begin{array}{c}\mathrm{TC} \\
\mathrm{SHC} \\
\mathrm{kW}\end{array}$ & & & & & & & & $\begin{array}{c}56.34 \\
11.50 \\
8.3\end{array}$ & $\begin{array}{c}56.66 \\
16.95 \\
8.3\end{array}$ \\
\hline 35.00 & $\begin{array}{c}\mathrm{TC} \\
\mathrm{SHC} \\
\mathrm{kW}\end{array}$ & & & & & & & & & $\begin{array}{c}60.29 \\
10.84 \\
8.6\end{array}$ \\
\hline
\end{tabular}

\begin{tabular}{|c|c|c|c|c|c|c|c|c|c|c|}
\hline $\mathrm{ODB}\left({ }^{\circ} \mathrm{C}\right)$ & 18.33 & & & & & & & & & \\
\hline \multirow{2}{*}{$\begin{array}{l}\text { EWB } \\
\left({ }^{\circ} \mathrm{C}\right)\end{array}$} & & \multicolumn{9}{|c|}{$\mathrm{EDB}\left({ }^{\circ} \mathrm{C}\right)$} \\
\hline & & 12.78 & 15.56 & 18.33 & 21.11 & 23.89 & 26.67 & 29.44 & 32.22 & 35.00 \\
\hline 4.44 & $\begin{array}{c}\mathrm{TC} \\
\mathrm{SHC} \\
\mathrm{kW}\end{array}$ & $\begin{array}{c}26.00 \\
26.00 \\
6.5\end{array}$ & & & & & & & & \\
\hline 7.22 & $\begin{array}{c}\mathrm{TC} \\
\mathrm{SHC} \\
\mathrm{kW}\end{array}$ & $\begin{array}{c}26.26 \\
25.36 \\
6.6\end{array}$ & $\begin{array}{c}27.73 \\
27.73 \\
6.7\end{array}$ & $\begin{array}{c}29.49 \\
29.49 \\
6.9\end{array}$ & & & & & & \\
\hline 10.00 & $\begin{array}{c}\mathrm{TC} \\
\mathrm{SHC} \\
\mathrm{kW}\end{array}$ & $\begin{array}{c}28.52 \\
19.83 \\
6.8\end{array}$ & $\begin{array}{c}28.60 \\
25.56 \\
6.8\end{array}$ & $\begin{array}{c}29.49 \\
29.49 \\
6.9\end{array}$ & $\begin{array}{c}31.27 \\
31.27 \\
7.1\end{array}$ & & & & & \\
\hline 12.78 & $\begin{array}{c}\mathrm{TC} \\
\mathrm{SHC} \\
\mathrm{kW}\end{array}$ & $\begin{array}{c}31.13 \\
13.92 \\
7.1 \\
\end{array}$ & $\begin{array}{c}31.17 \\
19.74 \\
7.1 \\
\end{array}$ & $\begin{array}{c}31.19 \\
25.46 \\
7.1 \\
\end{array}$ & $\begin{array}{c}31.58 \\
30.63 \\
7.1 \\
\end{array}$ & $\begin{array}{c}33.09 \\
33.09 \\
7.3 \\
\end{array}$ & & & & \\
\hline 15.56 & $\begin{array}{c}\mathrm{TC} \\
\mathrm{SHC} \\
\mathrm{kW}\end{array}$ & & $\begin{array}{c}33.91 \\
13.76 \\
7.3\end{array}$ & $\begin{array}{c}34.00 \\
19.53 \\
7.3\end{array}$ & $\begin{array}{c}34.02 \\
25.22 \\
7.3\end{array}$ & $\begin{array}{c}34.18 \\
30.66 \\
7.4\end{array}$ & $\begin{array}{c}34.96 \\
34.91 \\
7.4\end{array}$ & $\begin{array}{c}36.80 \\
36.80 \\
7.6\end{array}$ & & \\
\hline 18.33 & $\begin{array}{c}\mathrm{TC} \\
\mathrm{SHC} \\
\mathrm{kW}\end{array}$ & & & $\begin{array}{c}36.87 \\
13.49 \\
7.6 \\
\end{array}$ & $\begin{array}{c}36.99 \\
19.21 \\
7.6 \\
\end{array}$ & $\begin{array}{c}37.05 \\
24.87 \\
7.6 \\
\end{array}$ & $\begin{array}{c}37.10 \\
30.39 \\
7.6 \\
\end{array}$ & $\begin{array}{c}37.49 \\
35.41 \\
7.7 \\
\end{array}$ & $\begin{array}{c}38.68 \\
38.68 \\
7.8 \\
\end{array}$ & \\
\hline 21.11 & $\begin{array}{c}\mathrm{TC} \\
\mathrm{SHC} \\
\mathrm{kW}\end{array}$ & & & & $\begin{array}{c}40.06 \\
13.14 \\
7.9\end{array}$ & $\begin{array}{c}40.15 \\
18.79 \\
7.9\end{array}$ & $\begin{array}{c}40.25 \\
24.40 \\
7.9\end{array}$ & $\begin{array}{c}40.27 \\
29.91 \\
7.9\end{array}$ & $\begin{array}{c}40.46 \\
35.18 \\
8.0\end{array}$ & $\begin{array}{c}41.05 \\
39.82 \\
8.0\end{array}$ \\
\hline 23.89 & $\begin{array}{c}\mathrm{TC} \\
\mathrm{SHC} \\
\mathrm{kW}\end{array}$ & & & & & $\begin{array}{c}43.35 \\
12.70 \\
8.2\end{array}$ & $\begin{array}{c}43.52 \\
18.30 \\
8.2\end{array}$ & $\begin{array}{c}43.61 \\
23.85 \\
8.2\end{array}$ & $\begin{array}{c}43.67 \\
29.34 \\
8.3\end{array}$ & $\begin{array}{c}43.76 \\
34.67 \\
8.3\end{array}$ \\
\hline 26.67 & $\begin{array}{c}\mathrm{TC} \\
\mathrm{SHC} \\
\mathrm{kW}\end{array}$ & & & & & & $\begin{array}{c}46.88 \\
12.20 \\
8.6\end{array}$ & $\begin{array}{c}47.04 \\
17.74 \\
8.6\end{array}$ & $\begin{array}{c}47.19 \\
23.25 \\
8.6 \\
\end{array}$ & $\begin{array}{c}47.25 \\
28.67 \\
8.6\end{array}$ \\
\hline 29.44 & $\begin{array}{c}\mathrm{TC} \\
\mathrm{SHC} \\
\mathrm{kW}\end{array}$ & & & & & & & $\begin{array}{c}50.50 \\
11.65 \\
8.9\end{array}$ & $\begin{array}{c}50.77 \\
17.13 \\
8.9\end{array}$ & $\begin{array}{c}50.91 \\
22.57 \\
8.9\end{array}$ \\
\hline 32.22 & $\begin{array}{c}\mathrm{TC} \\
\mathrm{SHC} \\
\mathrm{kW}\end{array}$ & & & & & & & & $\begin{array}{c}54.28 \\
11.05 \\
9.2 \\
\end{array}$ & $\begin{array}{c}54.60 \\
16.47 \\
9.3 \\
\end{array}$ \\
\hline 35.00 & $\begin{array}{c}\mathrm{TC} \\
\mathrm{SHC} \\
\mathrm{kW}\end{array}$ & & & & & & & & & $\begin{array}{c}58.24 \\
10.43 \\
9.6\end{array}$ \\
\hline
\end{tabular}


Table 1-7a. Equipment Full-Load Performance with Gross Capacities (SI Units), continued

\begin{tabular}{|c|c|c|c|c|c|c|c|c|c|c|}
\hline \multirow{3}{*}{$\begin{array}{c}\mathrm{ODB}\left({ }^{\circ} \mathrm{C}\right) \\
\mathrm{EWB} \\
\left({ }^{\circ} \mathrm{C}\right)\end{array}$} & \multirow[t]{3}{*}{23.89} & \multirow{2}{*}{\multicolumn{9}{|c|}{$\operatorname{EDB}\left({ }^{\circ} \mathrm{C}\right)$}} \\
\hline & & & & & & & & & & \\
\hline & & 12.78 & 15.56 & 18.33 & 21.11 & 23.89 & 26.67 & 29.44 & 32.22 & 35.00 \\
\hline 4.44 & $\begin{array}{c}\text { TC } \\
\text { SHC } \\
\mathrm{kW}\end{array}$ & $\begin{array}{c}24.88 \\
24.88 \\
7.1\end{array}$ & & & & & & & & \\
\hline 7.22 & $\begin{array}{c}\mathrm{TC} \\
\mathrm{SHC} \\
\mathrm{kW}\end{array}$ & $\begin{array}{c}25.06 \\
24.52 \\
7.1\end{array}$ & $\begin{array}{c}26.59 \\
26.59 \\
7.3\end{array}$ & $\begin{array}{c}28.31 \\
28.31 \\
7.6\end{array}$ & & & & & & \\
\hline 10.00 & $\begin{array}{c}\text { TC } \\
\text { SHC } \\
\mathrm{kW}\end{array}$ & $\begin{array}{c}27.20 \\
19.12 \\
7.4\end{array}$ & $\begin{array}{c}27.29 \\
24.80 \\
7.4\end{array}$ & $\begin{array}{c}28.31 \\
28.31 \\
7.6\end{array}$ & $\begin{array}{c}30.08 \\
30.08 \\
7.8\end{array}$ & & & & & \\
\hline 12.78 & $\begin{array}{c}\mathrm{TC} \\
\mathrm{SHC} \\
\mathrm{kW}\end{array}$ & $\begin{array}{c}29.72 \\
13.22 \\
7.7\end{array}$ & $\begin{array}{c}29.77 \\
19.05 \\
7.7\end{array}$ & $\begin{array}{c}29.81 \\
24.78 \\
7.7\end{array}$ & $\begin{array}{c}30.26 \\
29.74 \\
7.8\end{array}$ & $\begin{array}{c}31.86 \\
31.86 \\
8.0\end{array}$ & & & & \\
\hline 15.56 & $\begin{array}{c}\text { TC } \\
\text { SHC } \\
\mathrm{kW}\end{array}$ & & $\begin{array}{c}32.44 \\
13.09 \\
8.0\end{array}$ & $\begin{array}{c}32.48 \\
18.83 \\
8.0\end{array}$ & $\begin{array}{c}32.52 \\
24.54 \\
8.0\end{array}$ & $\begin{array}{c}32.74 \\
29.94 \\
8.1\end{array}$ & $\begin{array}{c}33.68 \\
33.68 \\
8.2\end{array}$ & $\begin{array}{c}35.53 \\
35.53 \\
8.4\end{array}$ & & \\
\hline 18.33 & $\begin{array}{c}\mathrm{TC} \\
\mathrm{SHC} \\
\mathrm{kW}\end{array}$ & & & $\begin{array}{c}35.29 \\
12.84 \\
8.4\end{array}$ & $\begin{array}{c}35.42 \\
18.56 \\
8.4\end{array}$ & $\begin{array}{c}35.47 \\
24.22 \\
8.4\end{array}$ & $\begin{array}{c}35.54 \\
29.70 \\
8.4\end{array}$ & $\begin{array}{c}35.99 \\
34.61 \\
8.4\end{array}$ & $\begin{array}{c}37.39 \\
37.39 \\
8.6\end{array}$ & \\
\hline 21.11 & $\begin{array}{c}\text { TC } \\
\text { SHC } \\
\mathrm{kW}\end{array}$ & & & & $\begin{array}{c}38.38 \\
12.52 \\
8.7 \\
\end{array}$ & \begin{tabular}{|l}
38.48 \\
18.17 \\
8.7 \\
\end{tabular} & $\begin{array}{c}38.56 \\
23.78 \\
8.7\end{array}$ & $\begin{array}{c}38.57 \\
29.26 \\
8.7\end{array}$ & $\begin{array}{c}38.83 \\
34.48 \\
8.8 \\
\end{array}$ & $\begin{array}{c}39.51 \\
38.90 \\
8.8 \\
\end{array}$ \\
\hline 23.89 & $\begin{array}{c}\mathrm{TC} \\
\mathrm{SHC} \\
\mathrm{kW}\end{array}$ & & & & & $\begin{array}{c}41.59 \\
12.11 \\
9.1\end{array}$ & $\begin{array}{c}41.75 \\
17.71 \\
9.1 \\
\end{array}$ & $\begin{array}{c}41.85 \\
23.27 \\
9.1 \\
\end{array}$ & $\begin{array}{c}41.89 \\
28.74 \\
9.1\end{array}$ & $\begin{array}{c}41.97 \\
34.04 \\
9.1\end{array}$ \\
\hline 26.67 & $\begin{array}{c}\text { TC } \\
\text { SHC } \\
\mathrm{kW}\end{array}$ & & & & & & $\begin{array}{c}44.96 \\
11.64 \\
9.4 \\
\end{array}$ & $\begin{array}{c}45.17 \\
17.19 \\
9.4 \\
\end{array}$ & $\begin{array}{c}45.30 \\
22.69 \\
9.5 \\
\end{array}$ & $\begin{array}{c}45.37 \\
28.12 \\
9.5 \\
\end{array}$ \\
\hline 29.44 & $\begin{array}{c}\mathrm{TC} \\
\mathrm{SHC} \\
\mathrm{kW}\end{array}$ & & & & & & & $\begin{array}{c}48.48 \\
11.12 \\
9.8 \\
\end{array}$ & $\begin{array}{c}48.76 \\
16.61 \\
9.8 \\
\end{array}$ & $\begin{array}{c}48.92 \\
22.06 \\
9.9 \\
\end{array}$ \\
\hline 32.22 & $\begin{array}{c}\mathrm{TC} \\
\mathrm{SHC} \\
\mathrm{kW}\end{array}$ & & & & & & & & $\begin{array}{c}52.09 \\
10.56 \\
10.2\end{array}$ & $\begin{array}{c}52.49 \\
15.98 \\
10.2\end{array}$ \\
\hline 35.00 & $\begin{array}{c}\mathrm{TC} \\
\mathrm{SHC} \\
\mathrm{kW}\end{array}$ & & & & & & & & & $\begin{array}{c}55.98 \\
9.98 \\
10.6\end{array}$ \\
\hline
\end{tabular}

\begin{tabular}{|c|c|c|c|c|c|c|c|c|c|c|}
\hline $\mathrm{ODB}\left({ }^{\circ} \mathrm{C}\right)$ & 29.44 & & & & & & & & & \\
\hline EWB & & & & & & $\operatorname{EDB}\left({ }^{\circ} \mathrm{C}\right.$ & & & & \\
\hline$\left({ }^{\circ} \mathrm{C}\right)$ & & 12.78 & 15.56 & 18.33 & 21.11 & 23.89 & 26.67 & 29.44 & 32.22 & 35.00 \\
\hline 4.44 & $\begin{array}{c}\mathrm{TC} \\
\mathrm{SHC} \\
\mathrm{kW}\end{array}$ & $\begin{array}{c}23.74 \\
23.74 \\
7.7\end{array}$ & & & & & & & & \\
\hline 7.22 & $\begin{array}{c}\mathrm{TC} \\
\mathrm{SHC} \\
\mathrm{kW}\end{array}$ & $\begin{array}{c}23.80 \\
23.59 \\
7.7\end{array}$ & $\begin{array}{c}25.40 \\
25.40 \\
7.9\end{array}$ & $\begin{array}{c}27.11 \\
27.11 \\
8.2\end{array}$ & & & & & & \\
\hline 10.00 & $\begin{array}{c}\mathrm{TC} \\
\mathrm{SHC} \\
\mathrm{kW}\end{array}$ & $\begin{array}{c}25.82 \\
18.39 \\
8.0 \\
\end{array}$ & $\begin{array}{c}25.94 \\
24.02 \\
8.0 \\
\end{array}$ & $\begin{array}{c}27.11 \\
27.11 \\
8.2 \\
\end{array}$ & $\begin{array}{c}28.84 \\
28.84 \\
8.4 \\
\end{array}$ & & & & & \\
\hline 12.78 & $\begin{array}{c}\mathrm{TC} \\
\mathrm{SHC} \\
\mathrm{kW}\end{array}$ & $\begin{array}{c}28.25 \\
12.50 \\
8.3\end{array}$ & $\begin{array}{c}28.31 \\
18.33 \\
8.4\end{array}$ & $\begin{array}{c}28.34 \\
24.03 \\
8.4\end{array}$ & $\begin{array}{c}28.91 \\
28.76 \\
8.4\end{array}$ & $\begin{array}{c}30.60 \\
30.60 \\
8.7\end{array}$ & & & & \\
\hline 15.56 & $\begin{array}{c}\mathrm{TC} \\
\mathrm{SHC} \\
\mathrm{kW}\end{array}$ & & $\begin{array}{c}30.89 \\
12.39 \\
8.7\end{array}$ & $\begin{array}{c}30.95 \\
18.15 \\
8.7\end{array}$ & $\begin{array}{c}30.98 \\
23.85 \\
8.7\end{array}$ & $\begin{array}{c}31.24 \\
29.17 \\
8.8\end{array}$ & $\begin{array}{c}32.39 \\
32.39 \\
8.9\end{array}$ & $\begin{array}{c}34.20 \\
34.20 \\
9.2\end{array}$ & & \\
\hline 18.33 & $\begin{array}{c}\mathrm{TC} \\
\mathrm{SHC} \\
\mathrm{kW}\end{array}$ & & & $\begin{array}{c}33.68 \\
12.17 \\
9.1 \\
\end{array}$ & $\begin{array}{c}33.77 \\
17.89 \\
9.1 \\
\end{array}$ & $\begin{array}{c}33.82 \\
23.54 \\
9.1 \\
\end{array}$ & $\begin{array}{c}33.92 \\
29.01 \\
9.1 \\
\end{array}$ & $\begin{array}{c}34.47 \\
33.71 \\
9.2 \\
\end{array}$ & $\begin{array}{c}36.04 \\
36.04 \\
9.4 \\
\end{array}$ & \\
\hline 21.11 & $\begin{array}{c}\mathrm{TC} \\
\mathrm{SHC} \\
\mathrm{kW}\end{array}$ & & & & $\begin{array}{c}36.64 \\
11.88 \\
9.5 \\
\end{array}$ & $\begin{array}{c}36.75 \\
17.54 \\
9.5 \\
\end{array}$ & $\begin{array}{c}36.83 \\
23.14 \\
9.5 \\
\end{array}$ & $\begin{array}{c}36.87 \\
28.63 \\
9.5 \\
\end{array}$ & $\begin{array}{c}37.15 \\
33.74 \\
9.5 \\
\end{array}$ & $\begin{array}{c}37.97 \\
37.82 \\
9.7 \\
\end{array}$ \\
\hline 23.89 & $\begin{array}{c}\mathrm{TC} \\
\mathrm{SHC} \\
\mathrm{kW}\end{array}$ & & & & & $\begin{array}{c}39.74 \\
11.51 \\
9.9\end{array}$ & $\begin{array}{c}39.90 \\
17.10 \\
9.9\end{array}$ & $\begin{array}{c}40.01 \\
22.66 \\
9.9\end{array}$ & $\begin{array}{c}40.03 \\
28.13 \\
9.9\end{array}$ & $\begin{array}{c}40.15 \\
33.40 \\
9.9\end{array}$ \\
\hline 26.67 & $\begin{array}{c}\mathrm{TC} \\
\mathrm{SHC} \\
\mathrm{kW}\end{array}$ & & & & & & $\begin{array}{c}43.01 \\
11.07 \\
10.3\end{array}$ & $\begin{array}{c}43.20 \\
16.61 \\
10.3\end{array}$ & $\begin{array}{c}43.33 \\
22.11 \\
10.4\end{array}$ & $\begin{array}{c}43.41 \\
27.54 \\
10.4\end{array}$ \\
\hline 29.44 & $\begin{array}{c}\mathrm{TC} \\
\mathrm{SHC} \\
\mathrm{kW}\end{array}$ & & & & & & & $\begin{array}{c}46.40 \\
10.58 \\
10.7 \\
\end{array}$ & $\begin{array}{c}46.67 \\
16.07 \\
10.8 \\
\end{array}$ & $\begin{array}{c}46.81 \\
21.50 \\
10.8 \\
\end{array}$ \\
\hline 32.22 & $\begin{array}{c}\mathrm{TC} \\
\mathrm{SHC} \\
\mathrm{kW}\end{array}$ & & & & & & & & $\begin{array}{c}49.93 \\
10.06 \\
11.2\end{array}$ & $\begin{array}{c}50.27 \\
15.48 \\
11.2\end{array}$ \\
\hline 35.00 & $\begin{array}{c}\mathrm{TC} \\
\mathrm{SHC} \\
\mathrm{kW}\end{array}$ & & & & & & & & & $\begin{array}{c}53.64 \\
9.51 \\
11.7\end{array}$ \\
\hline
\end{tabular}


Table 1-7a. Equipment Full-Load Performance with Gross Capacities (SI Units), continued

\begin{tabular}{|c|c|c|c|c|c|c|c|c|c|c|}
\hline $\mathrm{ODB}\left({ }^{\circ} \mathrm{C}\right)$ & 35.00 & & & & & & & & & \\
\hline EWB & & & & & & $\overline{E D B}\left({ }^{\circ} \mathrm{C}\right.$ & & & & \\
\hline$\left({ }^{\circ} \mathrm{C}\right)$ & & 12.78 & 15.56 & 18.33 & 21.11 & 23.89 & 26.67 & 29.44 & 32.22 & 35.00 \\
\hline 7.22 & $\begin{array}{l}\text { TC } \\
\text { SHC } \\
\text { kW }\end{array}$ & $\begin{array}{c}22.57 \\
22.56 \\
8.6\end{array}$ & $\begin{array}{c}24.19 \\
24.19 \\
8.5\end{array}$ & $\begin{array}{c}25.85 \\
25.85 \\
8.8\end{array}$ & & & & & & \\
\hline 10.00 & $\begin{array}{l}\mathrm{TC} \\
\mathrm{SHC} \\
\mathrm{kW}\end{array}$ & $\begin{array}{c}24.42 \\
17.66 \\
8.6\end{array}$ & $\begin{array}{c}24.56 \\
23.20 \\
8.6\end{array}$ & $\begin{array}{c}25.85 \\
25.85 \\
8.8\end{array}$ & $\begin{array}{c}27.56 \\
27.56 \\
9.1\end{array}$ & & & & & \\
\hline 12.78 & $\begin{array}{l}\text { TC } \\
\text { SHC } \\
\text { kW }\end{array}$ & $\begin{array}{c}26.79 \\
11.77 \\
9.0\end{array}$ & $\begin{array}{c}26.81 \\
17.60 \\
9.0\end{array}$ & $\begin{array}{c}26.85 \\
23.27 \\
9.0\end{array}$ & $\begin{array}{c}27.56 \\
27.56 \\
9.1\end{array}$ & $\begin{array}{c}29.28 \\
29.28 \\
9.4\end{array}$ & & & & \\
\hline 15.56 & $\begin{array}{l}\mathrm{TC} \\
\mathrm{SHC} \\
\mathrm{kW}\end{array}$ & & $\begin{array}{c}29.32 \\
11.68 \\
9.4\end{array}$ & $\begin{array}{c}29.37 \\
17.46 \\
9.4\end{array}$ & $\begin{array}{c}29.39 \\
23.15 \\
9.4\end{array}$ & $\begin{array}{c}29.72 \\
28.33 \\
9.4\end{array}$ & $\begin{array}{c}31.05 \\
31.05 \\
9.7\end{array}$ & $\begin{array}{c}32.82 \\
32.82 \\
9.9\end{array}$ & & \\
\hline 18.33 & $\begin{array}{l}\text { TC } \\
\text { SHC } \\
\mathrm{kW}\end{array}$ & & & $\begin{array}{c}32.01 \\
11.49 \\
9.8\end{array}$ & $\begin{array}{c}32.07 \\
17.20 \\
9.8\end{array}$ & $\begin{array}{c}32.12 \\
22.87 \\
9.8\end{array}$ & $\begin{array}{c}32.26 \\
28.28 \\
9.9\end{array}$ & $\begin{array}{c}32.92 \\
32.68 \\
10.0\end{array}$ & $\begin{array}{c}34.63 \\
34.63 \\
10.2\end{array}$ & \\
\hline $19.44^{*}$ & $\begin{array}{l}\mathrm{TC} \\
\mathrm{SHC} \\
\mathrm{kW}\end{array}$ & & & & & & $\begin{array}{c}33.28 \\
26.04 \\
10.0\end{array}$ & & & \\
\hline 21.11 & $\begin{array}{c}\mathrm{TC} \\
\mathrm{SHC} \\
\mathrm{kW}\end{array}$ & & & & $\begin{array}{c}34.82 \\
11.22 \\
10.2\end{array}$ & $\begin{array}{c}34.94 \\
16.87 \\
10.3\end{array}$ & $\begin{array}{c}35.02 \\
22.48 \\
10.3\end{array}$ & $\begin{array}{c}35.05 \\
27.96 \\
10.3\end{array}$ & $\begin{array}{c}35.41 \\
32.97 \\
10.3\end{array}$ & $\begin{array}{c}36.45 \\
36.45 \\
10.5\end{array}$ \\
\hline 23.89 & $\begin{array}{c}\mathrm{TC} \\
\mathrm{SHC} \\
\mathrm{kW}\end{array}$ & & & & & $\begin{array}{c}37.81 \\
10.87 \\
10.7\end{array}$ & $\begin{array}{c}37.96 \\
16.47 \\
10.7\end{array}$ & $\begin{array}{c}38.07 \\
22.03 \\
10.7\end{array}$ & $\begin{array}{c}38.10 \\
27.49 \\
10.7\end{array}$ & $\begin{array}{c}38.28 \\
32.72 \\
10.8\end{array}$ \\
\hline 26.67 & $\begin{array}{l}\text { TC } \\
\text { SHC } \\
\text { kW }\end{array}$ & & & & & & $\begin{array}{c}40.96 \\
10.48 \\
11.2\end{array}$ & $\begin{array}{c}41.15 \\
16.02 \\
11.2\end{array}$ & $\begin{array}{c}41.29 \\
21.52 \\
11.2\end{array}$ & $\begin{array}{c}41.33 \\
26.95 \\
11.7\end{array}$ \\
\hline 29.44 & $\begin{array}{c}\mathrm{TC} \\
\mathrm{SHC} \\
\mathrm{kW}\end{array}$ & & & & & & & $\begin{array}{c}44.23 \\
10.03 \\
11.7\end{array}$ & $\begin{array}{c}44.49 \\
15.51 \\
11.7\end{array}$ & $\begin{array}{c}44.64 \\
20.95 \\
11.7\end{array}$ \\
\hline 32.22 & $\begin{array}{c}\mathrm{TC} \\
\mathrm{SHC} \\
\mathrm{kW}\end{array}$ & & & & & & & & $\begin{array}{c}47.66 \\
9.54 \\
12.2\end{array}$ & $\begin{array}{c}47.92 \\
14.95 \\
12.2\end{array}$ \\
\hline 35.00 & $\begin{array}{c}\text { TC } \\
\text { SHC } \\
\text { kW }\end{array}$ & & & & & & & & & $\begin{array}{c}51.18 \\
9.03 \\
12.7\end{array}$ \\
\hline
\end{tabular}

\begin{tabular}{|c|c|c|c|c|c|c|c|c|c|c|}
\hline $\mathrm{ODB}\left({ }^{\circ} \mathrm{C}\right)$ & 40.56 & & & & & & & & & \\
\hline EWB & & & & & & $\mathrm{EDB}\left({ }^{\circ} \mathrm{C}\right.$ & & & & \\
\hline$\left({ }^{\circ} \mathrm{C}\right)$ & & 12.78 & 15.56 & 18.33 & 21.11 & 23.89 & 26.67 & 29.44 & 32.22 & 35.00 \\
\hline 7.22 & $\begin{array}{c}\mathrm{TC} \\
\mathrm{SHC} \\
\mathrm{kW}\end{array}$ & $\begin{array}{c}21.34 \\
21.34 \\
8.8\end{array}$ & $\begin{array}{c}22.92 \\
22.92 \\
9.1\end{array}$ & $\begin{array}{c}24.56 \\
24.56 \\
9.4\end{array}$ & & & & & & \\
\hline 10.00 & $\begin{array}{c}\mathrm{TC} \\
\mathrm{SHC} \\
\mathrm{kW}\end{array}$ & $\begin{array}{c}22.95 \\
16.89 \\
9.1\end{array}$ & $\begin{array}{c}23.16 \\
22.33 \\
9.1\end{array}$ & $\begin{array}{c}24.56 \\
24.56 \\
9.4\end{array}$ & $\begin{array}{c}26.23 \\
26.23 \\
9.7\end{array}$ & & & & & \\
\hline 12.78 & $\begin{array}{c}\mathrm{TC} \\
\mathrm{SHC} \\
\mathrm{kW}\end{array}$ & $\begin{array}{c}25.27 \\
11.03 \\
9.6\end{array}$ & $\begin{array}{c}25.26 \\
16.86 \\
9.5\end{array}$ & $\begin{array}{c}25.35 \\
22.51 \\
9.6\end{array}$ & $\begin{array}{c}26.24 \\
26.24 \\
9.7\end{array}$ & $\begin{array}{c}27.93 \\
27.93 \\
10.1\end{array}$ & & & & \\
\hline 15.56 & $\begin{array}{c}\mathrm{TC} \\
\mathrm{SHC} \\
\mathrm{kW}\end{array}$ & & $\begin{array}{c}27.68 \\
10.96 \\
10.0\end{array}$ & $\begin{array}{c}27.73 \\
16.74 \\
10.0\end{array}$ & $\begin{array}{c}27.75 \\
22.42 \\
10.0\end{array}$ & $\begin{array}{c}28.17 \\
27.41 \\
10.1\end{array}$ & $\begin{array}{c}29.65 \\
29.65 \\
10.4\end{array}$ & & & \\
\hline 18.33 & $\begin{array}{c}\text { TC } \\
\text { SHC } \\
\mathrm{kW}\end{array}$ & & & $\begin{array}{c}30.28 \\
10.80 \\
10.5\end{array}$ & $\begin{array}{c}30.34 \\
16.51 \\
10.5\end{array}$ & $\begin{array}{c}30.37 \\
22.18 \\
10.5\end{array}$ & $\begin{array}{c}30.56 \\
27.51 \\
10.6\end{array}$ & $\begin{array}{c}31.39 \\
31.39 \\
10.7\end{array}$ & $\begin{array}{c}33.17 \\
33.17 \\
11.0\end{array}$ & \\
\hline 21.11 & $\begin{array}{c}\mathrm{TC} \\
\mathrm{SHC} \\
\mathrm{kW}\end{array}$ & & & & $\begin{array}{c}32.98 \\
10.57 \\
11.0\end{array}$ & $\begin{array}{c}33.12 \\
16.23 \\
11.0\end{array}$ & $\begin{array}{c}33.17 \\
21.82 \\
11.0\end{array}$ & $\begin{array}{c}33.21 \\
27.26 \\
11.0\end{array}$ & $\begin{array}{c}33.67 \\
32.13 \\
11.1\end{array}$ & $\begin{array}{c}34.97 \\
34.97 \\
11.3\end{array}$ \\
\hline 23.89 & $\begin{array}{c}\mathrm{TC} \\
\mathrm{SHC} \\
\mathrm{kW}\end{array}$ & & & & & $\begin{array}{c}35.85 \\
10.26 \\
11.5\end{array}$ & $\begin{array}{c}36.01 \\
15.85 \\
11.5\end{array}$ & $\begin{array}{c}36.08 \\
21.40 \\
11.5\end{array}$ & $\begin{array}{c}36.13 \\
26.86 \\
11.5\end{array}$ & $\begin{array}{c}36.37 \\
32.00 \\
11.6\end{array}$ \\
\hline 26.67 & $\begin{array}{c}\mathrm{TC} \\
\mathrm{SHC} \\
\mathrm{kW}\end{array}$ & & & & & & $\begin{array}{c}38.86 \\
9.89 \\
12.0 \\
\end{array}$ & $\begin{array}{c}39.07 \\
15.42 \\
12.1 \\
\end{array}$ & $\begin{array}{l}39.18 \\
20.91 \\
12.1 \\
\end{array}$ & $\begin{array}{c}39.22 \\
26.37 \\
12.1 \\
\end{array}$ \\
\hline 29.44 & $\begin{array}{c}\mathrm{TC} \\
\mathrm{SHC} \\
\mathrm{kW}\end{array}$ & & & & & & & $\begin{array}{c}42.00 \\
9.47 \\
12.6\end{array}$ & $\begin{array}{c}42.24 \\
14.94 \\
12.6\end{array}$ & $\begin{array}{c}42.38 \\
20.37 \\
12.6\end{array}$ \\
\hline 32.22 & $\begin{array}{c}\mathrm{TC} \\
\mathrm{SHC} \\
\mathrm{kW}\end{array}$ & & & & & & & & $\begin{array}{c}45.27 \\
9.03 \\
13.1\end{array}$ & $\begin{array}{c}45.55 \\
14.42 \\
13.2\end{array}$ \\
\hline 35.00 & $\begin{array}{c}\mathrm{TC} \\
\mathrm{SHC} \\
\mathrm{kW}\end{array}$ & & & & & & & & & $\begin{array}{c}48.65 \\
8.54 \\
13.7\end{array}$ \\
\hline
\end{tabular}


Table 1-7a. Equipment Full-Load Performance with Gross Capacities (SI Units), continued

\begin{tabular}{|c|c|c|c|c|c|c|c|c|c|c|}
\hline ODB $\left({ }^{\circ} \mathrm{C}\right.$ & 46.11 & & & & & & & & & \\
\hline EWB & & & & & & $\mathrm{EDB}\left({ }^{\circ} \mathrm{C}\right.$ & & & & \\
\hline$\left({ }^{\circ} \mathrm{C}\right)$ & & 12.78 & 15.56 & 18.33 & 21.11 & 23.89 & 26.67 & 29.44 & 32.22 & 35.00 \\
\hline 7.22 & $\begin{array}{l}\mathrm{TC} \\
\text { SHC } \\
\mathrm{kW}\end{array}$ & $\begin{array}{c}20.08 \\
20.08 \\
9.3\end{array}$ & $\begin{array}{c}21.64 \\
21.64 \\
9.6\end{array}$ & $\begin{array}{c}33.24 \\
23.24 \\
10.0\end{array}$ & & & & & & \\
\hline 10.00 & $\begin{array}{l}\mathrm{TC} \\
\text { SHC } \\
\mathrm{kW}\end{array}$ & $\begin{array}{c}21.45 \\
16.13 \\
9.6\end{array}$ & $\begin{array}{c}21.74 \\
21.39 \\
9.6\end{array}$ & $\begin{array}{c}23.24 \\
23.24 \\
10.0\end{array}$ & $\begin{array}{c}24.87 \\
24.87 \\
10.4\end{array}$ & & & & & \\
\hline 12.78 & $\begin{array}{l}\mathrm{TC} \\
\text { SHC } \\
\mathrm{kW}\end{array}$ & $\begin{array}{c}23.68 \\
10.27 \\
10.1\end{array}$ & $\begin{array}{c}23.69 \\
16.12 \\
10.1\end{array}$ & $\begin{array}{c}23.80 \\
21.71 \\
10.1\end{array}$ & $\begin{array}{c}24.87 \\
24.87 \\
10.4\end{array}$ & $\begin{array}{c}26.53 \\
26.53 \\
10.7\end{array}$ & & & & \\
\hline 15.56 & $\begin{array}{l}\text { TC } \\
\text { SHC } \\
\text { kW }\end{array}$ & & $\begin{array}{c}26.01 \\
10.23 \\
10.6\end{array}$ & $\begin{array}{c}26.06 \\
16.01 \\
10.6\end{array}$ & $\begin{array}{c}26.09 \\
21.68 \\
10.6\end{array}$ & $\begin{array}{c}26.61 \\
26.38 \\
10.7\end{array}$ & $\begin{array}{c}28.22 \\
28.22 \\
11.1\end{array}$ & & & \\
\hline 18.33 & $\begin{array}{l}\text { TC } \\
\text { SHC } \\
\text { kW }\end{array}$ & & & $\begin{array}{c}28.52 \\
10.10 \\
11.2\end{array}$ & $\begin{array}{c}28.57 \\
15.83 \\
11.2\end{array}$ & $\begin{array}{c}28.58 \\
21.49 \\
11.2\end{array}$ & $\begin{array}{c}28.84 \\
26.69 \\
11.2\end{array}$ & $\begin{array}{c}29.93 \\
29.93 \\
11.5\end{array}$ & $\begin{array}{c}31.67 \\
31.67 \\
11.8\end{array}$ & \\
\hline 21.11 & $\begin{array}{l}\text { TC } \\
\text { SHC } \\
\mathrm{kW}\end{array}$ & & & & $\begin{array}{c}31.12 \\
9.89 \\
11.7\end{array}$ & $\begin{array}{c}31.22 \\
15.56 \\
11.7\end{array}$ & $\begin{array}{c}31.26 \\
21.15 \\
11.7\end{array}$ & $\begin{array}{c}31.36 \\
26.57 \\
11.8\end{array}$ & $\begin{array}{c}31.91 \\
31.16 \\
11.9\end{array}$ & $\begin{array}{c}33.42 \\
33.42 \\
12.2\end{array}$ \\
\hline 23.89 & $\begin{array}{l}\mathrm{TC} \\
\mathrm{SHC} \\
\mathrm{kW}\end{array}$ & & & & & $\begin{array}{c}33.82 \\
9.62 \\
12.3\end{array}$ & $\begin{array}{c}34.00 \\
15.22 \\
12.3\end{array}$ & $\begin{array}{c}34.06 \\
20.78 \\
12.3\end{array}$ & $\begin{array}{c}34.11 \\
26.21 \\
12.3\end{array}$ & $\begin{array}{c}34.44 \\
31.23 \\
12.4\end{array}$ \\
\hline 26.67 & $\begin{array}{l}\text { TC } \\
\text { SHC } \\
\mathrm{kW}\end{array}$ & & & & & & $\begin{array}{c}36.71 \\
9.29 \\
12.8\end{array}$ & $\begin{array}{c}36.90 \\
14.81 \\
12.9\end{array}$ & $\begin{array}{c}37.02 \\
20.32 \\
12.9\end{array}$ & $\begin{array}{c}37.08 \\
25.75 \\
12.9\end{array}$ \\
\hline 29.44 & $\begin{array}{l}\text { TC } \\
\text { SHC } \\
\mathrm{kW}\end{array}$ & & & & & & & $\begin{array}{c}39.72 \\
8.91 \\
13.4\end{array}$ & $\begin{array}{c}39.95 \\
14.36 \\
13.5\end{array}$ & $\begin{array}{c}40.10 \\
19.82 \\
13.5\end{array}$ \\
\hline 32.22 & $\begin{array}{l}\mathrm{TC} \\
\mathrm{SHC} \\
\mathrm{kW} \\
\end{array}$ & & & & & & & & $\begin{array}{c}42.77 \\
8.50 \\
14.0\end{array}$ & $\begin{array}{c}43.12 \\
13.88 \\
14.1\end{array}$ \\
\hline 35.00 & $\begin{array}{l}\text { TC } \\
\text { SHC } \\
\text { kW }\end{array}$ & & & & & & & & & $\begin{array}{c}46.05 \\
8.04 \\
14.7\end{array}$ \\
\hline
\end{tabular}

Notes:

1. $\mathrm{TC}=$ gross total capacity $(\mathrm{kW}$ thermal $)$

2. $\mathrm{SHC}=$ gross sensible heat capacity $(\mathrm{kW}$ thermal $)$

3. $\mathrm{kW}=$ compressor power $(\mathrm{kW})$

4. $\mathrm{ODB}=$ ambient dry-bulb temperature $=$ air temperature $\left({ }^{\circ} \mathrm{C}\right)$ entering condenser

5. $\mathrm{EDB}=$ dry-bulb temperature $\left({ }^{\circ} \mathrm{C}\right)$ entering indoor coil

6. $\mathrm{EWB}=$ wet-bulb temperature $\left({ }^{\circ} \mathrm{C}\right)$ entering indoor coil

7. Airflow rate $=$ indoor coil airflow rate $\left(6796 \mathrm{~m}^{3} / \mathrm{h}[4000\right.$ cubic feet per minute $(\mathrm{CFM})]$ for all data)

8. Blue background (shaded upper left cells) $=$ potential for freezing indoor coil

9. Red background ( shaded lower right cells) = compressor outside operating envelope

CANNOT RUN HERE (for prolonged operation)

10. Each point has optimum charge (R22 charge not constant)

11. Computer model used to generate catalog data

12. Computer model based on test data

13. Computer model validated within the operating envelope of compressor

14. Computer model iterates and determines if the coil is wet or dry

15. Data are for 38AKS012 matched with a 40RM012 $\left(6796 \mathrm{~m}^{3} / \mathrm{h}\right.$ indoors)

16. Original data provided $6 / 27 / 01$; additional data provided $9 / 25 / 01$ and $9 / 18 / 02$

17. Data received from D. Barkley and J. Pegues of Carrier Corporation, Syracuse, New York, US.

18. SI data converted from original IP data by J. Neymark, J. Neymark \& Associates, Golden, Colorado, US. 
Table 1-7b. Equipment Full-Load Performance with Gross Capacities (IP Units)

\begin{tabular}{|c|c|c|c|c|c|c|c|c|c|c|}
\hline \multirow{3}{*}{$\begin{array}{c}\text { ODB }\left({ }^{\circ} \mathrm{F}\right) \\
\text { EWB } \\
\left({ }^{\circ} \mathrm{F}\right)\end{array}$} & 55 & & & & & & & & & \\
\hline & & \multicolumn{9}{|c|}{$\mathrm{EDB}\left({ }^{\circ} \mathrm{F}\right)$} \\
\hline & & 55 & 60 & 65 & 70 & 75 & 80 & 85 & 90 & 95 \\
\hline 40 & $\begin{array}{c}\text { TC } \\
\text { SHC } \\
\mathrm{kW}\end{array}$ & $\begin{array}{c}92.3 \\
92.3 \\
6.0\end{array}$ & & & & & & & & \\
\hline 45 & $\begin{array}{c}\text { TC } \\
\text { SHC } \\
\mathrm{kW}\end{array}$ & $\begin{array}{c}93.7 \\
89.2 \\
6.0\end{array}$ & $\begin{array}{c}98.3 \\
98.3 \\
6.1\end{array}$ & $\begin{array}{c}104.4 \\
104.4 \\
6.3\end{array}$ & & & & & & \\
\hline 50 & $\begin{array}{c}\mathrm{TC} \\
\mathrm{SHC} \\
\mathrm{kW}\end{array}$ & $\begin{array}{c}101.7 \\
70.1 \\
6.2\end{array}$ & $\begin{array}{c}101.9 \\
89.6 \\
6.2\end{array}$ & $\begin{array}{c}104.4 \\
104.4 \\
6.3\end{array}$ & $\begin{array}{c}110.6 \\
110.6 \\
6.4\end{array}$ & & & & & \\
\hline 55 & $\begin{array}{c}\text { TC } \\
\text { SHC } \\
\mathrm{kW}\end{array}$ & $\begin{array}{c}110.9 \\
49.9 \\
6.4\end{array}$ & $\begin{array}{c}110.9 \\
69.7 \\
6.4\end{array}$ & $\begin{array}{c}111.1 \\
89.3 \\
6.4\end{array}$ & $\begin{array}{c}112.1 \\
107.2 \\
6.4\end{array}$ & $\begin{array}{c}116.8 \\
116.8 \\
6.6\end{array}$ & & & & \\
\hline 60 & $\begin{array}{c}\mathrm{TC} \\
\mathrm{SHC} \\
\mathrm{kW}\end{array}$ & & $\begin{array}{c}120.5 \\
49.2 \\
6.6\end{array}$ & $\begin{array}{c}120.9 \\
68.9 \\
6.6 \\
\end{array}$ & $\begin{array}{c}120.9 \\
88.2 \\
6.6 \\
\end{array}$ & $\begin{array}{c}121.4 \\
107.1 \\
6.7\end{array}$ & $\begin{array}{c}123.7 \\
122.6 \\
6.7 \\
\end{array}$ & $\begin{array}{c}129.6 \\
129.6 \\
6.8\end{array}$ & & \\
\hline 65 & $\begin{array}{c}\mathrm{TC} \\
\mathrm{SHC} \\
\mathrm{kW}\end{array}$ & & & $\begin{array}{c}131.1 \\
48.2 \\
6.9\end{array}$ & $\begin{array}{c}131.3 \\
67.7 \\
6.9\end{array}$ & $\begin{array}{c}131.5 \\
87.0 \\
6.9\end{array}$ & $\begin{array}{c}131.7 \\
105.9 \\
6.9\end{array}$ & $\begin{array}{c}132.8 \\
123.4 \\
6.9\end{array}$ & $\begin{array}{c}136.2 \\
136.2 \\
7.0\end{array}$ & $\begin{array}{c}142.7 \\
142.7 \\
7.1\end{array}$ \\
\hline 70 & $\begin{array}{c}\text { TC } \\
\text { SHC } \\
\mathrm{kW}\end{array}$ & & & & $\begin{array}{c}142.1 \\
46.9 \\
7.1 \\
\end{array}$ & $\begin{array}{c}142.5 \\
66.2 \\
7.1\end{array}$ & $\begin{array}{c}142.8 \\
85.3 \\
7.1 \\
\end{array}$ & $\begin{array}{c}142.9 \\
104.1 \\
7.1\end{array}$ & $\begin{array}{c}143.4 \\
122.3 \\
7.2 \\
\end{array}$ & $\begin{array}{c}145.1 \\
124.0 \\
7.2\end{array}$ \\
\hline 75 & $\begin{array}{c}\mathrm{TC} \\
\mathrm{SHC} \\
\mathrm{kW}\end{array}$ & & & & & $\begin{array}{c}153.6 \\
45.3 \\
7.4\end{array}$ & $\begin{array}{c}154.2 \\
64.4 \\
7.4\end{array}$ & $\begin{array}{c}154.6 \\
83.3 \\
7.4\end{array}$ & $\begin{array}{c}154.8 \\
102.0 \\
7.4\end{array}$ & $\begin{array}{c}155.0 \\
120.3 \\
7.4\end{array}$ \\
\hline 80 & $\begin{array}{c}\mathrm{TC} \\
\mathrm{SHC} \\
\mathrm{kW}\end{array}$ & & & & & & $\begin{array}{c}166.0 \\
43.4 \\
7.7\end{array}$ & $\begin{array}{c}166.8 \\
62.4 \\
7.7\end{array}$ & $\begin{array}{c}167.1 \\
81.2 \\
7.7\end{array}$ & $\begin{array}{c}167.3 \\
99.6 \\
7.7\end{array}$ \\
\hline 85 & $\begin{array}{c}\mathrm{TC} \\
\mathrm{SHC} \\
\mathrm{kW}\end{array}$ & & & & & & & $\begin{array}{c}178.6 \\
41.4 \\
8.0 \\
\end{array}$ & $\begin{array}{c}179.7 \\
60.1 \\
8.0 \\
\end{array}$ & $\begin{array}{c}180.3 \\
78.8 \\
8.0 \\
\end{array}$ \\
\hline 90 & $\begin{array}{c}\text { TC } \\
\text { SHC } \\
\mathrm{kW}\end{array}$ & & & & & & & & $\begin{array}{c}192.2 \\
39.3 \\
8.3\end{array}$ & $\begin{array}{c}193.3 \\
57.8 \\
8.3\end{array}$ \\
\hline 95 & $\begin{array}{c}\mathrm{TC} \\
\mathrm{SHC} \\
\mathrm{kW}\end{array}$ & & & & & & & & & $\begin{array}{c}205.7 \\
37.0 \\
8.6\end{array}$ \\
\hline
\end{tabular}

\begin{tabular}{|c|c|c|c|c|c|c|c|c|c|c|}
\hline $\mathrm{ODB}\left({ }^{\circ} \mathrm{F}\right)$ & 65 & & & & & & & & & \\
\hline EWB & & & & & & $\mathrm{EDB}\left({ }^{\circ} \mathrm{F}\right)$ & & & & \\
\hline$\left({ }^{\circ} \mathrm{F}\right)$ & & 55 & 60 & 65 & 70 & 75 & 80 & 85 & 90 & 95 \\
\hline 40 & $\begin{array}{c}\mathrm{TC} \\
\mathrm{SHC} \\
\mathrm{kW}\end{array}$ & $\begin{array}{c}88.7 \\
88.7 \\
6.5\end{array}$ & & & & & & & & \\
\hline 45 & $\begin{array}{c}\mathrm{TC} \\
\mathrm{SHC} \\
\mathrm{kW}\end{array}$ & $\begin{array}{l}89.6 \\
86.5 \\
6.6 \\
\end{array}$ & $\begin{array}{c}94.6 \\
94.6 \\
6.7 \\
\end{array}$ & $\begin{array}{c}100.6 \\
100.6 \\
6.9 \\
\end{array}$ & & & & & & \\
\hline 50 & $\begin{array}{l}\mathrm{TC} \\
\mathrm{SHC} \\
\mathrm{kW}\end{array}$ & $\begin{array}{c}97.3 \\
67.7 \\
6.8 \\
\end{array}$ & $\begin{array}{c}97.6 \\
87.2 \\
6.8 \\
\end{array}$ & $\begin{array}{c}100.6 \\
100.6 \\
6.9 \\
\end{array}$ & $\begin{array}{c}106.7 \\
106.7 \\
7.1 \\
\end{array}$ & & & & & \\
\hline 55 & $\begin{array}{c}\mathrm{TC} \\
\mathrm{SHC} \\
\mathrm{kW}\end{array}$ & $\begin{array}{c}106.2 \\
47.5 \\
7.1 \\
\end{array}$ & $\begin{array}{c}106.4 \\
67.4 \\
7.1 \\
\end{array}$ & $\begin{array}{c}106.4 \\
86.9 \\
7.1 \\
\end{array}$ & $\begin{array}{c}107.7 \\
104.5 \\
7.1 \\
\end{array}$ & $\begin{array}{c}112.9 \\
112.9 \\
7.3 \\
\end{array}$ & & & & \\
\hline 60 & $\begin{array}{c}\mathrm{TC} \\
\mathrm{SHC} \\
\mathrm{kW} \\
\end{array}$ & & $\begin{array}{c}115.7 \\
47.0 \\
7.3 \\
\end{array}$ & $\begin{array}{c}116.0 \\
66.6 \\
7.3 \\
\end{array}$ & $\begin{array}{c}116.1 \\
86.0 \\
7.3 \\
\end{array}$ & $\begin{array}{c}116.6 \\
104.6 \\
7.4 \\
\end{array}$ & $\begin{array}{c}119.3 \\
119.1 \\
7.4 \\
\end{array}$ & $\begin{array}{c}125.5 \\
125.5 \\
7.6 \\
\end{array}$ & & \\
\hline 65 & $\begin{array}{c}\mathrm{TC} \\
\mathrm{SHC} \\
\mathrm{kW}\end{array}$ & & & $\begin{array}{c}125.8 \\
46.0 \\
7.6 \\
\end{array}$ & $\begin{array}{c}126.2 \\
65.6 \\
7.6 \\
\end{array}$ & $\begin{array}{c}126.4 \\
84.9 \\
7.6\end{array}$ & $\begin{array}{c}126.6 \\
103.7 \\
7.6 \\
\end{array}$ & $\begin{array}{c}127.9 \\
120.8 \\
7.7 \\
\end{array}$ & $\begin{array}{c}132.0 \\
132.0 \\
7.8 \\
\end{array}$ & \\
\hline 70 & $\begin{array}{c}\mathrm{TC} \\
\mathrm{SHC} \\
\mathrm{kW}\end{array}$ & & & & $\begin{array}{c}136.7 \\
44.8 \\
7.9 \\
\end{array}$ & $\begin{array}{c}137.0 \\
64.1 \\
7.9 \\
\end{array}$ & $\begin{array}{c}137.3 \\
83.3 \\
7.9 \\
\end{array}$ & \begin{tabular}{c|}
137.4 \\
102.1 \\
7.9 \\
\end{tabular} & $\begin{array}{c}138.0 \\
120.0 \\
8.0 \\
\end{array}$ & \begin{tabular}{|c|}
140.1 \\
135.8 \\
8.0 \\
\end{tabular} \\
\hline 75 & $\begin{array}{c}\mathrm{TC} \\
\mathrm{SHC} \\
\mathrm{kW}\end{array}$ & & & & & $\begin{array}{c}147.9 \\
43.3 \\
8.2 \\
\end{array}$ & $\begin{array}{c}148.5 \\
62.4 \\
8.2 \\
\end{array}$ & $\begin{array}{c}148.8 \\
81.4 \\
8.2 \\
\end{array}$ & $\begin{array}{c}149.0 \\
100.1 \\
8.3 \\
\end{array}$ & $\begin{array}{c}149.3 \\
118.3 \\
8.3 \\
\end{array}$ \\
\hline 80 & $\begin{array}{l}\mathrm{TC} \\
\mathrm{SHC} \\
\mathrm{kW}\end{array}$ & & & & & & $\begin{array}{c}159.9 \\
41.6 \\
8.6 \\
\end{array}$ & $\begin{array}{c}160.5 \\
60.5 \\
8.6 \\
\end{array}$ & $\begin{array}{c}161.0 \\
79.3 \\
8.6 \\
\end{array}$ & $\begin{array}{c}161.2 \\
97.8 \\
8.6 \\
\end{array}$ \\
\hline 85 & $\begin{array}{c}\text { TC } \\
\text { SHC } \\
\mathrm{kW}\end{array}$ & & & & & & & $\begin{array}{c}172.3 \\
39.7 \\
8.9 \\
\end{array}$ & $\begin{array}{c}173.2 \\
58.4 \\
8.9\end{array}$ & $\begin{array}{c}173.7 \\
77.0 \\
8.9\end{array}$ \\
\hline 90 & $\begin{array}{c}\mathrm{TC} \\
\mathrm{SHC} \\
\mathrm{kW}\end{array}$ & & & & & & & & $\begin{array}{c}185.2 \\
37.7 \\
9.2 \\
\end{array}$ & $\begin{array}{c}186.3 \\
56.2 \\
9.3 \\
\end{array}$ \\
\hline 95 & $\begin{array}{c}\mathrm{TC} \\
\mathrm{SHC} \\
\mathrm{kW}\end{array}$ & & & & & & & & & $\begin{array}{c}198.7 \\
35.6 \\
9.6 \\
\end{array}$ \\
\hline
\end{tabular}


Table 1-7b. Equipment Full-Load Performance with Gross Capacities (IP Units), continued

\begin{tabular}{|c|c|c|c|c|c|c|c|c|c|c|}
\hline \multirow{3}{*}{$\begin{array}{c}\mathrm{ODB}\left({ }^{\circ} \mathrm{F}\right) \\
\mathrm{EWB} \\
\left({ }^{\circ} \mathrm{F}\right)\end{array}$} & 75 & & & & & & & & & \\
\hline & & \multicolumn{9}{|c|}{$\overline{\mathrm{EDB}\left({ }^{\circ} \mathrm{F}\right)}$} \\
\hline & & 55 & 60 & 65 & 70 & 75 & 80 & 85 & 90 & 95 \\
\hline 40 & $\begin{array}{c}\text { TC } \\
\text { SHC } \\
\mathrm{kW}\end{array}$ & $\begin{array}{c}84.9 \\
84.9 \\
7.1\end{array}$ & & & & & & & & \\
\hline 45 & $\begin{array}{c}\mathrm{TC} \\
\mathrm{SHC} \\
\mathrm{kW}\end{array}$ & $\begin{array}{c}85.5 \\
83.7 \\
7.1\end{array}$ & $\begin{array}{c}90.7 \\
90.7 \\
7.3\end{array}$ & $\begin{array}{c}96.6 \\
96.6 \\
7.6\end{array}$ & & & & & & \\
\hline 50 & $\begin{array}{c}\mathrm{TC} \\
\mathrm{SHC} \\
\mathrm{kW}\end{array}$ & $\begin{array}{c}92.8 \\
65.2 \\
7.4\end{array}$ & $\begin{array}{c}93.1 \\
84.6 \\
7.4\end{array}$ & $\begin{array}{c}96.6 \\
96.6 \\
7.6\end{array}$ & $\begin{array}{c}102.6 \\
102.6 \\
7.8\end{array}$ & & & & & \\
\hline 55 & $\begin{array}{c}\mathrm{TC} \\
\mathrm{SHC} \\
\mathrm{kW}\end{array}$ & $\begin{array}{c}101.4 \\
45.1 \\
7.7\end{array}$ & $\begin{array}{c}101.6 \\
65.0 \\
7.7\end{array}$ & $\begin{array}{c}101.7 \\
84.5 \\
7.7\end{array}$ & $\begin{array}{c}103.2 \\
101.5 \\
7.8\end{array}$ & $\begin{array}{c}108.7 \\
108.7 \\
8.0\end{array}$ & & & & \\
\hline 60 & $\begin{array}{c}\mathrm{TC} \\
\mathrm{SHC} \\
\mathrm{kW}\end{array}$ & & $\begin{array}{c}110.7 \\
44.7 \\
8.0\end{array}$ & $\begin{array}{c}110.8 \\
64.3 \\
8.0\end{array}$ & $\begin{array}{c}110.9 \\
83.7 \\
8.0\end{array}$ & $\begin{array}{c}111.7 \\
102.2 \\
8.1\end{array}$ & $\begin{array}{c}114.9 \\
114.9 \\
8.2\end{array}$ & $\begin{array}{c}121.2 \\
121.2 \\
8.4\end{array}$ & & \\
\hline 65 & $\begin{array}{c}\mathrm{TC} \\
\mathrm{SHC} \\
\mathrm{kW}\end{array}$ & & & $\begin{array}{c}120.4 \\
43.8 \\
8.4\end{array}$ & $\begin{array}{c}120.8 \\
63.3 \\
8.4\end{array}$ & $\begin{array}{c}121.0 \\
82.6 \\
8.4\end{array}$ & $\begin{array}{c}121.3 \\
101.3 \\
8.4\end{array}$ & $\begin{array}{c}122.8 \\
118.1 \\
8.4\end{array}$ & $\begin{array}{c}127.6 \\
127.6 \\
8.6\end{array}$ & \\
\hline 70 & $\begin{array}{c}\mathrm{TC} \\
\mathrm{SHC} \\
\mathrm{kW}\end{array}$ & & & & $\begin{array}{c}131.0 \\
42.7 \\
8.7\end{array}$ & $\begin{array}{c}131.3 \\
62.0 \\
8.7\end{array}$ & $\begin{array}{c}131.6 \\
81.1 \\
8.7\end{array}$ & $\begin{array}{c}131.6 \\
99.8 \\
8.7\end{array}$ & $\begin{array}{c}132.5 \\
117.7 \\
8.8\end{array}$ & $\begin{array}{c}134.8 \\
132.7 \\
8.8\end{array}$ \\
\hline 75 & $\begin{array}{c}\mathrm{TC} \\
\mathrm{SHC} \\
\mathrm{kW}\end{array}$ & & & & & $\begin{array}{c}141.9 \\
41.3 \\
9.1\end{array}$ & $\begin{array}{c}142.4 \\
60.4 \\
9.1\end{array}$ & $\begin{array}{c}142.8 \\
79.4 \\
9.1\end{array}$ & $\begin{array}{c}142.9 \\
98.1 \\
9.1\end{array}$ & $\begin{array}{c}143.2 \\
116.1 \\
9.1\end{array}$ \\
\hline 80 & $\begin{array}{c}\mathrm{TC} \\
\mathrm{SHC} \\
\mathrm{kW}\end{array}$ & & & & & & $\begin{array}{c}153.4 \\
39.7 \\
9.4\end{array}$ & $\begin{array}{c}154.1 \\
58.6 \\
9.4\end{array}$ & $\begin{array}{c}154.5 \\
77.4 \\
9.5\end{array}$ & $\begin{array}{c}154.8 \\
95.9 \\
9.5\end{array}$ \\
\hline 85 & $\begin{array}{c}\mathrm{TC} \\
\mathrm{SHC} \\
\mathrm{kW}\end{array}$ & & & & & & & $\begin{array}{c}165.4 \\
37.9 \\
9.8\end{array}$ & $\begin{array}{c}166.4 \\
56.7 \\
9.8\end{array}$ & $\begin{array}{c}166.9 \\
75.3 \\
9.9\end{array}$ \\
\hline 90 & $\begin{array}{c}\mathrm{TC} \\
\mathrm{SHC} \\
\mathrm{kW}\end{array}$ & & & & & & & & $\begin{array}{c}177.7 \\
36.0 \\
10.2\end{array}$ & $\begin{array}{c}179.1 \\
54.5 \\
10.2\end{array}$ \\
\hline 95 & $\begin{array}{c}\mathrm{TC} \\
\mathrm{SHC} \\
\mathrm{kW}\end{array}$ & & & & & & & & & $\begin{array}{c}191.0 \\
34.0 \\
10.6\end{array}$ \\
\hline
\end{tabular}

\begin{tabular}{|c|c|c|c|c|c|c|c|c|c|c|}
\hline \multirow{3}{*}{$\begin{array}{c}\mathrm{ODB}\left({ }^{\circ} \mathrm{F}\right) \\
\mathrm{EWB} \\
\left({ }^{\circ} \mathrm{F}\right)\end{array}$} & \multirow[t]{3}{*}{85} & \multirow{2}{*}{\multicolumn{9}{|c|}{$\mathrm{EDB}\left({ }^{\circ} \mathrm{F}\right)$}} \\
\hline & & & & & & & & & & \\
\hline & & 55 & 60 & 65 & 70 & 75 & 80 & 85 & 90 & 95 \\
\hline 40 & $\begin{array}{l}\mathrm{TC} \\
\mathrm{SHC} \\
\mathrm{kW}\end{array}$ & $\begin{array}{l}81.0 \\
81.0 \\
7.7\end{array}$ & & & & & & & & \\
\hline 45 & $\begin{array}{l}\mathrm{TC} \\
\mathrm{SHC} \\
\mathrm{kW}\end{array}$ & $\begin{array}{l}81.2 \\
80.5 \\
7.7\end{array}$ & $\begin{array}{c}86.7 \\
86.7 \\
7.9\end{array}$ & $\begin{array}{c}92.5 \\
92.5 \\
8.2\end{array}$ & & & & & & \\
\hline 50 & $\begin{array}{l}\mathrm{TC} \\
\mathrm{SHC} \\
\mathrm{kW}\end{array}$ & $\begin{array}{c}88.1 \\
62.7 \\
8.0 \\
\end{array}$ & $\begin{array}{c}88.5 \\
82.0 \\
8.0 \\
\end{array}$ & $\begin{array}{c}92.5 \\
92.5 \\
8.2 \\
\end{array}$ & $\begin{array}{c}98.4 \\
98.4 \\
8.4 \\
\end{array}$ & & & & & \\
\hline 55 & $\begin{array}{l}\mathrm{TC} \\
\mathrm{SHC} \\
\mathrm{kW}\end{array}$ & $\begin{array}{c}96.4 \\
42.6 \\
8.3\end{array}$ & $\begin{array}{c}96.6 \\
62.5 \\
8.4\end{array}$ & $\begin{array}{c}96.7 \\
82.0 \\
8.4\end{array}$ & $\begin{array}{c}98.6 \\
98.1 \\
8.4\end{array}$ & $\begin{array}{c}104.4 \\
104.4 \\
8.7\end{array}$ & & & & \\
\hline 60 & $\begin{array}{l}\mathrm{TC} \\
\mathrm{SHC} \\
\mathrm{kW}\end{array}$ & & $\begin{array}{c}105.4 \\
42.3 \\
8.7\end{array}$ & $\begin{array}{c}105.6 \\
61.9 \\
8.7\end{array}$ & $\begin{array}{c}105.7 \\
81.4 \\
8.7\end{array}$ & $\begin{array}{c}106.6 \\
99.5 \\
8.8\end{array}$ & $\begin{array}{c}110.5 \\
110.5 \\
8.9\end{array}$ & $\begin{array}{c}116.7 \\
116.7 \\
9.2\end{array}$ & & \\
\hline 65 & $\begin{array}{l}\mathrm{TC} \\
\mathrm{SHC} \\
\mathrm{kW}\end{array}$ & & & $\begin{array}{c}114.9 \\
41.5 \\
9.1\end{array}$ & $\begin{array}{c}115.2 \\
61.0 \\
9.1\end{array}$ & $\begin{array}{c}115.4 \\
80.3 \\
9.1\end{array}$ & $\begin{array}{c}115.7 \\
99.0 \\
9.1\end{array}$ & $\begin{array}{c}117.6 \\
115.0 \\
9.2\end{array}$ & $\begin{array}{c}123.0 \\
123.0 \\
9.4\end{array}$ & \\
\hline 70 & $\begin{array}{l}\mathrm{TC} \\
\mathrm{SHC} \\
\mathrm{kW}\end{array}$ & & & & $\begin{array}{c}125.0 \\
40.5 \\
9.5\end{array}$ & $\begin{array}{c}125.4 \\
59.8 \\
9.5\end{array}$ & $\begin{array}{c}125.6 \\
78.9 \\
9.5\end{array}$ & $\begin{array}{c}125.8 \\
97.7 \\
9.5\end{array}$ & $\begin{array}{c}126.8 \\
115.1 \\
9.5\end{array}$ & $\begin{array}{c}129.6 \\
129.0 \\
9.7\end{array}$ \\
\hline 75 & $\begin{array}{l}\mathrm{TC} \\
\mathrm{SHC} \\
\mathrm{kW}\end{array}$ & & & & & $\begin{array}{c}135.6 \\
39.3 \\
9.9 \\
\end{array}$ & $\begin{array}{c}136.1 \\
58.4 \\
9.9 \\
\end{array}$ & \begin{tabular}{|c|}
136.5 \\
77.3 \\
9.9 \\
\end{tabular} & $\begin{array}{c}136.6 \\
96.0 \\
9.9\end{array}$ & $\begin{array}{c}137.0 \\
114.0 \\
9.9 \\
\end{array}$ \\
\hline 80 & $\begin{array}{l}\mathrm{TC} \\
\mathrm{SHC} \\
\mathrm{kW}\end{array}$ & & & & & & $\begin{array}{c}146.7 \\
37.8 \\
10.3 \\
\end{array}$ & $\begin{array}{l}147.4 \\
56.7 \\
10.3 \\
\end{array}$ & $\begin{array}{l}147.9 \\
75.4 \\
10.4 \\
\end{array}$ & $\begin{array}{l}148.1 \\
94.0 \\
10.4 \\
\end{array}$ \\
\hline 85 & $\begin{array}{l}\mathrm{TC} \\
\mathrm{SHC} \\
\mathrm{kW}\end{array}$ & & & & & & & $\begin{array}{l}158.3 \\
36.1 \\
10.7\end{array}$ & $\begin{array}{l}159.2 \\
54.8 \\
10.8\end{array}$ & $\begin{array}{l}159.7 \\
73.4 \\
10.8\end{array}$ \\
\hline 90 & $\begin{array}{l}\mathrm{TC} \\
\mathrm{SHC} \\
\mathrm{kW}\end{array}$ & & & & & & & & $\begin{array}{c}170.4 \\
34.3 \\
11.2\end{array}$ & $\begin{array}{l}171.5 \\
52.8 \\
11.2\end{array}$ \\
\hline 95 & $\begin{array}{c}\mathrm{TC} \\
\mathrm{SHC} \\
\mathrm{kW}\end{array}$ & & & & & & & & & $\begin{array}{l}183.0 \\
32.4 \\
11.7\end{array}$ \\
\hline
\end{tabular}


Table 1-7b. Equipment Full-Load Performance with Gross Capacities (IP Units), continued

\begin{tabular}{|c|c|c|c|c|c|c|c|c|c|c|}
\hline $\mathrm{ODB}\left({ }^{\circ} \mathrm{F}\right)$ & 95 & & & & & & & & & \\
\hline EWB & & & & & & EDB $\left({ }^{\circ} \mathrm{F}\right.$ & & & & \\
\hline$\left({ }^{\circ} \mathrm{F}\right)$ & & 55 & 60 & 65 & 70 & 75 & 80 & 85 & 90 & 95 \\
\hline 45 & $\begin{array}{c}\mathrm{TC} \\
\mathrm{SHC} \\
\mathrm{kW}\end{array}$ & $\begin{array}{c}77.0 \\
77.0 \\
8.6\end{array}$ & $\begin{array}{c}82.5 \\
82.5 \\
8.5\end{array}$ & $\begin{array}{c}88.2 \\
88.2 \\
8.8\end{array}$ & & & & & & \\
\hline 50 & $\begin{array}{c}\mathrm{TC} \\
\mathrm{SHC} \\
\mathrm{kW}\end{array}$ & $\begin{array}{c}83.3 \\
60.2 \\
8.6\end{array}$ & $\begin{array}{c}83.8 \\
79.2 \\
8.6\end{array}$ & $\begin{array}{c}88.2 \\
88.2 \\
8.8\end{array}$ & $\begin{array}{c}94.0 \\
94.0 \\
9.1\end{array}$ & & & & & \\
\hline 55 & $\begin{array}{c}\mathrm{TC} \\
\mathrm{SHC} \\
\mathrm{kW}\end{array}$ & $\begin{array}{c}91.4 \\
40.2 \\
9.0\end{array}$ & $\begin{array}{c}91.5 \\
60.1 \\
9.0 \\
\end{array}$ & $\begin{array}{c}91.6 \\
79.4 \\
9.0\end{array}$ & $\begin{array}{c}94.0 \\
94.0 \\
9.1\end{array}$ & $\begin{array}{c}99.9 \\
99.9 \\
9.4\end{array}$ & & & & \\
\hline 60 & $\begin{array}{c}\mathrm{TC} \\
\mathrm{SHC} \\
\mathrm{kW}\end{array}$ & & $\begin{array}{c}100.0 \\
39.9 \\
9.4\end{array}$ & $\begin{array}{c}100.2 \\
59.6 \\
9.4\end{array}$ & $\begin{array}{c}100.3 \\
79.0 \\
9.4\end{array}$ & $\begin{array}{c}101.4 \\
96.7 \\
9.4\end{array}$ & $\begin{array}{c}105.9 \\
105.9 \\
9.7\end{array}$ & $\begin{array}{c}112.0 \\
112.0 \\
9.9\end{array}$ & & \\
\hline 65 & $\begin{array}{c}\text { TC } \\
\text { SHC } \\
\text { kW }\end{array}$ & & & $\begin{array}{c}109.2 \\
39.2 \\
9.8 \\
\end{array}$ & $\begin{array}{c}109.4 \\
58.7 \\
9.8 \\
\end{array}$ & $\begin{array}{c}109.6 \\
78.0 \\
9.8 \\
\end{array}$ & $\begin{array}{c}110.1 \\
96.5 \\
9.9 \\
\end{array}$ & $\begin{array}{c}112.3 \\
111.5 \\
10.0 \\
\end{array}$ & $\begin{array}{c}118.1 \\
118.1 \\
10.2 \\
\end{array}$ & \\
\hline 67 & $\begin{array}{c}\mathrm{TC} \\
\mathrm{SHC} \\
\mathrm{kW}\end{array}$ & & & & & & $\begin{array}{c}113.5 \\
88.9 \\
10.0 \\
\end{array}$ & & & \\
\hline 70 & $\begin{array}{c}\mathrm{TC} \\
\mathrm{SHC} \\
\mathrm{kW}\end{array}$ & & & & $\begin{array}{c}118.8 \\
38.3 \\
10.2\end{array}$ & $\begin{array}{l}119.2 \\
57.6 \\
10.3\end{array}$ & $\begin{array}{l}119.5 \\
76.7 \\
10.3\end{array}$ & $\begin{array}{l}119.6 \\
95.4 \\
10.3\end{array}$ & $\begin{array}{c}120.8 \\
112.5 \\
10.3\end{array}$ & $\begin{array}{c}124.4 \\
124.4 \\
10.5\end{array}$ \\
\hline 75 & $\begin{array}{c}\mathrm{TC} \\
\mathrm{SHC} \\
\mathrm{kW}\end{array}$ & & & & & $\begin{array}{l}129.0 \\
37.1 \\
10.7 \\
\end{array}$ & $\begin{array}{l}129.5 \\
56.2 \\
10.7 \\
\end{array}$ & $\begin{array}{c}129.9 \\
75.1 \\
10.7 \\
\end{array}$ & $\begin{array}{c}130.0 \\
93.8 \\
10.7 \\
\end{array}$ & $\begin{array}{c}130.6 \\
111.6 \\
10.8 \\
\end{array}$ \\
\hline 80 & $\begin{array}{c}\mathrm{TC} \\
\mathrm{SHC} \\
\mathrm{kW}\end{array}$ & & & & & & $\begin{array}{l}139.8 \\
35.8 \\
11.2 \\
\end{array}$ & $\begin{array}{c}140.4 \\
54.6 \\
11.2 \\
\end{array}$ & $\begin{array}{c}140.9 \\
73.4 \\
11.2 \\
\end{array}$ & $\begin{array}{c}141.0 \\
91.9 \\
11.7 \\
\end{array}$ \\
\hline 85 & $\begin{array}{c}\mathrm{TC} \\
\mathrm{SHC} \\
\mathrm{kW}\end{array}$ & & & & & & & $\begin{array}{c}150.9 \\
34.2 \\
11.7\end{array}$ & $\begin{array}{c}151.8 \\
52.9 \\
11.7\end{array}$ & $\begin{array}{l}152.3 \\
71.5 \\
11.7\end{array}$ \\
\hline 90 & $\begin{array}{c}\mathrm{TC} \\
\mathrm{SHC} \\
\mathrm{kW}\end{array}$ & & & & & & & & $\begin{array}{c}162.6 \\
32.5 \\
12.2 \\
\end{array}$ & $\begin{array}{c}163.5 \\
51.0 \\
12.2 \\
\end{array}$ \\
\hline 95 & $\begin{array}{c}\mathrm{TC} \\
\mathrm{SHC} \\
\mathrm{kW}\end{array}$ & & & & & & & & & $\begin{array}{c}174.6 \\
30.8 \\
12.7\end{array}$ \\
\hline
\end{tabular}

\begin{tabular}{|c|c|c|c|c|c|c|c|c|c|c|}
\hline \multirow{3}{*}{$\begin{array}{c}\mathrm{ODB}\left({ }^{\circ} \mathrm{F}\right) \\
\mathrm{EWB} \\
\left({ }^{\circ} \mathrm{F}\right)\end{array}$} & 105 & & & & & & & & & \\
\hline & & \multicolumn{9}{|c|}{$\overline{E D B}\left({ }^{\circ} \mathrm{F}\right)$} \\
\hline & & 55 & 60 & 65 & 70 & 75 & 80 & 85 & 90 & 95 \\
\hline 45 & $\begin{array}{l}\mathrm{TC} \\
\mathrm{SHC} \\
\mathrm{kW}\end{array}$ & $\begin{array}{c}72.8 \\
72.8 \\
8.8\end{array}$ & $\begin{array}{c}78.2 \\
78.2 \\
9.1\end{array}$ & $\begin{array}{c}83.8 \\
83.8 \\
9.4\end{array}$ & & & & & & \\
\hline 50 & $\begin{array}{l}\text { TC } \\
\text { SHC } \\
\mathrm{kW}\end{array}$ & $\begin{array}{c}78.3 \\
57.6 \\
9.1\end{array}$ & $\begin{array}{c}79.0 \\
76.2 \\
9.1\end{array}$ & $\begin{array}{c}83.8 \\
83.8 \\
9.4\end{array}$ & $\begin{array}{l}89.5 \\
89.5 \\
9.7\end{array}$ & & & & & \\
\hline 55 & $\begin{array}{l}\mathrm{TC} \\
\mathrm{SHC} \\
\mathrm{kW}\end{array}$ & $\begin{array}{c}86.2 \\
37.6 \\
9.6\end{array}$ & $\begin{array}{c}86.2 \\
57.5 \\
9.5\end{array}$ & $\begin{array}{c}86.5 \\
76.8 \\
9.6 \\
\end{array}$ & $\begin{array}{l}89.5 \\
89.5 \\
9.7 \\
\end{array}$ & $\begin{array}{l}95.3 \\
95.3 \\
10.1\end{array}$ & & & & \\
\hline 60 & $\begin{array}{l}\mathrm{TC} \\
\mathrm{SHC} \\
\mathrm{kW}\end{array}$ & & $\begin{array}{l}94.4 \\
37.4 \\
10.0\end{array}$ & $\begin{array}{l}94.6 \\
57.1 \\
10.0\end{array}$ & $\begin{array}{l}94.7 \\
76.5 \\
10.0\end{array}$ & $\begin{array}{l}96.1 \\
93.5 \\
10.1\end{array}$ & $\begin{array}{c}101.2 \\
101.2 \\
10.4\end{array}$ & & & \\
\hline 65 & $\begin{array}{l}\mathrm{TC} \\
\mathrm{SHC} \\
\mathrm{kW}\end{array}$ & & & $\begin{array}{l}103.3 \\
36.8 \\
10.5\end{array}$ & $\begin{array}{l}103.5 \\
56.3 \\
10.5\end{array}$ & $\begin{array}{l}103.6 \\
75.7 \\
10.5\end{array}$ & $\begin{array}{l}104.3 \\
93.9 \\
10.6\end{array}$ & $\begin{array}{c}107.1 \\
107.1 \\
10.7\end{array}$ & $\begin{array}{c}113.2 \\
113.2 \\
11.0\end{array}$ & \\
\hline 70 & $\begin{array}{l}\mathrm{TC} \\
\mathrm{SHC} \\
\mathrm{kW}\end{array}$ & & & & $\begin{array}{l}112.5 \\
36.0 \\
11.0\end{array}$ & $\begin{array}{c}113.0 \\
55.4 \\
11.0\end{array}$ & $\begin{array}{l}113.2 \\
74.4 \\
11.0\end{array}$ & $\begin{array}{l}113.3 \\
93.0 \\
11.0\end{array}$ & $\begin{array}{c}114.9 \\
109.6 \\
11.1\end{array}$ & $\begin{array}{c}119.3 \\
119.3 \\
11.3\end{array}$ \\
\hline 75 & $\begin{array}{l}\mathrm{TC} \\
\mathrm{SHC} \\
\mathrm{kW}\end{array}$ & & & & & $\begin{array}{c}122.3 \\
35.0 \\
11.5\end{array}$ & $\begin{array}{c}122.9 \\
54.1 \\
11.5\end{array}$ & $\begin{array}{l}123.1 \\
73.0 \\
11.5\end{array}$ & $\begin{array}{l}123.3 \\
91.7 \\
11.5\end{array}$ & $\begin{array}{c}124.1 \\
109.2 \\
11.6\end{array}$ \\
\hline 80 & $\begin{array}{l}\mathrm{TC} \\
\mathrm{SHC} \\
\mathrm{kW}\end{array}$ & & & & & & $\begin{array}{l}132.6 \\
33.7 \\
12.0\end{array}$ & $\begin{array}{l}133.3 \\
52.6 \\
12.1\end{array}$ & $\begin{array}{l}133.7 \\
71.3 \\
12.1\end{array}$ & $\begin{array}{l}133.8 \\
90.0 \\
12.1\end{array}$ \\
\hline 85 & $\begin{array}{l}\mathrm{TC} \\
\mathrm{SHC} \\
\mathrm{kW}\end{array}$ & & & & & & & $\begin{array}{c}143.3 \\
32.3 \\
12.6\end{array}$ & $\begin{array}{l}144.1 \\
51.0 \\
12.6\end{array}$ & $\begin{array}{l}144.6 \\
69.5 \\
12.6\end{array}$ \\
\hline 90 & $\begin{array}{l}\mathrm{TC} \\
\mathrm{SHC} \\
\mathrm{kW}\end{array}$ & & & & & & & & $\begin{array}{l}154.4 \\
30.8 \\
13.1\end{array}$ & $\begin{array}{c}155.4 \\
49.2 \\
13.2\end{array}$ \\
\hline 95 & $\begin{array}{l}\mathrm{TC} \\
\mathrm{SHC} \\
\mathrm{kW}\end{array}$ & & & & & & & & & $\begin{array}{l}166.0 \\
29.1 \\
13.7\end{array}$ \\
\hline
\end{tabular}


Table 1-7b. Equipment Full-Load Performance with Gross Capacities (IP Units), continued

\begin{tabular}{|c|c|c|c|c|c|c|c|c|c|c|}
\hline \multirow{3}{*}{$\frac{\mathrm{ODB}\left({ }^{\circ} \mathrm{F}\right)}{\mathrm{EWB}}$} & 115 & & & & & & & & & \\
\hline & & \multicolumn{9}{|c|}{$\overline{\mathrm{EDB}\left({ }^{\circ} \mathrm{F}\right)}$} \\
\hline & & 55 & 60 & 65 & 70 & 75 & 80 & 85 & 90 & 95 \\
\hline 45 & $\begin{array}{c}\mathrm{TC} \\
\mathrm{SHC} \\
\mathrm{kW}\end{array}$ & $\begin{array}{c}68.5 \\
68.5 \\
9.3\end{array}$ & $\begin{array}{c}73.8 \\
73.8 \\
9.6\end{array}$ & $\begin{array}{l}79.3 \\
79.3 \\
10.0\end{array}$ & & & & & & \\
\hline 50 & $\begin{array}{c}\mathrm{TC} \\
\mathrm{SHC} \\
\mathrm{kW}\end{array}$ & $\begin{array}{c}73.2 \\
55.0 \\
9.6\end{array}$ & $\begin{array}{c}74.2 \\
73.0 \\
9.6\end{array}$ & $\begin{array}{l}79.3 \\
79.3 \\
10.0\end{array}$ & $\begin{array}{l}84.9 \\
84.9 \\
10.4\end{array}$ & & & & & \\
\hline 55 & $\begin{array}{c}\mathrm{TC} \\
\mathrm{SHC} \\
\mathrm{kW}\end{array}$ & $\begin{array}{l}80.8 \\
35.1 \\
10.1\end{array}$ & $\begin{array}{l}80.8 \\
55.0 \\
10.1\end{array}$ & $\begin{array}{l}81.2 \\
74.1 \\
10.1\end{array}$ & $\begin{array}{l}84.9 \\
84.9 \\
10.4\end{array}$ & $\begin{array}{l}90.5 \\
90.5 \\
10.7\end{array}$ & & & & \\
\hline 60 & $\begin{array}{c}\mathrm{TC} \\
\mathrm{SHC} \\
\mathrm{kW}\end{array}$ & & $\begin{array}{l}88.7 \\
34.9 \\
10.6\end{array}$ & $\begin{array}{l}88.9 \\
54.6 \\
10.6\end{array}$ & $\begin{array}{l}89.0 \\
74.0 \\
10.6\end{array}$ & $\begin{array}{l}90.8 \\
90.0 \\
10.7\end{array}$ & $\begin{array}{l}96.3 \\
96.3 \\
11.1\end{array}$ & & & \\
\hline 65 & $\begin{array}{c}\mathrm{TC} \\
\mathrm{SHC} \\
\mathrm{kW}\end{array}$ & & & $\begin{array}{l}97.3 \\
34.5 \\
11.2\end{array}$ & $\begin{array}{l}97.5 \\
54.0 \\
11.2\end{array}$ & $\begin{array}{l}97.5 \\
73.3 \\
11.2\end{array}$ & $\begin{array}{l}98.4 \\
91.1 \\
11.2\end{array}$ & $\begin{array}{c}102.1 \\
102.1 \\
11.5\end{array}$ & $\begin{array}{c}108.0 \\
108.0 \\
11.8\end{array}$ & \\
\hline 70 & $\begin{array}{c}\mathrm{TC} \\
\mathrm{SHC} \\
\mathrm{kW}\end{array}$ & & & & $\begin{array}{l}106.2 \\
33.8 \\
11.7\end{array}$ & $\begin{array}{c}106.5 \\
53.1 \\
11.7\end{array}$ & $\begin{array}{l}106.7 \\
72.2 \\
11.7\end{array}$ & $\begin{array}{c}107.0 \\
90.6 \\
11.8\end{array}$ & $\begin{array}{c}108.9 \\
106.3 \\
11.9\end{array}$ & $\begin{array}{c}114.0 \\
114.0 \\
12.2\end{array}$ \\
\hline 75 & $\begin{array}{l}\mathrm{TC} \\
\mathrm{SHC} \\
\mathrm{kW}\end{array}$ & & & & & $\begin{array}{c}115.4 \\
32.8 \\
12.3\end{array}$ & $\begin{array}{l}116.0 \\
51.9 \\
12.3\end{array}$ & $\begin{array}{l}116.2 \\
70.9 \\
12.3\end{array}$ & $\begin{array}{c}116.4 \\
89.4 \\
12.3\end{array}$ & $\begin{array}{c}117.5 \\
106.5 \\
12.4\end{array}$ \\
\hline 80 & $\begin{array}{c}\mathrm{TC} \\
\mathrm{SHC} \\
\mathrm{kW}\end{array}$ & & & & & & $\begin{array}{l}125.3 \\
31.7 \\
12.8\end{array}$ & $\begin{array}{l}125.9 \\
50.5 \\
12.9\end{array}$ & $\begin{array}{l}126.3 \\
69.3 \\
12.9\end{array}$ & $\begin{array}{l}126.5 \\
87.9 \\
12.9\end{array}$ \\
\hline 85 & $\begin{array}{c}\mathrm{TC} \\
\mathrm{SHC} \\
\mathrm{kW}\end{array}$ & & & & & & & $\begin{array}{l}135.5 \\
30.4 \\
13.4\end{array}$ & $\begin{array}{l}136.3 \\
49.0 \\
13.5\end{array}$ & $\begin{array}{l}136.8 \\
67.6 \\
13.5\end{array}$ \\
\hline 90 & $\begin{array}{c}\mathrm{TC} \\
\mathrm{SHC} \\
\mathrm{kW}\end{array}$ & & & & & & & & $\begin{array}{l}145.9 \\
29.0 \\
14.0\end{array}$ & $\begin{array}{l}147.1 \\
47.4 \\
14.1\end{array}$ \\
\hline 95 & $\begin{array}{l}\mathrm{TC} \\
\mathrm{SHC} \\
\mathrm{kW}\end{array}$ & & & & & & & & & $\begin{array}{l}157.1 \\
27.4 \\
14.7\end{array}$ \\
\hline
\end{tabular}

Notes:

1. $\mathrm{TC}=$ gross total capacity $(\mathrm{kBtu} / \mathrm{h})$

2. $\mathrm{SHC}=$ gross sensible heat capacity $(\mathrm{kBtu} / \mathrm{h})$

3. $\mathrm{kW}=$ compressor power $(\mathrm{kW})$

4. $\mathrm{ODB}=$ ambient dry-bulb temperature $=$ air temperature $\left({ }^{\circ} \mathrm{F}\right)$ entering condenser

5. $\mathrm{EDB}=$ dry-bulb temperature $\left({ }^{\circ} \mathrm{F}\right)$ entering indoor coil

6. $\mathrm{EWB}=$ wet-bulb temperature $\left({ }^{\circ} \mathrm{F}\right)$ entering indoor coil

7. $\mathrm{CFM}=$ indoor coil airflow rate in cubic feet per minute (4000 CFM for all data)

8. Blue background (shaded upper left cells) $=$ potential for freezing indoor coil

9. Red background $($ shaded lower right cells $)=$ compressor outside operating envelop

CANNOT RUN HERE (for prolonged operation)

10. Each point has optimum charge (R22 charge not constant)

11. Computer model used to generate catalog data

12. Computer model based on test data

13. Computer model validated within the operating envelope of compressor

14. Computer model iterates and determines if the coil is wet or dry

15. Data are for 38AKS012 matched with a 40RM012 (4000 CFM indoors)

16. Original data provided $6 / 27 / 01$; additional data provided $9 / 25 / 01$ and $9 / 18 / 02$

17. Data received from D. Barkley and J. Pegues of Carrier Corporation, Syracuse New York, US. 
These tables use ODB, EDB, and EWB as independent variables for performance data; the locations of EDB and EWB are shown in Figure 1-2. In these tables each block of data represents an f(EDB, EWB) data set for a different ODB.

The expanded data set was developed by a manufacturer, using the company's "in-house" engineering software for developing catalog data. This expanded data set goes outside the range of data that is normally available from typical published catalogs (as was used in the E100 series cases), and even outside the range of what can typically be obtained from the computer program that this manufacturer normally provides to design engineers for sizing equipment that frequently operates outside the range of typical design conditions. The computer model that was used to develop the expanded data set was generated to match the test data as perfectly as possible (in this case within $0.5 \%$ ) at the rating condition of $\mathrm{EDB} / \mathrm{EWB} / \mathrm{ODB}=26.67^{\circ} \mathrm{C} / 19.44^{\circ} \mathrm{C} / 35.00^{\circ} \mathrm{C}\left(80^{\circ} \mathrm{F} / 67^{\circ} \mathrm{F} / 95^{\circ} \mathrm{F}\right)$. Once the model is generated from the test data, the model is normalized to the compressor curve (provided by the compressor manufacturer).

The data set includes ranges where only limited system operation is recommended. These ranges are indicated by red and blue background shading in the tables (see the electronic version of E300MAP.XLS). The red shading indicates the range where the refrigerant temperature discharged from the compressor is higher than it should be. Prolonged operation in this region would shorten the life of the compressor. The blue shading indicates the range where frost may form on the coil, affecting the performance of the system.

The data set assumes that the refrigerant charge is always optimal at each listed full-load operating point. In reality, a refrigerant charge that is optimal for one point in the data may not be optimal for some other point in the data set. The manufacturer estimates that as a worst case the effect of the refrigerant charge makes about one-half to three-quarters of a percentage point difference (on the listed values). For the purpose of these tests, we are assuming that the refrigerant charge is always optimal.

The unit as described actually uses a 1242-W fan. So the "adjusted net capacity" (using same terminology as in the E100 series cases per Appendix C of this document) is

$$
(\text { net cap })_{\text {adj }}=(\text { gross cap })_{\text {listed }}-(\text { fan power }) \text {. }
$$

Thus, for the net total (sensible + latent) capacity at $\mathrm{ODB}=95^{\circ} \mathrm{F}, \mathrm{EDB}=75^{\circ} \mathrm{F}$, and $\mathrm{EWB}=65^{\circ} \mathrm{F}$ and 4000 CFM:

$$
(\text { net cap })_{\text {adj }}=32,122 \mathrm{~W}-1242 \mathrm{~W}=30,880 \mathrm{~W} \text {. }
$$

The technique for determining net sensible capacities is similar.

\subsection{Validity of Listed Data (VERY IMPORTANT). EWB given for the listed compressor $\mathrm{kW}$} (kilowatts) and gross capacities given in Tables 1-7a and 1-7b are valid only for "wet" coils (when dehumidification is occurring). A dry-coil condition - no dehumidification - occurs when the entering air humidity ratio is decreased to the point where the entering air dew point temperature is less than the effective coil surface temperature (apparatus dew point). In Tables 1-7a and 1-7b, the dry-coil data (indicated with italics) are evident for conditions where the listed sensible capacity is equal to the corresponding total capacity. For a given EDB and ODB, the compressor power, total capacity, and sensible capacity for wet coils change with varying EWB. Once the coil becomes dry, for a given EDB, compressor power and capacities remain constant with decreasing EWB (Brandemuehl 1993; pp. 4-82-83). 
For the purpose of interpolating data between listed wet-coil and dry-coil data points, it is necessary to evaluate the maximum EWB for the occurrence of the listed dry-coil data point. One method for establishing the maximum EWB where total and sensible capacities are equal is to linearly extrapolate EWB for a given EDB and ODB. For example, the data shown in Table 1-8 (extracted from Table 1-7b) can be used to determine the dry-coil compressor power for $\mathrm{ODB} / \mathrm{EDB}=95.0^{\circ} \mathrm{F} / 80^{\circ} \mathrm{F}$.

Table 1-8. Determination of Maximum Dry-Coil EWB Using Extrapolation

\begin{tabular}{||l|l|l|l||}
\hline \hline $\begin{array}{l}\text { EWB } \\
\left({ }^{\circ} \mathrm{F}\right)\end{array}$ & $\begin{array}{l}\text { Gross Total } \\
\text { Capacity } \\
\text { (kBtu/h) }\end{array}$ & $\begin{array}{l}\text { Gross Sensible } \\
\text { Capacity } \\
\text { (kBtu/h) }\end{array}$ & $\begin{array}{l}\text { Compressor } \\
\text { Power } \\
\text { (kW) }\end{array}$ \\
\hline \hline $\begin{array}{l}62.77 \text { (on TC) } \\
62.63 \text { (on SHC) }\end{array}$ & 105.9 & 105.9 & 9.7 \\
\hline 65 & 110.1 & 96.5 & 9.9 \\
\hline 70 & 119.5 & 76.7 & 10.3 \\
\hline
\end{tabular}

* Italicized values are not specifically listed with the original performance data; they are determined based on the accompanying discussion. Data in bold font are from the original performance data.

At the dry-coil condition:

Gross total capacity $=$ gross sensible capacity $=105.9 \mathrm{kBtu} / \mathrm{h}$

where these data are listed in the row in Table $1-7 \mathrm{~b}$ for $\mathrm{EWB}=60^{\circ} \mathrm{F}$.

Linear extrapolation based on gross total capacity gives

Maximum EWB for the dry-coil condition $=62.77^{\circ} \mathrm{F}$.

Linear extrapolation based on gross sensible capacity gives

Maximum EWB for the dry-coil condition $=62.63^{\circ} \mathrm{F}$.

Therefore, maximum dry-coil $\mathrm{EWB} \approx 62.7^{\circ} \mathrm{F}$.

(Because the values of maximum EWB based on extrapolation using total capacity versus sensible capacity are very close, but not exactly the same, there may be a small amount of error associated with assuming linearity in this determination, or there may be some uncertainty - perhaps from rounding - in the listed values. The listed compressor power data do not have as many significant digits as the capacity data, so these data were not used here for extrapolating EWB.)

1.3.1.4.3.2 Extrapolation of Performance Data. Allow your software to perform any necessary extrapolations. The need for doing extrapolations has been minimized by the inclusion of an expanded performance data set, and by specifying reduced internal gains during cooler weather. 
1.3.1.4.3.3 Cooling Coil Bypass Factor. If your software does not require an input for bypass factor (BF), or automatically calculates it based on other inputs, ignore this information.

For this system:

$$
\mathrm{BF}=0.070 .
$$

This value provided by the manufacturer (Pegues 2001). For this system, BF varies only with airflow rate, which is constant for these test cases.

1.3.1.4.3.4 Minimum Supply Air Temperature. This system is a variable temperature system, meaning that the supply air temperature varies with the operating conditions. If your software requires an input for minimum allowable supply air temperature, use

Minimum supply air temperature $\leq 1.66^{\circ} \mathrm{C}\left(34.6^{\circ} \mathrm{F}\right)$.

Appendix D contains calculation of minimum supply air temperature.

If your software does not require this input, ignore this information.

1.3.1.4.4 Part-Load Operation. The system efficiency degradation that results from part-load operation is described in Figure 1-3. This representation is the same as that for the E100 series cases. In this figure the COP degradation factor (CDF) is a multiplier to be applied to the full-load system COP (as defined in Appendix C) at a given PLR, where:

$$
\mathrm{COP}(\mathrm{PLR})=(\text { full load COP }(\mathrm{ODB}, \mathrm{EWB}, \mathrm{EDB})) * \mathrm{CDF}(\mathrm{PLR})
$$

It might be helpful to think of the efficiency degradation as being caused by additional compressor startup run time required to bring the evaporator coil temperature down to its equilibrium temperature for the time(s) when the compressor is required to operate during an hour with part load. When the simplifying assumption is made that continuous operation of the air distribution fan has a negligible effect on the compressor's part-load energy use, CDF from Figure 1-3 applies similarly to $\mathrm{COP}_{2}$ as to COP. That is,

$$
\left(\mathrm{COP}_{2} \text { at part load }\right)=(\mathrm{CDF}) \times\left(\mathrm{COP}_{2} \text { at full load }\right)
$$

where $\mathrm{COP}_{2}$ at full load is determined as described in Section 1.3.1.2 (Output Requirements: Annual Means, Maxima, and Minima).

Because the compressor controller is ideal on/off cycling (see Section 1.3.1.4.2),

hourly fractional compressor and outdoor fan run time $=$ PLR/CDF. 


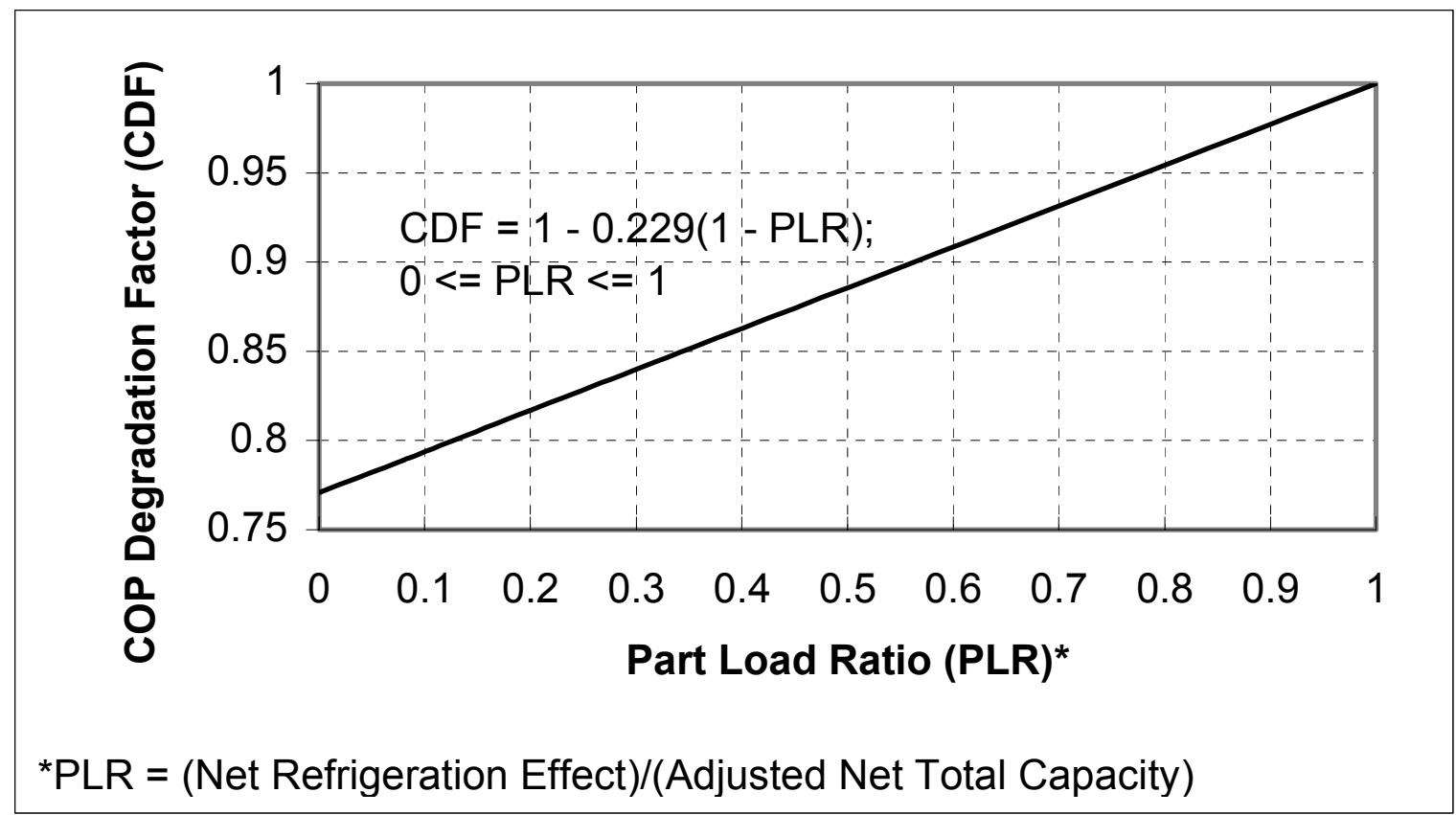

Figure 1-3. Cooling equipment part-load performance (COP degradation factor versus PLR)

In Figure 1-3, the PLR may be calculated by:

(Gross Total Evaporator Coil Load)

(Gross Total Capacity)

where the gross total evaporator coil load and gross total capacity are as defined in the Glossary (Appendix C). Per Appendix E, this definition is similar to the definition supplied in the E100 series cases:

(Net Refrigeration Effect)

(Adjusted Net Total Capacity)

where the net refrigeration effect and the adjusted net total capacity are as defined in the Glossary (Appendix C). Demonstration of the similarity of these definitions of PLR is included in Appendix E.

Simplifying assumptions in Figure 1-3 are

- There is no minimum on/off time for the compressor and outdoor condenser fan; they may cycle on/off as often as necessary to maintain the set point

- The decrease in efficiency with increased on/off cycling at very low PLR remains linear.

Because there is a continuously operating indoor air fan in the E300 and E400 series cases, the definition of PLR applying gross total evaporator coil load and gross total capacity is more convenient to apply. If you are defining PLR based on net refrigeration effect and adjusted net capacity, then for the E300 and E400 series cases indoor air distribution fan operation for times when the evaporator coil is not removing 
heat must still be considered in the simulation. Indoor air distribution fan operation for times when the evaporator coil is not removing heat does not affect the net refrigeration effect or the adjusted net total capacity.

For cases E300-E440, the CDF is not applicable to the continuously operating indoor air distribution fan energy consumption.

Appendix B of Volume 1 (Neymark and Judkoff 2002) includes additional details about how Figure 1-3 was derived.

If your software utilizes cooling coil bypass factor, model the BF as independent of (not varying with) the PLR (Cawley 1997).

\subsection{Fans.}

\subsection{Indoor Air Distribution Fan.}

- Airflow rate $=1.888 \mathrm{~m}^{3} / \mathrm{s}=6796 \mathrm{~m}^{3} / \mathrm{h}=4000 \mathrm{CFM}$

- Indoor fan electric power $=1242 \mathrm{~W}$

- Indoor fan mechanical shaft power $=1167 \mathrm{~W}$ (1.565 brake horsepower [BHP])

- External static fan pressure $=74.7 \mathrm{~Pa}=0.3$ in. $w g$ (water gauge)

- Fan static efficiency $=0.121$

- Motor/drive efficiency $=0.940$

- Supply air temperature rise from fan heat $=0.54^{\circ} \mathrm{C}=0.97^{\circ} \mathrm{F}$

- Air distribution efficiency $=100 \%$ (adiabatic ducts).

For further discussion of these inputs, see Appendix F.

The draw-through indoor air distribution fan operates continuously at 4000 CFM $\left(6796.0 \mathrm{~m}^{3} / \mathrm{h}\right)$ for the entire simulation period. For calculating additional heating of the distribution air related to waste heat from the indoor distribution fan, assume that the distribution fan motor is mounted in the distribution air stream so that $100 \%$ of the heat from fan energy use goes to the distribution (supply) air.

\subsection{Outdoor Condenser Fan.}

- Outdoor fan power $=930 \mathrm{~W}$.

The draw-through outdoor condenser fan cycles on and off with the compressor.

1.3.1.4.6 Outside Air. The indoor air distribution fan operates continuously at $4000 \mathrm{CFM}\left(6796.0 \mathrm{~m}^{3} / \mathrm{h}\right)$. Dampers are adjusted to continuously supply $15 \%$ outside air mixed with the return air; that is, of the 4000 CFM $\left(6796.0 \mathrm{~m}^{3} / \mathrm{h}\right)$ of mixed supply air, $600 \mathrm{CFM}\left(1019.4 \mathrm{~m}^{3} / \mathrm{h}\right)$ is outside air and $3400 \mathrm{CFM}$ $\left(5776.6 \mathrm{~m}^{3} / \mathrm{h}\right)$ is return air. As fresh air is introduced from the outside, a corresponding amount of zone air exits through the relief damper (see Figure 1-2). 


\subsubsection{Additional E300 Series Cases}

This section describes sequential revisions to the base case required to model additional E300 series cases. Case E300 is the base case for all the E300 series cases. Unless otherwise noted, the required outputs for these cases are the same as for Case E300, but the hourly outputs for June 28 and the weather data checks are excluded.

\subsubsection{Case E310: High Latent Gains}

Case E310 is exactly as Case E300 except the latent internal heat gains are revised per Table 1-9. Only the latent internal gains are changed; sensible internal gains shown here are the same as for Case E300.

Table 1-9. Case E310 Hourly Internal Gains Schedule (IP and SI Units)

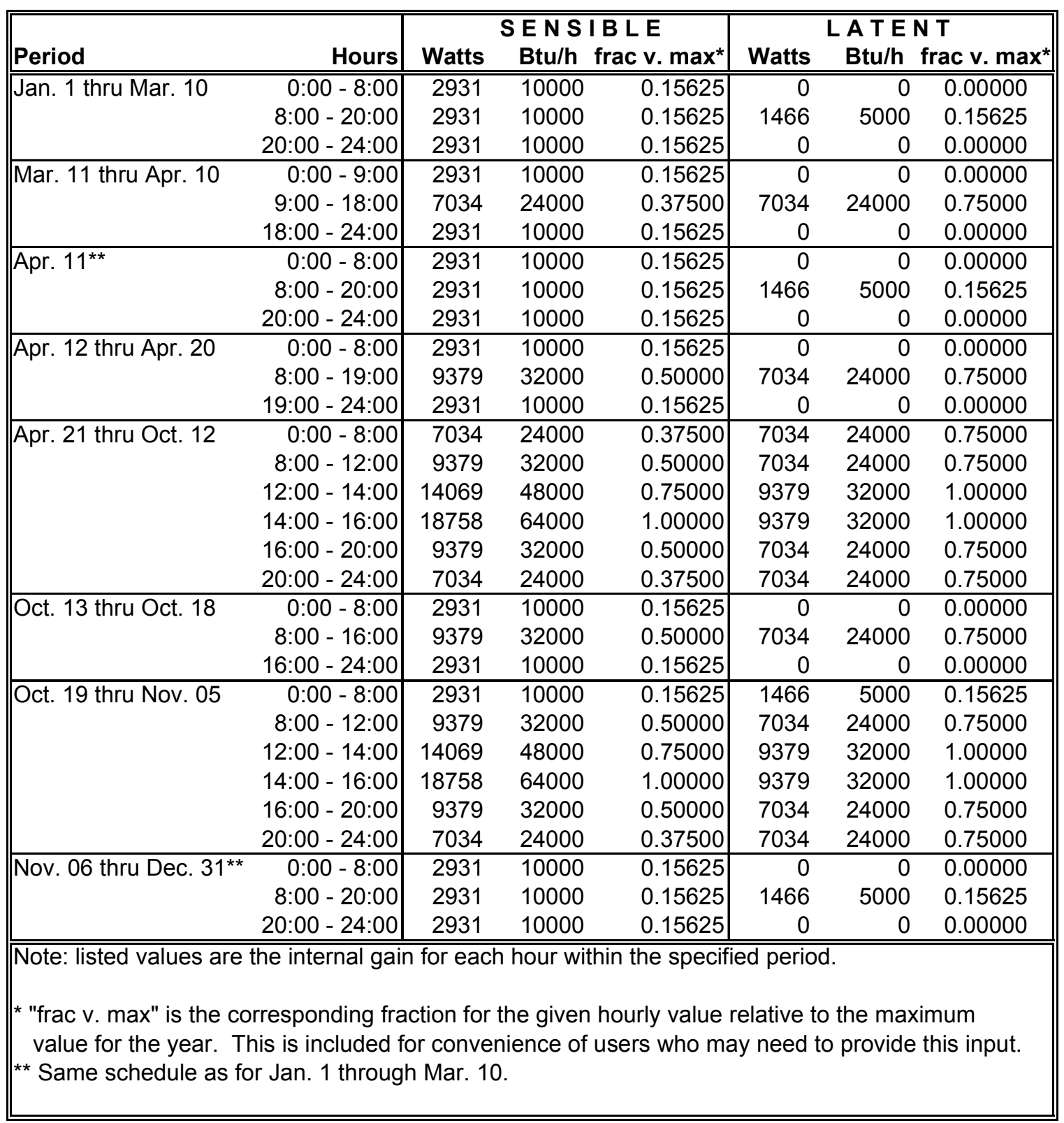

e300intgains.xls e310sch! 
Sensible gains remain as $100 \%$ convective.

These are internally generated sources of heat and humidity that are not related to operation of the mechanical cooling system or its air distribution fan.

If your software requires input of water vapor mass flow rate rather than latent internal gains, to convert the latent gains to water vapor mass flow rate for each listed time period, use the heat of vaporization that your software assumes for condensation at the coil.

If your software requires input of total internal gains, use the sum of sensible + latent internal gains for each listed time period.

\subsubsection{Case E320: High Infiltration}

Case E320 is exactly as Case 300 except infiltration and outside air are revised as follows.

\subsection{Infiltration Schedule.}

From January 1 through April 20:

\section{Infiltration Rate}

$1.734 \mathrm{ACH}\left(1019.4 \mathrm{~m}^{3} / \mathrm{h}, 600 \mathrm{CFM}\right)$

From April 21 through October 12:

$\begin{array}{lr}\text { From } 00: 00 \text { to } 08: 00 & 1.734 \mathrm{ACH} \\ \text { From } 08: 00 \text { to } 20: 00 & \left.11019.4 \mathrm{~m}^{3} / \mathrm{h}, 600 \mathrm{CFM}\right) \\ \text { From 20:00 to } 24: 00 & 1.734 \mathrm{ACH}\left(6796.0 \mathrm{~m}^{3} / \mathrm{h}, 4000 \mathrm{CFM}\right) \\ & \end{array}$

From October 13 through December 31: $1.734 \mathrm{ACH}\left(1019.4 \mathrm{~m}^{3} / \mathrm{h}, 600 \mathrm{CFM}\right)$

Infiltration is leakage of air through any building element (e.g., walls, windows, and doors). The listed infiltration rates are independent of factors such as wind speed, and indoor/outdoor temperature difference. This specific infiltration schedule was chosen to facilitate comparison between this case and Case E330 for outside air.

1.3.2.2.2 Outside Air. Outside air fraction $=0.0$ (no outside air) for the full annual simulation period.

\subsubsection{Case E330: High Outside Air}

Case E330 is exactly as Case E300 except outside air fraction (as a percentage of total fan flow, OA\%) is scheduled as follows.

From January 1 through April 20:

OA Fraction

$15 \%$

From April 21 through October 12:

$\begin{array}{ll}\text { From 00:00 to } 08: 00 & 15 \% \\ \text { From 08:00 to 20:00 } & 100 \% \\ \text { From 20:00 to 24:00 } & 15 \% \\ & \\ & 15 \%\end{array}$

From October 13 through December 31: $\quad 15 \%$ 
Note that an outside air fraction of $15 \%$ corresponds to 4000 CFM $\left(6796.0 \mathrm{~m}^{3} / \mathrm{h}\right)$ of mixed air containing $600 \mathrm{CFM}\left(1019.4 \mathrm{~m}^{3} / \mathrm{h}\right)$ of outside air and $3400 \mathrm{CFM}\left(5776.6 \mathrm{~m}^{3} / \mathrm{h}\right)$ of return air. Similarly, an outside air fraction of $100 \%$ corresponds to $4000 \mathrm{CFM}\left(6796.0 \mathrm{~m}^{3} / \mathrm{h}\right)$ of mixed air containing $4000 \mathrm{CFM}(6796.0$ $\left.\mathrm{m}^{3} / \mathrm{h}\right)$ of outside air and $0 \mathrm{CFM}\left(0 \mathrm{~m}^{3} / \mathrm{h}\right)$ of return air.

\subsubsection{Case E340: Infiltration and Outside Air Interaction}

Case E340 is exactly as Case 300 except infiltration and outside air are scheduled as follows.

\subsection{Infiltration Schedule.}

From January 1 through April 20:

\section{Infiltration Rate}

$0 \mathrm{ACH}$

From April 21 through October 12:

From 00:00 to 08:00

$0 \mathrm{ACH}$

From 08:00 to 20:00

$5.779 \mathrm{ACH}$

$0 \mathrm{ACH}$

$\left(3398.0 \mathrm{~m}^{3} / \mathrm{h} ; 2000 \mathrm{CFM}\right)$

From 20:00 to 24:00

From October 13 through December 31: $\quad 0 \mathrm{ACH}$

Infiltration is leakage of air through any building element (e.g., walls, windows, and doors). The listed infiltration rates are independent of factors such as wind speed, and indoor/outdoor temperature difference.

\subsection{Outside Air Schedule.}

From January 1 through April 20:

\section{OA Fraction}

$15 \%$

From April 21 through October 12:

$\begin{array}{ll}\text { From } 00: 00 \text { to } 08: 00 & 15 \% \\ \text { From } 08: 00 \text { to } 20: 00 & 50 \% \\ \text { From 20:00 to } 24: 00 & 15 \%\end{array}$

From October 13 through December 31: $\quad 15 \%$

Note that an outside air fraction of $15 \%$ corresponds to 4000 CFM $\left(6796.0 \mathrm{~m}^{3} / \mathrm{h}\right)$ of mixed air containing 600 CFM $\left(1019.4 \mathrm{~m}^{3} / \mathrm{h}\right)$ of outside air and 3400 CFM $\left(5776.6 .0 \mathrm{~m}^{3} / \mathrm{h}\right)$ of return air. Similarly, an outside air fraction of $50 \%$ corresponds to $4000 \mathrm{CFM}\left(6796.0 \mathrm{~m}^{3} / \mathrm{h}\right)$ of mixed air containing $2000 \mathrm{CFM}(3398.0$ $\left.\mathrm{m}^{3} / \mathrm{h}\right)$ of outside air and $2000 \mathrm{CFM}\left(3398.0 \mathrm{~m}^{3} / \mathrm{h}\right)$ of return air. 


\subsubsection{Case E350: Thermostat Set Up}

Case E350 is exactly as Case E300 except the thermostat is scheduled as follows for the entire year:

From January 1 through April 20:

\section{Cooling Set Point}

$25^{\circ} \mathrm{C} \quad\left(77^{\circ} \mathrm{F}\right)$

From April 21 through October 12:

$\begin{array}{lll}\text { From 00:00 to } 07: 00 & 35^{\circ} \mathrm{C} & \left(95^{\circ} \mathrm{F}\right) \\ \text { From 07:00 to 20:00 } & 25^{\circ} \mathrm{C} & \left(77^{\circ} \mathrm{F}\right) \\ \text { From 20:00 to 24:00 } & 35^{\circ} \mathrm{C} & \left(95^{\circ} \mathrm{F}\right) \\ & & \\ & 25^{\circ} \mathrm{C} & \left(77^{\circ} \mathrm{F}\right)\end{array}$

Note that set up begins at 07:00, which is 1 hour before the internal gains increase.

\subsubsection{Case E360: Undersized System}

Case E360 is exactly as Case E300 except the internal heat gains are revised per Table 1-10. Only the sensible internal gains are changed for the period from April 21 through October 12; the latent internal gains and other sensible internal gains shown in the table are the same as for Case E300.

Sensible gains remain as $100 \%$ convective.

These are internally generated sources of heat and humidity that are not related to operation of the mechanical cooling system or its air distribution fan.

If your software requires input of water vapor mass flow rate rather than latent internal gains, to convert the latent gains to water vapor mass flow rate for each listed time period, use the heat of vaporization that your software assumes for condensation at the coil.

If your software requires input of total internal gains, use the sum of sensible + latent internal gains for each listed time period. 
Table 1-10. Case E360 Hourly Internal Gains Schedule (IP and SI Units)

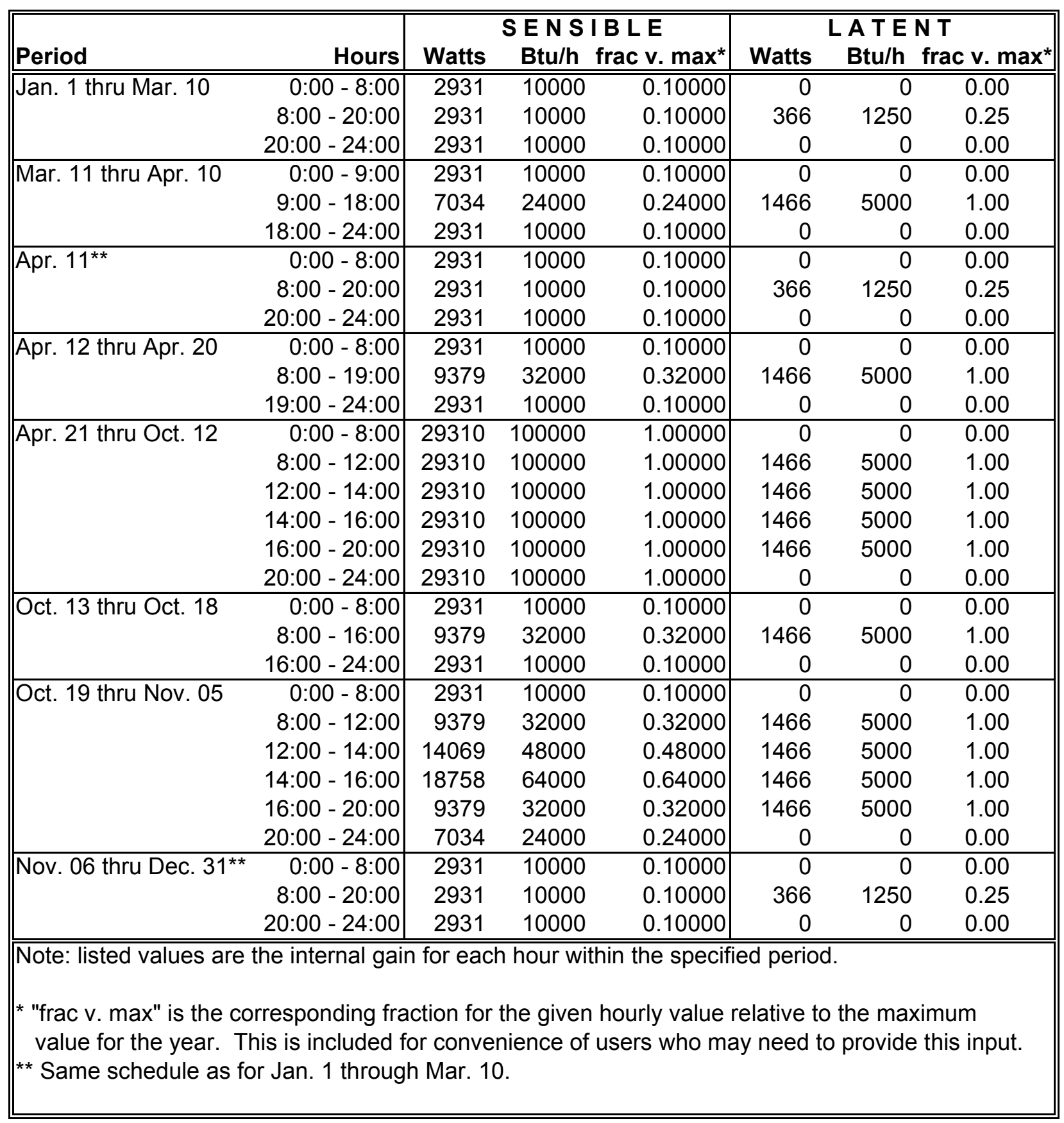

e300intgains.xls e360sch! 


\subsubsection{Economizer Series (E400 Series) Cases}

This section describes sequential revisions to the base case required to model the E400 economizer series cases. Most of the economizer series cases are based on Case E400; appropriate base cases for a given economizer case are

$\begin{array}{lc}\text { Case } & \text { Basis for that case } \\ \text { E400 } & \text { E300 } \\ \text { E410 } & \text { E400 } \\ \text { E420 } & \text { E400 } \\ \text { E430 } & \text { E400 } \\ \text { E440 } & \text { E430 }\end{array}$

\subsubsection{Case E400: Economizer with ODB/IDB Control and Integrated Compressor Control}

Case E400 is exactly as Case E300 except the outside air and relief dampers (see Figure 1-2) are adjusted using economizer control based on ODB and return air temperature as described below. Because these cases assume no thermal losses or gains in the ducts, the return air temperature and the zone air temperature (IDB) may be assumed to be equal.

\subsection{Economizer and Compressor Control Strategy (E400).}

Economizer $=$ ON AND Compressor $=$ OFF IF

IDB $>25.0^{\circ} \mathrm{C}\left(77.0^{\circ} \mathrm{F}\right)$ AND $\mathrm{ODB} \leq \mathrm{IDB}$ AND all cooling load for the given hour is compensated by the economizer.

Economizer $=\mathrm{ON}$ AND Compressor $=\mathrm{ON}$ IF IDB $>25.0^{\circ} \mathrm{C}\left(77.0^{\circ} \mathrm{F}\right)$ AND ODB $\leq$ IDB AND all cooling load for the given hour is NOT compensated by the economizer.

(In this configuration outside air is at the $100 \%$ maximum setting for the full hour.)

Economizer $=\mathrm{OFF}$ AND Compressor $=\mathrm{ON}$ IF

IDB $>25.0^{\circ} \mathrm{C}\left(77.0^{\circ} \mathrm{F}\right)$ AND $\mathrm{ODB}>\mathrm{IDB}$.

Economizer $=$ OFF AND Compressor $=$ OFF IF

IDB $\leq 25.0^{\circ} \mathrm{C}\left(77.0^{\circ} \mathrm{F}\right)$.

where for:

Economizer $=\mathrm{ON}$, outside air is provided as needed up to $100 \%$ outside air for the entire hour, but not less than the $15 \%$ minimum outside air setting for any time during the hour

Economizer $=\mathrm{OFF}$, outside air is provided at the $15 \%$ minimum outside air setting for that hour

Compressor $=\mathrm{ON}$, the compressor and condenser fan will operate only as long as necessary to handle the sensible cooling load not compensated by the economizer 
Compressor $=\mathrm{OFF}$, the compressor and condenser fan do not operate for the hour.

Note that there is no lower limit temperature, which means that the economizer control strategy is not affected by how cold the outside air may become.

1.3.3.1.3 Outputs. Outputs are the same as for Case E300, but the hourly outputs for June 28 and the weather data checks are excluded.

\subsubsection{Case E410: Economizer with ODB/IDB Control and Nonintegrated Compressor}

Case E410 is exactly as Case E400 except while the economizer is operating, the compressor is not allowed to operate. The economizer takes precedence over the compressor but is only allowed to operate whenever it can satisfy the entire cooling load by itself.

\section{Economizer and Compressor Control Strategy (E410)}

Economizer $=\mathrm{ON}$ AND Compressor $=\mathrm{OFF}$ IF IDB $>25.0^{\circ} \mathrm{C}\left(77.0^{\circ} \mathrm{F}\right)$ AND ODB $\leq$ IDB AND all cooling load for the given hour is compensated by the economizer.

Economizer $=$ ON AND Compressor $=$ ON NOT allowed

Economizer $=$ OFF AND Compressor $=\mathrm{ON}$ IF IDB $>25.0^{\circ} \mathrm{C}\left(77.0^{\circ} \mathrm{F}\right)$ AND $\{(\mathrm{ODB}>\mathrm{IDB})$ OR (all cooling load for the given hour CANNOT be compensated by the economizer)\}.

Economizer $=$ OFF AND Compressor $=$ OFF IF $\mathrm{IDB} \leq 25.0^{\circ} \mathrm{C}\left(77.0^{\circ} \mathrm{F}\right)$.

Economizer/Compressor ON/OFF are as defined for Case E400.

\subsubsection{Case E420: Economizer with ODB Limit Control}

Case E420 is exactly as Case E400 except when ODB $>20^{\circ} \mathrm{C}\left(68^{\circ} \mathrm{F}\right)$, the outside air and relief dampers are maintained at $15 \%$ outside air.

\subsection{Economizer and Compressor Control Strategy (E420).}

Economizer $=$ ON AND Compressor $=$ OFF IF

IDB $>25.0^{\circ} \mathrm{C}\left(77.0^{\circ} \mathrm{F}\right)$ AND $\mathrm{ODB} \leq 20.0^{\circ} \mathrm{C}\left(68.0^{\circ} \mathrm{F}\right)$ AND all cooling load for the given hour is compensated by the economizer.

Economizer $=\mathrm{ON}$ AND Compressor $=\mathrm{ON}$ IF IDB $>25.0^{\circ} \mathrm{C}\left(77.0^{\circ} \mathrm{F}\right)$ AND $\mathrm{ODB} \leq 20.0^{\circ} \mathrm{C}\left(68.0^{\circ} \mathrm{F}\right)$ AND all cooling load for the given hour is NOT compensated by the economizer.

(In this configuration outside air is at the $100 \%$ maximum setting for the full hour.) 
Economizer $=$ OFF AND Compressor $=\mathrm{ON}$ IF

IDB $>25.0^{\circ} \mathrm{C}\left(77.0^{\circ} \mathrm{F}\right)$ AND ODB $>20.0^{\circ} \mathrm{C}\left(68.0^{\circ} \mathrm{F}\right)$.

Economizer $=$ OFF AND Compressor $=$ OFF IF

$\mathrm{IDB} \leq 25.0^{\circ} \mathrm{C}\left(77.0^{\circ} \mathrm{F}\right)$.

Economizer/Compressor ON/OFF are as defined for Case E400.

\subsubsection{Case E430: Enthalpy Economizer with Integrated Compressor Control}

Case E430 is exactly as Case E400 except the outside air and relief dampers are adjusted using economizer control based on outdoor air enthalpy $\left(\mathrm{h}_{\mathrm{amb}}\right)$ and return air enthalpy $\left(\mathrm{h}_{\mathrm{ra}}\right)$ as described below. Because these cases assume no thermal losses or gains in the ducts, the return air enthalpy and the zone air enthalpy may be assumed to be equal. Enthalpy has units of energy per mass of dry air.

\subsection{Economizer and Compressor Control Strategy (E430).}

Economizer $=$ ON AND Compressor $=$ OFF IF

IDB $>25.0^{\circ} \mathrm{C}\left(77.0^{\circ} \mathrm{F}\right)$ AND $\mathrm{h}_{\mathrm{amb}} \leq \mathrm{h}_{\mathrm{ra}}$ AND all cooling load for the given hour is compensated by the economizer.

Economizer $=$ ON AND Compressor $=$ ON IF IDB $>25.0^{\circ} \mathrm{C}\left(77.0^{\circ} \mathrm{F}\right)$ AND $\mathrm{h}_{\mathrm{amb}} \leq \mathrm{h}_{\mathrm{ra}}$ AND all cooling load for the given hour is NOT compensated by the economizer.

(In this configuration outside air is at the $100 \%$ maximum setting for the full hour.)

Economizer $=$ OFF AND Compressor $=\mathrm{ON} \mathrm{IF}$

IDB $>25.0^{\circ} \mathrm{C}\left(77.0^{\circ} \mathrm{F}\right)$ AND $\mathrm{h}_{\mathrm{amb}}>\mathrm{h}_{\mathrm{ra}}$.

Economizer $=$ OFF AND Compressor $=$ OFF IF

$\mathrm{IDB} \leq 25.0^{\circ} \mathrm{C}\left(77.0^{\circ} \mathrm{F}\right)$.

Economizer/Compressor ON/OFF are as defined for Case E400.

\subsubsection{Case E440: Economizer with Enthalpy Limit Control}

Case E440 is exactly as Case E430 except when $h_{\text {amb }}>47.25 \mathrm{~kJ} / \mathrm{kg}(28.0 \mathrm{Btu} / \mathrm{lb})$, the outside air and relief dampers are maintained at $15 \%$ outside air.

\subsection{Economizer and Compressor Control Strategy (E440).}

Economizer $=$ ON AND Compressor $=$ OFF IF IDB $>25.0^{\circ} \mathrm{C}\left(77.0^{\circ} \mathrm{F}\right)$ AND $\mathrm{h}_{\mathrm{amb}} \leq 47.25 \mathrm{~kJ} / \mathrm{kg}(28.0 \mathrm{Btu} / \mathrm{lb})$ AND all cooling load for the given hour is compensated by the economizer.

Economizer $=$ ON AND Compressor $=$ ON IF

IDB $>25.0^{\circ} \mathrm{C}\left(77.0^{\circ} \mathrm{F}\right)$ AND $\mathrm{h}_{\mathrm{amb}} \leq 47.25 \mathrm{~kJ} / \mathrm{kg}(28.0 \mathrm{Btu} / \mathrm{lb})$ AND all cooling load for the given hour is NOT compensated by the economizer.

(In this configuration outside air is at the $100 \%$ maximum setting for the full hour.) 
Economizer $=$ OFF AND Compressor $=\mathrm{ON} \mathrm{IF}$

IDB $>25.0^{\circ} \mathrm{C}\left(77.0^{\circ} \mathrm{F}\right)$ AND $\mathrm{h}_{\mathrm{amb}}>47.25 \mathrm{~kJ} / \mathrm{kg}(28.0 \mathrm{Btu} / \mathrm{lb})$.

Economizer $=$ OFF AND Compressor $=$ OFF IF

IDB $\leq 25.0^{\circ} \mathrm{C}\left(77.0^{\circ} \mathrm{F}\right)$.

Economizer/Compressor ON/OFF are as defined for Case E400.

\subsubsection{Cases with No Outside Air, Annual Simulation Context (E500 Series)}

This section describes sequential revisions to the base case required to model the E500 series cases.

Appropriate base cases for a given case are

$\begin{array}{lc}\text { Case } & \text { Basis for that case } \\ \text { E500 } & \text { E300 } \\ \text { E510 } & \text { E500 } \\ \text { E520 } & \text { E500 } \\ \text { E522 } & \text { E520 } \\ \text { E525 } & \text { E520 } \\ \text { E530 } & \text { E500 } \\ \text { E540 } & \text { E530 } \\ \text { E545 } & \text { E540 }\end{array}$

\subsubsection{Case E500: Base Case with No Outside Air}

Case E500 is exactly as Case E300 except for the changes related to internal heat gains and thermostat control strategy as described in the subsections below.

1.3.4.1.1 Internal Heat Gains. The hourly internal gains are as indicated in Table 1-11. For this case the "frac v. max" values in Table 1-11 are the same for both sensible and latent loads.

Sensible internal gains remain as $100 \%$ convective.

These are internally generated sources of heat that are not related to operation of the mechanical cooling system or its air distribution fan.

If your software requires input of water vapor mass flow rate rather than latent internal gains, to convert the latent gains to water vapor mass flow rate for each listed time period, use the heat of vaporization that your software assumes for condensation at the coil. 
Table 1-11. Case E500 Hourly Internal Gains Schedule (IP and SI Units)

\begin{tabular}{|c|c|c|c|c|c|c|c|}
\hline & & & $\overline{\text { SEN S I }}$ & B LE & & $\overline{\mid A T E I}$ & \\
\hline Period & Hours & Watts & Btu/h & frac v. $\max ^{*}$ & Watts & Btu/h & frac v. max* \\
\hline Jan. 1 thru Mar. 10 & 0:00 - 8:00 & 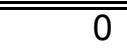 & 0 & 0.00000 & 0 & 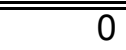 & 0.000 \\
\hline & $8: 00-20: 00$ & 0 & 0 & 0.00000 & 0 & 0 & 0.000 \\
\hline & $20: 00-24: 00$ & 0 & 0 & 0.00000 & 0 & 0 & 0.000 \\
\hline Mar. 11 thru Apr. 10 & $0: 00-9: 00$ & 0 & 0 & 0.00000 & 0 & 0 & 0.000 \\
\hline & $9: 00-16: 00$ & 7034 & 24000 & 0.37500 & 2858 & 9750 & 0.375 \\
\hline & $16: 00-24: 00$ & 0 & 0 & 0.00000 & 0 & 0 & 0.000 \\
\hline Apr. 11** & $0: 00-8: 00$ & 0 & 0 & 0.00000 & 0 & 0 & 0.000 \\
\hline & $8: 00-20: 00$ & 0 & 0 & 0.00000 & 0 & 0 & 0.000 \\
\hline & $20: 00-24: 00$ & 0 & 0 & 0.00000 & 0 & 0 & 0.000 \\
\hline Apr. 12 thru Apr. 20 & $0: 00-8: 00$ & 0 & 0 & 0.00000 & 0 & 0 & 0.000 \\
\hline & $8: 00-17: 00$ & 9379 & 32000 & 0.50000 & 3810 & 13000 & 0.500 \\
\hline & $17: 00-24: 00$ & 0 & 0 & 0.00000 & 0 & 0 & 0.000 \\
\hline Apr. 21 thru Oct. 11 & $0: 00-8: 00$ & 7034 & 24000 & 0.37500 & 2858 & 9750 & 0.375 \\
\hline & $8: 00-12: 00$ & 9379 & 32000 & 0.50000 & 3810 & 13000 & 0.500 \\
\hline & $12: 00-14: 00$ & 14069 & 48000 & 0.75000 & 5715 & 19500 & 0.750 \\
\hline & $14: 00-16: 00$ & 18758 & 64000 & 1.00000 & 7621 & 26000 & 1.000 \\
\hline & $16: 00-20: 00$ & 9379 & 32000 & 0.50000 & 3810 & 13000 & 0.500 \\
\hline & $20: 00-24: 00$ & 7034 & 24000 & 0.37500 & 2858 & 9750 & 0.375 \\
\hline Oct. 12 thru Oct. 18 & $0: 00-8: 00$ & 0 & 0 & 0.00000 & 0 & 0 & 0.000 \\
\hline & $8: 00-14: 00$ & 9379 & 32000 & 0.50000 & 3810 & 13000 & 0.500 \\
\hline & $14: 00-24: 00$ & 0 & 0 & 0.00000 & 0 & 0 & 0.000 \\
\hline Oct. 19 thru Nov. 05 & $0: 00-8: 00$ & 0 & 0 & 0.00000 & 0 & 0 & 0.000 \\
\hline & $8: 00-12: 00$ & 9379 & 32000 & 0.50000 & 3810 & 13000 & 0.500 \\
\hline & $12: 00-14: 00$ & 14069 & 48000 & 0.75000 & 5715 & 19500 & 0.750 \\
\hline & $14: 00-16: 00$ & 18758 & 64000 & 1.00000 & 7621 & 26000 & 1.000 \\
\hline & $16: 00-20: 00$ & 9379 & 32000 & 0.50000 & 3810 & 13000 & 0.500 \\
\hline & $20: 00-24: 00$ & 7034 & 24000 & 0.37500 & 2858 & 9750 & 0.375 \\
\hline Nov. 06 thru Dec. 31** & $0: 00-8: 00$ & 0 & 0 & 0.00000 & 0 & 0 & 0.000 \\
\hline & $8: 00-20: 00$ & 0 & 0 & 0.00000 & 0 & 0 & 0.000 \\
\hline & $20: 00-24: 00$ & 0 & 0 & 0.00000 & 0 & 0 & 0.000 \\
\hline $\begin{array}{l}\text { * "frac v. max" is the co } \\
\text { value for the year. Tr } \\
\text { ** Same schedule as fo }\end{array}$ & $\begin{array}{l}\text { rresponding fr } \\
\text { is is included } \\
\text { r Jan. } 1 \text { throu }\end{array}$ & $\begin{array}{l}\text { ion for } \\
\text { conve } \\
\text { Mar. } 1\end{array}$ & $\begin{array}{l}\text { our witl } \\
\text { e given } \\
\text { ence of }\end{array}$ & $\begin{array}{l}\text { hourly value } \\
\text { users who }\end{array}$ & $\begin{array}{l}\text { lative } \\
\text { need }\end{array}$ & $\begin{array}{l}\text { le max } \\
\text { rovide }\end{array}$ & $\begin{array}{l}\text { num } \\
\text { his input. }\end{array}$ \\
\hline
\end{tabular}

e300intgains.xls e500sch!

If your software requires input of total internal gains, use the sum of sensible + latent internal gains for each listed time period.

The internal gains schedule for E500 was developed to serve the following purposes:

- To avoid extrapolations of performance data, the compressor is intended to be off when $\mathrm{ODB}<12.78^{\circ} \mathrm{C}\left(55.0^{\circ} \mathrm{F}\right)$. 
- Sensible internal gains variations are intended to correspond with additional building shell and solar loads toward midday when possible (this may allow for additional analysis that scales the significance of disagreements in software found here for real buildings); such shell loads would not otherwise be included in a near-adiabatic building model.

- The latent gains schedule allows for a PLR test versus E510 using constant sensible heat ratio (SHR) between E510 and E500.

1.3.4.1.2 Indoor Fan Control and Part-Load Operation. The indoor air distribution fan cycles on and off with the compressor. For this type of control CDF applies to the indoor fan energy consumption (see Section 1.3.1.4.4 and Figure 1-3). Although the fan now cycles rather than operating continuously, the equivalence still holds for using gross total capacity to calculate PLR as an alternative to using net refrigeration effect and adjusted net capacity. See Appendix E for more discussion.

\subsection{Outside Air. Outside air fraction $=0.0$ (no outside air) for the full annual simulation} period. Note that setting both infiltration and outside air to 0 may cause anomalous results for some software. If problems occur, use the lowest values that your software allows (e.g., $\left.1 \times 10^{-x}\right)$. (We found in NREL's DOE-2 simulations that simultaneous use of " 0 " outside air and " 0 " infiltration caused an error in the simulations. We worked around this by specifying minimum outside air $=0.000001 \mathrm{ft}^{3} / \mathrm{min}$. We recommend that you run a sensitivity test to ensure that using 0 for both these inputs does not cause a problem.)

\subsection{Outputs.}

1.3.4.1.4.1 Annual Maxima and Minima. For cases E500-E545 the outputs listed immediately below are to include the hourly integrated maximum and minimum values for the period of April 1 through December 31.

- $\quad$ Minimum zone IDB $\left({ }^{\circ} \mathrm{C}\right)$

- Minimum zone humidity ratio $(\mathrm{kg} / \mathrm{kg})$

- Maximum zone relative humidity (\%)

- Minimum zone relative humidity $(\%)$

Extract this output from a normal annual run. Do not do an additional simulation beginning on April 1 because the above results could contain temperature history errors. These four values are selected after the first three months of simulation to avoid differences in results that could be caused by differences in zone initialization techniques.

Include the other required maximum and minimum value outputs as usual for the entire simulation period (January 1 through December 31).

1.3.4.1.4.2 ODB Sensitivity. For obtaining a sensitivity test of performance as a function of ODB, in addition to the usual outputs (for cases E310-E440), include the following daily average per hour outputs (consumptions and coil loads are full day sums divided by 24 [hours]) for April 30 and June 25 (0:0024:00):

- Total consumption (compressor + outdoor condenser fan + indoor air distribution fan, Wh)

- Compressor electric consumption (Wh)

- Outdoor condenser fan electric consumption (Wh)

- Indoor air distribution fan electric consumption (Wh) 
- Total evaporator coil load (sensible + latent), (Wh)

- Sensible evaporator coil load (Wh)

- Latent evaporator coil load (Wh)

- $\mathrm{COP}_{2}=\Sigma$ (total coil load) $/(\Sigma$ (compressor energy) $+\Sigma$ (outdoor fan energy) $)$, for the given day

- Zone humidity ratio $(\mathrm{kg} / \mathrm{kg})$

- $\operatorname{ODB}\left({ }^{\circ} \mathrm{C}\right)$

- $\operatorname{EDB}\left({ }^{\circ} \mathrm{C}\right)$.

1.3.4.1.4.3 PLR Sensitivity. For developing a sensitivity test of performance as a function of PLR versus Case E510, also include the following summed, mean, and other outputs only for the period of May 1 through September 30. Extract this output from a normal annual run. Do not run only the required months because the results could contain temperature history errors.

- $\quad$ Summed Values

○ Total consumption (compressor + outdoor condenser fan + indoor air distribution fan, $\mathrm{kWh}$ )

- Compressor electric consumption (kWh)

- Outdoor condenser fan electric consumption $(\mathrm{kWh})$

- Indoor air distribution fan electric consumption $(\mathrm{kWh})$

- Total evaporator coil load (sensible + latent), $(\mathrm{kWh})$

- Sensible evaporator coil load $(\mathrm{kWh})$

$\circ \quad$ Latent evaporator coil load $(\mathrm{kWh})$

- Mean Values

- $\mathrm{COP}_{2}$

- Zone IDB $\left({ }^{\circ} \mathrm{C}\right)$

- Zone humidity ratio $(\mathrm{kg} / \mathrm{kg})$

$\circ$ Zone relative humidity $(\%)$.

\subsubsection{Case E510: High Part-Load Ratio}

Case E510 is exactly as Case E500 except for the internal gains and outputs as described below.

1.3.4.2.1 Internal Heat Gains. The hourly internal gains are as indicated in Table 1-12. The loads are only changed from Case E500 for the period of April 21 through October 11. This results, however, in changes to the listed "frac v. max" multipliers for the other time periods. For this case the "frac v. max" values in Table 1-12 are the same for both sensible and latent loads.

Sensible gains remain as $100 \%$ convective.

These are internally generated sources of heat that are not related to operation of the mechanical cooling system or its air distribution fan.

If your software requires input of water vapor mass flow rate rather than latent internal gains, to convert the latent gains to water vapor mass flow rate for each listed time period, use the heat of vaporization that your software assumes for condensation at the coil.

If your software requires input of total internal gains, use the sum of sensible + latent internal gains for each listed time period. 
Table 1-12. Case E510 Hourly Internal Gains Schedule (IP and SI Units)

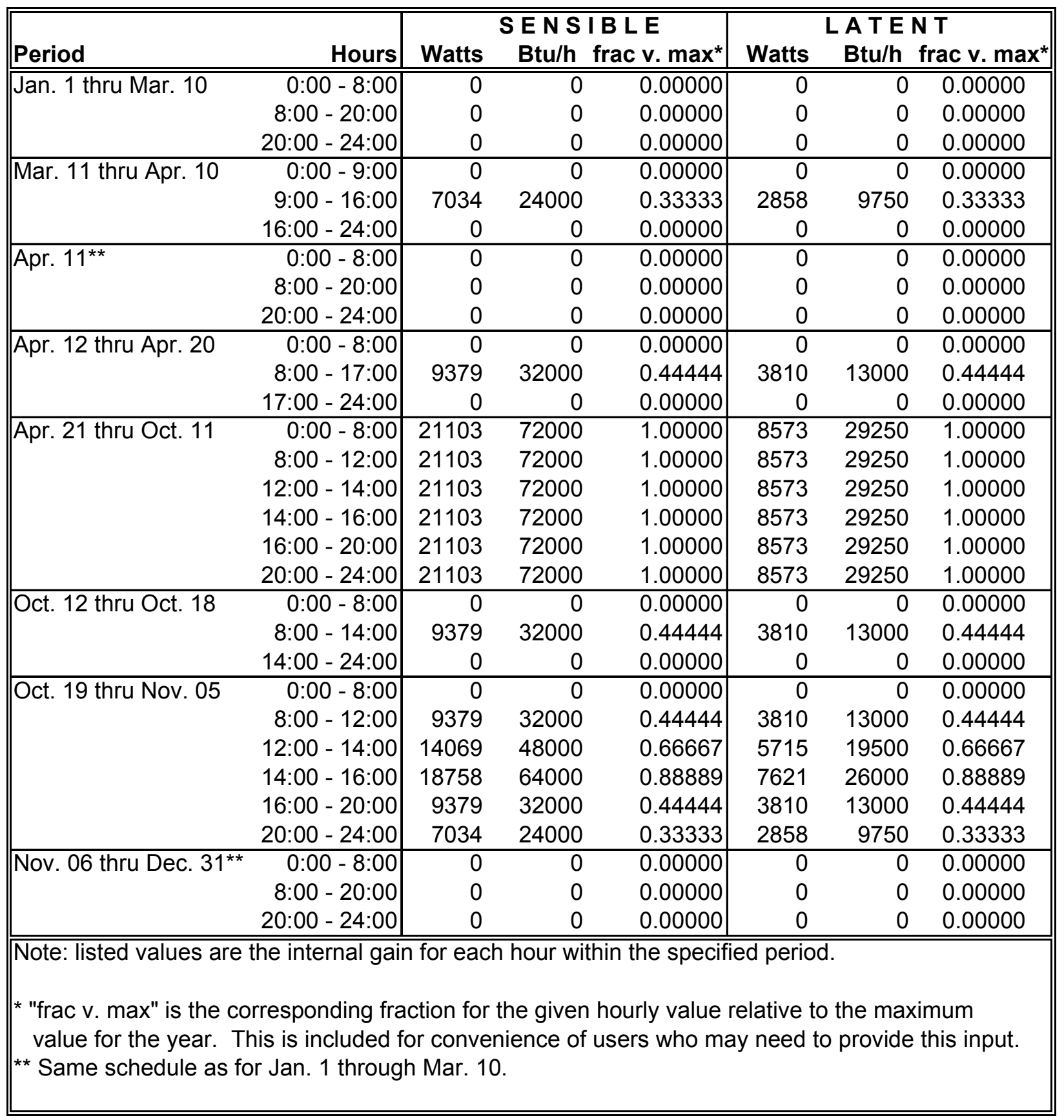

e300intgains.xls e510sch!

1.3.4.2.2 Outputs. The outputs are as for E500 except the following summed, mean, and other outputs are included only for the period of May 1 through September 30:

- $\quad$ Summed Values

○ Total consumption (compressor + outdoor condenser fan + indoor air distribution fan, $\mathrm{kWh}$ )

- Compressor electric consumption $(\mathrm{kWh})$ 
- Outdoor condenser fan electric consumption $(\mathrm{kWh})$

- Indoor air distribution fan electric consumption $(\mathrm{kWh})$

- Total evaporator coil load (sensible + latent), $(\mathrm{kWh})$

- Sensible evaporator coil load (kWh)

- Latent evaporator coil load $(\mathrm{kWh})$

- Mean Values

$\circ \mathrm{COP}_{2}$

- Zone IDB $\left({ }^{\circ} \mathrm{C}\right)$

- Zone humidity ratio $(\mathrm{kg} / \mathrm{kg})$

- Zone relative humidity $(\%)$.

Extract this output from a normal annual run. Do not run only the required months because the results could contain temperature history errors. Do not include these outputs for the period from January 1 through December 31 (as is required for all the other cases).

Include the other required maximum and minimum value outputs as described for Case E500. Do not include average daily outputs for April 30 and June 25.

\subsubsection{Case E520: Reduced Thermostat Set Point $\left(E D B=15^{\circ} \mathrm{C}\right)$}

Case E520 is exactly as Case E500 except the thermostat control strategy and outputs are as described below.

\subsection{Thermostat Control Strategy.}

Heat $=$ off.

$\mathrm{Cool}=$ on if zone air temperature $>15.0^{\circ} \mathrm{C}\left(59.0^{\circ} \mathrm{F}\right)$; otherwise Cool $=$ off.

All other features of the thermostat remain as before.

\subsection{Outputs.}

The required outputs are the typical outputs required for cases E310-E440. As in Case E500, however, the outputs listed immediately below are to include the hourly integrated maximum and minimum values for the period from April 1 through December 31.

- Minimum zone IDB $\left({ }^{\circ} \mathrm{C}\right)$

- Minimum zone humidity ratio $(\mathrm{kg} / \mathrm{kg})$

- Maximum zone relative humidity (\%)

- Minimum zone relative humidity (\%)

Extract this output from a normal annual run. Do not do an additional simulation beginning on April 1 because the above results could contain temperature history errors. These four values are selected after the first three months of simulation to avoid differences in results that could be caused by differences in zone initialization techniques.

Include the other required maximum and minimum value outputs as usual for the entire simulation period (January 1-December 31). 


\subsubsection{Case E522: Reduced Thermostat Set Point $\left(E D B=20^{\circ} \mathrm{C}\right)$}

Case E522 is exactly as Case E520 except the thermostat control strategy is as described below.

Heat $=$ off.

Cool $=$ on if zone air temperature $>20.0^{\circ} \mathrm{C}\left(68.0^{\circ} \mathrm{F}\right)$; otherwise Cool $=$ off.

All other features of the thermostat remain as before.

\subsubsection{Case E525: Increased Thermostat Set Point (EDB Sensitivity)}

Case E525 is exactly as Case E520 except the thermostat control strategy is as described below.

Heat $=$ off.

Cool $=$ on if zone air temperature $>35.0^{\circ} \mathrm{C}\left(95.0^{\circ} \mathrm{F}\right)$; otherwise Cool $=$ off.

All other features of the thermostat remain as before.

\subsubsection{Case E530: Dry Coil}

Case E530 is exactly as Case E500 except the latent internal gains and outputs are as described below.

1.3.4.6.1 Internal Gains. The latent internal gains are 0 for the entire annual simulation period. The sensible internal gains remain as in Case E500. If your software requires input of total internal gains, use the sensible internal gains for each listed time period.

1.3.4.6.2 Outputs. For obtaining a sensitivity test of performance as a function of ODB, in addition to the usual outputs (for Case E520), include the following daily average per hour outputs (consumptions and coil loads are full day sums divided by 24 [hours]) for April 30 and June 25 (0:00-24:00):

- Total consumption (compressor + outdoor condenser fan + indoor air distribution fan), (Wh)

- Compressor electric consumption (Wh)

- Outdoor condenser fan electric consumption (Wh)

- Indoor air distribution fan electric consumption (Wh)

- Total evaporator coil load (sensible + latent, Wh)

- Sensible evaporator coil load (Wh)

- Latent evaporator coil load (Wh)

- $\mathrm{COP}_{2}=\Sigma$ (total coil load) $/(\Sigma$ (compressor energy) $+\Sigma$ (outdoor fan energy) $)$, for the given day

- Zone humidity ratio $(\mathrm{kg} / \mathrm{kg})$

- $\operatorname{ODB}\left({ }^{\circ} \mathrm{C}\right)$

- $\operatorname{EDB}\left({ }^{\circ} \mathrm{C}\right)$. 


\subsubsection{Case E540: Reduced Thermostat Set Point (EDB Sensitivity)}

Case E540 is exactly as Case E530 except the thermostat control strategy and outputs are as described below.

\subsection{Thermostat Control Strategy.}

Heat $=$ off.

Cool $=$ on if zone air temperature $>15.0^{\circ} \mathrm{C}\left(59.0^{\circ} \mathrm{F}\right)$; otherwise Cool $=$ off.

All other features of the thermostat remain as before.

\subsection{Outputs.}

The required outputs are only the typical outputs required for Case E520.

\subsubsection{Case E545: Increased Thermostat Set Point (EDB Sensitivity)}

Case E545 is exactly as Case E540 except the thermostat control strategy is as described below.

Heat $=$ off.

$\mathrm{Cool}=$ on if zone air temperature $>35.0^{\circ} \mathrm{C}\left(95.0^{\circ} \mathrm{F}\right)$; otherwise Cool $=$ off.

All other features of the thermostat remain as before. 


\section{APPENDIX A}

\section{TMY2 Weather Data Format Description}

The following TMY2 format description is extracted from Section 3 of the TMY2 user manual (Marion and Urban 1995).

For each station, a TMY2 file contains 1 year of hourly solar radiation, illuminance, and meteorological data. The files consist of data for the typical calendar months during 1961-1990 that are concatenated to form the typical meteorological year for each station.

Each hourly record in the file contains values for solar radiation, illuminance, and meteorological elements. A two-character source and uncertainty flag is attached to each data value to indicate whether the data value was measured, modeled, or missing, and to provide an estimate of the uncertainty of the data value.

Users should be aware that the format of the TMY2 data files is different from the format used for the NSRDB and the original TMY data files.

\section{File Convention}

File naming convention uses the Weather Bureau Army Navy (WBAN) number as the file prefix, with the characters TM2 as the file extension. For example, 13876.TM2 is the TMY2 file name for Birmingham, Alabama. The TMY2 files contain computer readable ASCII characters and have a file size of $1.26 \mathrm{MB}$.

\section{File Header}

The first record of each file is the file header that describes the station. The file header contains the WBAN number, city, state, time zone, latitude, longitude, and elevation. The field positions and definitions of these header elements are given in Table A-1, along with sample FORTRAN and C formats for reading the header. A sample of a file header and data for January 1 is shown in Figure A-1.

\section{Hourly Records}

Following the file header, 8,760 hourly data records provide 1 year of solar radiation, illuminance, and meteorological data, along with their source and uncertainty flags. Table A-2 provides field positions, element definitions, and sample FORTRAN and C formats for reading the hourly records.

Each hourly record begins with the year (field positions 2-3) from which the typical month was chosen, followed by the month, day, and hour information in field positions 4-9. The times are in local standard time (previous TMYs based on SOLMET/ERSATZ data are in solar time). 
SD $\quad-6$ N $43 \quad 34$ W $96 \quad 44 \quad 435$

$85010101000000000000 ? 00000 ? 00000 ? 00000 ? 00000 ? 00000 ? 00000 ? 010 \mathrm{~A} 710 \mathrm{~A} 7-150 \mathrm{~A} 7-211 \mathrm{~A} 7060 \mathrm{~A} 70975 \mathrm{~A} 7360 \mathrm{~A} 7052 \mathrm{~A} 70161 \mathrm{~A} 700945 \mathrm{~A} 709990999999004 \mathrm{E} 7050 \mathrm{~F} 8000 \mathrm{~A} 700 \mathrm{E} 7$ $85010102000000000000 ? .00000 ? .00000 ? 200000 ? 00000 ? 00000 ? 00000 ? 010 \mathrm{~A} 710 \mathrm{~A} 7-1.140 \mathrm{~A} 7-21-20$ 85010103000000000000?00000?00000?00000?00000?00000?00000?010A710A7-144A7-200A7063A70975A 7340A7062A70161A700732A70999099999004E7050F8000A 700E7 $85010104000000000000 ? 00000 ? 00000 ? 00000 ? 00000 ? 00000 ? 00000 ? 010 \mathrm{~A} 710 \mathrm{~A} 7-150 \mathrm{~A} 7-206 \mathrm{~A} 7063 \mathrm{~A} 70976 \mathrm{~A} 7330 \mathrm{~A} 7072 \mathrm{~A} 70161 \mathrm{~A} 700640 \mathrm{~A} 70999099999004 \mathrm{E} 7050 \mathrm{~F} 8000 \mathrm{~A} 700 \mathrm{E} 7$

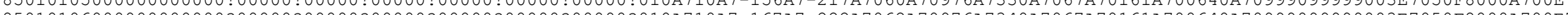
$8501010600000000000 ? 00000$ ? 00000 ? 00000 ? 00000 ? $00000 ? 00000$ ? $010 \mathrm{~A} 710 \mathrm{~A} 7-167 \mathrm{~A} 7-222 \mathrm{~A} 7062 \mathrm{~A} 70976 \mathrm{~A} 7340 \mathrm{~A} 7067 \mathrm{~A} 70161 \mathrm{~A} 700640 \mathrm{~A} 70999099999003 \mathrm{E} 7050 \mathrm{~F} 8000 \mathrm{~A} 700 \mathrm{E} 7$ $850101080000000000003000003000003000003000003000003000003002 A 702 A 7-19 A A 7-244 A 7065 A 70978 A 7310 A 7036 A 70193 A 7777777 A 70999999999003 E 7050 F 8000 A 700 \mathrm{~B} 7$

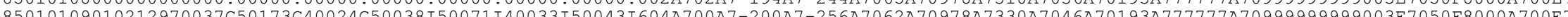

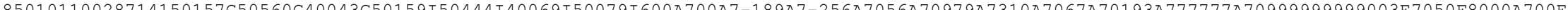
$85010111043614150276 \mathrm{G} 40714 \mathrm{G} 40056 \mathrm{G} 50286 \mathrm{I} 40642 \mathrm{I} 40088 \mathrm{I} 50111 \mathrm{I} 500 \mathrm{~A} 700 \mathrm{~A} 7-172 \mathrm{~A} 7-250 \mathrm{~A} 7051 \mathrm{~A} 70979 \mathrm{~A} 7310 \mathrm{~A} 7062 \mathrm{~A} 70161 \mathrm{~A} 777777 \mathrm{~A} 70999999999003 \mathrm{E} 7050 \mathrm{~F} 8000 \mathrm{AA700 \textrm {E } 7}$

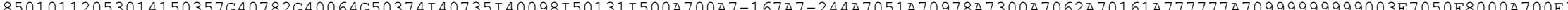
$85010113056214150387 \mathrm{G} 40806 \mathrm{G} 40067 \mathrm{G} 50407$ I 40767 I 40101I50139I500A700A7-156A7-244A7047A 70978A7320A7067A70193A7777777A709999999999003E7050F8000A700E7 $85010114053014150359 G 40788 G 40064$ G50377I 40742I 40098I50131I500A700A7-144A7-239A7045A70978A7310A7062A70193A7777777A709999999999003E7050F8000A 700E7 85010115043614150277 G40716G40056G50289I40645I40088I50111I500A700A7-139A7-239A7043A70978A7330A7052A70193A7777777A709999999999003E7050F8000A700E7

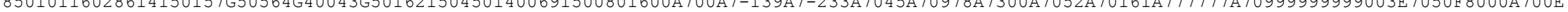
85010117010412730038 G50209G40021G50038I50104I40030I50038I600A700A7-150A7-233A7049A70978A7290A7041A A $241 \mathrm{~A} 777777 \mathrm{~A} 70999999999003 \mathrm{E} 7050 \mathrm{~F} 8000 \mathrm{~A} 700 \mathrm{E} 7$ $85010118000000000000 ? 00000 ? 00000 ? 00000 ? 00000 ? 00000 ? 00000 ? 000 \mathrm{~A} 700 \mathrm{~A} 7-167 \mathrm{~A} 7-233 \mathrm{~A} 7057 \mathrm{~A} 70978 \mathrm{~A} 7000 \mathrm{~A} 7000 \mathrm{~A} 70241 \mathrm{~A} 777777 \mathrm{~A} 70999999999003 \mathrm{E} 7050 \mathrm{~F} 8000 \mathrm{~A} 700 \mathrm{E} 7$ 8501011900000000000?0000? $00000 ? 00000 ? 00000 ? 00000 ? 00000 ? 000 \mathrm{~A} 700 \mathrm{~A} 7-172 \mathrm{~A} 7-233 \mathrm{~A} 7059 \mathrm{~A} 70978 \mathrm{~A} 7000 \mathrm{~A} 7000 \mathrm{~A} 70241 \mathrm{~A} 777777 \mathrm{~A} 70999999999003 \mathrm{E} 7050 \mathrm{~F} 8000 \mathrm{~A} 700 \mathrm{E} 7$ $85010120000000000000 ? 00000 ? 00000 ? 00000 ? 00000 ? 00000 ? 00000 ? 000 \mathrm{~A} 700 \mathrm{~A} 7-178 \mathrm{~A} 7-233 \mathrm{~A} 7062 \mathrm{~A} 70978 \mathrm{~A} 7000 \mathrm{~A} 7000 \mathrm{~A} 70241 \mathrm{~A} 7777777 \mathrm{~A} 709999999999003 \mathrm{E} 7050 \mathrm{~F} 8000 \mathrm{~A} 700 \mathrm{E} 7$ 850101210000000000?0000? $00000 ? 0000$ ? $00000 ? 00000 ? 0000 ? .000 \mathrm{~A} 700 \mathrm{~A} 7-183 \mathrm{~A} 7-239 \mathrm{~A} 7062 \mathrm{~A} 70978 \mathrm{~A} 7260 \mathrm{~A} 7015 \mathrm{~A} 70241 \mathrm{~A} 777777 \mathrm{~A} 70999999999003 \mathrm{E} 7050 \mathrm{E} 8000 \mathrm{~A} 700 \mathrm{E} 7$

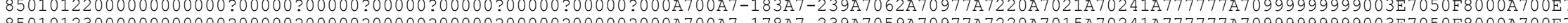

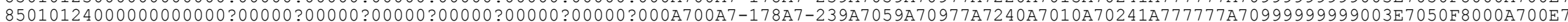

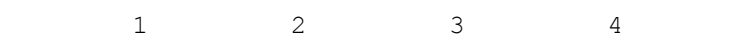
1 1 1 1234567890123456789012345678901234567890123456789012345678901234567890123456789012345678901234567890123456789012345678901234567890123456789012 (for field position identification only)

\section{Figure A-1. Sample file header and data in the TMY2 format for January 1}


Table A-1. Header Elements in the TMY2 Format (For First Record of Each File)

\begin{tabular}{|c|c|c|}
\hline Field Position & Element & Definition \\
\hline $002-006$ & WBAN Number & $\begin{array}{l}\text { Station's Weather Bureau Army Navy number (see Table 2-1 of Marion and Urban } \\
\text { [1995]) }\end{array}$ \\
\hline $008-029$ & City & City where the station is located (maximum of 22 characters) \\
\hline $031-032$ & State & State where the station is located (abbreviated to two letters) \\
\hline $034-036$ & Time Zone & $\begin{array}{l}\text { Time zone is the number of hours by which the local standard time is ahead of or } \\
\text { behind Universal Time. For example, Mountain Standard Time is designated -7 } \\
\text { because it is } 7 \text { hours behind Universal Time. }\end{array}$ \\
\hline $\begin{array}{l}\mathbf{0 3 8}-\mathbf{0 4 4} \\
038 \\
040-041 \\
043-044\end{array}$ & Latitude & $\begin{array}{l}\text { Latitude of the station } \\
\mathrm{N}=\text { North of equator } \\
\text { Degrees } \\
\text { Minutes }\end{array}$ \\
\hline $\begin{array}{l}\mathbf{0 4 6}-\mathbf{0 5 3} \\
046 \\
048-050 \\
052-053\end{array}$ & Longitude & $\begin{array}{l}\text { Longitude of the station } \\
\mathrm{W}=\text { West, } \mathrm{E}=\text { East } \\
\text { Degrees } \\
\text { Minutes }\end{array}$ \\
\hline $056-059$ & Elevation & Elevation of station in meters above sea level \\
\hline \multicolumn{3}{|c|}{ 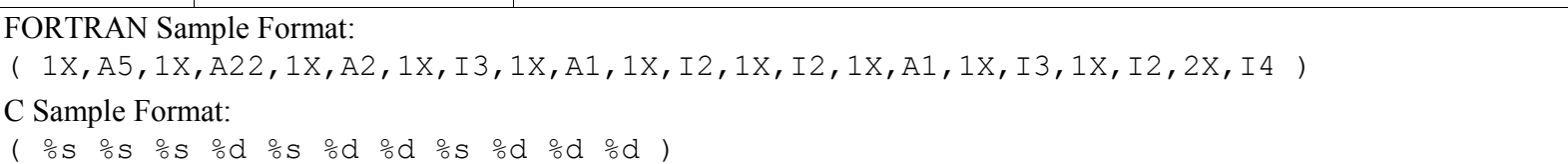 } \\
\hline
\end{tabular}

Table A-2. Data Elements in the TMY2 Format (For All Except the First Record)

\begin{tabular}{|c|c|c|c|}
\hline Field Position & Element & Values & Definition \\
\hline $\begin{array}{l}\mathbf{0 0 2}-\mathbf{0 0 9} \\
002-003 \\
004-005 \\
006-007 \\
008-009\end{array}$ & $\begin{array}{l}\text { Local Standard Time } \\
\text { Year } \\
\text { Month } \\
\text { Day } \\
\text { Hour }\end{array}$ & $\begin{array}{l}61-90 \\
1-12 \\
1-31 \\
1-24\end{array}$ & $\begin{array}{l}\text { Year, 1961-1990 } \\
\text { Month } \\
\text { Day of month } \\
\text { Hour of day in local standard time }\end{array}$ \\
\hline $010-013$ & $\begin{array}{l}\text { Extraterrestrial Horizontal } \\
\text { Radiation }\end{array}$ & $0-1415$ & $\begin{array}{l}\text { Amount of solar radiation in } \mathrm{Wh} / \mathrm{m}^{2} \text { received on a } \\
\text { horizontal surface at the top of the atmosphere } \\
\text { during the } 60 \text { minutes preceding the hour indicated }\end{array}$ \\
\hline $014-017$ & $\begin{array}{l}\text { Extraterrestrial Direct Normal } \\
\text { Radiation }\end{array}$ & $0-1415$ & $\begin{array}{l}\text { Amount of solar radiation in } \mathrm{Wh} / \mathrm{m}^{2} \text { received on a } \\
\text { surface normal to the sun at the top of the } \\
\text { atmosphere during the } 60 \text { minutes preceding the } \\
\text { hour indicated }\end{array}$ \\
\hline $\begin{array}{l}\mathbf{0 1 8}-\mathbf{0 2 3} \\
018-021 \\
022 \\
023\end{array}$ & $\begin{array}{l}\text { Global Horizontal Radiation } \\
\text { Data Value } \\
\text { Flag for Data Source } \\
\text { Flag for Data Uncertainty }\end{array}$ & $\begin{array}{c}0-1200 \\
\text { A - H, ? } \\
0-9\end{array}$ & $\begin{array}{l}\text { Total amount of direct and diffuse solar radiation } \\
\text { in } \mathrm{Wh} / \mathrm{m}^{2} \text { received on a horizontal surface during } \\
\text { the } 60 \text { minutes preceding the hour indicated }\end{array}$ \\
\hline $\begin{array}{l}\mathbf{0 2 4} \mathbf{- 0 2 9} \\
024-027 \\
028 \\
029\end{array}$ & $\begin{array}{l}\text { Direct Normal Radiation } \\
\text { Data Value } \\
\text { Flag for Data Source } \\
\text { Flag for Data Uncertainty }\end{array}$ & $\begin{array}{c}0-1100 \\
\mathrm{~A}-\mathrm{H}, ? \\
0-9\end{array}$ & $\begin{array}{l}\text { Amount of solar radiation in } \mathrm{Wh} / \mathrm{m}^{2} \text { received } \\
\text { within a } 5.7^{\circ} \text { field of view centered on the sun, } \\
\text { during the } 60 \text { minutes preceding the hour indicated }\end{array}$ \\
\hline
\end{tabular}


Table A-2. Data Elements in the TMY2 Format (Continued)

\begin{tabular}{|c|c|c|c|}
\hline $\begin{array}{c}\text { Field } \\
\text { Position }\end{array}$ & Element & Values & Definition \\
\hline $\begin{array}{l}\mathbf{0 3 0} \mathbf{- 0 3 5} \\
030-033 \\
034 \\
035\end{array}$ & $\begin{array}{l}\text { Diffuse Horizontal Radiation } \\
\text { Data Value } \\
\text { Flag for Data Source } \\
\text { Flag for Data Uncertainty }\end{array}$ & $\begin{array}{c}0-700 \\
\mathrm{~A}-\mathrm{H}, ? \\
0-9\end{array}$ & $\begin{array}{l}\text { Amount of solar radiation in } \mathrm{Wh} / \mathrm{m}^{2} \\
\text { received from the sky (excluding the solar } \\
\text { disk) on a horizontal surface during the } 60 \\
\text { minutes preceding the hour indicated }\end{array}$ \\
\hline $\begin{array}{l}\mathbf{0 3 6} \mathbf{- 0 4 1} \\
036-039 \\
040 \\
041\end{array}$ & $\begin{array}{l}\text { Global Horiz. Illuminance } \\
\text { Data Value } \\
\text { Flag for Data Source } \\
\text { Flag for Data Uncertainty }\end{array}$ & $\begin{array}{c}0-1,300 \\
\text { I, ? } \\
0-9\end{array}$ & $\begin{array}{l}\text { Average total amount of direct and diffuse } \\
\text { illuminance in hundreds of lux received } \\
\text { on a horizontal surface during the } 60 \\
\text { minutes preceding the hour indicated. } \\
0 \text { to } 1,300=0 \text { to } 130,000 \text { lux }\end{array}$ \\
\hline $\begin{array}{l}\mathbf{0 4 2} \mathbf{- 0 4 7} \\
042-045 \\
046 \\
047\end{array}$ & $\begin{array}{l}\text { Direct Normal Illuminance } \\
\text { Data Value } \\
\text { Flag for Data Source } \\
\text { Flag for Data Uncertainty }\end{array}$ & $\begin{array}{c}0-1,100 \\
\text { I, ? } \\
0-9\end{array}$ & $\begin{array}{l}\text { Average amount of direct normal } \\
\text { illuminance in hundreds of lux received } \\
\text { within a } 5.7 \text { degree field of view centered } \\
\text { on the sun during the } 60 \text { minutes } \\
\text { preceding the hour indicated. } \\
0 \text { to } 1,100=0 \text { to } 110,000 \text { lux }\end{array}$ \\
\hline $\begin{array}{l}\mathbf{0 4 8} \mathbf{- 0 5 3} \\
048-051 \\
052 \\
053\end{array}$ & $\begin{array}{l}\text { Diffuse Horiz. Illuminance } \\
\text { Data Value } \\
\text { Flag for Data Source } \\
\text { Flag for Data Uncertainty }\end{array}$ & $\begin{array}{c}0-800 \\
\mathrm{I}, ? \\
0-9\end{array}$ & $\begin{array}{l}\text { Average amount of illuminance in } \\
\text { hundreds of lux received from the sky } \\
\text { (excluding the solar disk) on a horizontal } \\
\text { surface during the } 60 \text { minutes preceding } \\
\text { the hour indicated. } \\
0 \text { to } 800=0 \text { to } 80,000 \text { lux }\end{array}$ \\
\hline $\begin{array}{l}\mathbf{0 5 4} \mathbf{- 0 5 9} \\
054-057 \\
058 \\
059\end{array}$ & $\begin{array}{l}\text { Zenith Luminance } \\
\text { Data Value } \\
\text { Flag for Data Source } \\
\text { Flag for Data Uncertainty }\end{array}$ & $\begin{array}{c}0-7,000 \\
\text { I, ? } \\
0-9\end{array}$ & $\begin{array}{l}\text { Average amount of luminance at the sky's } \\
\text { zenith in tens of } \mathrm{Cd} / \mathrm{m}^{2} \text { during the } 60 \\
\text { minutes preceding the hour indicated. } \\
0 \text { to } 7,000=0 \text { to } 70,000 \mathrm{Cd} / \mathrm{m}^{2}\end{array}$ \\
\hline $\begin{array}{l}\mathbf{0 6 0}-\mathbf{0 6 3} \\
060-061 \\
062 \\
063\end{array}$ & $\begin{array}{l}\text { Total Sky Cover } \\
\text { Data Value } \\
\text { Flag for Data Source } \\
\text { Flag for Data Uncertainty }\end{array}$ & $\begin{array}{c}0-10 \\
\mathrm{~A}-\mathrm{F}, ? \\
0-9\end{array}$ & $\begin{array}{l}\text { Amount of sky dome in tenths covered by } \\
\text { clouds or obscuring phenomena at the } \\
\text { hour indicated }\end{array}$ \\
\hline $\begin{array}{l}\mathbf{0 6 4 - 0 6 7} \\
064-065 \\
066 \\
067\end{array}$ & $\begin{array}{l}\text { Opaque Sky Cover } \\
\text { Data Value } \\
\text { Flag for Data Source } \\
\text { Flag for Data Uncertainty }\end{array}$ & $\begin{array}{l}0-10 \\
A-F \\
0-9\end{array}$ & $\begin{array}{l}\text { Amount of sky dome in tenths covered by } \\
\text { clouds or obscuring phenomena that } \\
\text { prevent observing the sky or higher cloud } \\
\text { layers at the hour indicated }\end{array}$ \\
\hline $\begin{array}{l}\mathbf{0 6 8}-\mathbf{0 7 3} \\
068-071 \\
072 \\
073\end{array}$ & $\begin{array}{l}\text { Dry-Bulb Temperature } \\
\text { Data Value } \\
\text { Flag for Data Source } \\
\text { Flag for Data Uncertainty }\end{array}$ & $\begin{array}{c}-500 \text { to } 500 \\
\text { A }-\mathrm{F} \\
0-9\end{array}$ & $\begin{array}{l}\text { Dry-bulb temperature in tenths of }{ }^{\circ} \mathrm{C} \text { at } \\
\text { the hour indicated. } \\
-500 \text { to } 500=-50.0 \text { to } 50.0 \text { degrees } \mathrm{C}\end{array}$ \\
\hline $\begin{array}{l}\mathbf{0 7 4 - 0 7 9} \\
074-077 \\
078 \\
079\end{array}$ & $\begin{array}{l}\text { Dew Point Temperature } \\
\text { Data Value } \\
\text { Flag for Data Source } \\
\text { Flag for Data Uncertainty }\end{array}$ & $\begin{array}{c}-600 \text { to } 300 \\
\text { A }-\mathrm{F} \\
0-9\end{array}$ & $\begin{array}{l}\text { Dew point temperature in tenths of }{ }^{\circ} \mathrm{C} \text { at } \\
\text { the hour indicated. } \\
-600 \text { to } 300=-60.0 \text { to } 30.0^{\circ} \mathrm{C}\end{array}$ \\
\hline $\begin{array}{l}\mathbf{0 8 0} \mathbf{- 0 8 4} \\
080-082 \\
083 \\
084\end{array}$ & $\begin{array}{l}\text { Relative Humidity } \\
\text { Data Value } \\
\text { Flag for Data Source } \\
\text { Flag for Data Uncertainty }\end{array}$ & $\begin{array}{l}0-100 \\
\text { A - F } \\
0-9\end{array}$ & $\begin{array}{l}\text { Relative humidity in percent at the hour } \\
\text { indicated }\end{array}$ \\
\hline
\end{tabular}


Table A-2. Data Elements in the TMY2 Format (Continued)

\begin{tabular}{|c|c|c|c|}
\hline $\begin{array}{c}\text { Field } \\
\text { Position }\end{array}$ & Element & Values & Definition \\
\hline $\begin{array}{l}\mathbf{0 8 5}-\mathbf{0 9 0} \\
085-088 \\
089 \\
090\end{array}$ & $\begin{array}{l}\text { Atmospheric Pressure } \\
\text { Data Value } \\
\text { Flag for Data Source } \\
\text { Flag for Data Uncertainty }\end{array}$ & $\begin{array}{l}700-1100 \\
\text { A - F } \\
0-9\end{array}$ & $\begin{array}{l}\text { Atmospheric pressure at station in millibars at the } \\
\text { hour indicated }\end{array}$ \\
\hline $\begin{array}{l}\mathbf{0 9 1} \mathbf{- 0 9 5} \\
091-093 \\
094 \\
095\end{array}$ & $\begin{array}{l}\text { Wind Direction } \\
\text { Data Value } \\
\text { Flag for Data Source } \\
\text { Flag for Data Uncertainty }\end{array}$ & $\begin{array}{l}0-360 \\
A-F \\
0-9\end{array}$ & $\begin{array}{l}\text { Wind direction in degrees at the hour indicated. } \\
(\mathrm{N}=0 \text { or } 360, \mathrm{E}=90, \mathrm{~S}=180, \mathrm{~W}=270) \text {. For } \\
\text { calm winds, wind direction equals zero. }\end{array}$ \\
\hline $\begin{array}{l}\mathbf{0 9 6}-\mathbf{1 0 0} \\
096-98 \\
99 \\
100\end{array}$ & $\begin{array}{l}\text { Wind Speed } \\
\text { Data Value } \\
\text { Flag for Data Source } \\
\text { Flag for Data Uncertainty }\end{array}$ & $\begin{array}{l}0-400 \\
A-F \\
0-9\end{array}$ & $\begin{array}{l}\text { Wind speed in tenths of meters per second at the } \\
\text { hour indicated. } \\
0 \text { to } 400=0 \text { to } 40.0 \mathrm{~m} / \mathrm{s}\end{array}$ \\
\hline $\begin{array}{l}\mathbf{1 0 1} \mathbf{- 1 0 6} \\
101-104 \\
105 \\
106\end{array}$ & $\begin{array}{l}\text { Visibility } \\
\text { Data Value } \\
\text { Flag for Data Source } \\
\text { Flag for Data Uncertainty }\end{array}$ & $\begin{array}{c}0-1609 \\
\mathrm{~A}-\mathrm{F}, ? \\
0-9\end{array}$ & $\begin{array}{l}\text { Horizontal visibility in tenths of kilometers at the } \\
\text { hour indicated. } \\
7777=\text { unlimited visibility } \\
0 \text { to } 1609=0.0 \text { to } 160.9 \mathrm{~km} \\
9999=\text { missing data }\end{array}$ \\
\hline $\begin{array}{l}\mathbf{1 0 7}-\mathbf{1 1 3} \\
107-111 \\
112 \\
113\end{array}$ & $\begin{array}{l}\text { Ceiling Height } \\
\text { Data Value } \\
\text { Flag for Data Source } \\
\text { Flag for Data Uncertainty }\end{array}$ & $\begin{array}{l}0-30450 \\
\mathrm{~A}-\mathrm{F}, ? \\
0-9\end{array}$ & $\begin{array}{l}\text { Ceiling height in meters at the hour indicated. } \\
77777 \text { = unlimited ceiling height } \\
88888 \text { = cirroform } \\
99999=\text { missing data }\end{array}$ \\
\hline $114-123$ & Present Weather & $\begin{array}{l}\text { See } \\
\text { Appendix B of } \\
\text { Marion and } \\
\text { Urban (1995) }\end{array}$ & $\begin{array}{l}\text { Present weather conditions denoted by a 10-digit } \\
\text { number. See Appendix B of Marion and Urban } \\
\text { (1995) for key to present weather elements. }\end{array}$ \\
\hline $\begin{array}{l}\mathbf{1 2 4} \mathbf{- 1 2 8} \\
124-126 \\
127 \\
128\end{array}$ & $\begin{array}{l}\text { Precipitable Water } \\
\text { Data Value } \\
\text { Flag for Data Source } \\
\text { Flag for Data Uncertainty }\end{array}$ & $\begin{array}{l}0-100 \\
A-F \\
0-9\end{array}$ & $\begin{array}{l}\text { Precipitable water in millimeters at the hour } \\
\text { indicated }\end{array}$ \\
\hline $\begin{array}{l}129-\mathbf{1 3 3} \\
129-131 \\
132 \\
133\end{array}$ & $\begin{array}{l}\text { Aerosol Optical Depth } \\
\text { Data Value } \\
\text { Flag for Data Source } \\
\text { Flag for Data Uncertainty }\end{array}$ & $\begin{array}{c}0-240 \\
A-F \\
0-9\end{array}$ & $\begin{array}{l}\text { Broadband aerosol optical depth (broad-band } \\
\text { turbidity) in thousandths on the day indicated. } \\
0 \text { to } 240=0.0 \text { to } 0.240\end{array}$ \\
\hline $\begin{array}{l}\mathbf{1 3 4} \mathbf{- 1 3 8} \\
134-136 \\
137 \\
138\end{array}$ & $\begin{array}{l}\text { Snow Depth } \\
\text { Data Value } \\
\text { Flag for Data Source } \\
\text { Flag for Data Uncertainty }\end{array}$ & $\begin{array}{c}0-150 \\
\mathrm{~A}-\mathrm{F}, ? \\
0-9\end{array}$ & $\begin{array}{l}\text { Snow depth in centimeters on the day indicated. } \\
999=\text { missing data }\end{array}$ \\
\hline $\begin{array}{l}139-142 \\
139-140 \\
141 \\
142\end{array}$ & $\begin{array}{l}\text { Days Since Last Snowfall } \\
\text { Data Value } \\
\text { Flag for Data Source } \\
\text { Flag for Data Uncertainty }\end{array}$ & $\begin{array}{c}0-88 \\
\mathrm{~A}-\mathrm{F}, ? \\
0-9\end{array}$ & $\begin{array}{l}\text { Number of days since last snowfall } \\
88=88 \text { or greater days } \\
99=\text { missing data }\end{array}$ \\
\hline \multicolumn{4}{|c|}{$\begin{array}{l}\text { FORTRAN Sample Format: } \\
(1 \mathrm{X}, 4 \mathrm{I} 2,2 \mathrm{I} 4,7(\mathrm{I} 4, \mathrm{~A} 1, \mathrm{I} 1), 2(\mathrm{I} 2, \mathrm{~A} 1, \mathrm{I} 1), 2(\mathrm{I} 4, \mathrm{~A} 1, \mathrm{I} 1), 1(\mathrm{I} 3, \mathrm{~A} 1, \mathrm{I} 1), \\
1(\mathrm{I} 4, \mathrm{~A} 1, \mathrm{I} 1), 2(\mathrm{I} 3, \mathrm{~A} 1, \mathrm{I} 1), 1(\mathrm{I} 4, \mathrm{~A} 1, \mathrm{I} 1), 1(\mathrm{I} 5, \mathrm{~A} 1, \mathrm{I} 1), 10 \mathrm{I} 1,3(\mathrm{I} 3, \mathrm{~A} 1, \mathrm{I} 1), \\
1(\mathrm{I} 2, \mathrm{~A} 1, \mathrm{I} 1))\end{array}$} \\
\hline \multicolumn{4}{|c|}{ 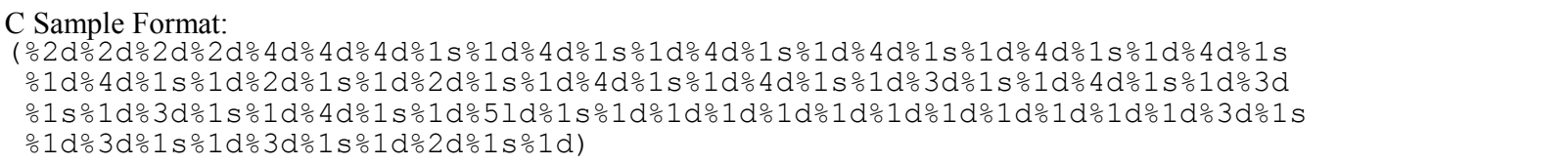 } \\
\hline
\end{tabular}


For solar radiation and illuminance elements, the data values represent the energy received during the 60 minutes preceding the hour indicated. For meteorological elements (with a few exceptions), observations or measurements were made at the hour indicated. A few of the meteorological elements had observations, measurements, or estimates made at daily, instead of hourly, intervals. Consequently, the data values for broadband aerosol optical depth, snow depth, and days since last snowfall represent the values available for the day indicated.

\section{Missing Data}

Data for some stations, times, and elements are missing. The causes for missing data include such things as equipment problems, some stations not operating at night, and a National Oceanic and Atmospheric Administration (NOAA) cost-saving effort from 1965 to 1981 that digitized data for only every third hour.

Although both the National Solar Radiation Database (NSRDB) and the TMY2 data sets used methods to fill data where possible, some elements, because of their discontinuous nature, did not lend themselves to interpolation or other data-filling methods. Consequently, data in the TMY2 data files may be missing for horizontal visibility, ceiling height, and present weather for up to 2 consecutive hours for Class A stations and for up to 47 hours for Class B stations. For Colorado Springs, Colorado, snow depth and days since last snowfall may also be missing. No data are missing for more than 47 hours, except for snow depth and days since last snowfall for Colorado Springs, Colorado. As indicated in Table A-2, missing data values are represented by 9's and the appropriate source and uncertainty flags.

\section{Source and Uncertainty Flags}

With the exception of extraterrestrial horizontal and extraterrestrial direct radiation, the two field positions immediately following the data value provide source and uncertainty flags both to indicate whether the data were measured, modeled, or missing, and to provide an estimate of the uncertainty of the data. Source and uncertainty flags for extraterrestrial horizontal and extraterrestrial direct radiation are not provided because these elements were calculated using equations considered to give exact values.

For the most part, the source and uncertainty flags in the TMY2 data files are the same as the ones in NSRDB, from which the TMY2 files were derived. However, differences do exist for data that were missing in the NSRDB, but then filled while developing the TMY2 data sets. Uncertainty values apply to the data with respect to when the data were measured, and not as to how "typical" a particular hour is for a future month and day. More information on data filling and the assignment of source and uncertainty flags is found in Appendix A of Marion and Urban (1995).

Tables A-3 through A-6 define the source and uncertainty flags for the solar radiation, illuminance, and meteorological elements. 
Table A-3. Solar Radiation and Illuminance Source Flags

\begin{tabular}{|c|l|}
\hline Flag & \multicolumn{1}{|c|}{ Definition } \\
\hline A & $\begin{array}{l}\text { Post-1976 measured solar radiation data as received from NCDC or } \\
\text { other sources }\end{array}$ \\
\hline B & $\begin{array}{l}\text { Same as "A" except the global horizontal data underwent a } \\
\text { calibration correction }\end{array}$ \\
\hline C & $\begin{array}{l}\text { Pre-1976 measured global horizontal data (direct and diffuse were } \\
\text { not measured before 1976), adjusted from solar to local time, usually } \\
\text { with a calibration correction }\end{array}$ \\
\hline D & $\begin{array}{l}\text { Data derived from the other two elements of solar radiation using the } \\
\text { relationship, global = diffuse + direct } \times \text { cosine (zenith) }\end{array}$ \\
\hline E & $\begin{array}{l}\text { Modeled solar radiation data using inputs of } \text { observed sky cover } \\
\text { (cloud amount) and aerosol optical depths derived from direct } \\
\text { normal data collected at the same location }\end{array}$ \\
\hline F & $\begin{array}{l}\text { Modeled solar radiation data using interpolated sky cover and } \\
\text { aerosol optical depths derived from direct normal data collected at } \\
\text { the same location }\end{array}$ \\
\hline G & $\begin{array}{l}\text { Modeled solar radiation data using } \text { observed } \text { sky cover and aerosol } \\
\text { optical depths estimated from geographical relationships }\end{array}$ \\
\hline H & $\begin{array}{l}\text { Modeled solar radiation data using interpolated sky cover and } \\
\text { estimated aerosol optical depths }\end{array}$ \\
\hline I & $\begin{array}{l}\text { Modeled illuminance or luminance data derived from measured or } \\
\text { modeled solar radiation data }\end{array}$ \\
\hline$?$ & $\begin{array}{l}\text { Source does not fit any of the above categories. Used for nighttime } \\
\text { values, calculated extraterrestrial values, and missing data }\end{array}$ \\
\hline
\end{tabular}

Table A-4. Solar Radiation and Illuminance Uncertainty Flags

\begin{tabular}{|c|c|}
\hline Flag & Uncertainty Range (\%) \\
\hline 1 & Not used \\
2 & $2-4$ \\
3 & $4-6$ \\
4 & $6-9$ \\
5 & $9-13$ \\
6 & $13-18$ \\
7 & $18-25$ \\
8 & $25-35$ \\
9 & $35-50$ \\
0 & Not applicable \\
\hline
\end{tabular}


Table A-5. Meteorological Source Flags

\begin{tabular}{|c|l|}
\hline Flag & \multicolumn{1}{|c|}{ Definition } \\
\hline A & Data as received from NCDC, converted to SI units \\
\hline B & Linearly interpolated \\
\hline C & $\begin{array}{l}\text { Non-linearly interpolated to fill data gaps from 6 to } 47 \text { hours in } \\
\text { length }\end{array}$ \\
\hline D & Not used \\
\hline E & $\begin{array}{l}\text { Modeled or estimated, except: precipitable water, calculated from } \\
\text { radiosonde data; dew point temperature calculated from dry-bulb } \\
\text { temperature and relative humidity; and relative humidity calculated } \\
\text { from dry-bulb temperature and dew point temperature }\end{array}$ \\
\hline F & $\begin{array}{l}\text { Precipitable water, calculated from surface vapor pressure; aerosol } \\
\text { optical depth, estimated from geographic correlation }\end{array}$ \\
\hline$?$ & \begin{tabular}{l} 
Source does not fit any of the above. Used mostly for missing data \\
\hline
\end{tabular} \\
\hline
\end{tabular}

Table A-6. Meteorological Uncertainty Flags

\begin{tabular}{|c|l|}
\hline Flag & \multicolumn{1}{|c|}{ Definition } \\
\hline $1-6$ & Not used \\
\hline 7 & $\begin{array}{l}\text { Uncertainty consistent with NWS practices and the instrument or } \\
\text { observation used to obtain the data }\end{array}$ \\
\hline 8 & $\begin{array}{l}\text { Greater uncertainty than 7 because values were interpolated or } \\
\text { estimated }\end{array}$ \\
\hline 9 & Greater uncertainty than 8 or unknown \\
\hline 0 & Not definable \\
\hline
\end{tabular}




\section{Appendix B \\ Output Spreadsheet Instructions}

E3000UT2.XLS

Output spreadsheet for HVAC BESTEST, Cases E300 - E545

INSTRUCTIONS

1. Use specified units.

2. Data entry is restricted to the following ranges:

B62..L82:

M62..N62:

B89..L112:

B120..L121:

B129..L130:

Q62..AB81:

AC62..AH62:

Q89..AN108:
Annual Sums, Annual Means, and Other

Annual Means, E300 Only

June 28 Hourly Output, Case E300

Case E500 Average Daily Outputs

Case E530 Average Daily Outputs

Annual Hourly Integrated Maxima, Consumptions and Loads

Annual Hourly Integrated Maxima, Case E300 - Weather Check

Annual Hourly Integrated Maxima and Minima, COP2 and Zone

3. Annual totals are consumption and/or loads just for the entire annual simulation. Similarly, annual means, maxima, and minima are those values that occur for the entire annual simulation. "May-Sep" results are taken using May 1 - September 30 data extracted from a full annual simulation.

4. Output terminology is defined in the output section of the specification for each case where applicable or in the Glossary (Appendix C).

5. Format dates using the appropriate two-digit date followed by a three-letter month code and two-digit hour code (24-hour clock) as shown below.

MONTH CODES:

$\begin{array}{lc}\text { MONTH } & \text { CODE } \\ \text { JANUARY } & \text { Jan } \\ \text { FEBRUARY } & \text { Feb } \\ \text { MARCH } & \text { Mar } \\ \text { APRIL } & \text { Apr } \\ \text { MAY } & \text { May } \\ \text { JUNE } & \text { Jun } \\ \text { JULY } & \text { Jul } \\ \text { AUGUST } & \text { Aug } \\ \text { SEPTEMBER } & \text { Sep } \\ \text { OCTOBER } & \text { Oct } \\ \text { NOVEMBER } & \text { Nov } \\ \text { DECEMBER } & \text { Dec }\end{array}$

For example a maximum value occuring on August 16 during the 15th hour interval (2-3 P.M.), should be input as:

Date Hour 


\section{Appendix C \\ Glossary}

Glossary terms used in the definitions of other terms are highlighted with italics.

References for terms listed here that are not specific to this test procedure include ANSI/ARI 210/240-89 (1989); ASHRAE Handbook of Fundamentals (2001); ASHRAE Psychrometric Chart No. 1 (1992); ASHRAE Terminology of Heating, Ventilation, Air-Conditioning, and Refrigeration (1991); Brandemuehl (1993); Cawley (1997); Lindeburg (1990); McQuiston and Parker (1994); and Van Wylen and Sonntag (1985).

Adjusted net sensible capacity is the gross sensible capacity less the actual fan power.

Adjusted net total capacity is the gross total capacity less the actual fan power.

Apparatus dew point (ADP) is the effective coil surface temperature when there is dehumidification; this is the temperature to which all the supply air would be cooled if $100 \%$ of the supply air contacted the coil. On the psychrometric chart, this is the intersection of the condition line and the saturation curve, where the condition line is the line passing through the entering air conditions with the slope defined by the sensible heat ratio ((sensible capacity)/(total capacity)).

Bypass factor (BF) can be thought of as the percentage of the distribution air that does not come into contact with the cooling coil; the remaining air is assumed to exit the coil at the average coil temperature (apparatus dew point).

Coefficient of performance (COP) for a cooling (refrigeration) system is the ratio, using the same units, of the net refrigeration effect to the corresponding energy input. For the purpose of calculating COP, corresponding energy input is the related cooling energy consumption, except for cases E300-E440 where the indoor air distribution fan energy is included only during times when heat is being extracted by the evaporator coil.

Cooling energy consumption is the site electric energy consumption of the mechanical cooling equipment including the compressor, air distribution fan (regardless of whether the compressor is on or off), condenser fan, and related auxiliaries.

$\mathrm{COP}_{2}$ (or COP2) is the ratio, using the same units, of the gross total evaporator coil load to the sum of the compressor and outdoor condenser fan energy consumptions.

COP degradation factor $(\mathbf{C D F})$ is a multiplier $(\leq 1)$ applied to the full-load system COP or COP2. CDF is a function of part-load ratio.

Dew point temperature is the temperature of saturated air at a given humidity ratio and pressure. As moist air is cooled at constant pressure, the dew point is the temperature at which condensation begins.

Economizer is a control system that conserves energy, usually by using outside air and control logic to maintain a fixed minimum of outside air when increased outside-air flow rates are not called for. 
Entering dry-bulb temperature (EDB) is the temperature that a thermometer would measure for air entering the evaporator coil. For a draw-through fan configuration with no heat gains or losses in the ductwork and no outside air mixed with return air, EDB equals the indoor (or zone-air) dry-bulb temperature. For a similar configuration but when outside air is mixed with return air, EDB equals the mixed air dry-bulb temperature.

Entering wet-bulb temperature (EWB) is the temperature that the wet-bulb portion of a psychrometer would measure if exposed to air entering the evaporator coil. For a draw-through fan with no heat gains or losses in the ductwork and no outside air mixed with return air, this would also be the zone-air wetbulb temperature. For a similar configuration but when outside air is mixed with return air, EWB equals the mixed air wet-bulb temperature. For mixtures of water vapor and dry air at atmospheric temperatures and pressures, the wet-bulb temperature is approximately equal to the adiabatic saturation temperature (temperature of the air after undergoing a theoretical adiabatic saturation process). The wet-bulb temperature given in psychrometric charts is really the adiabatic saturation temperature.

Evaporator coil loads are the actual sensible heat and latent heat removed from the distribution air by the evaporator coil. Sensible evaporator coil load applies only to sensible heat removal. Latent evaporator coil load applies only to latent heat removal.

Gross sensible capacity is the rate of sensible heat removal by the cooling coil for a given set of operating conditions. This value varies as a function of performance parameters such as EWB, ODB, EDB, and airflow rate.

Gross total capacity is the total rate of both sensible heat and latent heat removal by the cooling coil for a given set of operating conditions. This value varies as a function of performance parameters such as EWB, ODB, EDB, and airflow rate.

Gross total evaporator coil load is the sum of the sensible heat and latent heat removed from the distribution air by the evaporator coil.

Humidity ratio is the ratio of the mass of water vapor to the mass of dry air in a moist air sample.

Indoor dry-bulb temperature (IDB) is the temperature that a thermometer would measure if exposed to indoor air.

Infiltration is leakage of air through any building element (e.g., walls, windows, and doors).

Latent heat is the change in enthalpy associated with a change in humidity ratio, caused by the addition or removal of moisture.

Net refrigeration effect is the rate of heat removal (sensible + latent) by the evaporator coil, as regulated by the thermostat (i.e., not necessarily the full-load capacity), after deducting internal and external heat transfers to air passing over the evaporator coil. For cases E500-E545 (and cases E100-E200), the net refrigeration effect is the evaporator coil load less the air distribution fan heat. For cases E300-E440, the net refrigeration effect is the evaporator coil load less the air distribution fan heat for times when the evaporator coil is removing heat. 
Outdoor dry-bulb temperature (ODB) is the temperature that a thermometer would measure if exposed to outdoor air. This is the temperature of air entering the condenser coil.

Part-load ratio (PLR) is the ratio of the net refrigeration effect to the adjusted net total capacity for the cooling coil. As shown in Appendix E, for the purpose of calculating the COP degradation factor (CDF), defining PLR as the ratio of the gross total evaporator coil load to the gross total capacity produces an equivalent $\mathrm{CDF}$.

Relative humidity is the ratio of the mole fraction of water vapor in a given moist air sample to the mole fraction in an air sample that is saturated and at the same temperature and pressure. This is equivalent to the ratio of partial pressure of the water vapor in a sample to the saturation pressure at the same temperature.

Sensible heat is the change in enthalpy associated with a change in dry-bulb temperature, caused by the addition or removal of heat.

Sensible heat ratio (SHR), also known as sensible heat factor (SHF), is the ratio of sensible heat transfer to total (sensible + latent) heat transfer for a process. See also sensible heat and latent heat. 


\section{Appendix D \\ Calculation of Minimum Supply Air Temperature}

$\mathrm{T}_{\mathrm{sa}, \min }=\mathrm{EDB}+\Delta \mathrm{T}$

where $\mathrm{T}_{\mathrm{sa}, \min } \equiv$ minimum supply air temperature

$\mathrm{EDB} \equiv$ entering dry-bulb temperature

$\Delta \mathrm{T} \equiv$ temperature change through coil/air-handling system (value is negative for cooling).

$\Delta \mathrm{T}$ is determined from

$\mathrm{q}=\mathrm{mc}_{\mathrm{p}} \Delta \mathrm{T}$

where $q \equiv$ cooling capacity

$\mathrm{c}_{\mathrm{p}} \equiv$ specific heat of air

$\mathrm{m} \equiv$ mass flow rate of entering air $=\rho \mathrm{Q}$

where $\rho \equiv$ density of air

$\mathrm{Q} \equiv$ airflow rate.

For $\rho=0.075 \mathrm{lb} / \mathrm{ft}^{3}, \mathrm{c}_{\mathrm{p}}=0.24 \mathrm{Btu} / \mathrm{lb}^{\circ} \mathrm{F}$ implies that (2) can be rewritten as

$$
\Delta \mathrm{T}=\mathrm{q} / 1.08(\mathrm{CFM})
$$

where $\mathrm{CFM}=$ entering airflow rate in $\mathrm{ft}^{3} / \mathrm{min}$.

Then for $\mathrm{Q}=4000 \mathrm{CFM}$, and $\mathrm{q}=-92,300 \mathrm{Btu} / \mathrm{h}$ (maximum sensible cooling capacity for $\mathrm{EDB}=55^{\circ} \mathrm{F}$ ), and using equation (3), gives

$$
\Delta \mathrm{T}_{\text {coil }}=-21.37^{\circ} \mathrm{F} \text {. }
$$

However, there is draw-through fan heat of $1242 \mathrm{~W}(4238 \mathrm{Btu} / \mathrm{h})$, which causes a temperature increase using equation (3) of

$$
\Delta \mathrm{T}_{\text {fan }}=0.98^{\circ} \mathrm{F},
$$

Then

$\Delta \mathrm{T}=\Delta \mathrm{T}_{\text {coil }}+\Delta \mathrm{T}_{\text {fan }}=-20.38^{\circ} \mathrm{F}$.

Returning to equation (1), the internal gains have been scheduled so that the lowest EDB that should occur is $\mathrm{EDB}=55^{\circ} \mathrm{F}$ (in Case E330), so that from (1)

$$
\mathrm{T}_{\mathrm{sa}, \min }=55^{\circ} \mathrm{F}-20.38^{\circ} \mathrm{F}=34.62^{\circ} \mathrm{F}\left(1.46^{\circ} \mathrm{C}\right) .
$$

Note that this calculation assumes typical dry air properties. Using moist air properties at actual entering conditions would give minor variation. For example, $\mathrm{EWB}=40^{\circ} \mathrm{F}$ and $\mathrm{EDB}=55^{\circ} \mathrm{F}$ at sea level gives $v=$ $13.1 \mathrm{ft}^{3} / \mathrm{lb}$ and $\omega=0.0018 \mathrm{~kg} / \mathrm{kg}$, resulting in $\mathrm{T}_{\mathrm{sa}, \min }=35.06^{\circ} \mathrm{F}\left(1.70^{\circ} \mathrm{C}\right)$. 


\section{Appendix E \\ PLR Definition Similarity}

We have defined PLR in cases E100-E200 based on guidance from an equipment manufacturer as

$$
\text { PLR1 = Qnet / CAPnet, }
$$

where

Qnet $=$ net refrigeration effect

CAPnet $=$ adjusted net total capacity.

For the E300 series cases we wish to define PLR as

PLR2 = Qgtc / CAPgtc,

where

Qgtc $=$ gross total coil load

CAPgtc $=$ gross total capacity .

The net refrigeration effect $=$ Qgtc - Qfan

where Qfan is the air distribution fan heat.

For cases E500-E545 (and cases E100-E200), the net refrigeration effect is the evaporator coil load less the air distribution fan heat. For cases E300-E440, the net refrigeration effect is the evaporator coil load less the air distribution fan heat for times when the evaporator coil is removing heat.

The adjusted net capacity $=$ CAPgtc - Pfan

where Pfan $=$ fan rated power.

Then for PLR1 = PLR2 to be true implies

Qgtc / CAPgtc $=($ Qgtc - Qfan $) /($ CAPgtc - Pfan $)$,

which is true if

$$
\text { Qfan / Pfan = Qgtc / CAPgtc, }
$$

that is, if the fan heat for a given period is the fan's run-time fraction for that period multiplied by the fan power, where Qgtc/CAPgtc inherently defines the required fraction of a time period that the evaporator coil is to be removing heat at a given capacity. The above relation is true if there is no additional fan run time (and fan heat) associated with additional compressor start-up run time that occurs during part-load operation. This is true for Case E300 where the fan is always on and may be thought of as only being accounted for in the net refrigeration effect term when the coil is actually cold enough to remove heat (i.e. additional start-up run time not included). (For this discussion we are ignoring that the coil removes heat at a small rate during start-up, a rate that gradually increases until the evaporator coil temperature reaches stability.) Then for Case E300, 


$$
\text { Qfan }=\text { Pfan } * \text { PLR2 }=\text { Pfan * Qgtc } / \text { CAPgtc, }
$$

and it would follow that PLR1 = PLR2.

For cases E100-E200, because the indoor fan cycles on/off with the compressor, we originally defined the net refrigeration effect to subtract out fan heat for the time when the compressor is operating (which is longer than the time that the coil is actually removing heat at rated capacity).

For that situation, which also applies to cases E500-E545, it is useful to think of

$$
\text { Qfan / Pfan }=\text { PLR / CDF. }
$$

This relation, however, implies

$$
\text { Qfan / Pfan } \neq \text { Qgtc / CAPgtc, }
$$

with the theoretical result that PLR1 $\neq$ PLR2.

Table E-1 provides an analysis of the difference between PLR1 and PLR2 and corresponding resultant CDF1 and CDF2 that could be used in evaluating part-load performance for cases where the air distribution fan operates continuously and where the fan cycles on/off with the compressor. This analysis applies reasonable hypothetical values of coil capacity and fan power. The analysis indicates (see far right column of Table E-1) that the resulting difference between CDF1 and CDF2 and, therefore, the compressor energy consumptions related to applying those CDFs, is $<0.1 \%$, which is negligible. Thus, for the purpose of calculating CDF, either PLR1 or PLR2 may be used.

\section{Table E-1. Comparison of PLR Definitions}

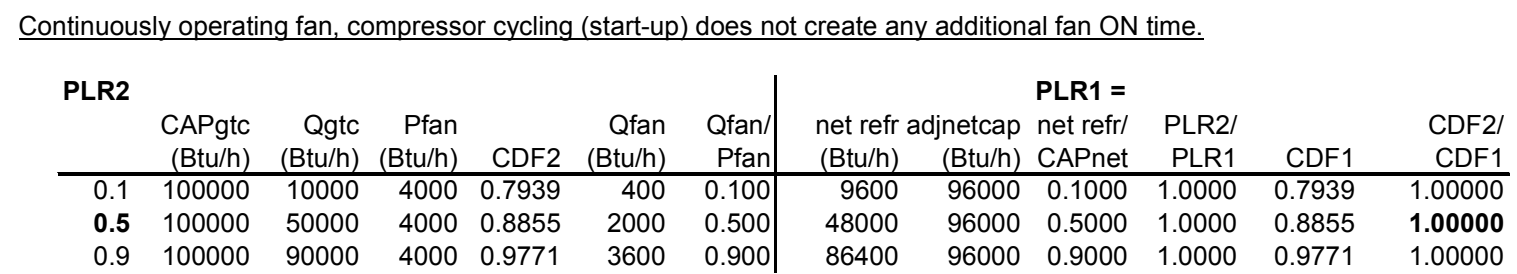

\begin{tabular}{|c|c|c|c|c|c|c|c|c|c|c|c|c|}
\hline \multirow[t]{2}{*}{ PLR2 } & & & & & & & \multicolumn{6}{|c|}{ PLR1 = } \\
\hline & $\begin{array}{r}\text { CAPgtc } \\
\text { (Btu/h) }\end{array}$ & $\begin{array}{r}\text { Qgtc } \\
(\mathrm{Btu} / \mathrm{h})\end{array}$ & $\begin{array}{r}\text { Pfan } \\
\text { (Btu/h) }\end{array}$ & CDF2 & $\begin{array}{r}\text { Qfan } \\
\text { (Btu/h) }\end{array}$ & $\begin{array}{r}\text { Qfan/ } \\
\text { Pfan }\end{array}$ & $\begin{array}{l}\text { net refr } \\
\text { (Btu/h) }\end{array}$ & $\begin{array}{l}\text { netcap } \\
\text { (Btu/h) }\end{array}$ & $\begin{array}{l}\text { net refr/ } \\
\text { CAPnet }\end{array}$ & $\begin{array}{r}\text { PLR2/ } \\
\text { PLR1 }\end{array}$ & CDF1 & $\begin{array}{c}\text { CDF2/ } \\
\text { CDF1 }\end{array}$ \\
\hline 0.1 & 100000 & 10000 & 4000 & 0.7939 & 504 & 0.126 & 9496 & 96000 & 0.0989 & 0.9892 & 37 & 1.000312 \\
\hline 0.35 & 100 & 35000 & 4000 & 0.8512 & 164 & 411 & & & & & & \\
\hline 0. & 1000 & 000 & 4000 & 0.86 & 5 & 64 & & & & & & 705 \\
\hline 0.45 & 100000 & 5000 & 4000 & 0.8741 & 2059 & 0.5 & & 96000 & & & & 0708 \\
\hline 0 & 100000 & 50000 & 4000 & 0.8855 & 259 & & & 96000 & & & & 1.000697 \\
\hline 0.55 & 100000 & 5000 & 4000 & 0.897 & & & & 96000 & & & & 1.000673 \\
\hline $0 . c^{-1}$ & 100000 & 0000 & 000 & 0.9771 & 3684 & 0.921 & 86316 & 96000 & 0.8991 & 0.9990 & 0.9769 & 1.000206 \\
\hline
\end{tabular}

So for E300 the ratio of net refr effect to adj net cap exactly equals the ratio of Qgtc to CAPgtc, as shown previously.

Fan cycles ON/OFF with compressor, compressor cycling creates additional fan ON time. 
Notes regarding Table E-1:

Bold font indicates value of CDF2/CDF1 at PLR2 $=0.5$, and value of PLR2 at maximum value of CDF2/CDF1.

For the case where the fan cycles on/off with the compressor, the total fan run-time fraction, including the additional start-up run time during which little or no cooling occurs, = PLR/CDF. Actually, fan heat should be slightly higher because the additional fan run time resulting from CDF creates a slight amount of additional fan heat that, in turn, causes slightly more additional run time. In accord with an analytical solution by Technische Universität Dresden, Germany for mid-PLR case E170 (see HVAC BESTEST Volume 1 [Neymark and Judkoff 2002: Section 2.3.1]), the additional run time (fan heat) is $0.5 \%$ greater if this effect is taken into account. Because this is a $0.5 \%$ effect on a quantity that makes up at most $4 \%$ of the coil load (i.e., $0.02 \%$ effect overall), for the purpose of calculating $C D F=f(P L R)$, we ignore it. 


\section{Appendix F \\ Indoor Fan Data Equivalence}

Fan performance data for indoor fan electric power $(1242 \mathrm{~W})$, mechanical shaft power $(1.565 \mathrm{BHP}=$ $1167 \mathrm{~W})$ and airflow rate $\left(4000 \mathrm{CFM}=1.888 \mathrm{~m}^{3} / \mathrm{s}\right)$ are based on dry air at standard fan rating conditions. ASHRAE defines a standard condition as 1 atmosphere $(101.325 \mathrm{kPa}$ or $14.696 \mathrm{psi})$ and $68^{\circ} \mathrm{F}\left(20^{\circ} \mathrm{C}\right)$ with a density of $0.075 \mathrm{lb} / \mathrm{ft}^{3}\left(1.204 \mathrm{~kg} / \mathrm{m}^{3}\right)$ (Howell, Sauer, and Coad 1998: p. 3.4).

The static pressure of 0.3 in. wg $(74.7 \mathrm{~Pa})$ is based on the Air-Conditioning and Refrigeration Institute (ARI) rating condition (Pegues 2001).

The fan static efficiency is based on:

$$
\mathrm{Eff}_{\mathrm{s}}=\mathrm{Q} * \Delta \mathrm{P}_{\mathrm{s}} / \mathrm{W}_{\mathrm{sh}}
$$

(McQuiston and Parker 1994: p. 463; ANSI/AMCA 210-85, ANSI/ASHRAE 51, 1985: pp. 4, 40, 46-48)

where

$\mathrm{Q} \equiv$ indoor fan airflow rate $\left(\mathrm{m}^{3} / \mathrm{s}\right)$

$\Delta \mathrm{P}_{\mathrm{s}} \equiv$ static fan pressure $(\mathrm{Pa})$

$\mathrm{W}_{\text {sh }} \equiv$ fan shaft power input (W)

Eff $_{\mathrm{s}} \equiv$ static fan efficiency.

Solving for $\mathrm{Eff}_{\mathrm{s}}$

$$
\operatorname{Eff}_{\mathrm{s}}=1.888 \mathrm{~m}^{3} / \mathrm{s} * 74.7 \mathrm{~Pa} / 1167 \mathrm{~W}=0.121=12.1 \% \text {. }
$$

The motor/drive efficiency is based on

$$
\mathrm{Eff}_{\mathrm{m}}=\mathrm{W}_{\mathrm{sh}} / \mathrm{W},
$$

where

$$
\begin{aligned}
& \mathrm{Eff}_{\mathrm{m}} \equiv \text { motor/drive efficiency } \\
& \mathrm{W}_{\mathrm{sh}} \equiv \text { fan shaft power input }(\mathrm{W}) \\
& \mathrm{W} \equiv \text { fan electric power input (W) }
\end{aligned}
$$

Solving for $\mathrm{Eff}_{\mathrm{m}}$

$$
\mathrm{Eff}_{\mathrm{m}}=1167 \mathrm{~W} / 1242 \mathrm{~W}=0.940=94.0 \% .
$$

The supply air temperature rise from fan heat is based on

$$
\mathrm{q}_{\mathrm{fan}}=\rho * \mathrm{c}_{\mathrm{p}} * \mathrm{Q} * \Delta \mathrm{T} * \mathrm{C}
$$

where

$$
\begin{aligned}
& \mathrm{q}_{\mathrm{fan}} \equiv \text { fan heat }(\mathrm{Btu} / \mathrm{h} \text { or } \mathrm{W}), \text { motor } / \text { drive in air stream } \\
& \rho \quad \equiv \text { standard air density }=0.075 \mathrm{lb} / \mathrm{ft}^{3}\left(1.204 \mathrm{~kg} / \mathrm{m}^{3}\right)
\end{aligned}
$$




$$
\begin{aligned}
& \mathrm{c}_{\mathrm{p}} \equiv \text { specific heat of air }\left(\mathrm{Btu} /\left(\mathrm{lb}^{\circ} \mathrm{F}\right) \text { or } \mathrm{kJ} /(\mathrm{kgK})\right) \\
& \mathrm{Q} \equiv \text { indoor fan airflow rate }\left(\mathrm{ft}^{3} / \mathrm{min} \text { or } \mathrm{m}^{3} / \mathrm{s}\right) \\
& \Delta \mathrm{T} \equiv \text { supply air temperature rise from fan heat }\left({ }^{\circ} \mathrm{F} \text { or }{ }^{\circ} \mathrm{C}\right) \\
& \mathrm{C} \equiv \text { units conversion constant. }
\end{aligned}
$$

Solving for $\Delta \mathrm{T}$

$$
\Delta \mathrm{T}=\mathrm{q}_{\mathrm{fan}} /\left(\rho * \mathrm{c}_{\mathrm{p}} * \mathrm{Q} * \mathrm{C}\right),
$$

where

$$
\begin{aligned}
& \mathrm{q}_{\mathrm{fan}}=1242 \mathrm{~W}=4237 \mathrm{Btu} / \mathrm{h} ; \mathrm{Q}=4000 \mathrm{CFM}=1.888 \mathrm{~m}^{3} / \mathrm{s} \\
& \mathrm{c}_{\mathrm{p}}=0.24 \mathrm{Btu} / \mathrm{lb} \mathrm{F} \text { for dry air, or } \\
& \mathrm{c}_{\mathrm{p}}=0.2445 \mathrm{Btu} / \mathrm{lb} \mathrm{F} \text { when humidity ratio }=0.01(\text { Howell, Sauer, and Coad } 1998 ; \text { p. 3.5). }
\end{aligned}
$$

Then, $\Delta \mathrm{T}=4237 \mathrm{Btu} / \mathrm{h} /\left\{0.075 \mathrm{lb} / \mathrm{ft}^{3} * 4000 \mathrm{ft}^{3} / \mathrm{min} * 60 \mathrm{~min} / \mathrm{h} * 0.2445 \mathrm{Btu} /\left(\mathrm{lb}{ }^{\circ} \mathrm{F}\right)\right\}$

$\Delta \mathrm{T}=0.963^{\circ} \mathrm{F}\left(0.535^{\circ} \mathrm{C}\right)$, or

for $\mathrm{c}_{\mathrm{p}}=0.24 \mathrm{Btu} /\left(\mathrm{b}^{\circ} \mathrm{F}\right)$, gives $\Delta \mathrm{T}=0.981^{\circ} \mathrm{F}\left(0.545^{\circ} \mathrm{C}\right)$. 


\section{Appendix G \\ Diagnosing the Results Using the Flow Diagrams}

\section{G.1 General Description}

Figures G-1, G-2, and G-3 contain a set of flow diagrams that serve as a guide for diagnosing the cause of disagreeing results that may arise from using this test. These flow diagrams list the feature(s) being tested, thus indicating potential sources of algorithmic differences. Flow diagrams are included here for both the Volume 1 cases E100-E200 (Figure G-1) and the Volume 2 cases E300-E545 (Figures G-2 and G-3). Cases E100-E200 (Neymark and Judkoff 2002) are to be run first. These are steady-state cases that test basic performance-map modeling capabilities, and utilize comparisons with analytical solutions that constitute a mathematical truth standard. It is very important to have confidence in your results for cases E100-E200 before proceeding to the other cases.

After successfully completing cases E100-E200, go on to cases E300-E545. These cases test additional model features under more dynamic conditions. Example simulation results (see Part III) for cases E300 E545 do not include analytical solutions, so analytical verification versus a mathematical truth standard is not possible for those cases. The flow diagrams for cases E300-E545 may be used in two ways. The most powerful but time-consuming way is to perform all cases E300-E545, and then use the diagnostic logic in the flow diagrams to analyze the results. The least time-consuming way is to perform the tests in sequence according to the flow diagrams, beginning with Figure G-2.

\section{G.2 Comparing Tested Software Results to Analytical Solution Results (cases E100-E200)}

See the discussion in Appendix F of Volume 1 (Neymark and Judkoff 2002).

\section{G.3 Comparing Tested Software Results to Other Example Results (cases E300- E545)}

"Example results" are either results presented in Part III of this document or other results that were generated using this test procedure.

For cases E300-E545 we provide no formal criteria for when results agree or disagree. Determination of agreement or disagreement of results is left to the user. In making this determination the user should consider:

- Magnitude of results for individual cases

- Magnitude of difference in results between certain cases (e.g., "Case E310-Case E300")

- Same direction of sensitivity (positive or negative) for difference in results between certain cases (e.g., "Case E310-Case E300")

- Example results do not represent a truth standard

- Results that are logically counterintuitive with respect to known or expected physical behavior.

Check the program being tested for agreement (see above) with example results for both the absolute outputs and the sensitivity (or "delta") outputs. For example, when comparing to the example results, for 
Case "E310-E300" in Figure G-2, the program results are compared with both the Case E310 example results and the Case E310-E300 example sensitivity results.

Compare all available output types specified for each case that can be produced by the program being tested. This includes appropriate energy consumption, coil load, zone temperature results, humidity ratio results, and so forth for all of the required outputs that the software is capable of producing. A disagreement with any one of the output types may be cause for concern.

The flow diagram of Figure G-2 begins with a basic performance test (Case E300). It is very important to have confidence in your Case E300 results before proceeding to the other cases. If output from the tested program agrees satisfactorily with other example results for Case E300, then continue to check output for the remaining cases according to the flow diagram. If output from the tested program disagrees with other example results for Case E300, then follow the diagnostic logic accordingly. The diagnostic logic for cases E500-E545 is presented in Figure G-3. Cases E500-E545 test similar effects as cases E100-E200, but in an hourly dynamic context using expanded performance data without analytical verification. The sensitivity result "E500-E300" isolates the effect of outside air, but with some noise because of varying internal gains schedules between Case E300 and Case E500, and because the air distribution fan cycles with the compressor in Case E500. In contrast with steady-state cases E100-E200 that were solved analytically, the more realistic nature of cases E300-E545 allows us to gauge the importance of being able to simulate various effects accurately in terms of annual energy performance. For example, a large percentage difference for a given result that has only a very small impact on annual energy use may not be of concern, whereas a small percentage difference with a large impact on annual energy use may be deemed important.

There are some cases where it is possible to proceed even if disagreements were uncovered in the previous case. For example, in Case E410, inability to model an economizer with compressor lockout does not necessarily affect the usefulness of the program (or the ability to further test the program) for modeling other types of economizer controls or other mechanical equipment features. Thus the flow diagram has an extra arrow connecting Case E410 and Case E420, which denotes that you may proceed regardless of the results for Case E410. Where cases are connected by a single arrow, a satisfactory result is required in order to proceed to the next case. For example, in Case E310, the inability to model latent load removal makes it difficult to proceed with these tests until the disagreement is reconciled.

\section{G.3.1 If Tested Software Results Disagree with Example Results}

If the tested program shows disagreement (as defined above) with the example results, then recheck the inputs against the specified values. Use the diagnostic logic flow diagrams to help isolate the source of the difference; in some cases it may be useful to recheck E100 series results. If no input error can be found, then look for an error in the software. If an error is found, then fix it and rerun the tests. If in the engineering judgment of the user the disagreement is caused by a reasonable difference in algorithms between the tested software and the example results, then continue with the next test case.

\section{G.3.2 Example}

A program shows disagreement with E300. Because this is the base case for the E300 series, Figure G-2 suggests a number of potential sources of algorithmic differences including dynamic variation of load, $15 \%$ outside air (mixed with return air), continuous indoor fan operation, or hourly dynamic equipment performance as $\mathrm{f}(\mathrm{EDB}, \mathrm{EWB}, \mathrm{ODB}, \mathrm{PLR})$. The user is directed to check diagnostics $\mathrm{C} 1$ and $\mathrm{C} 2$. If the disagreement persists for $\mathrm{C} 1$ and/or $\mathrm{C} 2$, this likely eliminates outside air mixing and continuous fan 
operation as the cause of the problem. The user is then directed to recheck results from cases E100E200. If the E100 results are still satisfactory, then the problem is likely isolated to performance-map parameter $\mathrm{f}(\mathrm{ODB}, \mathrm{EWB}, \mathrm{EDB})$ sensitivity over the expanded range of performance data or some other problem related to hourly dynamic modeling.

Section 2.4 (Part II) gives examples of how the tests were used to trace and correct specific algorithmic and input errors in the programs used in the field trials. 
START
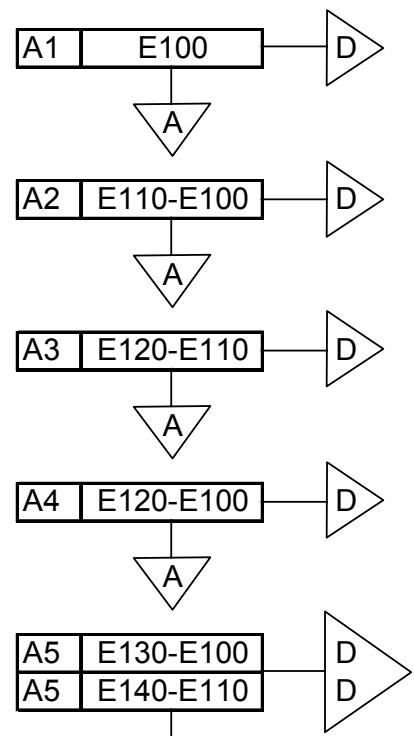<smiles>C12C3C1C23</smiles>

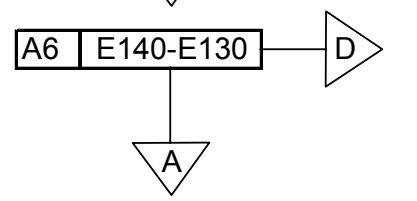

GOTO

CONTINUE (B)

(WET COIL)
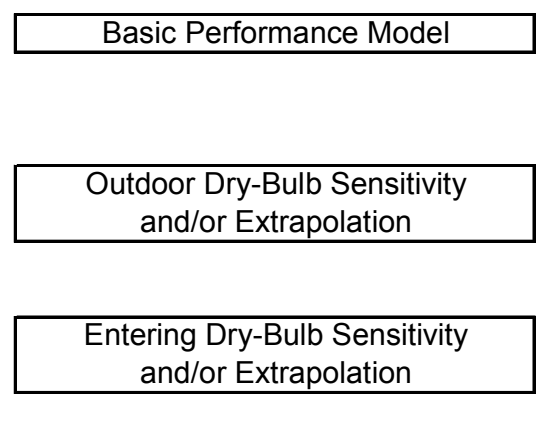

ODB + EDB Interaction
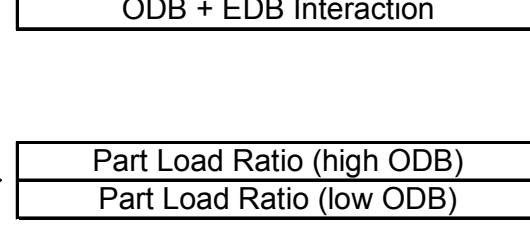

Part Load Ratio (low ODB)

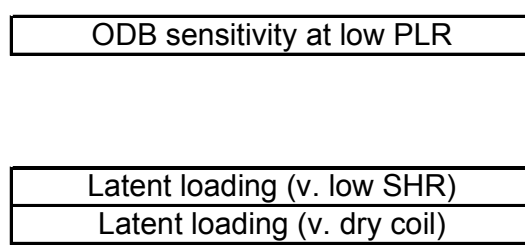

Latent loading (v. dry, lo PLR, lo ODB Latent loading (v. dry, lo PLR, hi ODB

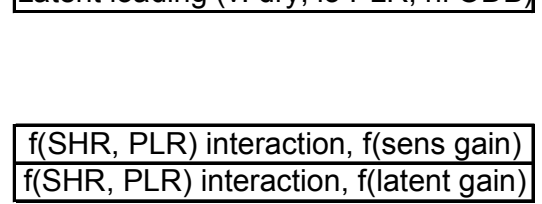

Basic Performance Model

(Full load at ARI conditions also tests set point $w /$ very small overload)
CONTINUE (B)*
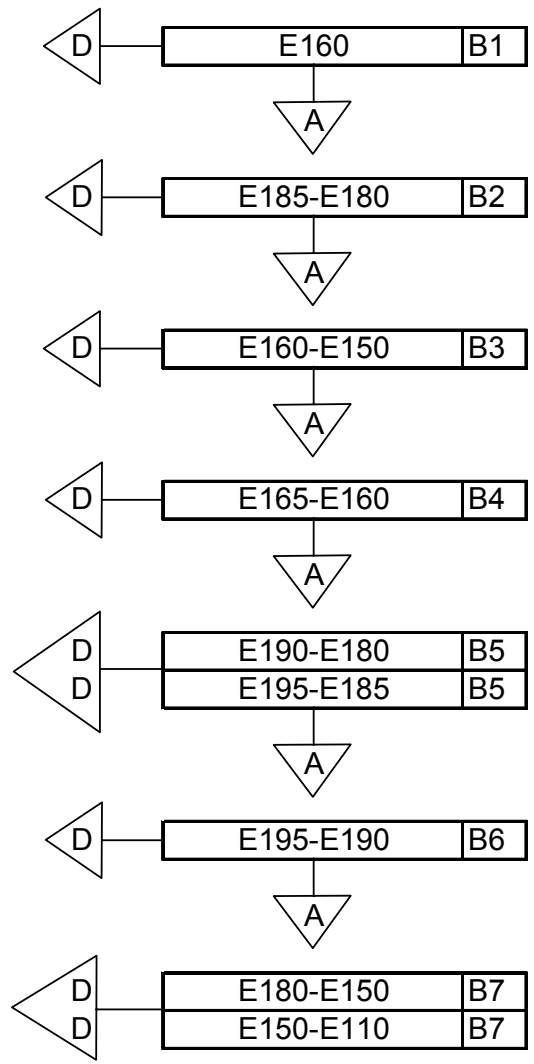

\begin{tabular}{|l|l|}
\hline E195-E130 & B8 \\
\hline
\end{tabular}<smiles>C12C3C4C1C234</smiles>
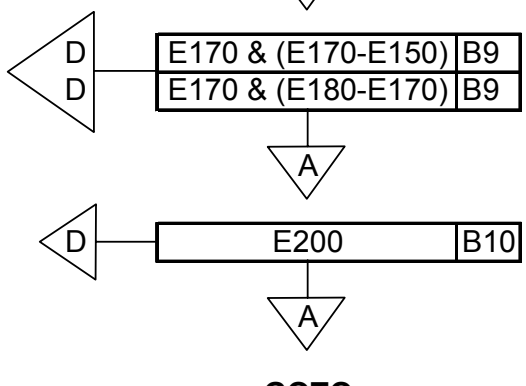

GOTO

CONTINUE (E300)

\footnotetext{
ABBREVIATIONS

$A=$ Agree; i.e., agree with analytical solution results for the case itself and the sensitivity case. E.g., to check for agreement regarding Case E130, compare example results for Case E130 and E130-E100 sensitivity.

$\mathrm{D}=$ Disagree; i.e., show disagreement with analytical solution results. NOTES

* It is better to perform/analyze results of these tests in blocks such as E100-E140 and E150-E200.
}

Figure G-1. Cases E100-E200 (steady-state analytical verification) diagnostic logic flow diagram 
START
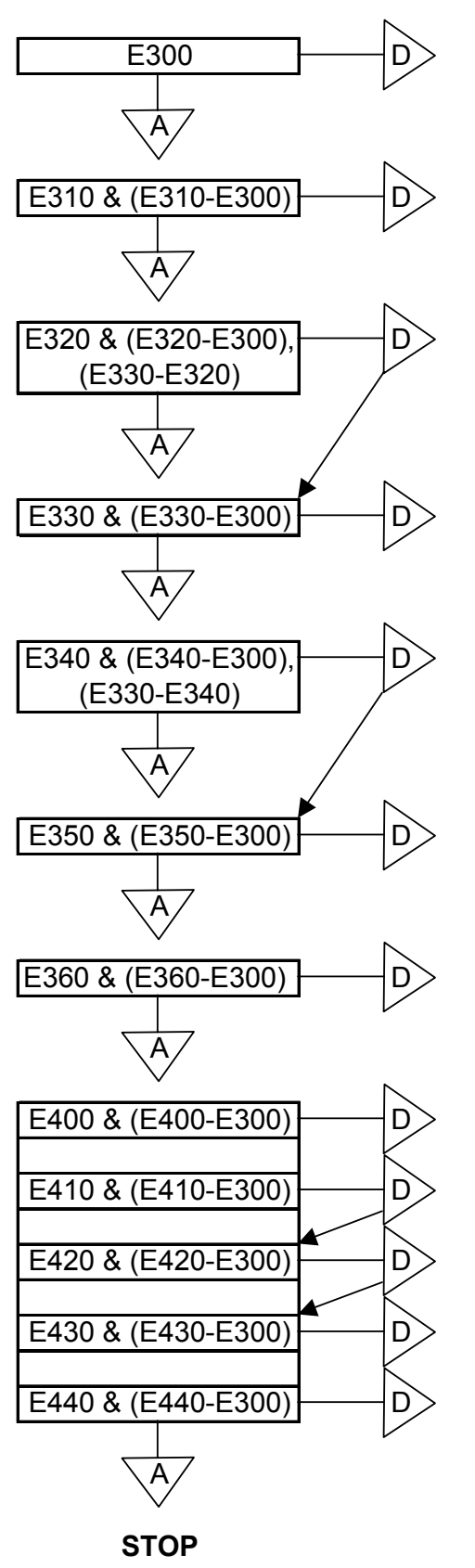

PROBABLE CAUSE OF DISAGREEMENT

DIAGNOSE (GOTO)

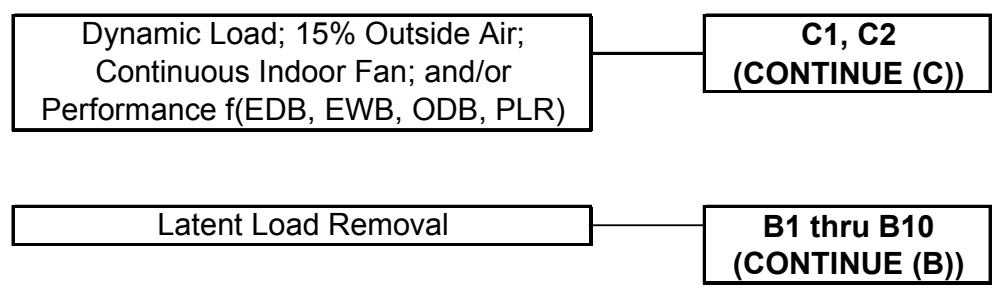

Infiltration, Psychrometrics

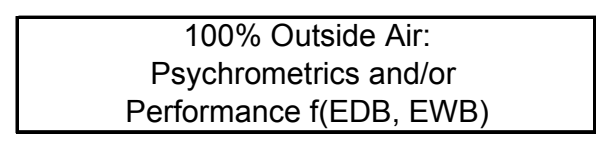

Infiltration/Outside Air Interaction
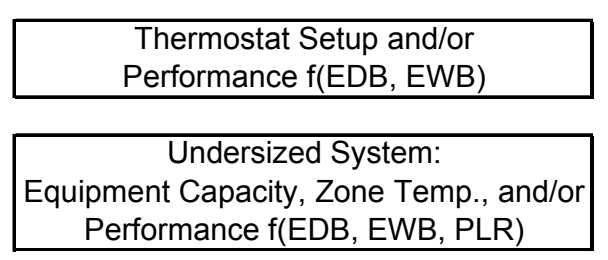

\begin{tabular}{|c|}
\hline Economizer w/ Temperature Control \\
\hline \\
\hline $\begin{array}{c}\text { Economizer w/ Temperature Control } \\
+ \text { Compressor Lockout }\end{array}$ \\
\hline $\begin{array}{c}\text { Economizer w/ Temperature Control } \\
+ \text { ODB Limit }\end{array}$ \\
\hline Economizer w/ Enthalpy Control \\
\hline $\begin{array}{c}\text { Economizer w/ Enthalpy Control } \\
+ \text { Outdoor Enthalpy Limit }\end{array}$ \\
\hline
\end{tabular}

\footnotetext{
ABBREVIATIONS

$\mathrm{A}=$ Agree $; \mathrm{D}=$ Disagree. For the E300 series, agreement/disagreement is determined relative to example simulation results or other user-provided results and the sensitivity case.
}

Figure G-2. Cases E300-E440 (dynamic dases with outside air) diagnostic logic flow diagram 


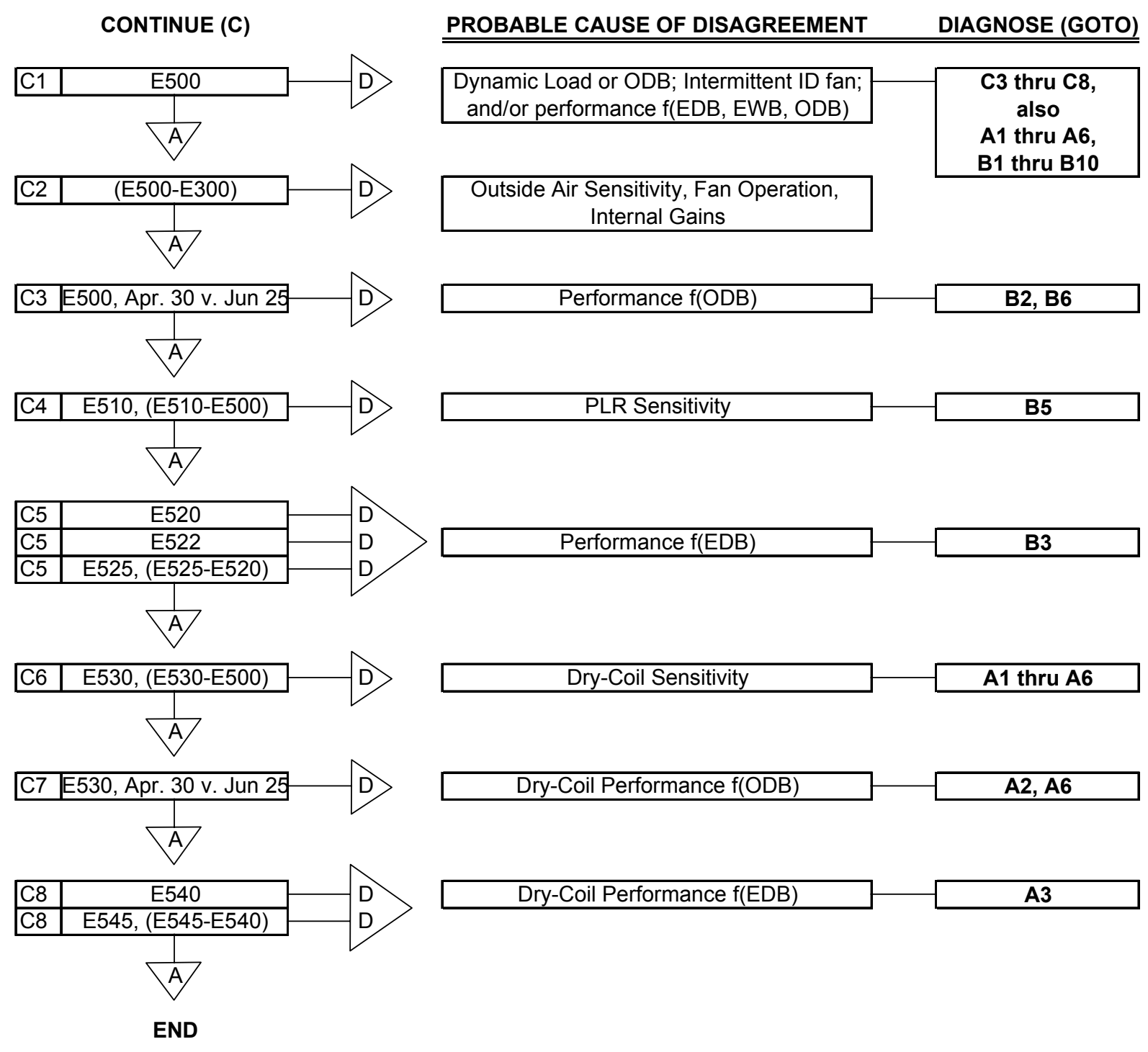

\footnotetext{
ABBREVIATIONS

$\mathrm{A}=$ Agree; $\mathrm{D}=$ Disagree. For the E300 series, agreement/disagreement is determined relative to example simulation results or other user-provided results and the sensitivity case.
}

Figure G-3. Cases E500-E545 (dynamic cases without outside air) diagnostic logic flow diagram 


\section{Appendix $\mathrm{H}$ \\ Abbreviations and Acronyms}

Terms denoted with "*” are defined in the glossary (Appendix C).

$\mathrm{ACH} \quad$ air changes per hour

ANSI

American National Standards Institute

ARI Air-Conditioning and Refrigeration Institute

ASHRAE

American Society of Heating, Refrigerating, and Air-Conditioning Engineers

$\mathrm{BF}^{*}$

bypass factor

BHP

brake horsepower

Btu

British thermal unit

$\mathrm{CDF}^{*}$

coefficient of performance degradation factor

CFM

Coef

cubic feet per minute

COP*

coefficient

$\mathrm{COP}_{2}{ }^{*}$

coefficient of performance

alternative coefficient of performance

EDB*

entering dry-bulb temperature

EWB*

entering wet-bulb temperature

Ext

exterior

HVAC heating, ventilating, and air-conditioning

HVAC BESTEST International Energy Agency Building Energy Simulation Test and Diagnostic Method for Heating, Ventilating, and Air-Conditioning Equipment Models

ID

indoor

IDB*

indoor dry-bulb temperature

IEA

Int

International Energy Agency

IP

interior

inch-pound

$\mathrm{k}$

thermal conductivity $(\mathrm{W} /(\mathrm{m} \cdot \mathrm{K}))$

$\mathrm{kW}$

$\mathrm{kWh}$

compressor power $(\mathrm{kW})$, as used in Tables 1-7a and 1-7b only

kilowatt-hour

NSRDB

National Solar Radiation Database

ODB*

outdoor dry-bulb temperature

PLR*

part-load ratio

$\mathrm{R}$

unit thermal resistance $\left(\mathrm{m}^{2} \cdot \mathrm{K} / \mathrm{W}\right)$

SHC

$\mathrm{SHC}^{*}$

Solar Heating and Cooling Programme

SHR*

gross sensible capacity ( $\mathrm{kW}$ thermal)

SI

sensible heat ratio

Système Internationale

Surf

surface 
$\mathrm{TC}^{*}$

TMY2

$\mathrm{U}$

UA

WBAN

wg

Wh gross total capacity ( $\mathrm{kW}$ thermal)

typical meteorological year 2

unit thermal conductance or overall heat transfer coefficient $\left(\mathrm{W} /\left(\mathrm{m}^{2} \cdot \mathrm{K}\right)\right)$

thermal conductance $(\mathrm{W} / \mathrm{K})$

Weather Bureau Army Navy

water gauge

watt-hour 


\section{References for Part I}

ANSI/AMCA 210-85, ANSI/ASHRAE 51-1985. (1985). Laboratory Methods of Testing Fans for Rating. Jointly published by Air Movement and Control Association Inc., Arlington Heights, Illinois; and American Society of Heating, Refrigerating, and Air-Conditioning Engineers, Atlanta, Georgia, US.

ANSI/ARI 210/240-89. (1989). Unitary Air-Conditioning and Air-Source Heat Pump Equipment. Arlington, Virginia, US: Air-Conditioning and Refrigeration Institute.

ASHRAE Handbook of Fundamentals. (2001). Atlanta, Georgia, US: American Society of Heating, Refrigerating, and Air-Conditioning Engineers.

ASHRAE Psychrometric Chart No. 1. (1992). Atlanta, Georgia, US: American Society of Heating, Refrigerating, and Air-Conditioning Engineers.

ASHRAE Terminology of Heating, Ventilation, Air Conditioning, and Refrigeration. (1991). Atlanta, Georgia, US: American Society of Heating, Refrigerating, and Air-Conditioning Engineers.

Brandemuehl, M. (1993). HVAC 2 Toolkit. Atlanta, Georgia, US: American Society of Heating, Refrigerating, and Air-Conditioning Engineers.

Carrier Corporation, Syracuse, New York, US. (May 2001-September 2002). Personal communications with James Pegues about transmission of data set (developed by David Barkley, also of Carrier Corporation) generated from Carrier's in-house engineering software for developing catalog data; regarding how the data were developed and constraints of their application; and clarifying overall system specifications.

Cawley, D. (November 1997). Personal communication. Trane Company, Tyler, Texas, US.

Howell, R.H.; Sauer, H.J.; Coad, W.J. (1998). Principles of Heating, Ventilating, and Air Conditioning. Atlanta, Georgia, US: American Society of Heating, Refrigerating, and Air-Conditioning Engineers.

Lindeburg, M. (1990). Mechanical Engineering Reference Manual. 8th ed. Belmont, California, US: Professional Publications, Inc.

Marion W.; Urban, K. (1995). User's Manual for TMY2's Typical Meteorological Years. Golden, Colorado, US: National Renewable Energy Laboratory.

McQuiston, F.; Parker, J. (1994). HVAC Analysis and Design. 4th ed. New York, New York, US: John Wiley \& Sons.

Neymark, J.; Judkoff, R. (2002). International Energy Agency Building Energy Simulation Test and Diagnostic Method for Mechanical Equipment (HVAC BESTEST). NREL/TP-550-30152. Golden, Colorado, US: National Renewable Energy Laboratory. Available from http://www.nrel.gov/docs/fy02osti/30152.pdf.

Pegues, J. (May 2001-October 2001). Personal communications. Carrier Corporation, Syracuse, New York, US.

Van Wylen, G.; Sonntag, R. (1985). Fundamentals of Classical Thermodynamics. New York, New York, US: John Wiley \& Sons. 


\subsection{Part II: Production of Simulation Results}

\subsection{Introduction}

In this section we describe what the working group members did to produce example results with several detailed programs that were considered to represent the state of the art for building energy simulation in Europe and the United States. The objectives of developing the simulation results were

- To demonstrate the applicability and usefulness of the Building Energy Simulation Test for Heating, Ventilating, and Air-Conditioning Equipment Models (HVAC BESTEST) test suite

- To improve the test procedure through field trials

- To identify the range of disagreement that may be expected for simulation programs relative to each other (see Part III).

The field trial effort took about 4 years and involved several revisions to the HVAC BESTEST specifications and subsequent reexecution of the computer simulations. The process was iterative in that executing the simulations led to the refinement of HVAC BESTEST, and the results of the tests led to improving and debugging the mechanical system models in the programs. This process underscores the importance of International Energy Agency (IEA) participation in this project; such extensive field trials, and resulting enhancements to the tests, were much more cost-effective with the participation of the IEA Solar Heating and Cooling (SHC) Programme Task 22 experts.

Table 2-1 describes the programs used to generate the simulation results. Appendix II (Section 2.9) presents reports written by the modelers for each simulation program.

The tables and graphs in Part III present the final results from all the simulation programs used in this study.

Abbreviations and acronyms used in Sections 2.2 through 2.6 are given in Section 2.7. References cited in Section 2.2 through 2.6 are given in Section 2.8.

Table 2-1. Participating Organizations and Computer Programs

\begin{tabular}{|c|c|c|}
\hline Simulation Program & Authoring Organization & Implemented by \\
\hline CODYRUN/LGIMAT & Université de la Reunion Island, France & $\begin{array}{l}\text { Université de la Reunion Island, } \\
\text { France }\end{array}$ \\
\hline DOE-2.1E-ESTSC version & LANL/LBNL/ESTSC/JJH, ${ }^{\mathrm{a}, \mathrm{b}, \mathrm{c}, \mathrm{d}}$ United States & NREL/JNA, ${ }^{e}$ United States \\
\hline DOE-2.2 NT & LBNL/JJH, ${ }^{\mathrm{b}, \mathrm{d}}$ United States & NREL/JNA, ${ }^{e}$ United States \\
\hline ENERGYPLUS & $\begin{array}{l}\text { LBNL/UIUC/CERL/OSU/GARD } \\
\text { Analytics/FSEC/DOE-BT, }, \text {,f,g,h,i,j United States }\end{array}$ & GARD Analytics, United States \\
\hline НОТ3000 & CETC/ESRU, ${ }^{\mathrm{k}, \mathrm{l}}$ Canada/United Kingdom & CETC, ${ }^{k}$ Canada \\
\hline $\begin{array}{l}\text { TRNSYS 14.2-TUD } \\
\text { with real controller model }\end{array}$ & $\begin{array}{l}\text { University of Wisconsin, United States; } \\
\text { Technische Universität Dresden, Germany }\end{array}$ & $\begin{array}{l}\text { Technische Universität Dresden, } \\
\text { Germany }\end{array}$ \\
\hline
\end{tabular}

${ }^{a}$ LANL: Los Alamos National Laboratory, United States

${ }^{\mathrm{b}}$ LBNL: Lawrence Berkeley National Laboratory, United States

${ }^{c}$ ESTSC: Energy Science and Technology Software Center (at Oak Ridge National Laboratory, United States)

dJJH: James J. Hirsch \& Associates, United States 
${ }^{\text {e}}$ NREL/JNA: National Renewable Energy Laboratory/J. Neymark \& Associates, United Sates

fUIUC: University of Illinois Urbana/Champaign, United States

${ }^{g}$ CERL: U.S. Army Corps of Engineers, Construction Engineering Research Laboratories, United States

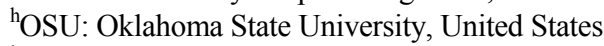

${ }^{\mathrm{i}}$ FSEC: University of Central Florida, Florida Solar Energy Center, United States

${ }^{j}$ DOE-BT: U.S. Department of Energy, Office of Building Technologies, Energy Efficiency and Renewable Energy, United States

${ }^{k}$ CETC: CANMET Energy Technology Centre, Natural Resources Canada, Canada

'ESRU: Energy Systems Research Unit, University of Strathclyde, Scotland, United Kingdom

\subsection{Selection of Simulation Programs and Modeling Rules for Simulations}

The countries participating in this IEA task made the initial selections of the simulation programs used in this study. The selection criteria required that

- A program be a true simulation based on hourly weather data and calculative time increments of 1 hour or less

- A program be representative of the state of the art in whole-building energy simulation as defined by the country making the selection.

The modeling rules were somewhat different (more stringent) for the simulation programs used for Part III example results than for a given program to be normally tested with HVAC BESTEST (see Section 1.2.2, Modeling Rules). For the Part III simulation results, we allowed a variety of modeling approaches. However, we required that these cases be modeled in the most detailed way possible for each simulation program within the limits of the test specification (e.g., detailed component data are not given for the compressor, condenser, and thermal expansion device).

To minimize the potential for user error, we encouraged more than one modeler to develop input files for each program. Where only a single modeler was involved, we strongly recommended that another modeler familiar with the program check the inputs carefully.

Where improvements to simulation programs or simulation inputs were made as a result of running the tests, such improvements must have a mathematical and physical basis, and must be applied consistently across tests. In addition, all improvements were required to be documented in modeler reports. Arbitrary modification of a simulation program's input or internal code just for the purpose of more closely matching a given set of results is not allowed. The diagnostic process of trapping bugs discussed in Section 2.4 also isolated input errors that were corrected, as noted there and in the modeler reports (Section 2.9).

\subsection{Improvements to the Test Specification as a Result of the Field Trials}

Based on comments by the other IEA SHC Task 22 participants during the field trials, observations from our own DOE-2.1E.simulations, and comments by industry engineers, we made a number of improvements and revisions to the test specification. Although researching the comments and communicating specification revisions to the field trial participants was very time-consuming, the importance of the accuracy and clarity of the test specification for this type of work cannot be overstated.

The contribution of the IEA SHC Task 22 participating countries was particularly valuable because the Task 22 experts supplied continuous feedback throughout the 4-year field trial effort. Their feedback resulted in several revisions to the HVAC BESTEST specifications and subsequent reexecution of the computer simulations. This iterative process led to refinement of HVAC BESTEST, and the results of the tests led to the improvement and debugging of the programs. The process underscores the leveraging of 
resources for the IEA countries participating in this project. Such extensive field trials, and resulting enhancements to the tests, would not have occurred without the participation of the IEA SHC Task 22 experts.

\subsubsection{Major Revisions to Initially Proposed Test Specification}

The initial specification of these test cases was issued in May 1999. The parametric sensitivity tests were mostly similar to the current E300-E545 tests, but the base case was significantly different: using the same full-load performance data as in the Volume 1 (E100-E200) cases, and a realistic building envelope similar to that of IEA BESTEST (Judkoff and Neymark 1995a). Observations of the initial results based on simulations performed by some of the E100-E200 field trial participants indicated the following issues.

- The range of disagreement (max-min/mean) regarding electricity use (compressor + outdoor fan) among the simulation programs for these cases was:

E300 series: $13 \%-24 \%$
E400 series: 4\%-23\%
E500 series: $8 \%-36 \%$.

- Disagreement caused by the more realistic building shell, based on a case developed specifically to evaluate that, appeared to be about $25 \%$. Much of this disagreement may have been caused either by a bug or an input error in one of the simulations. Even excluding the one suspect simulation result, the disagreement is $8 \%$, much of which may have been from differences in window models. In any case, it was apparent that for the purpose of testing mechanical equipment models, applying a realistic building envelope was adding unnecessary complexity (i.e., increased potential for user input error) to the tests.

- Results differences related to variations in performance data extrapolation techniques and different extrapolation boundaries in the various programs were significant.

Based on these observations, the following revisions were made:

- Utilization of a near-adiabatic envelope with dynamic internal gains schedules; this removed disagreements caused by variation among building envelope models.

- Utilization of an expanded performance data set that we were able to obtain for a larger unitary system, along with establishment of internal gains schedules that required little or no extrapolation of the performance data; this removed disagreements caused by variations in extrapolation techniques. 


\subsubsection{Second Round of Revisions}

Field trials of the revised test specification engendered further revisions as listed below.

- Case E320 revised to exclude outside air, has scheduled infiltration only

- Case E340 added for outside air/infiltration interaction

- Revised output requirements

$\circ$ Added outputs

- Total annual (compressor + indoor [ID] fan + outdoor [OD] fan) consumption

- Total annual coil (sensible + latent); previously these were only disaggregated

- Annual mean and maximum outdoor dry-bulb temperature (ODB) and outdoor humidity ratio (OHR), E300 only (weather data checks)

- June 28 hourly total coil load and OHR, E300 only

- Daily outputs for April 30 and June 25 for Case E500 and Case E530: total consumption, total coil load, ODB, and entering dry-bulb temperature (EDB)

- Revised output requirement period as April 1 to December 31 for minimum indoor drybulb temperature (IDB), humidity ratio and relative humidity (RH), and maximum relative humidity (to exclude results caused by initialization differences)

$\circ$ Deleted outputs that did not enhance diagnostic capability

- Peak compressor + OD fan only

- Annual compressor operating hours

- Annual number of under cooled hours

- Annual number of hours with $\mathrm{RH}>60 \%$

- Glossary revisions

- Coefficient of performance (COP): clarified for when to include ID fan with energy input (E300-E440)

- Evaporator coil loads: clarifications of definitions of sensible and latent coil loads

- Net refrigeration effect: clarifications of accounting for air distribution fan (especially cases E300-E440)

- Deleted a number of terms that were previously useful for Volume 1 cases E100-E200, but not applicable for cases E300-E545

- Other changes

- Added discussions explaining the purposes of various internal gains schedules

- Added discussion about the relationship between latent internal gains and heat of vaporization

- Deleted unnecessary text discussion about when fan heat is accounted in coil load (coil load is whatever heat the coil removes)

- COP degradation factor (CDF) discussion better emphasizes the option to use gross total coil load/gross total capacity (Qgtc/CAPgtc) for defining part-load ratio (PLR) in E300E440 when there is continuously operating indoor fan

- Improved version of weather data appendix (Appendix A) transferred over from E100 cases

- Clarifications to appendices

- Appendix E (PLR definition equivalence)

- Appendix G (diagnostic logic)

$\circ \quad$ More units as both Système Internationale (SI) and English (IP)

○ Other minor edits. 


\subsubsection{Third Round of Revisions}

Additional field trials of the revised test specification engendered further revisions as listed below.

- Added discussion to weather data appendix noting that solar data and meteorological data included within typical meteorological year 2 (TMY2) data utilize different time conventions.

- Manufacturer provided system performance data were added for typical rating conditions $\left(\mathrm{ODB} / \mathrm{EDB} / \mathrm{entering}\right.$ wet-bulb temperature $[\mathrm{EWB}]=95^{\circ} \mathrm{F} / 80^{\circ} \mathrm{F} / 67^{\circ} \mathrm{F}$, and corresponding SI units).

\subsubsection{Fourth Round of Revisions}

Disagreeing results for TRNSYS-TUD uncovered an error in the test specification regarding IP and SI unit equivalent values for enthalpy limits given in Case E440. SI enthalpies were changed from $65.13 \mathrm{~kJ} / \mathrm{kg}$ to $47.25 \mathrm{~kJ} / \mathrm{kg}$ to account for different reference temperatures used in IP versus SI psychrometric charts that were not initially considered.

\subsection{Examples of Error Trapping with HVAC BESTEST Diagnostics}

This section summarizes a few examples that demonstrate how the HVAC BESTEST procedure was used to isolate and correct bugs in the reference programs. Further description may be found in the individual code reports presented in Appendix II (see Section 2.9).

Simulations were performed for each test case with the participating computer programs using hourly TMY2 weather data. At each stage of the exercise, output data from the simulations were compared to each other according to the diagnostic logic of the test cases (see Part I, Appendix G). The test diagnostics revealed (and led to the correction of) bugs, faulty algorithms, input errors, or some combination of those in all but one of the programs. Several examples follow.

\subsubsection{EnergyPlus}

EnergyPlus is the program recently released by the United States Department of Energy (DOE), and is the department's next-generation building energy simulation program. GARD Analytics (GARD) used the "Unitary Air-to-Air Heat Pump" system in EnergyPlus for its model.

GARD submitted eight iterations of simulation results. Table 2-2 describes input file and software modifications for each iteration; a single results set was submitted corresponding to changes described in each row of the table. Version 1.0.2.004 was used for the initial results set. 
Table 2-2. Summary of EnergyPlus Changes That Were Implemented

\begin{tabular}{|c|c|c|}
\hline Version & Input File Changes & Code Changes \\
\hline 1.0.2.004 & - $\quad$ ARI performance data point interpolated & $\begin{array}{ll} & \text { Error message improvement }\end{array}$ \\
\hline 1.0 .3 .001 & & $\begin{array}{l}\text { - Latent cooling load: hg function replace previous hfg } \\
\text { function }\end{array}$ \\
\hline 1.0.3.005 & & $\begin{array}{l}\text { - Dry-coil condition coil outlet condition calculation error } \\
\text { fixed }\end{array}$ \\
\hline 1.0.3.005 & $\begin{array}{l}\text { - New curve fits generated for given ARI data point } \\
\text { performance in revised test specification }\end{array}$ & \\
\hline 1.0.3.006 & $\begin{array}{l}\text { Initialization with small amount of infiltration } \\
\text { during first simulation week for } 0 \text { OA dry-coil } \\
\text { cases (E530, E540, and E545); to achieve } \\
\text { initialization specified in modeling requirements }\end{array}$ & $\begin{array}{l}\text { - Weather data subhourly time step interpolation } \\
\text { method }\end{array}$ \\
\hline 1.0.3.013 & $\begin{array}{l}\text { - } \quad \text { Fan outlet node name related to economizer } \\
\text { control fixed (E400-E440) } \\
\text { - } \quad \text { 4410 deleted; compressor lockout capability not } \\
\text { yet included in the program } \\
\text { - } \quad \text { Economizer high-temperature-limit specification } \\
\text { fixed (E420) } \\
\text { - Relaxation of temperature limits associated with } \\
\text { use of performance curves }\end{array}$ & \\
\hline 1.1.0.004 & - $\quad$ External output reporting error fixed & $\begin{array}{l}\text { - Space internal loads accounted for before system } \\
\text { simulation }\end{array}$ \\
\hline 1.1.0.020 & $\begin{array}{l}\text { - For Case E440, set economizer enthalpy limit to } \\
47,250 \mathrm{~J} / \mathrm{kg} \text { per change to specification }\end{array}$ & \\
\hline
\end{tabular}

\subsubsection{Documentation Improvement Regarding Input Requirements at ARI Rating Conditions}

The initial test specification did not give equipment performance at Air-Conditioning and Refrigeration Institute (ARI) rating conditions (ODB/EDB $\left./ \mathrm{EWB}=35^{\circ} \mathrm{C} / 26.67^{\circ} \mathrm{C} / 19.44^{\circ} \mathrm{C}\left[=95^{\circ} \mathrm{F} / 80^{\circ} \mathrm{F} / 67^{\circ} \mathrm{F}\right]\right)$. Initially the EnergyPlus testing team assumed that performance curves could be normalized to some other point as long as such normalization was consistent for all performance curves, and implemented this in their system inputs. This input caused a fatal error as described in the EnergyPlus modeler report (see Section 2.9). Because of this the source code was changed to include an improved error message to assist users if detailed performance-map data do not identify performance at ARI rating conditions.

\subsubsection{Latent Cooling Load Calculation}

As shown in Figure 2-1, the space temperature was not always maintained at $25^{\circ} \mathrm{C}$ in cases $\mathrm{E} 300$ (base case) and E310 (high latent loads), or went above the $35^{\circ} \mathrm{C}$ set-up set point in Case E350 (thermostat set up). Additionally, Figure 2-2 indicates a substantial disagreement for minimum $\mathrm{COP}_{2}$ for Case $\mathrm{E} 350\left(\mathrm{COP}_{2}\right.$ is defined in Section 2.7). In the first attempt at correcting this, the program authors replaced an hfg function with an hg function in the psychrometric routines. According to GARD, this change produced only a small change in results; the GARD modeling team did not document this change in their intermediate results set. 


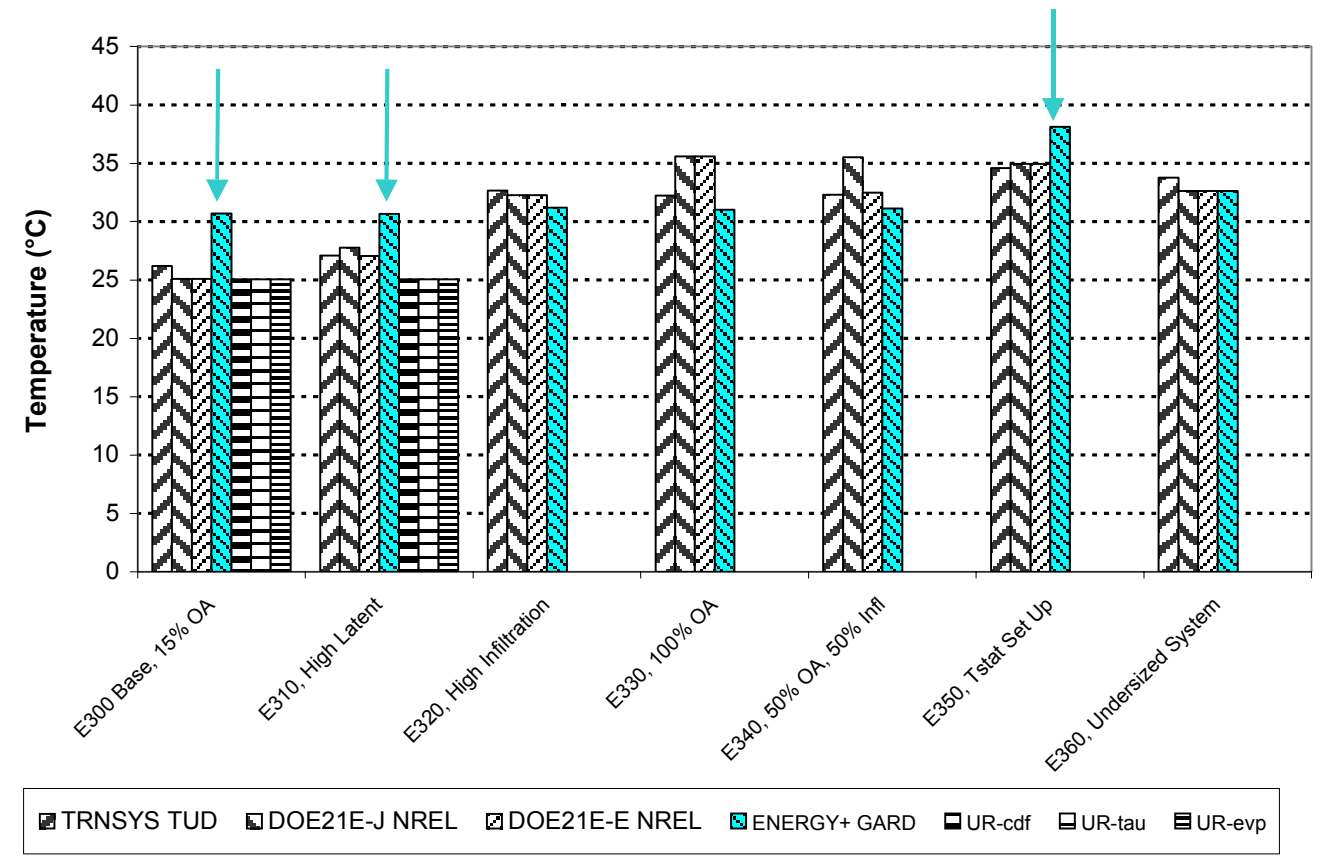

Figure 2-1. Maximum indoor dry-bulb temperature disagreement, initial results

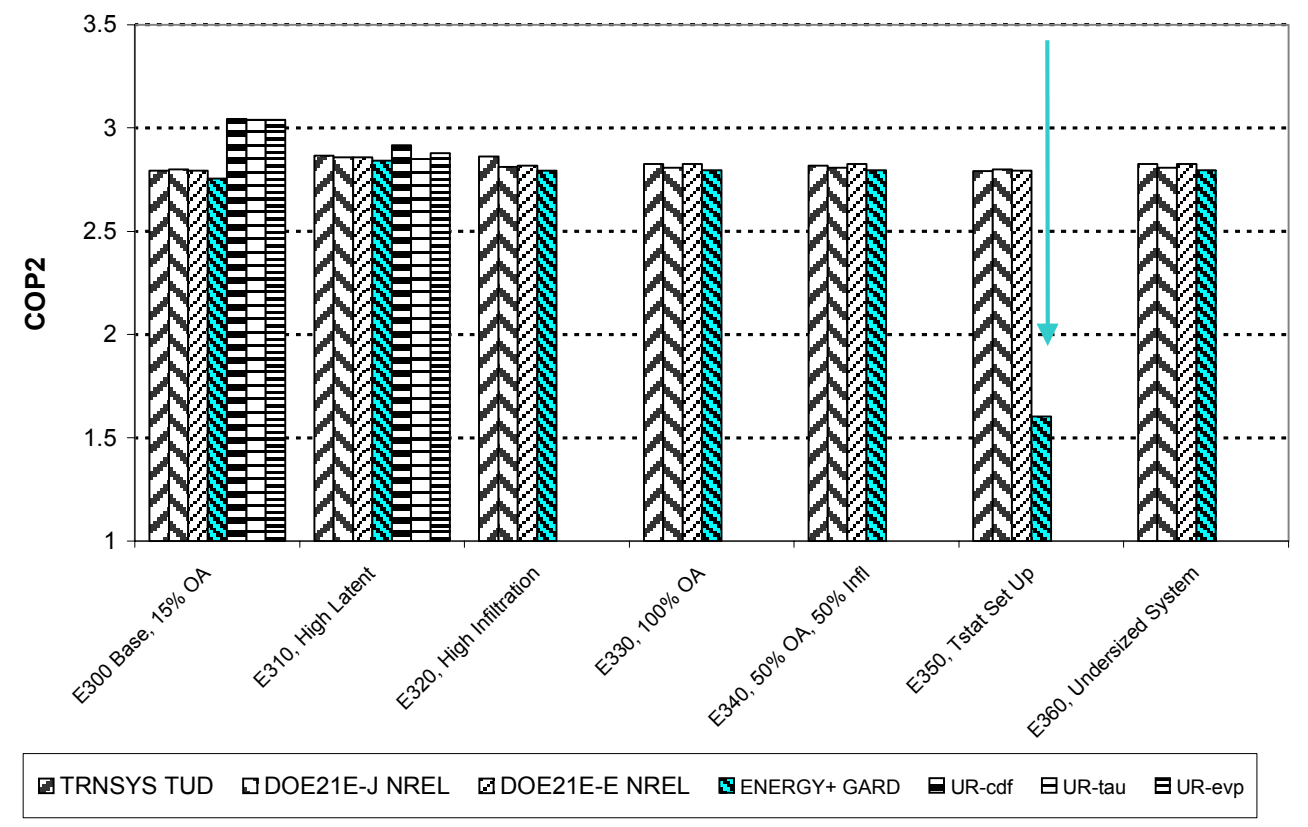

Figure 2-2. Minimum COP2 disagreement, initial results 


\subsubsection{System Control during Low Part Loading (1\%-2\% compressor + OD fan consumption decrease for E300 series cases)}

On further review of the disagreement indicated in Figure 2-1 by the code authors, the temperature control problems were found to be occurring during periods of low or no internal loads when the air conditioner did not cycle on to provide cooling. Detailed review isolated an error related to calculating cooling coil outlet temperature and humidity ratio during dry-coil conditions (before GARD had run the E500 series cases, so we do not know what the dry-coil cases [E530-E545] would have indicated). This error caused the heat pump not to operate during certain hours. After this error was corrected, the illustrated disagreements were ameliorated. The corrections decreased combined compressor and OD fan annual energy consumption and total peak-hour consumption by $1 \%-2 \%$ for the E300 series cases.

\subsubsection{Weather Data Interpolation When Using Subhourly Time Steps (0\%-1\% compressor $+O D$ fan consumption increase and $0 \%-2 \%$ total peak-hour consumption increase for E300 series cases)}

For fourth iteration results compiled during July 2002, it was noticed that the hourly COP2 for June 28 was 1 hour out of phase with the other programs as shown in Figure 2-3. Further review indicated that hourly ODB was also out of phase as shown in Figure 2-4, and that based on the given weather data, the listed hourly ODB results for the other programs are more logical than those for EnergyPlus. A similar disagreement was apparent in the hourly outdoor humidity ratio results. The code authors traced this problem to weather data interpolations that are performed when subhourly time steps are implemented in the model. This interpolation method was revised so that the EnergyPlus hourly results now show better agreement with the other results. The corrections increased combined compressor and OD fan energy consumption $0.0 \%-0.8 \%$ and increase total peak-hour consumption by $0.0 \%-2.1 \%$ for the $\mathrm{E} 300$ series cases.

HVAC BESTEST: E300

June 28 Hourly COP2

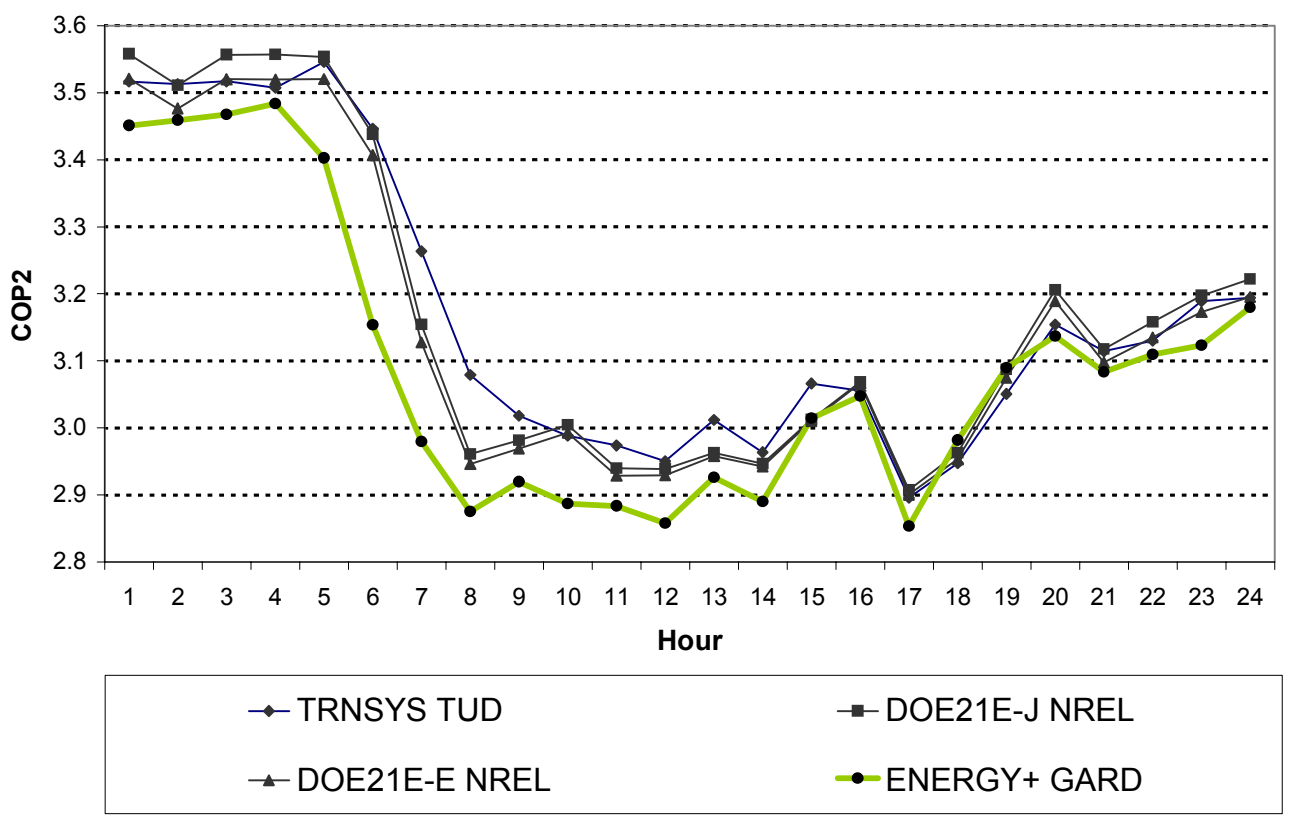

Figure 2-3. Hourly COP2 out of phase 
HVAC BESTEST: E300

June 28 Hourly ODB

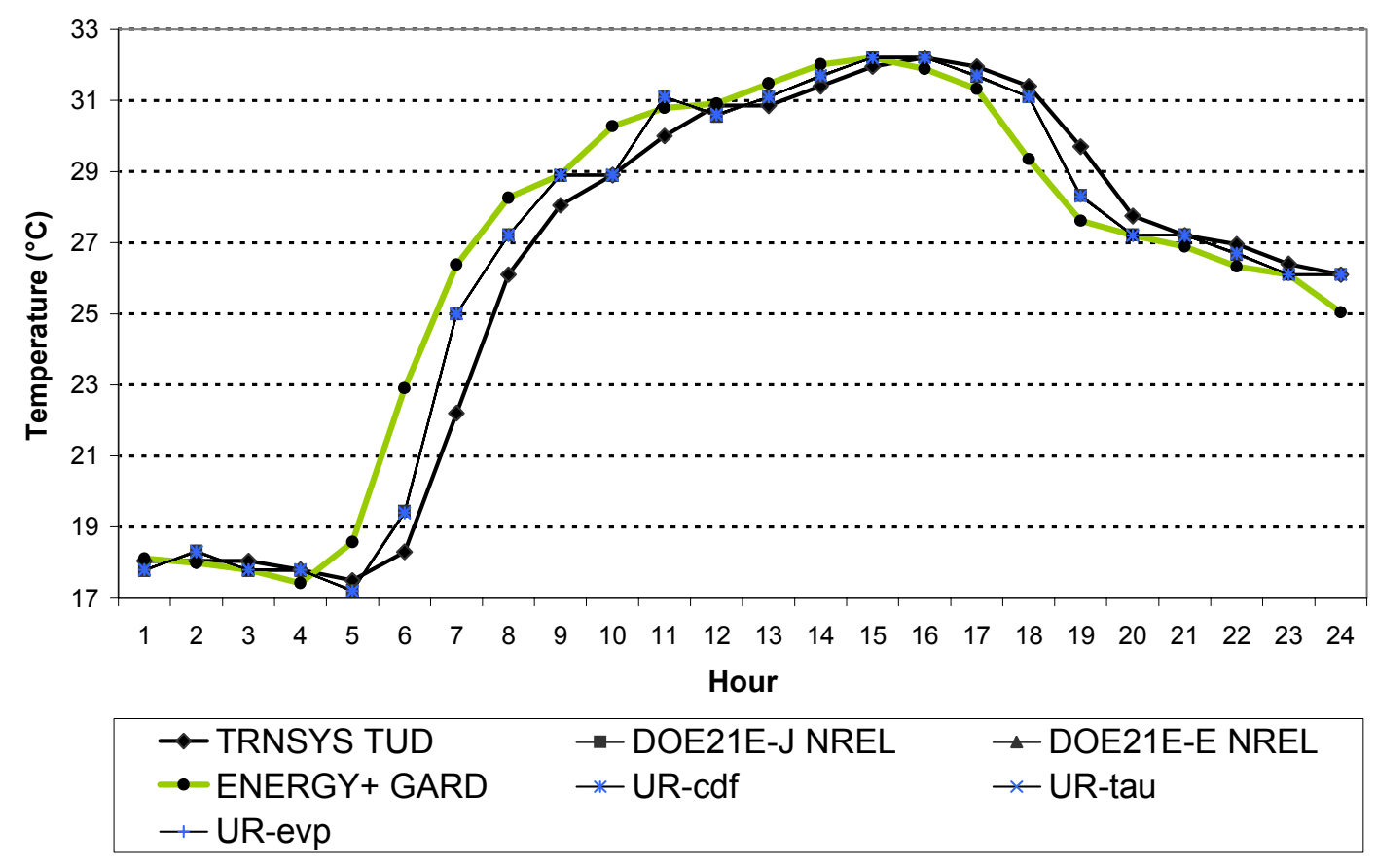

Figure 2-4. Weather data out of phase (interpolation error)

\subsubsection{Economizer Compressor Lockout Feature Allows Input for Algorithm Not Yet Implemented (Modeling feature to be added, code authors notified)}

In the first iteration of E400 and E500 series cases, the results for cases E410 and E400 were identical. EnergyPlus indicates the availability of an optional compressor lockout feature, but it has not yet been implemented within the code.

\subsubsection{Moisture Balance (Negligible effect on annual and peak-hour total consumptions)}

After addressing previous errors (6th iteration overall, 2nd iteration of E500 series), it was found that maximum space humidity ratios were high for cases E500-E545 as shown in Figure 2-5. Further investigation into the problem indicated that these maximum humidity ratios were occurring 1 to 2 hours after the scheduled internal gains and the HVAC system were off. The error was traced to a problem in the moisture balance algorithm, where internal loads during each time step were being accounted for after the HVAC system simulation, rather than before. Fixing this error corrected the maximum humidity ratio results, but had negligible effect on annual consumption results for all cases, and peak-hour consumption results for cases E300-E440. It was not possible to identify the effect on peak load results for the E500 series cases because of a simultaneous correction to a reporting error for those results from the previous iteration. 


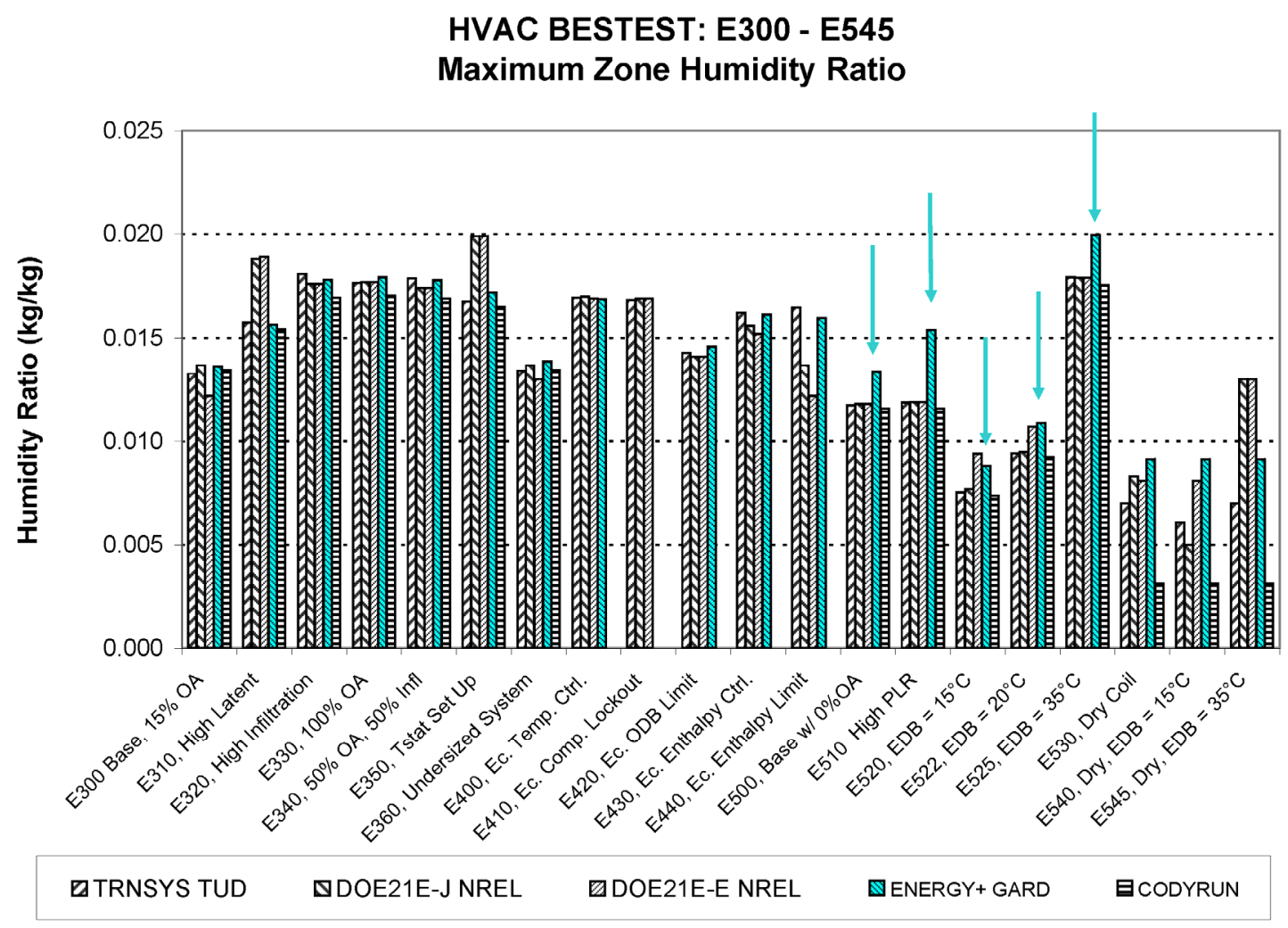

Figure 2-5. Maximum zone humidity ratio disagreement (moisture balance error)

\subsubsection{Input Error Summary}

A number of input errors were also documented in the EnergyPlus modeler report. These related to description of economizer operation for cases E400, E420, E430, and E440, and performance-curve operation boundaries (at low EDB) for cases E520 and E540.

\subsubsection{CODYRUN}

CODYRUN is a whole-building simulation program under development at Laboratoire de Génie Industriel (Industrial Engineering Laboratory) of University of Reunion Island (UR), France. UR submitted seven iterations of simulation results. Table 2-3 describes input file and software modifications for each iteration; a single results set was submitted corresponding to changes described in each row of the table. 
Table 2-3. Summary of CODYRUN Changes That Were Implemented

\begin{tabular}{|c|c|c|}
\hline Iteration & Input File Changes & Code Changes \\
\hline \multicolumn{3}{|l|}{$\begin{array}{c}1 \\
(E 300, E 310) \\
\end{array}$} \\
\hline $\begin{array}{c}2 \\
(E 300-E 360)\end{array}$ & & $\begin{array}{l}\text { - Fix of inconsistent use of gross versus net capacities } \\
\text { in different subroutines (building loads versus coil } \\
\text { loads) } \\
\text { - Allow extrapolation of dry-coil performance in neural } \\
\text { network performance map model }\end{array}$ \\
\hline 3 & - Internal gains corrected & $\begin{array}{l}\text { - Inclusion of subhourly iterative loop for moisture } \\
\text { balance (entering air humidity ratio) solution }\end{array}$ \\
\hline $\begin{array}{c}4 \\
\text { (E300-E360, } \\
\text { E500-E545) }\end{array}$ & & $\begin{array}{l}\text { - Allow IDB to be greater than set point if system } \\
\text { capacity is less than the load (e.g. in Case E360) }\end{array}$ \\
\hline 5 & - Decreased thermal capacitance of walls & $\begin{array}{l}\text { - Inclusion of subhourly iterative loop for thermal } \\
\text { balance (entering air humidity ratio) solution } \\
\text { - Fixed an amalgamation of air infiltration and outside } \\
\text { air mixing }\end{array}$ \\
\hline 6 & & $\begin{array}{l}\text { - } \quad \text { Fixed improper accounting of CDF/PLR in fan } \\
\text { calculations } \\
\text { - Neural network equipment performance calculation } \\
\text { improvement }\end{array}$ \\
\hline 7 & & $\begin{array}{l}\text { - Improved iterative balance of zone air conditions and } \\
\text { equipment performance parameters }\end{array}$ \\
\hline
\end{tabular}

\subsubsection{Inconsistent Accounting of Fan Heat in Building Loads Calculations versus Coil Loads Calculations, and Dry-Coil Performance-Map Modeling Improvement (14\% underestimation of annual compressor consumption, $9 \%$ underestimation of peak-hour total consumption)}

In the initial runs (done only for cases E300 and E310) using three different modeling techniques, the annual average COP2 disagreed with those of the other programs by about $30 \%$ as shown in Figure 2-6. The main source of disagreement was found to be inconsistent accounting of indoor air distribution fan heat in the calculation of sensible building loads, evaporator coil loads, and compressor consumption. In addition, the neural network performance-mapping model did not allow the calculation of EWB at the "intersection point" (greatest value of dry-coil EWB for given EDB and ODB) where dry-coil conditions occur. Fixing this error in cases E300 and E310 caused annual compressor consumption to increase by $14 \%$ and peakhour total consumption to increase by $9 \%$ in both cases. 


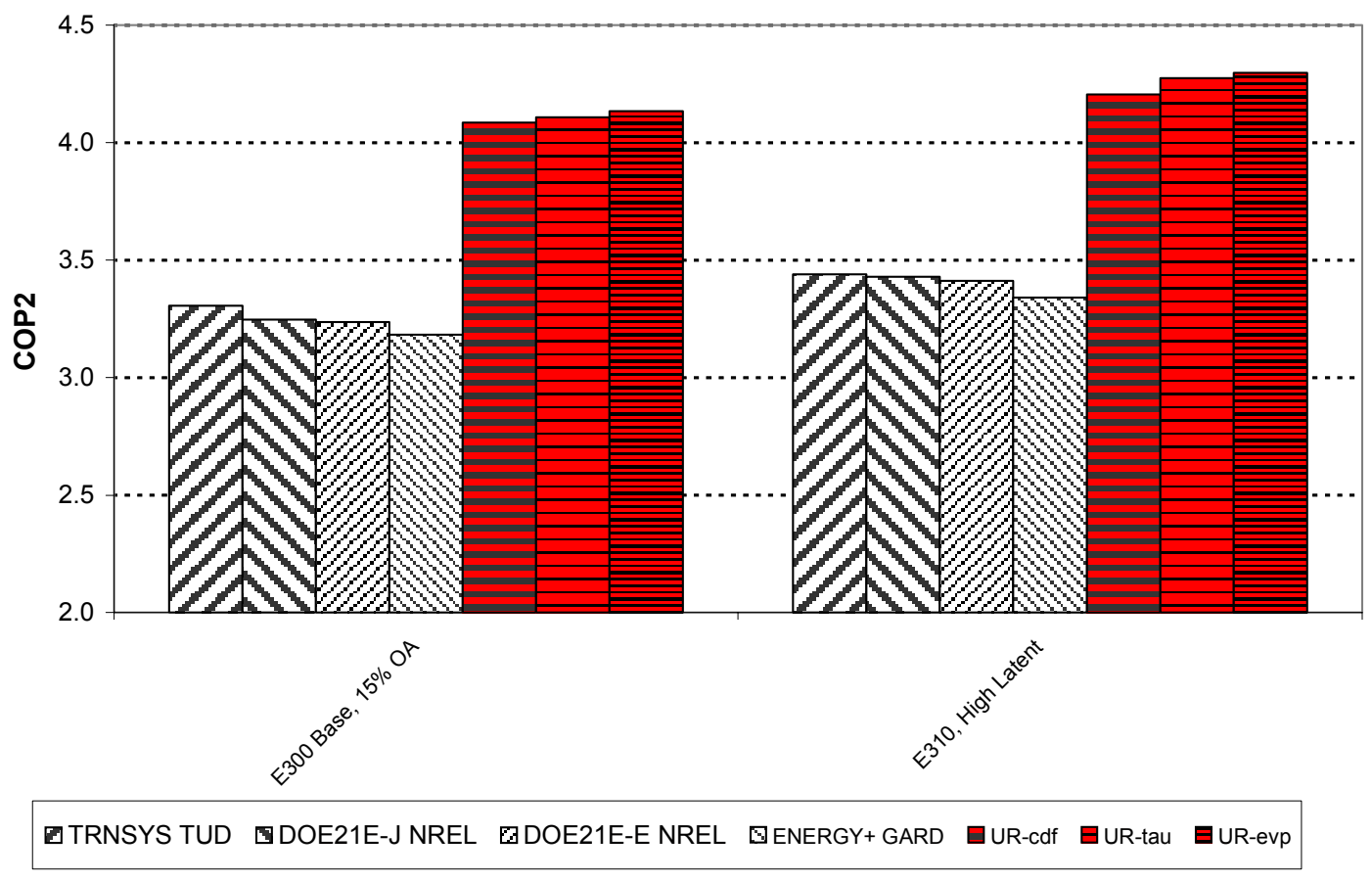

Figure 2-6. COP2 disagreement (fan heat accounting inconsistencies)

2.4.2.2 Moisture Balance Calculation Problem (1\% underestimation of compressor consumption for $E 360,4 \%-5 \%$ overestimation of peak-hour total consumption for E300, E310, E320, and E360)

Analysis by the code authors of hourly zone humidity ratio results (see Figure 2-7) indicated greater oscillations than expected, especially for Case E360. This problem was traced to not accounting for latent loading during the appropriate time step. The problem was fixed by including a subhourly iterative loop for moisture balance calculation within each time step. Zone air humidity ratio predictions became more stable, as shown in Figure 2-8. Fixing this error caused an increase in annual compressor consumption of $1.3 \%$ in Case E360 (other cases negligible), and a 4\%-5\% decrease in peak-hour total consumption for cases E300, E310, E350, and E360 (high infiltration and/or outside air (OA) cases E320-E340 were not significantly affected). 


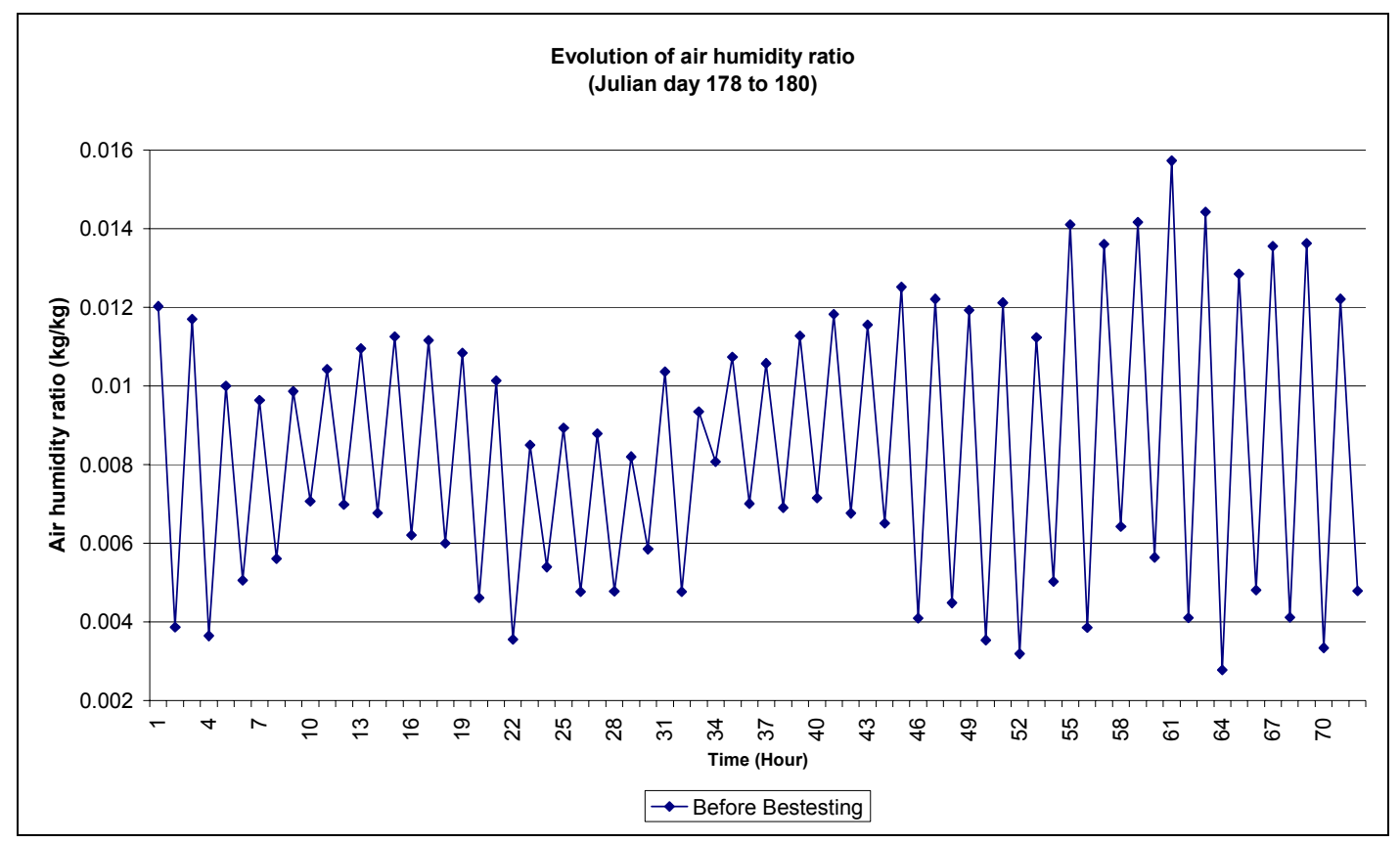

Figure 2-7. Case E360 hourly zone air humidity ratio oscillations before fixing moisture balance calculation

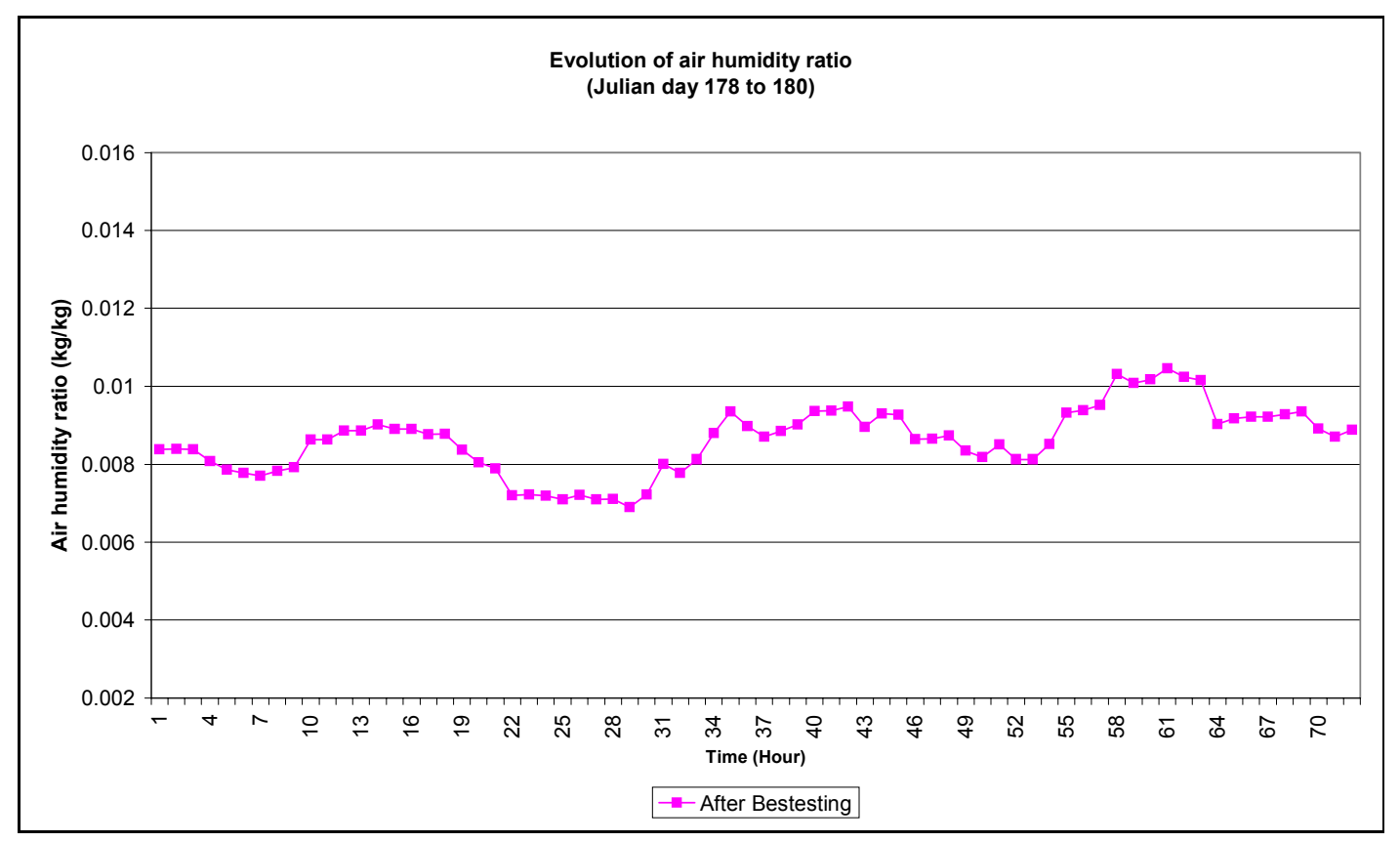

Figure 2-8. Case E360 hourly zone air humidity ratio oscillations after fixing moisture balance calculation 


\subsubsection{IDB Not Allowed above Set Point When Equipment Overloaded $10.5 \%-14 \%$ overestimation of annual compressor consumption, $0 \%-1 \%$ underestimation of peak- hour total consumption)}

Review of the next set of results for November 2002 indicated high total consumptions for cases E320, E330, and E340, which were most clearly apparent from consumption sensitivity disagreements illustrated in Figure 2-9. Further review indicated high sensible cooling loads for these cases but a low sensible cooling load for Case E360 as shown in Figure 2-10. Latent cooling loads (not shown) were similarly high for E320 through E340 and also high for E360. Figure 2-11 (maximum IDB) indicates a possible cause for the problem in that CODYRUN does not allow IDB to go above the set point during hours when equipment is overloaded, as indicated by maximum IDB for the other programs. This wrongly locates performance in a less efficient part of the performance map during overloaded hours. Fixing the software to allow IDB to float above the set point when equipment is overloaded caused a 13\%-14\% overestimation of compressor consumption in the cases with high infiltration and outside-air flow rates (cases E320-E340) and a 0.5\%$1.5 \%$ variation in compressor consumptions for the remaining E300 series cases. This was accompanied by negligible peak-hour total consumption variation for cases E320, E330, E340, and E360, and by about 1\% peak-hour total consumption increase for cases E300, E310, and E350.

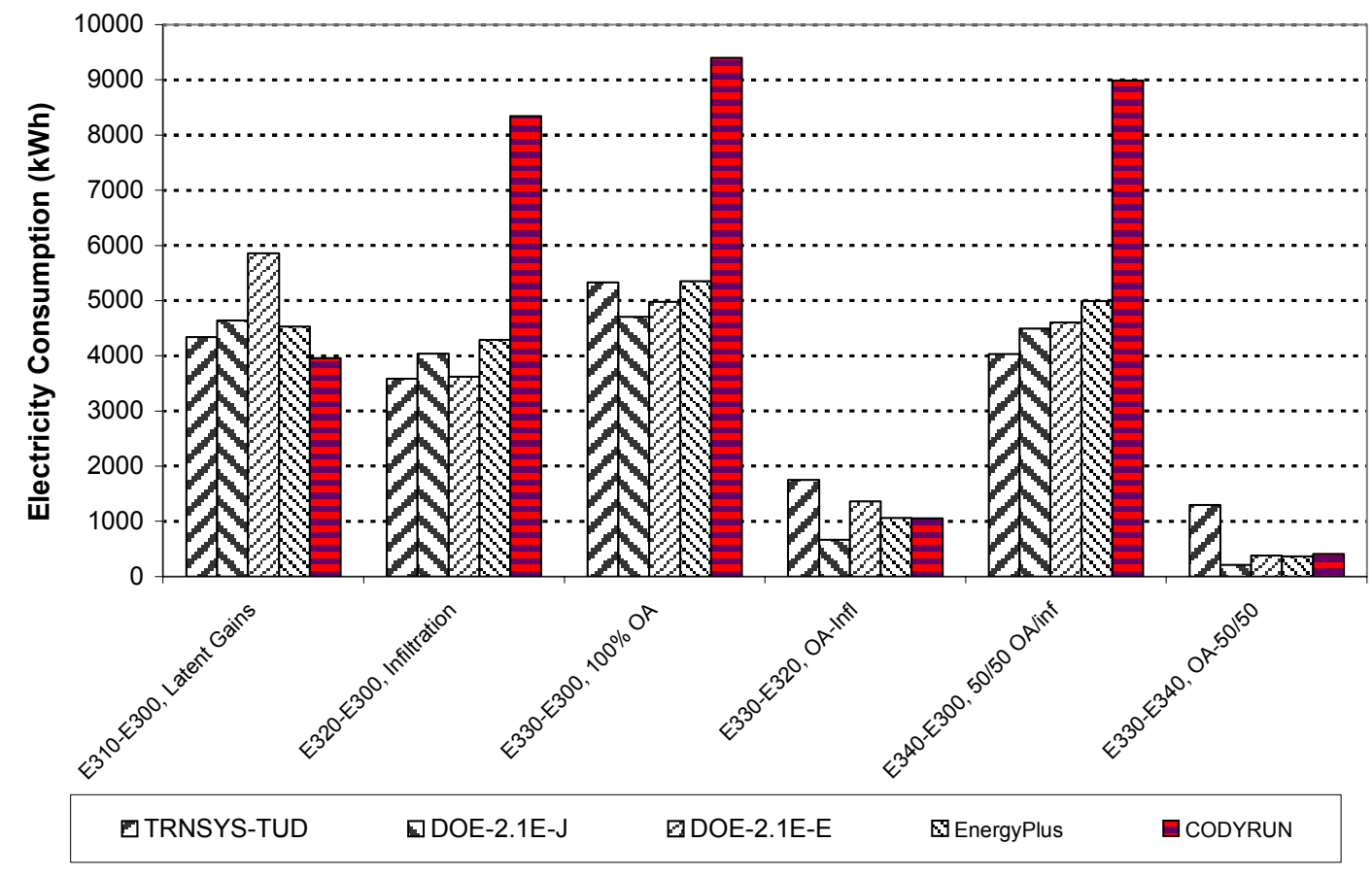

Figure 2-9. CODYRUN total space cooling electricity consumption sensitivity disagreements (E320E300, E330-E300, E340-E300) 


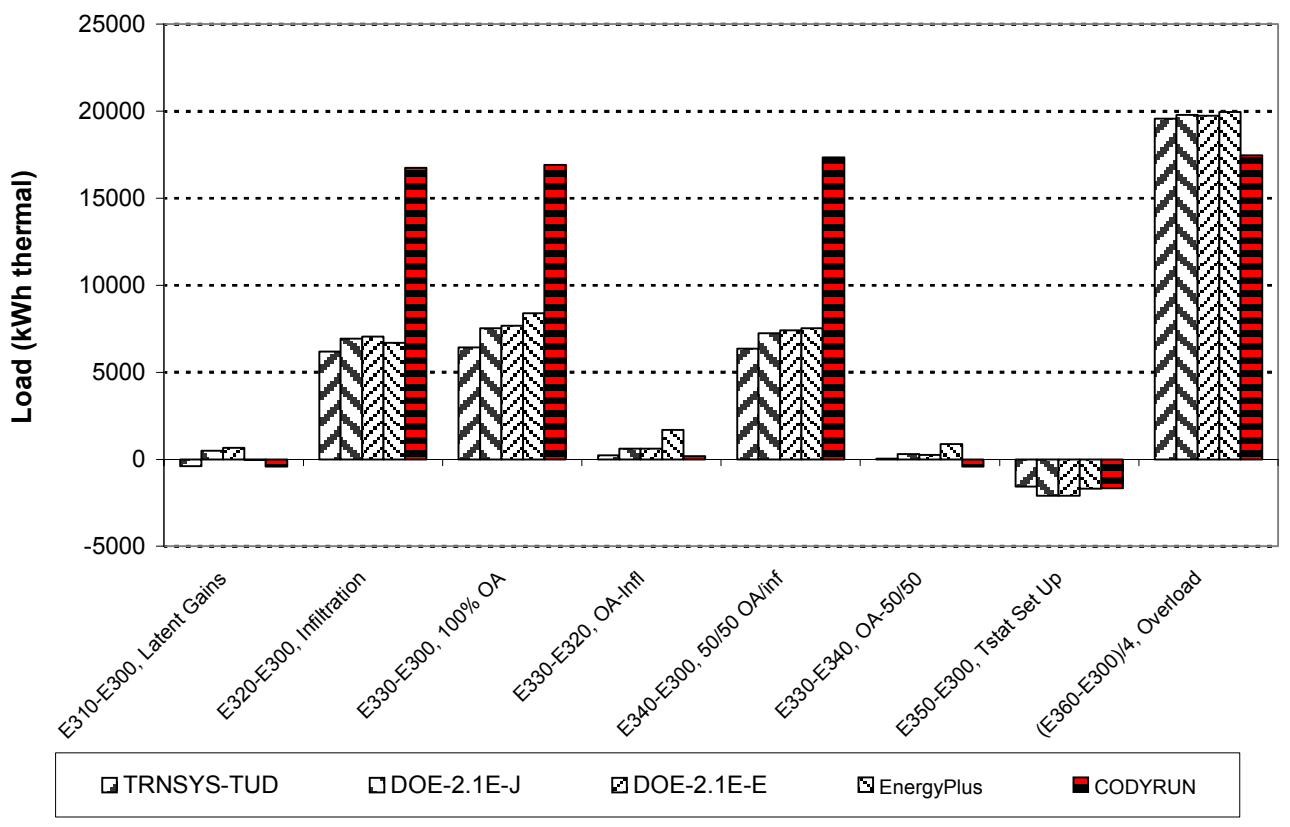

Figure 2-10. CODYRUN sensible coil load sensitivity disagreements (E320-E300, E330-E300, E340-E300)

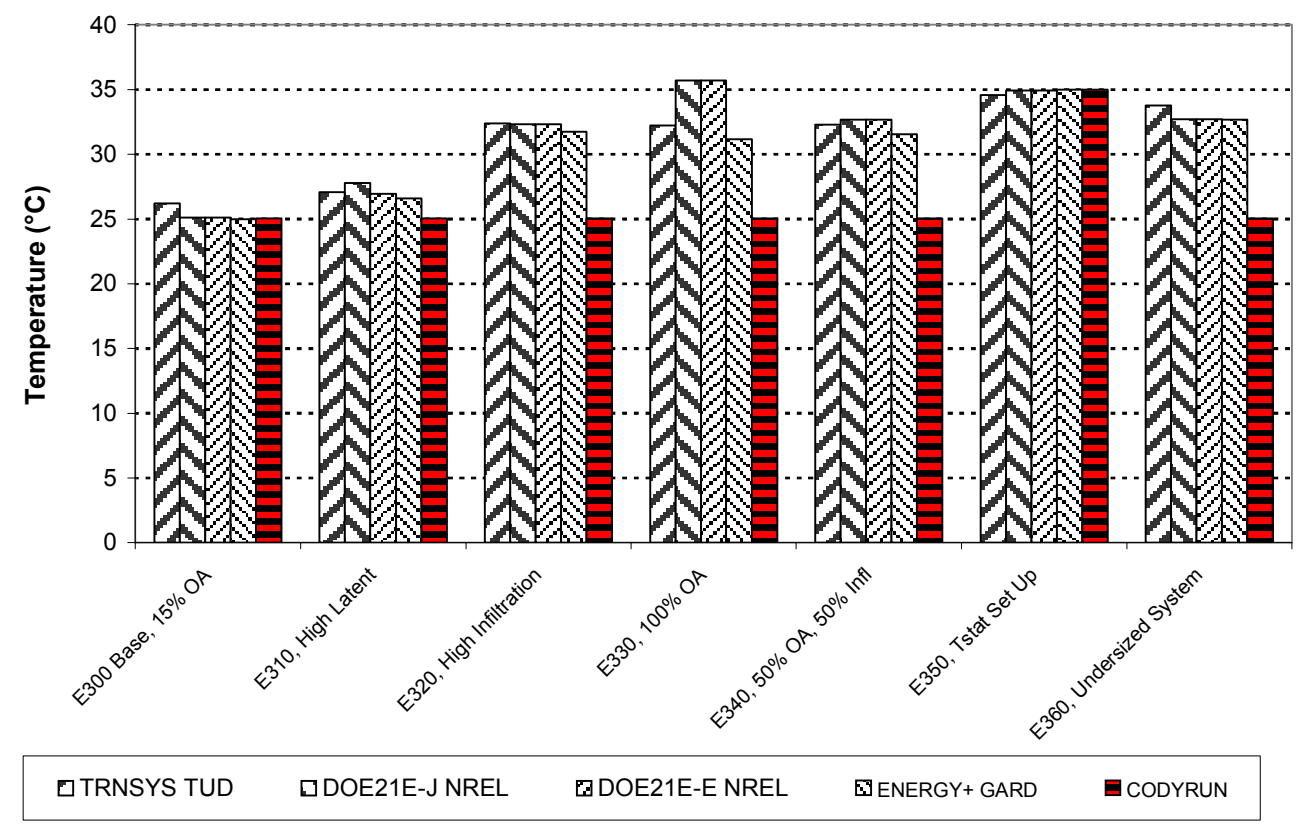

Figure 2-11. CODYRUN maximum IDB not floating when overloaded 


\subsubsection{Thermal Balance Calculation Improvement, Amalgamation of Air Infiltration and Outside Air Mixing, and Input-Reduced Thermal Capacitance (Affects annual total and peak-hour total consumptions by up to $3.2 \%$ and $4.3 \%$, respectively)}

After fixing the previous bugs, some further disagreements were uncovered. Figure 2-12 illustrates a variety of disagreements versus other programs for Case E360, including that peak-hour total consumption is $3 \%$ low, annual sensible coil load is $7 \%$ low, annual average IDB is $3^{\circ} \mathrm{C}$ high, and peak-hour IDB is $17^{\circ} \mathrm{C}$ high. Interestingly, with all of these disagreements, the annual total consumption is in agreement with the other programs. Additional disagreements for Case E320 (illustrated using sensitivity disagreements for E320E300 as shown in Figure 2-13) indicate that sensible coil load sensitivity is $42 \%$ low, latent coil load sensitivity is $86 \%$ high, and maximum IDB sensitivity is $4.1^{\circ} \mathrm{C}$ high, with good agreement for annual total consumption.

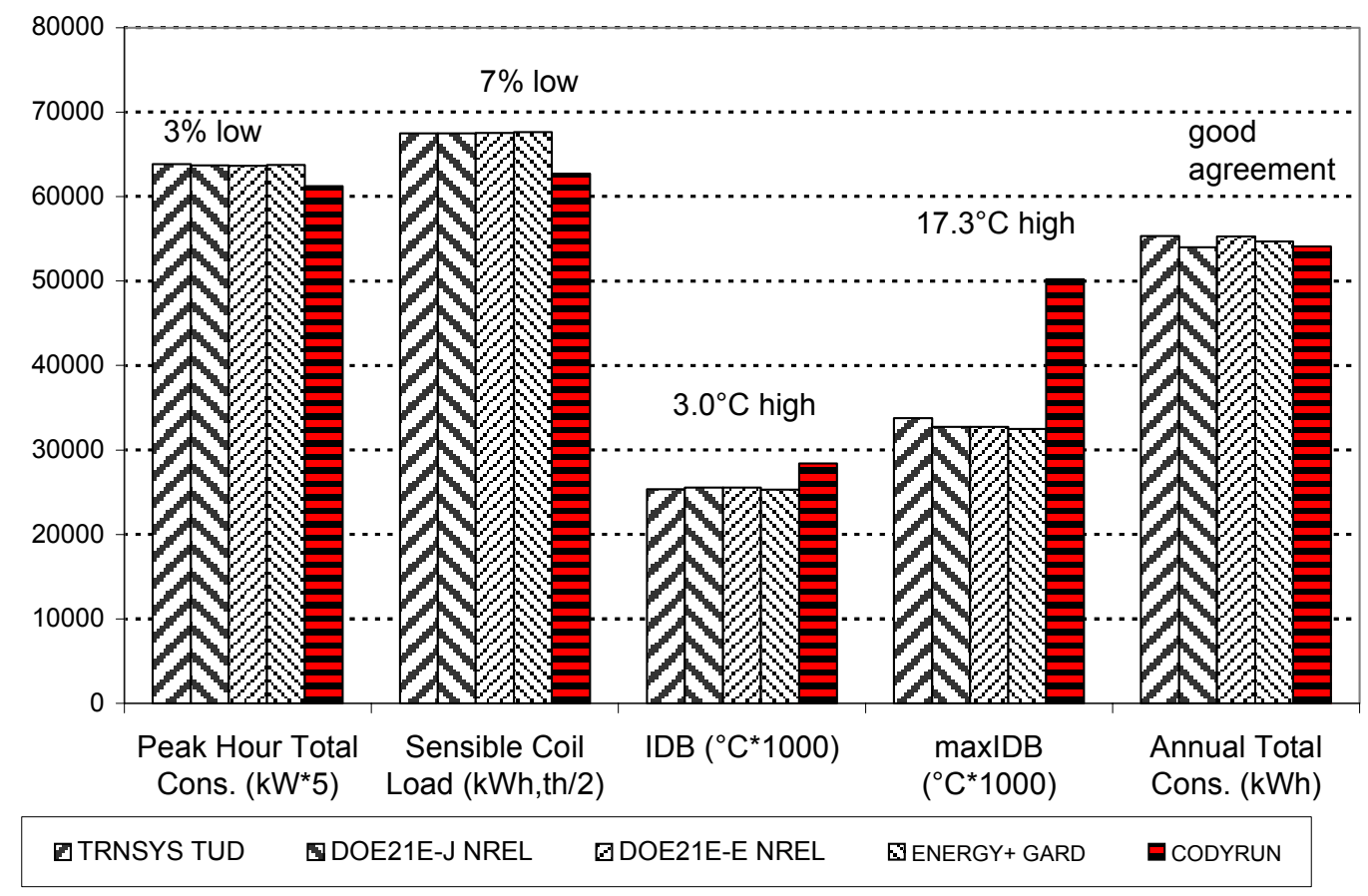

Figure 2-12. Remaining disagreements for Case E360 from 4th simulation iteration 


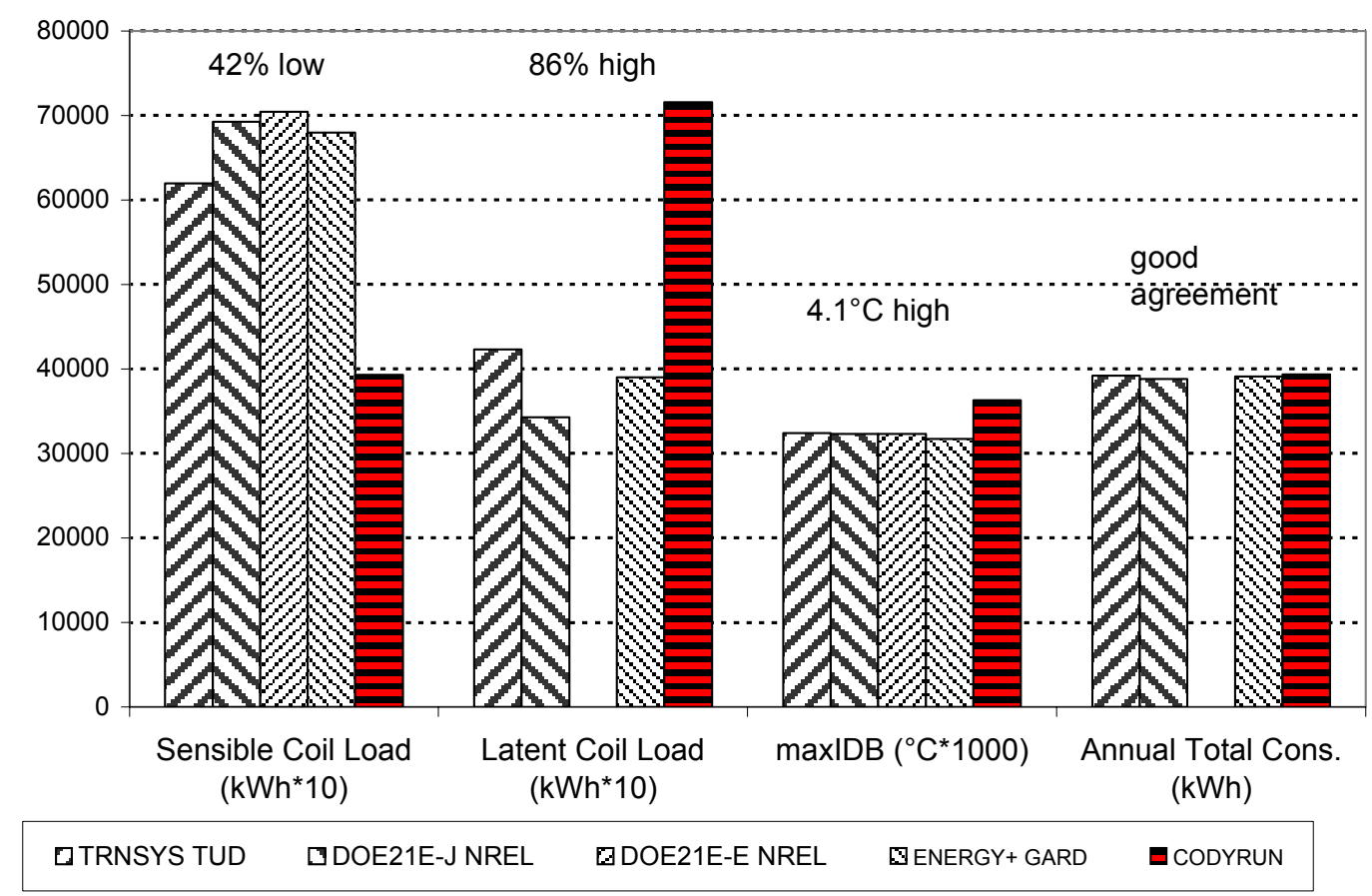

Figure 2-13. Remaining disagreements for Case E320-E300 from 4th simulation iteration

This fourth overall iteration of simulations also included initial results for cases E500-E545 (not shown). These results had generally good agreement except for cases with low EDB $\left(15^{\circ}-20^{\circ} \mathrm{C}\right.$, cases E520, E522, and E540), where maximum COP2 was 10\%-50\% high and minimum COP2 was about $10 \%$ lower than the other programs. Additionally, annual average zone humidity ratio was $0.002-0.004 \mathrm{~kg} / \mathrm{kg}$ lower than the other programs.

Identification of these three sets of disagreements led to the following software improvements:

- Inclusion of a subhourly iterative loop for thermal balance calculation within each time step (addressed the E360-E300 disagreements)

- Fixing of an error in the program that corresponded to an amalgamation of air infiltration and outside air mixing (addressed the E320-E300 disagreements).

Additionally, the input for thermal capacitance of wall materials (previously input as polystyrene) was reduced.

The code authors did not disaggregate the effect of each case in their results. The aggregate effect of these changes, however, was to fix the above disagreements with overall effect on annual and peak-hour total consumptions of up to $3.2 \%$ and $4.3 \%$, respectively. 


\subsubsection{CDF/PLR Not Properly Accounted for in Fan Energy Consumptions}

After correction of previous errors, the second iteration of results for cases E500-E545 (fifth iteration for cases E300-E360) indicated low OD fan energy consumption for wet-coil case results E500-E525, as shown in Figure 2-14. This disagreement was not apparent in early results, indicating the presence of compensating errors and the importance of rechecking all results after each iteration of software correction.

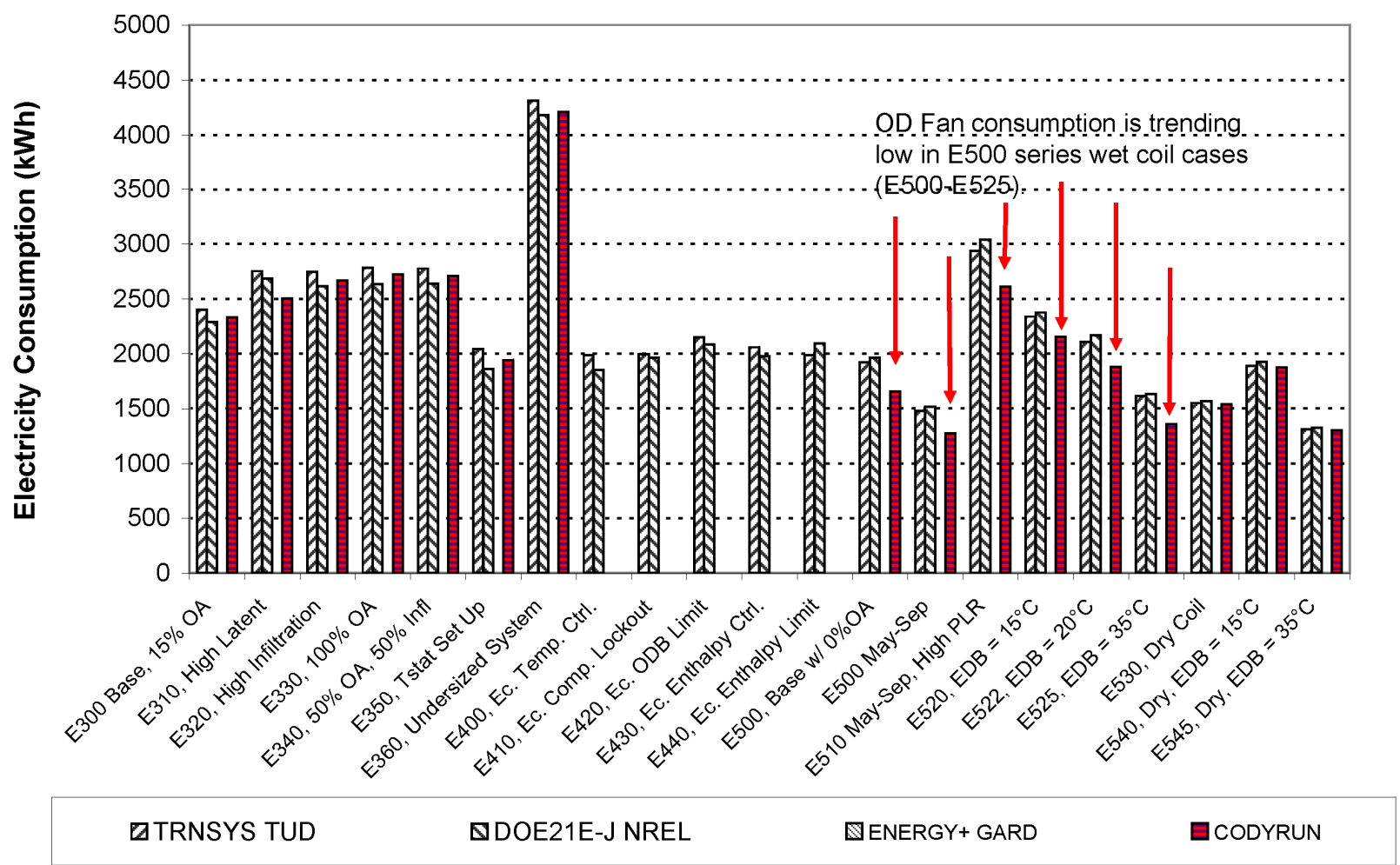

Figure 2-14. OD fan consumption disagreements for Cases E500-E525 from 5th simulation iteration

Based on these disagreements, the code authors discovered that CDF/PLR was not properly accounted for in the calculation of fan energy consumptions. Improvement of the software to eliminate these disagreements resulted in an $8 \%-18 \%$ increase in both ID and OD fan annual energy consumptions $(1 \%-3 \%$ increase in annual total energy consumption) for wet-coil cases E500-E525. The dry-coil cases E530-E545 fan energy consumption results indicated no disagreement in the previous results iteration, and were not affected by this software improvement.

\subsubsection{Neural Network Equipment Performance Calculation Improvement (for Case E360 only: $21 \%$ decrease in peak-hour sensible coil load, $1 \%$ increase in total annual energy consumption)}

After previous errors were corrected, the fifth iteration of results indicated a disagreement for peak-hour sensible coil load results for Case E360, as shown in Figure 2-15. This disagreement was traced to a problem with the accuracy of the neural network algorithm used for calculating performance parameters at temperatures above $33^{\circ} \mathrm{C}$; see CODYRUN modeler report. Improvement of the neural network algorithm gave better agreement for peak sensible coil load results (15\% decrease from previous results), and caused a 
$1.1 \%$ increase in annual total energy consumption for Case E360 (because of simultaneous adjustment to resulting performance parameters at $\mathrm{EDB}<33^{\circ} \mathrm{C}$ ).

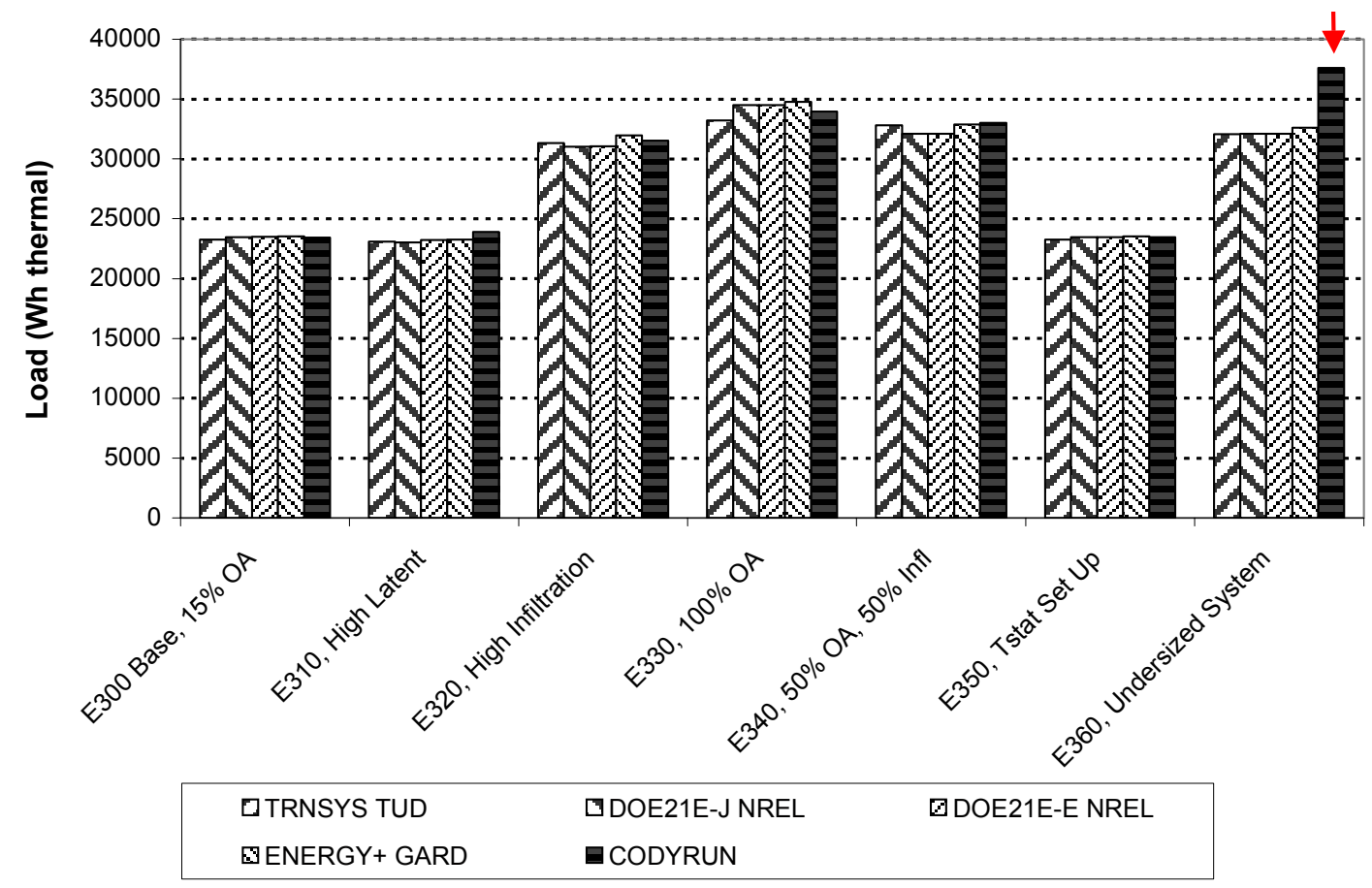

Figure 2-15. Peak-hour sensible coil load disagreement, Case E360

\subsubsection{Algorithm for Iterative Balance of Zone Air Conditions and Equipment Performance Parameters (36\% and $53 \%$ overestimation of peak latent coil loads in cases E520 and E522, respectively; $2 \%$ underestimation and $6.5 \%$ overestimation of peak-hour total consumption loads in cases E520 and E522, respectively)}

The fifth and sixth iterations of results indicated disagreements for peak latent coil loads for cases E520 and E522 (low EDB), as shown in Figure 2-16. Discrepancies in zone air humidity were also noted for these cases. The code authors traced this problem to a basic thermal balance calculation, and wrote a new algorithm for iterative balance of zone air conditions and equipment performance parameters, as documented in their modeler report. Application of this new algorithm resulted in $36 \%$ and $53 \%$ decreases in peak-hour latent coil load results for cases E520 and E522, respectively. This was accompanied by a 2\% increase and 6.5\% decrease in peak-hour total consumption for cases E520 and E522, respectively. The effect on annual total consumption was negligible. CODYRUN now shows better agreement with other simulation results for all results. 


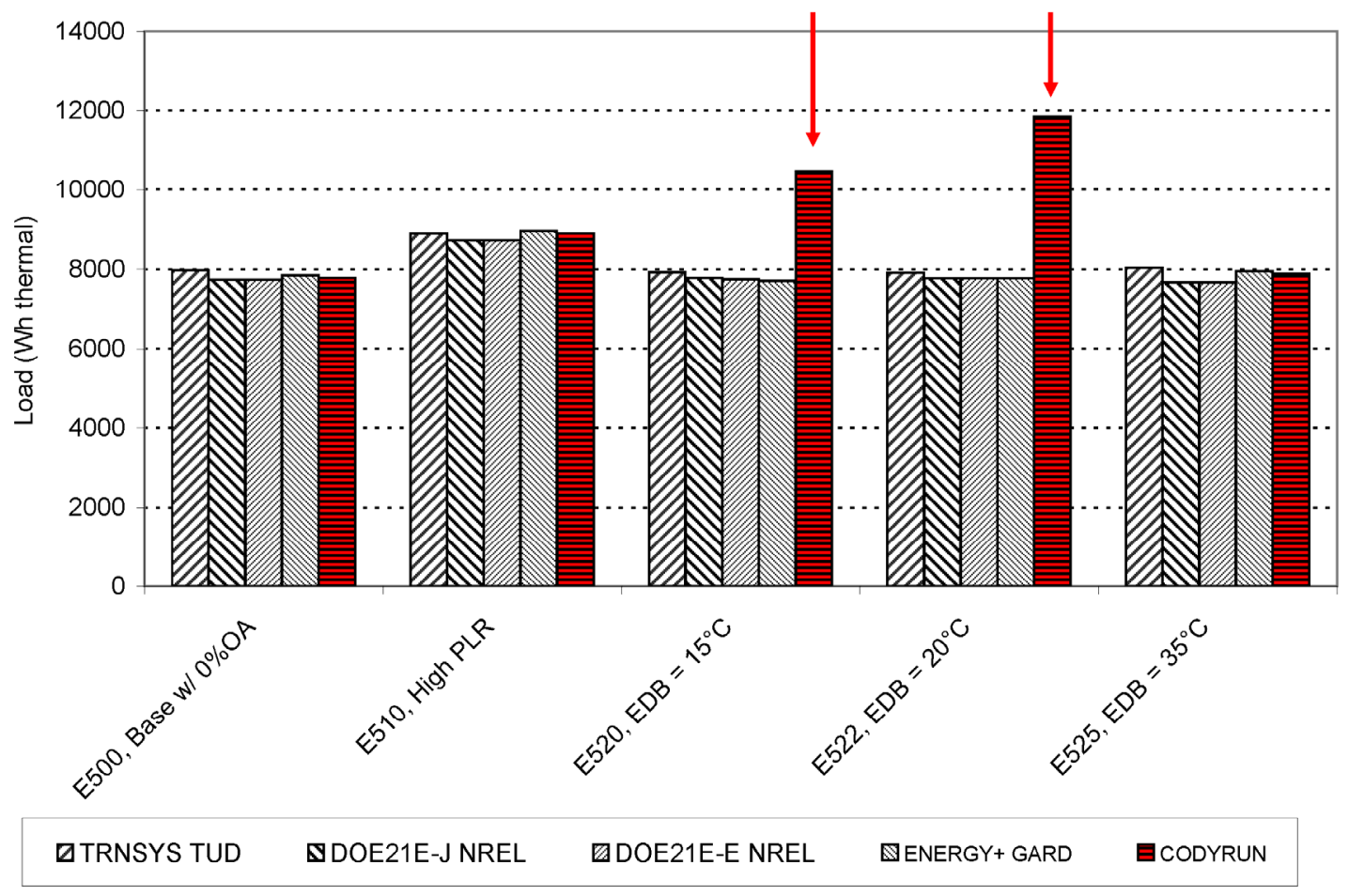

Figure 2-16. Peak-hour latent coil load disagreement, cases E520 and E522.

\subsubsection{Input Error Summary}

The CODYRUN modeler report also documents the correction of one additional input error after the third iteration of results. This was evident from analysis of hourly results and was related to a 1-hour offset of internal gains.

\subsubsection{TRNSYS-TUD with Realistic Controller}

TRNSYS is considered to be the most advanced program that DOE has sponsored for simulating active solar systems. The program was originally written at the University of Wisconsin. Technische Universität Dresden (TUD) acquired a license for the source code and has since developed new source code for TUD's own calculation routines. This new version is designated TRNSYS-TUD, and some new routines developed at TUD were tested for this project. For this project TUD ran TRNSYS-TUD using a realistic controller.

No software errors were found in the simulations. Errors previously discovered and corrected using HVAC BESTEST cases E100-E200 were documented in HVAC BESTEST Volume 1 (Neymark and Judkoff 2002).

\subsubsection{External Post-Processor Error Summary}

Illogical results (shown in Figure 2-17) in the high outside air cases (E320-E340) led to the discovery of an output post-processor error. In these cases consumption results for $\mathrm{E} 340(50 \% \mathrm{OA}$ and $50 \% \mathrm{OA}$ as infiltration) should fall in between those for E320 (100\% OA) and E330 (100\% OA as infiltration). This post-processor error was fixed. 


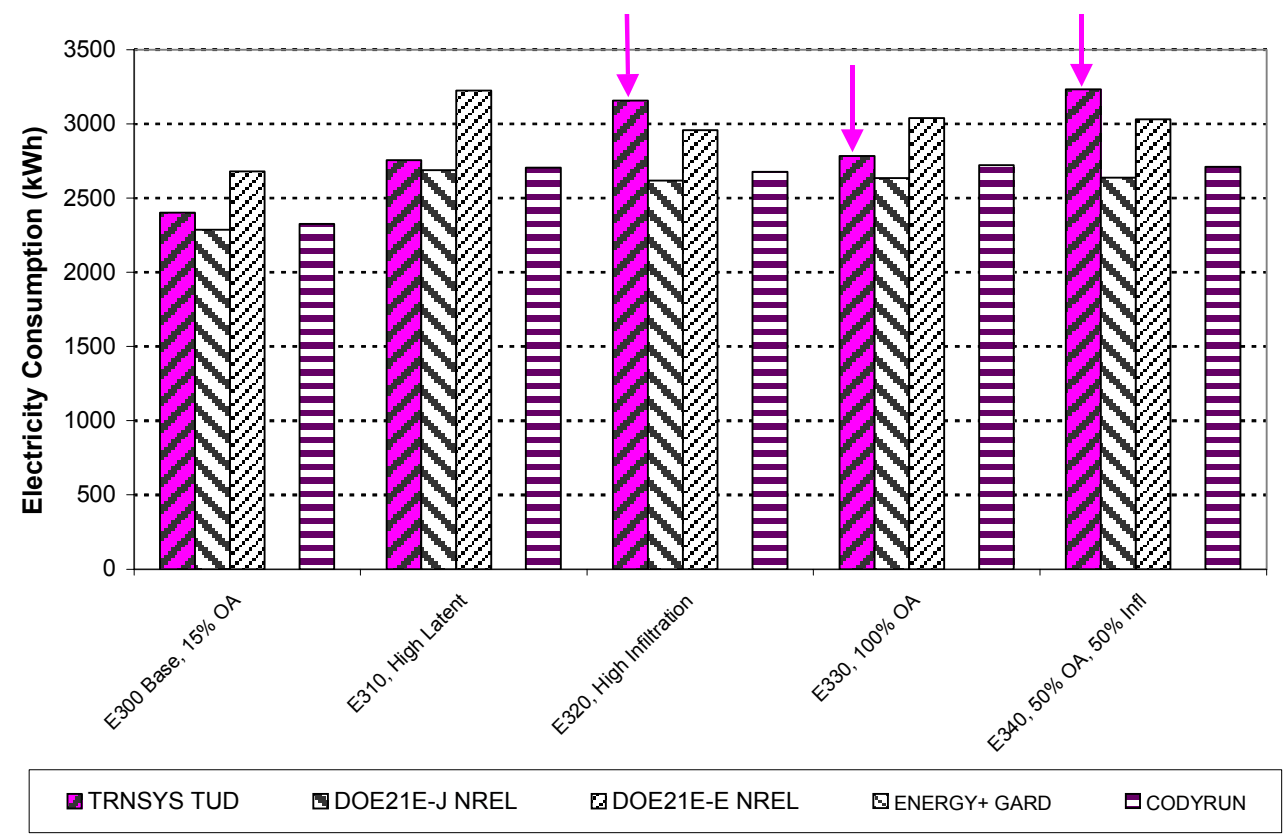

Figure 2-17. Illogical outdoor fan consumption results, post-processor error

\subsubsection{DOE-2.1E ESTSC Version}

Until recently, DOE-2 was the main building energy analysis program supported by DOE; many of its algorithms have been incorporated into DOE's next-generation simulation software, EnergyPlus.

\subsubsection{Bypass Factor f(PLR) Curve, Misleading Documentation (30\%-115\% overestimation of annual latent coil loads resulting in $7 \%-22 \%$ overestimation of total annual consumption for continuous fan operation in cases with typical range of PLR)}

In DOE-2.1E ESTSC version 119, cases E300-E350 and E400-E440 annual latent coil loads were overestimated by $30 \%-115 \%$ (see Figure 2-18), resulting in overestimation of annual total energy consumption of 7\%-22\% (see Figure 2-19). This problem was traced to detailed input for DOE-2's equipment performance curve (COIL-BF-FPLR) that adjusts bypass factor (BF) as a function of PLR. Initially, curve-fit data were specified according to DOE-2's documentation to achieve no variation of bypass factor as a function of PLR, as indicated in the test specification. This caused the disagreements shown in Figures 2-18 and 2-19 for cases with continuously operating air distribution fan and typical ranges of PLR. No related disagreements occurred for the E500 series cases because the BF $=f(P L R)$ adjustment is applied differently in the DOE-2.1E ESTSC version for intermittent (cycling) operation versus for continuous fan operation; for intermittent operation, variation of input for COIL-BF-FPLR has a negligible effect. After reviewing DOE-2's documentation of COIL-BF-FPLR and NREL's input decks, the code authors concluded that, "the documentation for this algorithm is misleading and will lead to incorrect results if a fixed [bypass factor] is applied with a continuously operating fan" (Buhl 2003). Use of DOE-2's default curve for COIL-BF-FPLR gave results with better agreement. 


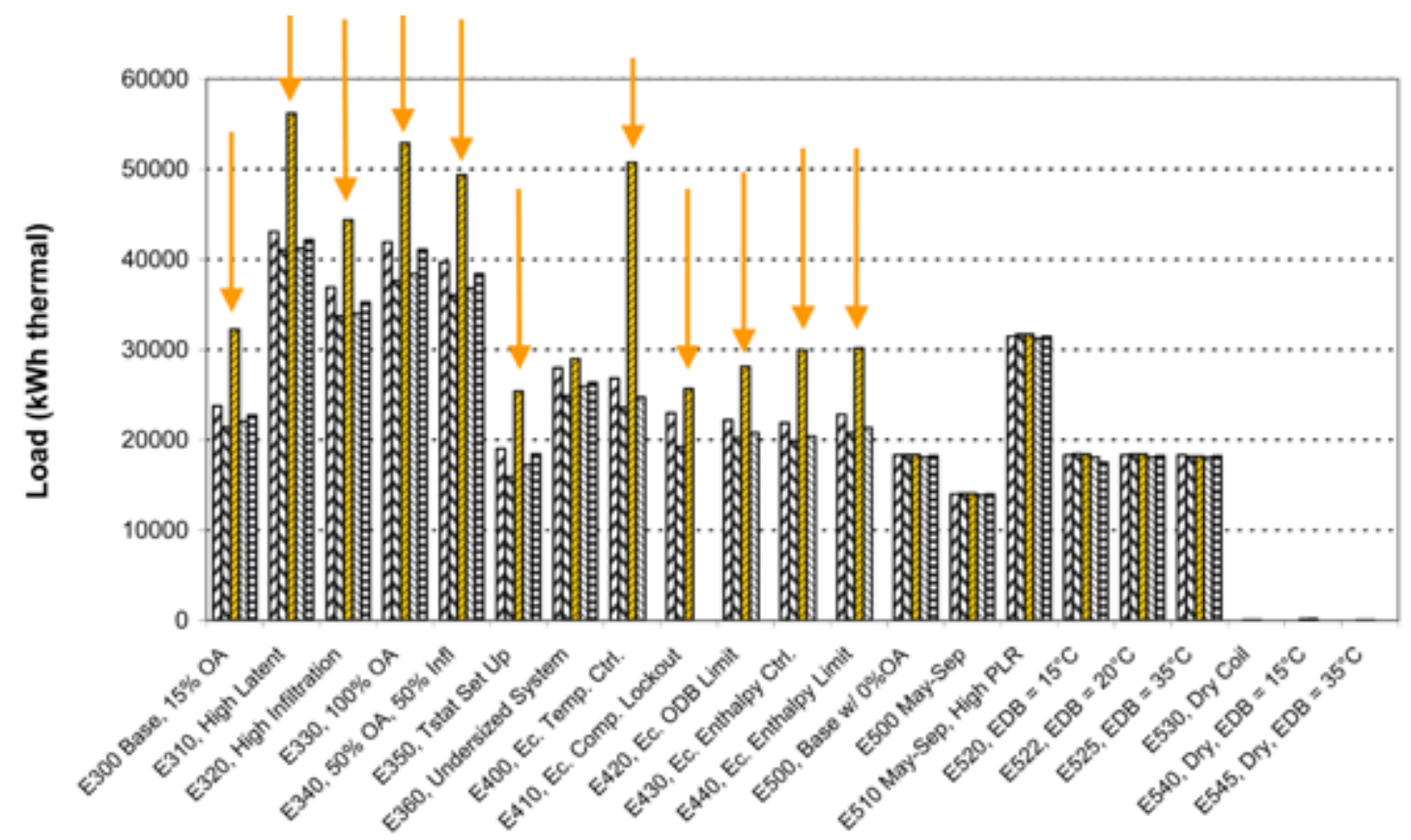

DTRNSYS TUD $\triangle D O E 21 E-J$ NREL $\square D O E 21 E-E N R E L$ QENERGY+GARD ECODYRUN

Figure 2-18. Latent coil load disagreements for DOE-2.1E, ESTSC version 119

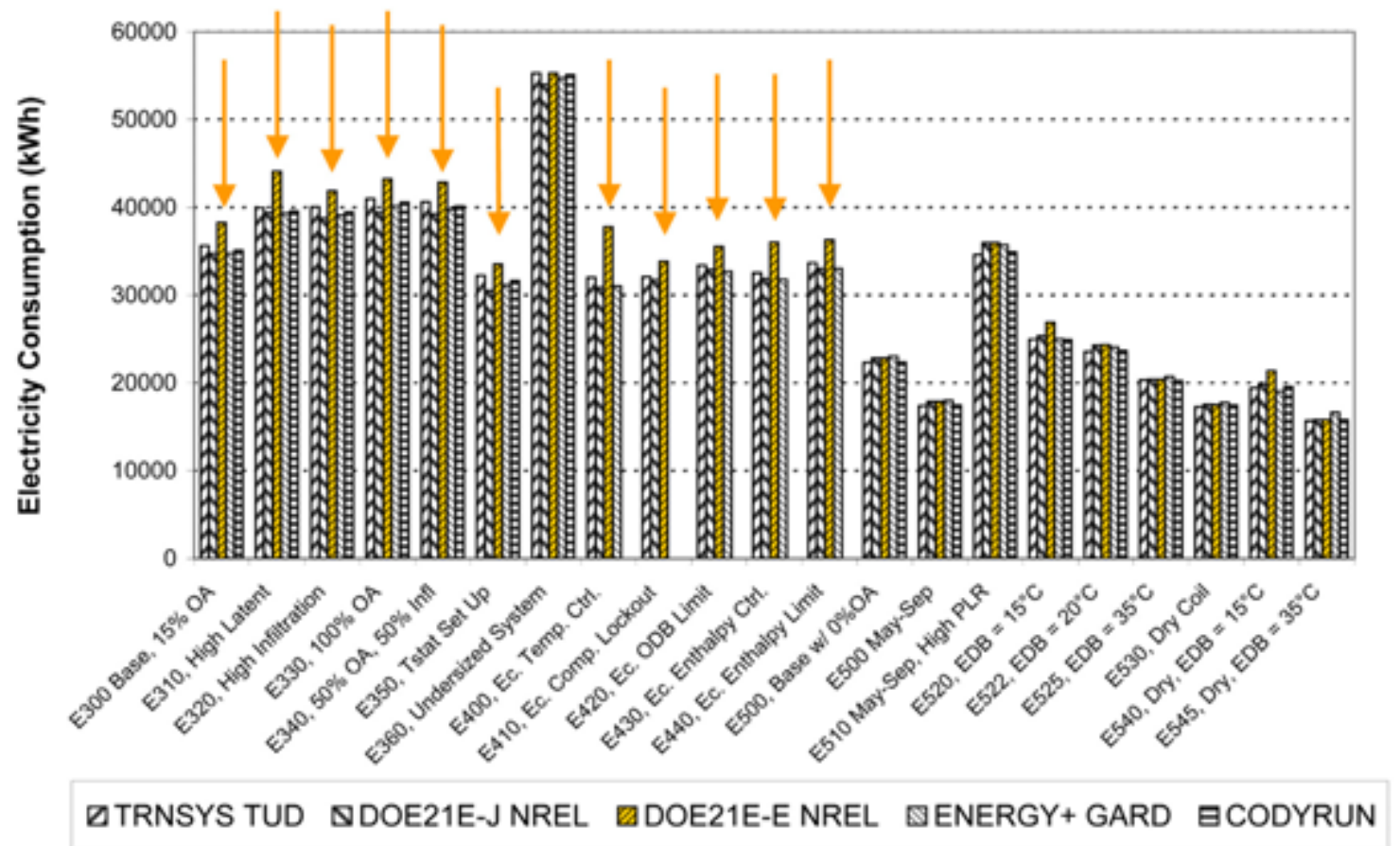

Figure 2-19. Total energy consumption disagreements for DOE-2.1E, ESTSC version 119, cases E300-E350 and E400-E440 


\subsubsection{Hard-Wired Lower Limit of $60^{\circ} \mathrm{F}\left(15.6^{\circ} \mathrm{C}\right)$ on the Coil Entering Wet-Bulb}

Temperature (Low EDB cases E520 and E540 only: 65\%-109\% overestimation of annual indoor fan electricity, 6\%-13\% underestimation of annual condenser fan electricity, and $1 \%-4 \%$ underestimation of annual compressor electricity, resulting in $6 \%-8 \%$ overestimation of annual total electricity consumption)

After applying DOE-2's default curve for COIL-BF-FPLR, further disagreements remained for the indoor fan electricity consumption of cases E520 and E540, as shown in Figure 2-20. Cases E520 and E540 have relatively low entering dry-bulb temperature of $15^{\circ} \mathrm{C}$ for wet- and dry-coil conditions, respectively. Other disagreements for cases E520 and E540 (not shown) also occurred for the outdoor fan electricity consumption and maximum IDB. As discussed in the modeler report (see Appendix II-E), the reason for this difference was a hard-wired lower limit of $60^{\circ} \mathrm{F}\left(15.6^{\circ} \mathrm{C}\right)$ on coil EWB. For cases E520 and E540 only, versus previous results, modification of the EWB lower limit caused 39\%-52\% decrease in indoor fan electricity, $7 \%-15 \%$ increase in outdoor fan electricity, and 1\%-5\% increase in compressor electricity, resulting in a $6 \%-7 \%$ decrease in total energy consumption. All this resulted in better agreement with the other programs (see Part III).

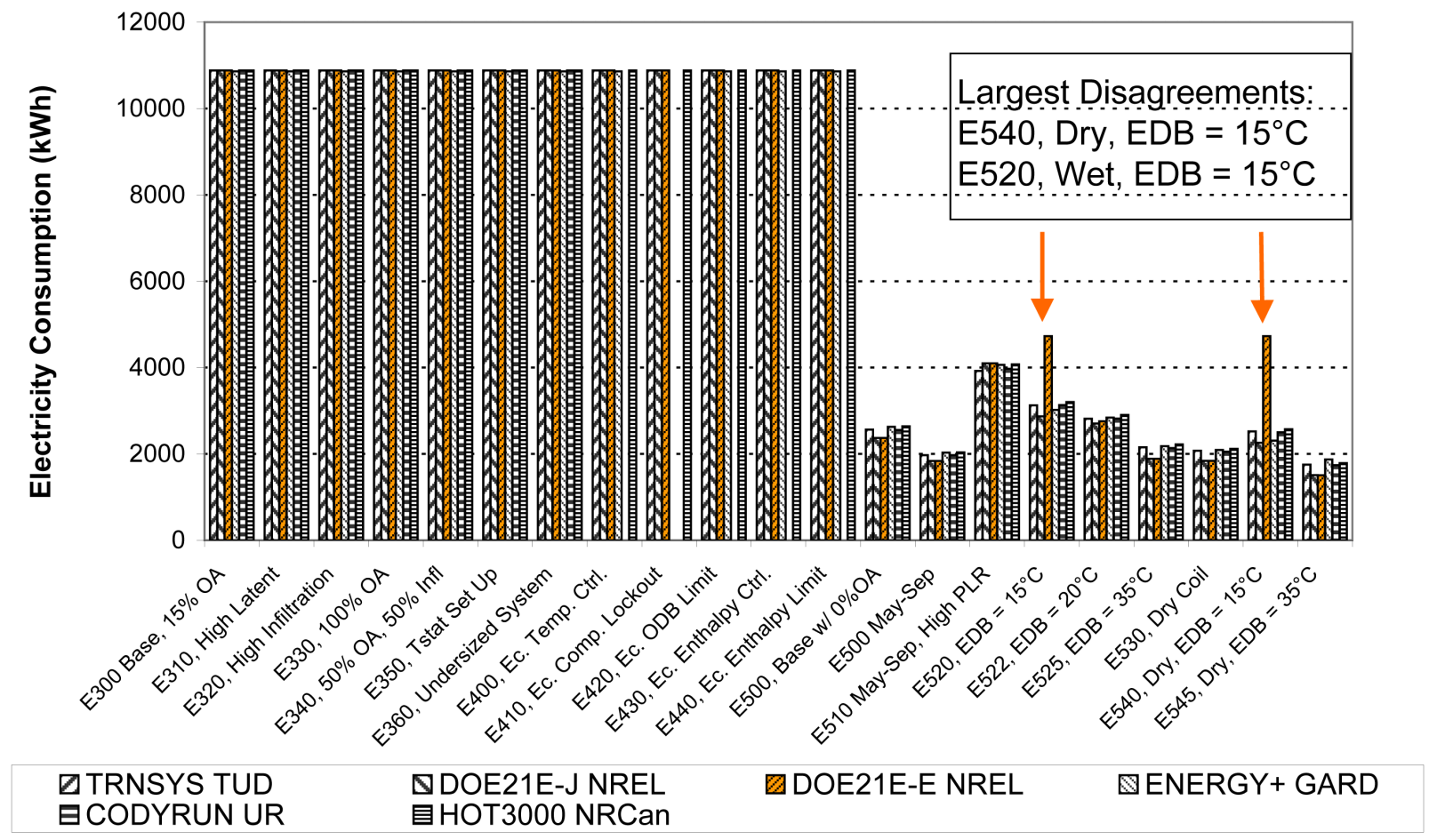

Figure 2-20. Indoor fan electricity consumption disagreements for DOE-2.1E, ESTSC version 119, cases E520 and E540 


\subsubsection{Single-Pass HVAC Calculation with 1-Hour Time Step (20\%-50\% overestimation of peak-hour latent coil loads for cases E320, E330, E340, and E400; $20 \%, 18 \%$, and $80 \%$ overestimation of peak-hour zone humidity ratio for cases E310, E350, and E545, respectively)}

After fixing the low EWB limit problem, there are still some disagreements in DOE-2.1E ESTSC version 120.

A $20 \%-50 \%$ overestimation of peak latent coil loads for cases E320, E330, E340, and E400 is apparent in Figure 2-21. As discussed in the modeler report (see Appendix II-E), the basis of the disagreement is that DOE-2 does a single-pass HVAC calculation with a 1-hour time step. To obtain good annual energy use estimates in this calculation environment and to save execution time, the code authors had previously chosen to use the previous hour's mixed air wet-bulb temperature in DOE-2's performance curve that modifies sensible capacity as a function of EWB and ODB. When the entering humidity ratio changes abruptly between adjacent hours, as occurs because of the scheduling of high rates of infiltration or outside air in cases E320-E340 and because of economizer operation in Case E400, the sensible capacity is misestimated. This leads to a misestimate of minimum supply temperature that ultimately leads to a misestimate of moisture removal. If DOE-2.1E is used for sizing equipment, the current disagreement regarding peak-hour latent coil loads could affect comfort-related equipment selection decisions for buildings in humid climates with high amounts of outside air, natural ventilation, and/or infiltration. There do not appear to be any corresponding disagreements for annual or peak-hour energy consumption estimates.

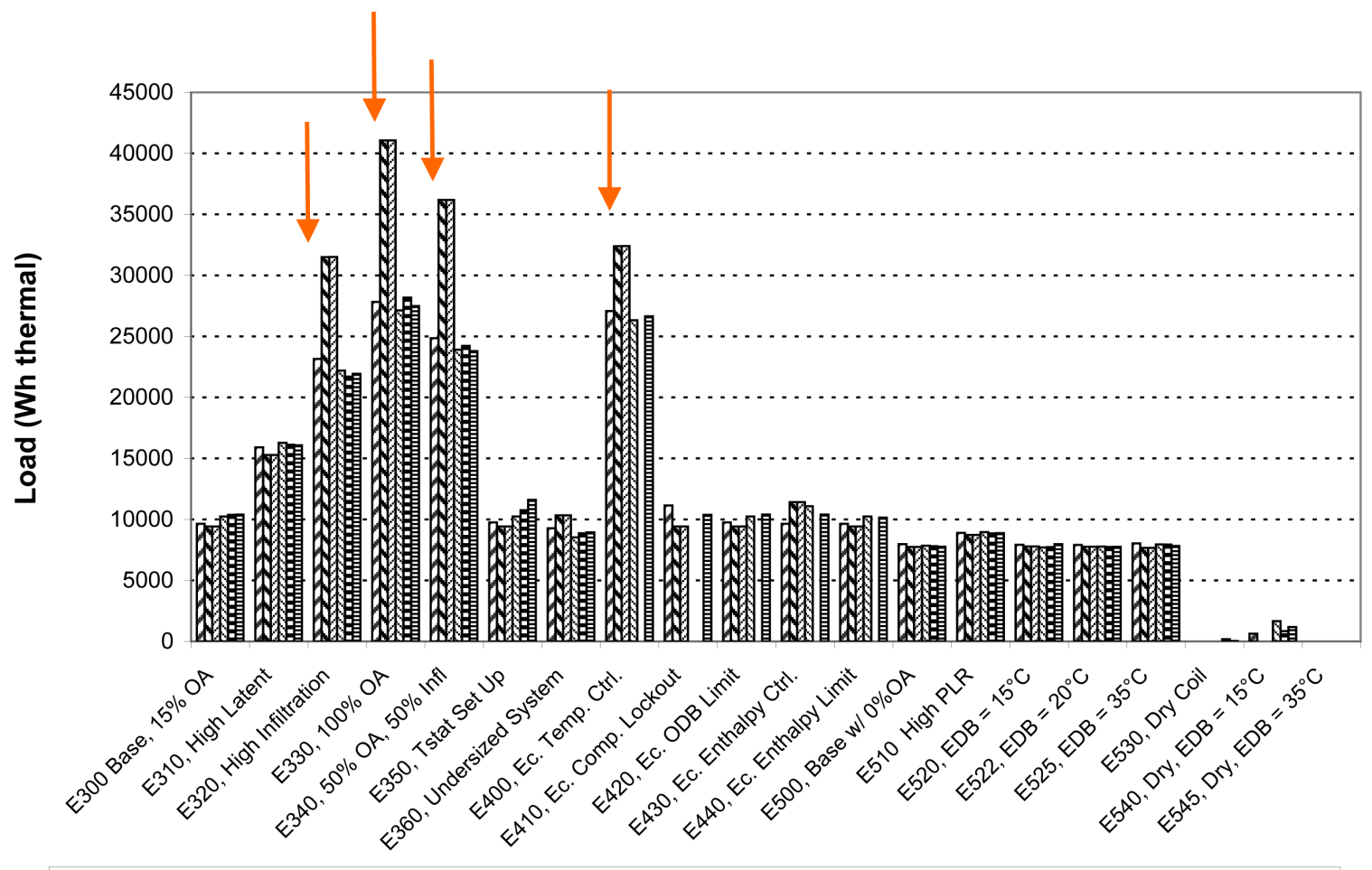

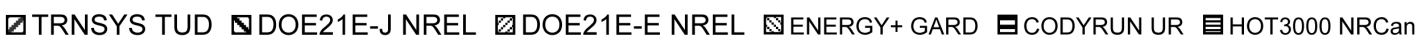

Figure 2-21. Peak-hour latent coil load disagreements for DOE-2.1E, ESTSC version 120, cases E320-E340 and E400 
Another set of remaining disagreements for peak-hour humidity ratio is shown in Figure 2-22. The peakhour zone humidity ratios for cases E310, E350, and E545 are overestimated by $20 \%, 18 \%$, and $80 \%$, respectively. Examination of this disagreement for Case E310 by one of the code authors indicates the following cause for the disagreement. During the hour where the peak humidity ratio is occurring in DOE-2, sensible and latent gains have increased, but the cooling system remains off; for the other programs, the cooling system comes on during that hour. This occurs because during the hour, the average zone temperature is below the cooling set point, and the cooling system remains off for DOE- 2 . Other programs that use smaller time steps, however, can switch the system on during the hour and remove some moisture from the zone. There do not appear to be any corresponding disagreements in annual or peak-hour energy consumption or coil loads, or in annual mean or hourly maximum or minimum zone temperature.

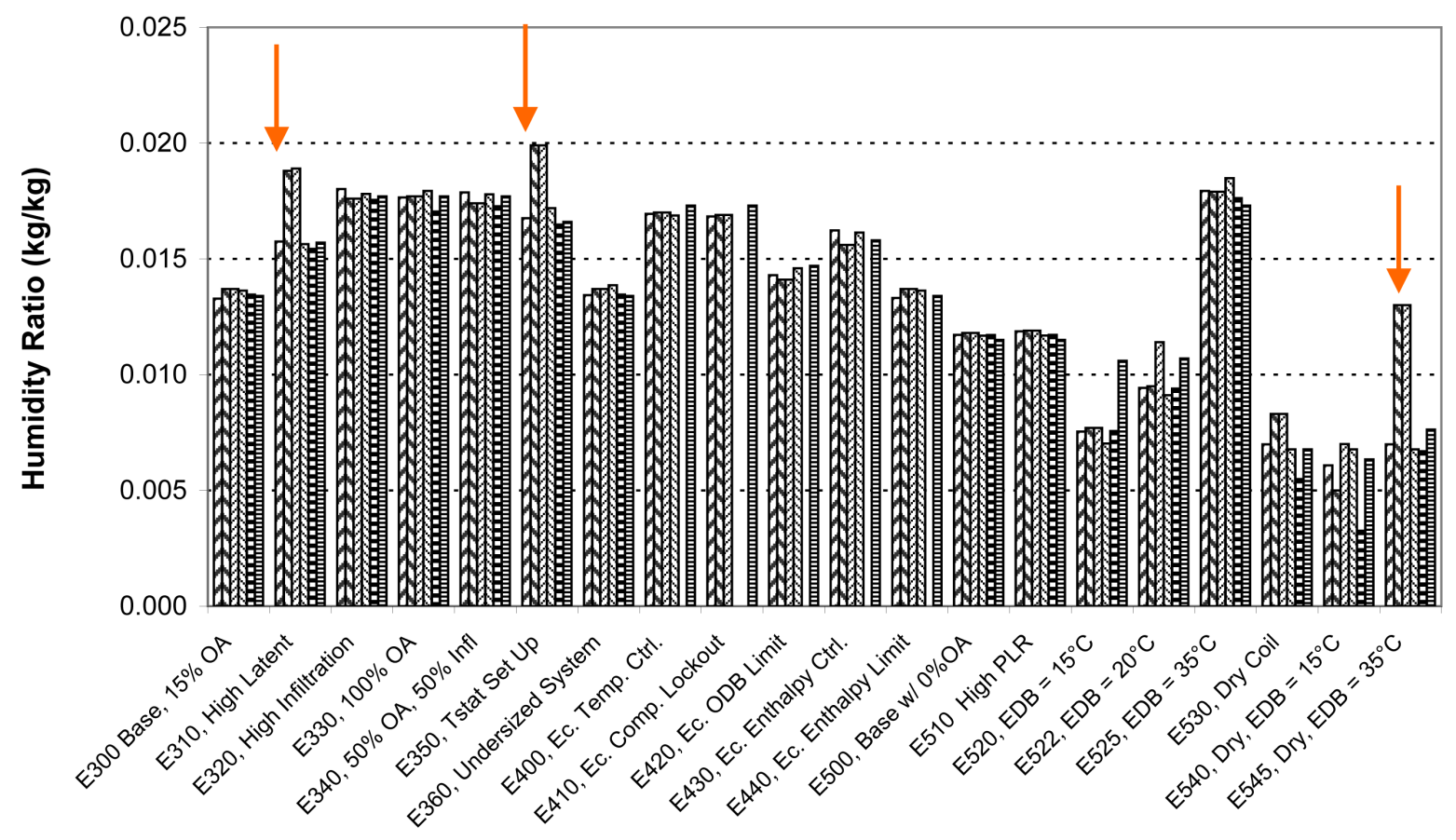

口TRNSYS TUD QDOE21E-J NREL DDOE21E-E NREL GENERGY+GARD ECODYRUN UR 目HOT3000 NRCan

Figure 2-22. Maximum zone humidity ratio disagreements for DOE-2.1E, ESTSC version 120, cases E310, E350, and E545

The disagreements noted in Figures 2-21 and 2-22 would decrease with decreasing time steps, if that were possible in DOE-2 (Buhl 2003). But the authors do not plan any changes to the DOE-2.1E ESTSC version, as it would involve rewriting DOE-2's HVAC calculation, and DOE has already resolved these disagreements in its next-generation software (EnergyPlus). 


\subsubsection{Variation of Zone Humidity Ratio in Dry-Coil Cases at Constant Set Point with Cooling On (10\%-25\% overestimation of humidity ratio in E530)}

Figure 2-23 indicates a variation of zone humidity ratio for dry-coil case E530 that is not present in the other programs. For this case we expect-during the simulation period of April 21 through October 11 (when the cooling system is always on) - that the simulation programs would establish a zone humidity ratio that corresponds to the set point, and that because there are no zonal moisture gains or losses, that humidity ratio would remain fixed. For DOE-2, however, the zone humidity ratio is set to the humidity ratio that would occur assuming $100 \%$ relative humidity air at the coil surface temperature. Because the coil surface temperature varies with the load, so does the zone humidity ratio. The code authors do not plan to make any changes to DOE-2.1E ESTSC version 120 related to this issue. There do not appear to be any corresponding disagreements in specific day energy consumption or coil loads.

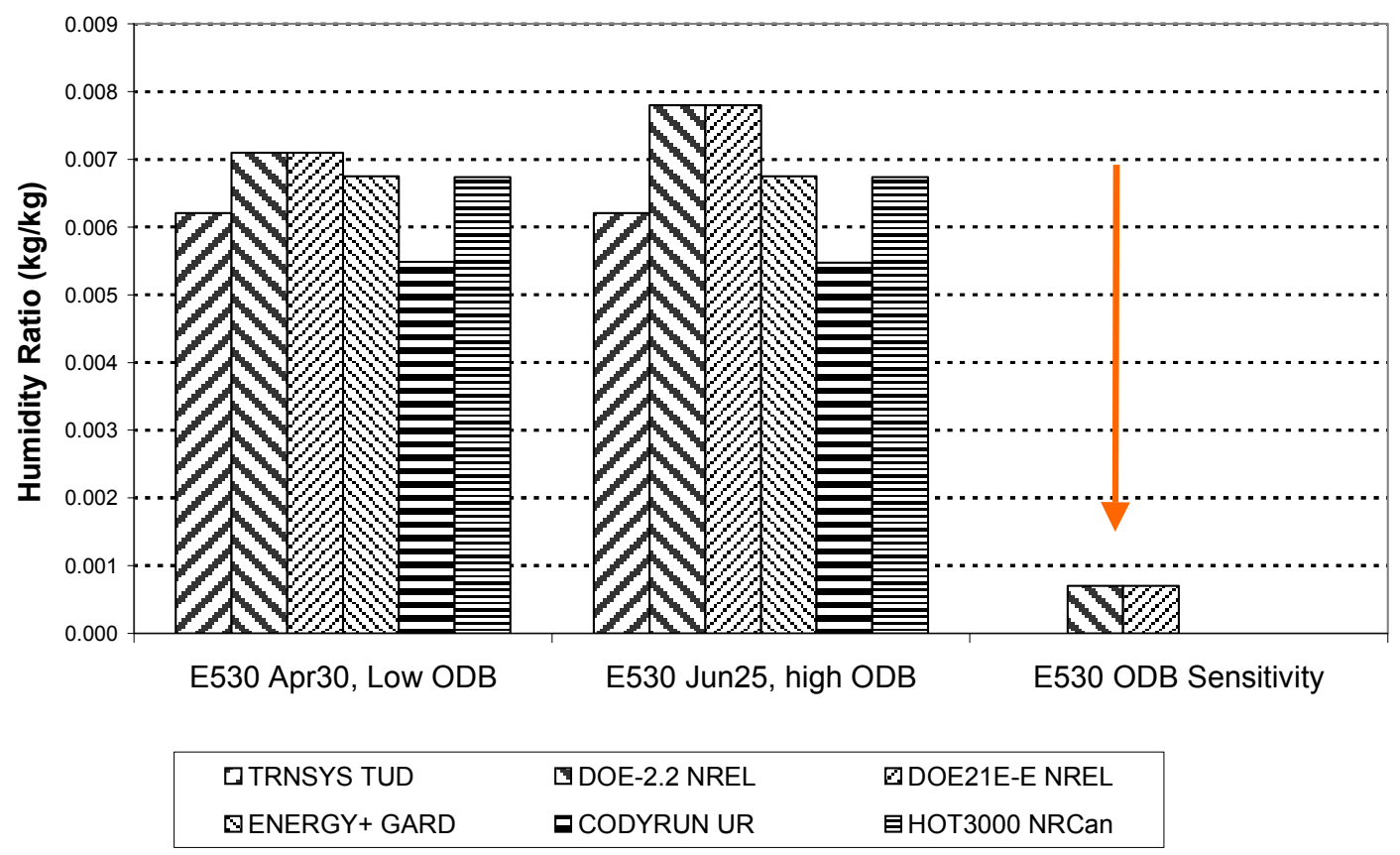

Figure 2-23. Specific day humidity ratio, Case E530 


\subsubsection{HOT3000/ESP-r}

HOT3000 was developed and is maintained by CANMET Energy Technology Centre at Natural Resources Canada. HOT3000 is a modified version of ESP-r (developed and maintained at the University of Strathclyde, Scotland, United Kingdom) that retains ESP-r's modeling approach but includes new models for ground coupling, air infiltration, furnace, unitary space cooling equipment, air- and groundsource heat pumps, domestic hot water, and fuel cells.

2.4.5.1 Outside Air Modeling (4\% underestimation of total consumption, 5\% underestimation of sensible coil load, and $9 \%$ underestimation of latent coil load in Case E330; 0.3\% underestimation of total consumption in Case E300)

After early input errors were corrected, the initial results for HOT3000 total consumption sensitivities disagreed for all comparisons involving Case E330, as shown in Figure 2-24. These disagreements were accompanied by observed disagreements in sensible cooling load sensitivities (see Figure 2-25) and similar latent cooling load sensitivity disagreements (not shown). The code authors traced the disagreements to modeling the sensible effect of outside air on the space load in a manner similar to modeling a sensible internal gain/loss from lights or another source (see modeler report, Appendix II-D). This problem has been fixed, and the revised software now models the effect of outdoor air on the space load the same as infiltration air; effects of outside air on resulting coil performance are modeled separately. This improvement gives a better account of the effect of outdoor air on the space load, and gives better agreement with the other simulation programs.

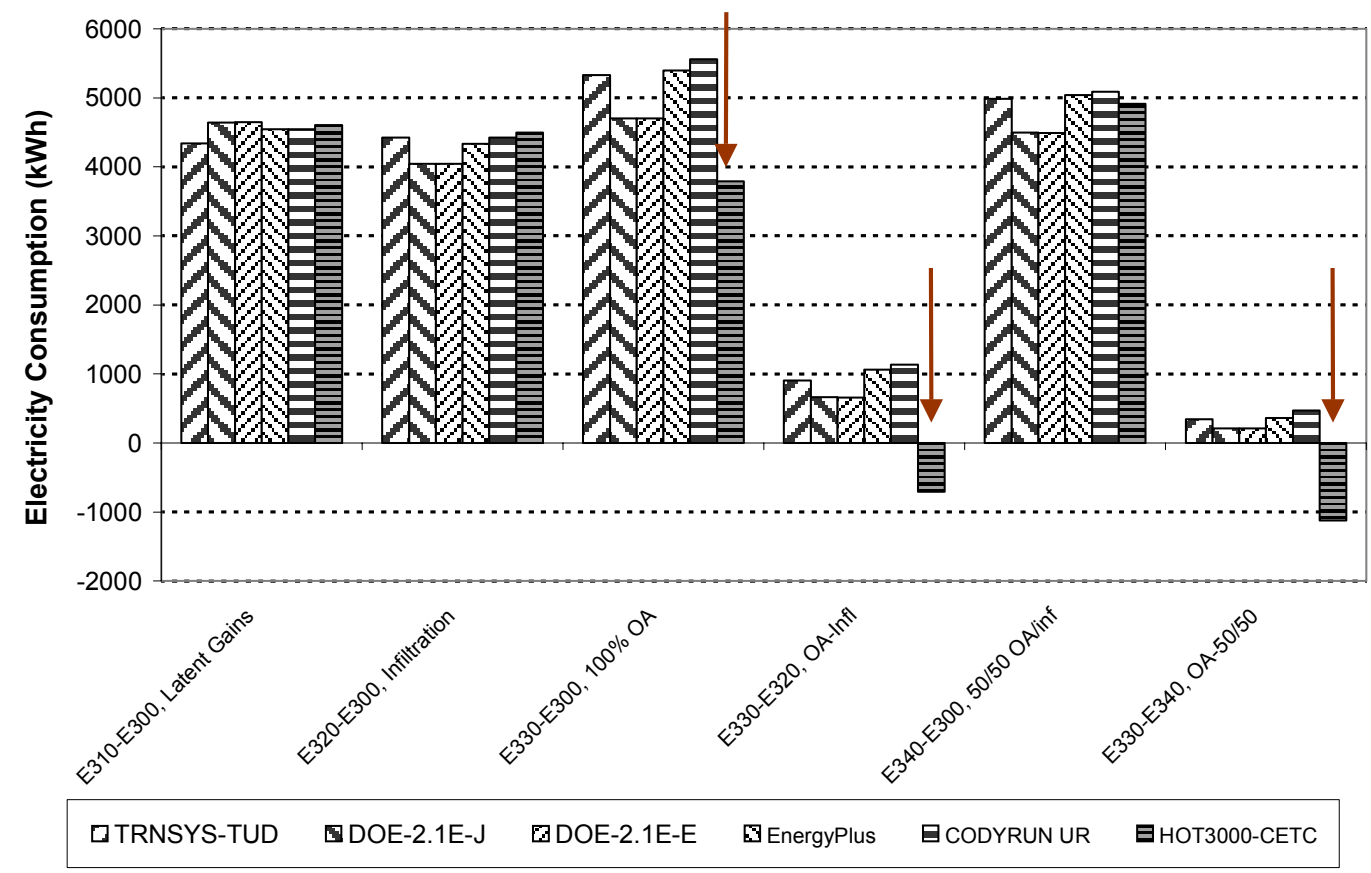

Figure 2-24. Total space cooling electricity consumption sensitivity disagreements for HOT3000, cases E330-E300, E330-E320, and E330-E340 


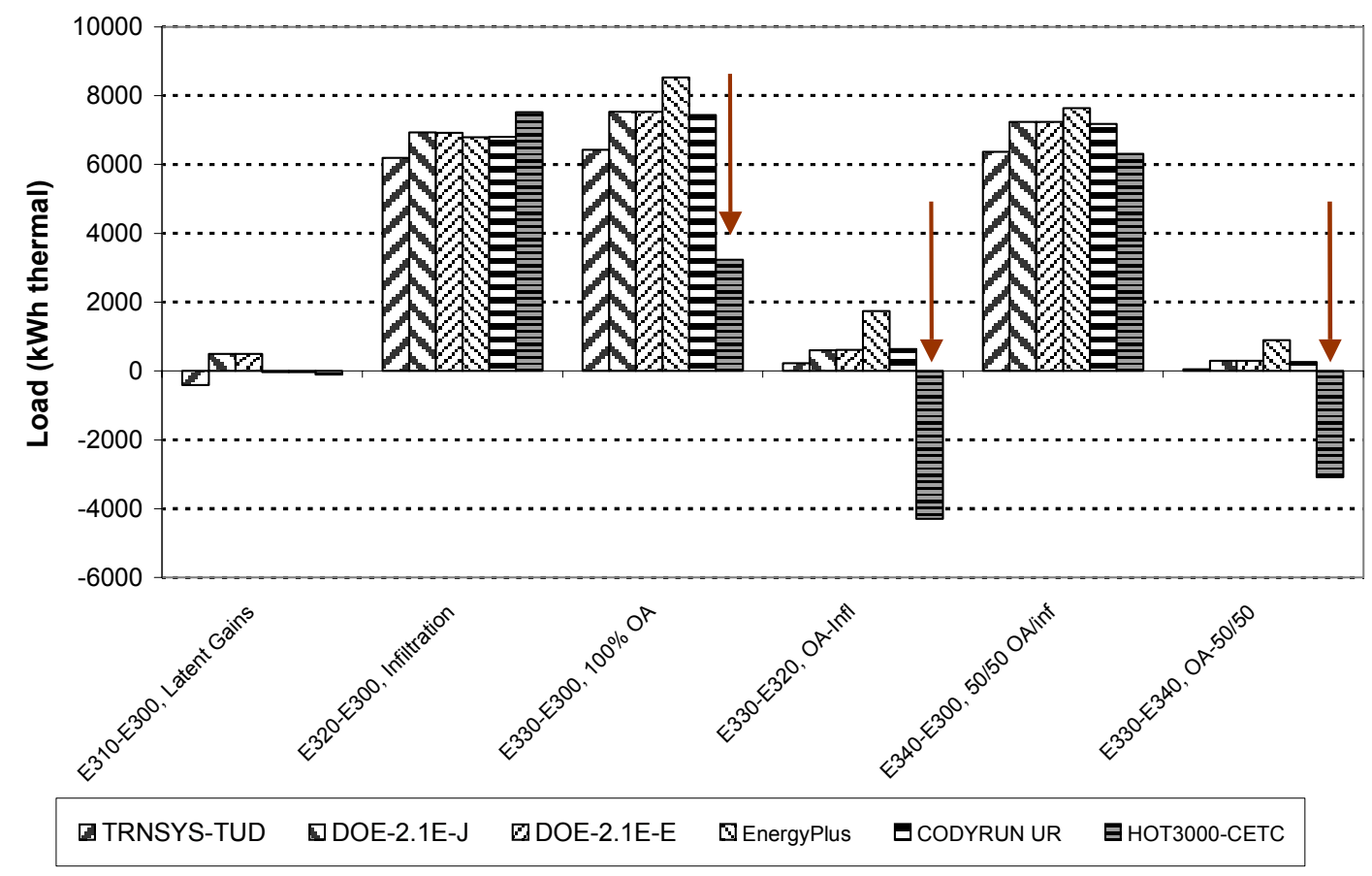

Figure 2-25. Total sensible cooling load sensitivity disagreements for HOT3000, cases E330-E300, E330-E320, and E330-E340

\subsubsection{Does Not Calculate Loads and Energy Use within the Same Time Step (Likely $3 \%$ underestimation of peak-hour total consumption for cases E310 and E520; code authors could not complete software improvement in time for publication of this report)}

After fixing the previous problem related to outside air modeling, a few disagreements remained related to some of the peak consumption, load, and zone condition results. The peak-hour total consumption disagreements for cases E310 and E520 are illustrated in Figure 2-26. If HOT3000 is used for estimating utility peak demand charges, the current disagreement regarding peak-hour electricity consumption could affect energy-cost-related equipment selection decisions for buildings with high latent loads. There do not appear to be any corresponding disagreements in annual total consumption, or in annual or peak-hour coil loads.

As shown in Table 2-4, the peak-hour consumptions for economizer cases E400 and E440 did not match that for E300. Those peak-hour results should match E300 because high-temperature outside air conditions that cause the peak load also cause the outside air dampers to be at the minimum setting (15\% $\mathrm{OA}$ as in E300) during peak load hours; this is evident in the results for the other programs (see Part III). There do not appear to be any corresponding disagreements in annual or peak-hour total consumption or coil loads, or in annual mean or hourly maximum or minimum zone temperature or humidity. Other disagreements for zone temperature and humidity ratio extremes for some of the E500 series cases (not shown) were also observed. Except for the remaining peak-hour total consumption disagreement previously described for Case E520, there appear to be no corresponding disagreements in annual or peak-hour total consumption or coil loads. 
As noted in the modeler report (see Appendix II-D), the code authors have determined that the likely cause of these disagreements is related to the software not iteratively calculating building loads and system operation within the same time step. The modeler report notes that for a given time step, system operating parameters are based on zone conditions determined during the previous time step. The code authors plan to revise HOT3000 so that loads and systems calculations are performed iteratively within the same time step. Because of unavoidable delays in getting started with their field trials, the code authors were unable to complete this software revision in time for final publication of this report.
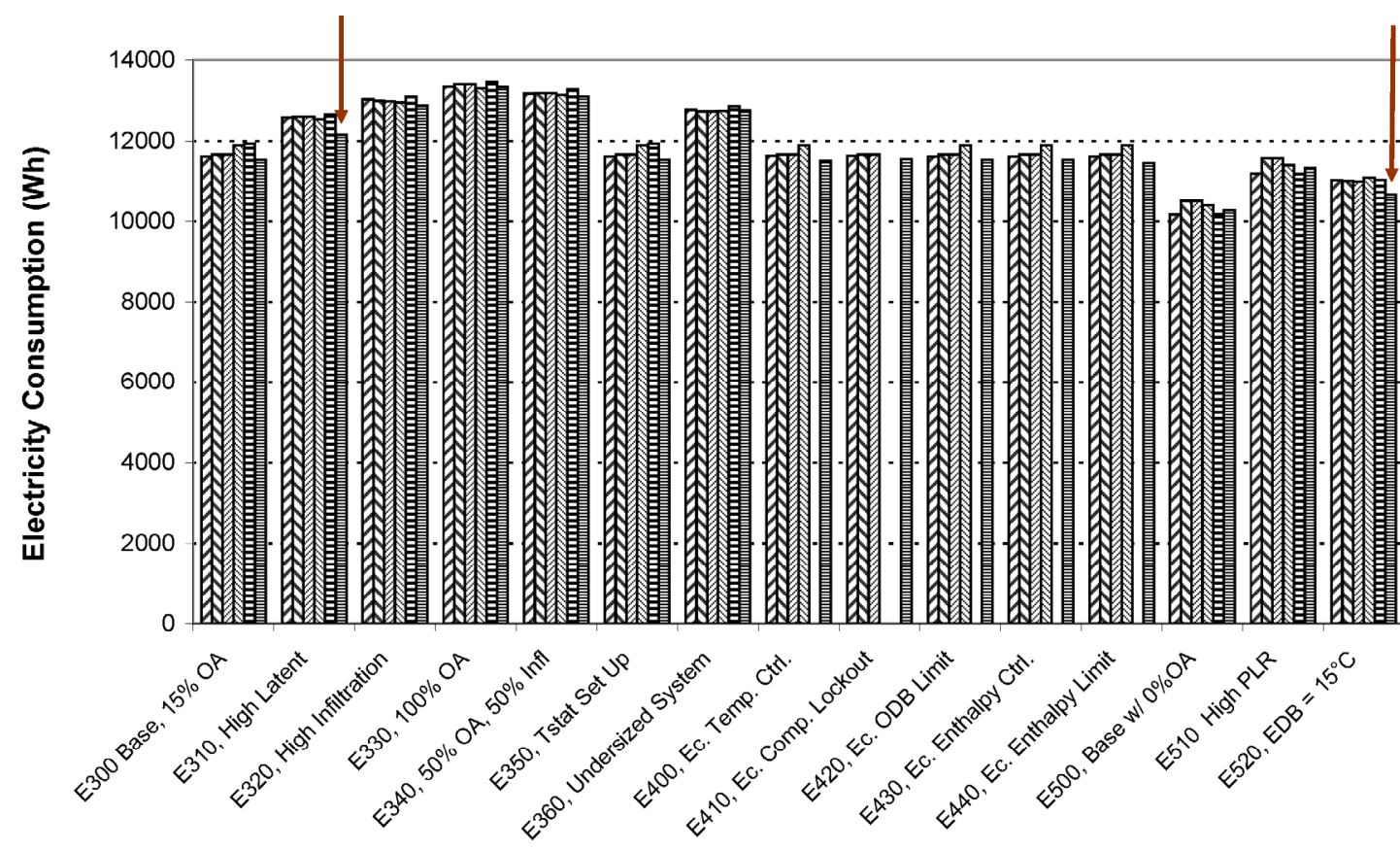

UTRNSYS TUD \&DOE21E-J NREL QDOE21E-E NREL QENERGY+ GARD 目CODYRUN UR 目HOT3000 NRCan

Figure 2-26. Peak-hour total electricity consumption disagreements for HOT3000, cases E310 and E520

Table 2-4. Economizer Peak Consumption Disagreements for HOT3000, Cases E400 and E440

\begin{tabular}{|l|l|l|l|}
\hline Case & Peak Consumption (Wh) & Date & Hour \\
\hline E300 & 11,548 & Jul. 20 & 15 \\
\hline E400 & 11,519 & Jul. 20 & 15 \\
\hline E410 & 11,549 & Jul. 20 & 15 \\
\hline E420 & 11,548 & Jul. 20 & 15 \\
\hline E430 & 11,548 & Jul. 20 & 15 \\
\hline E440 & 11,461 & Aug. 16 & 16 \\
\hline
\end{tabular}




\subsubsection{DOE-2.2}

DOE-2.2 was developed by Lawrence Berkeley National Laboratory (LBNL) and James J. Hirsch \& Associates, and is distributed by James J. Hirsch \& Associates. DOE-2.2 is based on DOE-2.1E, which was developed by LBNL with the assistance of James J. Hirsch \& Associates.

\subsubsection{Incorrect Entering Wet-Bulb Temperature Used for Estimating Capacity and Supply Temperature (50\%, $20 \%$, and $20 \%$ overestimation of peak-hour latent coil loads in cases E330, E340, and E400, respectively; $1.0 \%$ effect on annual energy consumption in Case E330)}

Figure 2-27 indicates approximately $20 \%-50 \%$ overestimation of peak-hour latent coil loads for DOE2.2 NT41n for cases E320-E340 and E400 versus the other programs (except the DOE-2.1E ESTSC version). Based on these results one of the code authors found an incorrect line of logic in DOE-2.2. This logic caused DOE-2.2 to use the previous-hour entering wet-bulb temperature for estimating current-hour system capacity and supply temperature, without correcting for current-hour conditions. The code author noted that this problem would only affect hours of simulation where both the internal and external conditions (load, dry-bulb temperature, and humidity) change abruptly during 2 consecutive hours when the system fans are operating (Hirsch 2003). Correction of this error in an updated version of DOE-2.2 (DOE-2.2 NT42j) caused 35\%, 16\%, and 21\% reductions of peak-hour latent coil loads in cases E330, E340, and E400, respectively; these cases have high continuous or controlled high outside-air flows. Other effects of this improvement are noted in Table 2-5. There was negligible effect on results for Case E320, which has zero outside air but high infiltration airflow.

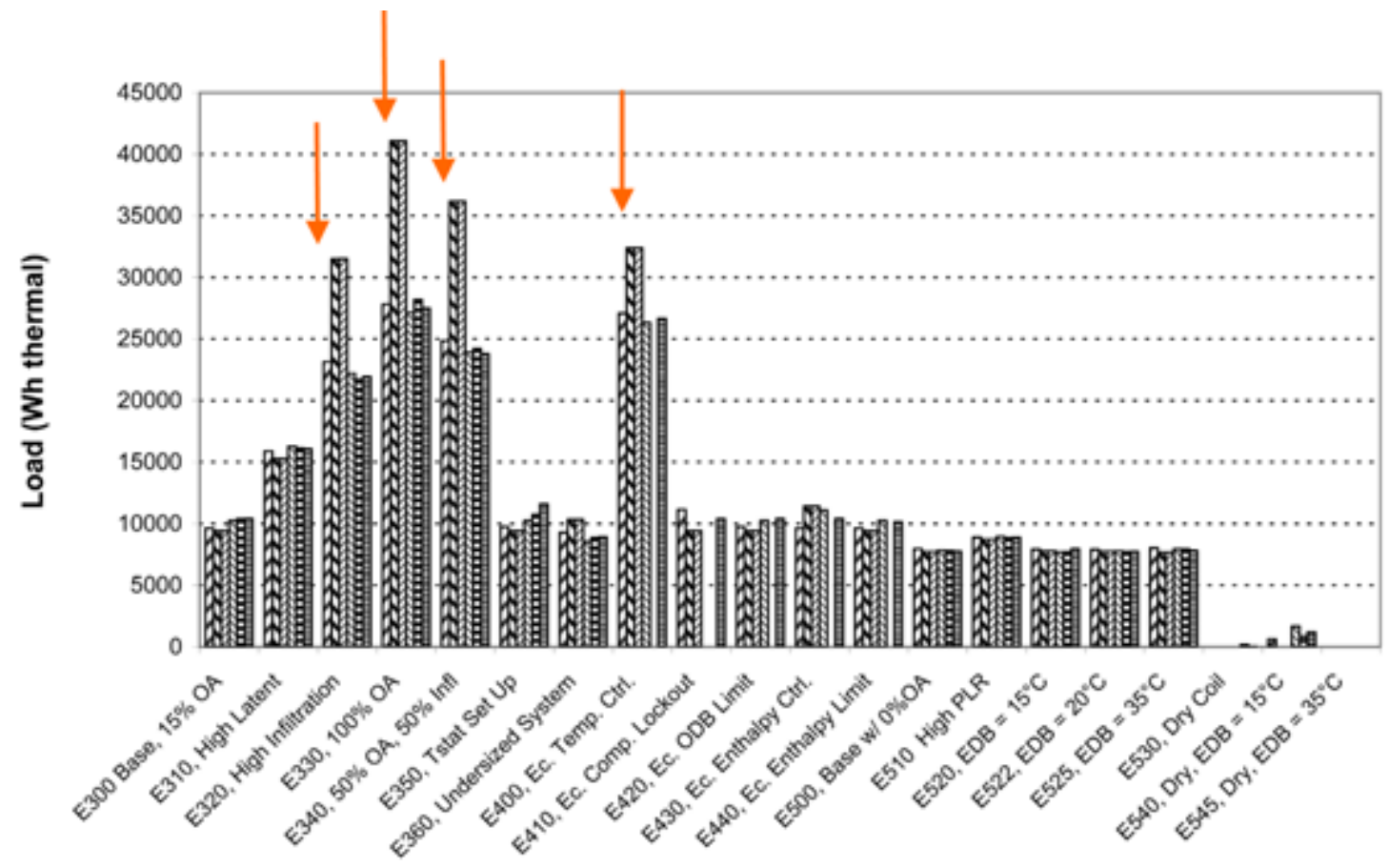

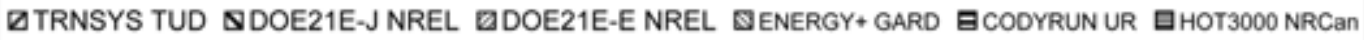

Figure 2-27. DOE-2.2 NT41n, peak-hour latent coil load disagreements, cases E320, E330, E340, and E400 
Table 2-5. Effects of Improvement to DOE-2.2 Regarding Calculation of Entering Wet-Bulb Temperature for Estimating System Capacity and Supply Air Temperature

\begin{tabular}{|l||c|c||c|c||c||}
\hline \multicolumn{1}{|c||}{ Version } & \multicolumn{2}{c||}{ NT41n } & \multicolumn{2}{c||}{ NT42j } & Date \\
\cline { 1 - 5 } Output & Value & $\begin{array}{c}\text { Date } \\
(\mathrm{mm} / \mathrm{dd} / \mathrm{hh})\end{array}$ & Value & $\begin{array}{c}\text { (mm/dd/hh) } \\
\text { Change }\end{array}$ \\
\hline \hline Peak-hour latent coil load $(\mathrm{kW})$ & 41.065 & $10 / 02 / 09$ & 26.491 & $09 / 18 / 15$ & $35 \%$ \\
\hline Peak-hour sensible coil load $(\mathrm{kW})$ & 34.490 & $06 / 14 / 15$ & 33.410 & $06 / 14 / 14$ & $3 \%$ \\
\hline Peak-hour total consumption $(\mathrm{kW})$ & 13.317 & $07 / 20 / 15$ & 13.212 & $07 / 20 / 15$ & $1 \%$ \\
\hline Annual total consumption $(\mathrm{kWh})$ & 39.315 & --- & 39.708 & --- & $1 \%$ \\
\hline
\end{tabular}

\subsubsection{Remaining Disagreements}

Figure 2-28 indicates approximately $40 \%$ and $25 \%$ overestimation of peak-hour latent coil loads for DOE-2.2 NT42j for cases E320 and E340, respectively, versus the other programs (except the DOE-2.1E ESTSC version). These disagreements occur during the same hour (October 2, hour 9) as disagreements described in Figure 2-27, meaning that a similar problem may be occurring here related to calculation of EWB with high infiltration airflow, as was previously found for calculation of EWB with high OA flow as described in Section 2.4.6.1.

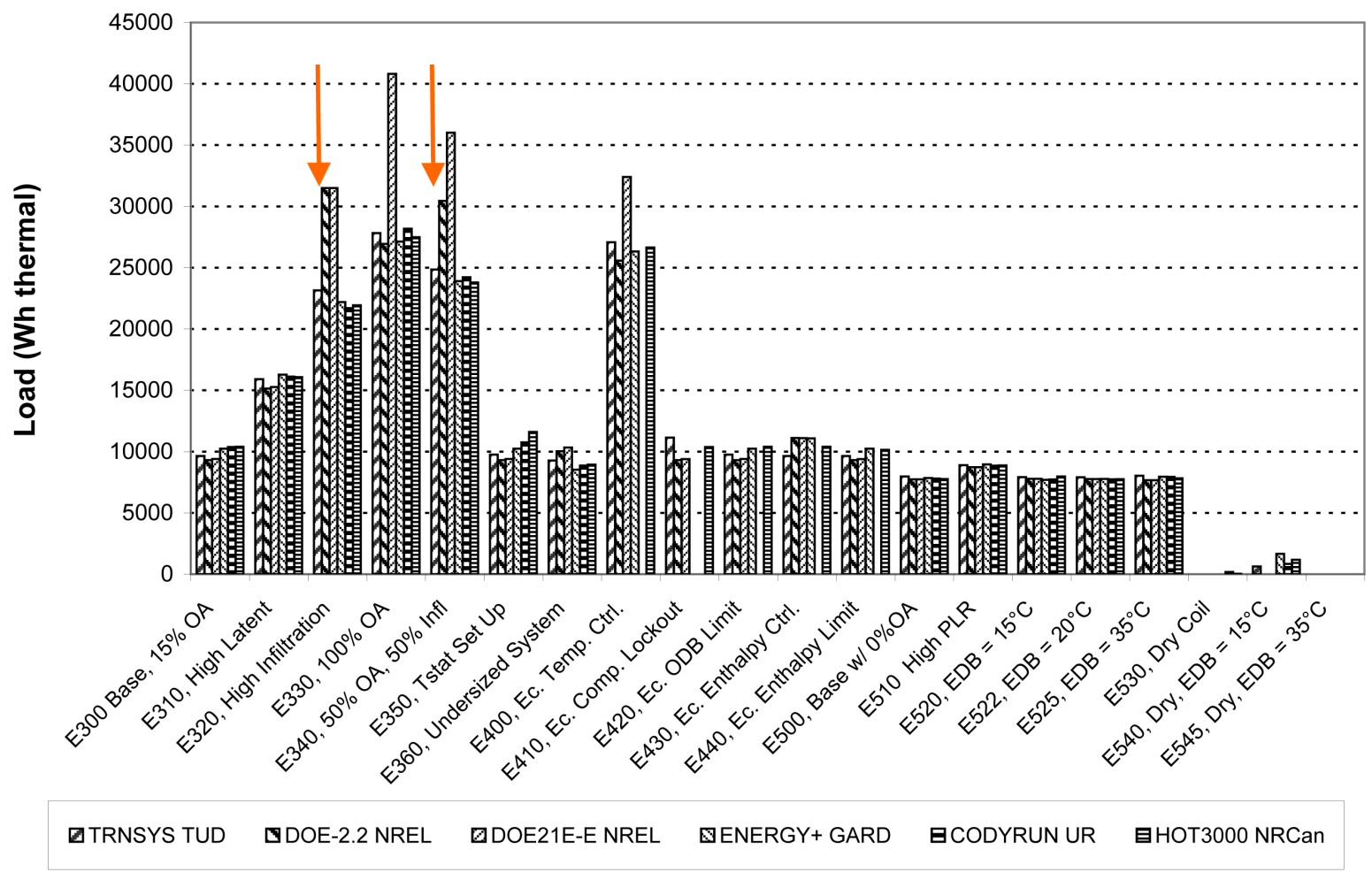

Figure 2-28. DOE-2.2NT42j, peak-hour latent coil load disagreements, cases E320 and E340 
If DOE-2.2 is used for sizing equipment, the current disagreement regarding peak-hour latent coil loads could affect related equipment-selection decisions for buildings in humid climates with high amounts of infiltration or zone-based natural ventilation. Based on Table 2-5, the corresponding disagreements for annual and peak-hour energy consumption estimates may be roughly $1 \%$.

Figure 2-29 indicates up to approximately $75 \%$ overestimation of maximum hour COP2 in the E500 series (zero outside air) wet-coil cases, as well as approximately $25 \%$ and $10 \%$ disagreements for cases E320 and E340, respectively. There appear to be no corresponding disagreements in annual or peak-hour energy consumption or coil loads, or in annual mean or hourly maximum or minimum zone temperature or zone humidity. Figure 2-30 indicates approximately $20 \%, 20 \%$, and $90 \%$ overestimation of maximum hour zone humidity ratio for cases E310, E350, and E545, respectively. There do not appear to be any corresponding disagreements in annual or peak-hour energy consumption or coil loads, or in annual mean or hourly maximum or minimum zone temperature or zone humidity. Additionally, the apparently minor disagreement regarding variation of specific day zone humidity ratio in dry-coil cases at constant set point with cooling on (10\%-25\% overestimation of humidity ratio in E530) - described for the DOE2.1E ESTSC version (see Section 2.4.4.4) - also occurred for DOE-2.2. Based on the current results sets, the code authors are planning to examine remaining disagreements and revise their software if necessary, but were not able to address the remaining disagreements in time for publication of this report.

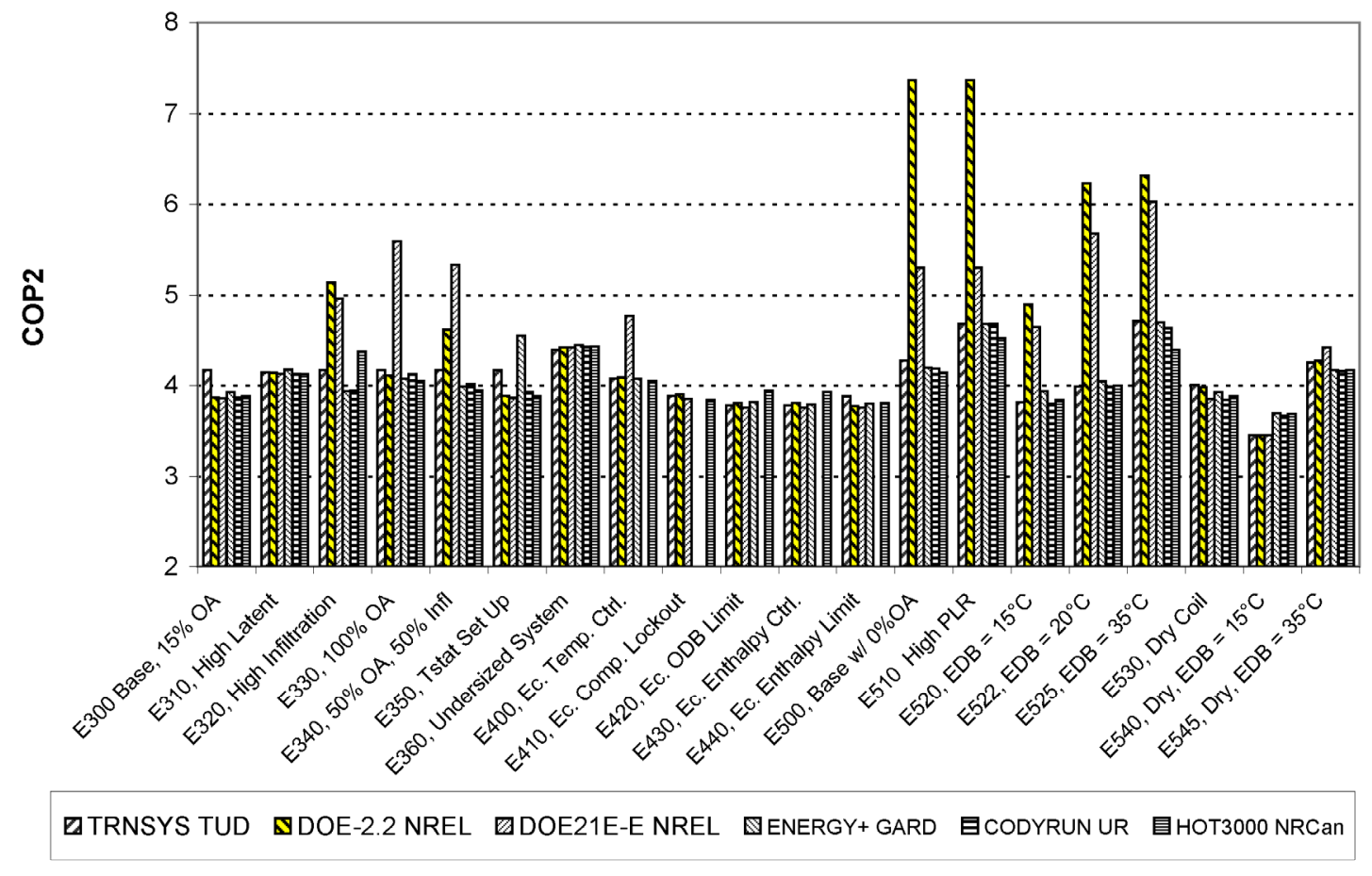

Figure 2-29. DOE-2.2NT42j, maximum COP2 disagreements, cases E320, E340, and E500 series 


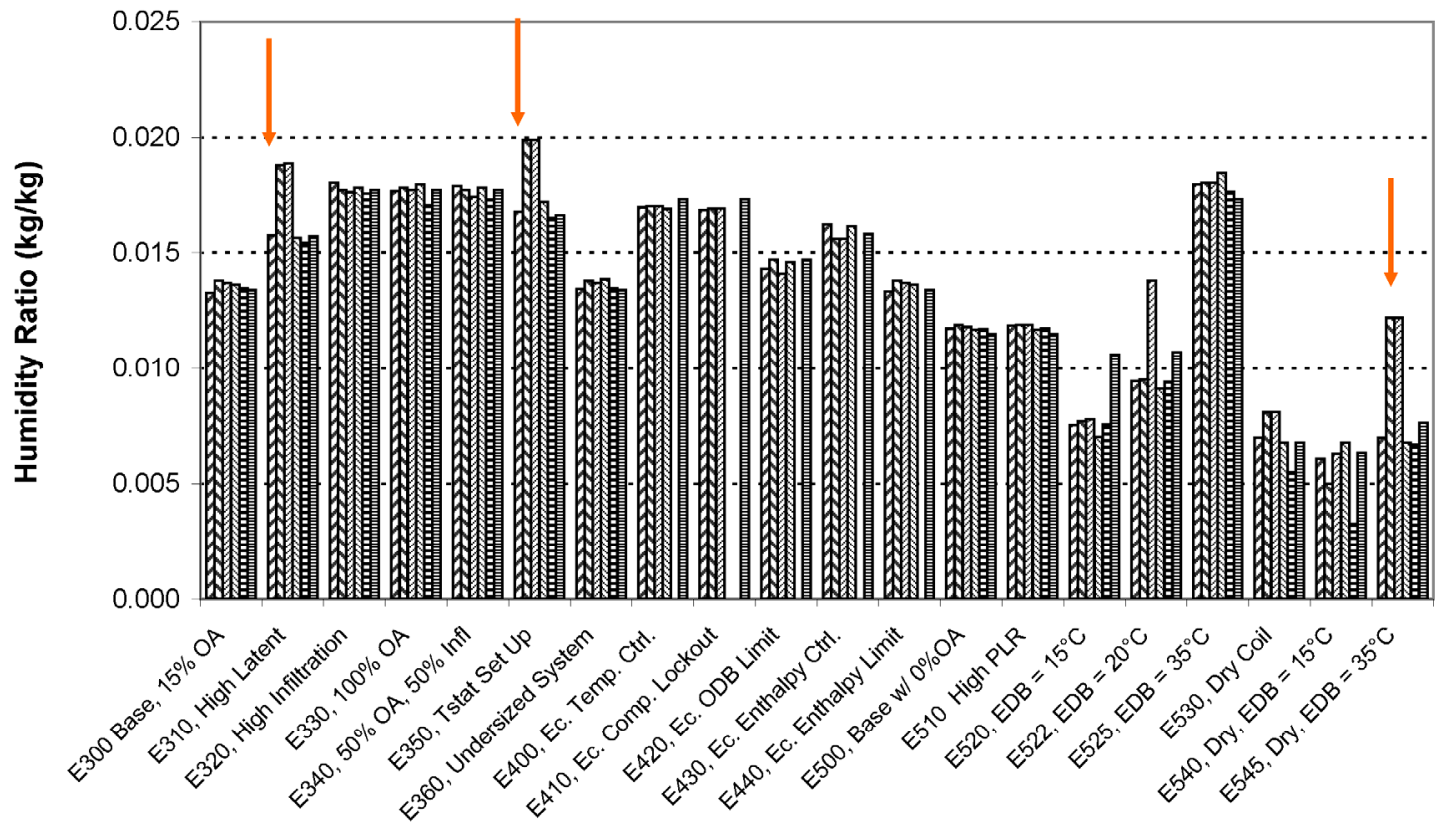

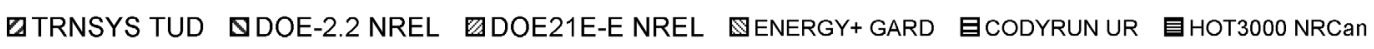

Figure 2-30. DOE-2.2 NT42j, peak-hour humidity ratio disagreements for cases E310, $\mathrm{E} 350$, and E545 
This page is intentionally blank. 


\subsection{Interpretation of Results}

The tables and graphs in Part III present the final results from all the simulation programs used in this study. Unlike the results of cases E100-E200, these cases do not have analytical solution results. Therefore, this set of simulation results does not establish either an absolute or a mathematical truth standard (see International Energy Agency Building Energy Simulation Test and Diagnostic Method for Heating, Ventilating and Air-Conditioning Equipment Models, (HVAC BESTEST) Volume 1 [Neymark and Judkoff 2002: Section 3.5]). These reference results do represent the best current state of the art in whole-building energy simulation predictions as defined by our group of international experts. Because there is no truth standard, for any given case a program that yields values in the middle of the range of the reference results should not be perceived as better or worse than a program that yields values at the borders of the range. The ranges represent algorithmic differences in the current state of the art.

Programs that fall outside the ranges of reference results are producing results that differ from the current state of the art in whole-building energy simulation. One must rely on engineering judgment to assess the significance of results that disagree. For simulation results that disagree significantly with the reference simulation results, investigating the source(s) of the difference(s) is worthwhile, but the existence of a difference does not necessarily mean that a program is faulty. However, our collective experience in this task has indicated that when programs show disagreement, we often find a bug, a questionable algorithm, or a documentation problem.

Because of iterative correction of input errors, software bugs, and clarification of the test specifications, the agreement among simulation results improved with each iteration of the field trials. Improvements to the simulation programs are evident when the initial results set in Figure 2-31 is compared to the final results set in Figure 2-32. (In these figures abbreviations along the $\mathrm{x}$-axis are shorthand for the case descriptions given in Part I.) Improvements to simulation programs or simulation inputs made by participants must have a mathematical and physical basis, and must be applied consistently across tests. Also, all improvements were required to be documented in modeler reports. Arbitrary modification of a simulation program's input or internal code just for the purpose of more closely matching a given set of results is not allowed.

For Figure 2-31, the participants submitted their initial results as follows. Initial results submitted for CODYRUN and EnergyPlus were only for cases E300-E310 and E300-E360 respectively. The EnergyPlus results for E400-E545 were submitted after several iterations of fixing errors in cases E300E360; the initial E400-E545 results then indicated that a few disagreements remained for those cases. The CODYRUN results for E320-E360 were submitted after one iteration of error correction for cases E300 and E310; these results indicate disagreements for E320-E340. CODYRUN results for E500-E545 were submitted after errors for cases E320-E340 were addressed, so no new disagreements for total consumption are indicated for E500-E545, although a few disagreements for other outputs were observed (see Section 2.4). Initial results for DOE-2.2 (distributed by James J. Hirsch \& Associates) are represented by the DOE21E-J results, which use a James J. Hirsch \& Associates version of DOE-2.1E. Initial results for DOE21E-J, DOE21E-E (DOE-2.1E ESTSC version), and TRNSYS-TUD were submitted for the full set of test cases. All results for TRNSYS-TUD use a realistic controller (time step $=90$ seconds) and interpolated weather data (based on the given hourly data) within each time step. For HOT3000, results were initially submitted only for cases E300-E320 and E340-E350. The next set of HOT3000 results was submitted for E300-E360. HOT3000 results for cases E400-E545 were submitted after a software improvement to fix a problem with HOT3000's Case E330 results. 


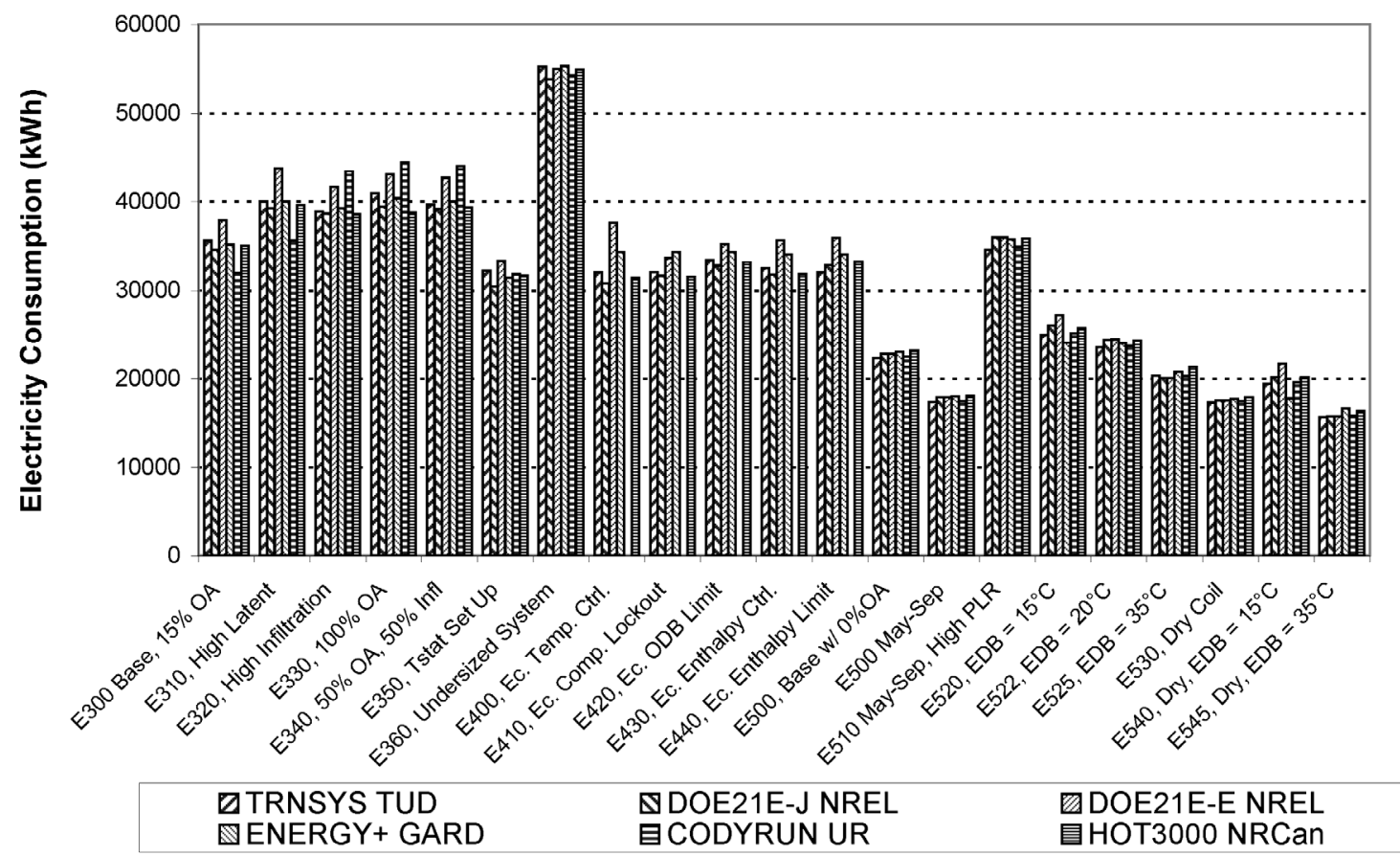

Figure 2-31. HVAC BESTEST E300-E545-total electricity consumption, before BESTESTing (Abbreviations along the X-axis are shorthand for the case descriptions; see Part I for full case descriptions.)

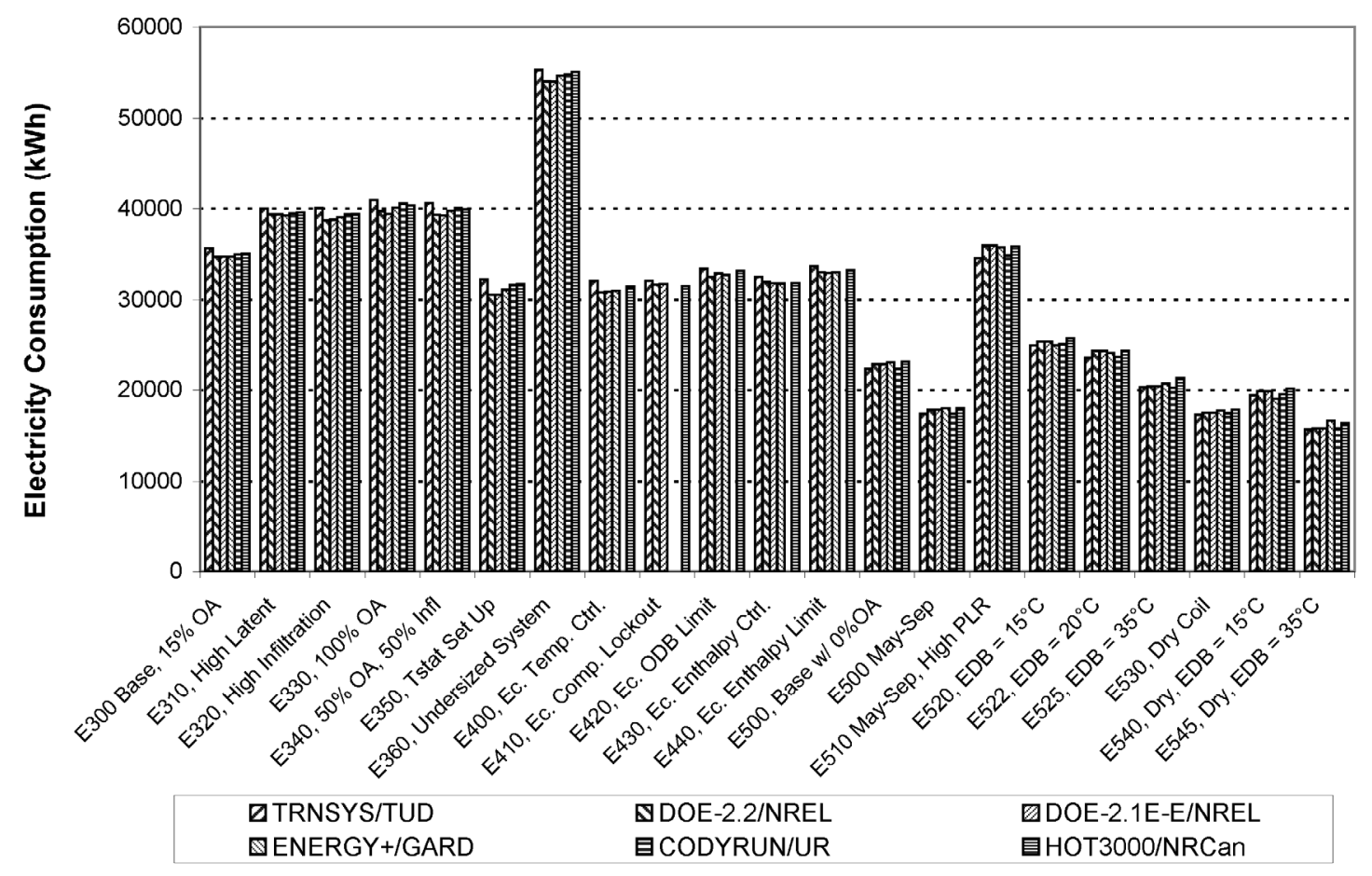

Figure 2-32. HVAC BESTEST E300-E545-total electricity consumption, after BESTESTing (Abbreviations along the $\mathrm{x}$-axis are shorthand for the case descriptions; see Part I for full case descriptions.) 
The results shown in Figure 2-31 indicate that there was initially a 3\%-21\% disagreement among the cases for the simulated energy consumption results, and that there was a lot of scatter among the programs. Here disagreement is the difference between the maximum and minimum result for each case, divided by the mean of the results for each case $((\max -\min ) /$ mean $)$. The initial results disagreements are smaller for these results than for the E100-E200 cases (4\%-40\%) possibly because TRNSYS-TUD, DOE-2.1E, and EnergyPlus were already improved during the earlier field trials of cases E100-E200.

Figure 2-32 shows that after correcting software errors using HVAC BESTEST diagnostics, the remaining disagreements of results for annual total energy consumption for the programs are $2 \%-6 \%$, with very little scatter among the programs. This shows how the HVAC BESTEST method is used to diagnose and correct faulty algorithms in complex simulation programs.

Final ranges of disagreement are further summarized in Table 2-6 for predictions of various outputs. The outputs are disaggregated for cases E300-E440 (continuous outside air and/or infiltration, and continuous fan operation) and for cases E500-E545 (no outside air nor infiltration, indoor fan cycles on/off with compressor). The higher level of indoor dry-bulb temperature (IDB) and humidity ratio disagreement in cases E500-E545 may be caused by the wider range of thermostat set points that was used in those cases.

Table 2-6. Ranges of Disagreement among Simulation Results

\begin{tabular}{||l|l|l||}
\hline \hline Cases & E300-E440 & E500-E545 \\
\hline $\begin{array}{l}\text { Annual total electric } \\
\text { consumption }\end{array}$ & $2 \%-5 \%$ & $3 \%-6 \%$ \\
\hline $\begin{array}{l}\text { Annual mean zone } \\
\text { humidity ratio }\end{array}$ & $2 \%-3 \%$ & $4 \%-23 \%$ \\
\hline $\begin{array}{l}\text { Annual mean zone } \\
\text { temperature }\end{array}$ & $0.1^{\circ} \mathrm{C}-0.6^{\circ} \mathrm{C}$ & $0.4^{\circ} \mathrm{C}-4.1^{\circ} \mathrm{C}^{*}$ \\
\hline
\end{tabular}

* Higher IDB by HOT3000 for cases E500-E545 was attributed by the HOT3000 modelers to the use of an adiabatic zone in their model, versus the near-adiabatic zone specified in Part I.

Based on results after several iterations of HVAC BESTESTing, and resulting model improvements, the tested programs now appear reliable for performance-map modeling of space-cooling equipment over an expanded range of dynamic performance conditions. The programs also appear reliable for modeling outside air mixing, infiltration, thermostat set up, overloaded conditions, and various economizer control schemes. This set of results may therefore be used as a reference or benchmark against which other software can be tested.

The current set of reference results applies a simplifying assumption in the test specification (Part I, Section 1.3.1.4.1) that, "All moisture that condenses on the evaporator coil ... leaves the system through a condensate drain." This simplifying assumption is common to the simulation tools used in the field trials. Recently published work (Shirey and Henderson 2004) indicates that this simplification deviates from reality at a part-load condition, and especially for single-stage systems where the indoor air distribution fan operates continuously, as in cases E300-E440. This is because of latent performance degradation caused by evaporation of condensate from the evaporator coil during the compressor offcycle, which effectively causes a trade-off of reduced latent capacity for increased sensible capacity (or sensible zone-load reduction) because of the evaporative cooling that results. The latent performance degradation effect is greatly reduced when the air distribution fan cycles on/off with the compressor, as 
in the E100 and E500 series cases. Shirey and Henderson (2004) note that most mainstream hourly whole-building energy simulation programs do not consider part-load latent performance degradation and therefore tend to overestimate moisture removal. Their article cites a study that showed $5 \%-10 \%$ underprediction of relative humidity levels in a typical small office application for a single-stage system with continuous air distribution fan operation in a humid climate. Personal communications with the authors indicate that the corresponding overprediction in energy use may also be $5 \%-10 \%$, and that they are working to incorporate the part-load latent degradation model that they have been using into EnergyPlus (Shirey 2004; Henderson 2004). One issue with the use of the model is that parameters necessary to accurately estimate latent performance degradation exist only for a limited number of cooling coils and equipment configurations. To address this, the authors are working to develop guidelines for selecting model parameters for a greater variety of cooling coils and equipment configurations.

\subsubsection{Importance of Simulated Effects on Real Buildings}

The E500 series cases repeat some of the tests of cases E100-E200, but use dynamic loading, dynamic weather data, and expanded mechanical equipment performance data to test the ability to model the effects of variation of part-load ratio (PLR), and outdoor dry-bulb temperature (ODB) and entering dry-bulb temperature (EDB) performance sensitivities.

In addition to testing these effects in a dynamic context, there is also value in having these tests to scale the importance of being able to simulate these effects for real buildings. For example, a large percentage difference for a given result that has only a very small impact on annual energy use may not be of concern, whereas a small percentage difference with a large impact on annual energy use may be deemed important. The same is true for features tested in the E300 series and E400 series cases. The internal gains schedules for cases E300-E545 combine aspects of both building thermal fabric and typical internal gains loading. Because there is almost no uncertainty regarding the load to which the mechanical system is responding, all disagreements in simulation results may be attributed to HVAC system models. It is therefore apparent from the initial results for Case E300 that improper modeling of mechanical equipment can easily account for $10 \%-20 \%$ errors in energy consumption estimates for real buildings; this was after some of the programs had already corrected errors found from running cases E100-E200. Similar initial disagreements were likely not found for the initial results of the E500 series cases either because all the participating programs had found bugs from running the E100-E200 series cases or because the E300 series cases had been run before they began field testing the E500 series cases.

\subsubsection{Test Cases for Future Work}

We suggest that additional work related to model testing and validation, outlined in the sections that follow, be considered.

\subsubsection{Mechanical Equipment}

For the current set of all HVAC BESTEST cases, it would be interesting to include:

- Heat pumps

- A test of the ability to extrapolate from a set of typical manufacturer catalog performance data (using a limited set of performance data with smaller increments of ODB, entering wet-bulb temperature $[\mathrm{EWB}]$, and $\mathrm{EDB}$ over a typical design range for the same equipment for which the current expanded performance data have been obtained) 
- Variation of part-load performance based on more detailed data

- Five-minute minimum on/off or hysteresis control, or both; preliminary work by TUD documented in the Volume 1 TRNSYS-TUD modeler report suggests that it might be interesting to try:

- Case E140 with 5-minute minimum on and 5-minute minimum off

- Case E130 with $2^{\circ} \mathrm{C}$ hysteresis

$\circ$ Five-minute minimum off (a common manufacturer setting)

- Combination of minimum on/off and hysteresis

- Proportional control

$\circ$ Adding equipment run time to outputs.

Additional possible cases include:

- Variable-air volume fan performance and control

- Repeat one or two of the E100-E200 series cases using expanded performance data

- Fan heat test using continuous fan operation at low compressor part load

- Latent capacity degradation test using continuous fan operation at low compressor part load

- PLR effect test using Air-Conditioning and Refrigeration Instiute (ARI) conditions for ODB, EWB, and EDB

- Outside dew point temperature (humidity ratio) effect on performance (see the DOE-2.1E/NREL modeler report of Volume 1 [Appendix III-A])

- Combination of mechanical equipment tests with a realistic building envelope (although combining these adds noise, which makes diagnostics more difficult).

Obtaining additional simulation results would also be useful. Possible additional programs to test include FSEC 3.0, HVACSIM+, the American Society of Heating, Refrigerating, and Air-Conditioning Engineers (ASHRAE) HVAC2 Toolkit, and others.

Other BESTEST-type test suites that have been developed within International Energy Agency (IEA) Solar Heating and Cooling Programme (SHC) Task 22 include:

- HVAC BESTEST Fuel-Fired Furnace Test Cases (Purdy and Beausoleil-Morrison 2003)

- RADTEST Radiant Heating and Cooling Test Cases [hydronic system model test cases] (Achermann and Zweifel 2003).

For the longer term, there has been discussion of trying to gather data that would allow highly detailed equivalent primary-loop component models of, for example, compressors, condensers, evaporators, and expansion valves, to be incorporated into the test specification. Incorporating and verifying data for such models to enhance the current HVAC BESTEST specification is expected to be a major effort. Additional long-term work would also include:

- Thermal storage equipment

- Air-to-air heat exchanger

- Fuel-fired domestic hot water

- Combination hot water/space-heating systems

- Solar domestic hot water systems

- More complex systems associated with larger buildings including:

$\circ \quad$ Large chillers

- Chilled water loops

- Cooling towers and related circulation loops 
- More complex air-handling systems

O Other "plant" equipment

- Field trials of ASHRAE RP-865 air-side analytical tests (Yuill and Haberl 2002).

Within IEA SHC Task 22, economizer model empirical validation tests have been completed. (Maxwell, Loutzenhiser, and Klaassen 2004). Empirical studies being developed within new IEA SHC/Energy Conservation in Buildings and Community Systems (ECBCS) Task 34/Annex 43 are aimed at better characterizing HVAC systems, controls, and components. Development of additional empirical validation test cases related to mechanical equipment models may be proposed in the future.

\subsubsection{Building Thermal Fabric (envelope)}

IEA SHC Task 22 began developing improvements to existing IEA BESTEST (Judkoff and Neymark 1995a) and HERS BESTEST (Judkoff and Neymark 1995b) cases related to ground-coupled heat transfer through floor slabs and basement walls. This work is described in an IEA Working Document (Deru, Judkoff, and Neymark 2003), and is being continued within new IEA SHC/ECBCS Task 34/Annex 43 (IEA 34/43). Additional building thermal fabric test cases being developed within IEA 34/43 are for testing the ability to model multizone envelope heat transfer (Neymark and Judkoff 2004). Cases for testing models of single- and multizone airflow (including infiltration) based on structural and weather conditions are also being proposed for development within IEA 34/43.

A number of other interesting areas relating to envelope models for which BESTEST cases could be developed include:

- Variation of radiant fraction of heat sources

- Moisture adsorption/desorption

- Daylighting controls.

ASHRAE has developed a series of building thermal fabric analytical verification tests under RP-1052 (Spitler, Rees, and Xiao 2001). Future work could also include field trials of these tests.

The current IEA BESTEST envelope tests should be updated periodically to include:

- New simulation results for the current set of programs, and simulation results for other detailed hourly simulation programs not currently shown

- Application of updated weather data (e.g., TMY2 or other)

- Additional radiative exchange tests (see IEA BESTEST [Judkoff and Neymark 1995a: Table 2-51])

- Other improvements that may be recommended by users.

Within IEA SHC Task 22, daylighting control empirical validation tests have been completed (Maxwell, Loutzenhiser, and Klaassen 2003). Empirical validation tests being developed within IEA 34/43 include tests for models of:

- Daylighting, shading, and related load interaction

- Double-skin buildings.

Based on the outcome of the IEA 34/43 projects, development of additional empirical validation test cases related to modeling the building thermal fabric may be proposed in the future. 


\subsection{Conclusions and Recommendations}

\subsubsection{Conclusions}

Additional test cases for mechanical space cooling equipment have been added to the International Energy Agency's (IEA)'s existing method for systematically comparing whole-building energy software and determining the algorithms responsible for prediction differences. Similar to previous test suites that applied the Building Energy Simulation Test and Diagnositc Method (BESTEST), these new cases have a variety of uses, including:

- Comparing several building energy simulation programs to determine the degree of disagreement among them

- Diagnosing the algorithmic sources of prediction differences among several building energy simulation programs

- Comparing predictions from other building energy programs to the simulation results in this report

- Checking a program against a previous version of itself after the internal code has been modified, to ensure that only the intended changes actually resulted

- Checking a program against itself after a single algorithmic change to understand the sensitivity among algorithms.

Previous BESTEST procedures have been adopted by codes and standards authorities in the United States. (e.g., American National Standards Institue [ANSI]/American Society of Heating, Refrigerating, and AirConditioning Engineers [ASHRAE] Standard 140-2001 [2001]), and adopted as software qualification tests for agencies in Europe and Australia. Further details are discussed in Section 2.6.2.

Adding new mechanical equipment tests to the existing set of envelope and mechanical equipment tests gives building energy software developers and users an expanded ability to test a program for reasonableness of results and to determine if a program is appropriate for a particular application. The current set of steady-state tests (cases E100-E200) and dynamic tests (E300-E545) represent the beginning of work in this area. Additional cases for future consideration beyond these were discussed in Section 2.5.2.

The procedure has been field-tested using a number of advanced building energy simulation programs from the United States and Europe. The method has proven effective at isolating the sources of predictive differences. The diagnostic procedures revealed bugs, faulty algorithms, limitations, and input errors in all but one of the building energy computer programs tested in this study. Table 2-7 summarizes the notable examples.

Many of the errors listed in Table 2-7 were significant, with up to $22 \%$ effect on total annual electricity consumption for some cases. Some errors had relatively minor $(<2 \%)$ effect on total consumption. Where a program had multiple errors of smaller magnitude, such errors did not necessarily compensate for each other, and may have been cumulative in some cases. Therefore, correcting the minor errors as well as the major errors was important. 
Table 2-7. Summary of Software Problems Found Using HVAC BESTEST Cases E300-E545

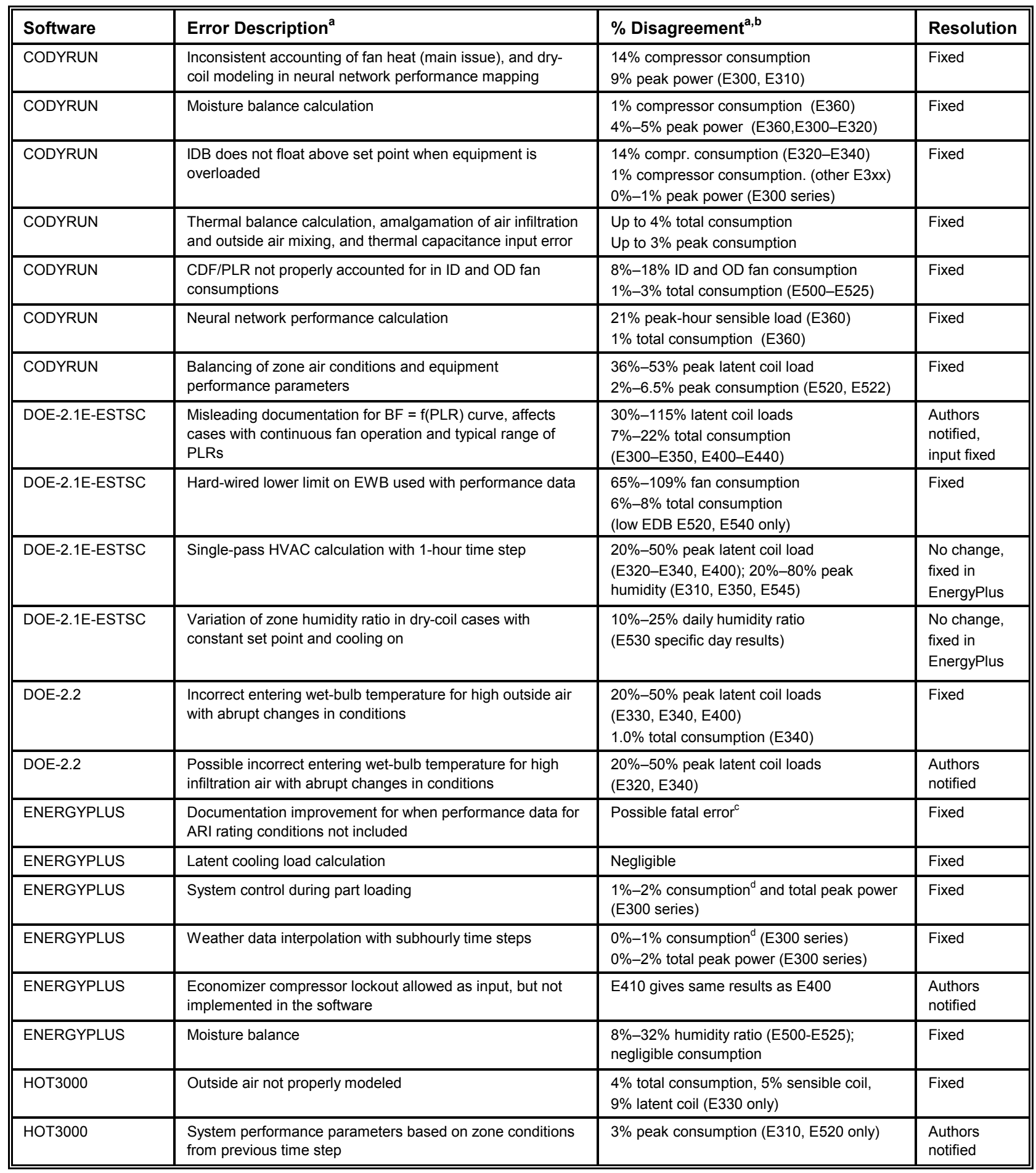

a Acronyms and abbreviations used in this column are defined in Section 2.7.

b Specific cases or conditions relevant to the described disagreement(s) are included in parentheses.

c Fatal error occurs if ARI-condition data point is not used for curve fit normalization.

d Compressor + OD fan. 
Some of the errors were discovered in programs that had already corrected errors found during the HVAC BESTEST Volume 1 tests (cases E100-E200; Neymark and Judkoff 2002)-e.g., DOE-2.1E and EnergyPlus. The Volume 1 cases are in-depth diagnostic, steady-state, test cases over a limited range of operation, which have quasi-analytical solutions formulated outside of a whole-building energy simulation program. The Volume 2 test cases employ operating conditions that vary hourly and over a wider range than for Volume 1, as well as additional parametric sensitivities. Therefore, the discovery of remaining software errors using HVAC BESTEST Volume 2, after testing software with Volume 1, indicates the importance of also testing the programs with the Volume 2 test cases.

Performance of the Volume 2 tests resulted in quality improvements to all the building energy simulation programs used in the field trials except for TRNSYS-TUD (which did have software corrections in the Volume 1 tests). Some of the bugs that were found may well have been present for many years. The fact that they have just now been uncovered shows the power of BESTEST and also suggests the importance of continuing to develop formalized validation and diagnostic methods. It is only after coding bugs have been eliminated that the assumptions and approximations in the algorithms can be evaluated where necessary.

Checking a building energy simulation program for the first time with HVAC BESTEST Volume 2 (cases E300-E545) requires about 1 person-week for an experienced simulation user, not including any necessary improvements to the software. Subsequent program checks are faster because existing input decks may be reused. Because the simulation programs have taken many years to produce, HVAC BESTEST provides a very cost-effective way of testing them. As we continue to develop new test cases, we will adhere to the principle of parsimony so that the entire suite of BESTEST cases may be implemented by users within a reasonable time span.

After correcting software errors using HVAC BESTEST diagnostics, the remaining disagreements of results for annual total energy consumption for the programs are $2 \%-6 \%$ with very little scatter among the programs. This shows how the HVAC-BESTEST method is used to diagnose and correct faulty algorithms in complex simulation programs.

Based on results after several iterations of HVAC BESTESTing and resulting model improvements, the tested programs now appear reliable for performance-map modeling of space-cooling equipment over an expanded range of dynamic performance conditions. The programs also appear reliable for modeling outside air mixing, infiltration, thermostat set up, overloaded conditions, and various economizer control schemes. This set of results may therefore be used as a reference or benchmark against which other software can be tested.

In contrast with steady-state cases E100-E200, which were solved analytically, the more realistic nature of cases E300-E545 allows us to gauge the importance of differences in simulation results, and if desired, annual energy cost (although not done here). This is a good way to understand the importance of the differences in results. For example, a large percentage difference for a given result that has only a very small impact on annual energy use may not be of concern, whereas a small percentage difference with a large impact on annual energy use may be deemed important. The internal gains schedules for cases E300-E545 combine aspects of both building thermal fabric loads and typical internal gains loading. Because there is almost no uncertainty regarding the load to which the mechanical system is responding, all disagreements in simulation results may be attributed to the HVAC system models. It is therefore apparent from the initial results for Case E300 that faulty algorithms in mechanical equipment models can easily account for 10\%$20 \%$ errors in energy consumption estimates for real buildings; this was after some of the programs had already corrected errors found from running cases E100-E200. 
In practice, simulation tools often use data from the manufacturer to predict energy performance.

Manufacturers typically supply catalog equipment performance data for equipment selection at given common design load conditions. Data for atypical conditions, which can commonly occur in buildings with outside air requirements or high internal gains, are not generally included. Significant effort was required to obtain the expanded performance data set needed for cases E300-E545. We reviewed three manufacturer equipment selection software packages typically used by HVAC engineers for specifying equipment. None of these, however, were satisfactory for developing the range of data we desired; the performance data we ultimately obtained were custom-generated by a manufacturer. In general if the state of the art in annual simulation of mechanical systems is to improve, manufacturers need to either readily provide expanded data sets on the performance of their equipment, or improve existing equipment selection software to facilitate generation of such data sets.

Within the BESTEST structure, there is room to add new test cases when required. BESTEST is better developed in areas related to energy flows and energy storage in the architectural fabric of the building. BESTEST work related to mechanical equipment is still in its early phases. Other BESTEST-type test suites that have been developed within IEA Solar Heating and Cooling Programme (SHC) Task 22 include

- HVAC BESTEST Fuel-Fired Furnace Test Cases (Purdy and Beausoleil-Morrison 2003)

- RADTEST Radiant Heating and Cooling Test Cases for hydronic systems (Achermann and Zweifel 2003).

IEA SHC Task 22 began developing improvements to existing BESTEST building thermal fabric test cases with ground-coupled heat transfer through floor slabs and basement walls (Deru, Judkoff, and Neymark 2003). This work is continuing under new IEA SHC/Energy Conservation in Buildings and Community Systems (ECBCS) Task 34/Annex 43 (Judkoff and Neymark 2004).

For the longer term we hope to add test cases that emphasize special modeling issues associated with more complex building types and HVAC systems as listed in Section 2.5.2.

\subsubsection{Recommendations}

The work presented in this report, and the work that has preceded it in IEA SHC Tasks 8, 12 (ECBCS Annex 21), and 22 is significant for two reasons. First, the methods have been extremely successful at correcting software errors in advanced building energy simulation programs throughout the world. Second, the methods are finding their way into industry by being adopted as the theoretical basis for formalized standard methods of test and software certification schemes; in this sense the work may be thought of as pre-normative research.

The previous IEA BESTEST envelope test cases (Judkoff and Neymark 1995a) and the overall validation methodology (Judkoff et al. 1983; Judkoff 1988) have been code-language adapted and formally approved as a standard method of test, ASHRAE Standard 140-2001 (ANSI/ASHRAE 2001). ASHRAE Standard 90.1 (ANSI/ASHRAE/Illuminating Engineering Society of North America [IESNA] 2004) requires that software used for demonstrating performance compliance with Standard 90.1 be tested using ASHRAE Standard 140. Standard 90.1 is ASHRAE's consensus energy code for commercial buildings, and other non-low-rise residential buildings. IEA BESTEST is also being used for simulation certification tests in The Netherlands (ISSO 2003) and Australia (SEDA 2003; Pears 1998). 
The HVAC BESTEST Volume 1, cases E100-E200 (Neymark and Judkoff 2002) have been code-language adapted and formally approved as Addendum $a$ to ASHRAE Standard 140 (ANSI/ASHRAE 2004). HVAC BESTEST Fuel-Fired Furnace Test Cases (Purdy and Beausoleil-Morrison 2003) are being code-language adapted for Standard 140. We anticipate that HVAC BESTEST Volume 2 cases E300-E545, other work from IEA SHC Task 22, and new work from IEA SHC/ECBCS Task 34/Annex 43 will also be added to Standard 140 in the future. In the United States, the National Association of State Energy Officials (NASEO) Residential Energy Services Network (RESNET) has adopted HERS BESTEST (Judkoff and Neymark 1995b) as the basis for certifying software to be used for Home Energy Rating Systems under the NASEO/RESNET national accreditation standard (NASEO/RESNET 2002). HERS BESTEST is also being code-language adapted for future inclusion with ASHRAE Standard 140 (SSPC-140 2004).

The BESTEST procedures are also being used as teaching tools for simulation courses at universities in the United States and Europe. We hope that as the procedures become better known, developers will automatically run the tests as part of their normal in-house quality control efforts. The large number of requests (more than 1000) that we have received for the various BESTEST reports indicates that this is beginning to happen. For example, we recently learned that Carrier Corporation and Trane, which are among the largest suppliers of HVAC equipment in the world, are testing their respective software HAP and TRACE with Standard 140. Also, EnergyPlus, the United States Department of Energy's most advanced simulation program for building energy analysis, distributes their Standard 140 validation results with their CDs and from their website.

Because new energy-related technologies are continually being introduced into the buildings market, there will always be a need for further development of simulation models, combined with a substantial program of testing and validation. Such an effort should contain all the elements of an overall validation methodology (see HVAC BESTEST Volume 1 [Neymark and Judkoff 2002: Background Section]), including:

- Analytical verification

- Comparative testing and diagnostics

- Empirical validation.

Future work should therefore encompass:

- Continued production of a standard set of analytical tests

- Development of a set of diagnostic comparative tests that emphasize the modeling issues important in large commercial buildings, such as zoning, infiltration airflow rate determination, and more tests for heating, ventilating, and air-conditioning systems

- Development of a sequentially ordered series of high-quality data sets for empirical validation.

Continued support of model development and validation activities is essential because occupied buildings are not amenable to classical controlled, repeatable experiments. The few buildings that are truly useful for empirical validation studies have been designed primarily as test facilities. The energy, comfort, and lighting performance of buildings depend on the interactions among a large number of transfer mechanisms, components, and systems. Simulation is the only practical way to bring a systems integration problem of this magnitude within the grasp of designers. Greatly reducing the energy intensity of buildings through better design is possible with the use of simulation tools (Torcellini, Hayter, and Judkoff 1999). However, building energy simulation programs will not be widely used unless the design and engineering communities have confidence in these programs. Confidence and quality can best be encouraged by combining a rigorous development and validation effort with user-friendly interfaces. 
Development and validation of whole-building energy simulation programs is one of the most important activities meriting the support of national energy research programs. The IEA Executive Committees for Solar Heating and Cooling and for Energy Conservation in Buildings and Community Systems should diligently consider what sort of future collaborations would best support this essential research area.

\subsection{Abbreviations and Acronyms for Part II}

These acronyms are used in Sections 2.2 through 2.6.

\begin{tabular}{|c|c|}
\hline ANSI & American National Standards Institute \\
\hline ARI & Air-Conditioning and Refrigeration Institute \\
\hline ASHRAE & American Society of Heating, Refrigerating, and Air-Conditioning Engineers \\
\hline BESTEST & Building Energy Simulation Test \\
\hline $\mathrm{BF}$ & bypass factor \\
\hline CAPgtc & gross total capacity \\
\hline $\mathrm{CDF}$ & $\begin{array}{l}\text { COP degradation factor is a multiplier }(\leq 1) \text { applied to the full-load system COP; CDF is a } \\
\text { function of PLR }\end{array}$ \\
\hline CETC & CANMET Energy Technology Centre, Natural Resources Canada \\
\hline Compr. & compressor \\
\hline $\mathrm{COP}$ & coefficient of performance; for definition, see Part I, Appendix C (Glossary) \\
\hline $\mathrm{COP} 2$ & $\begin{array}{l}\text { (or } \mathrm{COP}_{2} \text { ) is the ratio, using same units, of the gross total evaporator coil load to the sum of } \\
\text { the compressor and outdoor condenser fan energy consumptions }\end{array}$ \\
\hline Ctrl & control \\
\hline DOE & U.S. Department of Energy \\
\hline Ec. & economizer \\
\hline ECBCS & Energy Conservation in Buildings and Community Systems programme (of the IEA) \\
\hline EDB & $\begin{array}{l}\text { entering dry-bulb temperature, the temperature that a thermometer would measure for air } \\
\text { entering the evaporator coil }\end{array}$ \\
\hline ESTSC & Energy Science and Technology Software Center (of the U.S. Department of Energy) \\
\hline EWB & entering wet-bulb temperature; for definition, see Part I, Appendix C (Glossary) \\
\hline GARD & GARD Analytics \\
\hline HERS & Home Energy Rating System \\
\hline HVAC & heating, ventilating, and air-conditioning \\
\hline $\mathrm{ID}$ & indoor \\
\hline IDB & indoor dry-bulb temperature; for definition, see Part I, Appendix C (Glossary) \\
\hline IEA & International Energy Agency \\
\hline
\end{tabular}




\begin{tabular}{|c|c|}
\hline IEA $34 / 43$ & $\begin{array}{l}\text { International Energy Agency joint Solar Heating and Cooling Programme Task } 34 \text { and } \\
\text { Energy Conservation in Buildings and Community Systems Programme Annex } 43\end{array}$ \\
\hline IESNA & Illuminating Engineering Society of North America \\
\hline Inf & infiltration \\
\hline Infl & infiltration \\
\hline IP & inch-pound \\
\hline ISSO & $\begin{array}{l}\text { Instituut voor Studie en Stimulering van Onderzoek op het Gebied van Gebouwinstallaties } \\
\text { (Netherlands) }\end{array}$ \\
\hline LBNL & Lawrence Berkeley National Laboratory \\
\hline Max & maximum \\
\hline Min & minimum \\
\hline NASEO & National Association of State Energy Officials \\
\hline NREL & National Renewable Energy Laboratory \\
\hline $\mathrm{OA}$ & outside air \\
\hline OD & outdoor \\
\hline ODB & outdoor dry-bulb temperature; for definition, see Part I, Appendix C (Glossary) \\
\hline OHR & outdoor humidity ratio \\
\hline PLR & part-load ratio; for definition, see Part I, Appendix C (Glossary) \\
\hline Qgtc & gross total coil load \\
\hline RADTEST & radiant heating and cooling test cases \\
\hline RESNET & Residential Energy Services Network \\
\hline RH & relative humidity \\
\hline SEDA & Sustainable Energy Development Authority (Australia) \\
\hline $\mathrm{SHC}$ & Solar Heating and Cooling Programme (of the IEA) \\
\hline SI & Système Internationale \\
\hline SSPC & Standing Standard Project Committee (of ASHRAE) \\
\hline TMY2 & Typical Meteorological Year 2 \\
\hline Tstat & thermostat \\
\hline TUD & Technische Universität Dresden \\
\hline UR & University of Reunion Island \\
\hline
\end{tabular}




\subsection{References for Part II}

Achermann, M.; Zweifel, G. (2003). RADTEST Radiant Heating and Cooling Test Cases. Horw-Lucerne, Switzerland: Lucerne School of Engineering and Architecture, University of Applied Sciences of Central Switzerland. Available from http://www.iea-shc.org/task22/reports/RADTEST_final.pdf.

ANSI/ASHRAE Addendum $a$ to ANSI/ASHRAE Standard 140-2001. (2004). Standard Method of Test for the Evaluation of Building Energy Analysis Computer Programs. Atlanta, Georgia, US: American Society of Heating, Refrigerating, and Air-Conditioning Engineers.

ANSI/ASHRAE Standard 140-2001. (2001). Standard Method of Test for the Evaluation of Building Energy Analysis Computer Programs. Atlanta, Georgia, US: American Society of Heating, Refrigerating, and Air-Conditioning Engineers.

ANSI/ASHRAE/IESNA. (2004). ANSI/ASHRAE/IESNA Addendum $p$ to ANSI/ASHRAE/IESNA Standard 90.1-2001. Energy Standard for Buildings Except Low-Rise Residential Buildings. Atlanta, Georgia, US: American Society of Heating, Refrigerating, and Air-Conditioning Engineers.

Buhl, F. (May 15, 2003; October 7, 2003). E-mail communications. Berkeley, California, US: Lawrence Berkeley National Laboratory.

Deru, M.; Judkoff, R.; Neymark, J. (2003). Proposed IEA BESTEST Ground-Coupled Cases. International Energy Agency, Solar Heating and Cooling Programme Task 22, Working Document, September 2003. Golden, Colorado, US: National Renewable Energy Laboratory.

Henderson, H. (July 2004). Personal communications. Cazenovia, New York, US: CDH Energy.

Hirsch, J. (November 2003). E-mail communication. Camarillo, California, US: James J. Hirsch \& Associates.

ISSO. (2003). Energie Diagnose Referentie Versie 3.0. ISSO Publicatie 54. Rotterdam, The Netherlands: Institut voor Studie en Stimulering van Onderzoekop Het Gebied van Gebouwinstallaties (in Dutch).

Judkoff, R. (1988). "Validation of Building Energy Analysis Simulation Programs at the Solar Energy Research Institute." Energy and Buildings, Vol. 10, No. 3, p. 235. Lausanne, Switzerland: Elsevier Sequoia.

Judkoff, R.; Neymark, J. (1995a). International Energy Agency Building Energy Simulation Test (IEA BESTEST) and Diagnostic Method. NREL/TP-472-6231. Golden, Colorado, US: National Renewable Energy Laboratory. Available from http://www.nrel.gov/docs/legosti/old/6231.pdf (PDF 13.8 MB).

Judkoff, R.; Neymark, J. (1995b). Home Energy Rating System Building Energy Simulation Test (HERS BESTEST). NREL/TP-472-7332. Golden, Colorado, US: National Renewable Energy Laboratory. Volume 1: Tier 1 and Tier 2 Tests User's Manual, NREL/TP-472-7332a, available from http://www.nrel.gov/docs/legosti/fy96/7332a.pdf (PDF 5.6 MB). Volume 2: Tier 1 and Tier 2 Tests Reference Results, NREL/TP-472-7332b, available from http://www.nrel.gov/docs/legosti/fy96/7332b.pdf (PDF 1.9 MB). 
Judkoff, R. (Operating Agent); Neymark, J. (2004). IEA SHC Task 34/ECBCS Annex 43, Testing and Validation of Building Energy Simulation Tools. Annex Document. Paris, France: International Energy Agency: Solar Heating and Cooling Programme, and Energy Conservation in Buildings and Community Systems.

Judkoff, R.; Wortman, D.; O'Doherty, B.; Burch, J. (1983). A Methodology for Validating Building Energy Analysis Simulations. SERI/TR-254-1508. Golden, Colorado, US: Solar Energy Research Institute, now National Renewable Energy Laboratory.

Maxwell G.; Loutzenhiser, P.; Klaassen, C. (2003). Daylighting-HVAC Interaction Tests for the Empirical Validation of Building Energy Analysis Tools. Ankeny, Iowa, US: Iowa Energy Center. Available from www.iea-shc.org/task22/deliverables.htm.

Maxwell, G.; Loutzenhiser, P.; Klaassen, C. (2004). Economizer Control Tests for the Empirical Validation of Building Energy Analysis Tools. Ankeny, Iowa, US: Iowa Energy Center.

NASEO/RESNET. (2002). Mortage Industry National Home Energy Rating Systems Accreditation Standards. Oceanside, California, US: Residential Energy Services Network. June 15, 2002. Available from www.natresnet.com.

Neymark, J.; Judkoff, R. (2002). International Energy Agency Building Energy Simulation Test and Diagnostic Method for Heating, Ventilating, and Air-Conditioning Equipment Models (HVAC BESTEST), Volume 1: Cases E100-E200. NREL/TP-550-30152. Golden, Colorado, US: National Renewable Energy Laboratory. Available from www.nrel.gov/docs/fy02osti/30152.pdf.

Neymark, J.; Judkoff, R. (May 2004). Proposed IEA BESTEST Multi-Zone Conduction Cases. Draft. Golden, Colorado, US: National Renewable Energy Laboratory.

Pears, A. (1998). Rating Energy Efficiency of Non-Residential Buildings: A Path Forward for New South Wales. Report for the Sustainable Energy Development Authority. Brighton, Victoria, Australia: Sustainable Solutions Pty Ltd. Available from www.abgr.com.au.

Purdy, J.; Beausoleil-Morrison, I. (2003). Building Energy Simulation Test and Diagnostic Method for Heating, Ventilation, and Air-Conditioning Equipment Models (HVAC BESTEST): Fuel-Fired Furnace Test Cases. Ottawa, Ontario, Canada: CANMET Energy Technology Center, Natural Resources Canada. Available from www.iea-shc.org/task22/deliverables.htm.

SEDA. (2003). Guidelines for the Use of Simulation in Commitment Agreements. Grosvenor Place, New South Wales, Australia: Sustainable Energy Development Authority.

Shirey, D. (July 2004). Personal communications. Cocoa, Florida, US: Florida Solar Energy Center.

Shirey, D.; Henderson H. (2004). "Dehumidification at Part Load." ASHRAE Journal. Volume 46, Number 4, April. Atlanta, Georgia, US: American Society of Heating, Refrigerating and AirConditioning Engineers.

Spitler, J.; Rees, S.; Xiao, D. (2001). Development of an Analytical Verification Test Suite for Whole Building Energy Simulation Programs—Building Fabric. Draft Final Report for ASHRAE 1052-RP. Stillwater, Oklahoma, US: Oklahoma State University School of Mechanical and Aerospace Engineering. 
SSPC-140. (2004). Minutes SSPC-140 Standard Method of Test for Building Energy Software. ASHRAE Annual Meeting, Nashville, Tennessee, US. June 26-30, 2004. Atlanta, Georgia, US: American Society of Heating, Refrigerating, and Air-Conditioning Engineers.

Torcellini, P.; Hayter, S.; Judkoff, R. (1999). "Low Energy Building Design: The Process and a Case Study." ASHRAE Transactions 1999, Volume 105, Number 2. Atlanta, Georgia, US: American Society of Heating, Refrigerating, and Air-Conditioning Engineers.

Yuill, G.; Haberl, J. (2002). Development of Accuracy Tests for Mechanical System Simulation. Final Report for ASHRAE 865-RP, July 29, 2002. Omaha, Nebraska, US: University of Nebraska. 


\subsection{APPENDIX II: Simulation Modeler Reports}

In Appendix II, we present reports written by the modeler(s) for each simulation program. The modelers were asked to document:

- Modeling assumptions (required inputs not explicitly described in the test specification)

- Modeling options (alternative modeling techniques)

- Difficulties experienced in developing input files for the test cases with their program

- Bugs, faulty algorithms, documentation problems, or input errors uncovered using the HVAC BESTEST diagnostics

- Source code or input modifications made because of the diagnostic results

- Comments on agreement or disagreement of results compared to other simulation results

- Any odd results obtained with their programs

- Sensitivity studies conducted to further understand the sources of differences between their programs and the others

- Conclusions and recommendations about their simulation programs, HVAC BESTEST, or both.

Modelers also filled out a pro-forma description that defines many of the algorithms within their programs. These pro-forma reports, which appear as they were submitted with minimal reformatting and editing, are presented at the end of each modeler report, except for Appendix II-D. 


\title{
Appendix II-A
}

\section{HVAC BESTEST MODELER REPORT FOR CASES E300-E545 \\ ENERGYPLUS VERSION 1.1.0.020}

\author{
PREPARED BY \\ R. HENNINGER AND M. WITTE, GARD ANALYTICS, INC. \\ D. CRAWLEY, U.S. DEPT. OF ENERGY
}

\author{
JULY 2003

\section{Introduction}

\section{Software:} \\ Authoring Organization: \\ Authoring Country: \\ EnergyPlus Version 1.1.0.020 \\ Lawrence Berkeley National Laboratory, U.S. Department of Energy; \\ University of Illinois \\ United States
}

This report describes the modeling methodology and results for several rounds of testing done for the IEA HVAC BESTEST Cases E300 through E545 that were simulated using the EnergyPlus software. During the early rounds of testing only cases E300-E360 were analyzed. Beginning with Round 3C, the results for cases E400-E440 and cases E500-E545 are also included. The specifications for the model building and HVAC equipment for each case are described in International Energy Agency Building Energy Simulation Test and Diagnostic Method for Heating, Ventilating, and Air-Conditioning Equipment Models (HVAC BESTEST), Volume 2: Cases E300-E545, J. Neymark and R. Judkoff, National Renewable Energy Laboratory, September 2002 (referred to as the BESTEST specification in this report).

\section{Modeling Methodology}

For modeling of the simple unitary vapor compression cooling system, the EnergyPlus Unitary Air-to-Air Heat Pump model was utilized. The Heat Pump model was the only DX cooling system available in EnergyPlus that allowed a draw-through fan configuration. Since cooling only was required during the simulation, the heat pump controls were set to prevent operation of the heat pump in the heating mode. As configured for this test series, the following heat pump modules were exercised: a DX cooling coil, an indoor fan and outside air mixer.

The building envelope loads and internal loads were calculated each hour to determine the zone load that the mechanical HVAC system must satisfy. The EnergyPlus DX coil model then uses performance information at rated conditions along with curve fits for variations in total capacity, energy input ratio and part-load fraction to determine performance at part-load conditions. Sensible/latent capacity splits are determined by the rated sensible heat ratio (SHR) and the apparatus dew point/bypass factor approach.

The EnergyPlus DX coil model requires that the rated total cooling capacity, rated sensible heat ratio, rated $\mathrm{COP}$ and rated air volume flow rate be specified for the ARI rating condition of $35^{\circ} \mathrm{C}$ outside air dry-bulb, $26.7^{\circ} \mathrm{C}$ entering evaporator dry-bulb and $19.4^{\circ} \mathrm{C}$ entering evaporator wet-bulb. Since the 
equipment performance data as provided in the BESTEST specification dated March 2002 did not include equipment performance data at the ARI rating point, the performance data were first curve fit and then the resulting curves were used to determine the cooling capacity, energy consumption and SHR at the ARI rating condition. In September 2002, revised specifications were provided which included performance at the ARI rating point. The revised rating point was used in Round 3B and later.

Five equipment performance curves were required:

1) The Total Cooling Capacity Modifier Curve (function of temperature) is a bi-quadratic curve with two independent variables: wet-bulb temperature of the air entering (EWB) the cooling coil, and outdoor dry-bulb temperature (ODB) of the air entering the air-cooled condenser. The output of this curve is multiplied by the rated total cooling capacity to give the total cooling capacity at specific temperature operating conditions (i.e., at temperatures different from the rating point temperatures).

2) The Total Cooling Capacity Modifier Curve (function of flow fraction) is a quadratic curve with the independent variable being the ratio of the actual airflow rate across the cooling coil to the rated airflow rate (i.e., fraction of full-load flow). The output of this curve is multiplied by the rated total cooling capacity and the total cooling capacity modifier curve (function of temperature) to give the total cooling capacity at the specific temperature and airflow conditions at which the coil is operating.

3) The Energy Input Ratio (EIR) Modifier Curve (function of temperature) is a bi-quadratic curve with two independent variables: wet-bulb temperature of the air entering (EWB) the cooling coil, and outdoor dry-bulb temperature (ODB) of the air entering the air-cooled condenser. The output of this curve is multiplied by the rated EIR (inverse of the rated COP) to give the EIR at specific temperature operating conditions (i.e., at temperatures different from the rating point temperatures).

4) The Energy Input Ratio (EIR) Modifier Curve (function of flow fraction) is a quadratic curve with the independent variable being the ratio of the actual airflow rate across the cooling coil to the rated airflow rate (i.e., fraction of full-load flow). The output of this curve is multiplied by the rated EIR (inverse of the rated COP) and the EIR modifier curve (function of temperature) to give the EIR at the specific temperature and airflow conditions at which the coil is operating.

5) The part-load fraction correlation (function of part-load ratio) is a quadratic curve with the independent variable being part-load ratio (sensible cooling load/steady-state sensible cooling capacity). The output of this curve is used in combination with the rated EIR and EIR modifier curves to give the "effective" EIR for a given simulation time step. The part-load fraction correlation accounts for efficiency losses due to compressor cycling.

\section{Modeling Assumptions}

\section{Thermostat Control}

Ideal thermostat control was assumed with no throttling range. 


\section{ARI Rating Point Conditions}

Since the modeling specifications (March 2002) did not list the equipment performance at the ARI rated conditions of $35^{\circ} \mathrm{C}$ outside air dry-bulb, $26.7^{\circ} \mathrm{C}$ entering evaporator dry-bulb and $19.4^{\circ} \mathrm{C}$ entering evaporator wet-bulb, an initial set of performance curves were developed using $35^{\circ} \mathrm{C} / 26.7^{\circ} \mathrm{C} / 18.33^{\circ} \mathrm{C}$ as the nominal point. This, however, caused problems with the simulation (see Section 5). These initial curve fits were then used to interpolate and determine the following estimated ARI standard rated performance:

$\begin{array}{ll}\text { Rated gross cooling capacity } & 33.084 \mathrm{~kW} \\ \text { Rated sensible heat ratio } & 0.8043 \\ \text { Rated COP } & 3.028 \\ \text { Rated energy consumption } & 10.924 \mathrm{~kW}\end{array}$

The rated energy consumption includes the compressor $(9.994 \mathrm{~kW})$ and outdoor condenser fans $(0.93$ $\mathrm{kW}$ ). These values were revised in Round 3B when an updated HVAC BESTEST E300-E400-E500 test specification was issued in March 2002, which contained the manufacturer performance data for ARI standard conditions.

\section{Coil Curve Fits}

Equipment performance data from Table 1-7b [Part I] Equipment Full-Load Performance with Gross Capacities - SI Units of the BESTEST specification were used to develop the input parameters required for the EnergyPlus performance curves. Although performance data for a range of entering dry-bulb temperatures (EDB) is given in the table, the EnergyPlus performance curves were developed for the ARI rated condition of $26.67^{\circ} \mathrm{C}$ EDB. The resulting coefficients are presented below. These curves are normalized around the standard ARI rating conditions of $35^{\circ} \mathrm{C}$ outside air dry-bulb, $26.7^{\circ} \mathrm{C}$ entering evaporator dry-bulb and $19.4^{\circ} \mathrm{C}$ entering evaporator wet-bulb.

1) Total cooling capacity modifier curve (function of temperature)

Form: Bi-quadratic curve

$$
\text { curve }=\mathrm{a}+\mathrm{b} * \mathrm{EWB}+\mathrm{c} * \mathrm{EWB}^{* * 2}+\mathrm{d} * \text { ODB }+\mathrm{e}^{*} \text { ODB } * * 2+\mathrm{f}^{*} \mathrm{EWB} * \text { ODB }
$$

Independent variables: wet-bulb temperature of the air entering (EWB) the cooling coil, and drybulb temperature of the air entering (ODB) the air-cooled condenser.

$$
\begin{array}{lr}
\mathrm{a}= & 0.953441251 \\
\mathrm{~b}= & -0.000938414 \\
\mathrm{c}= & 0.000932679 \\
\mathrm{~d}= & -0.001299058 \\
\mathrm{e}= & -2.67478 \mathrm{E}-05 \\
\mathrm{f}= & -0.000306850
\end{array}
$$

These values were revised in Round 3B.

2) Total cooling capacity modifier curve (function of flow fraction)

Form: Quadratic curve

$$
\text { curve }=\mathrm{a}+\mathrm{b} * \mathrm{FF}+\mathrm{c} * \mathrm{FF} * * 2
$$

Independent variables: ratio of the actual airflow rate across the cooling coil to the rated airflow rate (i.e., fraction of full-load flow, FF). 
Since indoor fan always operates at constant volume flow, modifier will be 1.0, therefore:

$$
\begin{array}{ll}
\mathrm{a}= & 1.0 \\
\mathrm{~b}= & 0.0 \\
\mathrm{c}= & 0.0
\end{array}
$$

3) Energy input ratio (EIR) modifier curve (function of temperature)

Form: Bi-quadratic curve

$$
\text { curve }=\mathrm{a}+\mathrm{b} * \mathrm{EWB}+\mathrm{c} * \mathrm{EWB} * 2+\mathrm{d}^{*} \text { ODB }+\mathrm{e}^{*} \text { ODB } * * 2+\mathrm{f}^{*} \mathrm{EWB} * \text { ODB }
$$

Independent variables: wet-bulb temperature of the air entering (EWB) the cooling coil, and drybulb temperature of the air entering (ODB) the air-cooled condenser.

$$
\begin{array}{lr}
\mathrm{a}= & 0.537791667 \\
\mathrm{~b}= & -0.000895849 \\
\mathrm{c}= & -0.000154388 \\
\mathrm{~d}= & 0.012700780 \\
\mathrm{e}= & 0.000162966 \\
\mathrm{f}= & -0.000157276
\end{array}
$$

These values were revised in Round 3B.

4) Energy input ratio (EIR) modifier curve (function of flow fraction)

Form: Quadratic curve

$$
\text { curve }=\mathrm{a}+\mathrm{b} * \mathrm{FF}+\mathrm{c} * \mathrm{FF} * * 2
$$

Independent variables: ratio of the actual airflow rate across the cooling coil to the rated airflow rate (i.e., fraction of full-load flow, FF).

Since indoor fan always operates at constant volume flow, modifier will be 1.0, therefore:

$$
\begin{array}{ll}
\mathrm{a}= & 1.0 \\
\mathrm{~b}= & 0.0 \\
\mathrm{c}= & 0.0
\end{array}
$$

5) Part-load fraction correlation (function of part-load ratio, PLR)

Form: Quadratic curve

$$
\text { curve }=\mathrm{a}+\mathrm{b} * \text { PLR }+\mathrm{c} * \text { PLR } * * 2
$$

Independent variable: part-load ratio (sensible cooling load/steady state sensible cooling capacity)

Part-load performance specified in Figure 1-3 [Part I] of the BESTEST specification, therefore:

$$
\begin{array}{lr}
\mathrm{a}= & 0.771 \\
\mathrm{~b}= & -0.229 \\
\mathrm{c}= & 0.0
\end{array}
$$




\section{Modeling Difficulties}

\section{Building Envelope Construction}

The BESTEST specification for the building envelope indicates that the exterior walls, roof and floor are made up of one opaque layer of insulation ( $\mathrm{R}=325$, SI units) with differing radiative properties for the interior surface and exterior surface (ref. Table 1-5 [Part I] of BESTEST specification). To allow the surface radiative properties to be set at different values, the exterior wall, roof and floor had to be simulated as two insulation layers, each with an $\mathrm{R}=162.5$. The EnergyPlus description for this construction was as follows:

\begin{tabular}{ll} 
MATERIAL:Regular-R, & \\
INSULATION-EXT, & ! Material Name \\
VerySmooth, & ! Roughness \\
162.5, & ! Thermal Resistance $\left\{\mathrm{m}^{2}-\mathrm{K} / \mathrm{W}\right\}$ \\
0.9000, & ! Thermal Absorptance \\
0.1000, & ! Solar Absorptance \\
$0.1000 ;$ & ! Visible Absorptance \\
& \\
MATERIAL:Regular-R, & ! Material Name \\
INSULATION-INT, & ! Roughness \\
VerySmooth, & ! Thermal Resistance $\left\{\mathrm{m}^{2}-\mathrm{K} / \mathrm{W}\right\}$ \\
162.5, & ! Thermal Absorptance \\
0.9000, & ! Solar Absorptance \\
0.6000, & ! Visible Absorptance \\
0.6000; & \\
\multicolumn{2}{l}{} \\
CONSTRUCTON, & ! Construction Name \\
LTWALL, & \\
INSULATION-EXT, & \\
INSULATION-INT; &
\end{tabular}

\section{Compressor and Condenser Fan Breakout}

The rated COP required as input by the EnergyPlus DX coil model requires that the input power be the combined power for the compressor and condenser fans. As such, there are no separate input variables or output variables available for the compressor or condenser fan. The only output variable available for reporting in EnergyPlus is the DX coil electricity consumption, which includes compressor plus condenser fan.

\section{Software Errors Discovered and/or Comparison Between Different Versions of the Same Software - Round 1}

\section{1) Rated Performance and Bypass Factor Calculations}

As mentioned in Section 3, the initial set of performance data was based on using $18.33^{\circ} \mathrm{C} \mathrm{EWB}$, because this was directly available from the performance data tables. Even though the EnergyPlus documentation stated clearly that the rated performance inputs were to be entered for rated ARI conditions $\left(19.4^{\circ} \mathrm{C}\right.$ 
EWB), it was wrongly assumed that a different entering condition could be used as long as the performance curves were normalized around the same condition. This caused a fatal error, because EnergyPlus attempts to calculate a rated bypass factor by starting with entering air at ARI standard conditions and then applying the nominal total capacity and SHR. Using a data point corresponding to a drier entering condition caused the leaving air to be supersaturated and the bypass factor search algorithm failed. Further investigation by the EnergyPlus development team resulted in source code changes for additional error checking in the DX coil routines and an improved error message to help users know how to solve this problem.

\section{2) Temperatures Out of Control}

The draft BESTEST specification dated March 2002 did not contain any empirical results or results from other programs to compare to, so it is not possible to determine for certain if any software errors exist. One potential problem was identified, however. For cases E300 and E310, the air-conditioner did not maintain the space temperature at the required $25^{\circ} \mathrm{C}$. There were hours during periods of low or no internal loads, November 6 for example, when the air-conditioner did not cycle on to provide cooling and subsequently the space temperature rose to as high as $30^{\circ} \mathrm{C}$. A change request (bug report) was submitted. The software will be examined to determine why the air-conditioner would not operate during low part-load conditions.

\section{6. $\quad$ Results - Round 1}

Results from the Round 1 modeling with EnergyPlus Version 1.0.2.004 are presented below.

\begin{tabular}{|c|c|c|c|c|c|c|c|c|c|c|c|c|c|}
\hline \multirow[b]{3}{*}{ Cases } & \multicolumn{7}{|c|}{ Annual Sums } & \multicolumn{4}{|c|}{ Annual Means } & \multirow{2}{*}{\multicolumn{2}{|c|}{ 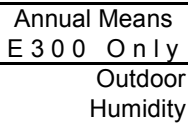 }} \\
\hline & \multirow{2}{*}{\multicolumn{4}{|c|}{$\begin{array}{c}\text { Cooling Energy Consumption } \\
\text { Total Compressor Cond Fan Indoor Fan }\end{array}$}} & \multicolumn{3}{|c|}{ Evaporator Coil Load } & \multirow[b]{2}{*}{ COP2 } & \multicolumn{2}{|c|}{$\begin{array}{r}\text { Zone } \\
\text { Humidity }\end{array}$} & \multirow{2}{*}{$\begin{array}{r}\text { Zone } \\
\text { Relative } \\
\text { Humidity } \\
(\%)\end{array}$} & & \\
\hline & & & & $\begin{array}{r}\text { or Fan } \\
(\mathrm{kWh})\end{array}$ & $\begin{array}{r}\text { Total } \\
(\mathrm{kWh})\end{array}$ & $\begin{array}{r}\text { Sensible } \\
(\mathrm{kWh})\end{array}$ & $\begin{array}{r}\text { Latent } \\
(\mathrm{kWh})\end{array}$ & & $\begin{array}{l}\text { IDB } \\
\left({ }^{\circ} \mathrm{C}\right)\end{array}$ & $\begin{array}{r}\text { Ratio } \\
(\mathrm{kg} / \mathrm{kg})\end{array}$ & & $\begin{array}{r}\mathrm{ODB} \\
\left({ }^{\circ} \mathrm{C}\right)\end{array}$ & $\begin{array}{r}\text { Ratio } \\
(\mathrm{kg} / \mathrm{kg})\end{array}$ \\
\hline E300 & 35149 & 24287 & Note 1 & 10862 & 77308 & 55108 & 22199 & 3.18 & 24.11 & 0.0093 & 48.7 & 19.9 & 0.0116 \\
\hline E310 & 39999 & 29137 & Note 1 & 10862 & 97350 & 55157 & 42193 & 3.34 & 24.10 & 0.0114 & 59.0 & & \\
\hline E320 & 39274 & 28411 & Note 1 & 10862 & 94961 & 61250 & 33712 & 3.34 & 24.26 & 0.0101 & 52.0 & & \\
\hline E330 & 40373 & 29511 & Note 1 & 10862 & 101066 & 62845 & 38221 & 3.42 & 24.29 & 0.0100 & 51.3 & & \\
\hline E340 & 39997 & 29135 & Note 1 & 10862 & 98579 & 62053 & 36526 & 3.38 & 24.31 & 0.0100 & 51.2 & & \\
\hline E350 & 31447 & 20585 & Note 1 & 10862 & 65640 & 48271 & 17369 & 3.19 & 26.26 & 0.0100 & 45.3 & & \\
\hline E360 & 55351 & 44489 & Note 1 & 10862 & 160883 & 134944 & 25940 & 3.62 & 25.41 & 0.0088 & 42.4 & & \\
\hline
\end{tabular}

Note 1: Condenser fan energy consumption included with compressor energy consumption; cannot break out.

\begin{tabular}{|c|c|c|c|c|c|c|c|c|c|c|c|c|c|}
\hline \multirow{4}{*}{ Cases } & \multicolumn{9}{|c|}{ Annual Hourly Integrated Maxima Consumptions and Loads } & \multicolumn{4}{|c|}{ E300 Only, Maxima } \\
\hline & \multirow{2}{*}{\multicolumn{2}{|c|}{$\begin{array}{l}\text { Energy Consumption } \\
\text { Compr + Both Fans }\end{array}$}} & \multicolumn{7}{|c|}{ Evaporator Coil Loads } & \multicolumn{4}{|c|}{ Weather Data Checks } \\
\hline & & & & nsible & & & Latent & Sens & + Latent & & ODB & Outdoor & umidity Ratio \\
\hline & Wh & Date Hour & Wh & Date & Hour & Wh & Date Hour & Wh & Date Hour & ${ }^{\circ} \mathrm{C}$ & Date Hour & $\mathrm{kg} / \mathrm{kg}$ & Date Hour \\
\hline E300 & 11841 & 07/08 15:00 & 23280 & $08 / 16$ & $15: 00$ & 10406 & 09/03 15:00 & 32620 & 07/08 15:00 & 34.775 & $07 / 2014: 00$ & 0.0218 & 10/02 08:00 \\
\hline E310 & 12574 & 08/16 15:00 & 22975 & 07/11 & $16: 00$ & 16529 & 09/18 15:00 & 37342 & 09/03 16:00 & & & & \\
\hline E320 & 13049 & 07/20 14:00 & 31697 & $04 / 24$ & $15: 00$ & 21150 & 10/01 20:00 & 39583 & 09/03 16:00 & & & & \\
\hline E330 & 13436 & 07/20 14:00 & 34709 & $06 / 14$ & $13: 00$ & 27032 & 09/18 15:00 & 42547 & 10/02 09:00 & & & & \\
\hline E340 & 13265 & 07/20 14:00 & 32657 & $05 / 16$ & $15: 00$ & 23236 & 10/02 09:00 & 40741 & 09/03 15:00 & & & & \\
\hline E350 & 11841 & 07/08 15:00 & 23280 & $08 / 16$ & $15: 00$ & 10425 & 10/02 08:00 & 32620 & 07/08 15:00 & & & & \\
\hline E360 & 12910 & $07 / 2014: 00$ & 32542 & $04 / 24$ & $15: 00$ & 8471 & 09/03 17:00 & 38331 & 09/03 12:00 & & & & \\
\hline
\end{tabular}




\begin{tabular}{|c|c|c|c|c|c|c|c|c|c|c|c|}
\hline \multirow[b]{3}{*}{ Hour } & \multicolumn{11}{|c|}{ June 28 Hourly Output - Case E 300} \\
\hline & \multicolumn{2}{|c|}{ Energy Consumption } & \multicolumn{3}{|c|}{ Evaporator Coil Load } & \multirow{2}{*}{$\begin{array}{r}\text { Zone } \\
\text { Hum. Rat. } \\
(\mathrm{kg} / \mathrm{kg})\end{array}$} & \multirow[b]{2}{*}{ COP2 } & \multirow[b]{2}{*}{$\begin{array}{r}\text { ODB } \\
\left({ }^{\circ} \mathrm{C}\right)\end{array}$} & \multirow[b]{2}{*}{$\begin{array}{r}\text { EDB } \\
\left({ }^{\circ} \mathrm{C}\right)\end{array}$} & \multirow[b]{2}{*}{$\begin{array}{r}\mathrm{EWB} \\
\left({ }^{\circ} \mathrm{C}\right)\end{array}$} & \multirow{2}{*}{\begin{tabular}{|r|} 
Outdoor \\
Hum. Rat. \\
$(\mathrm{kg} / \mathrm{kg})$ \\
\end{tabular}} \\
\hline & $\begin{array}{r}\text { Compressor } \\
(\mathrm{Wh})\end{array}$ & $\begin{array}{r}\text { Cond Fan } \\
(\mathrm{Wh})\end{array}$ & $\begin{array}{l}\text { Total } \\
(\mathrm{Wh})\end{array}$ & $\begin{array}{r}\text { Sensible } \\
(\mathrm{Wh})\end{array}$ & $\begin{array}{r}\text { Latent } \\
(\mathrm{Wh})\end{array}$ & & & & & & \\
\hline 1 & 2175 & Note 1 & 7507 & 5853 & 1653 & 0.0094 & 3.45 & 18.1 & 24.0 & & 0.0113 \\
\hline 2 & 2155 & Note 1 & 7454 & 5809 & 1645 & 0.0094 & 3.46 & 18.0 & 23.9 & & 0.0112 \\
\hline 3 & 2116 & Note 1 & 7338 & 5744 & 1594 & 0.0093 & 3.47 & 17.8 & 23.9 & & 0.0111 \\
\hline 4 & 2037 & Note 1 & 7096 & 5614 & 1482 & 0.0092 & 3.48 & 17.4 & 23.9 & & 0.0105 \\
\hline 5 & 2184 & Note 1 & 7430 & 6015 & 1415 & 0.0090 & 3.40 & 18.6 & 24.0 & & 0.0106 \\
\hline 6 & 2924 & Note 1 & 9221 & 7531 & 1689 & 0.0093 & 3.15 & 22.9 & 24.7 & & 0.0123 \\
\hline 7 & 3563 & Note 1 & 10614 & 8756 & 1859 & 0.0096 & 2.98 & 26.4 & 25.2 & & 0.0118 \\
\hline 8 & 3862 & Note 1 & 11106 & 9419 & 1687 & 0.0096 & 2.88 & 28.3 & 25.5 & & 0.0116 \\
\hline 9 & 4928 & Note 1 & 14389 & 11995 & 2393 & 0.0099 & 2.92 & 28.9 & 25.6 & & 0.0124 \\
\hline 10 & 5467 & Note 1 & 15785 & 12488 & 3297 & 0.0105 & 2.89 & 30.3 & 25.8 & & 0.0140 \\
\hline 11 & 5729 & Note 1 & 16519 & 12671 & 3848 & 0.0109 & 2.88 & 30.8 & 25.9 & & 0.0138 \\
\hline 12 & 5605 & Note 1 & 16018 & 12705 & 3312 & 0.0107 & 2.86 & 30.9 & 25.9 & & 0.0120 \\
\hline 13 & 7212 & Note 1 & 21103 & 17594 & 3508 & 0.0102 & 2.93 & 31.5 & 26.0 & & 0.0115 \\
\hline 14 & 7259 & Note 1 & 20979 & 17785 & 3194 & 0.0100 & 2.89 & 32.0 & 26.1 & & 0.0121 \\
\hline 15 & 8968 & Note 1 & 27032 & 22559 & 4472 & 0.0100 & 3.01 & 32.2 & 26.1 & & 0.0135 \\
\hline 16 & 9036 & Note 1 & 27537 & 22458 & 5079 & 0.0102 & 3.05 & 31.9 & 26.0 & & 0.0145 \\
\hline 17 & 5818 & Note 1 & 16600 & 12868 & 3733 & 0.0108 & 2.85 & 31.3 & 26.0 & & 0.0153 \\
\hline 18 & 5620 & Note 1 & 16757 & 12171 & 4586 & 0.0112 & 2.98 & 29.4 & 25.7 & & 0.0149 \\
\hline 19 & 5353 & Note 1 & 16539 & 11556 & 4983 & 0.0113 & 3.09 & 27.6 & 25.4 & & 0.0159 \\
\hline 20 & 5429 & Note 1 & 17030 & 11414 & 5616 & 0.0117 & 3.14 & 27.2 & 25.3 & & 0.0168 \\
\hline 21 & 4416 & Note 1 & 13615 & 8952 & 4663 & 0.0118 & 3.08 & 26.9 & 25.3 & & 0.0168 \\
\hline 22 & 4273 & Note 1 & 13287 & 8753 & 4534 & 0.0117 & 3.11 & 26.3 & 25.2 & & 0.0168 \\
\hline 23 & 4236 & Note 1 & 13230 & 8674 & 4556 & 0.0117 & 3.12 & 26.1 & 25.2 & & 0.0171 \\
\hline 24 & 4007 & Note 1 & 12742 & 8297 & 4444 & 0.0117 & 3.18 & 25.0 & 25.0 & & 0.0165 \\
\hline
\end{tabular}

\begin{tabular}{|c|c|c|c|c|c|c|c|c|}
\hline \multirow{4}{*}{ Cases } & \multicolumn{8}{|c|}{ Annual Hourly Integrated Maxima and Minima - COP2 and Zone } \\
\hline & \multicolumn{4}{|c|}{ COP2 } & \multicolumn{4}{|c|}{ Indoor Drybulb Temperature } \\
\hline & \multicolumn{2}{|c|}{ Maximum } & \multicolumn{2}{|c|}{ Minimum } & \multicolumn{2}{|c|}{ Maximum } & \multicolumn{2}{|c|}{ Minimum* } \\
\hline & COP2 & Date Hour & COP2 & Date Hour & ${ }^{\circ} \mathrm{C}$ & Date Hour & ${ }^{\circ} \mathrm{C}$ & Date Hour \\
\hline$E 300$ & 4.33 & 11/06 17:00 & 2.75 & $06 / 1412: 00$ & 30.7 & 11/06 16:00 & 8.7 & 01/06 05:00 \\
\hline E310 & 4.31 & 11/06 17:00 & 2.84 & $12 / 0114: 00$ & 30.7 & 11/06 16:00 & 8.7 & 01/06 05:00 \\
\hline E320 & 4.26 & 11/06 17:00 & 2.79 & 03/31 14:00 & 31.2 & 07/08 15:00 & 7.8 & 01/06 05:00 \\
\hline E330 & 4.33 & 11/06 17:00 & 2.80 & 03/31 14:00 & 31.0 & 08/16 16:00 & 8.7 & 01/06 05:00 \\
\hline E340 & 4.33 & $11 / 06 \quad 17: 00$ & 2.80 & $03 / 31 \quad 14: 00$ & 31.1 & 08/16 16:00 & 8.7 & 01/06 05:00 \\
\hline E350 & 4.59 & $10 / 13$ 01:00 & 1.60 & $04 / 28 \quad 07: 00$ & 38.1 & $10 / 12 \quad 07: 00$ & 8.7 & 01/06 05:00 \\
\hline E360 & 4.40 & $10 / 0423: 00$ & 2.80 & $03 / 31 \quad 14: 00$ & 32.6 & 07/10 12:00 & 8.7 & 01/06 05:00 \\
\hline
\end{tabular}

\begin{tabular}{|c|c|c|c|c|c|c|c|c|}
\hline \multirow{4}{*}{ Cases } & \multicolumn{8}{|c|}{ Annual Hourly Integrated Maxima and Minima - COP2 and Zone } \\
\hline & \multicolumn{4}{|c|}{ Humidity Ratio } & \multicolumn{4}{|c|}{ Relative Humidity } \\
\hline & \multicolumn{2}{|c|}{ Maximum } & \multicolumn{2}{|c|}{ Minimum* } & \multicolumn{2}{|c|}{ Maximum* } & \multicolumn{2}{|c|}{ Minimum* } \\
\hline & $\mathrm{kg} / \mathrm{kg}$ & Date Hour & $\mathrm{kg} / \mathrm{kg}$ & Date Hour & $\%$ & Date Hour & $\%$ & Date Hour \\
\hline E300 & 0.0136 & 11/16 16:00 & 0.0019 & 01/05 06:00 & 68.4 & 11/16 16:00 & 13.0 & 11/06 15:00 \\
\hline E310 & 0.0159 & 10/02 08:00 & 0.0020 & 01/05 07:00 & 79.9 & 10/02 08:00 & 16.1 & 11/06 08:00 \\
\hline E320 & 0.0178 & 07/10 11:00 & 0.0019 & 01/05 06:00 & 82.7 & 09/16 20:00 & 13.2 & 11/06 15:00 \\
\hline E330 & 0.0181 & 07/10 11:00 & 0.0019 & 01/05 06:00 & 77.0 & 09/16 20:00 & 13.0 & $11 / 06$ 15:00 \\
\hline E340 & 0.0178 & 07/10 11:00 & 0.0019 & 01/05 06:00 & 80.7 & 09/16 20:00 & 13.0 & $11 / 06 \quad 15: 00$ \\
\hline E350 & 0.0172 & $10 / 0124: 00$ & 0.0019 & 01/05 06:00 & 68.4 & 11/16 16:00 & 13.0 & $11 / 06$ 15:00 \\
\hline E360 & 0.0139 & 07/10 12:00 & 0.0019 & 01/05 06:00 & 68.4 & $11 / 16$ 16:00 & 13.0 & $11 / 06$ 15:00 \\
\hline
\end{tabular}




\section{Software Errors Discovered and/or Comparison Between Different Versions of the Same Software - Round 3A}

Note: Other whole-building energy analysis simulation programs participating in this IEA comparative study have gone through two rounds of testing while EnergyPlus, which joined in later, has only gone through one round of testing. To be consistent with results that will be reported by other program participants, the latest round of testing with EnergyPlus as reported below is being referred to as Round 3 testing and results.

As a result of testing done during Round 1, two changes were made to the EnergyPlus code to correct algorithm errors and bring results more in line with what the BESTEST specification called for.

1) Latent Cooling Loads

In EnergyPlus Version 1.0.3.001, an hg function replaced the hfg function in the psychrometric routines. This change produced only small changes in the results.

2) Dry-Coil Conditions

An error found during Round 1 with calculating outlet conditions (humidity ratio and temperature) from the cooling coil when dry conditions (no dehumidification) occurred was corrected in EnergyPlus Version 1.0.3.005. This error was causing the heat pump not to operate during certain hours. NREL also noted this problem with the EnergyPlus results in their report and discussion on the latest results dated July 11,2002. The change made to the code to correct this problem in EnergyPlus Version 1.0.3.005 corrected the zone temperature control problems in cases E300 and E310 and corrected the low minimum COP that had occurred in case E350.

\section{Results - Round 3A}

Results from the Round 3A modeling with EnergyPlus Version 1.0.3.005 are presented below.

\begin{tabular}{|c|c|c|c|c|c|c|c|c|c|c|c|c|c|}
\hline \multirow{4}{*}{ Cases } & \multicolumn{7}{|c|}{ Annual Sums } & \multicolumn{4}{|c|}{ Annual Means } & \multirow{2}{*}{\multicolumn{2}{|c|}{ 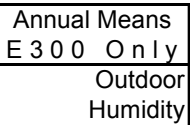 }} \\
\hline & \multirow{2}{*}{\multicolumn{4}{|c|}{$\begin{array}{l}\text { Cooling Energy Consumption } \\
\text { Compressor Cond Fan Indoor Fan }\end{array}$}} & \multicolumn{3}{|c|}{ Evaporator Coil Load } & \multirow{3}{*}{ COP2 } & \multicolumn{2}{|c|}{$\begin{array}{r}\text { Zone } \\
\text { Humidity }\end{array}$} & \multirow{2}{*}{$\begin{array}{r}\text { Zone } \\
\text { Relative } \\
\text { Humidity }\end{array}$} & & \\
\hline & & & & & Total & Sensible & Latent & & IDB & Ratio & & ODB & Ratio \\
\hline & (kWh) & $(\mathrm{kWh})$ & (kWh) & $(\mathrm{kWh})$ & $(\mathrm{kWh})$ & $(\mathrm{kWh})$ & $(\mathrm{kWh})$ & & $\left({ }^{\circ} \mathrm{C}\right)$ & $(\mathrm{kg} / \mathrm{kg})$ & (\%) & $\left({ }^{\circ} \mathrm{C}\right)$ & $(\mathrm{kg} / \mathrm{kg})$ \\
\hline E300 & 34879 & 24016 & Note 1 & 10862 & 77352 & 55255 & 22097 & 3.22 & 24.09 & 0.0093 & 48.6 & 19.9 & 0.0116 \\
\hline E310 & 39445 & 28583 & Note 1 & 10862 & 96434 & 55232 & 41201 & 3.37 & 24.09 & 0.0113 & 58.6 & & \\
\hline E320 & 38983 & 28121 & Note 1 & 10862 & 95107 & 61455 & 33652 & 3.38 & 24.24 & 0.0101 & 51.9 & & \\
\hline E330 & 40074 & 29212 & Note 1 & 10862 & 101239 & 63043 & 38196 & 3.47 & 24.27 & 0.0100 & 51.2 & & \\
\hline E340 & 39694 & 28832 & Note 1 & 10862 & 98715 & 62234 & 36482 & 3.42 & 24.29 & 0.0100 & 51.2 & & \\
\hline E350 & 31256 & 20394 & Note 1 & 10862 & 65804 & 48541 & 17263 & 3.23 & 26.24 & 0.0099 & 45.2 & & \\
\hline E360 & 54849 & 43987 & Note 1 & 10862 & 160937 & 135106 & 25831 & 3.66 & 25.38 & 0.0088 & 42.3 & & \\
\hline
\end{tabular}

Note 1: Condenser fan energy consumption included with compressor energy consumption; cannot break out. 


\begin{tabular}{|c|c|c|c|c|c|c|c|c|c|c|c|c|c|c|}
\hline \multirow{4}{*}{ Cases } & \multicolumn{9}{|c|}{ Annual Hourly Integrated Maxima Consumptions and Loads } & \multicolumn{5}{|c|}{ E300 Only, Maxima } \\
\hline & \multirow{2}{*}{\multicolumn{2}{|c|}{$\begin{array}{l}\text { Energy Consumption } \\
\text { Compr + Both Fans }\end{array}$}} & \multicolumn{7}{|c|}{ Evaporator Coil Loads } & \multicolumn{5}{|c|}{ Weather Data Checks } \\
\hline & & & \multicolumn{3}{|c|}{ Sensible } & \multicolumn{2}{|r|}{ Latent } & \multicolumn{2}{|c|}{ Sensible + Latent } & & ODB & & Outdoor & umidity Ratio \\
\hline & Wh & Date Hour & Wh & Date & Hour & Wh & Date Hour & Wh & Date Hour & ${ }^{\circ} \mathrm{C}$ & Date & Hour & $\mathrm{kg} / \mathrm{kg}$ & Date Hour \\
\hline E300 & 11703 & 07/08 15:00 & 23280 & $08 / 16$ & 15:00 & 10355 & 09/03 15:00 & 32570 & 07/08 15:00 & 34.775 & $07 / 20$ & $14: 00$ & 0.0218 & 10/02 08:00 \\
\hline E310 & 12423 & 08/16 15:00 & 23003 & $07 / 11$ & $16: 00$ & 16224 & 09/18 15:00 & 37073 & 09/03 16:00 & & & & & \\
\hline E320 & 12907 & $07 / 2014: 00$ & 31693 & $04 / 24$ & $15: 00$ & 21134 & $10 / 0120: 00$ & 39574 & 09/03 16:00| & & & & & \\
\hline E330 & 13291 & 07/20 14:00 & 34709 & $06 / 14$ & $13: 00$ & 27032 & 09/18 15:00 & 42547 & 10/02 09:00 & & & & & \\
\hline E340 & 13121 & $07 / 2014: 00$ & 32676 & $05 / 16$ & $15: 00$ & 23232 & 10/02 09:00 & 40738 & 10/02 09:00 & & & & & \\
\hline E350 & 11703 & 07/08 15:00 & 23280 & 08/16 & $15: 00$ & 10425 & 10/02 08:00 & 32570 & 07/08 15:00 & & & & & \\
\hline E360 & 12766 & $07 / 2014: 00$ & 32539 & $04 / 24$ & $15: 00$ & 8426 & 09/03 17:00 & 38300 & 09/03 12:00 & & & & & \\
\hline
\end{tabular}

\begin{tabular}{|c|c|c|c|c|c|c|c|c|c|c|c|}
\hline \multirow[b]{3}{*}{ Hour } & \multicolumn{11}{|c|}{ June 28 Hourly Output - Case E 300} \\
\hline & \multicolumn{2}{|c|}{ Energy Consumption } & \multicolumn{3}{|c|}{ Evaporator Coil Load } & \multirow{2}{*}{$\begin{array}{r}\text { Zone } \\
\text { Hum. Rat. } \\
(\mathrm{kg} / \mathrm{kg})\end{array}$} & \multirow[b]{2}{*}{ COP2 } & \multirow[b]{2}{*}{$\begin{array}{r}\text { ODB } \\
\left({ }^{\circ} \mathrm{C}\right)\end{array}$} & \multirow[b]{2}{*}{$\begin{array}{r}\text { EDB } \\
\left({ }^{\circ} \mathrm{C}\right)\end{array}$} & \multirow[b]{2}{*}{$\begin{array}{c}\mathrm{EWB} \\
\left({ }^{\circ} \mathrm{C}\right)\end{array}$} & \multirow{2}{*}{\begin{tabular}{|r|} 
Outdoor \\
Hum. Rat. \\
$(\mathrm{kg} / \mathrm{kg})$ \\
\end{tabular}} \\
\hline & $\begin{array}{r}\text { Compressor } \\
(\mathrm{Wh})\end{array}$ & $\begin{array}{r}\text { Cond Fan } \\
(\mathrm{Wh})\end{array}$ & $\begin{array}{l}\text { Total } \\
\text { (Wh) }\end{array}$ & $\begin{array}{r}\text { Sensible } \\
\text { (Wh) }\end{array}$ & $\begin{array}{r}\text { Latent } \\
(\mathrm{Wh})\end{array}$ & & & & & & \\
\hline 1 & 2149 & Note 1 & 7506 & 5853 & 1653 & 0.0094 & 3.49 & 18.1 & 24.0 & & 0.0113 \\
\hline 2 & 2129 & Note 1 & 7454 & 5809 & 1645 & 0.0094 & 3.50 & 18.0 & 23.9 & & 0.0112 \\
\hline 3 & 2091 & Note 1 & 7338 & 5744 & 1594 & 0.0093 & 3.51 & 17.8 & 23.9 & & 0.0111 \\
\hline 4 & 2013 & Note 1 & 7096 & 5614 & 1482 & 0.0092 & 3.53 & 17.4 & 23.9 & & 0.0105 \\
\hline 5 & 2158 & Note 1 & 7430 & 6015 & 1415 & 0.0090 & 3.44 & 18.6 & 24.0 & & 0.0106 \\
\hline 6 & 2889 & Note 1 & 9221 & 7531 & 1689 & 0.0093 & 3.19 & 22.9 & 24.7 & & 0.0123 \\
\hline 7 & 3520 & Note 1 & 10614 & 8756 & 1859 & 0.0096 & 3.02 & 26.4 & 25.2 & & 0.0118 \\
\hline 8 & 3817 & Note 1 & 11106 & 9419 & 1687 & 0.0096 & 2.91 & 28.3 & 25.5 & & 0.0116 \\
\hline 9 & 4868 & Note 1 & 14383 & 11995 & 2388 & 0.0099 & 2.95 & 28.9 & 25.6 & & 0.0124 \\
\hline 10 & 5395 & Note 1 & 15758 & 12488 & 3270 & 0.0105 & 2.92 & 30.3 & 25.8 & & 0.0140 \\
\hline 11 & 5651 & Note 1 & 16484 & 12671 & 3813 & 0.0109 & 2.92 & 30.8 & 25.9 & & 0.0138 \\
\hline 12 & 5529 & Note 1 & 15983 & 12705 & 3277 & 0.0107 & 2.89 & 30.9 & 25.9 & & 0.0120 \\
\hline 13 & 7115 & Note 1 & 21059 & 17594 & 3465 & 0.0101 & 2.96 & 31.5 & 26.0 & & 0.0115 \\
\hline 14 & 7163 & Note 1 & 20939 & 17785 & 3154 & 0.0100 & 2.92 & 32.0 & 26.1 & & 0.0121 \\
\hline 15 & 8850 & Note 1 & 26984 & 22559 & 4424 & 0.0100 & 3.05 & 32.2 & 26.1 & & 0.0135 \\
\hline 16 & 8918 & Note 1 & 27492 & 22458 & 5034 & 0.0101 & 3.08 & 31.9 & 26.0 & & 0.0145 \\
\hline 17 & 5740 & Note 1 & 16570 & 12868 & 3702 & 0.0108 & 2.89 & 31.3 & 26.0 & & 0.0153 \\
\hline 18 & 5544 & Note 1 & 16721 & 12171 & 4550 & 0.0112 & 3.02 & 29.4 & 25.7 & & 0.0149 \\
\hline 19 & 5280 & Note 1 & 16502 & 11557 & 4946 & 0.0113 & 3.13 & 27.6 & 25.4 & & 0.0159 \\
\hline 20 & 5355 & Note 1 & 16992 & 11414 & 5578 & 0.0116 & 3.17 & 27.2 & 25.3 & & 0.0168 \\
\hline 21 & 4357 & Note 1 & 13589 & 8952 & 4637 & 0.0118 & 3.12 & 26.9 & 25.3 & & 0.0168 \\
\hline 22 & 4220 & Note 1 & 13279 & 8753 & 4525 & 0.0117 & 3.15 & 26.3 & 25.2 & & 0.0168 \\
\hline 23 & 4185 & Note 1 & 13227 & 8674 & 4553 & 0.0117 & 3.16 & 26.1 & 25.2 & & 0.0171 \\
\hline 24 & 3959 & Note 1 & 12741 & 8297 & 4444 & 0.0117 & 3.22 & 25.0 & 25.0 & & 0.0165 \\
\hline
\end{tabular}

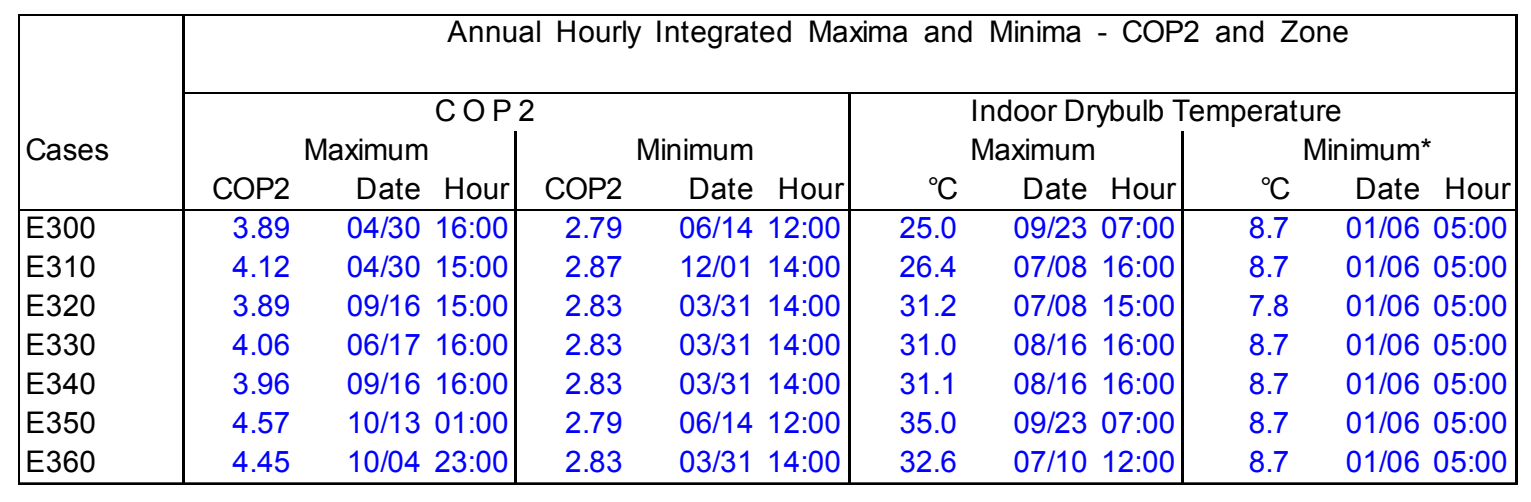




\begin{tabular}{|c|c|c|c|c|c|c|c|c|}
\hline \multirow{4}{*}{ Cases } & \multicolumn{8}{|c|}{ Annual Hourly Integrated Maxima and Minima - COP2 and Zone } \\
\hline & \multicolumn{4}{|c|}{ Humidity Ratio } & \multicolumn{4}{|c|}{ Relative Humidity } \\
\hline & \multicolumn{2}{|c|}{ Maximum } & \multicolumn{2}{|c|}{ Minimum* } & \multicolumn{2}{|c|}{ Maximum* } & \multicolumn{2}{|c|}{ Minimum* } \\
\hline & $\mathrm{kg} / \mathrm{kg}$ & Date Hour & $\mathrm{kg} / \mathrm{kg}$ & Date Hour & $\%$ & Date Hour & $\%$ & Date Hour \\
\hline E300 & 0.0136 & 11/16 16:00 & 0.0019 & 01/05 06:00 & 68.3 & $11 / 1616: 00$ & 14.5 & 11/06 05:00 \\
\hline E310 & 0.0158 & 10/02 08:00 & 0.0020 & 01/05 07:00 & 79.4 & $10 / 02$ 08:00 & 16.1 & $11 / 0608: 00$ \\
\hline E320 & 0.0178 & $07 / 10 \quad 11: 00$ & 0.0019 & 01/05 06:00 & 82.7 & $09 / 1620: 00$ & 14.7 & $11 / 0605: 00$ \\
\hline E330 & 0.0181 & 07/10 11:00 & 0.0019 & 01/05 06:00 & 77.0 & 09/16 20:00 & 14.5 & $11 / 0605: 00$ \\
\hline E340 & 0.0178 & 07/10 11:00 & 0.0019 & 01/05 06:00 & 80.7 & 09/16 20:00 & 14.5 & $11 / 06 \quad 05: 00$ \\
\hline E350 & 0.0172 & $10 / 0124: 00$ & 0.0019 & 01/05 06:00 & 68.3 & $11 / 1616: 00$ & 14.5 & $11 / 06 \quad 05: 00$ \\
\hline E360 & 0.0139 & 07/10 12:00 & 0.0019 & 01/05 06:00 & 68.3 & $11 / 1616: 00$ & 14.5 & $11 / 0605: 00$ \\
\hline
\end{tabular}

\section{Input Changes - Round 3B}

As was discussed in Section 3, the equipment performance data provided in the March 2002 version of the HVAC BESTEST, Volume 2 specification did not contain data for the ARI rating condition of $35^{\circ} \mathrm{C}$ $\mathrm{ODB} / 26.7^{\circ} \mathrm{C} \mathrm{EDB} / 19.4^{\circ} \mathrm{C} \mathrm{EWB}$. EnergyPlus uses this data point to normalize the performance data and produce curve fits for capacity and energy input. The September 2002 version of the specification now includes performance for the ARI rating point. A new set of curve fits was therefore generated for EnergyPlus based on this new data point. The coefficients for those curves that changed are shown below. The coefficients for the other EnergyPlus curves as described in Section 3 remained unchanged.

1) Total cooling capacity modifier curve (function of temperature)

Form: Bi-quadratic curve

$$
\text { curve }=\mathrm{a}+\mathrm{b} * \mathrm{EWB}+\mathrm{c} * \mathrm{EWB} * 2+\mathrm{d}^{*} \text { ODB }+\mathrm{e}^{*} \text { ODB } * * 2+\mathrm{f}^{*} \mathrm{EWB} * \text { ODB }
$$

Independent variables: wet-bulb temperature of the air entering (EWB) the cooling coil, and drybulb temperature of the air entering (ODB) the air-cooled condenser.

$$
\begin{array}{lr}
\mathrm{a}= & 0.952735372 \\
\mathrm{~b}= & -0.000932873 \\
\mathrm{c}= & 0.000927172 \\
\mathrm{~d}= & -0.001291389 \\
\mathrm{e}= & -2.65899 \mathrm{E}-05 \\
\mathrm{f}= & -0.000305038
\end{array}
$$

2) Energy input ratio (EIR) modifier curve (function of temperature)

Form: Bi-quadratic curve

$$
\text { curve }=\mathrm{a}+\mathrm{b} * \mathrm{EWB}+\mathrm{c} * \mathrm{EWB} * 2+\mathrm{d}^{*} \mathrm{ODB}+\mathrm{e}^{*} \mathrm{ODB} * * 2+\mathrm{f}^{*} \mathrm{EWB} * \text { ODB }
$$

Independent variables: wet-bulb temperature of the air entering (EWB) the cooling coil, and drybulb temperature of the air entering (ODB) the air-cooled condenser.

$$
\begin{array}{lr}
\mathrm{a}= & 0.535665387 \\
\mathrm{~b}= & -0.000900699 \\
\mathrm{c}= & -0.000155223 \\
\mathrm{~d}= & 0.012769543 \\
\mathrm{e}= & 0.000163848 \\
\mathrm{f}= & -0.000158128
\end{array}
$$


Use of the new curve fits lowered the annual cooling energy consumption slightly, which resulted in a correspondingly small increase in the COP.

\section{Results - Round 3B}

Results from the Round 3B modeling with EnergyPlus Version 1.0.3.005 are presented below.

\begin{tabular}{|c|c|c|c|c|c|c|c|c|c|c|c|c|c|}
\hline \multirow[b]{3}{*}{ Cases } & \multicolumn{7}{|c|}{ Annual Sums } & \multicolumn{4}{|c|}{ Annual Means } & \multirow{2}{*}{\multicolumn{2}{|c|}{ 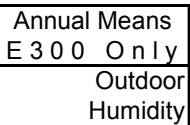 }} \\
\hline & \multirow{2}{*}{\multicolumn{4}{|c|}{$\begin{array}{c}\text { Cooling Energy Consumption } \\
\text { Total Compressor Cond Fan Indoor Fan }\end{array}$}} & \multicolumn{3}{|c|}{ Evaporator Coil Load } & \multirow[b]{2}{*}{ COP2 } & \multicolumn{2}{|c|}{$\begin{array}{r}\text { Zone } \\
\text { Humidity }\end{array}$} & \multirow{2}{*}{$\begin{array}{r}\text { Zone } \\
\text { Relative } \\
\text { Humidity } \\
(\%)\end{array}$} & & \\
\hline & & & & & $\begin{array}{r}\text { Total } \\
(\mathrm{kWh})\end{array}$ & $\begin{array}{r}\text { Sensible } \\
(\mathrm{kWh})\end{array}$ & $\begin{array}{r}\text { Latent } \\
(\mathrm{kWh})\end{array}$ & & $\begin{array}{l}\text { IDB } \\
\left({ }^{\circ} \mathrm{C}\right)\end{array}$ & $\begin{array}{r}\text { Ratio } \\
(\mathrm{kg} / \mathrm{kg})\end{array}$ & & $\begin{array}{r}\mathrm{ODB} \\
\left({ }^{\circ} \mathrm{C}\right)\end{array}$ & $\begin{array}{r}\text { Ratio } \\
(\mathrm{kg} / \mathrm{kg})\end{array}$ \\
\hline E300 & 34719 & 23857 & Note 1 & 10862 & 77332 & 55255 & 22077 & 3.24 & 24.09 & 0.0093 & 48.6 & 19.9 & 0.0116 \\
\hline E310 & 39250 & 28388 & Note 1 & 10862 & 96412 & 55231 & 41181 & 3.40 & 24.09 & 0.0113 & 58.6 & & \\
\hline E320 & 38785 & 27923 & Note 1 & 10862 & 95041 & 61439 & 33601 & 3.40 & 24.25 & 0.0101 & 51.9 & & \\
\hline E330 & 39859 & 28997 & Note 1 & 10862 & 101146 & 63023 & 38122 & 3.49 & 24.27 & 0.0100 & 51.2 & & \\
\hline E340 & 39486 & 28624 & Note 1 & 10862 & 98636 & 62216 & 36420 & 3.45 & 24.29 & 0.0100 & 51.2 & & \\
\hline E350 & 31119 & 20257 & Note 1 & 10862 & 65782 & 48540 & 17241 & 3.25 & 26.24 & 0.0099 & 45.2 & & \\
\hline E360 & 54530 & 43668 & Note 1 & 10862 & 160828 & 135068 & 25760 & 3.68 & 25.39 & 0.0088 & 42.3 & & \\
\hline
\end{tabular}

Note 1: Condenser fan energy consumption included with compressor energy consumption; cannot break out.

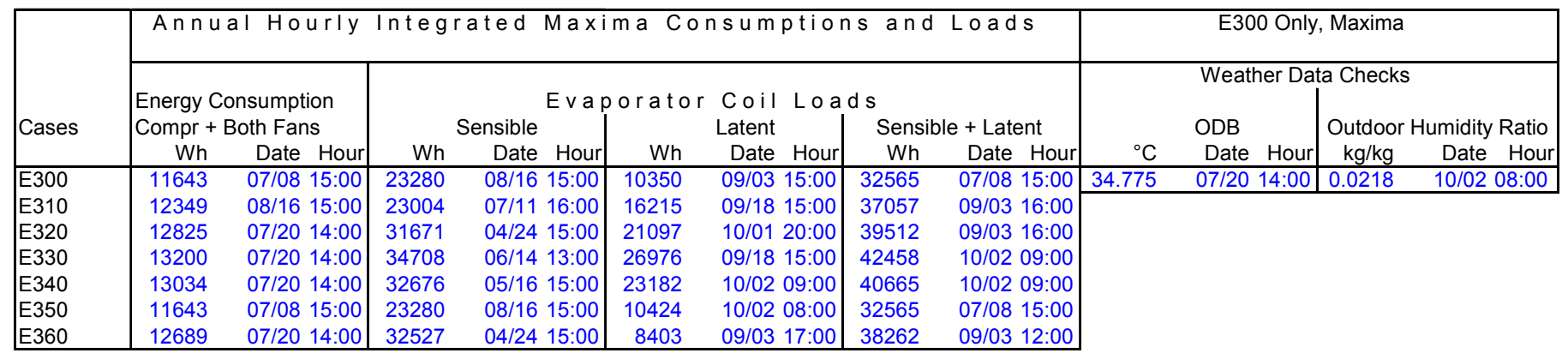

\begin{tabular}{|c|c|c|c|c|c|c|c|c|c|c|c|}
\hline \multirow[b]{3}{*}{ Hour } & \multicolumn{11}{|c|}{ June 28 Hourly Output - Case E300 } \\
\hline & \multicolumn{2}{|c|}{ Energy Consumption } & \multicolumn{3}{|c|}{ Evaporator Coil Load } & \multirow{2}{*}{$\begin{array}{r}\text { Zone } \\
\text { Hum. Rat. } \\
(\mathrm{kg} / \mathrm{kg})\end{array}$} & \multirow[b]{2}{*}{ COP2 } & \multirow[b]{2}{*}{$\begin{array}{l}\text { ODB } \\
\left({ }^{\circ} \mathrm{C}\right)\end{array}$} & \multirow[b]{2}{*}{$\begin{array}{l}\text { EDB } \\
\left({ }^{\circ} \mathrm{C}\right)\end{array}$} & \multirow[b]{2}{*}{$\begin{array}{r}\text { EWB } \\
\left({ }^{\circ} \mathrm{C}\right)\end{array}$} & \multirow{2}{*}{$\begin{array}{r}\text { Outdoor } \\
\text { Hum. Rat. } \\
(\mathrm{kg} / \mathrm{kg})\end{array}$} \\
\hline & $\begin{array}{r}\text { Compressor } \\
(\mathrm{Wh}) \\
\end{array}$ & $\begin{array}{r}\text { Cond Fan } \\
(\mathrm{Wh})\end{array}$ & $\begin{array}{l}\text { Total } \\
(\mathrm{Wh})\end{array}$ & $\begin{array}{r}\text { Sensible } \\
(\mathrm{Wh}) \\
\end{array}$ & $\begin{array}{r}\text { Latent } \\
(\mathrm{Wh})\end{array}$ & & & & & & \\
\hline 1 & 2133 & Note 1 & 7503 & 5853 & 1650 & 0.0094 & 3.52 & 18.1 & 24.0 & & 0.0113 \\
\hline 2 & 2113 & Note 1 & 7451 & 5809 & 1642 & 0.0094 & 3.53 & 18.0 & 23.9 & & 0.0112 \\
\hline 3 & 2075 & Note 1 & 7335 & 5744 & 1591 & 0.0093 & 3.54 & 17.8 & 23.9 & & 0.0111 \\
\hline 4 & 1997 & Note 1 & 7093 & 5614 & 1479 & 0.0092 & 3.55 & 17.4 & 23.9 & & 0.0105 \\
\hline 5 & 2141 & Note 1 & 7427 & 6015 & 1412 & 0.0090 & 3.47 & 18.6 & 24.0 & & 0.0106 \\
\hline 6 & 2869 & Note 1 & 9217 & 7531 & 1686 & 0.0093 & 3.21 & 22.9 & 24.7 & & 0.0123 \\
\hline 7 & 3497 & Note 1 & 10611 & 8756 & 1855 & 0.0096 & 3.03 & 26.4 & 25.2 & & 0.0118 \\
\hline 8 & 3793 & Note 1 & 11102 & 9419 & 1684 & 0.0096 & 2.93 & 28.3 & 25.5 & & 0.0116 \\
\hline 9 & 4838 & Note 1 & 14379 & 11995 & 2383 & 0.0099 & 2.97 & 28.9 & 25.6 & & 0.0124 \\
\hline 10 & 5362 & Note 1 & 15754 & 12488 & 3266 & 0.0105 & 2.94 & 30.3 & 25.8 & & 0.0140 \\
\hline 11 & 5617 & Note 1 & 16480 & 12671 & 3809 & 0.0109 & 2.93 & 30.8 & 25.9 & & 0.0138 \\
\hline 12 & 5496 & Note 1 & 15979 & 12705 & 3273 & 0.0107 & 2.91 & 30.9 & 25.9 & & 0.0120 \\
\hline 13 & 7074 & Note 1 & 21054 & 17594 & 3460 & 0.0101 & 2.98 & 31.5 & 26.0 & & 0.0115 \\
\hline 14 & 7121 & Note 1 & 20935 & 17785 & 3150 & 0.0100 & 2.94 & 32.0 & 26.1 & & 0.0121 \\
\hline 15 & 8799 & Note 1 & 26978 & 22559 & 4419 & 0.0100 & 3.07 & 32.2 & 26.1 & & 0.0135 \\
\hline 16 & 8866 & Note 1 & 27488 & 22458 & 5029 & 0.0101 & 3.10 & 31.9 & 26.0 & & 0.0145 \\
\hline 17 & 5707 & Note 1 & 16567 & 12868 & 3699 & 0.0108 & 2.90 & 31.3 & 26.0 & & 0.0153 \\
\hline 18 & 5509 & Note 1 & 16717 & 12171 & 4546 & 0.0112 & 3.03 & 29.4 & 25.7 & & 0.0149 \\
\hline 19 & 5246 & Note 1 & 16498 & 11557 & 4942 & 0.0113 & 3.14 & 27.6 & 25.4 & & 0.0159 \\
\hline 20 & 5320 & Note 1 & 16988 & 11414 & 5574 & 0.0116 & 3.19 & 27.2 & 25.3 & & 0.0168 \\
\hline 21 & 4328 & Note 1 & 13586 & 8952 & 4634 & 0.0118 & 3.14 & 26.9 & 25.3 & & 0.0168 \\
\hline 22 & 4192 & Note 1 & 13275 & 8753 & 4522 & 0.0117 & 3.17 & 26.3 & 25.2 & & 0.0168 \\
\hline 23 & 4157 & Note 1 & 13224 & 8674 & 4550 & 0.0117 & 3.18 & 26.1 & 25.2 & & 0.0171 \\
\hline 24 & 3932 & Note 1 & 12737 & 8297 & 4440 & 0.0117 & 3.24 & 25.0 & 25.0 & & 0.0165 \\
\hline
\end{tabular}




\begin{tabular}{|c|c|c|c|c|c|c|c|c|c|}
\hline \multirow{4}{*}{ Cases } & \multicolumn{9}{|c|}{ Annual Hourly Integrated Maxima and Minima - COP2 and Zone } \\
\hline & \multicolumn{5}{|c|}{ COP2 } & \multicolumn{4}{|c|}{ Indoor Drybulb Temperature } \\
\hline & \multicolumn{2}{|c|}{ Maximum } & \multicolumn{3}{|c|}{ Minimum } & \multicolumn{2}{|c|}{ Maximum } & \multicolumn{2}{|c|}{ Minimum* } \\
\hline & COP2 & Date Hour & COP2 & Date & Hour & ${ }^{\circ} \mathrm{C}$ & Date Hour & ${ }^{\circ} \mathrm{C}$ & Date Hour \\
\hline E300 & 3.92 & 04/30 16:00 & 2.80 & $06 / 14$ & $12: 00$ & 25.0 & 09/23 07:00 & 8.7 & 01/06 05:00 \\
\hline E310 & 4.15 & 04/30 15:00 & 2.89 & $12 / 01$ & $14: 00$ & 26.4 & 07/08 16:00 & 8.7 & 01/06 05:00 \\
\hline E320 & 3.92 & 09/16 15:00 & 2.84 & $03 / 31$ & 14: & 31.2 & 07/08 15:00 & 7.8 & 01/06 05:00 \\
\hline E330 & 4.08 & 06/17 16:00 & 2.85 & $03 / 31$ & 14: & 31.0 & 08/16 16:00 & 8.7 & 01/06 05:00 \\
\hline E340 & 3.99 & 09/16 16:00 & 2.85 & $03 / 31$ & $14: 00$ & 31.1 & 08/16 16:00 & 8.7 & 01/06 05:00 \\
\hline E350 & 4.61 & 10/13 01:00 & 2.80 & $06 / 14$ & $12: 00$ & 35.0 & 09/23 07:00 & 8.7 & 01/06 05:00 \\
\hline E360 & 4.49 & $10 / 0423: 00$ & 2.85 & $03 / 31$ & $14: 00$ & 32.6 & 07/10 12:00 & 8.7 & 01/06 05:00 \\
\hline
\end{tabular}

\begin{tabular}{|c|c|c|c|c|c|c|c|c|c|}
\hline \multirow{4}{*}{ Cases } & \multicolumn{9}{|c|}{ Annual Hourly Integrated Maxima and Minima - COP2 and Zone } \\
\hline & \multicolumn{4}{|c|}{ Humidity Ratio } & \multicolumn{5}{|c|}{ Relative Humidity } \\
\hline & \multicolumn{2}{|c|}{ Maximum } & \multicolumn{2}{|c|}{ Minimum* } & \multicolumn{2}{|c|}{ Maximum* } & \multicolumn{3}{|c|}{ Minimum* } \\
\hline & $\mathrm{kg} / \mathrm{kg}$ & Date Hour & $\mathrm{kg} / \mathrm{kg}$ & Date Hour & $\%$ & Date Hour & $\%$ & Date & Hour \\
\hline E300 & 0.0136 & 11/16 16:00 & 0.0019 & 01/05 06:00 & 68.4 & 11/16 16:00 & 14.5 & $11 / 06$ & $05: 00$ \\
\hline E310 & 0.0158 & 10/02 08:00 & 0.0020 & 01/05 07:00 & 79.4 & 10/02 08:00 & 16.1 & $11 / 06$ & 08:00 \\
\hline E320 & 0.0178 & 07/10 11:00 & 0.0019 & 01/05 06:00 & 82.7 & 09/16 20:00 & 14.7 & $11 / 06$ & 05:00 \\
\hline E330 & 0.0181 & 07/10 11:00 & 0.0019 & 01/05 06:00 & 77.0 & 09/16 20:00 & 14.5 & $11 / 06$ & 05:00 \\
\hline E340 & 0.0178 & 07/10 11:00| & 0.0019 & 01/05 06:00 & 80.7 & 09/16 20:00 & 14.5 & $11 / 06$ & 05:00 \\
\hline E350 & 0.0172 & 10/01 24:00 & 0.0019 & 01/05 06:00 & 68.4 & 11/16 16:00 & 14.5 & $11 / 06$ & 05:00 \\
\hline E360 & 0.0139 & 07/10 12:00 & 0.0019 & 01/05 06:00 & 68.4 & 11/16 16:00 & 14.5 & $11 / 06$ & 05:00 \\
\hline
\end{tabular}

\section{Software Errors Discovered and/or Comparison Between Different Versions of the Same Software - Round 3C}

\section{Change in Weather Data Interpolation}

In a report by NREL dated July 11, 2002, prepared for the IEA SHC Task 22, Subtask A2 working group, the results of the second round of testing for Cases E300-E545 are presented and discussed. One of the comments made by the authors was that the outdoor dry-bulb temperature seemed to be one hour out of phase with some of the other programs and that the method of "weather averaging" that EnergyPlus uses may be at fault. EnergyPlus does not do any weather averaging but rather uses "weather interpolation" to estimate the value of outdoor parameters when simulation time steps less than one hour are used. The EnergyPlus simulations performed for the HVAC BESTEST E300-E360 test series used a TIMESTEP = 4, which means the building envelope time step is 15 minutes, or 4 time steps per hour. In EnergyPlus Version 1.0.3.006, the interpolation method was changed. Further testing needs to be performed before this technique is accepted as a permanent change in the code, but for now it does seem to give better agreement with what other programs are using. 


\section{Results - Round 3C}

Results from the Round 3C modeling with EnergyPlus Version 1.0.3.006 are presented below. During Round 3C testing the following additional test cases were simulated for the first time: cases E400-E440 and cases E500-E545. The following comments are provided regarding certain input parameters, assumptions and results related to modeling of these new cases with EnergyPlus:

1) Case E410, Compressor Lockout Case E410 required the air conditioning compressor to be locked out from operation anytime the economizer was operating. The EnergyPlus CONTROLLER:OUTSIDE AIR input object does have an optional compressor lockout feature but it has not been implemented yet within the code. The EnergyPlus results for cases E400 and E410 are therefore identical.

2) Cases E500-E545, No Outside Air

For cases E500 through E545, during the initial period of simulation there is no sensible heat gain in the space due to the adiabatic building envelope, no outside air or infiltration, no fan heat because fan operates in a cycling mode, and no sensible internal load due to the schedule, which does not allow either a sensible or latent internal load until March 11. During the simulation of these cases EnergyPlus issued a warning that "Loads initialization did not converge." Putting a sensible load as small as $750 \mathrm{~W}$ for the first hour of the simulation or even changing to a continuous fan operation eliminated this error. The results reported below for cases E500 through E525 were simulated as per the specification with no sensible or latent loads from January 1 through March 10. The initialization warning issued by EnergyPlus appears to have very minimal impact on the results. For cases E530, E540 and E545, see discussion that follows in item (3) below.

3) Dry-Coil cases E530, E540, and E545

Initial simulations with EnergyPlus for these cases resulted in very low humidity levels in the space. This situation is due to EnergyPlus' initialization methodology and was alleviated by introducing a small amount of infiltration during the first week of the simulation. Even though EnergyPlus initializes all nodes to the outdoor humidity ratio at the beginning of the simulation, conditions during the simulation warmup days overdry the zone for these cases. Without the infiltration during the first week, there is no source of moisture to overcome the overdrying and establish the desired equilibrium. For cases E330, E340, and E345, a constant infiltration load of $1.0 \mathrm{~m}^{3} / \mathrm{s}$ was turned on for January 1 through January 7 and then turned off. 


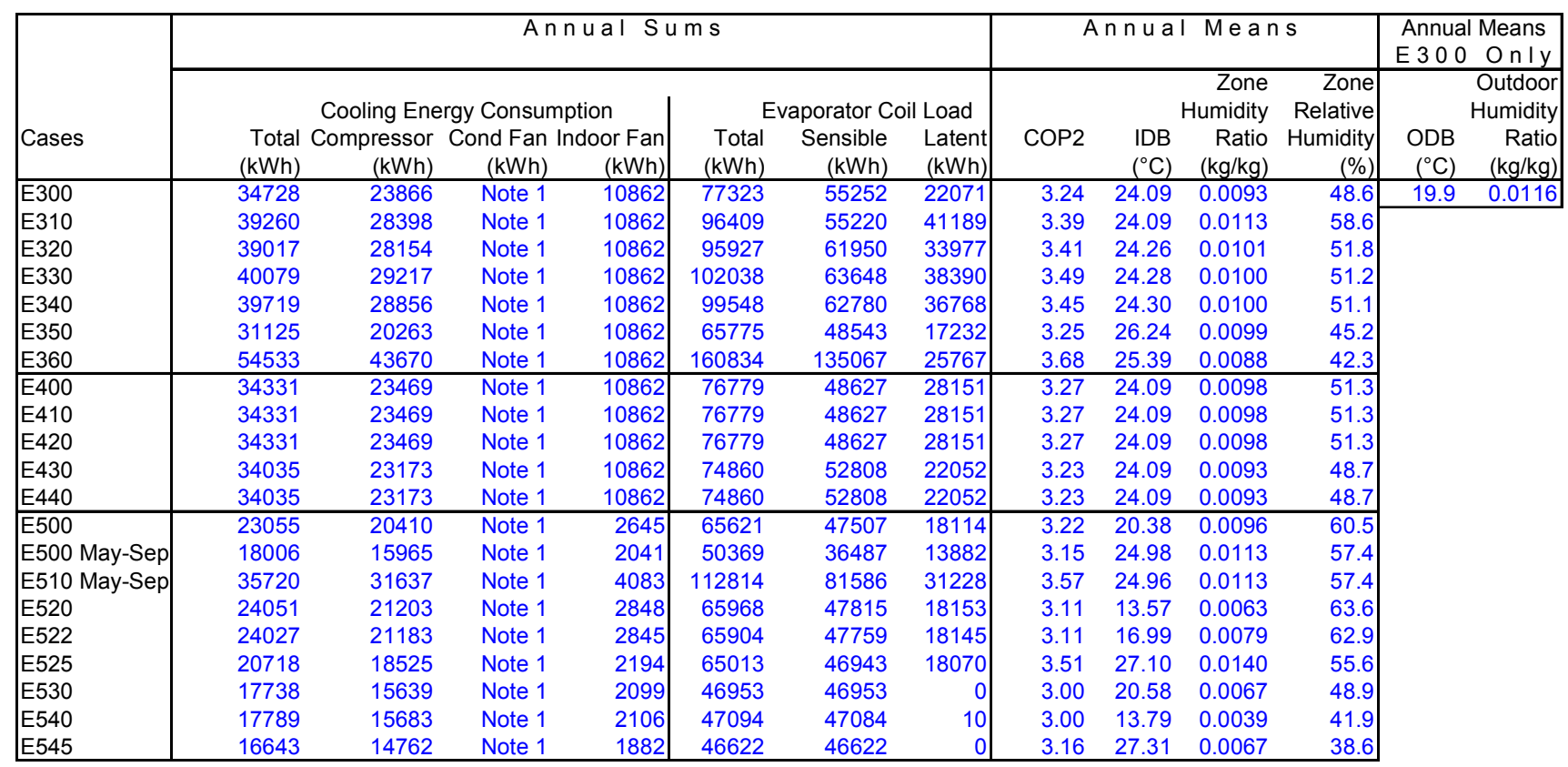

Note 1: Condenser fan energy consumption included with compressor energy consumption; cannot break out.

\begin{tabular}{|c|c|c|c|c|c|c|c|c|c|c|c|c|c|c|}
\hline \multirow{4}{*}{ Cases } & \multicolumn{2}{|c|}{ Annual Hourly } & \multicolumn{7}{|c|}{ d Maxima Consumptions and Loads } & \multicolumn{5}{|c|}{ E300 Only, Maxima } \\
\hline & \multirow{2}{*}{\multicolumn{2}{|c|}{$\begin{array}{l}\text { Energy Consumption } \\
\text { Compr + Both Fans }\end{array}$}} & \multicolumn{7}{|c|}{ Evaporator Coil Loads } & \multicolumn{5}{|c|}{ Weather Data Checks } \\
\hline & & & & ensible & & & Latent & Sens & e + Latent & & ODB & & Outdoor & Aumidity Ratio \\
\hline & Wh & Date Hour & Wh & Date & Hour & Wh & Date Hour & Wh & Date Hour & ${ }^{\circ} \mathrm{C}$ & Date & Hour & $\mathrm{kg} / \mathrm{kg}$ & Date Hour \\
\hline E300 & 11887 & 07/20 15:00 & 23531 & $07 / 20$ & $15: 00$ & 10238 & 07/10 13:00 & 32738 & $07 / 2015: 00$ & 34.775 & $07 / 20$ & $15: 00$ & 0.0218 & 10/02 09:00 \\
\hline E310 & 12479 & 07/20 15:00 & 23209 & $07 / 11$ & $16: 00$ & 16234 & 08/04 15:00 & 37009 & 09/17 15:00 & & & & & \\
\hline E320 & 12889 & 07/20 15:00 & 31800 & $04 / 24$ & $15: 00$ & 22072 & 10/02 10:00 & 39559 & 09/03 16:00 & & & & & \\
\hline E340 & 13066 & 07/20 15:00 & 32753 & $04 / 24$ & $15: 00$ & 23767 & $10 / 0210: 00$ & 41085 & 10/02 10:00 & & & & & \\
\hline E350 & 11887 & 07/20 15:00 & 23531 & $07 / 20$ & $15: 00$ & 10239 & 07/10 13:00 & 32738 & 07/20 15:00 & & & & & \\
\hline E360 & 12690 & 07/20 15:00 & 32528 & $04 / 24$ & $16: 00$ & 8448 & 10/02 11:00 & 38319 & 10/02 11:00 & & & & & \\
\hline E400 & 11887 & $07 / 2015: 00$ & 23531 & $07 / 20$ & $15: 00$ & 26261 & 09/16 14:00 & 40488 & 09/16 15:00 & & & & & \\
\hline E410 & 11887 & 07/20 15:00 & 23531 & $07 / 20$ & $15: 00$ & 26261 & $09 / 1614: 00$ & 40488 & 09/16 15:00 & & & & & \\
\hline E420 & 11887 & $07 / 2015: 00$ & 23531 & $07 / 20$ & $15: 00$ & 26261 & 09/16 14:00 & 40488 & 09/16 15:00 & & & & & \\
\hline E430 & 11887 & 07/20 15:00 & 23531 & $07 / 20$ & $15: 00$ & 10344 & 05/21 15:00 & 32738 & 07/20 15:00 & & & & & \\
\hline E440 & 11887 & 07/20 15:00 & 23531 & $07 / 20$ & $15: 00$ & 10344 & 05/21 15:00 & 32738 & 07/20 15:00 & & & & & \\
\hline E500 & 9223 & 07/20 15:00 & 19845 & $07 / 29$ & $16: 00$ & 7750 & 06/29 16:00 & 27563 & 06/29 16:00 & & & & & \\
\hline E520 & 9485 & $07 / 2015: 00$ & 19936 & $07 / 29$ & $16: 00$ & 7661 & 06/29 16:00 & 27560 & 06/29 16:00 & & & & & \\
\hline E522 & 9487 & $07 / 2015: 00$ & 19927 & $07 / 29$ & $16: 00$ & 7698 & 06/29 16:00 & 27589 & 06/29 16:00 & & & & & \\
\hline E525 & 8581 & 07/20 15:00 & 19660 & $07 / 20$ & $15: 00$ & 7812 & 06/29 16:00 & 27445 & 06/29 16:00| & & & & & \\
\hline E530 & 7301 & 07/20 15:00 & 19643 & $07 / 20$ & $15: 00$ & 2 & 03/16 10:00 & 19643 & 07/20 15:00 & & & & & \\
\hline E540 & 7315 & 07/20 15:00 & 19663 & $07 / 20$ & $15: 00$ & 1791 & 03/11 10:00 & 19663 & 07/20 15:00 & & & & & \\
\hline E545 & 6975 & $07 / 2015: 00$ & 19544 & $07 / 20$ & $15: 00$ & 0 & 09/21 13:00 & 19544 & 07/20 15:00 & & & & & \\
\hline
\end{tabular}




\begin{tabular}{|c|c|c|c|c|c|c|c|c|c|c|c|}
\hline \multirow[b]{3}{*}{ Hour } & \multicolumn{11}{|c|}{ June 28 Hourly Output - Case E300 } \\
\hline & \multicolumn{2}{|c|}{ Energy Consumption } & \multicolumn{3}{|c|}{ Evaporator Coil Load } & \multirow{2}{*}{$\begin{array}{r}\text { Zone } \\
\text { Hum. Rat. } \\
(\mathrm{kg} / \mathrm{kg})\end{array}$} & \multirow[b]{2}{*}{ COP2 } & \multirow[b]{2}{*}{$\begin{array}{l}\mathrm{ODB} \\
\left({ }^{\circ} \mathrm{C}\right)\end{array}$} & \multirow[b]{2}{*}{$\begin{array}{l}\text { EDB } \\
\left({ }^{\circ} \mathrm{C}\right)\end{array}$} & \multirow[b]{2}{*}{$\begin{array}{r}\text { EWB } \\
\left({ }^{\circ} \mathrm{C}\right)\end{array}$} & \multirow{2}{*}{\begin{tabular}{|} 
Outdoor \\
Hum. Rat. \\
$(\mathrm{kg} / \mathrm{kg})$
\end{tabular}} \\
\hline & $\begin{array}{r}\text { Compressor } \\
(\mathrm{Wh})\end{array}$ & $\begin{array}{r}\text { Cond Fan } \\
(\mathrm{Wh})\end{array}$ & $\begin{array}{l}\text { Total } \\
\text { (Wh) }\end{array}$ & $\begin{array}{r}\text { Sensible } \\
(\mathrm{Wh})\end{array}$ & $\begin{array}{r}\text { Latent } \\
(\mathrm{Wh})\end{array}$ & & & & & & \\
\hline 1 & 2119 & Note 1 & 7476 & 5811 & 1666 & 0.0094 & 3.53 & 18.0 & 23.9 & & 0.0112 \\
\hline 2 & 2131 & Note 1 & 7497 & 5853 & 1644 & 0.0094 & 3.52 & 18.1 & 24.0 & & 0.0113 \\
\hline 3 & 2113 & Note 1 & 7449 & 5809 & 1639 & 0.0094 & 3.53 & 18.0 & 23.9 & & 0.0112 \\
\hline 4 & 2075 & Note 1 & 7334 & 5744 & 1590 & 0.0093 & 3.54 & 17.8 & 23.9 & & 0.0111 \\
\hline 5 & 1997 & Note 1 & 7093 & 5614 & 1479 & 0.0092 & 3.55 & 17.4 & 23.9 & & 0.0105 \\
\hline 6 & 2141 & Note 1 & 7427 & 6015 & 1412 & 0.0090 & 3.47 & 18.6 & 24.0 & & 0.0106 \\
\hline 7 & 2869 & Note 1 & 9218 & 7532 & 1686 & 0.0093 & 3.21 & 22.9 & 24.7 & & 0.0123 \\
\hline 8 & 3497 & Note 1 & 10611 & 8756 & 1855 & 0.0096 & 3.03 & 26.4 & 25.2 & & 0.0118 \\
\hline 9 & 4650 & Note 1 & 13922 & 11767 & 2156 & 0.0097 & 2.99 & 28.3 & 25.5 & & 0.0116 \\
\hline 10 & 4929 & Note 1 & 14720 & 11997 & 2723 & 0.0102 & 2.99 & 28.9 & 25.6 & & 0.0124 \\
\hline 11 & 5399 & Note 1 & 15889 & 12488 & 3401 & 0.0106 & 2.94 & 30.3 & 25.8 & & 0.0140 \\
\hline 12 & 5628 & Note 1 & 16519 & 12671 & 3848 & 0.0109 & 2.94 & 30.8 & 25.9 & & 0.0138 \\
\hline 13 & 7127 & Note 1 & 21590 & 17401 & 4189 & 0.0104 & 3.03 & 30.9 & 25.9 & & 0.0120 \\
\hline 14 & 6978 & Note 1 & 20681 & 17592 & 3089 & 0.0100 & 2.96 & 31.5 & 26.0 & & 0.0115 \\
\hline 15 & 8564 & Note 1 & 26137 & 22481 & 3657 & 0.0098 & 3.05 & 32.0 & 26.1 & & 0.0121 \\
\hline 16 & 8724 & Note 1 & 26669 & 22557 & 4111 & 0.0099 & 3.06 & 32.2 & 26.1 & & 0.0135 \\
\hline 17 & 5715 & Note 1 & 16347 & 13062 & 3285 & 0.0106 & 2.86 & 31.9 & 26.0 & & 0.0145 \\
\hline 18 & 5877 & Note 1 & 17196 & 12870 & 4326 & 0.0112 & 2.93 & 31.3 & 26.0 & & 0.0153 \\
\hline 19 & 5552 & Note 1 & 16881 & 12170 & 4710 & 0.0113 & 3.04 & 29.4 & 25.7 & & 0.0149 \\
\hline 20 & 5256 & Note 1 & 16539 & 11556 & 4983 & 0.0113 & 3.15 & 27.6 & 25.4 & & 0.0159 \\
\hline 21 & 4354 & Note 1 & 13565 & 9063 & 4502 & 0.0117 & 3.12 & 27.2 & 25.3 & & 0.0168 \\
\hline 22 & 4292 & Note 1 & 13448 & 8953 & 4495 & 0.0116 & 3.13 & 26.9 & 25.3 & & 0.0168 \\
\hline 23 & 4175 & Note 1 & 13210 & 8753 & 4457 & 0.0116 & 3.16 & 26.3 & 25.2 & & 0.0168 \\
\hline 24 & 4152 & Note 1 & 13204 & 8674 & 4530 & 0.0117 & 3.18 & 26.1 & 25.2 & & 0.0171 \\
\hline
\end{tabular}

\begin{tabular}{|c|c|c|c|c|c|c|c|c|c|}
\hline \multirow{4}{*}{ Cases } & \multicolumn{9}{|c|}{ Annual Hourly Integrated Maxima and Minima - COP2 and Zone } \\
\hline & \multicolumn{5}{|c|}{ COP2 } & \multicolumn{4}{|c|}{ Indoor Drybulb Temperature } \\
\hline & \multicolumn{3}{|c|}{ Maximum } & \multicolumn{2}{|c|}{ Minimum } & \multicolumn{2}{|c|}{ Maximum } & \multicolumn{2}{|c|}{ Minimum* } \\
\hline & COP2 & Date & Hour & COP2 & Date Hour & ${ }^{\circ} \mathrm{C}$ & Date Hour & ${ }^{\circ} \mathrm{C}$ & Date Hour \\
\hline E300 & 3.93 & $04 / 30$ & 15:00 & 2.78 & $06 / 13 \quad 17: 00$ & 25.0 & 09/23 08:00 & 8.7 & $01 / 06 \quad 06: 00$ \\
\hline E310 & 4.18 & $04 / 30$ & $15: 00$ & 2.89 & 12/01 15:00 & 26.6 & 07/20 16:00 & 8.7 & 01/06 06:00 \\
\hline E320 & 3.94 & $09 / 16$ & $15: 00$ & 2.84 & 03/31 15:00 & 31.8 & 07/20 15:00 & 7.8 & 01/06 06:00 \\
\hline E330 & 4.07 & $09 / 16$ & $14: 00$ & 2.85 & 03/31 15:00 & 31.2 & 07/20 15:00 & 8.7 & 01/06 06:00 \\
\hline E340 & 3.99 & $09 / 16$ & $15: 00$ & 2.85 & 03/31 15:00 & 31.6 & 07/20 15:00 & 8.7 & 01/06 06:00 \\
\hline E350 & 4.58 & $10 / 13$ & 01:00 & 2.78 & $06 / 13 \quad 17: 00$ & 35.0 & 10/01 02:00 & 8.7 & 01/06 06:00 \\
\hline E360 & 4.49 & $10 / 05$ & 01:00 & 2.85 & $03 / 31 \quad 15: 00$ & 32.7 & 07/10 13:00 & 8.7 & 01/06 06:00 \\
\hline E400 & 4.07 & $09 / 16$ & $14: 00$ & 2.78 & $06 / 13 \quad 17: 00$ & 26.9 & 09/16 16:00 & 8.7 & 01/06 06:00 \\
\hline E410 & 4.07 & $09 / 16$ & $14: 00$ & 2.78 & $06 / 13 \quad 17: 00$ & 26.9 & 09/16 16:00 & 8.7 & 01/06 06:00 \\
\hline E420 & 4.07 & $09 / 16$ & $14: 00$ & 2.78 & $06 / 13 \quad 17: 00$ & 26.9 & 09/16 16:00 & 8.7 & 01/06 06:00 \\
\hline E430 & 3.80 & $04 / 30$ & $14: 00$ & 2.78 & $06 / 13 \quad 17: 00$ & 25.0 & 10/10 09:00 & 8.7 & 01/06 06:00 \\
\hline E440 & 3.80 & $04 / 30$ & $14: 00$ & 2.78 & $06 / 13 \quad 17: 00$ & 25.0 & 10/10 09:00 & 8.7 & 01/06 06:00 \\
\hline E500 & 4.17 & $04 / 30$ & $16: 00$ & 2.71 & $07 / 3012: 00$ & 25.0 & 03/31 18:00 & 14.5 & 11/23 09:00 \\
\hline E510 & 4.69 & $10 / 05$ & 01:00 & 2.90 & $03 / 31 \quad 18: 00$ & 25.0 & 03/31 18:00 & 14.5 & 11/23 09:00 \\
\hline E520 & 4.06 & $04 / 30$ & $16: 00$ & 2.62 & $07 / 30 \quad 12: 00$ & 15.0 & 03/25 08:00 & 12.8 & $11 / 14 \quad 08: 00$ \\
\hline E522 & 4.06 & $04 / 30$ & $16: 00$ & 2.62 & $07 / 30 \quad 12: 00$ & 20.0 & 04/02 08:00 & 13.8 & $11 / 23 \quad 09: 00$ \\
\hline E525 & 4.65 & $03 / 16$ & $10: 00$ & 2.94 & $07 / 30 \quad 12: 00$ & 35.0 & $03 / 1112: 00$ & 15.4 & $12 / 01 \quad 01: 00$ \\
\hline E530 & 3.88 & $03 / 16$ & $11: 00$ & 2.53 & $07 / 30 \quad 12: 00$ & 25.0 & 04/17 18:00 & 14.5 & 11/23 09:00 \\
\hline E540 & 3.88 & $03 / 16$ & $10: 00$ & 2.53 & $07 / 30 \quad 12: 00$ & 15.0 & 04/16 01:00 & 12.8 & 11/14 08:00 \\
\hline E545 & 4.10 & $03 / 16$ & $11: 00$ & 2.66 & $07 / 30 \quad 12: 00$ & 35.0 & 07/09 22:00 & 15.4 & 12/01 01:00 \\
\hline
\end{tabular}




\begin{tabular}{|c|c|c|c|c|c|c|c|c|}
\hline \multicolumn{4}{|c|}{ Humidity Ratio } & \multicolumn{4}{|c|}{ Relative Humidity } & \multirow{3}{*}{ Cases } \\
\hline \multicolumn{2}{|c|}{ Maximum } & \multicolumn{2}{|c|}{ Minimum* } & \multicolumn{2}{|c|}{ Maximum* } & \multicolumn{2}{|c|}{ Minimum* } & \\
\hline $\mathrm{kg} / \mathrm{kg}$ & Date Hour & $\mathrm{kg} / \mathrm{kg}$ & Date Hour & $\%$ & Date Hour & $\%$ & Date Hour & \\
\hline 0.0136 & 11/16 17:00 & 0.0019 & 01/11 03:00 & 68.4 & 11/16 17:00 & 14.4 & 11/06 06:00 & E300 \\
\hline 0.0156 & 10/01 $08: 00$ & 0.0019 & 01/05 07:00 & 78.6 & 10/02 08:00 & 15.6 & $11 / 0608: 00$ & E310 \\
\hline 0.0178 & 07/10 13:00 & 0.0019 & 01/11 03:00 & 83.0 & 09/18 10:00 & 14.7 & $11 / 06 \quad 06: 00$ & E320 \\
\hline 0.0181 & 07/10 12:00 & 0.0019 & 01/11 03:00 & 76.8 & 09/17 12:00 & 14.4 & 11/06 06:00 & E330 \\
\hline 0.0178 & 07/10 12:00 & 0.0019 & 01/11 03:00 & 80.8 & 09/18 10:00 & 14.4 & $11 / 06 \quad 06: 00$ & E340 \\
\hline 0.0172 & 10/02 01:00 & 0.0019 & 01/11 03:00 & 68.4 & 11/16 17:00 & 14.4 & 11/06 06:00 & E350 \\
\hline 0.0139 & 07/10 13:00 & 0.0019 & 01/11 03:00 & 68.4 & $11 / 16 \quad 17: 00$ & 14.4 & $11 / 06 \quad 06: 00$ & E360 \\
\hline \begin{tabular}{|l|}
0.0160 \\
\end{tabular} & 09/07 01:00 & 0.0019 & 01/11 03:00 & 80.4 & 09/07 01:00 & 14.2 & 11/06 06:00 & $\mathrm{E} 400$ \\
\hline 0.0160 & 09/07 01:00 & 0.0019 & 01/11 03:00 & 80.4 & 09/07 01:00 & 14.2 & $11 / 06 \quad 06: 00$ & E410 \\
\hline 0.0160 & 09/07 01:00 & 0.0019 & 01/11 03:00 & 80.4 & 09/07 01:00 & 14.2 & 11/06 06:00 & E420 \\
\hline 0.0136 & 11/16 17:00 & 0.0019 & 01/11 03:00 & 68.4 & 11/16 17:00 & 14.2 & $11 / 06 \quad 06: 00$ & E430 \\
\hline 0.0136 & 11/16 17:00 & 0.0019 & 01/11 03:00 & 68.4 & 11/16 17:00 & 14.2 & $11 / 06 \quad 06: 00$ & E440 \\
\hline 0.0134 & 04/18 19:00 & 0.0102 & 11/23 10:00 & 100.0 & 11/13 09:00 & 54.4 & $04 / 3013: 00$ & E500 \\
\hline 0.0154 & 10/12 02:00 & 0.0102 & 11/23 10:00 & 100.0 & 11/13 09:00 & 55.2 & $11 / 04 \quad 13: 00$ & E510 \\
\hline 0.0087 & 04/18 19:00 & 0.0064 & 04/30 13:00 & 84.1 & 10/18 08:00 & 60.7 & $04 / 30 \quad 13: 00$ & E520 \\
\hline 0.0108 & 04/18 19:00 & 0.0084 & 04/30 13:00 & 100.0 & $11 / 22 \quad 02: 00$ & 57.9 & $04 / 3013: 00$ & E522 \\
\hline 0.0199 & 04/18 19:00 & 0.0109 & $11 / 3024: 00$ & 100.0 & 11/12 01:00 & 47.3 & $04 / 30 \quad 13: 00$ & E525 \\
\hline 0.0091 & 01/03 15:00 & 0.0067 & 10/18 12:00 & 66.3 & 11/23 09:00 & 33.9 & 09/28 18:00 & E530 \\
\hline 0.0091 & 01/03 15:00 & 0.0033 & 10/17 09:00 & 36.0 & 11/22 10:00 & 30.8 & 09/28 18:00 & E540 \\
\hline 0.0091 & 01/03 15:00 & 0.0068 & 04/01 01:00 & 62.3 & $11 / 3023: 00$ & 19.2 & 04/18 17:00 & E545 \\
\hline
\end{tabular}

\begin{tabular}{|c|c|c|c|c|c|c|c|c|c|c|c|}
\hline \multirow[b]{3}{*}{ Day } & \multicolumn{11}{|c|}{ Case E500 Average Daily Outputs-f(ODB) sensitivity } \\
\hline & \multicolumn{4}{|c|}{ Energy Consumption } & \multicolumn{2}{|c|}{ Evaporator Coil Load } & \multirow{2}{*}{$\begin{array}{r}\text { Latent } \\
(\mathrm{Wh})\end{array}$} & \multirow{2}{*}{$\begin{array}{r}\text { Zone } \\
\text { Hum Rat } \\
(\mathrm{kg} / \mathrm{kg})\end{array}$} & \multirow[b]{2}{*}{ COP2 } & \multirow{2}{*}{$\begin{array}{r}\text { ODB } \\
\left({ }^{\circ} \mathrm{C}\right)\end{array}$} & \multirow[b]{2}{*}{$\begin{array}{r}\text { EDB } \\
\left({ }^{\circ} \mathrm{C}\right)\end{array}$} \\
\hline & Total & Compressor & Cond Fan & or Fan & Total & Sensible & & & & & \\
\hline April 30 & 4032 & 3510 & Note 1 & 522 & 13659 & 9887 & 3773 & 0.0110 & 3.85 & 16.8 & 24.98 \\
\hline June 25 & 5232 & 4663 & Note 1 & 569 & 13737 & 9956 & 3781 & 0.0115 & 2.95 & 29.5 & 24.98 \\
\hline
\end{tabular}

\begin{tabular}{|c|c|c|c|c|c|c|c|c|c|c|c|}
\hline \multirow[b]{3}{*}{ Day } & \multicolumn{11}{|c|}{ Case E530 Average Daily Outputs - f(ODB) sensitivity } \\
\hline & \multicolumn{4}{|c|}{ Energy Consumption } & \multicolumn{3}{|c|}{ Evaporator Coil Load } & \multicolumn{2}{|l|}{ Zone } & \multirow[b]{2}{*}{$\begin{array}{c}\text { ODB } \\
\left({ }^{\circ} \mathrm{C}\right)\end{array}$} & \multirow[b]{2}{*}{$\begin{array}{c}\text { EDB } \\
\left({ }^{\circ} \mathrm{C}\right)\end{array}$} \\
\hline & $\begin{array}{l}\text { Total } \\
\text { (Wh) }\end{array}$ & $\begin{array}{r}\text { Compressor } \\
\text { (Wh) }\end{array}$ & $\begin{array}{r}\text { Cond Fan } \\
(\mathrm{Wh})\end{array}$ & $\begin{array}{r}\text { or Fan } \\
(\mathrm{Wh})\end{array}$ & $\begin{array}{l}\text { Total } \\
(\mathrm{Wh})\end{array}$ & $\begin{array}{r}\text { Sensible } \\
(\mathrm{Wh})\end{array}$ & $\begin{array}{r}\text { Latent } \\
(\mathrm{Wh})\end{array}$ & $\begin{array}{r}\text { Hum Rat } \\
(\mathrm{kg} / \mathrm{kg})\end{array}$ & $\mathrm{COP} 2$ & & \\
\hline April 30 & 3094 & 2681 & Note 1 & 413 & 9775 & 9775 & 0 & 0.0067 & 3.45 & 16.8 & 25.00 \\
\hline June 25 & 4030 & 3578 & Note 1 & 453 & 9838 & 9838 & 0 & 0.0067 & 2.78 & 29.5 & 25.00 \\
\hline
\end{tabular}

\section{Input Errors Discovered and/or Comparison Between Different Versions of the Same Software - Round 4}

A comparison of EnergyPlus results from Round 3C with results from other programs (Ref: $H V A C$ BESTEST Cases E300-E545, Summary of $3^{\text {rd }}$ Set of Results, 12 Nov. 2002, J. Neymark) indicated that there were disagreements with regard to economizer control results (Cases E400-E440) and DX cooling system performance for Cases E500-E545. Further investigation into the reasons for these differences indicated that several input errors had been made: 
1) Cases $400-440$

A fan outlet node name for the mixed air set point manager had been incorrectly identified and caused the economizer control to operate not in accordance with the specification.

2) Case 410

This case required that the DX cooling compressor be locked out from operating whenever the economizer was in operation. This capability has not yet been implemented in EnergyPlus so no results are being shown for this case.

3) Case 420

The economizer high temperature limit of $20^{\circ} \mathrm{C}$ for this case had not been specified as required and was defaulting to a different setting.

4) Cases 500-545

The EnergyPlus total electricity consumption results for these cases are consistently low compared to the results of other programs. The DX coil model may be imposing some temperature limits on the use of the performance curves. During Round 4 the input temperature limits that defined the boundaries of the performance curves were opened up and some slight improvement in results occurred for Cases 520 and 540. This problem will be further investigated.

The results for Round 4, which are presented below, were produced using EnergyPlus 1.0.3.013.

\begin{tabular}{|c|c|c|c|c|c|c|c|c|c|c|c|c|c|}
\hline \multirow[b]{3}{*}{ Cases } & \multicolumn{7}{|c|}{ Annual Sums } & \multicolumn{4}{|c|}{ Annual Means } & \multirow{2}{*}{\multicolumn{2}{|c|}{ 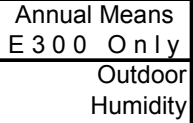 }} \\
\hline & \multicolumn{4}{|c|}{ Cooling Energy Consumption } & \multicolumn{3}{|c|}{ Evaporator Coil Load } & & & $\begin{array}{r}\text { Zone } \\
\text { tumidity }\end{array}$ & $\begin{array}{r}\text { Zone } \\
\text { Relative }\end{array}$ & & \\
\hline & $\begin{array}{r}\text { Total } \\
(\mathrm{kWh}) \\
\end{array}$ & $\begin{array}{r}\text { Compressor } \\
(\mathrm{kWh}) \\
\end{array}$ & $\begin{array}{r}\text { Cond Fan } \\
(\mathrm{kWh})\end{array}$ & $\begin{array}{r}\text { or Fan } \\
(\mathrm{kWh}) \\
\end{array}$ & $\begin{array}{r}\text { Total } \\
(\mathrm{kWh}) \\
\end{array}$ & $\begin{array}{r}\text { Sensible } \\
(\mathrm{kWh}) \\
\end{array}$ & $\begin{array}{r}\text { Latent } \\
(\mathrm{kWh}) \\
\end{array}$ & COP2 & $\begin{array}{l}\text { IDB } \\
\left({ }^{\circ} \mathrm{C}\right) \\
\end{array}$ & $\begin{array}{r}\text { Ratio } \\
(\mathrm{kg} / \mathrm{kg}) \\
\end{array}$ & $\begin{array}{r}\text { Humidity } \\
(\%) \\
\end{array}$ & $\begin{array}{r}\text { ODB } \\
\left({ }^{\circ} \mathrm{C}\right) \\
\end{array}$ & $\begin{array}{r}\text { Ratio } \\
(\mathrm{kg} / \mathrm{kg}) \\
\end{array}$ \\
\hline E300 & 34743 & 23881 & Note 1 & 10862 & 77307 & 55252 & 22055 & 3.24 & 24.09 & 0.0093 & 48.6 & 19.9 & 0.0116 \\
\hline E310 & 39282 & 28420 & Note 1 & 10862 & 96404 & 55225 & 41179 & 3.39 & 24.09 & 0.0113 & 58.6 & & \\
\hline E320 & 39084 & 28222 & Note 1 & 10862 & 96103 & 62045 & 34058 & 3.41 & 24.25 & 0.0101 & 51.9 & & \\
\hline E330 & 40151 & 29289 & Note 1 & 10862 & 102242 & 63778 & 38463 & 3.49 & 24.27 & 0.0100 & 51.2 & & \\
\hline E340 & 39789 & 28927 & Note 1 & 10862 & 99731 & 62887 & 36844 & 3.45 & 24.30 & 0.0100 & 51.2 & & \\
\hline E350 & 31138 & 20276 & Note 1 & 10862 & 65763 & 48545 & 17218 & 3.24 & 26.24 & 0.0099 & 45.2 & & \\
\hline E360 & 54703 & 43841 & Note 1 & 10862 & 161241 & 135286 & 25955 & 3.68 & 25.32 & 0.0088 & 42.4 & & \\
\hline $\begin{array}{l}\text { E400 } \\
\text { E410 }\end{array}$ & 31009 & 20147 & $\begin{array}{l}\text { Note } 1 \\
\text { Note } 1\end{array}$ & 10862 & 65399 & 40691 & 24708 & 3.25 & 24.09 & 0.0101 & 52.5 & & \\
\hline E420 & 32734 & 21872 & Note 1 & 10862 & 70343 & 49527 & 20816 & 3.22 & 24.09 & 0.0094 & 49.4 & & \\
\hline E430 & 31769 & 20907 & Note 1 & 10862 & 67129 & 46733 & 20396 & 3.21 & 24.09 & 0.0095 & 49.6 & & \\
\hline E440 & 31770 & 20908 & Note 1 & 10862 & 67131 & 46734 & 20397 & 3.21 & 24.09 & 0.0095 & 49.6 & & \\
\hline E500 & 23049 & 20419 & Note 1 & 2630 & 65605 & 47492 & 18113 & 3.21 & 20.38 & 0.0096 & 60.5 & & \\
\hline E500 May-Sep & 18001 & 15972 & Note 1 & 2030 & 50357 & 36476 & 13881 & 3.15 & 24.98 & 0.0113 & 57.4 & & \\
\hline E510 May-Sep & 35732 & 31669 & Note 1 & 4063 & 112793 & 81566 & 31226 & 3.56 & 24.96 & 0.0113 & 57.4 & & \\
\hline E520 & 25043 & 22021 & Note 1 & 3022 & 66154 & 47989 & 18165 & 3.00 & 13.58 & 0.0064 & 64.7 & & \\
\hline E522 & 24099 & 21254 & Note 1 & 2845 & 65904 & 47760 & 18144 & 3.10 & 16.99 & 0.0079 & 63.0 & & \\
\hline E525 & 20710 & 18529 & Note 1 & 2181 & 65000 & 46930 & 18069 & 3.51 & 27.10 & 0.0140 & 55.7 & & \\
\hline E530 & 17742 & 15652 & Note 1 & 2090 & 46944 & 46944 & 0 & 3.00 & 20.58 & 0.0067 & 49.0 & & \\
\hline E540 & 19061 & 16752 & Note 1 & 2309 & 47296 & 47288 & 9 & 2.82 & 13.79 & 0.0043 & 46.3 & & \\
\hline E545 & 16636 & 14765 & Note 1 & 1871 & 46612 & 46612 & 0 & 3.16 & 27.31 & 0.0067 & 38.6 & & \\
\hline
\end{tabular}

Note 1: Condenser fan energy consumption included with compressor energy consumption; cannot break out. 


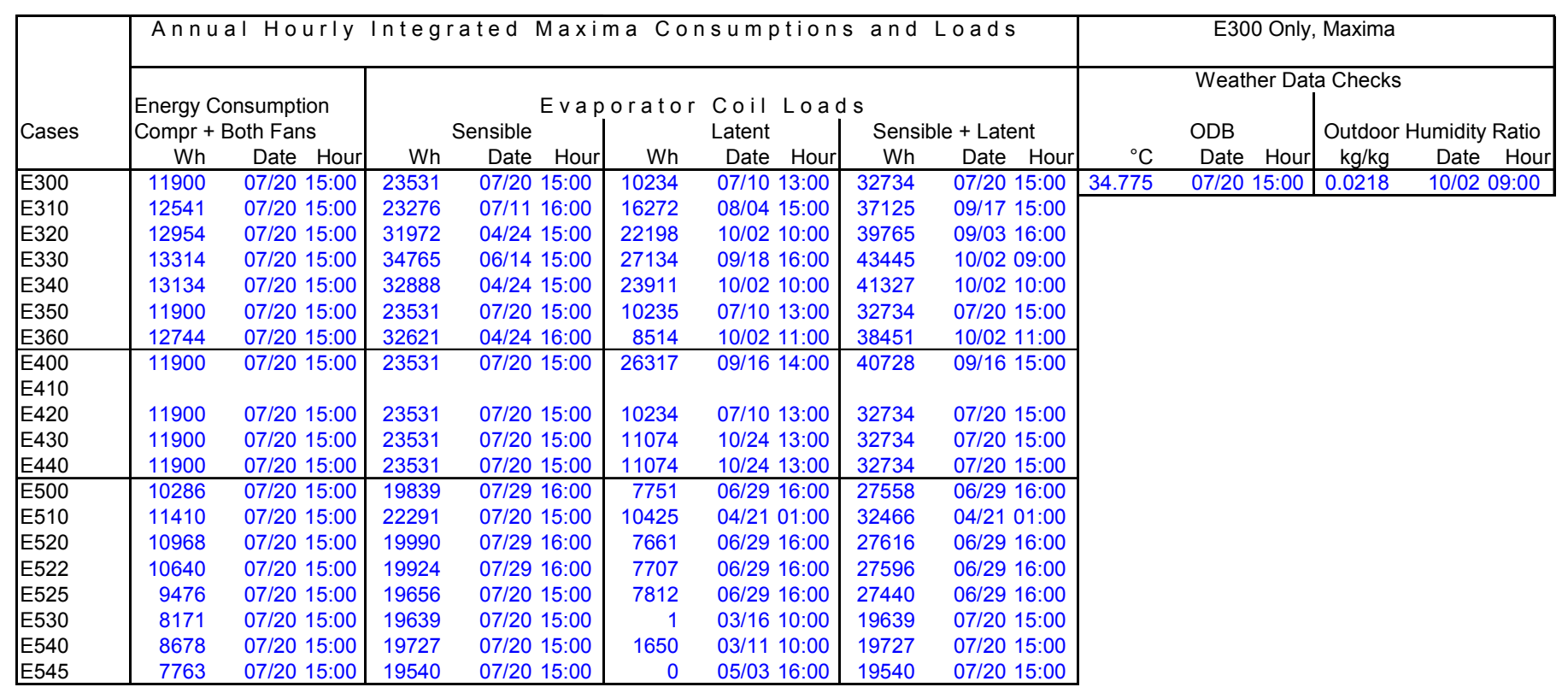

\begin{tabular}{|c|c|c|c|c|c|c|c|c|c|c|c|}
\hline \multirow[b]{3}{*}{ Hour } & \multicolumn{11}{|c|}{ June 28 Hourly Output - Case E 300} \\
\hline & \multicolumn{2}{|c|}{ Energy Consumption } & \multicolumn{3}{|c|}{ Evaporator Coil Load } & \multirow{2}{*}{$\begin{array}{r}\text { Zone } \\
\text { Hum. Rat. } \\
(\mathrm{kg} / \mathrm{kg})\end{array}$} & \multirow[b]{2}{*}{ COP2 } & \multirow[b]{2}{*}{$\begin{array}{r}\text { ODB } \\
\left({ }^{\circ} \mathrm{C}\right) \\
\end{array}$} & \multirow[b]{2}{*}{$\begin{array}{r}\text { EDB } \\
\left({ }^{\circ} \mathrm{C}\right)\end{array}$} & \multirow[b]{2}{*}{$\begin{array}{r}\mathrm{EWB} \\
\left({ }^{\circ} \mathrm{C}\right) \\
\end{array}$} & \multirow{2}{*}{$\begin{array}{r}\text { Outdoor } \\
\text { Hum. Rat } \\
(\mathrm{kg} / \mathrm{kg})\end{array}$} \\
\hline & $\begin{array}{r}\text { Compressor } \\
(\mathrm{Wh}) \\
\end{array}$ & $\begin{array}{r}\text { Cond Fan } \\
(\mathrm{Wh}) \\
\end{array}$ & $\begin{array}{l}\text { Total } \\
\text { (Wh) }\end{array}$ & $\begin{array}{r}\text { Sensible } \\
(\mathrm{Wh})\end{array}$ & $\begin{array}{r}\text { Latent } \\
(\mathrm{Wh})\end{array}$ & & & & & & \\
\hline 1 & 2119 & Note 1 & 7475 & 5811 & 1664 & 0.0094 & 3.53 & 18.0 & 23.9 & & 0.0112 \\
\hline 2 & 2132 & Note 1 & 7496 & 5853 & 1643 & 0.0094 & 3.52 & 18.1 & 24.0 & & 0.0113 \\
\hline 3 & 2113 & Note 1 & 7447 & 5809 & 1638 & 0.0094 & 3.52 & 18.0 & 23.9 & & 0.0112 \\
\hline 4 & 2075 & Note 1 & 7332 & 5744 & 1589 & 0.0093 & 3.53 & 17.8 & 23.9 & & 0.0111 \\
\hline 5 & 1997 & Note 1 & 7091 & 5614 & 1477 & 0.0092 & 3.55 & 17.4 & 23.9 & & 0.0105 \\
\hline 6 & 2142 & Note 1 & 7425 & 6015 & 1410 & 0.0090 & 3.47 & 18.6 & 24.0 & & 0.0106 \\
\hline 7 & 2869 & Note 1 & 9215 & 7532 & 1683 & 0.0093 & 3.21 & 22.9 & 24.7 & & 0.0123 \\
\hline 8 & 3498 & Note 1 & 10609 & 8756 & 1853 & 0.0096 & 3.03 & 26.4 & 25.2 & & 0.0118 \\
\hline 9 & 4652 & Note 1 & 13919 & 11767 & 2152 & 0.0097 & 2.99 & 28.3 & 25.5 & & 0.0116 \\
\hline 10 & 4931 & Note 1 & 14717 & 11997 & 2720 & 0.0102 & 2.98 & 28.9 & 25.6 & & 0.0124 \\
\hline 11 & 5401 & Note 1 & 15886 & 12488 & 3398 & 0.0106 & 2.94 & 30.3 & 25.8 & & 0.0140 \\
\hline 12 & 5631 & Note 1 & 16516 & 12671 & 3845 & 0.0109 & 2.93 & 30.8 & 25.9 & & 0.0138 \\
\hline 13 & 7132 & Note 1 & 21586 & 17401 & 4185 & 0.0104 & 3.03 & 30.9 & 25.9 & & 0.0120 \\
\hline 14 & 6983 & Note 1 & 20677 & 17592 & 3086 & 0.0100 & 2.96 & 31.5 & 26.0 & & 0.0115 \\
\hline 15 & 8572 & Note 1 & 26133 & 22481 & 3652 & 0.0098 & 3.05 & 32.0 & 26.1 & & 0.0121 \\
\hline 16 & 8733 & Note 1 & 26665 & 22557 & 4107 & 0.0099 & 3.05 & 32.2 & 26.1 & & 0.0135 \\
\hline 17 & 5718 & Note 1 & 16345 & 13062 & 3283 & 0.0106 & 2.86 & 31.9 & 26.0 & & 0.0145 \\
\hline 18 & 5881 & Note 1 & 17194 & 12870 & 4324 & 0.0112 & 2.92 & 31.3 & 26.0 & & 0.0153 \\
\hline 19 & 5555 & Note 1 & 16878 & 12170 & 4708 & 0.0113 & 3.04 & 29.4 & 25.7 & & 0.0149 \\
\hline 20 & 5259 & Note 1 & 16537 & 11556 & 4981 & 0.0113 & 3.14 & 27.6 & 25.4 & & 0.0159 \\
\hline 21 & 4356 & Note 1 & 13563 & 9063 & 4500 & 0.0117 & 3.11 & 27.2 & 25.3 & & 0.0168 \\
\hline 22 & 4294 & Note 1 & 13446 & 8953 & 4493 & 0.0116 & 3.13 & 26.9 & 25.3 & & 0.0168 \\
\hline 23 & 4177 & Note 1 & 13208 & 8753 & 4455 & 0.0116 & 3.16 & 26.3 & 25.2 & & 0.0168 \\
\hline 24 & 4153 & Note 1 & 13202 & 8674 & 4528 & 0.0117 & 3.18 & 26.1 & 25.2 & & 0.0171 \\
\hline
\end{tabular}




\begin{tabular}{|c|c|c|c|c|c|c|c|c|c|c|}
\hline \multirow{4}{*}{ Cases } & \multicolumn{10}{|c|}{ Annual Hourly Integrated Maxima and Minima - COP2 and Zone } \\
\hline & \multicolumn{6}{|c|}{ COP2 } & \multicolumn{4}{|c|}{ Indoor Drybulb Temperature } \\
\hline & \multicolumn{3}{|c|}{ Maximum } & \multicolumn{3}{|c|}{ Minimum } & \multicolumn{2}{|c|}{ Maximum } & \multicolumn{2}{|c|}{ Minimum* } \\
\hline & COP2 & Date & Hour & COP2 & Date & Hour & ${ }^{\circ} \mathrm{C}$ & Date Hour & ${ }^{\circ} \mathrm{C}$ & Date Hour \\
\hline E300 & 3.93 & $04 / 30$ & 15:00 & 2.78 & $06 / 13$ & 17:00 & 25.0 & 09/23 08:00 & 8.7 & $01 / 06 \quad 06: 00$ \\
\hline E310 & 4.17 & $04 / 30$ & 15:00 & 2.89 & $12 / 01$ & $15: 00$ & 26.5 & 07/20 16:00 & 8.7 & 01/06 06:00 \\
\hline E320 & 3.94 & $09 / 16$ & 15:00 & 2.84 & $03 / 31$ & 15:00 & 31.7 & 07/20 15:00 & 7.8 & 01/06 06:00 \\
\hline E330 & 4.07 & $09 / 16$ & $14: 00$ & 2.84 & $03 / 31$ & $15: 00$ & 31.1 & 07/08 16:00 & 8.7 & 01/06 06:00 \\
\hline E340 & 3.99 & $09 / 16$ & $15: 00$ & 2.84 & $03 / 31$ & $15: 00$ & 31.5 & 07/20 15:00 & 8.7 & 01/06 06:00 \\
\hline E350 & 4.56 & $10 / 13$ & 01:00 & 2.78 & $06 / 13$ & $17: 00$ & 35.0 & 10/01 $02: 00$ & 8.7 & 01/06 06:00 \\
\hline E360 & 4.46 & $10 / 04$ & $24: 00$ & 2.84 & $03 / 31$ & $15: 00$ & 32.5 & 07/10 13:00 & 8.7 & 01/06 06:00 \\
\hline E400 & 4.07 & $09 / 16$ & 14:00 & 2.78 & $06 / 13$ & 17:00 & 26.9 & 09/16 16:00 & 8.7 & 01/06 06:00 \\
\hline E410 & & & & & & & & & & \\
\hline $\mathrm{E} 420$ & 3.82 & $05 / 21$ & $15: 00$ & 2.78 & $06 / 13$ & $17: 00$ & 25.0 & 09/23 08:00 & 8.7 & 01/06 06:00 \\
\hline $\mathrm{E} 430$ & 3.79 & $05 / 21$ & $16: 00$ & 2.78 & $06 / 13$ & $17: 00$ & 25.0 & 05/18 19:00 & 8.7 & 01/06 06:00 \\
\hline E440 & 3.79 & $05 / 21$ & $16: 00$ & 2.78 & $06 / 13$ & $17: 00$ & 25.0 & 05/18 19:00 & 8.7 & 01/06 06:00 \\
\hline E500 & 4.22 & $03 / 16$ & 10:00 & 2.71 & $07 / 30$ & $12: 00$ & 25.0 & 03/31 18:00 & 14.5 & $\begin{array}{ll}11 / 23 & 09: 00\end{array}$ \\
\hline E510 & 4.68 & $10 / 05$ & 01:00 & 2.91 & $03 / 31$ & 18:00 & 25.0 & 03/31 18:00 & 14.5 & 11/23 09:00 \\
\hline E520 & 3.93 & $04 / 30$ & 16:00 & 2.53 & $07 / 30$ & $12: 00$ & 15.0 & $03 / 25$ 08:00 & 12.8 & 11/14 08:00 \\
\hline E522 & 4.06 & $03 / 16$ & 10:00 & 2.61 & $07 / 30$ & $12: 00$ & 20.0 & 04/02 08:00 & 13.8 & $11 / 23 \quad 09: 00$ \\
\hline E525 & 4.73 & $03 / 16$ & 10:00 & 2.94 & $07 / 30$ & $12: 00$ & 35.0 & $03 / 1112: 00$ & 15.4 & $12 / 01 \quad 01: 00$ \\
\hline E530 & 3.92 & $03 / 16$ & 10:00 & 2.53 & $07 / 30$ & $12: 00$ & 25.0 & 04/17 18:00 & 14.5 & 11/23 09:00 \\
\hline E540 & 3.70 & $03 / 16$ & 10:00 & 2.38 & $07 / 30$ & $12: 00$ & 15.0 & 04/16 01:00 & 12.8 & 11/14 08:00 \\
\hline E545 & 4.17 & $03 / 16$ & 10:00 & 2.66 & $07 / 30$ & $12: 00$ & 35.0 & 07/09 22:00 & 15.4 & $12 / 01 \quad 01: 00$ \\
\hline
\end{tabular}

\begin{tabular}{|c|c|c|c|c|c|c|c|c|}
\hline \multicolumn{8}{|c|}{ Annual Hourly Integrated Maxima and Minima - COP2 and Zone } & \multirow{4}{*}{ Cases } \\
\hline \multicolumn{4}{|c|}{ Humidity Ratio } & \multicolumn{4}{|c|}{ Relative Humidity } & \\
\hline \multicolumn{2}{|c|}{ Maximum } & \multicolumn{2}{|c|}{ Minimum* } & \multicolumn{2}{|c|}{ Maximum* } & \multicolumn{2}{|c|}{ Minimum* } & \\
\hline $\mathrm{kg} / \mathrm{kg}$ & Date Hour & $\mathrm{kg} / \mathrm{kg}$ & Date Hour & $\%$ & Date Hour & $\%$ & Date Hour & \\
\hline 0.0136 & 11/16 17:00 & 0.0019 & 01/11 03:00 & 68.4 & 11/16 17:00 & 14.4 & 11/06 06:00 & E300 \\
\hline 0.0156 & 10/01 08:00 & 0.0019 & 01/05 07:00 & 78.6 & 10/02 08:00 & 15.6 & 11/06 08:00 & E310 \\
\hline 0.0178 & 07/10 13:00 & 0.0019 & 01/11 03:00 & 83.0 & 09/18 10:00 & 14.7 & 11/06 06:00 & E320 \\
\hline 0.0179 & 07/10 12:00 & 0.0019 & 01/11 03:00 & 76.9 & 09/03 10:00 & 14.4 & $11 / 0606: 00$ & E330 \\
\hline 0.0178 & 07/10 12:00 & 0.0019 & 01/11 03:00 & 80.8 & 09/18 10:00 & 14.4 & $11 / 0606: 00$ & E340 \\
\hline 0.0172 & $10 / 02$ 01:00 & 0.0019 & 01/11 03:00 & 68.4 & $11 / 1617: 00$ & 14.4 & 11/06 06:00 & E350 \\
\hline 0.0139 & 07/10 13:00 & 0.0019 & 01/11 03:00 & 68.4 & $11 / 16 \quad 17: 00$ & 14.4 & $11 / 0606: 00$ & E360 \\
\hline 0.0169 & $04 / 05$ 22:00 & 0.0019 & 01/11 03:00 & 84.6 & $04 / 05$ 22:00 & 13.9 & 11/06 06:00 & $\begin{array}{l}\mathrm{E} 400 \\
\mathrm{E} 410\end{array}$ \\
\hline 0.0146 & $04 / 02$ 18:00 & 0.0019 & 01/11 03:00 & 73.3 & $04 / 02$ 18:00 & 13.9 & $11 / 0606: 00$ & E420 \\
\hline 0.0161 & 04/02 05:00 & 0.0019 & 01/11 03:00 & 80.8 & 04/02 05:00 & 13.9 & 11/06 06:00 & E430 \\
\hline 0.0160 & 04/02 05:00 & 0.0019 & 01/11 03:00 & 79.9 & 04/02 05:00 & 13.9 & $11 / 0606: 00$ & E440 \\
\hline 0.0134 & $04 / 18$ 19:00 & 0.0102 & $11 / 2310: 00$ & 100.0 & $11 / 1309: 00$ & 54.4 & $04 / 3013: 00$ & E500 \\
\hline 0.0154 & $10 / 1202: 00$ & 0.0102 & $11 / 2310: 00$ & 100.0 & $11 / 1309: 00$ & 55.3 & $11 / 0413: 00$ & E510 \\
\hline 0.0088 & 04/18 19:00 & 0.0066 & $04 / 3013: 00$ & 85.7 & 10/18 08:00 & 62.4 & 04/30 13:00 & E520 \\
\hline 0.0109 & 04/18 19:00 & 0.0085 & $04 / 3013: 00$ & 100.0 & $11 / 22 \quad 02: 00$ & 58.2 & $04 / 3013: 00$ & E522 \\
\hline 0.0199 & 04/18 19:00 & 0.0109 & $11 / 3024: 00$ & 100.0 & 11/11 24:00 & 47.4 & 04/30 13:00 & E525 \\
\hline 0.0091 & 01/03 15:00 & 0.0067 & $10 / 18$ 12:00 & 66.5 & $11 / 2309: 00$ & 34.0 & 09/28 18:00 & E530 \\
\hline 0.0091 & 01/03 15:00 & 0.0038 & 10/18 09:00 & 42.1 & $11 / 2210: 00$ & 36.0 & 09/28 16:00 & E540 \\
\hline 0.0091 & 01/03 15:00 & 0.0068 & 04/01 01:00 & 62.3 & $11 / 3023: 00$ & 19.2 & 04/18 17:00 & E545 \\
\hline
\end{tabular}




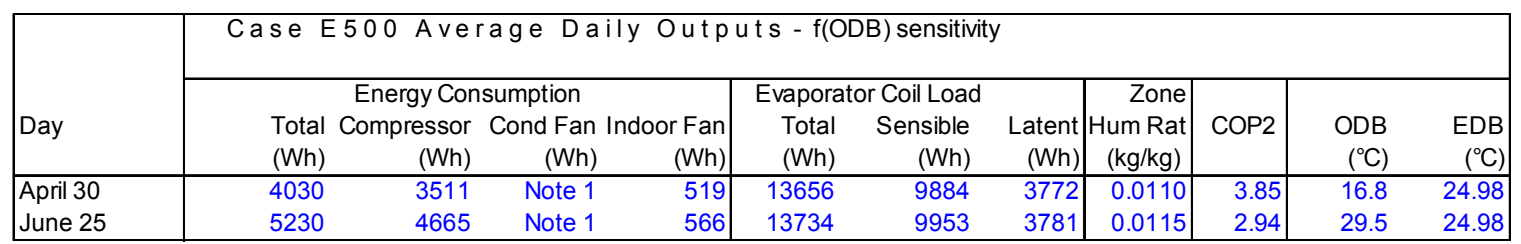

\begin{tabular}{|c|c|c|c|c|c|c|c|c|c|c|c|}
\hline \multirow[b]{3}{*}{ Day } & \multicolumn{11}{|c|}{ Case E530 Average Daily Outputs - f(ODB) sensitivity } \\
\hline & \multicolumn{4}{|c|}{ Energy Consumption } & \multicolumn{2}{|c|}{ Evaporator Coil Load } & \multicolumn{2}{|c|}{ Zone } & \multirow[b]{2}{*}{ COP2 } & \multirow[b]{2}{*}{$\begin{array}{r}\mathrm{ODB} \\
\left({ }^{\circ} \mathrm{C}\right)\end{array}$} & \multirow[b]{2}{*}{$\begin{array}{r}\text { EDB } \\
\left({ }^{\circ} \mathrm{C}\right)\end{array}$} \\
\hline & $\begin{array}{l}\text { Total } \\
\text { (Wh) }\end{array}$ & $\begin{array}{r}\text { Compressor } \\
(\mathrm{Wh})\end{array}$ & $\begin{array}{r}\text { Cond Fan } \\
\text { (Wh) }\end{array}$ & $\begin{array}{r}\text { or Fan } \\
(\text { Wh })\end{array}$ & $\begin{array}{l}\text { Total } \\
(\mathrm{Wh})\end{array}$ & $\begin{array}{r}\text { Sensible } \\
(\mathrm{Wh})\end{array}$ & $\begin{array}{r}\text { Latent } \\
(\mathrm{Wh})\end{array}$ & $\begin{array}{r}\text { Hum Rat } \\
(\mathrm{kg} / \mathrm{kg})\end{array}$ & & & \\
\hline April 30 & 3102 & 2689 & Note 1 & 412 & 9775 & 9775 & 0 & 0.0067 & 3.44 & 16.8 & 25.00 \\
\hline June 25 & 4029 & 3579 & Note 1 & 450 & 9835 & 9835 & 0 & 0.0067 & 2.78 & 29.5 & 25.00 \\
\hline
\end{tabular}

\section{Software Errors Discovered and/or Comparison Between Different Versions of the Same Software - Round 5}

\section{Error in Reporting Round 4 Results}

An error was made in the Round 4 "Energy Consumption - Compr + Both Fans" results reported in the "Annual Hourly Integrated Maxima Consumptions and Loads" table for Cases E500 through E545. The indoor fan energy consumption had been omitted from the totals. This error has been corrected in the results reported below for Round 5.

\section{Error in Space Humidity Ratio Algorithm}

A comparison of EnergyPlus results from Round 4 to the results of other programs indicated that the maximum space humidity ratios for Cases E500 through E545 were high. Further investigation into the problem indicated that these maximum values were actually happening one to two hours after the internal loads and HVAC system had been scheduled off. This was occurring because of the way the moisture balance algorithm had been set up. Internal loads during each time step of the simulation in EnergyPlus were being accounted for after the HVAC system simulation. With EnergyPlus version 1.1.0.004 and subsequent releases the space internal loads are now accounted for before the system simulation. This brought the EnergyPlus results more in line with the results of the other programs. Also, for cases E530, E540 and E545 the maximum space humidity ratio was occurring during the beginning of the year before the AC unit came on for the first time (March 11). The period for determining maximum space humidity ratio was therefore changed to March 11 through December 31. This then brought the EnergyPlus results for cases E530 and E540 closer to results for the other programs. The Round 5 results that follow present the revised results.

\section{Change in Economizer Enthalpy Limit for Case E440}

In accordance with changes to the test suite specification, the economizer enthalpy limit for case E440 was changed from $65.13 \mathrm{~kJ} / \mathrm{kg}$ to $47.25 \mathrm{~kJ} / \mathrm{kg}$.

The results for Round 5, which are presented below, were produced using EnergyPlus 1.1.0.020. 


\begin{tabular}{|c|c|c|c|c|c|c|c|c|c|c|c|c|c|}
\hline \multirow[b]{3}{*}{ Cases } & \multicolumn{7}{|c|}{ Annual Sums } & \multicolumn{4}{|c|}{ Annual Means } & \multirow{2}{*}{\multicolumn{2}{|c|}{ 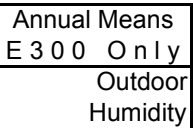 }} \\
\hline & \multicolumn{4}{|c|}{ Cooling Energy Consumption } & \multicolumn{3}{|c|}{ Evaporator Coil Load } & & & $\begin{array}{r}\text { Zone } \\
\text { tumidity }\end{array}$ & $\begin{array}{r}\text { Zone } \\
\text { Relative }\end{array}$ & & \\
\hline & $\begin{array}{r}\text { Total } \\
(\mathrm{kWh})\end{array}$ & $\begin{array}{r}\text { Compressor } \\
(\mathrm{kWh})\end{array}$ & $\begin{array}{r}\text { Cond Fan } \\
(\mathrm{kWh})\end{array}$ & $\begin{array}{r}\text { or Fan } \\
(\mathrm{kWh})\end{array}$ & $\begin{array}{r}\text { Total } \\
(\mathrm{kWh})\end{array}$ & $\begin{array}{r}\text { Sensible } \\
(\mathrm{kWh})\end{array}$ & $\begin{array}{r}\text { Latent } \\
(\mathrm{kWh})\end{array}$ & COP2 & $\begin{array}{l}\text { IDB } \\
\left({ }^{\circ} \mathrm{C}\right)\end{array}$ & $\begin{array}{r}\text { Ratio } \\
(\mathrm{kg} / \mathrm{kg})\end{array}$ & $\begin{array}{r}\text { Humidity } \\
(\%)\end{array}$ & $\begin{array}{l}\text { ODB } \\
\left({ }^{\circ} \mathrm{C}\right)\end{array}$ & $\begin{array}{r}\text { Ratio } \\
(\mathrm{kg} / \mathrm{kg})\end{array}$ \\
\hline E300 & 34746 & 23884 & Note 1 & 10862 & 77318 & 55252 & 22066 & 3.24 & 24.09 & 0.0093 & 48.6 & 19.9 & 0.0116 \\
\hline E310 & 39290 & 28428 & Note 1 & 10862 & 96448 & 55225 & 41222 & 3.39 & 24.09 & 0.0113 & 58.6 & & \\
\hline E320 & 39079 & 28217 & Note 1 & 10862 & 96084 & 62043 & 34040 & 3.41 & 24.25 & 0.0101 & 51.8 & & \\
\hline E330 & 40143 & 29281 & Note 1 & 10862 & 102211 & 63779 & 38433 & 3.49 & 24.27 & 0.0100 & 51.2 & & \\
\hline E340 & 39783 & 28921 & Note 1 & 10862 & 99709 & 62886 & 36823 & 3.45 & 24.30 & 0.0100 & 51.1 & & \\
\hline E350 & 31145 & 20283 & Note 1 & 10862 & 65790 & 48545 & 17245 & 3.24 & 26.24 & 0.0099 & 45.2 & & \\
\hline E360 & 54705 & 43843 & Note 1 & 10862 & 161248 & 135287 & 25961 & 3.68 & 25.32 & 0.0088 & 42.4 & & \\
\hline $\begin{array}{l}\text { E400 } \\
\text { E410 }\end{array}$ & 31013 & 20151 & $\begin{array}{l}\text { Note } 1 \\
\text { Note } 1\end{array}$ & 10862 & 65414 & 40688 & 24726 & 3.25 & 24.09 & 0.0101 & 52.5 & & \\
\hline E420 & 32736 & 21873 & Note 1 & 10862 & 70349 & 49524 & 20826 & 3.22 & 24.09 & 0.0094 & 49.4 & & \\
\hline E430 & 31772 & 20910 & Note 1 & 10862 & 67141 & 46739 & 20403 & 3.21 & 24.09 & 0.0095 & 49.6 & & \\
\hline E440 & 33032 & 22170 & Note 1 & 10862 & 71417 & 50060 & 21357 & 3.22 & 24.09 & 0.0093 & 48.8 & & \\
\hline E500 & 23035 & 20406 & Note 1 & 2628 & 65571 & 47491 & 18080 & 3.21 & 20.38 & 0.0094 & 59.2 & & \\
\hline E500 May-Sep & 17996 & 15967 & Note 1 & 2029 & 50354 & 36476 & 13879 & 3.15 & 24.98 & 0.0113 & 57.3 & & \\
\hline E510 May-Sep & 35732 & 31669 & Note 1 & 4063 & 112793 & 81566 & 31226 & 3.56 & 24.96 & 0.0113 & 57.4 & & \\
\hline E520 & 25017 & 21999 & Note 1 & 3019 & 66088 & 47986 & 18101 & 3.00 & 13.58 & 0.0060 & 61.4 & & \\
\hline E522 & 24078 & 21235 & Note 1 & 2843 & 65851 & 47758 & 18093 & 3.10 & 17.00 & 0.0076 & 60.8 & & \\
\hline E525 & 20702 & 18522 & Note 1 & 2180 & 64973 & 46930 & 18044 & 3.51 & 27.10 & 0.0138 & 55.0 & & \\
\hline E530 & 17742 & 15652 & Note 1 & 2090 & 46944 & 46944 & 0 & 3.00 & 20.59 & 0.0067 & 49.0 & & \\
\hline E540 & 19061 & 16752 & Note 1 & 2309 & 47297 & 47288 & 9 & 2.82 & 13.79 & 0.0043 & 46.3 & & \\
\hline E545 & 16636 & 14765 & Note 1 & 1871 & 46612 & 46612 & 0 & 3.16 & 27.31 & 0.0067 & 38.6 & & \\
\hline
\end{tabular}

Note 1: Condenser fan energy consumption included with compressor energy consumption; cannot break out.

\begin{tabular}{|c|c|c|c|c|c|c|c|c|c|c|c|c|c|c|}
\hline \multirow[b]{4}{*}{ Cases } & \multicolumn{2}{|c|}{ Annual Hourly } & Integ & a ted & \multicolumn{5}{|c|}{ Maxima Consumptions and Loads } & \multicolumn{5}{|c|}{ E300 Only, Maxima } \\
\hline & \multirow{3}{*}{\multicolumn{2}{|c|}{$\begin{array}{l}\text { Energy Consumption } \\
\text { Compr + Both Fans }\end{array}$}} & \multirow{2}{*}{\multicolumn{7}{|c|}{ Evaporator Coil Loads }} & \multicolumn{5}{|c|}{ Weather Data Checks } \\
\hline & & & & & & & & & & & & & & \\
\hline & & & & ensible & & & Latent & Sensi & + Latent & & ODB & & Outdoor & umidity Ratio \\
\hline E300 & 11900 & 07/20 15:00 & 23531 & $07 / 20$ & 15:00 & 10235 & $07 / 1013: 00$ & 32733 & 07/20 15:00 & 34.775 & $07 / 20$ & 15:00 & 0.0218 & 10/02 09:00 \\
\hline E310 & 12541 & 07/20 15:00 & 23276 & 07/11 & $16: 00$ & 16275 & 08/04 15:00 & 37126 & 09/17 15:00 & & & & & \\
\hline E320 & 12954 & 07/20 15:00 & 31972 & $04 / 24$ & $15: 00$ & 22195 & 10/02 10:00 & 39765 & 09/03 16:00 & & & & & \\
\hline E360 & 12744 & 07/20 15:00 & 32621 & $04 / 24$ & $16: 00$ & 8520 & 10/02 11:00 & 38460 & 10/02 11:00 & & & & & \\
\hline $\begin{array}{l}\text { E400 } \\
\text { E410 }\end{array}$ & 11900 & 07/20 15:00 & 23531 & $07 / 20$ & 15:00 & 26317 & 09/16 14:00 & 40728 & 09/16 15:00 & & & & & \\
\hline E420 & 11900 & 07/20 15:00 & 23531 & $07 / 20$ & $15: 00$ & 10235 & 07/10 13:00 & 32733 & 07/20 15:00 & & & & & \\
\hline E430 & 11900 & 07/20 15:00 & 23531 & $07 / 20$ & $15: 00$ & 11074 & $10 / 2413: 00$ & 32733 & 07/20 15:00 & & & & & \\
\hline E440 & 11900 & 07/20 15:00 & 23531 & $07 / 20$ & $15: 00$ & 10235 & 07/10 13:00 & 32733 & 07/20 15:00 & & & & & \\
\hline E500 & 10399 & 07/20 15:00 & 19849 & $07 / 20$ & $15: 00$ & 7839 & 06/29 16:00 & 27646 & 06/29 16:00 & & & & & \\
\hline E530 & 8171 & 07/20 15:00 & 19639 & $07 / 20$ & $15: 00$ & 1 & 03/16 10:00 & 19639 & 07/20 15:00 & & & & & \\
\hline E540 & 8677 & 07/20 15:00 & 19726 & $07 / 20$ & $15: 00$ & 1655 & 03/11 10:00 & 19726 & 07/20 15:00 & & & & & \\
\hline E545 & 7763 & $07 / 2015: 00$ & 19540 & $07 / 20$ & $15: 00$ & 0 & 05/23 15:00 & 19540 & 07/20 15:00 & & & & & \\
\hline
\end{tabular}




\begin{tabular}{|c|c|c|c|c|c|c|c|c|c|c|c|}
\hline \multirow[b]{3}{*}{ Hour } & \multicolumn{11}{|c|}{ June 28 Hourly Output - Case E300 } \\
\hline & \multicolumn{2}{|c|}{ Energy Consumption } & \multicolumn{3}{|c|}{ Evaporator Coil Load } & \multirow{2}{*}{$\begin{array}{r}\text { Zone } \\
\text { Hum. Rat. } \\
(\mathrm{kg} / \mathrm{kg})\end{array}$} & \multirow[b]{2}{*}{ COP2 } & \multirow[b]{2}{*}{$\begin{array}{r}\text { ODB } \\
\left({ }^{\circ} \mathrm{C}\right)\end{array}$} & \multirow[b]{2}{*}{$\begin{array}{r}\text { EDB } \\
\left({ }^{\circ} \mathrm{C}\right)\end{array}$} & \multirow[b]{2}{*}{$\begin{array}{r}\text { EWB } \\
\left({ }^{\circ} \mathrm{C}\right)\end{array}$} & \multirow{2}{*}{$\begin{array}{r}\text { Outdoor } \\
\text { Hum. Rat. } \\
(\mathrm{kg} / \mathrm{kg}) \\
\end{array}$} \\
\hline & $\begin{array}{r}\text { Compressor } \\
(\mathrm{Wh})\end{array}$ & $\begin{array}{r}\text { Cond Fan } \\
(\mathrm{Wh})\end{array}$ & $\begin{array}{l}\text { Total } \\
(\mathrm{Wh})\end{array}$ & $\begin{array}{r}\text { Sensible } \\
(\mathrm{Wh})\end{array}$ & $\begin{array}{r}\text { Latent } \\
(\mathrm{Wh})\end{array}$ & & & & & & \\
\hline 1 & 2119 & Note 1 & 7472 & 5811 & 1661 & 0.0094 & 3.53 & 18.0 & 23.9 & & 0.0112 \\
\hline 2 & 2131 & Note 1 & 7494 & 5853 & 1641 & 0.0094 & 3.52 & 18.1 & 24.0 & & 0.0113 \\
\hline 3 & 2113 & Note 1 & 7447 & 5809 & 1637 & 0.0094 & 3.52 & 18.0 & 23.9 & & 0.0112 \\
\hline 4 & 2075 & Note 1 & 7332 & 5744 & 1588 & 0.0093 & 3.53 & 17.8 & 23.9 & & 0.0111 \\
\hline 5 & 1997 & Note 1 & 7091 & 5614 & 1477 & 0.0092 & 3.55 & 17.4 & 23.9 & & 0.0105 \\
\hline 6 & 2142 & Note 1 & 7425 & 6015 & 1410 & 0.0090 & 3.47 & 18.6 & 24.0 & & 0.0106 \\
\hline 7 & 2870 & Note 1 & 9216 & 7532 & 1684 & 0.0093 & 3.21 & 22.9 & 24.7 & & 0.0123 \\
\hline 8 & 3499 & Note 1 & 10609 & 8757 & 1853 & 0.0096 & 3.03 & 26.4 & 25.2 & & 0.0118 \\
\hline 9 & 4682 & Note 1 & 14032 & 11767 & 2265 & 0.0098 & 3.00 & 28.3 & 25.5 & & 0.0116 \\
\hline 10 & 4948 & Note 1 & 14778 & 11996 & 2781 & 0.0102 & 2.99 & 28.9 & 25.6 & & 0.0124 \\
\hline 11 & 5407 & Note 1 & 15905 & 12488 & 3417 & 0.0106 & 2.94 & 30.3 & 25.8 & & 0.0140 \\
\hline 12 & 5632 & Note 1 & 16522 & 12671 & 3851 & 0.0109 & 2.93 & 30.8 & 25.9 & & 0.0138 \\
\hline 13 & 7133 & Note 1 & 21588 & 17401 & 4187 & 0.0104 & 3.03 & 30.9 & 25.9 & & 0.0120 \\
\hline 14 & 6983 & Note 1 & 20678 & 17592 & 3086 & 0.0100 & 2.96 & 31.5 & 26.0 & & 0.0115 \\
\hline 15 & 8572 & Note 1 & 26133 & 22481 & 3652 & 0.0098 & 3.05 & 32.0 & 26.1 & & 0.0121 \\
\hline 16 & 8733 & Note 1 & 26665 & 22557 & 4107 & 0.0099 & 3.05 & 32.2 & 26.1 & & 0.0135 \\
\hline 17 & 5718 & Note 1 & 16345 & 13061 & 3283 & 0.0106 & 2.86 & 31.9 & 26.0 & & 0.0145 \\
\hline 18 & 5881 & Note 1 & 17193 & 12870 & 4324 & 0.0112 & 2.92 & 31.3 & 26.0 & & 0.0153 \\
\hline 19 & 5555 & Note 1 & 16878 & 12170 & 4708 & 0.0113 & 3.04 & 29.4 & 25.7 & & 0.0149 \\
\hline 20 & 5259 & Note 1 & 16536 & 11556 & 4981 & 0.0113 & 3.14 & 27.6 & 25.4 & & 0.0159 \\
\hline 21 & 4326 & Note 1 & 13445 & 9063 & 4383 & 0.0116 & 3.11 & 27.2 & 25.3 & & 0.0168 \\
\hline 22 & 4279 & Note 1 & 13387 & 8953 & 4434 & 0.0116 & 3.13 & 26.9 & 25.3 & & 0.0168 \\
\hline 23 & 4173 & Note 1 & 13191 & 8753 & 4437 & 0.0116 & 3.16 & 26.3 & 25.2 & & 0.0168 \\
\hline 24 & 4152 & Note 1 & 13196 & 8674 & 4522 & 0.0117 & 3.18 & 26.1 & 25.2 & & 0.0171 \\
\hline
\end{tabular}

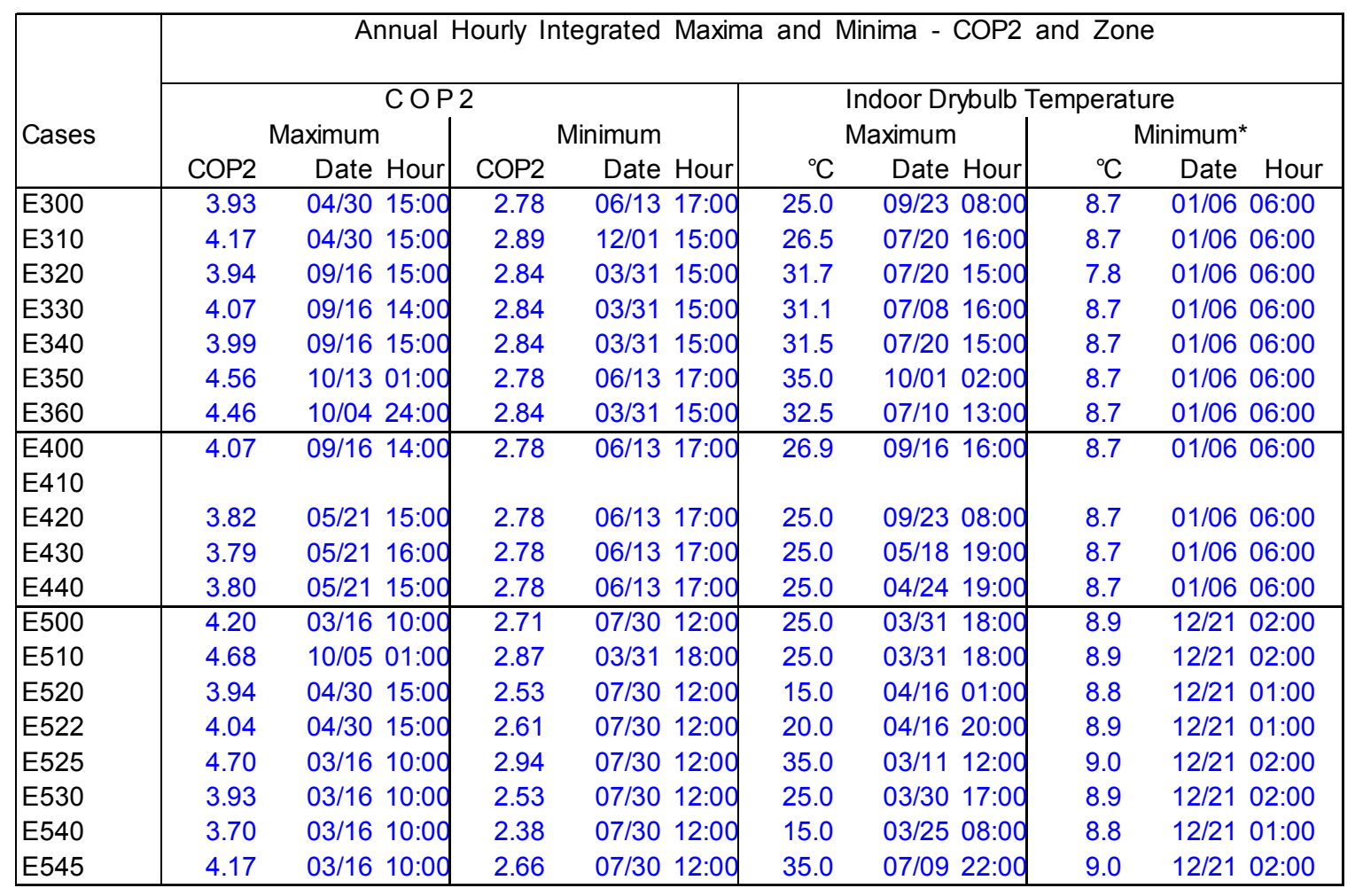




\begin{tabular}{|c|c|c|c|c|c|c|c|c|c|}
\hline \multicolumn{9}{|c|}{ Annual Hourly Integrated Maxima and Minima - COP2 and Zone } & \multirow{4}{*}{ Cases } \\
\hline \multicolumn{5}{|c|}{ Humidity Ratio } & \multicolumn{4}{|c|}{ Relative Humidity } & \\
\hline \multicolumn{2}{|c|}{ Maximum } & \multicolumn{3}{|c|}{ Minimum* } & \multicolumn{2}{|c|}{ Maximum* } & \multicolumn{2}{|c|}{ Minimum* } & \\
\hline $\mathrm{kg} / \mathrm{kg}$ & Date Hour & $\mathrm{kg} / \mathrm{kg}$ & Date & Hour & $\%$ & Date Hour & $\%$ & Date Hour & \\
\hline 0.0136 & 11/16 17:00 & 0.0019 & $01 / 11$ & 03:00 & 68.4 & $11 / 16 \quad 17: 00$ & 14.4 & $11 / 06 \quad 06: 00$ & E300 \\
\hline 0.0156 & 10/01 08:00 & 0.0019 & 01/05 & 07:00 & 78.6 & 10/02 08:00 & 15.5 & $11 / 06 \quad 08: 00$ & E310 \\
\hline 0.0178 & 07/10 13:00 & 0.0019 & $01 / 11$ & 03:00 & 83.0 & 09/18 10:00 & 14.6 & 11/06 06:00 & E320 \\
\hline 0.0179 & 07/10 12:00 & 0.0019 & $01 / 11$ & 03:00 & 76.9 & 09/03 10:00 & 14.4 & 11/06 06:00 & E330 \\
\hline 0.0178 & 07/10 12:00 & 0.0019 & $01 / 11$ & 03:00 & 80.8 & 09/18 10:00 & 14.4 & 11/06 06:00 & E340 \\
\hline 0.0172 & 10/02 01:00 & 0.0019 & $01 / 11$ & 03:00 & 68.4 & 11/16 17:00 & 14.4 & 11/06 06:00 & E350 \\
\hline 0.0139 & 07/10 13:00 & 0.0019 & $01 / 11$ & 03:00 & 68.4 & 11/16 17:00 & 14.4 & 11/06 06:00 & E360 \\
\hline 0.0169 & 04/05 22:00 & 0.0019 & $01 / 11$ & 03:00 & 84.6 & $04 / 05$ 22:00 & 13.9 & 11/06 06:00 & $\begin{array}{l}\text { E400 } \\
\text { E410 }\end{array}$ \\
\hline 0.0146 & 04/02 18:00 & 0.0019 & $01 / 11$ & 03:00 & 73.3 & 04/02 18:00 & 13.9 & 11/06 06:00 & E420 \\
\hline 0.0161 & 04/02 05:00 & 0.0019 & $01 / 11$ & 03:00 & 80.7 & 04/02 05:00 & 13.9 & 11/06 06:00 & E430 \\
\hline 0.0136 & 11/16 17:00 & 0.0019 & $01 / 11$ & 03:00 & 68.4 & 11/16 17:00 & 13.9 & 11/06 06:00 & E440 \\
\hline 0.0117 & 07/20 15:00 & 0.0070 & $12 / 20$ & $12: 00$ & 100.0 & 11/21 09:00 & 55.2 & $04 / 30 \quad 04: 00$ & E500 \\
\hline 0.0117 & 07/20 15:00 & 0.0070 & $12 / 20$ & $12: 00$ & 100.0 & 11/21 09:00 & 55.3 & 05/04 03:00 & E510 \\
\hline 0.0070 & 07/20 15:00 & 0.0065 & $11 / 10$ & 09:00 & 93.8 & $12 / 20 \quad 11: 00$ & 61.7 & $11 / 27 \quad 24: 00$ & E520 \\
\hline 0.0091 & 07/20 15:00 & 0.0070 & $12 / 20$ & $12: 00$ & 100.0 & $12 / 1522: 00$ & 59.2 & 04/30 04:00 & E522 \\
\hline 0.0185 & 07/20 15:00 & 0.0070 & $12 / 20$ & 12:00 & 100.0 & 11/12 19:00 & 47.9 & 10/05 02:00 & E525 \\
\hline 0.0068 & 03/11 01:00 & 0.0067 & 10/18 & 12:00 & 96.2 & $12 / 2011: 00$ & 34.0 & 04/18 18:00 & E530 \\
\hline 0.0068 & 03/11 01:00 & 0.0038 & $10 / 18$ & 09:00 & 55.2 & $12 / 2011: 00$ & 36.0 & 09/28 16:00 & E540 \\
\hline 0.0068 & $12 / 31 \quad 07: 00$ & 0.0068 & $04 / 01$ & 02:00 & 96.2 & $12 / 2011: 00$ & 19.2 & 04/18 $17: 00$ & E545 \\
\hline
\end{tabular}

\begin{tabular}{|c|c|c|c|c|c|c|c|c|c|c|c|}
\hline \multirow{4}{*}{ Day } & \multicolumn{11}{|c|}{ Case E500 Average Daily Outputs - f(ODB) sensitivity } \\
\hline & \multicolumn{4}{|c|}{ Energy Consumption } & \multicolumn{2}{|c|}{ Evaporator Coil Load } & \multirow{3}{*}{$\begin{array}{r}\text { Latent } \\
(\mathrm{Wh})\end{array}$} & \multirow{3}{*}{\begin{tabular}{|r|} 
Zone \\
Hum Rat \\
$(\mathrm{kg} / \mathrm{kg})$ \\
\end{tabular}} & \multirow{3}{*}{ COP2 } & \multirow{3}{*}{$\begin{array}{r}\text { ODB } \\
\left({ }^{\circ} \mathrm{C}\right)\end{array}$} & \multirow{3}{*}{$\begin{array}{r}\text { EDB } \\
\left({ }^{\circ} \mathrm{C}\right)\end{array}$} \\
\hline & \multirow{2}{*}{$\begin{array}{l}\text { Tota } \\
(\mathrm{Wh})\end{array}$} & Compressor & \multicolumn{2}{|c|}{ Cond Fan Indoor Fan } & \multirow{2}{*}{$\begin{array}{l}\text { Total } \\
(\mathrm{Wh})\end{array}$} & \multirow{2}{*}{$\begin{array}{r}\text { Sensible } \\
(\mathrm{Wh})\end{array}$} & & & & & \\
\hline & & (Wh) & $(\mathrm{Wh})$ & (Wh) & & & & & & & \\
\hline April 30 & 4029 & 3510 & Note 1 & 519 & 13655 & 9884 & 3772 & 0.0110 & 3.85 & 16.8 & 24.98 \\
\hline June 25 & 5229 & 4663 & Note 1 & 566 & 13733 & 9953 & 3781 & 0.0115 & 2.94 & 29.5 & 24.98 \\
\hline
\end{tabular}

\begin{tabular}{|c|c|c|c|c|c|c|c|c|c|c|c|}
\hline \multirow[b]{3}{*}{ Day } & \multicolumn{11}{|c|}{ Case E530 Average Daily Outputs-f(ODB) sensitivity } \\
\hline & \multicolumn{4}{|c|}{ Energy Consumption } & \multicolumn{2}{|c|}{ Evaporator Coil Load } & \multicolumn{2}{|r|}{ Zone } & \multirow[b]{2}{*}{ COP2 } & \multirow[b]{2}{*}{$\begin{array}{r}\mathrm{ODB} \\
\left({ }^{\circ} \mathrm{C}\right)\end{array}$} & \multirow[b]{2}{*}{$\begin{array}{c}\text { EDB } \\
\left({ }^{\circ} \mathrm{C}\right)\end{array}$} \\
\hline & $\begin{array}{l}\text { Tota } \\
\text { (Wh }\end{array}$ & $\begin{array}{l}\text { I) Compressor } \\
\text { ) (Wh) }\end{array}$ & $\begin{array}{r}\text { Cond Fan } \\
\text { (Wh) }\end{array}$ & $\begin{array}{r}\text { or Fan } \\
(\mathrm{Wh})\end{array}$ & $\begin{array}{l}\text { Total } \\
(\mathrm{Wh})\end{array}$ & $\begin{array}{r}\text { Sensible } \\
\text { (Wh) }\end{array}$ & $\begin{array}{r}\text { Latent } \\
(\mathrm{Wh})\end{array}$ & $\left|\begin{array}{c}\text { Hum Rat } \\
(\mathrm{kg} / \mathrm{kg})\end{array}\right|$ & & & \\
\hline \begin{tabular}{|l|} 
April 30 \\
\end{tabular} & 3101 & 2689 & Note 1 & 412 & 9775 & 9775 & 0 & 0.0068 & 3.44 & 16.8 & 25.00 \\
\hline June 25 & 4029 & 3579 & Note 1 & 450 & 9835 & 9835 & 0 & 0.0068 & 2.78 & 29.5 & 25.00 \\
\hline
\end{tabular}




\section{Program name (please include version number)}

EnergyPlus Version 1.1.0.004

\section{Your name, organisation, and country}

Robert H. Henninger, GARD Analytics, Inc., United States

In this description " $x$ " denotes used in the model; "a" denotes available, but not used for modeling the test cases.

\section{Program name (please include version number)}

EnergyPlus Version 1.1.0.004

\section{Your name, organisation, and country}

Robert H. Henninger, GARD Analytics, Inc., United States

\section{Program status}

\begin{tabular}{|l|l|}
\hline & Public domain \\
\hline & Commercial \\
\hline $\mathrm{x}$ & Research \\
\hline & $\begin{array}{l}\text { Other (please specify) Government-sponsored, end-user license is no charge, other license types } \\
\text { have fees associated with them }\end{array}$ \\
\hline
\end{tabular}

\section{Solution method for unitary space cooling equipment}

\begin{tabular}{|l|l}
$\mathrm{x}$ & Overall Performance Maps \\
\hline
\end{tabular} Individual Component Models

Constant Performance (no possible variation with entering or ambient conditions)

Other (please specify)

\section{Interaction between loads and systems calculations}

\begin{tabular}{|l|l}
$\mathrm{x}$ & Both are calculated during the same time step \\
\hline
\end{tabular}

First, loads are calculated for the entire simulation period, then equipment performance is calculated separately

Other (please specify)

\section{Time step}

\begin{tabular}{|l|l|}
\hline & Fixed within code (please specify time step): \\
\hline $\mathrm{x}$ & User-specified (please specify time step): one hour for envelope \\
\hline $\mathrm{x}$ & Other (please specify): program automatically adjusts HVAC time step, <= envelope time step \\
\hline
\end{tabular}




\section{Timing convention for meteorological data: sampling interval}

Fixed within code (please specify interval)

$\mathrm{x}$ User-specified: one hour

\section{Timing convention for meteorological data: period covered by first record}

$\mathrm{X}$ Fixed within code (please specify period or time which meteorological record covers): 0:00 - 1:00 User-specified

\section{Meteorological data reconstitution scheme}

Climate assumed stepwise constant over sampling interval

$\mathrm{x} \quad$ Linear interpolation used over climate sampling interval

Other (please specify)

\section{Output timing conventions}

Produces spot predictions at the end of each time step

Produces spot output at end of each hour

$\mathrm{x}$ Produces average outputs for each hour (please specify period to which value relates): userspecified, hourly data are average or sum for previous hour, can specify output at each time step

Treatment of zone air

$\mathrm{x} \quad$ Single temperature (i.e., good mixing assumed)

Stratified model

Simplified distribution model

Full CFD model

Other (please specify)

\section{Zone air initial conditions}

$\mathrm{x}$ Same as outside air

Other (please specify)

\section{Internal gains output characteristics}

Purely convective

Radiative/Convective split fixed within code

$\mathrm{x}$ Radiative/Convective split specified by user: $100 \%$ convective for these tests

Detailed modeling of source output 


\section{Mechanical systems output characteristics}

$\mathrm{x}$ Purely convective

Radiative/Convective split fixed within code

a Radiative/Convective split specified by user: for types of equipment not used in these tests

Detailed modeling of source output

\section{Control temperature}

$\mathrm{x}$ Air temperature

Combination of air and radiant temperatures fixed within the code

User-specified combination of air and radiant temperatures

User-specified construction surface temperatures

User-specified temperatures within construction

Other (please specify)

\section{Control properties}

$\mathrm{x} \quad$ Ideal control as specified in the user's manual

On/Off thermostat control

On/Off thermostat control with hysteresis

On/Off thermostat control with minimum equipment on and/or off durations

Proportional control

More comprehensive controls (please specify)

\section{Performance Map: characteristics}

\begin{tabular}{|l|l|}
\hline & Default curves \\
\hline$x$ & Custom curve fitting \\
\hline & Detailed mapping not available \\
\hline & Other (please specify) \\
\hline
\end{tabular}

\section{Performance Map: independent variables}

\begin{tabular}{|l|l|}
\hline & Entering Dry-Bulb Temperature: program calculates adjustments internally \\
\hline $\mathrm{x}$ & Entering Wet-Bulb Temperature \\
\hline $\mathrm{x}$ & Outdoor Dry-Bulb Temperature \\
\hline $\mathrm{x}$ & Part-Load Ratio \\
\hline $\mathrm{a}$ & Indoor Fan Airflow Rate: always=1, because fan always operates at rated conditions \\
\hline & Other (please specify) \\
\hline
\end{tabular}




\section{Performance Map: dependent variables}

\begin{tabular}{|l|l|}
\hline $\mathrm{x}$ & Coefficient of Performance (or other ratio of load to electricity consumption) \\
\hline $\mathrm{x}$ & Total Capacity \\
\hline & Sensible Capacity: program calculates internally based on user-specified nominal SHR \\
\hline & Bypass Factor: program calculates internally based on nominal SHR and current conditions \\
\hline $\mathrm{x}$ & Other (please specify) indoor fan power (function of PLR) \\
\hline
\end{tabular}

\section{Performance Map: available curve fit techniques}

\begin{tabular}{|l|l|}
\hline $\mathrm{x}$ & Linear, $\mathrm{f}($ one independent variable): flow fraction curves set to constant $=1$ \\
\hline $\mathrm{x}$ & Quadratic, $\mathrm{f}($ one independent variable): $P L F-F P L R$ (cycling loss) \\
\hline $\mathrm{a}$ & Cubic, $\mathrm{f}($ one independent variable): \\
\hline $\mathrm{a}$ & $\mathrm{Bi}$-Linear, $\mathrm{f}(\mathrm{two}$ independent variables) \\
\hline $\mathrm{x}$ & $\mathrm{Bi}-\mathrm{Quadratic}, \mathrm{f}(\mathrm{two}$ independent variables): $C A P-F T$, EIR-FT \\
\hline & Other (please specify) \\
\hline
\end{tabular}

\section{Performance Map: extrapolation limits}

\begin{tabular}{|l|l|}
\hline $\mathrm{x}$ & Limits independent variables: $27.4<=O D B<=48.1 ; 13.0<=E W B<=23.7,0.0<=P L R<=1.0$ \\
\hline & Limits dependent variables \\
\hline & No extrapolation limits \\
\hline & Extrapolation not allowed \\
\hline & Other (please specify) \\
\hline
\end{tabular}

\section{Cooling coil and supply air conditions model}

\begin{tabular}{|l|l|}
\hline & $\begin{array}{l}\text { Supply air temperature = apparatus dew point (ADP); supply air humidity ratio = humidity ratio of } \\
\text { saturated air at ADP }\end{array}$ \\
\hline & Bypass factor model using listed ADP data \\
\hline $\mathrm{x}$ & $\begin{array}{l}\text { Bypass factor model with ADP calculated from extending condition line: nominal BF is calculated } \\
\text { from user-specified nominal SHR }\end{array}$ \\
\hline $\mathrm{x}$ & Fan heat included \\
\hline & More comprehensive model (please specify) \\
\hline
\end{tabular}

\section{Disaggregation of fans' electricity use directly in the simulation and output}

\begin{tabular}{|l|l|}
\hline $\mathrm{X}$ & Indoor fan only \\
\hline & Outdoor fan only \\
\hline & Both indoor and outdoor fans disaggregated in the output \\
\hline & None - disaggregation of fan outputs with separate calculations by the user \\
\hline
\end{tabular}

\section{Economizer settings available (for E400 series)}

\begin{tabular}{|l|l|}
\hline $\mathrm{x}$ & Temperature, outdoor dry-bulb temperature versus return air temperature (E400, E410) \\
\hline $\mathrm{x}$ & Temperature, outdoor dry-bulb temperature high limit setting (E420) \\
\hline $\mathrm{x}$ & Enthalpy, outdoor air enthalpy versus return air enthalpy (E430) \\
\hline $\mathrm{x}$ & Enthalpy, outdoor air enthalpy high limit setting (E440) \\
\hline & Compressor Lockout (E410) (Could not run E410, capability not added yet) \\
\hline & Other (please specify) \\
\hline
\end{tabular}




\title{
Appendix II-B
}

\section{HVAC BESTEST MODELER REPORT \\ FOR CASES E300-E360 AND E500-E545 \\ CODYRUN}

\author{
PREPARED BY \\ T. A. MARA, E. FOCK, AND F. GARDE \\ UNIVERSITY OF REUNION ISLAND \\ MAY 2003
}

\section{Introduction}

\section{Software:}

Authoring Organization:

Authoring Country:

\section{CODYRUN}

Laboratoire de Génie Industriel, 15 Avenue René Cassin, BP

715197715 Saint-Denis Messag Cedex 9, La Réunion

FRANCE

This report describes the modeling methodology and results for several rounds of testing done for the IEA HVAC BESTEST Cases E300 through E360, which were simulated using the CODYRUN software. Only cases E300-E360 are analyzed. The specifications for the model building and HVAC equipment for each case are described in International Energy Agency Building Energy Simulation Test and Diagnostic Method for Heating, Ventilating, and Air-Conditioning Equipment Models (HVAC BESTEST), Volume 2: Cases E300-E545, J. Neymark and R. Judkoff, National Renewable Energy Laboratory, September 2002 (referred to as the BESTEST specification in this report).

\begin{tabular}{lllll}
\hline & Nomenclature & & & \\
\cline { 3 - 4 } & Hourly building load & $(\mathrm{W})$ & \multicolumn{2}{l}{ Subscripts } \\
$C_{r}$ & Cycling rate & $\left(\mathrm{h}^{-1}\right)$ & ai & Indoor air \\
$C I$ & Internal loads & $(\mathrm{W})$ & tot & Total \\
$C D F$ & Cooling Degradation Factor & & sens & Sensible \\
$\lambda$ & Fractional on-time $\left(=\mathrm{t}_{0} / \mathrm{t}_{\mathrm{cyc}}\right)$ & & lat & Latent \\
$\Omega$ & Nondimensionnal time $\left(t_{0} / \tau\right)$ & & $c y c$ & Cycle \\
$P_{a b s}$ & Electric power & $(\mathrm{kW})$ & $s s$ & Steady state \\
$P L R$ & Part-Load ratio & & odb & Outdoor dry-bulb \\
$\dot{Q}$ & Cooling capacity & $(\mathrm{kW})$ & edb & Entering dry-bulb \\
$T$ & Temperature & $\left({ }^{\circ} \mathrm{C}\right)$ & ewb & Entering wet-bulb \\
$t$ & Time & $(\mathrm{s})$ & & \\
$\tau$ & Time constant & $(\mathrm{s})$ & & \\
$t_{0}$ & On-time cycle & $(\mathrm{s})$ & & \\
$t_{c y c}$ & Cycle time & $(\mathrm{s})$ & & \\
$q_{L}$ & Constant evaporative cooling rate & $(\mathrm{kW})$ & & \\
$\Delta T_{c}$ & Dead band & $\left({ }^{\circ} \mathrm{C}\right)$ & & \\
$w$ & Zone humidity ratio & $(\mathrm{kg} / \mathrm{kg})$ & & \\
$H R$ & Relative humidity & $(\%)$ & &
\end{tabular}




\section{Description of the dynamic model}

\subsection{Classical approaches}

We assume a first order model for both total and sensible capacities of the form:

$$
\begin{aligned}
& \dot{Q}_{t o t, c y c}=\dot{Q}_{t o t, s s}\left(1-e^{-t / \tau}\right) \\
& \dot{Q}_{\text {sens }, c y c}=\dot{Q}_{\text {sens }, s s}\left(1-e^{-t / \tau}\right) \quad \text { when } t \leq t_{0} \\
& \dot{Q}_{\text {lat }, c y c}=\dot{Q}_{t o t, c y c}-\dot{Q}_{\text {sens }, c y c}
\end{aligned}
$$

Concerning the electrical power, the authors agree that there is no time constant for $P_{a b s}$ and that the dynamic regime value is the same as its steady-state value. At steady state the capacities are given by an empirical model, which is a function of the interior and exterior conditions. This model is built from the manufacturers' data.

Under the assumption that the steady-state capacities are unchanged during the operation, it can be proved that the coefficients of performance of the system have the following expressions:

$$
\begin{aligned}
& P L R=\lambda\left(1+\frac{1}{\Omega}\left(e^{-\Omega}-1\right)\right) \\
& C D F=1+\frac{1}{\Omega}\left(e^{-\Omega}-1\right)
\end{aligned}
$$

where $\Omega=\frac{t_{0}}{\tau}=\frac{\lambda t_{c y c}}{\tau}$ is a nondimensional time and $\lambda=\frac{t_{0}}{t_{c y c}}$ is the run-time fraction. From the previous equations, we deduce a first relationship between the two performance coefficients that is,

$$
P L R=\lambda * C D F
$$

The $P L R$ is assumed to be the ratio of the cooling load and air conditioner capacity. Consequently, in a hourly simulation, the $P L R$ can be calculated with a building energy simulation program. So evaluating the $C D F$ and $\lambda$ another relationship that takes into account the thermostat characteristics is necessary. McQuiston (1988) derived an empirical relationship of the form:

$$
C D F=1-C_{d}(1-P L R)
$$

$C_{d}$ is called the degradation coefficient and is in the range of $[0.1,0.25]$. The advantage of this approach is that it is easy to implement in a hourly building thermal simulation program. The main drawback is that the approach is parametric because it requires the knowledge of the parameter $C_{d}$. Such an approach also assumes an ideal system where $\tau=0$ seconds. 


\subsection{Our approach}

The factors that mainly affect the dynamic regime are the operating time $t_{0}$ and the cycling time $t_{c y c}$. We have, therefore, developed an hourly HVAC model that allows the calculation of $t_{0}$ and $t_{c y c}$. Then, the model is improved to take into account the effect of the evaporative cooling on the system performances in case of constant fan mode.

$\mathrm{t}_{0}$ is estimated from the following relationship,

$$
-2 C_{t h} \Delta T_{c}=B l_{\text {sens }} \cdot t_{0}-\dot{Q}_{\text {sens }, s s}\left(t_{0}+\tau\left(e^{-t_{0} / \tau}-1\right)\right)
$$

This equation can be rearranged in form of:

$f\left(t_{0}\right)=b+a t_{0}+K\left(e^{-t_{0} / \tau}-1\right)=0$

with $\mathrm{b}=2 \mathrm{C}_{\mathrm{th}} \Delta \mathrm{T}_{\mathrm{c}}, a=B l_{\text {sens }}-\dot{Q}_{\text {sens,ss }}$ and $K=-\tau \dot{Q}_{\text {sens,ss }}$ and $t_{0}$ being the root of $f$. Let us note that $f(t)=0$ has a root only if $a<0$; in other words $B l_{\text {sens }}<\dot{Q}_{\text {sens,ss }}$; otherwise, the system operates all the time without bringing $T_{i d b}$ to $T_{c}-\Delta T_{c}$.

The analytical expression to calculate the cycle time is:

$t_{c y c}=t_{0}+\left(2 C_{t h} \Delta T_{c}+q_{L} t_{w}\right) / B l_{\text {sens }}$

$q_{L}$ is the constant evaporative cooling rate. As far as $t_{w}$ is concerned, we have the following inequality which translates to the fact that the moisture added to the air stream during the off-cycle is at the most equal to the moisture removed from the air during the compressor operation:

$t_{w}=\min \left(\dot{Q}_{l a t, s s}\left(t_{0}+\tau\left(e^{-t_{0} / \tau}-1\right)\right) / q_{L},\left(t_{c y c}-t_{0}\right)\right)$

$t_{w}=\dot{Q}_{\text {lat }, s s}\left(t_{0}+\tau\left(e^{-t_{0} / \tau}-1\right)\right) / q_{L}$ means that the entire moisture removed (condensate on the coil) are added in the room, whereas $t_{w}=\left(t_{c y c}-t_{0}\right)$ means that only a part of the condensate is evaporated in the air stream during the off-cycle. Therefore, the modelers can tune the value of the evaporation capacity to fix the amount of moisture that stays on the coil after the off-cycle (and that, for instance, leaves the system through a condensate drain).

Given a system unit, its regulators' characteristics and a constant evaporation capacity, both equations (6) and (7) embedded in a building energy simulation program allow the modelers to determine the unit performances during an hourly simulation. Indeed, once $t_{0}$ and $t_{c y c}$ are determined, the PLR and the CDF can be hourly estimated and so on (the $C O P, C_{d}, \lambda, \ldots$ ). 


\section{Identification of the equivalent set of parameters}

The HVAC BESTEST procedure only concerns ideal systems. The thermostat is represented by the relationship (5) with $C_{d}=0.229$. As a consequence, for our model we have first to determine an equivalent set of parameters value for the couple $\left(\tau, \Delta T_{c}\right)$. This was done by applying the HVAC BESTEST E100-200 series cases. We found $\tau=0.8 \mathrm{sec}$ and $\Delta T_{c}=0.05^{\circ} \mathrm{C}$ which gave $C_{d}=0.226$ (instead of 0.229 for the idealistic model) and $C D F=0.9805$ (instead of 0.981). The same set of parameters is used to perform the E300-360 series cases.

\section{Modeling the steady-state capacities with neural networks}

The steady-state performances of the split-system are predicted using a neural network. This model was obtained using manufacturer data. Indeed, starting from the HVAC performances in extreme conditions (measured), a database was built in order to allow a neural network to learn the behavior of the system under several conditions. With such a model, the coil loads are obtained for values of the model inputs varying between the minimal and the maximal value of the learning database (no extrapolation).

\begin{tabular}{llll}
\hline & EDB & EWB & ODB \\
\hline Min & 12.78 & 4.4 & 12.78 \\
Max & 35.00 & 35.00 & 46.11 \\
\hline
\end{tabular}

However, the neural networks are unable to extrapolate in the case of dry-coil conditions. In such a case, the following expressions are used:

Tewb $=((17.8823-23.5512)+(-0.1128 * \mathrm{Todb}+0.3226 * \mathrm{Todb})+(1.9688 * \mathrm{Tedb}-$ $0.0046 * \mathrm{Tedb})) /(1.0882+2.1011)$; $\mathrm{Q}_{\text {tot,ss }}=23.5512-0.3226 * \mathrm{Todb}+0.0046 * \mathrm{Tedb}+1.0882 * \mathrm{Tewb}$; $\mathrm{P}_{\text {sens }, \text { s }}=17.8823-0.1128 *$ Todb $+1.9688 *$ Tedb $-2.1011 *$ Tewb;

$\mathrm{P}_{\mathrm{abs}, \mathrm{ss}}=2.3926+0.1390 *$ Todb $+0.0056^{*} \mathrm{Tedb}+0.1376^{*} \mathrm{Tewb}$;

These relationships ensure that $\mathrm{Q}_{\text {tot,ss }}=\mathrm{Q}_{\text {sens,ss. }}$. 

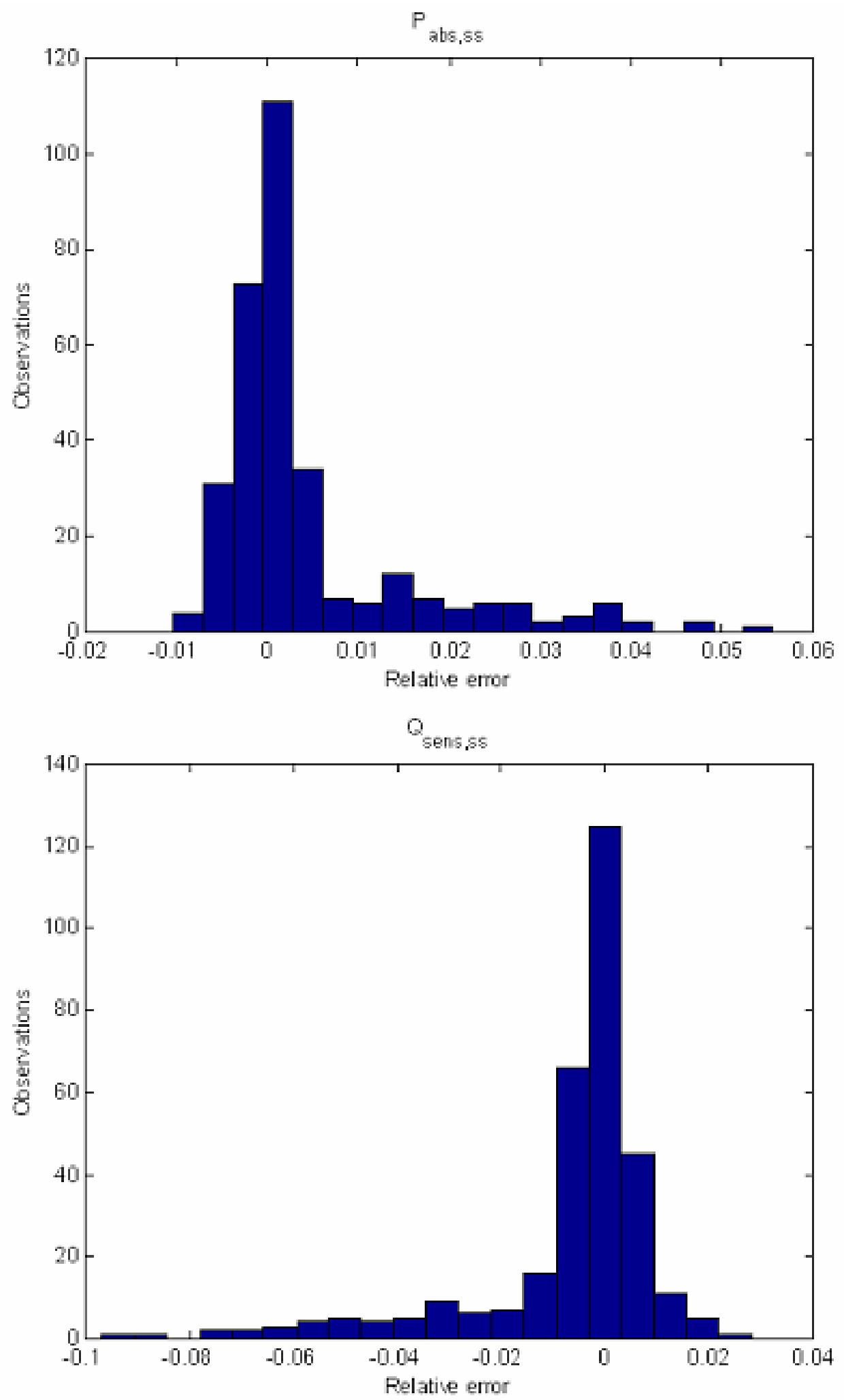


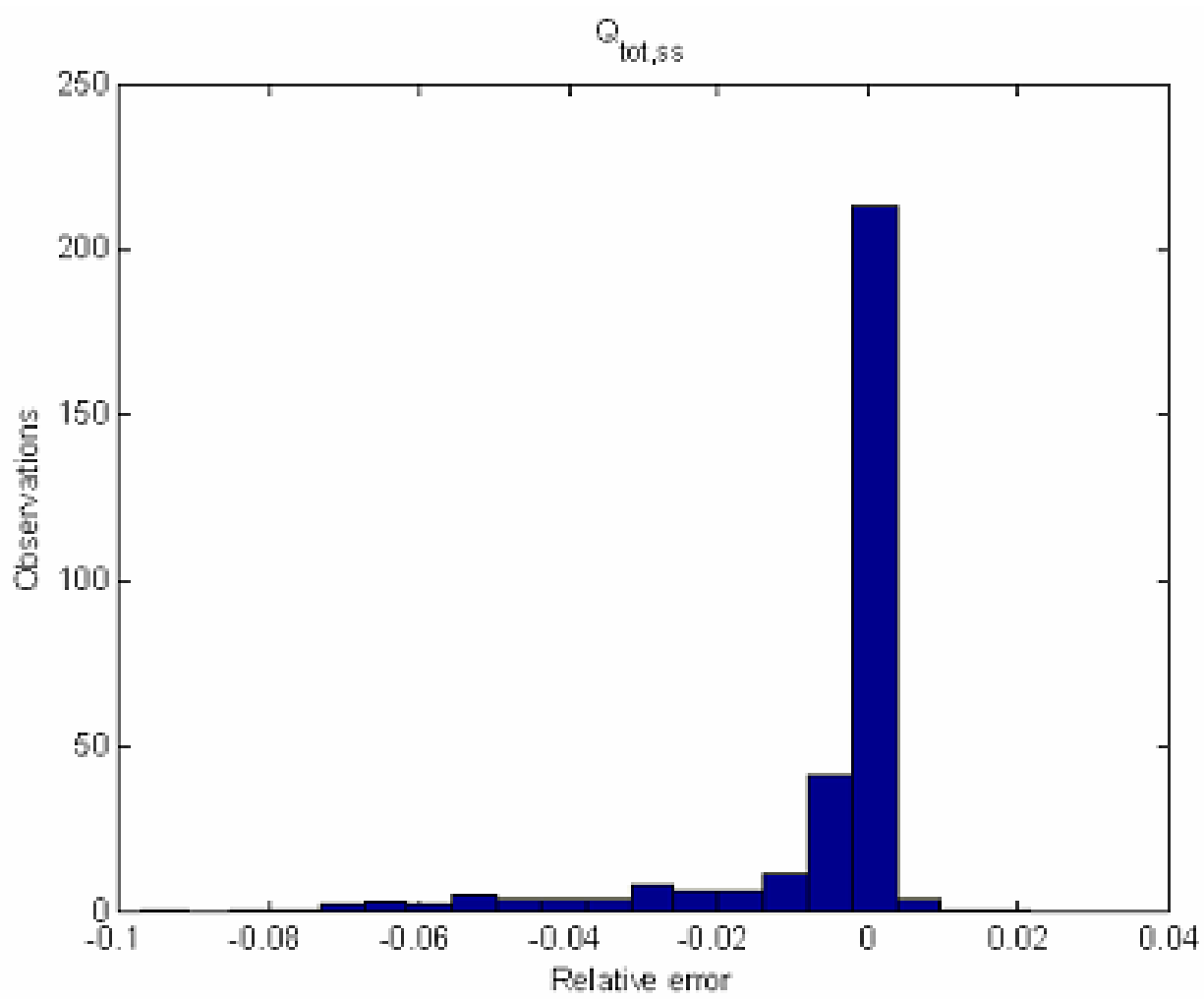

These figures show the distribution of the relative errors between the neural networks prediction and the manufacturer's data. The neural network model is quite accurate. 


\section{Results}

\subsection{Round 1}

In the first round only cases 300 and 310 were tested (July 2002).

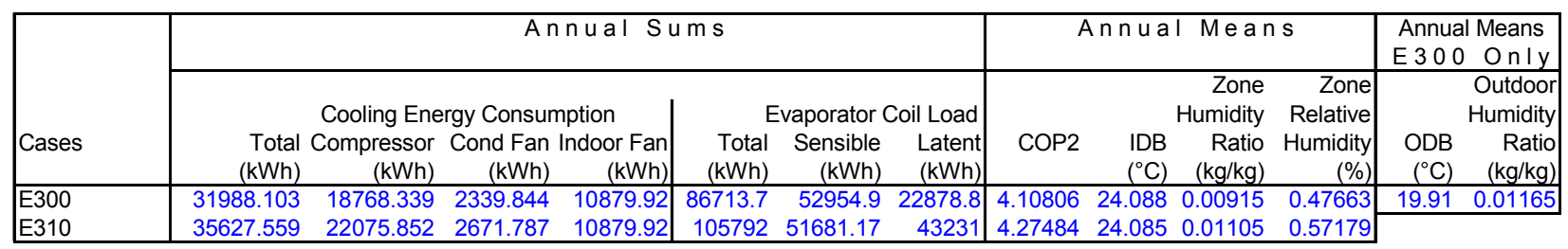

\begin{tabular}{|c|c|c|c|c|c|c|c|c|c|c|c|c|c|}
\hline \multirow{4}{*}{ Cases } & \multicolumn{9}{|c|}{ Annual Hourly Integrated Maxima Consumptions and Loads } & \multicolumn{4}{|c|}{ E300 Only, Maxima } \\
\hline & \multirow{2}{*}{\multicolumn{2}{|c|}{$\begin{array}{l}\text { Energy Consumption } \\
\text { Compr + Both Fans }\end{array}$}} & \multicolumn{7}{|c|}{ Evaporator Coil Loads } & \multicolumn{4}{|c|}{ Weather Data Checks } \\
\hline & & & & nsible & & & Latent & Sens & + Latent & & ODB & Outdoo & umidity Ratio \\
\hline & Wh & Date Hour & Wh & Date & Hour & Wh & Date Hour & Wh & Date Hour & ${ }^{\circ} \mathrm{C}$ & Date Hour & $\mathrm{kg} / \mathrm{kg}$ & Date Hour \\
\hline E300 & 11.176 & 201 & 22.095 & 155 & 15 & 19.765 & 255 & 36.486 & 255 & 35 & 201 & 0.0224 & 275 \\
\hline E310 & 11.734 & 201 & 22.456 & 201 & 15 & 29.453 & 216 & 40.751 & 275 & & & & \\
\hline
\end{tabular}

\begin{tabular}{|c|c|c|c|c|c|c|c|c|c|c|c|}
\hline \multirow[b]{3}{*}{ Hour } & \multicolumn{11}{|c|}{ June 28 Hourly Output - Case E300 } \\
\hline & \multicolumn{2}{|c|}{ Energy Consumption } & \multicolumn{3}{|c|}{ Evaporator Coil Load } & \multirow{2}{*}{\begin{tabular}{|r|} 
Zone \\
Hum. Rat. \\
$(\mathrm{kg} / \mathrm{kg})$
\end{tabular}} & \multirow[b]{2}{*}{ COP2 } & \multirow[b]{2}{*}{$\begin{array}{r}\text { ODB } \\
\left({ }^{\circ} \mathrm{C}\right)\end{array}$} & \multirow[b]{2}{*}{$\begin{array}{l}\text { EDB } \\
\left({ }^{\circ} \mathrm{C}\right) \\
\end{array}$} & \multirow[b]{2}{*}{$\begin{array}{r}\mathrm{EWB} \\
\left({ }^{\circ} \mathrm{C}\right)\end{array}$} & \multirow{2}{*}{$\begin{array}{r}\text { Outdoor } \\
\text { Hum. Rat. } \\
(\mathrm{kg} / \mathrm{kg}) \\
\end{array}$} \\
\hline & $\begin{array}{r}\text { Compressor } \\
(\mathrm{Wh})\end{array}$ & $\begin{array}{r}\text { Cond Fan } \\
(\text { Wh })\end{array}$ & $\begin{array}{l}\text { Total } \\
\text { (Wh) }\end{array}$ & $\begin{array}{r}\text { Sensible } \\
(\mathrm{Wh})\end{array}$ & $\begin{array}{r}\text { Latent } \\
(\mathrm{Wh})\end{array}$ & & & & & & \\
\hline 1 & 1600 & 240 & 7296 & 5539 & 1757 & 0.009098 & 3.96522 & 17.8 & 23.92 & 17.166 & 0.0111 \\
\hline 2 & 1650 & 245 & 7401 & 5705 & 1695 & 0.009301 & 3.90554 & 18.3 & 24 & 17.088 & 0.01146 \\
\hline 3 & 1599 & 240 & 7289 & 5539 & 1750 & 0.009104 & 3.96357 & 17.8 & 23.92 & 17.157 & 0.0111 \\
\hline 4 & 1583 & 238 & 7184 & 5541 & 1643 & 0.009114 & 3.94509 & 17.8 & 23.92 & 17.017 & 0.0111 \\
\hline 5 & 1501 & 229 & 6893 & 5346 & 1547 & 0.008608 & 3.98439 & 17.2 & 23.83 & 16.886 & 0.01018 \\
\hline 6 & 1737 & 253 & 7485 & 6075 & 1410 & 0.009048 & 3.76131 & 19.4 & 24.16 & 16.737 & 0.011 \\
\hline 7 & 2572 & 332 & 9856 & 7907 & 1950 & 0.010153 & 3.39394 & 25 & 25 & 17.599 & 0.01314 \\
\hline 8 & 3004 & 368 & 11126 & 8616 & 2510 & 0.008819 & 3.29953 & 27.2 & 25.33 & 18.228 & 0.01108 \\
\hline 9 & 3742 & 451 & 13312 & 11445 & 1867 & 0.010527 & 3.17482 & 28.9 & 25.59 & 17.44 & 0.012 \\
\hline 10 & 4107 & 485 & 15203 & 11394 & 3809 & 0.010152 & 3.31076 & 28.9 & 25.59 & 18.755 & 0.01276 \\
\hline 11 & 4480 & 509 & 15799 & 12118 & 3681 & 0.011412 & 3.16677 & 31.1 & 25.91 & 18.845 & 0.01481 \\
\hline 12 & 4608 & 523 & 16744 & 11924 & 4820 & 0.010016 & 3.2633 & 30.6 & 25.84 & 19.43 & 0.01325 \\
\hline 13 & 5658 & 648 & 20570 & 16616 & 3954 & 0.008947 & 3.26197 & 31.1 & 25.91 & 18.361 & 0.01133 \\
\hline 14 & 5496 & 630 & 19324 & 16852 & 2472 & 0.009942 & 3.15442 & 31.7 & 26 & 17.682 & 0.01173 \\
\hline 15 & 7120 & 800 & 26438 & 21451 & 4988 & 0.008796 & 3.33813 & 32.2 & 26.08 & 18.471 & 0.01238 \\
\hline 16 & 6854 & 777 & 25042 & 21489 & 3553 & 0.010649 & 3.28161 & 32.2 & 26.08 & 17.917 & 0.01423 \\
\hline 17 & 4682 & 525 & 16439 & 12302 & 4136 & 0.011196 & 3.1571 & 31.7 & 26 & 19.148 & 0.01473 \\
\hline 18 & 4769 & 535 & 17238 & 12079 & 5160 & 0.011219 & 3.25 & 31.1 & 25.91 & 19.636 & 0.01568 \\
\hline 19 & 4222 & 499 & 16171 & 11165 & 5006 & 0.010619 & 3.42533 & 28.3 & 25.5 & 19.383 & 0.01454 \\
\hline 20 & 3991 & 482 & 15609 & 10810 & 4799 & 0.012041 & 3.4896 & 27.2 & 25.33 & 19.211 & 0.01688 \\
\hline 21 & 3508 & 417 & 13804 & 8544 & 5260 & 0.011089 & 3.51694 & 27.2 & 25.33 & 20.111 & 0.01688 \\
\hline 22 & 3244 & 394 & 12662 & 8406 & 4256 & 0.011478 & 3.48048 & 26.7 & 25.25 & 19.493 & 0.01683 \\
\hline 23 & 3218 & 393 & 12844 & 8199 & 4645 & 0.011359 & 3.55691 & 26.1 & 25.16 & 19.728 & 0.01689 \\
\hline 24 & 3207 & 392 & 12786 & 8200 & 4586 & 0.01164 & 3.55265 & 26.1 & 25.16 & 19.691 & 0.01733 \\
\hline
\end{tabular}

\begin{tabular}{|c|c|c|c|c|c|c|c|c|c|c|}
\hline \multirow{4}{*}{ Cases } & $\mathrm{nnu}$ & ourly & & d & & a & Minima & C & $a n d$ & Zo \\
\hline & \multicolumn{5}{|c|}{$\mathrm{COP} 2$} & \multicolumn{5}{|c|}{ Indoor Drybulb Temperature } \\
\hline & \multicolumn{2}{|c|}{ Maximum } & \multicolumn{3}{|c|}{ Minimum } & \multicolumn{2}{|c|}{ Maximum } & \multicolumn{3}{|c|}{ Minimum* } \\
\hline & COP2 & Date Hour & COP2 & Date & Hour & ${ }^{\circ} \mathrm{C}$ & Date Hour & ${ }^{\circ} \mathrm{C}$ & Date & Hour \\
\hline E300 & $\overline{4.43}$ & 110 & 3.0 & 164 & 17 & 25.04 & 81 & 8.03 & 6 & 5 \\
\hline E310 & 4.9232 & 124 & 2.8509 & 210 & 17 & 25.04 & 81 & 8.02 & 6 & 5 \\
\hline
\end{tabular}




\begin{tabular}{|c|c|c|c|c|c|c|c|c|c|c|}
\hline \multirow{4}{*}{ Cases } & \multicolumn{10}{|c|}{ Annual Hourly Integrated Maxima and Minima-COP2 and Zo } \\
\hline & \multicolumn{5}{|c|}{ Humidity Ratio } & \multicolumn{5}{|c|}{ Relative Humidity } \\
\hline & \multicolumn{2}{|c|}{ Maximum } & \multicolumn{3}{|c|}{ imum* } & \multicolumn{2}{|c|}{ Maximum* } & \multicolumn{3}{|c|}{ Minimum* } \\
\hline & $\mathrm{Ka}$ & Date Hour & $\mathrm{kg} / \mathrm{kg}$ & Date & Hour & $\%$ & Date Hour & $\%$ & Date & Hour \\
\hline$E$ & 0 & 247 & 0.00 & 255 & 15 & 0.72 & 174 & 0.04 & 5 & 15 \\
\hline E310 & 0.0201 & 161 & 0.0019 & 11 & 2 & 1 & 112 & 0.13 & 226 & 16 \\
\hline
\end{tabular}

The results showed high gaps as compared to the other programs. It was found that the main error of the model was due to an amalgam between gross and net capacities. Indeed, the sensible building loads were calculated by accounting for the sensible gain due to the indoor ventilator $(1.242 \mathrm{~kW})$, whereas in the calculation of the evaporator coil loads net capacities were considered. We also noticed that the neural networks did not allow extrapolation in case of dry-coil conditions.

\subsection{Round 2}

Round 2 is an improvement of the previous program as it properly takes into account the gross capacities and also allows extrapolation at dry-coil conditions. For extrapolation the polynomials described earlier are used (see page 3).

Results from the Round 2 modeling with CODYRUN are presented below.

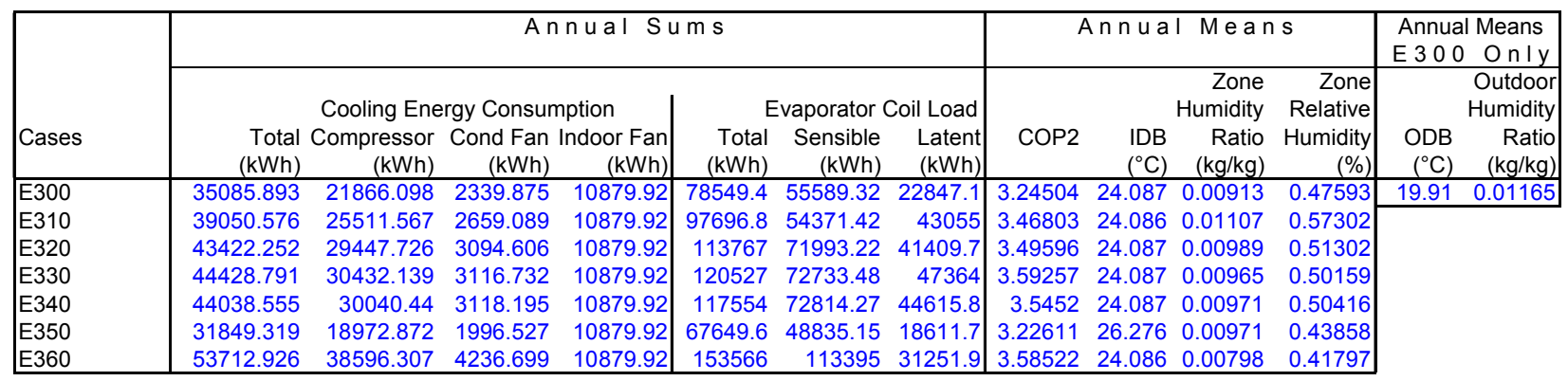

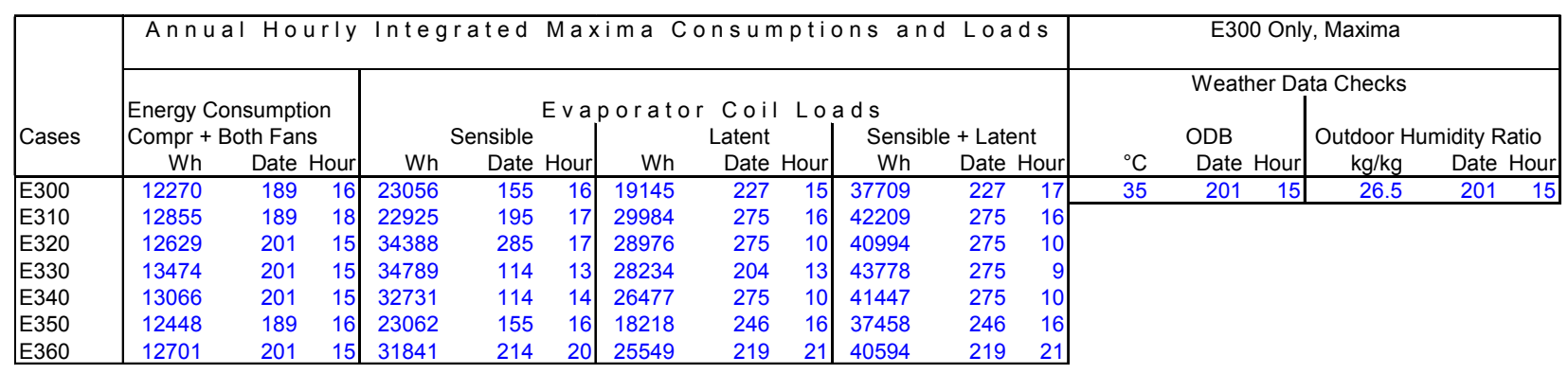




\begin{tabular}{|c|c|c|c|c|c|c|c|c|c|c|c|}
\hline \multirow[b]{3}{*}{ Hour } & \multicolumn{11}{|c|}{ June 28 Hourly Output - Case E300 } \\
\hline & \multicolumn{2}{|c|}{ Energy Consumption } & \multicolumn{3}{|c|}{ Evaporator Coil Load } & \multirow{2}{*}{$\begin{array}{r}\text { Zone } \\
\text { Hum. Rat. } \\
(\mathrm{kg} / \mathrm{kg})\end{array}$} & \multirow[b]{2}{*}{ COP2 } & \multirow[b]{2}{*}{$\begin{array}{r}\text { ODB } \\
\left({ }^{\circ} \mathrm{C}\right)\end{array}$} & \multirow[b]{2}{*}{$\begin{array}{l}\text { EDB } \\
\left({ }^{\circ} \mathrm{C}\right)\end{array}$} & \multirow[b]{2}{*}{$\begin{array}{r}\text { EWB } \\
\left({ }^{\circ} \mathrm{C}\right)\end{array}$} & \multirow{2}{*}{\begin{tabular}{|r} 
Outdoor \\
Hum. Rat. \\
(kg/kg)
\end{tabular}} \\
\hline & $\begin{array}{r}\text { Compressor } \\
\text { (Wh) }\end{array}$ & $\begin{array}{r}\text { Cond Fan } \\
(\mathrm{Wh})\end{array}$ & $\begin{array}{l}\text { Total } \\
\text { (Wh) }\end{array}$ & $\begin{array}{r}\text { Sensible } \\
\text { (Wh) }\end{array}$ & $\begin{array}{r}\text { Latent } \\
(\mathrm{Wh})\end{array}$ & & & & & & \\
\hline 1 & 1921 & 240 & 7555 & 5800 & 1755 & 0.009097 & 3.49607 & 17.8 & 23.92 & 17.163 & 0.0111 \\
\hline 2 & 1977 & 245 & 7667 & 5972 & 1695 & 0.009301 & 3.4505 & 18.3 & 24 & 17.088 & 0.01146 \\
\hline 3 & 1920 & 240 & 7550 & 5800 & 1750 & 0.009104 & 3.49537 & 17.8 & 23.92 & 17.157 & 0.0111 \\
\hline 4 & 1901 & 238 & 7443 & 5800 & 1643 & 0.009114 & 3.47966 & 17.8 & 23.92 & 17.017 & 0.0111 \\
\hline 5 & 1806 & 229 & 7141 & 5593 & 1547 & 0.008608 & 3.50909 & 17.2 & 23.83 & 16.886 & 0.01018 \\
\hline 6 & 2076 & 253 & 7759 & 6350 & 1410 & 0.009048 & 3.33147 & 19.4 & 24.16 & 16.737 & 0.011 \\
\hline 7 & 3015 & 332 & 10225 & 8276 & 1950 & 0.010153 & 3.05497 & 25 & 25 & 17.599 & 0.01314 \\
\hline 8 & 3496 & 368 & 11542 & 9032 & 2510 & 0.008819 & 2.98706 & 27.2 & 25.33 & 18.228 & 0.01108 \\
\hline 9 & 3575 & 371 & 11118 & 9617 & 1501 & 0.009686 & 2.81754 & 28.9 & 25.59 & 17.44 & 0.012 \\
\hline 10 & 4565 & 469 & 14868 & 11962 & 2906 & 0.010535 & 2.95352 & 28.9 & 25.59 & 18.186 & 0.01276 \\
\hline 11 & 5261 & 517 & 16858 & 12718 & 4140 & 0.011202 & 2.91762 & 31.1 & 25.91 & 19.104 & 0.01481 \\
\hline 12 & 5268 & 520 & 17184 & 12546 & 4638 & 0.010078 & 2.9689 & 30.6 & 25.84 & 19.336 & 0.01325 \\
\hline 13 & 4995 & 496 & 15651 & 12718 & 2933 & 0.00975 & 2.8503 & 31.1 & 25.91 & 18.389 & 0.01133 \\
\hline 14 & 6574 & 649 & 21191 & 17615 & 3576 & 0.009392 & 2.93382 & 31.7 & 26 & 18.243 & 0.01173 \\
\hline 15 & 6598 & 648 & 20963 & 17787 & 3176 & 0.009979 & 2.89304 & 32.2 & 26.08 & 18.102 & 0.01238 \\
\hline 16 & 8331 & 811 & 28151 & 22476 & 5676 & 0.009459 & 3.0793 & 32.2 & 26.08 & 18.716 & 0.01423 \\
\hline 17 & 8056 & 794 & 27230 & 22304 & 4926 & 0.010158 & 3.07684 & 31.7 & 26 & 18.393 & 0.01473 \\
\hline 18 & 5201 & 513 & 16587 & 12718 & 3868 & 0.011827 & 2.90287 & 31.1 & 25.91 & 18.952 & 0.01568 \\
\hline 19 & 5054 & 513 & 17565 & 11756 & 5809 & 0.010227 & 3.1552 & 28.3 & 25.5 & 19.784 & 0.01454 \\
\hline 20 & 4540 & 474 & 15711 & 11377 & 4333 & 0.012254 & 3.13343 & 27.2 & 25.33 & 18.951 & 0.01688 \\
\hline 21 & 5074 & 520 & 18361 & 11377 & 6983 & 0.01097 & 3.28227 & 27.2 & 25.33 & 20.268 & 0.01688 \\
\hline 22 & 3745 & 391 & 12993 & 8860 & 4133 & 0.011528 & 3.14144 & 26.7 & 25.25 & 19.413 & 0.01683 \\
\hline 23 & 3737 & 393 & 13270 & 8654 & 4616 & 0.0114 & 3.21308 & 26.1 & 25.16 & 19.709 & 0.01689 \\
\hline 24 & 3743 & 393 & 13299 & 8654 & 4645 & 0.01161 & 3.21543 & 26.1 & 25.16 & 19.728 & 0.01733 \\
\hline
\end{tabular}

\begin{tabular}{|c|c|c|c|c|c|c|c|c|c|c|c|c|}
\hline \multirow{4}{*}{ Cases } & \multicolumn{12}{|c|}{ Annual Hourly Integrated Maxima and Minima-COP2 and Zone } \\
\hline & \multicolumn{6}{|c|}{ COP 2} & \multicolumn{6}{|c|}{ Indoor Drybulb Temperature } \\
\hline & \multicolumn{3}{|c|}{ Maximum } & \multicolumn{3}{|c|}{ Minimum } & \multicolumn{3}{|c|}{ Maximum } & \multicolumn{3}{|c|}{ Minimum* } \\
\hline & COP2 & Date & Hour & COP2 & Date & Hour & ${ }^{\circ} \mathrm{C}$ & Date & Hour & ${ }^{\circ} \mathrm{C}$ & Date & Hour \\
\hline E300 & 3.9766 & 263 & 1 & 2.7401 & 227 & 18 & 25.04 & 81 & 2 & 8.03 & 6 & 5 \\
\hline E310 & 4.4114 & 110 & 5 & 2.6334 & 189 & 19 & 25.04 & 81 & 2 & 8.03 & 6 & 5 \\
\hline E320 & 4.565 & 120 & 10 & 2.7483 & 335 & 14 & 25.04 & 81 & 2 & 8.03 & 6 & 5 \\
\hline E330 & 4.3703 & 120 & 9 & 2.7483 & 335 & 14 & 25.04 & 81 & 2 & 8.03 & 6 & 5 \\
\hline E340 & 4.4495 & 120 & 9 & 2.7483 & 335 & 14 & 25.04 & 81 & 2 & 8.03 & 6 & 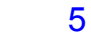 \\
\hline E350 & 3.9428 & 101 & 19 & 2.6385 & 163 & 9 & 35 & 111 & 1 & 8.03 & 6 & 5 \\
\hline E360 & 4.7579 & 110 & 4 & 2.7304 & 90 & 15 & 25.04 & 81 & 2 & 8.03 & 6 & 5 \\
\hline
\end{tabular}

\begin{tabular}{|c|c|c|c|c|c|c|c|c|c|c|c|c|}
\hline \multirow{4}{*}{ Cases } & \multicolumn{12}{|c|}{ Annual Hourly Integrated Maxima and Minima-COP2 and Zone } \\
\hline & \multicolumn{6}{|c|}{ Humidity Ratio } & \multicolumn{6}{|c|}{ Relative Humidity } \\
\hline & \multicolumn{3}{|c|}{ Maximum } & \multicolumn{3}{|c|}{ Minimum* } & \multicolumn{3}{|c|}{ Maximum* } & \multicolumn{3}{|c|}{ Minimum* } \\
\hline & $\mathrm{kg} / \mathrm{kg}$ & Date & Hour & $\mathrm{kg} / \mathrm{kg}$ & Date & Hour & $\%$ & Date & Hour & $\%$ & Date & Hour \\
\hline$\overline{E 300}$ & 0.0146 & 227 & 18 & 0.0019 & 11 & 2 & 0.73 & 227 & 16 & 0.13 & 310 & 5 \\
\hline E310 & 0.0201 & 112 & 17 & 0.0019 & 11 & 2 & 1 & 112 & 17 & 0.13 & 310 & 5 \\
\hline E320 & 0.0197 & 275 & 9 & 0.0019 & 11 & 2 & 0.98 & 275 & 9 & 0.13 & 310 & 5 \\
\hline E330 & 0.0179 & 191 & 12 & 0.0019 & 11 & 2 & 0.89 & 191 & 12 & 0.13 & 310 & 5 \\
\hline E340 & 0.0182 & 275 & 9 & 0.0019 & 11 & 2 & 0.91 & 275 & 9 & 0.13 & 310 & 5 \\
\hline E350 & 0.0173 & 213 & 21 & 0.0019 & 11 & 2 & 0.79 & 275 & 9 & 0.13 & 310 & 5 \\
\hline E360 & 0.0164 & 274 & 11 & -0.0006 & 219 & 21 & 0.82 & 191 & 12 & -0.03 & 219 & 21 \\
\hline
\end{tabular}

By analyzing the results in-depth, we noticed that the predicted indoor air humidity was not satisfactory. Indeed, as shown on the figure below, the predicted indoor humidity ratio strongly oscillates, especially 
for the case E360 (in this case, the minimal indoor air humidity ratio was negative). This is explained by the fact that the system capacities depend on the air humidity entering the evaporator coil. But in the original program, the air humidity entering the evaporator coil was calculated from the indoor air humidity estimated at the preceding time step (the previous hour). Consequently, the predicted steadycapacities were underestimated as the current internal latent load was not accounted for.

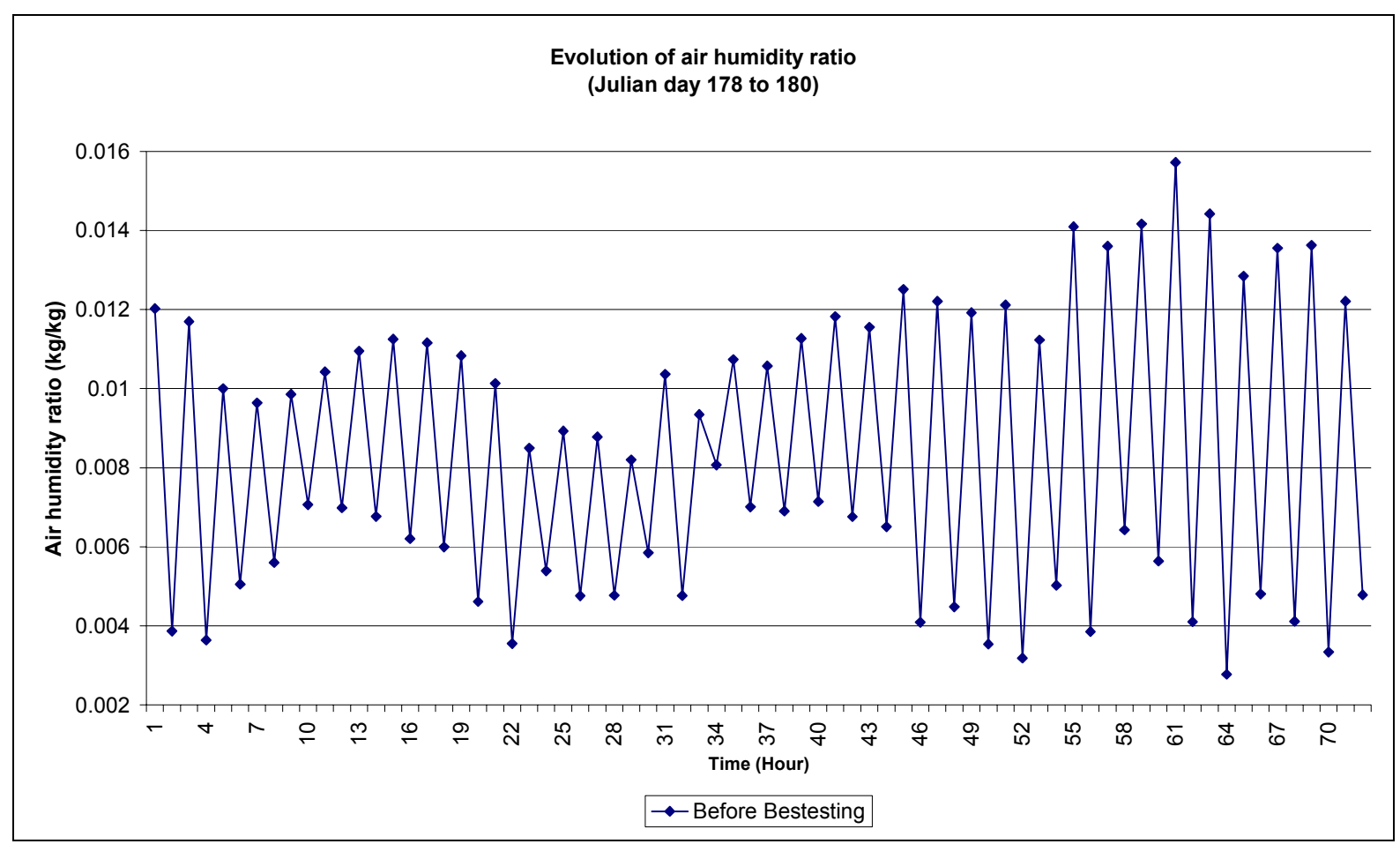

\subsection{Round 3}

To take into account the latent loads properly, an iterative loop at a short-time step (some minutes) was used to solve the humidity equation balance. The aim of the loop is to determine the appropriate entering air humidity for the hourly simulation. As expected, the predicted indoor air humidity ratio is improved. 


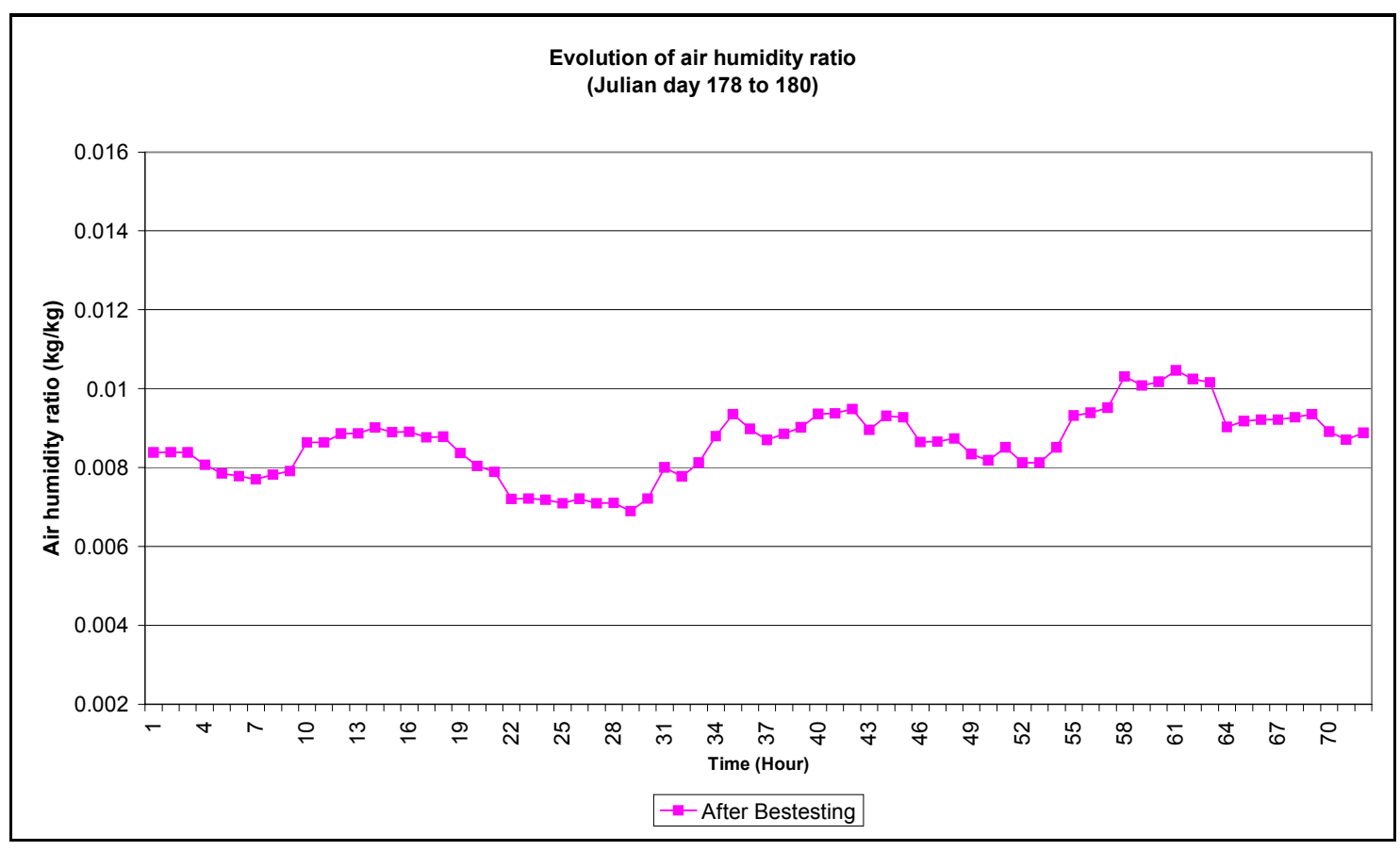

\begin{tabular}{|c|c|c|c|c|c|c|c|c|c|c|c|c|c|}
\hline \multirow[b]{3}{*}{ Cases } & \multicolumn{7}{|c|}{ Annual Sums } & \multicolumn{4}{|c|}{ Annual Means } & \multirow{2}{*}{\multicolumn{2}{|c|}{ 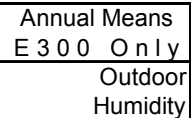 }} \\
\hline & \multicolumn{4}{|c|}{ Cooling Energy Consumption } & \multicolumn{3}{|c|}{ Evaporator Coil Load } & \multirow[b]{2}{*}{ COP2 } & \multicolumn{2}{|r|}{$\begin{array}{r}\text { Zone } \\
\text { Humidity }\end{array}$} & $\begin{array}{r}\text { Zone } \\
\text { elative }\end{array}$ & & \\
\hline & $\begin{array}{r}\text { Total } \\
(\mathrm{kWh})\end{array}$ & $\begin{array}{r}\text { Compressor } \\
(\mathrm{kWh})\end{array}$ & $\begin{array}{r}\text { Cond Fan } \\
(\mathrm{kWh})\end{array}$ & $\begin{array}{r}\text { ndoor Fan } \\
(\mathrm{kWh})\end{array}$ & $\begin{array}{r}\text { Total } \\
(\mathrm{kWh})\end{array}$ & $\begin{array}{r}\text { Sensible } \\
(\mathrm{kWh})\end{array}$ & $\begin{array}{r}\text { Latent } \\
(\mathrm{kWh})\end{array}$ & & $\begin{array}{l}\text { IDB } \\
\left({ }^{\circ} \mathrm{C}\right)\end{array}$ & $\begin{array}{r}\text { Ratio } \\
(\mathrm{kg} / \mathrm{kg})\end{array}$ & $\begin{array}{r}\text { Humidity } \\
(\%)\end{array}$ & $\begin{array}{l}\text { ODB } \\
\left({ }^{\circ} \mathrm{C}\right)\end{array}$ & $\begin{array}{r}\text { Ratio } \\
(\mathrm{kg} / \mathrm{kg})\end{array}$ \\
\hline E300 & 35086.586 & 21866.916 & 2339.75 & 10879.92 & 78568.1 & 55621.82 & 22856.6 & 3.24572 & 24.087 & 0.00913 & 0.47601 & $\frac{1}{19.91}$ & 0.01165 \\
\hline E310 & 39044.396 & 25505.057 & 2659.419 & 10879.92 & 97518.4 & 55202.41 & 42299.5 & 3.46246 & 24.086 & 0.01118 & 0.57904 & & \\
\hline E320 & 43434.026 & 29456.575 & 3097.531 & 10879.92 & 113750 & 72369.42 & 41029 & 3.49419 & 24.087 & 0.00989 & 0.51354 & & \\
\hline E330 & 44483.545 & 30483.373 & 3120.252 & 10879.92 & 120828 & 72548.49 & 47852.3 & 3.59568 & 24.087 & 0.00964 & 0.50094 & & \\
\hline E340 & 44076.572 & 30074.487 & 3122.165 & 10879.92 & 117707 & 72965.69 & 44619.9 & 3.54576 & 24.087 & 0.0097 & 0.50394 & & \\
\hline E350 & 31861.866 & 18984.607 & 1997.339 & 10879.92 & 67674.3 & 48971.95 & 18591.4 & 3.22536 & 26.276 & 0.00971 & 0.44024 & & \\
\hline E360 & 54305.655 & 39138.762 & 4286.973 & 10879.92 & 155663 & 125505.8 & 30077.4 & 3.58457 & 24.086 & 0.00814 & 0.42673 & & \\
\hline
\end{tabular}

\begin{tabular}{|c|c|c|c|c|c|c|c|c|c|c|c|c|c|c|c|c|c|}
\hline \multirow{5}{*}{ Cases } & \multicolumn{12}{|c|}{ Annual Hourly Integrated Maxima Consumptions and Loads } & \multicolumn{5}{|c|}{ E300 Only, Maxima } \\
\hline & \multirow{3}{*}{\multicolumn{3}{|c|}{$\begin{array}{l}\text { Energy Consumption } \\
\text { Compr + Both Fans }\end{array}$}} & \multirow{2}{*}{\multicolumn{9}{|c|}{ Evaporator Coil Loads }} & \multicolumn{5}{|c|}{ Weather Data Checks } \\
\hline & & & & & & & & & & & & & & & & & \\
\hline & & & & & nsible & & & Latent & & Sens & + Late & & & ODB & & Outdoor $\mathrm{H}$ & nidity Ratio \\
\hline & Wh & Date & Hour & Wh & Date & Hour & Wh & Date & Hour & Wh & Date & Hour & ${ }^{\circ} \mathrm{C}$ & Date & Hour & $\mathrm{kg} / \mathrm{kg}$ & Date Hour \\
\hline E300 & 11825 & 189 & 16 & 23064 & 228 & 16 & 11480 & 246 & 16 & 33409 & 246 & 16 & 35 & 201 & 15 & 26.5 & 201 \\
\hline E310 & 12392 & 228 & 16 & 22821 & 164 & 16 & 18290 & 261 & 16 & 38196 & 261 & 16 & & & & & \\
\hline E320 & 12634 & 201 & 15 & 34388 & 285 & 17 & 23034 & 275 & 11 & 39513 & 275 & 12 & & & & & \\
\hline E330 & 13480 & 201 & 15 & 34789 & 114 & 13 & 28246 & 112 & 18 & 43932 & 275 & 9 & & & & & \\
\hline E340 & 13072 & 201 & 15 & 32731 & 114 & 16 & 24898 & 246 & 17 & 40705 & 246 & 17 & & & & & \\
\hline E350 & 11821 & 189 & 16 & 23072 & 228 & 16 & 16521 & 275 & 8 & 33421 & 246 & 16 & & & & & \\
\hline E360 & 12236 & 201 & 15 & 31300 & 136 & 10 & 10749 & 246 & 17 & 35827 & 258 & 11 & & & & & \\
\hline
\end{tabular}




\begin{tabular}{|c|c|c|c|c|c|c|c|c|c|c|c|}
\hline \multirow[b]{3}{*}{ Hour } & \multicolumn{11}{|c|}{ June 28 Hourly Output - Case E300 } \\
\hline & \multicolumn{2}{|c|}{ Energy Consumption } & \multicolumn{3}{|c|}{ Evaporator Coil Load } & \multirow{2}{*}{$\begin{array}{r}\text { Zone } \\
\text { Hum. Rat. } \\
(\mathrm{kg} / \mathrm{kg})\end{array}$} & \multirow[b]{2}{*}{ COP2 } & \multirow[b]{2}{*}{$\begin{array}{r}\text { ODB } \\
\left({ }^{\circ} \mathrm{C}\right)\end{array}$} & \multirow[b]{2}{*}{$\begin{array}{l}\text { EDB } \\
\left({ }^{\circ} \mathrm{C}\right)\end{array}$} & \multirow[b]{2}{*}{$\begin{array}{r}\text { EWB } \\
\left({ }^{\circ} \mathrm{C}\right)\end{array}$} & \multirow{2}{*}{\begin{tabular}{|r} 
Outdoor \\
Hum. Rat. \\
(kg/kg)
\end{tabular}} \\
\hline & $\begin{array}{r}\text { Compressor } \\
\text { (Wh) }\end{array}$ & $\begin{array}{r}\text { Cond Fan } \\
(\mathrm{Wh})\end{array}$ & $\begin{array}{l}\text { Total } \\
\text { (Wh) }\end{array}$ & $\begin{array}{r}\text { Sensible } \\
\text { (Wh) }\end{array}$ & $\begin{array}{r}\text { Latent } \\
(\mathrm{Wh})\end{array}$ & & & & & & \\
\hline 1 & 1923 & 240 & 7566 & 5800 & 1766 & 0.009202 & 3.49792 & 17.8 & 23.92 & 17.178 & 0.0111 \\
\hline 2 & 1989 & 246 & 7734 & 5972 & 1762 & 0.009245 & 3.4604 & 18.3 & 24 & 17.173 & 0.01146 \\
\hline 3 & 1916 & 240 & 7530 & 5800 & 1730 & 0.009172 & 3.49258 & 17.8 & 23.92 & 17.131 & 0.0111 \\
\hline 4 & 1909 & 239 & 7489 & 5800 & 1690 & 0.009138 & 3.4865 & 17.8 & 23.92 & 17.079 & 0.0111 \\
\hline 5 & 1809 & 229 & 7157 & 5593 & 1564 & 0.008871 & 3.51178 & 17.2 & 23.83 & 16.91 & 0.01018 \\
\hline 6 & 2102 & 256 & 7909 & 6350 & 1559 & 0.00895 & 3.35411 & 19.4 & 24.16 & 16.931 & 0.011 \\
\hline 7 & 3002 & 330 & 10163 & 8276 & 1888 & 0.009557 & 3.05012 & 25 & 25 & 17.538 & 0.01314 \\
\hline 8 & 3397 & 360 & 11068 & 9032 & 2036 & 0.00926 & 2.94597 & 27.2 & 25.33 & 17.813 & 0.01108 \\
\hline 9 & 3660 & 378 & 11511 & 9617 & 1894 & 0.009404 & 2.85067 & 28.9 & 25.59 & 17.805 & 0.012 \\
\hline 10 & 4506 & 464 & 14592 & 11962 & 2630 & 0.010023 & 2.93602 & 28.9 & 25.59 & 17.999 & 0.01276 \\
\hline 11 & 5132 & 507 & 16270 & 12718 & 3552 & 0.010743 & 2.88526 & 31.1 & 25.91 & 18.769 & 0.01481 \\
\hline 12 & 5150 & 511 & 16642 & 12546 & 4096 & 0.010534 & 2.93976 & 30.6 & 25.84 & 19.042 & 0.01325 \\
\hline 13 & 5106 & 505 & 16153 & 12718 & 3435 & 0.010034 & 2.87881 & 31.1 & 25.91 & 18.699 & 0.01133 \\
\hline 14 & 6664 & 656 & 21607 & 17615 & 3993 & 0.009606 & 2.95178 & 31.7 & 26 & 18.44 & 0.01173 \\
\hline 15 & 6664 & 653 & 21268 & 17787 & 3482 & 0.009715 & 2.90666 & 32.2 & 26.08 & 18.252 & 0.01238 \\
\hline 16 & 8234 & 804 & 27683 & 22476 & 5207 & 0.009718 & 3.06296 & 32.2 & 26.08 & 18.551 & 0.01423 \\
\hline 17 & 8166 & 802 & 27764 & 22304 & 5461 & 0.009781 & 3.0959 & 31.7 & 26 & 18.586 & 0.01473 \\
\hline 18 & 5110 & 505 & 16174 & 12718 & 3456 & 0.010892 & 2.8805 & 31.1 & 25.91 & 18.712 & 0.01568 \\
\hline 19 & 4812 & 492 & 16394 & 11756 & 4638 & 0.010836 & 3.09087 & 28.3 & 25.5 & 19.187 & 0.01454 \\
\hline 20 & 4693 & 487 & 16465 & 11377 & 5088 & 0.011368 & 3.17857 & 27.2 & 25.33 & 19.365 & 0.01688 \\
\hline 21 & 4831 & 499 & 17149 & 11377 & 5772 & 0.01147 & 3.21745 & 27.2 & 25.33 & 19.712 & 0.01688 \\
\hline 22 & 3854 & 401 & 13527 & 8860 & 4666 & 0.011387 & 3.17908 & 26.7 & 25.25 & 19.752 & 0.01683 \\
\hline 23 & 3726 & 392 & 13216 & 8654 & 4562 & 0.011388 & 3.20932 & 26.1 & 25.16 & 19.676 & 0.01689 \\
\hline 24 & 3742 & 393 & 13294 & 8654 & 4640 & 0.011499 & 3.21499 & 26.1 & 25.16 & 19.725 & 0.01733 \\
\hline
\end{tabular}

\begin{tabular}{|c|c|c|c|c|c|c|c|c|c|c|c|c|}
\hline \multirow{4}{*}{ Cases } & \multicolumn{12}{|c|}{ Annual Hourly Integrated Ma } \\
\hline & \multicolumn{6}{|c|}{ COP 2} & \multicolumn{6}{|c|}{ Indoor Drybulb Temperature } \\
\hline & \multicolumn{3}{|c|}{ Maximum } & \multicolumn{3}{|c|}{ Minimum } & \multicolumn{3}{|c|}{ Maximum } & \multicolumn{3}{|c|}{ Minimum* } \\
\hline & COP2 & Date & Hour & COP2 & Date & Hour & ${ }^{\circ} \mathrm{C}$ & Date 1 & Hour & ${ }^{\circ} \mathrm{C}$ & Date & Hour \\
\hline E300 & 3.9428 & 101 & 19 & 2.7483 & 335 & 14 & 25.04 & 81 & 2 & 8.03 & 6 & $\pi$ \\
\hline E310 & 287 & 110 & 6 & 2.7621 & 335 & 15 & 25.04 & 81 & 2 & 8.03 & 6 & 5 \\
\hline E320 & 4.5616 & 277 & 20 & 2.7277 & 335 & 14 & 25.04 & 81 & 2 & 3.03 & 6 & 5 \\
\hline E330 & 4.3717 & 120 & 9 & 2.7483 & 335 & 14 & 25.04 & 81 & 2 & 3.03 & 6 & 5 \\
\hline E340 & 5 & 120 & 9 & 2.7483 & 335 & 14 & 25.04 & 81 & 2 & .03 & 6 & 5 \\
\hline E350 & 3.9428 & 101 & 19 & 2.7497 & 335 & 14 & 35.00 & 111 & 1 & 3.03 & 6 & 5 \\
\hline E360 & 4.6285 & 110 & 3 & 2.7483 & 335 & 14 & 25.04 & 81 & 2 & 8.03 & 6 & 5 \\
\hline \multirow{4}{*}{ Cases } & \multicolumn{12}{|c|}{ Annual Hourly Integrated Maxima and Minima-COP2 and Zone } \\
\hline & \multicolumn{6}{|c|}{ Humidity Ratio } & \multicolumn{6}{|c|}{ Relative Humidity } \\
\hline & \multicolumn{3}{|c|}{ Maximum } & \multicolumn{3}{|c|}{ nimum* } & \multicolumn{3}{|c|}{ Maximum* } & \multicolumn{3}{|c|}{ Minimum* } \\
\hline & $\mathrm{kg} / \mathrm{kg}$ & Date & Hour & $\mathrm{kg} / \mathrm{kg}$ & Date & Hour & $\%$ & Date & Hour & $\%$ & Date & Hour \\
\hline E300 & 0.0135 & 320 & 16 & 0.0020 & 11 & 3 & 0.68 & 320 & 16 & 0.15 & 310 & 5 \\
\hline E310 & 0.0157 & 275 & 9 & 0.0020 & 5 & 7 & 0.78 & 246 & 9 & 0.15 & 310 & \\
\hline E320 & 0.0173 & 191 & 12 & 0.0020 & 11 & 3 & 0.86 & 191 & 12 & 0.15 & 310 & 5 \\
\hline E330 & 0.0171 & 191 & 13 & 0.0020 & 11 & 3 & 0.85 & 191 & 12 & 0.15 & 310 & 5 \\
\hline E340 & 0.0171 & 191 & 12 & 0.0020 & 11 & 3 & 0.85 & 191 & 12 & 0.15 & 310 & \\
\hline E350 & 0.0166 & 275 & 2 & 0.0020 & 11 & 3 & 0.68 & 320 & 16 & 0.15 & 310 & 5 \\
\hline E360 & 0.0135 & 320 & 16 & 0.0020 & 11 & 3 & 0.68 & 320 & 16 & 0.15 & 310 & 5 \\
\hline
\end{tabular}


However, the predictions of CODYRUN strongly disagreed with those of the other programs. The sensitivity tests and the comparisons proposed by the procedure brought us to doubt about the internal loads file. Indeed, a shift in the hourly electrical consumption has been noticed. The internal loads files were checked and corrected. Then we performed the next round.

\subsection{Round 4}

We also modified CODYRUN so that the IDB value could be greater than the set point when the system is undersized. Previously, the IDB was fixed to the set point when the system was on. The results were then more in accordance with the other codes except for case E360. We think that this difference can be explained by the neural network performance. Even though its accuracy was assessed with the available data, we are unable to affirm that the neural networks perform well in the "blank cases conditions." These cases probably occur more frequently in the E360 case (undersized system).

\begin{tabular}{|c|c|c|c|c|c|c|c|c|c|c|c|c|}
\hline \multirow[b]{3}{*}{ Cases } & \multicolumn{7}{|c|}{ Annual Sums } & \multicolumn{4}{|c|}{ Annual Means } & \multirow{2}{*}{\begin{tabular}{|rr|}
\multicolumn{2}{|c|}{ Annual Means } \\
E 300 & O n I y \\
Outdoor \\
Humidity
\end{tabular}} \\
\hline & & Cooling Ene & rgy Consun & ption & & Evaporator & Coil Load & & & $\begin{array}{r}\text { Zone } \\
\text { Humidity }\end{array}$ & $\begin{array}{r}\text { Zone } \\
\text { Relative }\end{array}$ & \\
\hline & $\begin{array}{r}\text { Total } \\
(\mathrm{kWh})\end{array}$ & $\begin{array}{r}\text { Compressor } \\
(\mathrm{kWh})\end{array}$ & $\begin{array}{r}\text { Cond Fan } \\
(\mathrm{kWh})\end{array}$ & $\begin{array}{r}\text { ndoor Fan } \\
(\mathrm{kWh})\end{array}$ & $\begin{array}{r}\text { Total } \\
(\mathrm{kWh})\end{array}$ & $\begin{array}{r}\text { Sensible } \\
(\mathrm{kWh})\end{array}$ & $\begin{array}{l}\text { Latent } \\
(\mathrm{kWh})\end{array}$ & COP2 & $\begin{array}{l}\text { IDB } \\
\left({ }^{\circ} \mathrm{C}\right)\end{array}$ & $\begin{array}{r}\text { Ratio } \\
(\mathrm{kg} / \mathrm{kg})\end{array}$ & $\begin{array}{r}\text { Humidity } \\
(\%)\end{array}$ & $\begin{array}{rr}\text { ODB } & \text { Ratio } \\
\left({ }^{\circ} \mathrm{C}\right) & (\mathrm{kg} / \mathrm{kg})\end{array}$ \\
\hline E300 & 34958.787 & 21754.282 & 2324.585 & 10879.92 & 77684.4 & 55162.02 & 22520.9 & 3.22625 & 24.084 & 0.00918 & 0.47829 & $\begin{array}{cc}19.91 & 0.01165 \\
\end{array}$ \\
\hline E310 & 39500.164 & 25916.972 & 2703.272 & 10879.92 & 97202.6 & 55089.64 & 42111.7 & 3.39629 & 24.108 & 0.01117 & 0.57781 & \\
\hline E320 & 39361.996 & 25804.156 & 2677.92 & 10879.92 & 96499.3 & 59094.11 & 37403.5 & 3.38807 & 24.472 & 0.00999 & 0.50372 & \\
\hline E330 & 40518.956 & 26918.215 & 2720.821 & 10879.92 & 103678 & 62613.01 & 41063.4 & 3.49802 & 24.297 & 0.00981 & 0.50079 & \\
\hline E340 & 40019.637 & 26430.125 & 2709.592 & 10879.92 & 100381 & 60887.75 & 39491.6 & 3.44481 & 24.383 & 0.00984 & 0.49927 & \\
\hline E350 & 31638.101 & 18793.412 & 1964.769 & 10879.92 & 66965.2 & 48539.4 & 18424.1 & 3.22597 & 26.271 & 0.00974 & 0.44207 & \\
\hline E360 & 54073.58 & 38923.953 & 4269.707 & 10879.92 & 155126 & 125449 & 29675.4 & 3.5914 & 28.402 & 0.00816 & 0.34749 & \\
\hline
\end{tabular}

\begin{tabular}{|c|c|c|c|c|c|c|c|c|c|c|c|c|c|c|c|c|c|}
\hline \multirow{4}{*}{ Cases } & \multicolumn{3}{|c|}{ Annual Hourly } & \multicolumn{9}{|c|}{ d Maxima Consumptions and Loads } & \multicolumn{5}{|c|}{ E300 Only, Maxima } \\
\hline & \multirow{2}{*}{\multicolumn{3}{|c|}{$\begin{array}{l}\text { Energy Consumption } \\
\text { Compr + Both Fans }\end{array}$}} & \multicolumn{9}{|c|}{ Evaporator Coil Loads } & \multicolumn{5}{|c|}{ Weather Data Checks } \\
\hline & & & & & Sensible & & & Latent & & Sens & ble + Later & & & ODB & & Outdoo & umidity Ratio \\
\hline & Wh & Date & Hour & Wh & Date & Hour & Wh & Date & Hour & Wh & Date & Hour & ${ }^{\circ} \mathrm{C}$ & Date & Hour & $\mathrm{kg} / \mathrm{kg}$ & Date Hour \\
\hline E300 & 11914 & 20 -juil & 15 & 23441 & 20 -juil & 15 & 10331 & 3-sept & 15 & 32462 & 20 -juil & 15 & 35 & 20 -juil & 15 & 0.0224 & 2 -oct \\
\hline E310 & 12544 & 20-juil & 15 & 22973 & 10-sept & 15 & 16377 & 3-sept & 15 & 36938 & 3-sept & 15 & & & & & \\
\hline E320 & 12628 & 20-juil & 15 & 30816 & 24-avr & 16 & 22837 & 10-juil & 12 & 39008 & 18-sept & 15 & & & & & \\
\hline E330 & 13467 & 20-juil & 15 & 33969 & 24-avr & 16 & 28184 & 18-sept & 15 & 43978 & 2-oct & 9 & & & & & \\
\hline E340 & 13083 & 20-juil & 15 & 32835 & 24-avr & 16 & 24719 & 2-oct & 9 & 41022 & 2-oct & 9 & & & & & \\
\hline E350 & 11930 & 20-juil & 15 & 23449 & 20-juil & 15 & 10787 & 2-oct & 8 & 32613 & 20-juil & 15 & & & & & \\
\hline E360 & 12243 & 20-juil & 15 & 31156 & 16-mai & 10 & 10329 & 2-oct & 9 & 35375 & 22-sept & 19 & & & & & \\
\hline
\end{tabular}




\begin{tabular}{|c|c|c|c|c|c|c|c|c|c|c|c|}
\hline \multirow[b]{3}{*}{ Hour } & \multicolumn{11}{|c|}{ June 28 Hourly Output-Case E300 } \\
\hline & \multicolumn{2}{|c|}{ Energy Consumption } & \multicolumn{3}{|c|}{ Evaporator Coil Load } & \multirow{2}{*}{\begin{tabular}{|r} 
Zone \\
Hum. Rat. \\
$(\mathrm{kg} / \mathrm{kg})$
\end{tabular}} & \multirow[b]{2}{*}{ COP2 } & \multirow[b]{2}{*}{$\begin{array}{r}\text { ODB } \\
\left({ }^{\circ} \mathrm{C}\right)\end{array}$} & \multirow[b]{2}{*}{$\begin{array}{l}\text { EDB } \\
\left({ }^{\circ} \mathrm{C}\right)\end{array}$} & \multirow[b]{2}{*}{$\begin{array}{r}\mathrm{EWB} \\
\left({ }^{\circ} \mathrm{C}\right)\end{array}$} & \multirow{2}{*}{\begin{tabular}{|r} 
Outdoor \\
Hum. Rat. \\
(kg/kg)
\end{tabular}} \\
\hline & $\begin{array}{r}\text { Compressor } \\
\text { (Wh) }\end{array}$ & $\begin{array}{r}\text { Cond Fan } \\
(\mathrm{Wh})\end{array}$ & $\begin{array}{l}\text { Total } \\
\text { (Wh) }\end{array}$ & $\begin{array}{r}\text { Sensible } \\
\text { (Wh) }\end{array}$ & $\begin{array}{r}\text { Latent } \\
(\mathrm{Wh})\end{array}$ & & & & & & \\
\hline 1 & 1890 & 236 & 7488 & 5800 & 1689 & 0.009271 & 3.52211 & 17.8 & 23.92 & 17.114 & 0.0111 \\
\hline 2 & 1968 & 245 & 7722 & 5972 & 1750 & 0.009297 & 3.48938 & 18.3 & 24 & 17.249 & 0.01146 \\
\hline 3 & 1886 & 236 & 7466 & 5800 & 1666 & 0.009232 & 3.51838 & 17.8 & 23.92 & 17.096 & 0.0111 \\
\hline 4 & 1881 & 236 & 7445 & 5800 & 1645 & 0.009196 & 3.51677 & 17.8 & 23.92 & 17.084 & 0.0111 \\
\hline 5 & 1761 & 223 & 7023 & 5593 & 1429 & 0.008962 & 3.53982 & 17.2 & 23.83 & 16.683 & 0.01018 \\
\hline 6 & 2077 & 254 & 7922 & 6350 & 1573 & 0.009007 & 3.39854 & 19.4 & 24.16 & 17.049 & 0.011 \\
\hline 7 & 3031 & 338 & 10434 & 8276 & 2158 & 0.009493 & 3.09706 & 25 & 25 & 18.106 & 0.01314 \\
\hline 8 & 3303 & 350 & 10814 & 9032 & 1782 & 0.009314 & 2.96031 & 27.2 & 25.33 & 17.572 & 0.01108 \\
\hline 9 & 4477 & 467 & 14605 & 11962 & 2644 & 0.009714 & 2.95409 & 28.9 & 25.59 & 18.274 & 0.012 \\
\hline 10 & 4588 & 476 & 15074 & 11962 & 3112 & 0.010051 & 2.9767 & 28.9 & 25.59 & 18.567 & 0.01276 \\
\hline 11 & 5234 & 523 & 16708 & 12718 & 3990 & 0.010595 & 2.90221 & 31.1 & 25.91 & 19.351 & 0.01481 \\
\hline 12 & 5063 & 504 & 16247 & 12546 & 3701 & 0.010584 & 2.91845 & 30.6 & 25.84 & 18.935 & 0.01325 \\
\hline 13 & 6442 & 633 & 21090 & 17408 & 3682 & 0.009973 & 2.98092 & 31.1 & 25.91 & 18.092 & 0.01133 \\
\hline 14 & 6519 & 642 & 21051 & 17615 & 3436 & 0.009777 & 2.93967 & 31.7 & 26 & 18.193 & 0.01173 \\
\hline 15 & 7994 & 782 & 26610 & 22476 & 4135 & 0.009582 & 3.03213 & 32.2 & 26.08 & 18.162 & 0.01238 \\
\hline 16 & 8167 & 801 & 27407 & 22476 & 4931 & 0.009733 & 3.05609 & 32.2 & 26.08 & 18.614 & 0.01423 \\
\hline 17 & 5300 & 528 & 16681 & 12925 & 3756 & 0.010442 & 2.86222 & 31.7 & 26 & 19.329 & 0.01473 \\
\hline 18 & 5377 & 534 & 17296 & 12718 & 4578 & 0.010915 & 2.92607 & 31.1 & 25.91 & 19.636 & 0.01568 \\
\hline 19 & 4790 & 491 & 16225 & 11756 & 4469 & 0.010917 & 3.07233 & 28.3 & 25.5 & 19.199 & 0.01454 \\
\hline 20 & 4807 & 504 & 16860 & 11377 & 5483 & 0.011272 & 3.17454 & 27.2 & 25.33 & 19.78 & 0.01688 \\
\hline 21 & 3936 & 409 & 13471 & 9032 & 4438 & 0.011354 & 3.10035 & 27.2 & 25.33 & 19.73 & 0.01688 \\
\hline 22 & 3851 & 402 & 13319 & 8860 & 4458 & 0.011387 & 3.13167 & 26.7 & 25.25 & 19.709 & 0.01683 \\
\hline 23 & 3751 & 396 & 13137 & 8654 & 4483 & 0.011418 & 3.16783 & 26.1 & 25.16 & 19.706 & 0.01689 \\
\hline 24 & 3793 & 400 & 13319 & 8654 & 4664 & 0.01151 & 3.17648 & 26.1 & 25.16 & 19.841 & 0.01733 \\
\hline
\end{tabular}

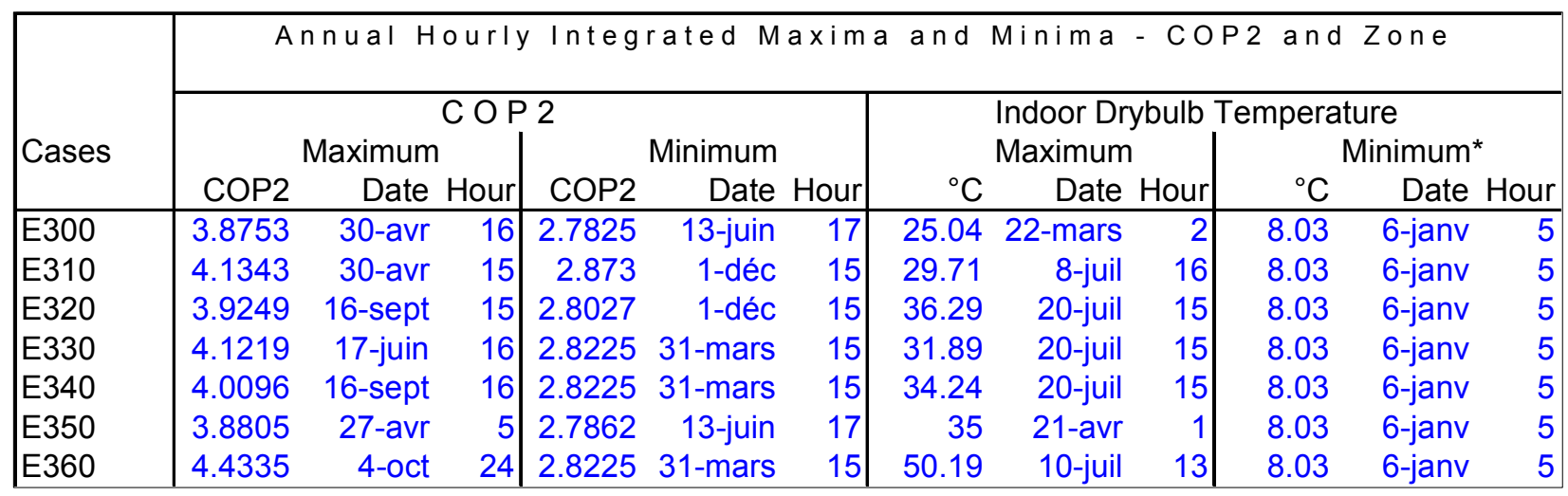

\begin{tabular}{|c|c|c|c|c|c|c|c|c|c|c|c|c|}
\hline \multirow{4}{*}{ Cases } & \multicolumn{12}{|c|}{ Annual Hourly Integrated Maxima and Minima - COP 2 and Zone } \\
\hline & \multicolumn{6}{|c|}{ Humidity Ratio } & \multicolumn{6}{|c|}{ Relative Humidity } \\
\hline & \multicolumn{3}{|c|}{ Maximum } & \multicolumn{3}{|c|}{ Minimum* } & \multicolumn{3}{|c|}{ Maximum* } & \multicolumn{3}{|c|}{ Minimum* } \\
\hline & $\mathrm{kg} / \mathrm{kg}$ & Date & Hour & $\mathrm{kg} / \mathrm{kg}$ & Date & Hour & $\%$ & Date & Hour & $\%$ & Date & Hour \\
\hline E300 & 0.0135 & 30-avr & 16 & 0.002 & 13-juin & 3 & $68 \%$ & 22-mars & 16 & $15 \%$ & 6-janv & - \\
\hline E310 & 154 & 30-avr & 8 & 0.002 & 1-déc & 7 & $77 \%$ & 8-juil & 8 & $16 \%$ & 6-janv & 8 \\
\hline E320 & 0.0169 & 16-sept & 12 & 0.002 & 1-déc & 3 & $82 \%$ & 20-juil & 18 & $15 \%$ & 6-janv & \\
\hline E330 & 0.017 & 17-juin & 13 & 0.002 & 31-mars & 3 & $76 \%$ & 20-juil & 18 & $15 \%$ & 6-janv & \\
\hline E340 & 0169 & 16-sept & 12 & 0.002 & 31-mars & 3 & $79 \%$ & 20-juil & 19 & $15 \%$ & 6-janv & \\
\hline E350 & 165 & 27-avr & 2 & 0.002 & 13-juin & 3 & $70 \%$ & 21-avr & 8 & $15 \%$ & 6-janv & \\
\hline E360 & 0.0135 & 4-oct & 16 & 0.002 & 31-mars & 3 & $68 \%$ & 10-juil & 16 & $14 \%$ & 6-janv & 13 \\
\hline
\end{tabular}




\subsection{Cases E500-E545}

We have tested the E500 cases series. It was the first round for this case. We noticed sensitivities to humidity ratio and COP2 for cases E530, E540, and E545. In the cases the building is perfectly closed (no indoor/outdoor air exchange) and no latent load is supplied; the results are sensitive to the initial indoor air conditions. For instance, we obtained for case E520 a maximum COP 2 between 5 to 6 by setting the initial indoor air conditions equal to the outdoor air conditions at the first time step.

\begin{tabular}{|c|c|c|c|c|c|c|c|c|c|c|c|}
\hline \multirow[b]{3}{*}{ Cases } & \multicolumn{7}{|c|}{ Annual Sums } & \multicolumn{4}{|c|}{ Annual Means } \\
\hline & \multirow{2}{*}{\multicolumn{4}{|c|}{$\begin{array}{l}\text { Cooling Energy Consumption } \\
\text { Compressor Cond Fan Indoor Fan }\end{array}$}} & \multicolumn{3}{|c|}{ Evaporator Coil Load } & \multirow[b]{2}{*}{ COP2 } & \multicolumn{2}{|r|}{$\begin{array}{r}\text { Zone } \\
\text { Humidity }\end{array}$} & \multirow{2}{*}{$\begin{array}{r}\text { Zone } \\
\text { Relative } \\
\text { Humidity } \\
(\%) \\
\end{array}$} \\
\hline & & & & & $\begin{array}{r}\text { Total } \\
(\mathrm{kWh})\end{array}$ & $\begin{array}{r}\text { Sensible } \\
(\mathrm{kWh})\end{array}$ & $\begin{array}{r}\text { Latent } \\
(\mathrm{kWh})\end{array}$ & & $\begin{array}{l}\text { IDB } \\
\left({ }^{\circ} \mathrm{C}\right)\end{array}$ & $\begin{array}{r}\text { Ratio } \\
(\mathrm{kg} / \mathrm{kg})\end{array}$ & \\
\hline E500 & 2438.141 & 17954.355 & 1919.891 & 2563.895 & 63341.4 & 45033.53 & 18307.8 & 3.18711 & 20.806 & 0.00959 & 0.57911 \\
\hline 500 & 17459.032 & 140 & 1475.843 & 1970.892 & 48424.4 & 34 & .5 & 55 & 25 & 0.01121 & 0.56475 \\
\hline $510 \mathrm{~N}$ & 34907.785 & 3.63 & 2975.449 & 3973.706 & 108964 & 774 & 9.9 & 45 & 25 & 0.01121 & 0.56479 \\
\hline 520 & 25161.221 & 19681.536 & 2346.402 & 3133.283 & 63193.2 & 6.2 & 18232.4 & 2.86878 & 13.409 & 0.00654 & 0.67188 \\
\hline 2 & 23741.477 & 9 & 2120.039 & 2831.289 & 63400.2 & 45 & 18310 & 3.0 & 17.254 & 0.0078 & 0.60079 \\
\hline 5 & 20303.238 & 1 & 1602.045 & 2139.442 & 63224.5 & 449 & 18303 & 08 & 27.851 & 0.01403 & 0.53952 \\
\hline & 17447.262 & 3599 & 1536.021 & 2051.324 & 44856.7 & $44 \varepsilon$ & 0 & 2.9 & 20.805 & 0.0031 & 0.23506 \\
\hline & $66=$ & 367 & 5.244 & 2504.359 & 44964.4 & 44 & 0.493 & 2. & 13.405 & 0.00269 & 0.30076 \\
\hline 45 & 15780.848 & 12742.127 & 1301.089 & 1737.632 & 44738.8 & 44724.75 & 0.486 & 3.18579 & 27.847 & 0.00274 & 0.17162 \\
\hline
\end{tabular}

\begin{tabular}{|c|c|c|c|c|c|c|c|c|c|c|c|}
\hline \multirow[b]{3}{*}{ Day } & \multicolumn{11}{|c|}{ Case E500 Average Daily Outputs - f(ODB) sensitivity } \\
\hline & & Energy Con & Isumption & & Evapora & tor Coil Loa & & Zone & & & \\
\hline & $\begin{array}{l}\text { Total } \\
\text { (Wh) }\end{array}$ & $\begin{array}{r}\text { I Compressor } \\
(\mathrm{Wh})\end{array}$ & $\begin{array}{r}\text { Cond Fan } \\
\text { (Wh) }\end{array}$ & $\begin{array}{r}\text { Indoor Fan } \\
(\mathrm{Wh})\end{array}$ & $\begin{array}{l}\text { Total } \\
\text { (Wh) }\end{array}$ & $\begin{array}{r}\text { Sensible } \\
(\mathrm{Wh})\end{array}$ & $\begin{array}{r}\text { Latent } \\
(\mathrm{Wh})\end{array}$ & $\begin{array}{r}\text { Hum Rat } \\
(\mathrm{kg} / \mathrm{kg})\end{array}$ & COP2 & $\begin{array}{r}\mathrm{ODB} \\
\left({ }^{\circ} \mathrm{C}\right)\end{array}$ & $\begin{array}{l}\text { EDB } \\
\left({ }^{\circ} \mathrm{C}\right)\end{array}$ \\
\hline April 30 & 3904.875 & 3024 & 377.0833 & 503.7917 & 13164.9 & 9359.917 & 3804.63 & 0.01089 & 3.8316 & 16.8833 & 25 \\
\hline June 25 & 5067.08333 & 4107.04167 & 411.0833 & 548.9583 & 13187.8 & 9376.917 & 3810.38 & 0.01134 & 2.9174 & 29.5167 & 25 \\
\hline
\end{tabular}

\begin{tabular}{|c|c|c|c|c|c|c|c|c|c|c|}
\hline \multirow[b]{2}{*}{ Day } & \multicolumn{3}{|c|}{ Energy Consumption } & \multicolumn{3}{|c|}{ Evaporator Coil Load } & \begin{tabular}{|r|} 
Zone \\
Hum Rat
\end{tabular} & \multirow[b]{2}{*}{ COP2 } & \multirow[b]{2}{*}{$\begin{array}{r}\text { ODB } \\
\left({ }^{\circ} \mathrm{C}\right)\end{array}$} & \multirow[b]{2}{*}{$\begin{array}{l}\text { EDB } \\
\left({ }^{\circ} \mathrm{C}\right)\end{array}$} \\
\hline & $\begin{array}{l}\text { Total Compressor } \\
(\mathrm{Wh}) \quad(\mathrm{Wh})\end{array}$ & $\begin{array}{r}\text { Cond Fan } \\
(\mathrm{Wh})\end{array}$ & $\begin{array}{r}\text { ndoor Fan } \\
(\mathrm{Wh}) \\
\end{array}$ & $\begin{array}{l}\text { Total } \\
(\mathrm{Wh}) \\
\end{array}$ & $\begin{array}{r}\text { Sensible } \\
(\mathrm{Wh})\end{array}$ & $\begin{array}{r}\text { Latent } \\
(\mathrm{Wh})\end{array}$ & $\begin{array}{r}\text { Hum Rat } \\
(\mathrm{kg} / \mathrm{kg})\end{array}$ & & & \\
\hline April 30 & 3090.916672377 .83333 & 305.3333 & 407.75 & 9362.17 & 9359.917 & 0 & 0.0031 & 3.46 & 16.8833 & 25 \\
\hline June 25 & $3936.375 \quad 3167.04167$ & 329.4167 & 439.9167 & 9383.08 & 9376.917 & 0 & 0.0031 & 2.6877 & 29.5167 & 25 \\
\hline
\end{tabular}




\begin{tabular}{|c|c|c|c|c|c|c|c|c|c|c|c|c|}
\hline \multirow{4}{*}{ Cases } & \multicolumn{5}{|c|}{ Annual Hourly Integrated } & \multicolumn{7}{|c|}{ Maxima Consumptions and Loads } \\
\hline & \multirow{2}{*}{\multicolumn{3}{|c|}{$\begin{array}{l}\text { Energy Consumption } \\
\text { Compr + Both Fans }\end{array}$}} & \multicolumn{9}{|c|}{ Evaporator Coil Loads } \\
\hline & & & & & Sensible & & & Latent & & Sens & ble + Late & \\
\hline & Wh & Date & Hour & Wh & Date & Hour & Wh & Date & Hour & Wh & Date & Hour \\
\hline$\overline{E 500}$ & 10154 & 20 -juil & 15 & 18762 & 14-août & 15 & 7833 & 29-juin & 16 & 26590 & 29-juin & 16 \\
\hline & & 20-juil & 15 & 21 & 14 & 12 & 8891 & & 14 & 90 & 17-juin & 14 \\
\hline $\mathrm{E}$ & & $20-$ & 15 & $18 \varepsilon$ & & 16 & 7716 & & 16 & 26578 & 20 -juil & 16 \\
\hline E & 10 & 20 & 15 & 187 & & 15 & 7770 & & 16 & 26536 & 30 -juin & 16 \\
\hline & & & 15 & 18 & & 16 & 7990 & & 16 & 26729 & 29-juin & 16 \\
\hline & & 20-juil & 15 & 187 & 14 & 15 & 0 & 1-janv & 1 & 18777 & 16-août & 15 \\
\hline & 8 & 20-juil & 15 & 18779 & oût & 15 & 90 & 11-mars & 14 & 18784 & 13-août & 15 \\
\hline E545 & 7367 & 20-juil & 15 & 18745 & 22-août & 16 & 57 & 11-mars & 11 & 18756 & 16-août & 15 \\
\hline
\end{tabular}

\begin{tabular}{|c|c|c|c|c|c|c|c|c|c|c|c|c|}
\hline \multirow{4}{*}{ Cases } & \multicolumn{12}{|c|}{ Annual Hourly Integratec } \\
\hline & \multicolumn{6}{|c|}{ C O P 2} & \multicolumn{6}{|c|}{ Indoor Drybulb Temperature } \\
\hline & \multicolumn{3}{|c|}{ Maximum } & \multicolumn{3}{|c|}{ Minimum } & \multicolumn{3}{|c|}{ Maximum } & \multicolumn{3}{|c|}{ Minimum* } \\
\hline & COP2 & Date & Hour & COP2 & Date & Hour & ${ }^{\circ} \mathrm{C}$ & Date & Hour & ${ }^{\circ} \mathrm{C}$ & Date & Hour \\
\hline E500 & 4.1702 & 16-mars & 10 & 2.6702 & 29-juil & 12 & 25 & 11-mars & 10 & 18.2 & 31-déc & 21 \\
\hline E510 & 4.6883 & 4-oct & 24 & 2.8773 & 31-mars & 15 & 25 & 11-mars & 10 & 18.2 & 31-déc & 21 \\
\hline E520 & 4.4 & 22-nov & 1 & 2.2857 & 8-nov & 11 & 17.26 & 16-août & 16 & 14.34 & 31-mars & 9 \\
\hline E522 & 5 & 10-nov & 12 & 2.3333 & 16-nov & 13 & 20.05 & 19-oct & 7 & 16.99 & 31-déc & 23 \\
\hline E525 & 4.6018 & 16-mars & 10 & 2.8966 & 29-juil & 12 & 35 & 11-mars & 10 & 20.51 & 31-déc & 24 \\
\hline E530 & 3.7304 & 16-mars & 10 & 2.4701 & 29-juil & 12 & 25 & 11-mars & 10 & 18.2 & 31-déc & 21 \\
\hline E540 & 6 & 16-déc & 2 & 2.1429 & 15-oct & 15 & 15.05 & 12-nov & 6 & 14.34 & 31-mars & 9 \\
\hline E545 & 4.1396 & 16-mars & 10 & 2.6918 & 29-juil & 12 & 35 & 11-mars & 10 & 20.51 & 31-déc & 23 \\
\hline
\end{tabular}

\begin{tabular}{|c|c|c|c|c|c|c|c|c|c|c|c|c|}
\hline \multirow{4}{*}{ Cases } & \multicolumn{12}{|c|}{ Annual Hourly Integrated Maxima and Minima - COP2 and Zone } \\
\hline & \multicolumn{6}{|c|}{ Humidity Ratio } & \multicolumn{6}{|c|}{ Relative Humidity } \\
\hline & \multicolumn{3}{|c|}{ Maximum } & \multicolumn{3}{|c|}{ Minimum* } & \multicolumn{3}{|c|}{ Maximum* } & \multicolumn{3}{|c|}{ Minimum* } \\
\hline & $\mathrm{kg} / \mathrm{kg}$ & Date & Hour & $\mathrm{kg} / \mathrm{kg}$ & Date & Hour & $\%$ & Date & Hour & $\%$ & Date & Hour \\
\hline E500 & 0.0116 & 16-mars & 15 & 0.0107 & 29-juil & 1 & $83 \%$ & 11-mars & 14 & $54 \%$ & 31-déc & 3 \\
\hline E510 & 0.0116 & 4-oct & 15 & 0.0107 & 31-mars & 24 & $83 \%$ & 11-mars & 14 & $54 \%$ & 31-déc & 5 \\
\hline E520 & 0.0074 & 22-nov & 15 & 0.007 & 8-nov & 24 & $71 \%$ & 16-août & 10 & $60 \%$ & 31-mars & 16 \\
\hline E522 & 0.0092 & 10-nov & 15 & 0.0086 & 16-nov & 9 & $71 \%$ & 19-oct & 4 & $59 \%$ & 31-déc & 2 \\
\hline E525 & 0.0175 & 16-mars & 15 & 0.0152 & 29-juil & 24 & $100 \%$ & 11-mars & 11 & $44 \%$ & 31-déc & 23 \\
\hline E530 & 0.0031 & 16-mars & 1 & 0.0031 & 29-juil & 1 & $24 \%$ & 11-mars & 22 & $16 \%$ & 31-déc & 10 \\
\hline E540 & 0.0031 & 16-déc & 1 & 0.0026 & 15-oct & 1 & $26 \%$ & 12-nov & 1 & $25 \%$ & 31-mars & 1 \\
\hline E545 & 0.0031 & 16-mars & 1 & 0.0026 & 29-juil & 24 & $17 \%$ & 11-mars & 23 & $7 \%$ & 31-déc & 24 \\
\hline
\end{tabular}




\subsection{Polynomial approximations of the whole manufacturer's data}

Neural networks are not easy to implement. Therefore, the steady-state capacities have been approximated by polynomial functions. The results obtained with those functions are close to the predictions from neural networks (see the tables below). We just noticed a slight shift in the calculation of the humidity ratio.

$$
\begin{aligned}
P_{a b s}= & a_{1}+a_{2} T_{E W B}+a_{3} T_{E D B}+a_{4} T_{O D B}+a_{5} T_{E W B}^{2}+a_{6} T_{O D B}^{2}+a_{7} T_{E W B} T_{O D B}+a_{8} T_{E W B}^{2} T_{E D B} \\
P_{t o t}= & a_{1}+a_{2} T_{E W B}+a_{3} T_{E D B}+a_{4} T_{O D B}+a_{5} T_{E W B}^{2}+a_{6} T_{E D B}^{2}+a_{7} T_{O D B}^{2}+a_{8} T_{E W B} T_{O D B} \\
& +a_{9} T_{E W B}^{3}+a_{10} T_{E W B}^{2} T_{E D B}+a_{11} T_{E D B}^{2} T_{E W B}+a_{12} T_{E D B} T_{E W B} T_{O D B}+a_{13} T_{E W B}^{3} T_{E D B} \\
& +a_{14} T_{E W B}^{4} T_{E D B}+a_{15} T_{E W B}^{3} T_{E D B}^{2} \\
& =a_{1}+a_{2} T_{E W B}+a_{3} T_{E D B}+a_{4} T_{O D B}+a_{5} T_{E W B}^{2}+a_{6} T_{E D B}^{2}+a_{7} T_{O D B}^{2}+a_{8} T_{E W B} T_{O D B} \\
& +a_{9} T_{E W B}^{3}+a_{10} T_{E W B}^{2} T_{E D B}+a_{11} T_{E D B}^{2} T_{E W B}+a_{12} T_{E D B} T_{E W B} T_{O D B}+a_{13} T_{E W B}^{3} T_{E D B} \\
& +a_{14} T_{E W B}^{4} T_{E D B}+a_{15} T_{E W B}^{3} T_{E D B}^{2}+a_{16} T_{E D B}^{3} T_{E W B}^{2}+a_{17} T_{E D B}^{3}
\end{aligned}
$$

$\begin{array}{cccc}\text { Coefficients } & \text { Pabs } & \text { Ptot } & \text { Psens } \\ \text { a1 } & 9.3254 & 35.5299 & 20.1656 \\ \text { a2 } & 1.6426 & 15.051 & -31.222 \\ \text { a3 } & 0.1589 & 1.0087 & 21.9428 \\ \text { a4 } & 2.2504 & -5.0211 & -1.4393 \\ \text { a5 } & 0.1867 & 2.0888 & -1.0333 \\ \text { a6 } & -0.0684 & -0.2118 & -0.1579 \\ \text { a7 } & 0.7169 & -0.262 & -0.1157 \\ \text { a8 } & 0.4376 & -1.8029 & 0.6444 \\ \text { a9 } & & -3.1211 & 8.5271 \\ \text { a10 } & & 6.1887 & -19.6709 \\ \text { a11 } & & -3.3151 & 11.0309 \\ \text { a12 } & & -0.4909 & -1.2676 \\ \text { a13 } & & 0.5559 & 0.0358 \\ \text { a14 } & & -2.8045 & 6.3097 \\ \text { a15 } & & 2.7819 & -7.3674 \\ \text { a16 } & & & 3.4213 \\ \text { a17 } & & & -2.2501\end{array}$




\subsection{Major improvements during round 5 (February 2003)}

To improve the performance of the model:

- We have included the thermal balance equation into the reduced time step loop just like we did with the humidity balance equation in the last round.

- Since we participated in the test, the walls of the building were modeled using a real material: polystyrene. But, we noticed that the discrepancies in the E500 series cases (max. COP2, min. indoor dry-bulb temp. ...) were due to the thermal capacitance of the building. Consequently, we decreased the thermal capacitance of the walls.

- We have also modified an error in the program that corresponded to an amalgam between the air infiltration and the mixing air rate at the entering of the evaporator.

\begin{tabular}{|c|c|c|c|c|c|c|c|c|c|c|c|}
\hline \multirow[b]{2}{*}{ Cases } & \multirow{2}{*}{\multicolumn{4}{|c|}{$\begin{array}{l}\text { Cooling Energy Consumption } \\
\text { Total Compressor Cond Fan Indoor Fan }\end{array}$}} & \multicolumn{3}{|c|}{ Evaporator Coil Load } & \multirow[b]{2}{*}{ OP2 } & \multirow[b]{2}{*}{$\begin{array}{l}\text { IDB } \\
\left({ }^{\circ} \mathrm{C}\right)\end{array}$} & \multirow{2}{*}{$\begin{array}{r}\text { Zone } \\
\text { Humidity } \\
\text { Ratio } \\
(\mathrm{kg} / \mathrm{kg})\end{array}$} & \multirow{2}{*}{$\begin{array}{r}\text { Zone } \\
\text { Relative } \\
\text { Humidity } \\
(\%) \\
\end{array}$} \\
\hline & & & & & $\begin{array}{r}\text { Total } \\
(\mathrm{kWh})\end{array}$ & $\begin{array}{r}\text { Sensible } \\
(k W h)\end{array}$ & $\begin{array}{l}\text { Latent } \\
(\mathrm{kWh})\end{array}$ & & & & \\
\hline & 06215 & 21853.1 & 233 & 10879 & 923.15 & 55162.02 & 2 & & 8404 & 009144 & \\
\hline & 9.80 & & 25 & 108 & & & & & & 0.011439 & 59.092 \\
\hline & 435.10 & & 2667.21 & 1087 & & 617 & 3542 & & 24.3 & 0.010035 & 51.0077 \\
\hline 330 & 40584.02 & 26980.64 & 2723.46 & 10879.92 & 103741.72 & 62621.23 & 41120.49 & 3.492504 & 24.29694 & 0.009799 & 50.0180 \\
\hline & 40106.50 & 26518.12 & 2708.47 & 10879.92 & 100696.95 & 62204.86 & 38492.10 & 3.445 & 24.31765 & 0.009853 & 50.1953 \\
\hline & 1480.67 & 18658.44 & 1942.31 & 10879.92 & 66558.03 & 48539.40 & 18018.60 & 3.2 & 26.27149 & 0.009793 & 44.48505 \\
\hline E360 & 54477.23 & 39387.32 & 4209.99 & 10879.92 & 159621.60 & 133190.04 & 26431.50 & 3.661272 & 25.80300 & 0.008622 & 41.289 \\
\hline
\end{tabular}

\begin{tabular}{|c|c|c|c|c|c|c|c|c|c|c|c|}
\hline \multirow[b]{3}{*}{ Cases } & \multicolumn{7}{|c|}{ Annual Sums } & \multicolumn{4}{|c|}{ Annual Means } \\
\hline & \multirow{2}{*}{\multicolumn{4}{|c|}{$\begin{array}{l}\text { Cooling Energy Consumption } \\
\text { Total Compressor Cond Fan Indoor Fan }\end{array}$}} & \multicolumn{3}{|c|}{ Evaporator Coil Load } & \multirow[b]{2}{*}{ COP2 } & \multirow[b]{2}{*}{$\begin{array}{l}\text { IDB } \\
\left({ }^{\circ} \mathrm{C}\right)\end{array}$} & \multirow{2}{*}{$\begin{array}{r}\text { Zone } \\
\text { Humidity } \\
\text { Ratio } \\
(\mathrm{kg} / \mathrm{kg})\end{array}$} & \multirow{2}{*}{$\begin{array}{r}\text { Zone } \\
\text { Relative } \\
\text { Humidity } \\
(\%) \\
\end{array}$} \\
\hline & & & & & $\begin{array}{r}\text { Total } \\
(\mathrm{kWh})\end{array}$ & $\begin{array}{r}\text { Sensible } \\
(\mathrm{kWh})\end{array}$ & $\begin{array}{r}\text { Latent } \\
(\mathrm{kWh})\end{array}$ & & & & \\
\hline E500 & 21749.36 & 17880.80 & 1656.37 & 2212.18 & 63100.77 & 44873.82 & 18227.01 & 3.22978 & 20.88422 & 0.010147 & 61.74658 \\
\hline E500 May- & 16983.69 & 14004.70 & 1275.49 & 1703.50 & 48439.62 & 34448.18 & 13991.48 & 3.170093 & 25.00000 & 0.012364 & 62.18655 \\
\hline E510 May- & 34015.29 & 27919.70 & 2610.00 & 3485.59 & 108978.87 & 77498.98 & 31479.87 & 3.569601 & 25.00826 & 0.012856 & 64.58660 \\
\hline E520 & 24700.50 & 19675.10 & 2151.91 & 2873.49 & 63208.03 & 44976.28 & 18231.77| & 2.895862 & 14.04710 & 0.006621 & 65.18699 \\
\hline E522 & 23100.03 & 18716.63 & 1876.91 & 2506.49 & 63152.87 & 44923.54 & 18229.28 & 3.066634 & 17.56455 & 0.008314 & 63.80925 \\
\hline E525 & 19667.36 & 16496.76 & 1357.59 & 1813.01 & 62995.93 & 44774.47 & 18221.45 & 3.528323 & 27.51462 & 0.014429 & 55.84966 \\
\hline E530 & 17457.77 & 13867.97 & 1537.19 & 2052.61 & 44874.21 & 44873.82 & 0.39 & 2.912934 & 21.01572 & 0.006293 & 44.70753 \\
\hline E540 & 19572.27 & 15191.38 & 1875.81 & 2505.08 & 44979.00 & 44976.55 & 2.45 & 2.635407 & 14.15885 & 0.004515 & 46.11461 \\
\hline E545 & 15791.06 & 12750.28 & 1302.05 & 1738.74 & 44774.47 & 44774.47 & 0.00 & 3.186267 & 27.64612 & 0.006597 & 36.53242 \\
\hline
\end{tabular}




\begin{tabular}{|c|c|c|c|c|c|c|c|c|c|c|c|}
\hline \multirow[b]{3}{*}{ Hour } & \multicolumn{11}{|c|}{ June 28 Hourly Output - Case E 300} \\
\hline & \multicolumn{2}{|c|}{ Energy Consumption } & \multicolumn{3}{|c|}{ Evaporator Coil Load } & \multirow{2}{*}{$\begin{array}{r}\text { Zone } \\
\text { Hum. Rat. } \\
(\mathrm{kg} / \mathrm{kg})\end{array}$} & \multirow[b]{2}{*}{ COP2 } & \multirow[b]{2}{*}{$\begin{array}{l}\text { ODB } \\
\left({ }^{\circ} \mathrm{C}\right)\end{array}$} & \multirow[b]{2}{*}{$\begin{array}{l}\text { EDB } \\
\left({ }^{\circ} \mathrm{C}\right)\end{array}$} & \multirow[b]{2}{*}{$\begin{array}{r}\text { EWB } \\
\left({ }^{\circ} \mathrm{C}\right)\end{array}$} & \multirow{2}{*}{\begin{tabular}{|r} 
Outdoor \\
Hum. Rat. \\
$(\mathrm{kg} / \mathrm{kg})$
\end{tabular}} \\
\hline & $\begin{array}{r}\text { Compressor } \\
(\mathrm{Wh})\end{array}$ & $\begin{array}{r}\text { Cond Fan } \\
(\mathrm{Wh})\end{array}$ & $\begin{array}{l}\text { Total } \\
(\mathrm{Wh})\end{array}$ & $\begin{array}{r}\text { Sensible } \\
\text { (Wh) }\end{array}$ & $\begin{array}{r}\text { Latent } \\
(\mathrm{Wh})\end{array}$ & & & & & & \\
\hline 1 & 1903 & 237 & 7524 & 5800 & 1724 & 0.009222 & 3.515888 & 17.80 & 23.92 & 17.084 & 0.011100 \\
\hline 2 & 1981 & 246 & 7760 & 5972 & 1788 & 0.009249 & 3.484508 & 18.30 & 24.00 & 17.220 & 0.011462 \\
\hline 3 & 1898 & 237 & 7502 & 5800 & 1702 & 0.009186 & 3.513817 & 17.80 & 23.92 & 17.067 & 0.011100 \\
\hline 4 & 1894 & 237 & 7481 & 5800 & 1682 & 0.009150 & 3.510558 & 17.80 & 23.92 & 17.055 & 0.011100 \\
\hline 5 & 1773 & 224 & 7054 & 5593 & 1461 & 0.008918 & 3.532298 & 17.20 & 23.83 & 16.659 & 0.010180 \\
\hline 6 & 2091 & 255 & 7960 & 6350 & 1611 & 0.008963 & 3.393009 & 19.40 & 24.16 & 17.020 & 0.011001 \\
\hline 7 & 3056 & 340 & 10498 & 8276 & 2222 & 0.009438 & 3.091284 & 25.00 & 25.00 & 18.069 & 0.013140 \\
\hline 8 & 3325 & 351 & 10859 & 9032 & 1827 & 0.009259 & 2.954026 & 27.20 & 25.33 & 17.541 & 0.011075 \\
\hline 9 & 4507 & 469 & 14687 & 11962 & 2726 & 0.009645 & 2.951568 & 28.90 & 25.59 & 18.224 & 0.011995 \\
\hline 10 & 4620 & 478 & 15165 & 11962 & 3203 & 0.009969 & 2.974696 & 28.90 & 25.59 & 18.511 & 0.012760 \\
\hline 11 & 5265 & 526 & 16818 & 12718 & 4100 & 0.010497 & 2.904162 & 31.10 & 25.91 & 19.288 & 0.014809 \\
\hline 12 & 5092 & 506 & 16341 & 12546 & 3795 & 0.010481 & 2.919078 & 30.60 & 25.84 & 18.866 & 0.013253 \\
\hline 13 & 6465 & 635 & 21161 & 17408 & 3752 & 0.009876 & 2.980423 & 31.10 & 25.91 & 18.035 & 0.011329 \\
\hline 14 & 6539 & 643 & 21116 & 17615 & 3502 & 0.009686 & 2.940128 & 31.70 & 26.00 & 18.136 & 0.011729 \\
\hline 15 & 8012 & 783 & 26678 & 22476 & 4202 & 0.009494 & 3.033314 & 32.20 & 26.08 & 18.111 & 0.012379 \\
\hline 16 & 8195 & 803 & 27525 & 22476 & 5049 & 0.009627 & 3.059013 & 32.20 & 26.08 & 18.544 & 0.014232 \\
\hline 17 & 5327 & 530 & 16776 & 12925 & 3851 & 0.010334 & 2.864265 & 31.70 & 26.00 & 19.259 & 0.014730 \\
\hline 18 & 5404 & 536 & 17390 & 12718 & 4672 & 0.010805 & 2.927609 & 31.10 & 25.91 & 19.566 & 0.015684 \\
\hline 19 & 4818 & 494 & 16301 & 11756 & 4546 & 0.010812 & 3.068712 & 28.30 & 25.50 & 19.143 & 0.014539 \\
\hline 20 & 4830 & 505 & 16911 & 11377 & 5534 & 0.011181 & 3.169822 & 27.20 & 25.33 & 19.730 & 0.016878 \\
\hline 21 & 3956 & 410 & 13521 & 9032 & 4488 & 0.011273 & 3.096885 & 27.20 & 25.33 & 19.693 & 0.016878 \\
\hline 22 & 3872 & 404 & 13368 & 8860 & 4507 & 0.011313 & 3.126286 & 26.70 & 25.26 & 19.672 & 0.016832 \\
\hline 23 & 3772 & 397 & 13184 & 8654 & 4530 & 0.011350 & 3.162389 & 26.10 & 25.16 & 19.676 & 0.016889 \\
\hline 24 & 3813 & 402 & 13363 & 8654 & 4709 & 0.011446 & 3.170344 & 26.10 & 25.16 & 19.811 & 0.017329 \\
\hline
\end{tabular}

\begin{tabular}{|c|c|c|c|c|c|c|c|c|c|c|c|}
\hline \multirow[b]{2}{*}{ Day } & \multicolumn{4}{|c|}{ Energy Consumption } & \multicolumn{3}{|c|}{ Evaporator Coil Load } & \multirow{2}{*}{$\begin{array}{r}\text { Zone } \\
\text { Hum Rat } \\
(\mathrm{kg} / \mathrm{kg})\end{array}$} & \multirow[b]{2}{*}{ COP2 } & \multirow[b]{2}{*}{$\begin{array}{r}\text { ODB } \\
\left({ }^{\circ} \mathrm{C}\right) \\
\end{array}$} & \multirow[b]{2}{*}{$\begin{array}{r}\text { EDB } \\
\left({ }^{\circ} \mathrm{C}\right) \\
\end{array}$} \\
\hline & $\begin{array}{l}\text { Total } \\
(\mathrm{Wh})\end{array}$ & $\begin{array}{r}\text { mpressor } \\
(\mathrm{Wh}) \\
\end{array}$ & $\begin{array}{l}\text { ond Fan II } \\
\text { (Wh) }\end{array}$ & $\begin{array}{r}\text { loor Fan } \\
(\mathrm{Wh})\end{array}$ & $\begin{array}{l}\text { Total } \\
\text { (Wh) }\end{array}$ & $\begin{array}{r}\text { Sensible } \\
(\mathrm{Wh})\end{array}$ & $\begin{array}{r}\text { Latent } \\
(\mathrm{Wh})\end{array}$ & & & & \\
\hline April 30 & 3802.75 & 3023.63 & 333.58 & 445.54 & 13167.25 & 9365.50 & 3801.79 & 0.011789 & 3.883338 & 16.88333 & 25 \\
\hline June 25 & 4929.71 & 4106.08 & 352.75 & 470.88 & 13197.96 & 9387.38 & 3810.63 & 0.012585 & 2.959242 & 29.51667 & 25 \\
\hline
\end{tabular}

\begin{tabular}{|c|c|c|c|c|c|c|c|c|c|c|c|}
\hline \multirow{4}{*}{ Day } & \multicolumn{11}{|c|}{ Case E530 Average Daily Outputs - f(ODB) sensitivity } \\
\hline & \multirow{2}{*}{\multicolumn{4}{|c|}{$\begin{array}{c}\text { Energy Consumption } \\
\text { Total Compressor Cond Fan Indoor Fan }\end{array}$}} & \multicolumn{2}{|c|}{ Evaporator Coil Load } & \multirow{3}{*}{$\begin{array}{r}\text { Latent } \\
(\mathrm{Wh})\end{array}$} & \multirow{3}{*}{$\begin{array}{r}\text { Zone } \\
\text { Hum Rat } \\
(\mathrm{kg} / \mathrm{kg})\end{array}$} & \multirow{3}{*}{ COP2 } & \multirow{3}{*}{$\begin{array}{r}\mathrm{ODB} \\
\left({ }^{\circ} \mathrm{C}\right) \\
\end{array}$} & \multirow{3}{*}{$\begin{array}{r}\text { EDB } \\
\left({ }^{\circ} \mathrm{C}\right) \\
\end{array}$} \\
\hline & & & & & Total & Sensible & & & & & \\
\hline & $(\mathrm{Wh})$ & (Wh) & $(\mathrm{Wh})$ & (Wh) & $(\mathrm{Wh})$ & (Wh) & & & & & \\
\hline April 30 & 3091.71 & 2378.54 & 305.42 & 407.75 & 9365.50 & 9365.50 & 0.00 & 0.006206 & 3.46022 & 16.88333 & 25 \\
\hline June 25 & 3937.75 & 3168.33 & 329.42 & 440.00 & 9387.38 & 9387.38 & 0.00 & 0.006206 & 2.687874 & 29.51667 & 25 \\
\hline
\end{tabular}

\begin{tabular}{|c|c|c|c|c|c|c|c|c|c|c|c|c|}
\hline \multirow{3}{*}{ Cases } & \multicolumn{12}{|c|}{ Annual Hourly Integrated Maxima Consumptions and Loads } \\
\hline & \multicolumn{3}{|c|}{$\begin{array}{l}\text { Energy Consumption } \\
\text { Compr + Both Fans }\end{array}$} & \multicolumn{6}{|c|}{ Sensible ${ }_{\text {Evaporator Coil Loads }}^{\text {Latent }}$} & \multicolumn{3}{|c|}{ Sensible + Latent } \\
\hline & Wh & Date & Hour & Wh & Date & Hour & Wh & Date & Hour & Wh & Date & Hour \\
\hline E300 & 11930 & 20-juil & 15 & 23441 & 20 -juil & 15 & 10461 & 03-sept & 15 & 32612 & 20 -juil & 15 \\
\hline E310 & 12560 & 20-juil & 15 & 23907 & 08-juil & 16 & 16862 & 03-sept & 15 & 37105 & 03-sept & 15 \\
\hline E320 & 12996 & 20-juil & 15 & 31514 & 24-avr & 16 & 22501 & 02-oct & 9 & 40393 & 20-juil & 16 \\
\hline E330 & 13480 & 20-juil & 15 & 33969 & 24-avr & 16 & 28111 & 18-sept & 15 & 43942 & 02-oct & 9 \\
\hline E340 & 13233 & 20-juil & 15 & 33006 & 24-avr & 16 & 24625 & 02-oct & 9 & 41242 & 02-oct & 10 \\
\hline E350 & 11934 & 20-juil & 15 & 23449 & 20-juil & 15 & 11915 & 02-oct & 9 & 32632 & 20-juil & 15 \\
\hline E360 & 12793 & 20-juil & 14 & 37614 & 10-juil & 14 & 12800 & 03-sept & 17 & 39688 & 01-oct & 10 \\
\hline
\end{tabular}




\begin{tabular}{|c|c|c|c|c|c|c|c|c|c|c|c|c|}
\hline \multirow{3}{*}{ Cases } & \multicolumn{12}{|c|}{ Annual Hourly Integrated Maxima Consumptions and Loads } \\
\hline & \multicolumn{3}{|c|}{$\begin{array}{l}\text { Energy Consumption } \\
\text { Compr + Both Fans }\end{array}$} & \multicolumn{6}{|c|}{ Sensible $\begin{array}{r}\text { Evaporator Coil Loads } \\
\text { Latent }\end{array}$} & \multicolumn{3}{|c|}{ Sensible + Latent } \\
\hline & Wh & Date & Hour & Wh & Date & Hour & Wh & Date & Hour & $\mathrm{Wh}$ & Date & Hour \\
\hline E500 & 9825 & 20 -juil & 15 & 18770 & 10-juil & 16 & 7972 & 29-juin & 16 & 26739 & 29-juin & 16 \\
\hline E510 & 10825 & 20 -juil & 15 & 21170 & 14-juil & 19 & 9185 & 17-juin & 14 & 30292 & 17-juin & 14 \\
\hline E520 & 11037 & 20-juil & 15 & 19640 & 20-juil & 16 & 8227 & 20 -juil & 15 & 26476 & 05-mai & 16 \\
\hline E522 & 10309 & 20-juil & 15 & 18778 & 25-juin & 16 & 7925 & 29-juin & 16 & 26701 & 29-juin & 16 \\
\hline E525 & 9079 & 20 -juil & 15 & 18752 & 25-juin & 15 & 8100 & 29-juin & 16 & 26849 & 29-juin & 16 \\
\hline E530 & 7999 & 20-juil & 15 & 18770 & 10-juil & 16 & 139 & 16-mars & 10 & 18770 & 10-juil & 16 \\
\hline E540 & 8864 & 20 -juil & 15 & 18787 & 10-juil & 16 & 1133 & 11-mars & 10 & 18787 & 10-juil & 16 \\
\hline E545 & 7365 & 20 -juil & 15 & 18752 & 25-juin & 15 & 0 & 01-janv & 1 & 18752 & 25-juin & 15 \\
\hline
\end{tabular}

\begin{tabular}{|c|c|c|c|c|c|c|c|c|c|c|c|c|}
\hline \multirow{4}{*}{ Cases } & \multicolumn{12}{|c|}{ Annual Hourly Integrated Maxima and Minima - COP2 and Zone } \\
\hline & \multicolumn{6}{|c|}{$\mathrm{COP} 2$} & \multicolumn{6}{|c|}{ Indoor Drybulb Temperature } \\
\hline & \multicolumn{3}{|c|}{ Maximum } & \multicolumn{3}{|c|}{ Minimum } & \multicolumn{3}{|c|}{ Maximum } & \multicolumn{3}{|c|}{ Minimum* } \\
\hline & COP2 & Date & Hour & COP2 & Date & Hour & ${ }^{\circ} \mathrm{C}$ & Date & Hour & ${ }^{\circ} \mathrm{C}$ & Date & Hour \\
\hline E300 & 3.864536 & 30-avr & 16 & 2.785981 & 13-juin & 17 & 25.04 & 22-mars & 2 & 8.03 & 06-janv & 5 \\
\hline E310 & 4.132477 & 30-avr & 15 & 2.854977 & 01-déc & 15 & 30.15 & 20-juil & 15 & 8.03 & 06-janv & 5 \\
\hline E320 & 3.935372 & 18-sept & 16 & 2.804582 & 01-déc & 15 & 33.25 & 20-juil & 15 & 8.03 & 06-janv & 5 \\
\hline E330 & 4.114632 & 17-juin & 16 & 2.795699 & 28-avr & 9 & 31.89 & 20-juil & 15 & 8.03 & 06-janv & 5 \\
\hline E340 & 4.016122 & 16-sept & 16 & 2.804582 & 01-déc & 14 & 32.66 & 20-juil & 15 & 8.03 & 06-janv & 5 \\
\hline E350 & 3.883092 & 30-avr & 8 & 2.786090 & 13-juin & 17 & 35.00 & 21-avr & 1 & 8.03 & 06-janv & 5 \\
\hline E360 & 4.415068 & 04-oct & 24 & 2.803367 & 01-déc & 15 & 45.31 & 20-juil & 15 & 8.03 & 06-janv & 5 \\
\hline
\end{tabular}

\begin{tabular}{|c|c|c|c|c|c|c|c|c|c|c|c|c|}
\hline \multirow{4}{*}{ Cases } & \multicolumn{12}{|c|}{ Annual Hourly Integrated Maxima and Minima-COP2 and Zone } \\
\hline & \multicolumn{6}{|c|}{ Humidity Ratio } & \multicolumn{6}{|c|}{ Relative Humidity } \\
\hline & \multicolumn{3}{|c|}{ Maximum } & \multicolumn{3}{|c|}{ Minimum* } & \multicolumn{3}{|c|}{ Maximum* } & \multicolumn{3}{|c|}{ Minimum* } \\
\hline & $\mathrm{kg} / \mathrm{kg}$ & Date & Hour & $\mathrm{kg} / \mathrm{kg}$ & Date & Hour & $\%$ & Date & Hour & $\%$ & Date & Hour \\
\hline E300 & 0.013576 & 16-nov & 16 & 0.001968 & 11-janv & 3 & 68.00 & 16-nov & 16 & 15 & 06-nov & 5 \\
\hline E310 & 0.016887 & 02-oct & 8 & 0.002019 & 05-janv & 7 & 84.00 & 03-août & 8 & 16 & 06-nov & 8 \\
\hline E320 & 0.017391 & 10-juil & 12 & 0.001968 & 11-janv & 3 & 86.00 & 03-sept & 17 & 15 & 06-nov & 5 \\
\hline E330 & 0.017054 & 10-juil & 13 & 0.001968 & 11-janv & 3 & 77.00 & 16-août & 20 & 15 & 06-nov & 5 \\
\hline E340 & 0.017172 & 10-juil & 13 & 0.001968 & 11-janv & 3 & 83.00 & 03-sept & 17 & 15 & 06-nov & 5 \\
\hline E350 & 0.016495 & 02-oct & 2 & 0.001968 & 11-janv & 3 & 82.00 & 02-oct & 8 & 15 & 06-nov & 5 \\
\hline E360 & 0.014708 & 20-juil & 14 & 0.001968 & 11-janv & 3 & 74.00 & 20-juil & 14 & 15 & 06-nov & 5 \\
\hline
\end{tabular}

\begin{tabular}{|c|c|c|c|c|c|c|c|c|c|c|c|c|}
\hline \multirow{4}{*}{ Cases } & \multicolumn{12}{|c|}{ Annual Hourly Integrated Maxima and Minima - COP2 and Zone } \\
\hline & \multicolumn{6}{|c|}{$\mathrm{COP} 2$} & \multicolumn{6}{|c|}{ Indoor Drybulb Temperature } \\
\hline & \multicolumn{3}{|c|}{ Maximum } & \multicolumn{3}{|c|}{ Minimum } & \multicolumn{3}{|c|}{ Maximum } & \multicolumn{3}{|c|}{ Minimum* } \\
\hline & COP2 & Date & Hour & COP2 & Date & Hour & ${ }^{\circ} \mathrm{C}$ & Date & Hour & ${ }^{\circ} \mathrm{C}$ & Date & Hour \\
\hline E500 & 4.264286 & 16-mars & 10 & 2.705858 & 29-juil & 12 & 25.00 & 11-mars & 10 & 8.86 & 20-déc & 24 \\
\hline E510 & 4.745364 & 04-oct & 24 & 2.916962 & 31-mars & 15 & 25.30 & 10-juil & 15 & 8.86 & 20-déc & 24 \\
\hline E520 & 3.818576 & 30-avr & 16 & 2.000000 & 30-janv & 14 & 19.30 & 20-juil & 15 & 8.82 & 21-déc & 1 \\
\hline E522 & 4.018273 & 30-avr & 16 & 2.555556 & 31-mars & 18 & 20.11 & 04-juin & 16 & 8.86 & 20-déc & 24 \\
\hline E525 & 4.710872 & 16-mars & 10 & 2.936880 & 29-juil & 12 & 35.00 & 11-mars & 10 & 8.86 & 21-déc & 1 \\
\hline E530 & 3.853005 & 16-mars & 10 & 2.470263 & 29-juil & 12 & 25.00 & 11-mars & 10 & 8.86 & 20-déc & 24 \\
\hline E540 & 4.000000 & 22-mars & 1 & 2.000000 & 08-avr & 17 & 15.05 & 29-janv & 24 & 8.82 & 21-déc & 1 \\
\hline E545 & 4.162586 & 16-mars & 10 & 2.692043 & 30-juil & 12 & 35.00 & 11-mars & 10 & 8.86 & 21-déc & 1 \\
\hline
\end{tabular}




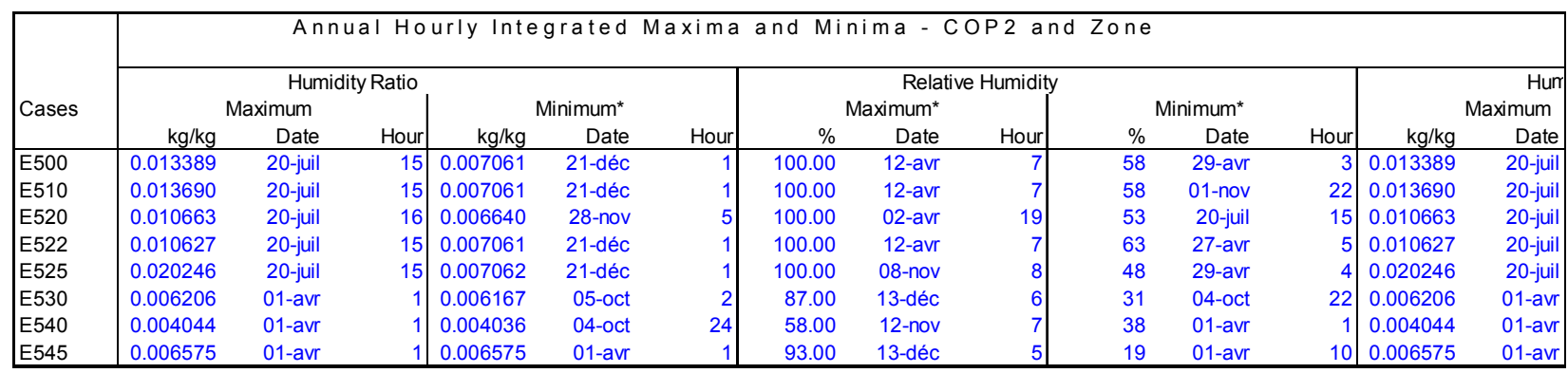

\subsection{Major improvements during round 6 (March 2003)}

First improvement: The discrepancies observed in the previous round concerning the fan consumption are explained by the fraction on-time $(\lambda)$ that was not properly taken into account in their calculation. More exactly, we used the value of $\lambda$ obtained at the end of the subhourly loop instead of the average value. This was fixed. Then, the results for some cases remain (almost) unchanged whereas some others were improved. This can be explained by the fact that, in the latter cases, the value of $\lambda$ changed during the simulation time step (average value of $\lambda$ is different from value of $\lambda$ at the end of the subhourly loop).

Second improvement: The case E360 exploring the extreme value of the performance map, we tested the neural networks predictions. The neural network employed so far performs accurately for values of Tedb included in the interval $\left[21^{\circ} \mathrm{C}, 33^{\circ} \mathrm{C}\right]$ but performs poorly above $33^{\circ} \mathrm{C}$ (see figure below). During this step, we improved the neural network as shown on the figure below. 


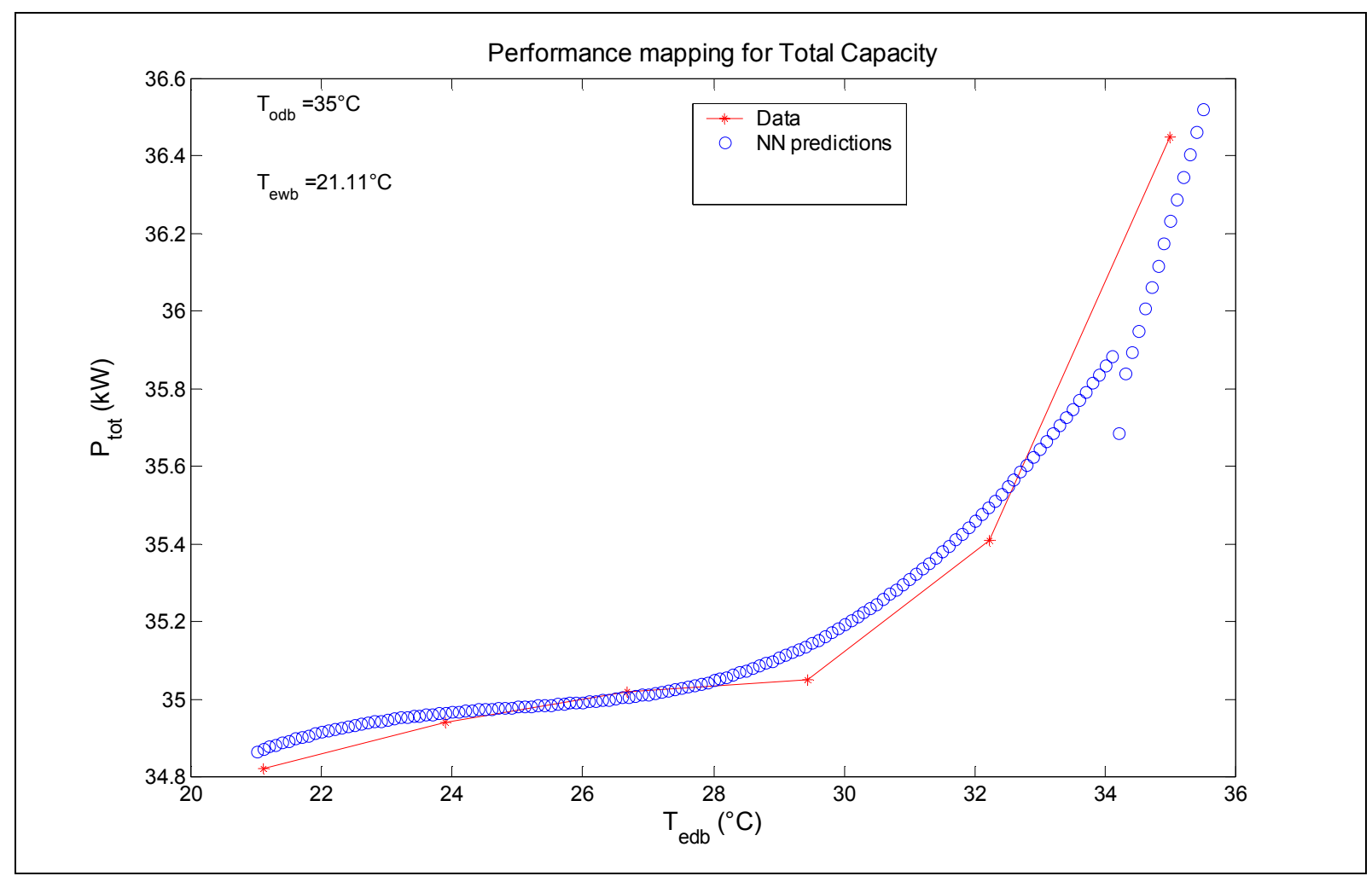

Performance mapping of the previous neural network

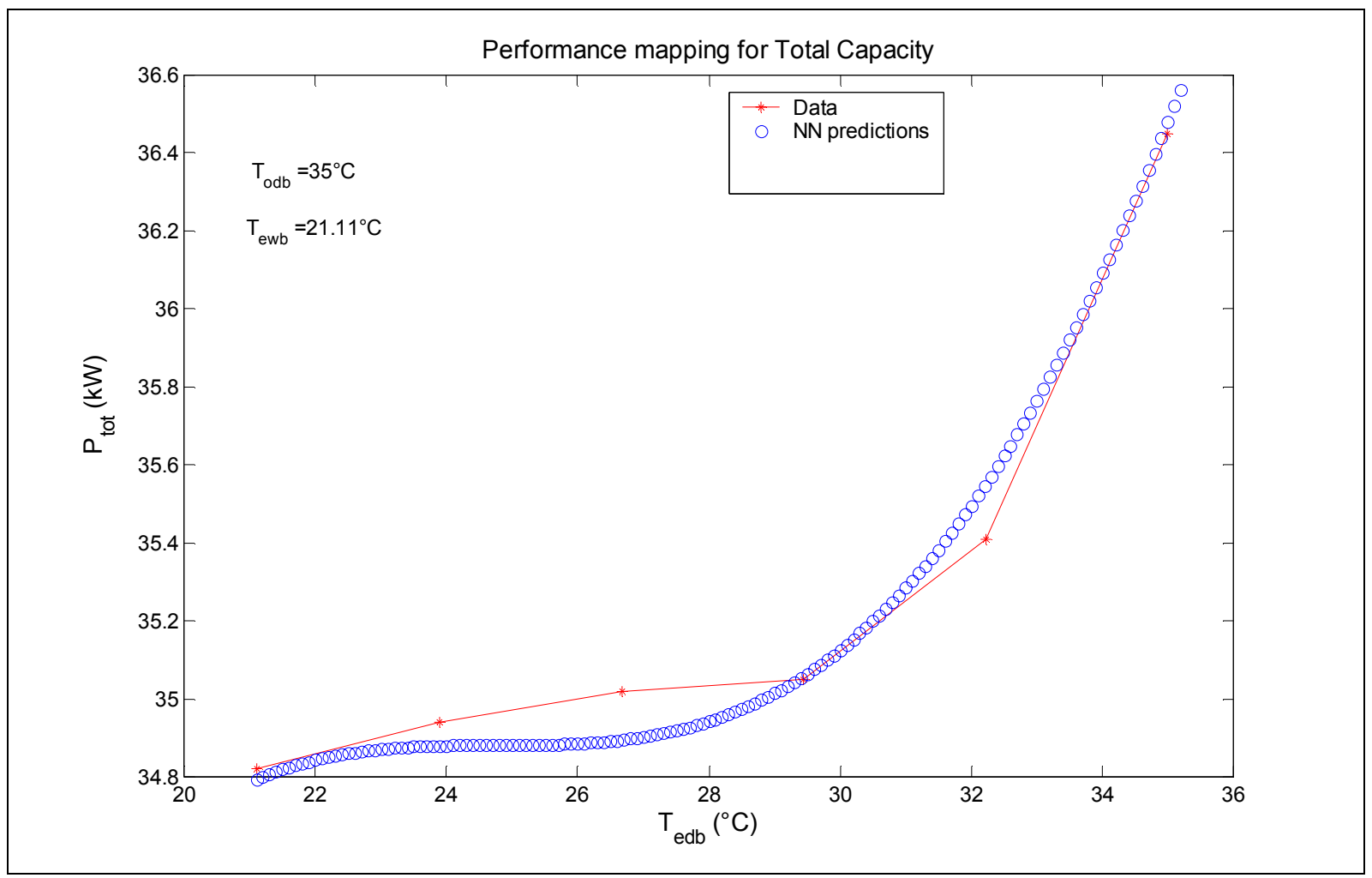

Performance mapping of the new neural network (Round March 2003) 


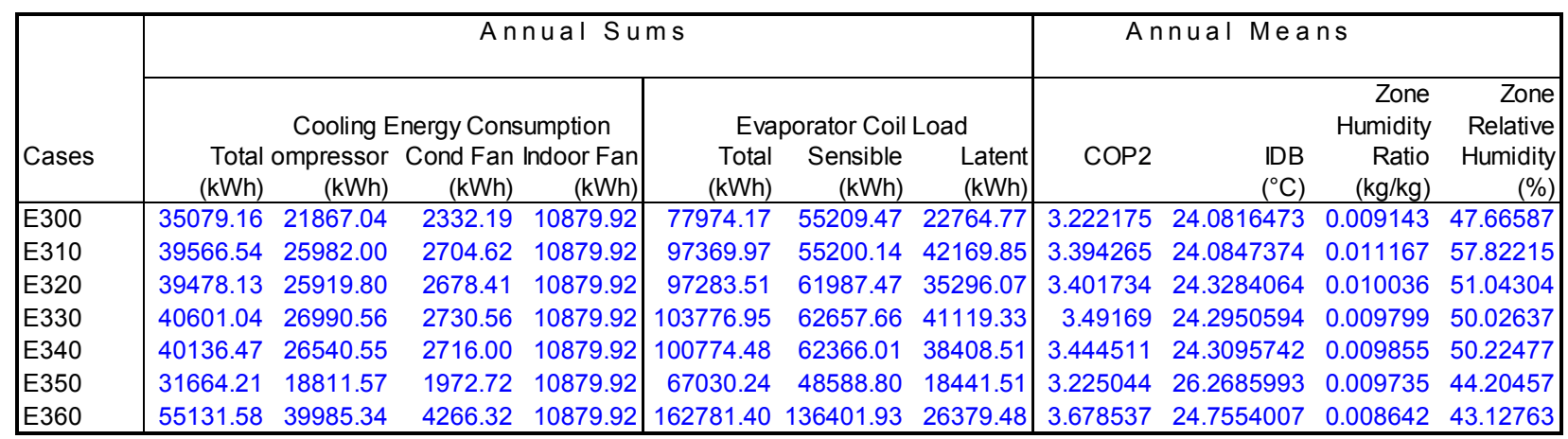

\begin{tabular}{|c|c|c|c|c|c|c|c|c|c|c|c|}
\hline \multirow[b]{3}{*}{ Cases } & \multicolumn{7}{|c|}{ Annual Sums } & \multicolumn{4}{|c|}{ Annual Means } \\
\hline & & Cool & nergy & ption & Evap & orat & d & & & $\begin{array}{c}\text { Zone } \\
\text { Humidity }\end{array}$ & $\begin{array}{r}\text { Zone } \\
\text { Relative }\end{array}$ \\
\hline & & mpressor & Cond Far & or Fan & Total & Sensible & Latent & COP2 & IDB & Ratio & Humidity \\
\hline E50 & 2363.07 & 17895.73 & 1912.86 & 2554.48 & 3102.07 & 44874.22 & 18227.81 & 3.185592 & 0.86661 & 0.009374 & 57.83984 \\
\hline E500 May-Sep & 464.42 & 14016.66 & 1476.30 & 1971.47 & 8439.66 & 34448.15 & 13991.49 & 3.12656 & 25.00000 & 0.011211 & 56.47032 \\
\hline E510 May-Sep & 4912.47 & 27962.28 & 2975.86 & 3974.33 & 108979.12 & 77498.99 & 31480.01 & 3.522485 & 25.00000 & 0.01121 & 56.47549 \\
\hline E520 & 24923.62 & 19501.61 & 2321.67 & 3100.34 & 62484.52 & 44976.74 & 17507.61 & 2.863204 & 14.0194075 & 0.006457 & 63.73379 \\
\hline E522 & 23656.19 & 18724.26 & 2111.81 & 2820.12 & 63153.72 & 44924.11 & 18229.83 & 3.03098 & 17.5525868 & 0.007749 & 59.92374 \\
\hline E525 & 20239.61 & 16511.06 & 1596.51 & 2132.04 & 62997.97 & 44775.10 & 18222.87 & 3.479096 & 27.487395 & 0.013162 & 52.23995 \\
\hline E530 & 58.19 & 8.35 & 7.28 & 2052.56 & 74.52 & 44874.22 & 0.29 & 2.912864 & 20.9980582 & 0.006275 & 44.50639 \\
\hline E5 & 7305 & 2.28 & 1875.77 & 2505.00 & 79.08 & 44976.75 & 2.33 & 2.63528 & 14.1406473 & 0.004494 & 45.85959 \\
\hline E545 & 15790.84 & 12750.39 & 1301.78 & 1738.67 & 44775.10 & 44775.10 & 0.00 & 3.186349 & 27.6188436 & 0.006495 & 36.17683 \\
\hline
\end{tabular}




\begin{tabular}{|c|c|c|c|c|c|c|c|c|c|c|c|}
\hline \multirow[b]{3}{*}{ Hour } & \multicolumn{11}{|c|}{ June 28 Hourly Output - Case E 300} \\
\hline & \multirow{2}{*}{\multicolumn{2}{|c|}{\begin{tabular}{|c|} 
Energy Consumption \\
ompressor Cond Fan
\end{tabular}}} & \multicolumn{3}{|c|}{ Evaporator Coil Load } & \multirow{2}{*}{$\begin{array}{r}\text { Zone } \\
\text { Hum. Rat. } \\
(\mathrm{kg} / \mathrm{kg})\end{array}$} & \multirow[b]{2}{*}{ COP2 } & \multirow[b]{2}{*}{$\begin{array}{r}\text { ODB } \\
\left({ }^{\circ} \mathrm{C}\right)\end{array}$} & \multirow[b]{2}{*}{$\begin{array}{r}\text { EDB } \\
\left({ }^{\circ} \mathrm{C}\right)\end{array}$} & \multirow[b]{2}{*}{$\begin{array}{r}\text { EWB } \\
\left({ }^{\circ} \mathrm{C}\right)\end{array}$} & \multirow{2}{*}{$\begin{array}{r}\text { Outdoor } \\
\text { Hum. Rat. } \\
(\mathrm{kg} / \mathrm{kg})\end{array}$} \\
\hline & & $\begin{array}{r}\text { Cond Fan } \\
(\mathrm{Wh})\end{array}$ & $\begin{array}{l}\text { Total } \\
\text { (Wh) }\end{array}$ & $\begin{array}{r}\text { Sensible } \\
(\mathrm{Wh})\end{array}$ & $\begin{array}{r}\text { Latent } \\
(\mathrm{Wh})\end{array}$ & & & & & & \\
\hline 1 & 1898 & 237 & 7505 & 5788 & 1717 & 0.009227 & 3.515222 & 17.80 & 23.92 & 17.12 & 0.011100 \\
\hline 2 & 1977 & 245 & 7743 & 5961 & 1782 & 0.009255 & 3.484698 & 18.30 & 24.00 & 17.20 & 0.011462 \\
\hline 3 & 1895 & 237 & 7487 & 5788 & 1700 & 0.009190 & 3.511726 & 17.80 & 23.92 & 17.10 & 0.011100 \\
\hline 4 & 1890 & 237 & 7465 & 5788 & 1677 & 0.009155 & 3.509638 & 17.80 & 23.92 & 17.07 & 0.011100 \\
\hline 5 & 1768 & 225 & 7033 & 5580 & 1453 & 0.008925 & 3.528851 & 17.20 & 23.83 & 16.76 & 0.010180 \\
\hline 6 & 2088 & 254 & 7949 & 6341 & 1608 & 0.008969 & 3.394108 & 19.40 & 24.16 & 17.00 & 0.011001 \\
\hline 7 & 3060 & 335 & 10514 & 8277 & 2237 & 0.009436 & 3.096907 & 25.00 & 25.00 & 17.87 & 0.013140 \\
\hline 8 & 3324 & 353 & 10856 & 9038 & 1818 & 0.009261 & 2.952407 & 27.20 & 25.33 & 17.61 & 0.011075 \\
\hline 9 & 4511 & 464 & 14703 & 11971 & 2732 & 0.009644 & 2.955377 & 28.90 & 25.59 & 18.07 & 0.011995 \\
\hline 10 & 4623 & 474 & 15176 & 11971 & 3205 & 0.009968 & 2.977438 & 28.90 & 25.59 & 18.38 & 0.012760 \\
\hline 11 & 5269 & 518 & 16830 & 12731 & 4098 & 0.010497 & 2.908243 & 31.10 & 25.91 & 19.08 & 0.014809 \\
\hline 12 & 5096 & 506 & 16359 & 12559 & 3800 & 0.010479 & 2.920207 & 30.60 & 25.84 & 18.87 & 0.013253 \\
\hline 13 & 6465 & 643 & 21158 & 17422 & 3736 & 0.009881 & 2.976646 & 31.10 & 25.91 & 18.26 & 0.011329 \\
\hline 14 & 6542 & 646 & 21129 & 17629 & 3500 & 0.009690 & 2.939482 & 31.70 & 26.00 & 18.21 & 0.011729 \\
\hline 15 & 8017 & 787 & 26695 & 22491 & 4204 & 0.009496 & 3.032144 & 32.20 & 26.08 & 18.18 & 0.012379 \\
\hline 16 & 8196 & 801 & 27526 & 22491 & 5035 & 0.009634 & 3.059464 & 32.20 & 26.08 & 18.49 & 0.014232 \\
\hline 17 & 5336 & 521 & 16810 & 12939 & 3871 & 0.010331 & 2.870070 & 31.70 & 26.00 & 19.00 & 0.014730 \\
\hline 18 & 5408 & 530 & 17405 & 12729 & 4676 & 0.010802 & 2.931122 & 31.10 & 25.91 & 19.39 & 0.015684 \\
\hline 19 & 4818 & 493 & 16299 & 11761 & 4538 & 0.010813 & 3.068914 & 28.30 & 25.50 & 19.13 & 0.014539 \\
\hline 20 & 4832 & 500 & 16917 & 11381 & 5536 & 0.011181 & 3.172731 & 27.20 & 25.33 & 19.59 & 0.016878 \\
\hline 21 & 3957 & 409 & 13521 & 9036 & 4484 & 0.011274 & 3.096885 & 27.20 & 25.33 & 19.65 & 0.016878 \\
\hline 22 & 3873 & 403 & 13372 & 8864 & 4509 & 0.011313 & 3.127222 & 26.70 & 25.25 & 19.65 & 0.016832 \\
\hline 23 & 3771 & 396 & 13180 & 8656 & 4524 & 0.011352 & 3.162947 & 26.10 & 25.16 & 19.65 & 0.016889 \\
\hline 24 & 3811 & 400 & 13357 & 8656 & 4701 & 0.011451 & 3.171931 & 26.10 & 25.16 & 19.76 & 0.017329 \\
\hline
\end{tabular}

\begin{tabular}{|c|c|c|c|c|c|c|c|c|c|c|c|}
\hline \multirow[b]{3}{*}{ Day } & \multicolumn{11}{|c|}{ Case E500 Average Daily Outputs - f(ODB) sensitivity } \\
\hline & & Energy $\mathrm{C}$ & onsumption & & Evaporator & Coil Load & & Zone & & & \\
\hline & $\begin{array}{l}\text { Total c } \\
(\mathrm{Wh})\end{array}$ & $\begin{array}{r}\text { ompressor } \\
(\mathrm{Wh}) \\
\end{array}$ & $\begin{array}{r}\text { Cond Fan } \\
(\mathrm{Wh})\end{array}$ & $\begin{array}{r}\text { loor Fan } \\
(\mathrm{Wh})\end{array}$ & $\begin{array}{l}\text { Total } \\
(\mathrm{Wh}) \\
\end{array}$ & $\begin{array}{r}\text { Sensible } \\
(\mathrm{Wh})\end{array}$ & $\begin{array}{r}\text { Latent } \\
(\mathrm{Wh})\end{array}$ & $\begin{array}{c}\text { Hum Rat } \\
(\mathrm{kg} / \mathrm{kg})\end{array}$ & COP2 & $\begin{array}{r}\text { ODB } \\
\left({ }^{\circ} \mathrm{C}\right)\end{array}$ & $\begin{array}{l}\text { EDB } \\
\left({ }^{\circ} \mathrm{C}\right)\end{array}$ \\
\hline April 30 & 3906.50 & 3025.25 & 377.33 & 503.92 & 13170.92 & 9365.46 & 3805.50 & 0.010888 & 3.83164106 & 16.88333 & 25 \\
\hline June 25 & 5070.54 & 4109.79 & 411.33 & 549.42 & 13197.96 & 9387.63 & 3810.50 & 0.011340 & 2.91775448 & 29.51667 & 25 \\
\hline
\end{tabular}

\begin{tabular}{|c|c|c|c|c|c|c|c|c|c|c|c|}
\hline \multirow[b]{3}{*}{ Day } & \multicolumn{11}{|c|}{ Case E530 Average Daily Outputs - f(ODB) sensitivity } \\
\hline & \multicolumn{4}{|c|}{ Energy Consumption } & \multicolumn{3}{|c|}{ Evaporator Coil Load } & \multirow{2}{*}{$\begin{array}{r}\text { Zone } \\
\text { Hum Rat } \\
(\mathrm{kg} / \mathrm{kg})\end{array}$} & \multirow[b]{2}{*}{ COP2 } & \multirow[b]{2}{*}{$\begin{array}{l}\text { ODB } \\
\left({ }^{\circ} \mathrm{C}\right)\end{array}$} & \multirow[b]{2}{*}{$\begin{array}{l}\text { EDB } \\
\left({ }^{\circ} \mathrm{C}\right)\end{array}$} \\
\hline & $\begin{array}{l}\text { Total } \\
(\mathrm{Wh})\end{array}$ & $\begin{array}{r}\text { mpressor } \\
(\mathrm{Wh})\end{array}$ & $\begin{array}{r}\text { Cond Fan } \\
\text { (Wh) }\end{array}$ & $\begin{array}{r}\text { door Fan } \\
(W h)\end{array}$ & $\begin{array}{l}\text { Total } \\
(\mathrm{Wh})\end{array}$ & $\begin{array}{r}\text { Sensible } \\
(\mathrm{Wh})\end{array}$ & $\begin{array}{r}\text { Latent } \\
(\mathrm{Wh})\end{array}$ & & & & \\
\hline April 30 & 3091.63 & 2378.54 & 305.33 & 407.75 & 9365.46 & 9365.46 & 0.00 & 0.006209 & 3.46034391 & 16.88333 & 25 \\
\hline June 25 & 3937.75 & 3168.38 & 329.42 & 439.96 & 9387.63 & 9387.63 & 0.00 & 0.006209 & 2.68788687 & 29.51667 & 25 \\
\hline
\end{tabular}

\begin{tabular}{|c|c|c|c|c|c|c|c|c|c|c|c|c|}
\hline \multirow{3}{*}{ Cases } & \multicolumn{12}{|c|}{ Annual Hourly Integrated Maxima Consumptions and Loads } \\
\hline & \multicolumn{3}{|c|}{$\begin{array}{l}\text { Energy Consumption } \\
\text { Compr + Both Fans }\end{array}$} & \multicolumn{6}{|c|}{ Sensible ${ }_{\text {Evaporator Coil Loads }}^{\text {Latent }}$} & \multicolumn{3}{|c|}{ Sensible + Latent } \\
\hline & Wh & Date & Hour & Wh & Date & Hour & Wh & Date & Hour & Wh & Date & Hour \\
\hline E300 & 11945 & 20 -juil & 15 & 23457 & 20 -juil & 15 & 10480 & 03-sept & 15 & 32641 & 20-juil & 15 \\
\hline E310 & 12682 & 20-juil & 15 & 23122 & 20-juil & 15 & 16148 & 04-août & 15 & 37396 & 03-sept & 15 \\
\hline E320 & 13103 & 20-juil & 15 & 31640 & 24-avr & 16 & 21623 & 17-sept & 12 & 39862 & 03-sept & 16 \\
\hline E330 & 13480 & 20-juil & 15 & 33997 & 24-avr & 16 & 28111 & 18-sept & 15 & 43942 & 02-oct & 9 \\
\hline E340 & 13281 & 20-juil & 15 & 33102 & 24-avr & 16 & 24054 & 03-sept & 17 & 41309 & 03-sept & 15 \\
\hline E350 & 11951 & 20-juil & 15 & 23457 & 20-juil & 15 & 10756 & 02-oct & 8 & 32665 & 20-juil & 15 \\
\hline E360 & 13011 & 20-juil & 15 & 32792 & 20-juil & 15 & 8583 & 03-sept & 17 & 39320 & 10-juil & 12 \\
\hline
\end{tabular}




\begin{tabular}{|c|c|c|c|c|c|c|c|c|c|c|c|c|}
\hline \multirow{3}{*}{ Cases } & \multicolumn{12}{|c|}{ Annual Hourly Integrated Maxima Consumptions and Loads } \\
\hline & \multicolumn{3}{|c|}{$\begin{array}{l}\text { Energy Consumption } \\
\text { Compr + Both Fans }\end{array}$} & \multicolumn{6}{|c|}{ Sensible $\begin{array}{r}\text { Evaporator Coil Loads } \\
\text { Latent }\end{array}$} & \multicolumn{3}{|c|}{ Sensible + Latent } \\
\hline & Wh & Date & Hour & Wh & Date & Hour & Wh & Date & Hour & $\mathrm{Wh}$ & Date & Hour \\
\hline E500 & 10152 & 20 -juil & 15 & 18776 & 04-juin & 15 & 7783 & 29-juin & 16 & 26545 & 29-juin & 16 \\
\hline E510 & 11169 & 20 -juil & 15 & 21121 & 04-juin & 13 & 8895 & 30-juin & 16 & 30003 & 30-juin & 16 \\
\hline E520 & 10820 & 10-sept & 15 & 18804 & 12-juil & 16 & 10470 & 28-sept & 15 & 29243 & 28-sept & 15 \\
\hline E522 & 11333 & 25-juil & 16 & 18785 & 04-juin & 15 & 11848 & 25-juil & 16 & 30630 & 25-juil & 16 \\
\hline E525 & 9412 & 20-juil & 15 & 18759 & 04-juin & 15 & 7886 & 29-juin & 16 & 26631 & 29-juin & 16 \\
\hline E530 & 8002 & 20-juil & 15 & 18776 & 04-juin & 15 & 107 & 16-mars & 10 & 18776 & 04-juin & 15 \\
\hline E540 & 8867 & 20-juil & 15 & 18794 & 04-juin & 15 & 834 & 11-mars & 10 & 18794 & 04-juin & 15 \\
\hline E545 & 7367 & 20-juil & 15 & 18759 & 04-juin & 15 & 0 & 01-janv & 1 & 18759 & 04-juin & 15 \\
\hline
\end{tabular}

\begin{tabular}{|c|c|c|c|c|c|c|c|c|c|c|c|c|}
\hline \multirow{3}{*}{ Cases } & \multicolumn{12}{|c|}{ Annual Hourly Integrated Maxima and Minima - COP2 and Zone } \\
\hline & \multicolumn{6}{|c|}{$\mathrm{COP} 2$} & \multicolumn{6}{|c|}{ Indoor Drybulb Temperature } \\
\hline & COP2 & Date & Hour & COP2 & Date & Hour & ${ }^{\circ} \mathrm{C}$ & Date & Hour & ${ }^{\circ} \mathrm{C}$ & Date & Hour \\
\hline E300 & 3.861217 & 30-avr & 16 & 2.788429 & 13-juin & \begin{tabular}{l|}
17 \\
\end{tabular} & 25.05 & 21-févr & 17 & 8 & 06-janv & 5 \\
\hline E310 & 4.124828 & $30-a v r$ & 15 & 2.854701 & 01-déc & 15 & 25.62 & 20-juil & 15 & 8 & 06-janv & 5 \\
\hline E320 & 3.936881 & 16-sept & 15 & 2.805108 & 01-déc & 14 & 32.34 & 20-juil & 15 & 8 & 06-janv & 5 \\
\hline E330 & 4.114644 & 17-juin & 16 & 2.805108 & 01-déc & 14 & 31.9 & 20-juil & 15 & 8 & 06-janv & 5 \\
\hline E340 & 4.011976 & 16-sept & 16 & 2.805108 & 01-déc & 14 & 32.17 & 20-juil & 15 & 8 & 06-janv & 5 \\
\hline E350 & 3.884146 & 04-oct & 24 & 2.788429 & 13-juin & 17 & 35 & 21-avr & 1 & 8 & 06-janv & 5 \\
\hline E360 & 4.41361 & 04-oct & 24 & 2.805108 & 01-déc & 14 & 28.48 & 20-juil & 15 & 8 & 06-janv & 5 \\
\hline
\end{tabular}

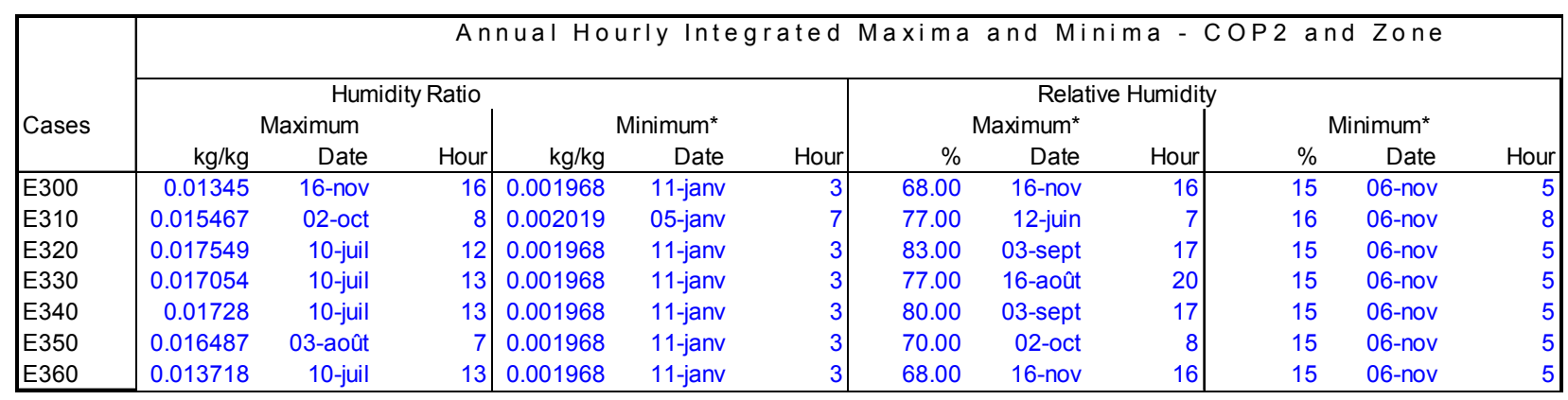

\begin{tabular}{|c|c|c|c|c|c|c|c|c|c|c|c|c|}
\hline \multirow{4}{*}{ Cases } & \multicolumn{12}{|c|}{ Annual Hourly Integrated Maxima and Minima - COP2 and Zone } \\
\hline & \multicolumn{6}{|c|}{ COP 2} & \multicolumn{6}{|c|}{ Indoor Drybulb Temperature } \\
\hline & \multicolumn{3}{|c|}{ Maximum } & \multicolumn{3}{|c|}{ Minimum } & \multicolumn{3}{|c|}{ Maximum } & \multicolumn{3}{|c|}{ Minimum* } \\
\hline & COP2 & Date & Hour & COP2 & Date & Hour & ${ }^{\circ} \mathrm{C}$ & Date & Hour & ${ }^{\circ} \mathrm{C}$ & Date & Hour \\
\hline E500 & 4.18151 & 16-mars & 10 & 2.670385 & 29-juil & 12 & 25.02 & 30-mars & 17 & 8.54 & 20-déc & 20 \\
\hline E510 & 4.687263 & 04-oct & 24 & 2.876418 & 31-mars & 15 & 25.02 & 30-mars & 17 & 8.54 & 20-déc & 20 \\
\hline E520 & 3.705593 & 30-avr & 15 & 2.142857 & 30-janv & 17 & 15.06 & 12-juil & 15 & 8.51 & 20-déc & 20 \\
\hline E522 & 3.980778 & 30-avr & 16 & 2.411388 & 25-juil & 17 & 20.05 & 13-mars & 22 & 8.54 & 20-déc & 20 \\
\hline E525 & 4.615458 & 16-mars & 10 & 2.897192 & 29-juil & 12 & 35 & 11-mars & 10 & 8.54 & 20-déc & 20 \\
\hline E530 & 3.844617 & 16-mars & 10 & 2.470681 & 29-juil & 12 & 25.02 & 30-mars & 17 & 8.54 & 20-déc & 20 \\
\hline E540 & 3.666667 & 11-mars & 22 & 2.142857 & 05-avr & 20 & 15.05 & 28-janv & 20 & 8.51 & 20-déc & 20 \\
\hline E545 & 4.161783 & 16-mars & 10 & 2.692794 & 29-juil & 12 & 35 & 11-mars & 10 & 8.54 & 20-déc & 20 \\
\hline
\end{tabular}




\begin{tabular}{|c|c|c|c|c|c|c|c|c|c|c|c|c|}
\hline \multirow{4}{*}{ Cases } & \multicolumn{12}{|c|}{ Annual Hourly Integrated Maxima and Minima-COP2 and Zone } \\
\hline & \multicolumn{6}{|c|}{ Humidity Ratio } & \multicolumn{6}{|c|}{ Relative Humidity } \\
\hline & \multicolumn{3}{|c|}{ Maximum } & \multicolumn{3}{|c|}{ Minimum* } & \multicolumn{3}{|c|}{ Maximum* } & \multicolumn{3}{|c|}{ Minimum* } \\
\hline & $\mathrm{kg} / \mathrm{kg}$ & Date & Hour & $\mathrm{kg} / \mathrm{kg}$ & Date & Hour & $\%$ & Date & Hour & $\%$ & Date & Hour \\
\hline E500 & 0.011713 & 20-juil & 15 & 0.006908 & 20-déc & 20 & 100.00 & $12-a v r$ & 5 & 54 & 04-oct & 24 \\
\hline E510 & 0.011716 & 20-juil & 15 & 0.006908 & 20-déc & 20 & 100.00 & 12-avr & 5 & 54 & 04-oct & 23 \\
\hline E520 & 0.007566 & 20-juil & 15 & 0.006525 & 27-nov & 23 & 95.00 & 08-nov & 17 & 61 & 27-nov & 22 \\
\hline E522 & 0.009398 & 20-juil & 15 & 0.006908 & 20-déc & 20 & 100.00 & 12-avr & 1 & 60 & 04-oct & 23 \\
\hline E525 & 0.017626 & 20 -juil & 15 & 0.006909 & 20-déc & 20 & 100.00 & 08-nov & 23 & 44 & 04-mai & 4 \\
\hline E530 & 0.00549 & 01-avr & 1 & 0.005453 & 01-nov & 21 & 79.00 & 06-déc & 8 & 28 & 01-avr & 10 \\
\hline E540 & 0.003256 & 01-avr & 1 & 0.003253 & 29-avr & 23 & 47.00 & 12-avr & 6 & 31 & 01-avr & 1 \\
\hline E545 & 0.006689 & 01-avr & 1 & 0.006685 & 20-juil & 15 & 97.00 & 07-déc & 4 & 19 & $01-a v r$ & 10 \\
\hline
\end{tabular}

\subsection{Major improvements during round 7 (April 2003)}

By using the short time step loop, we were unable to find the same results as those of the other participants (specially for cases E500-E545 and E360). The discrepancies seem to result from the calculation of the indoor air humidity. Moreover, the short time step approach induces long calculation time. Consequently, we decided to derive a new algorithm, described on the chart below. At a given time step (1 hour), once the building sensible load is calculated, the new algorithm runs as follows:

1) The first loop consists of fixing the indoor air temperature to the average value of the temperatures obtained in the previous iteration and the current one (at the beginning of the loop, the indoor air temperature is fixed to the value of the previous hour).

2) The second loop, embedded in the previous one, consists of searching the optimal value of indoor air humidity (by exploring the performance map and solving the humidity balance equation).

3) Once the second loop has converged, the indoor air temperature is calculated (by solving the thermal balance equation). Then, a new iteration (step 1) is performed if the indoor air temperature has changed.

The iterations stop once both values of indoor air temperature and humidity have converged.

With the new approach, our results are globally close to those of the other programs. However, some non-negligible gaps still remain in the predictions of relative humidity ratio in the E530-E545 cases (dry coil). We explained that behavior by the fact that our building was less insulated than the other models. 


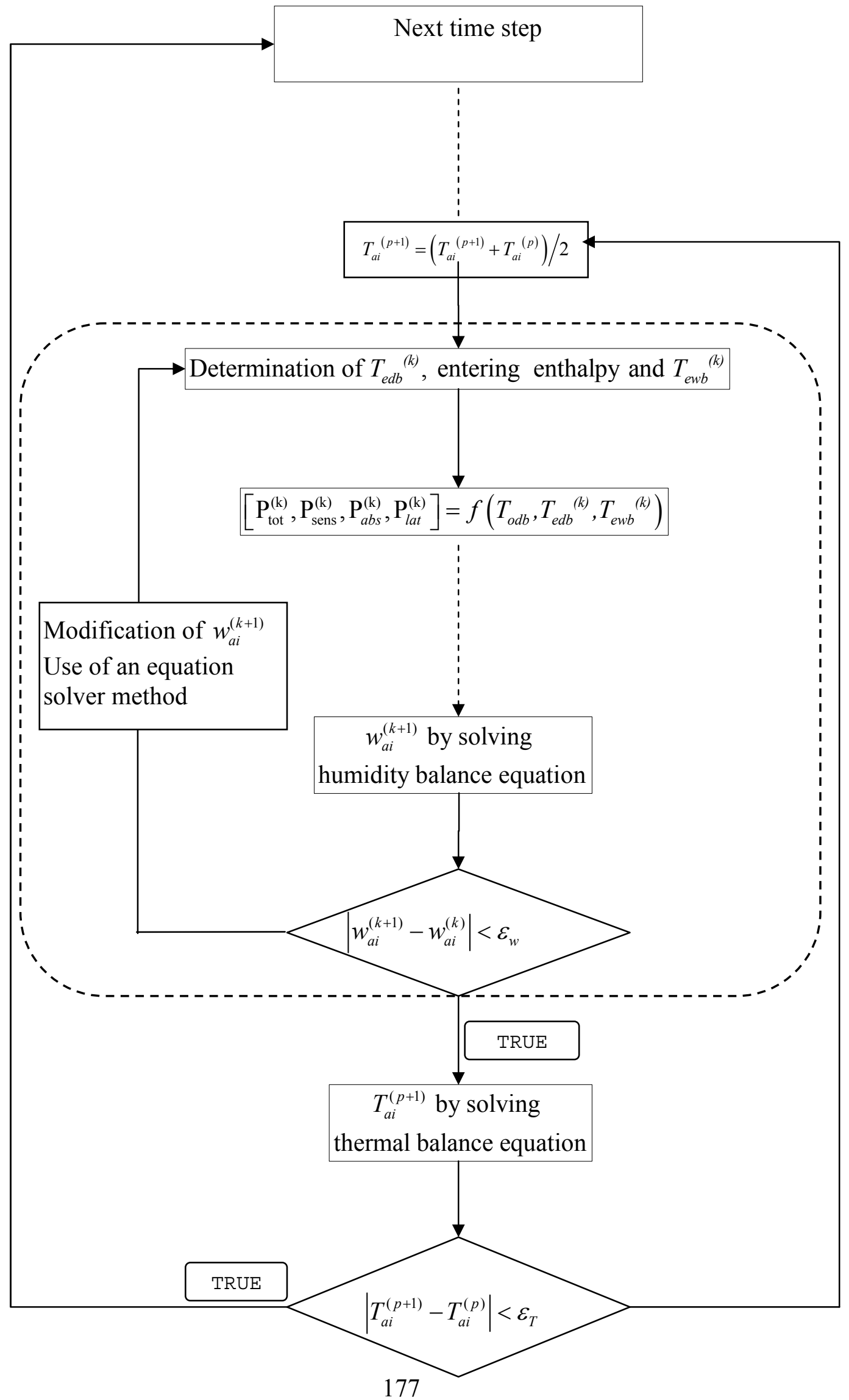




\begin{tabular}{|c|c|c|c|c|c|c|c|c|c|c|c|c|c|}
\hline \multirow{4}{*}{ Cases } & \multicolumn{7}{|c|}{ Annual Sums } & \multicolumn{4}{|c|}{ Annual Means } & \multicolumn{2}{|c|}{$\begin{array}{l}\text { Annual Means } \\
\text { E } 300 \quad \text { On Iy }\end{array}$} \\
\hline & & Cooling $\mathrm{E}$ & nergy Consı & umption & & aporator Co & oil Load & & & $\begin{array}{r}\text { Zone } \\
\text { Humidity }\end{array}$ & $\begin{array}{r}\text { Zone } \\
\text { Relative }\end{array}$ & & $\begin{array}{l}\text { Outdoor } \\
\text { Humidity }\end{array}$ \\
\hline & & Compressor & Cond Fan Ir & ndoor Fan & Total & Sensible & Latent & COP2 & & Ratio & Humidity & & \\
\hline & (kWh) & (kWh) & $(\mathrm{kWh})$ & $(\mathrm{kWh})$ & (kWh) & $(k W h)$ & $(\mathrm{kWh})$ & & $\left({ }^{\circ} \mathrm{C}\right)$ & $(\mathrm{kg} / \mathrm{kg})$ & $(\%)$ & 5) & $\mathrm{kg} / \mathrm{kg}$ ) \\
\hline E300 & 34976.41 & 21770.001 & 2326.49 & 10879.92 & 77744.59 & 55209.47 & 22535.14 & 3.226386 & 24.0816473 & 0.009175 & 47.82614 & 19.91445 & 0.011649 \\
\hline E310 & 39519.57 & 25936.821 & 2702.828 & 10879.92 & 97295.87 & 55185.07 & 42110.84 & 3.397244 & 24.0897089 & 0.011175 & 57.84098 & & \\
\hline E320 & 39400.82 & 25846.026 & 2674.869 & 10879.92 & 97141.31 & 62008.8 & 35132.59 & 3.40597 & 24.3273539 & 0.010049 & 51.10342 & & \\
\hline E330 & 40535.14 & 26927.733 & 2727.484 & 10879.92 & 103712.9 & 62649.46 & 41063.37 & 3.497291 & 24.2954692 & 0.009812 & 50.08482 & & \\
\hline E340 & 40065.26 & 26472.79 & 2712.551 & 10879.92 & 100676.2 & 62380.56 & 38295.62 & 3.449547 & 24.308863 & 0.009868 & 50.29669 & & \\
\hline E350 & 31586.59 & 18738.055 & 1968.617 & 10879.92 & 66860.16 & 48588.8 & 18271.39 & 3.228919 & 26.2685993 & 0.009759 & 44.31621 & & \\
\hline E360 & 54843.26 & 39697.162 & 4266.176 & 10879.92 & 161200.2 & 134205.7 & 26994.48 & 3.666696 & 25.4808767 & 0.008552 & 40.871 & & \\
\hline
\end{tabular}

\begin{tabular}{|c|c|c|c|c|c|c|c|c|c|c|c|}
\hline \multirow[b]{3}{*}{ Cases } & \multicolumn{7}{|c|}{ Annual Sums } & \multicolumn{4}{|c|}{ Annual Means } \\
\hline & & Coc & רe & n & & a & il Load & & & $\begin{array}{r}\text { Zone } \\
\text { Humidity }\end{array}$ & $\begin{array}{r}\text { Zone } \\
\text { Relative }\end{array}$ \\
\hline & $\begin{array}{r}\text { Tot } \\
(\mathrm{kW}\end{array}$ & $\begin{array}{r}\text { Compressor } \\
\text { (kWh) }\end{array}$ & $\begin{array}{l}\text { Cond } \mathrm{Fa} \\
(\mathrm{kW}\end{array}$ & $\begin{array}{r}\text { Jor Fan } \\
\text { (kWh) }\end{array}$ & $\begin{array}{r}\text { Total } \\
(\mathrm{kWh})\end{array}$ & $\begin{array}{r}\text { Sensible } \\
(\mathrm{kWh})\end{array}$ & $\begin{array}{c}\text { Latent } \\
\text { (kWh) }\end{array}$ & COP2 & $\begin{array}{l}\text { IDB } \\
\left({ }^{\circ} \mathrm{C}\right)\end{array}$ & $\begin{array}{r}\text { Ratio } \\
(\mathrm{kg} / \mathrm{kg})\end{array}$ & $\begin{array}{r}\text { Humidity } \\
(\%)\end{array}$ \\
\hline 500 & 322.95 & 17857. & 1911.869 & 2553.232 & 3105.37 & 44874.22 & 18231.14 & & 9783 & 0.010218 & 65.94189 \\
\hline E5C & 54 & & .528 & 197 & 484 & & & & 0000 & 329 & 7217 \\
\hline E51 & 64 & 279 & 2974.4 & 2.28 & 9 & & & 53 & 25.00000 & 328 & 6155 \\
\hline E520 & & & .827 & 271 & .1 & & & & 4.1420811 & 7023 & 22683 \\
\hline E522 & & & .833 & 112 & 3 & & & & 17.7290274 & 0858 & 68.23139 \\
\hline E525 & 20241.71 & 165 & 9.203 & 2135.708 & 63001.56 & 775.1 & 182 & & 27.7709395 & 0.01398 & 60.1387 \\
\hline E530 & 42.5 & 13855.961 & 1535.685 & 2050.858 & 44875.41 & 44874.22 & 1.182 & 2.9 & 21.0958482 & 0.00577 & 41.25776 \\
\hline E54 & 536.57 & 15163.82 & 1872.336 & 2500.416 & 44979.84 & 44976.75 & 3.09 & 2.640258 & 1406473 & 0.003855 & 40.05091 \\
\hline E545 & 15791.08 & 12750.623 & 1301.791 & 1738.667 & 44775.11 & 44775.1 & 0.004 & 3.186293 & 27.7166336 & 0.006749 & 36.8746 \\
\hline
\end{tabular}

\begin{tabular}{|c|c|c|c|c|c|c|c|c|c|c|c|}
\hline \multirow[b]{3}{*}{ Hour } & \multicolumn{11}{|c|}{ June 28 Hourly Output - Case E300 } \\
\hline & \multicolumn{2}{|c|}{ Energy Consumption } & \multicolumn{3}{|c|}{ Evaporator Coil Load } & \multirow{2}{*}{\begin{tabular}{|r|} 
Zone \\
Hum. Rat. \\
$(\mathrm{kg} / \mathrm{kg})$
\end{tabular}} & \multirow[b]{2}{*}{ COP2 } & \multirow[b]{2}{*}{$\begin{array}{l}\mathrm{ODB} \\
\left({ }^{\circ} \mathrm{C}\right)\end{array}$} & \multirow[b]{2}{*}{$\begin{array}{r}\text { EDB } \\
\left({ }^{\circ} \mathrm{C}\right)\end{array}$} & \multirow[b]{2}{*}{$\begin{array}{r}\text { EWB } \\
\left({ }^{\circ} \mathrm{C}\right)\end{array}$} & \multirow{2}{*}{$\begin{array}{r}\begin{array}{r}\text { Outdoor } \\
\text { Hum. Rat. } \\
(\mathrm{kg} / \mathrm{kg})\end{array} \\
\end{array}$} \\
\hline & $\begin{array}{r}\text { Compressor } \\
(\mathrm{Wh})\end{array}$ & $\begin{array}{r}\text { Cond Fan } \\
(\mathrm{Wh})\end{array}$ & $\begin{array}{l}\text { Total } \\
(\mathrm{Wh}) \\
\end{array}$ & $\begin{array}{r}\text { Sensible } \\
(\mathrm{Wh}) \\
\end{array}$ & $\begin{array}{r}\text { Latent } \\
(\mathrm{Wh})\end{array}$ & & & & & & \\
\hline 1 & 1886 & 237 & 7472 & 5788 & 1684 & 0.009276 & 3.519548 & 17.8 & 23.92 & 17.155 & 0.0111 \\
\hline 2 & 1964 & 244 & 7707 & 5961 & 1747 & 0.009302 & 3.490489 & 18.3 & 24 & 17.238 & 0.011462 \\
\hline 3 & 1881 & 236 & 7445 & 5788 & 1657 & 0.009239 & 3.516769 & 17.8 & 23.92 & 17.12 & 0.0111 \\
\hline 4 & 1878 & 236 & 7432 & 5788 & 1644 & 0.009201 & 3.51561 & 17.8 & 23.92 & 17.102 & 0.0111 \\
\hline 5 & 1756 & 224 & 7000 & 5580 & 1420 & 0.008969 & 3.535354 & 17.2 & 23.83 & 16.787 & 0.01018 \\
\hline 6 & 2075 & 253 & 7915 & 6341 & 1574 & 0.009012 & 3.399914 & 19.4 & 24.16 & 17.032 & 0.011001 \\
\hline 7 & 3035 & 334 & 10450 & 8277 & 2173 & 0.00949 & 3.101811 & 25 & 25 & 17.911 & 0.01314 \\
\hline 8 & 3303 & 352 & 10813 & 9038 & 1775 & 0.009314 & 2.958413 & 27.2 & 25.33 & 17.646 & 0.011075 \\
\hline 9 & 4483 & 463 & 14631 & 11971 & 2660 & 0.009708 & 2.958148 & 28.9 & 25.59 & 18.118 & 0.011995 \\
\hline 10 & 4594 & 472 & 15099 & 11971 & 3128 & 0.010041 & 2.980458 & 28.9 & 25.59 & 18.442 & 0.01276 \\
\hline 11 & 5238 & 516 & 16722 & 12731 & 3991 & 0.010588 & 2.906152 & 31.1 & 25.91 & 19.142 & 0.014809 \\
\hline 12 & 5066 & 504 & 16258 & 12559 & 3699 & 0.01058 & 2.918851 & 30.6 & 25.84 & 18.935 & 0.013253 \\
\hline 13 & 6442 & 642 & 21090 & 17422 & 3669 & 0.009975 & 2.977132 & 31.1 & 25.91 & 18.326 & 0.011329 \\
\hline 14 & 6523 & 645 & 21067 & 17629 & 3438 & 0.009778 & 2.939035 & 31.7 & 26 & 18.269 & 0.011729 \\
\hline 15 & 8000 & 785 & 26636 & 22491 & 4145 & 0.009579 & 3.031986 & 32.2 & 26.08 & 18.239 & 0.012379 \\
\hline 16 & 8169 & 799 & 27416 & 22491 & 4925 & 0.009733 & 3.057092 & 32.2 & 26.08 & 18.557 & 0.014232 \\
\hline 17 & 5306 & 519 & 16702 & 12939 & 3763 & 0.01044 & 2.867296 & 31.7 & 26 & 19.063 & 0.01473 \\
\hline 18 & 5381 & 528 & 17312 & 12729 & 4582 & 0.010912 & 2.929768 & 31.1 & 25.91 & 19.458 & 0.015684 \\
\hline 19 & 4791 & 492 & 16232 & 11761 & 4470 & 0.010914 & 3.072497 & 28.3 & 25.5 & 19.199 & 0.014539 \\
\hline 20 & 4809 & 498 & 16867 & 11381 & 5486 & 0.011269 & 3.178255 & 27.2 & 25.33 & 19.65 & 0.016878 \\
\hline 21 & 3939 & 408 & 13484 & 9036 & 4447 & 0.011348 & 3.101909 & 27.2 & 25.33 & 19.706 & 0.016878 \\
\hline 22 & 3852 & 402 & 13322 & 8864 & 4459 & 0.011383 & 3.131641 & 26.7 & 25.25 & 19.697 & 0.016832 \\
\hline 23 & 3752 & 395 & 13139 & 8656 & 4482 & 0.011416 & 3.168314 & 26.1 & 25.16 & 19.694 & 0.016889 \\
\hline 24 & 3794 & 399 & 13323 & 8656 & 4666 & 0.011507 & 3.177439 & 26.1 & 25.16 & 19.805 & 0.017329 \\
\hline
\end{tabular}




\begin{tabular}{|c|c|c|c|c|c|c|c|c|c|}
\hline \multirow[b]{2}{*}{ Day } & \multicolumn{2}{|c|}{ Energy Consumption } & \multicolumn{3}{|c|}{ Evaporator Coil Load } & \multirow{2}{*}{$\begin{array}{r}\text { Zone } \\
\text { Hum Rat } \\
(\mathrm{kg} / \mathrm{kg})\end{array}$} & \multirow[b]{2}{*}{ COP2 } & \multirow[b]{2}{*}{$\begin{array}{r}\text { ODB } \\
\left({ }^{\circ} \mathrm{C}\right) \\
\end{array}$} & \multirow[b]{2}{*}{$\begin{array}{c}\text { EDB } \\
\left({ }^{\circ} \mathrm{C}\right)\end{array}$} \\
\hline & $\begin{array}{l}\text { Total Compressor } \\
(\mathrm{Wh}) \quad(\mathrm{Wh})\end{array}$ & $\begin{array}{l}\text { Cond Fan Indoor Fan } \\
\begin{array}{ll}(\mathrm{Wh}) & (\mathrm{Wh})\end{array}\end{array}$ & $\begin{array}{l}\text { Total } \\
(\mathrm{Wh})\end{array}$ & $\begin{array}{r}\text { Sensible } \\
(\mathrm{Wh})\end{array}$ & $\begin{array}{r}\text { Latent } \\
(\mathrm{Wh})\end{array}$ & & & & \\
\hline April 30 & $3901.04167 \quad 3020.0417$ & 377.25 & 13169.54 & 9365.458 & 3804.375 & 0.010938 & 3.83716004 & 16.88333 & 25 \\
\hline June 25 & $5066.5 \quad 4105.9583$ & $411.3333 \quad 549.2083$ & 13198.08 & 9387.625 & 3810.417 & 0.011479 & 2.92126537 & 29.51667 & 25 \\
\hline
\end{tabular}

\begin{tabular}{|c|c|c|c|c|c|c|c|c|c|}
\hline \multirow[b]{3}{*}{ Day } & \multicolumn{9}{|c|}{ Case E530 Average Daily Outputs - f(ODB) sensitivity } \\
\hline & Energy Con & sumption & Evaporat & or Coil Load & & Zone & & & \\
\hline & $\begin{array}{l}\text { Total Compressor } \\
(\mathrm{Wh}) \quad(\mathrm{Wh})\end{array}$ & $\begin{array}{l}\text { Cond Fan Indoor Fan } \\
\begin{array}{rr}(\mathrm{Wh}) & \text { (Wh) }\end{array}\end{array}$ & $\begin{array}{l}\text { Total } \\
\text { (Wh) }\end{array}$ & $\begin{array}{r}\text { Sensible } \\
\text { (Wh) }\end{array}$ & $\begin{array}{r}\text { Latent } \\
(\mathrm{Wh})\end{array}$ & $\begin{array}{c}\text { Hum Rat } \\
(\mathrm{kg} / \mathrm{kg})\end{array}$ & COP2 & $\begin{array}{l}\text { ODB } \\
\left({ }^{\circ} \mathrm{C}\right)\end{array}$ & $\begin{array}{c}\text { EDB } \\
\left({ }^{\circ} \mathrm{C}\right)\end{array}$ \\
\hline April 30 & $3091.54167 \quad 2378.4583$ & 305.3333 & 9365.458 & 9365.458 & 0 & 0.005484 & 3.46043506 & 16.88333 & 25 \\
\hline June 25 & $3934.625 \quad 3165.5833$ & $329.25 \quad 439.7917$ & 9387.625 & 9387.625 & 0 & 0.005478 & 2.69003883 & 29.51667 & 25 \\
\hline
\end{tabular}

\begin{tabular}{|c|c|c|c|c|c|c|c|c|c|c|c|c|}
\hline \multirow{3}{*}{ Cases } & \multicolumn{12}{|c|}{ Annual Hourly Integrated Maxima Consumptions and Loads } \\
\hline & \multicolumn{3}{|c|}{$\begin{array}{l}\text { Energy Consumption } \\
\text { Compr + Both Fans }\end{array}$} & \multicolumn{3}{|c|}{ Sensible ${ }^{E v}$} & \multicolumn{3}{|c|}{$\begin{array}{c}\text { Coil Loads } \\
\text { Latent }\end{array}$} & \multicolumn{2}{|c|}{ Sensible + Latent } & \multirow[b]{2}{*}{ Hour } \\
\hline & Wh & Date & Hour & Wh & Date & Hour & Wh & Date & Hour & Wh & Date & \\
\hline E300 & 11932 & 20-juil & 15 & 23457 & 20 -juil & 15 & 10375 & 03-sept & 15 & 32502 & 20 -juil & 15 \\
\hline E310 & 12653 & 20-juil & 15 & 23078 & 10-sept & 15 & 16112 & 04-août & 15 & 37261 & 03-sept & 15 \\
\hline E320 & 13104 & 20 -juil & 15 & 31134 & 03-juin & 16 & 21697 & 17-sept & 12 & 39904 & 03-sept & 16 \\
\hline E330 & 13467 & 20-juil & 15 & 33997 & 24-avr & 16 & 28184 & 18-sept & 15 & 43978 & 02 -oct & 9 \\
\hline E340 & 13277 & 20 -juil & 15 & 32940 & 24-avr & 16 & 24225 & 03-sept & 17 & 41366 & 03-sept & 15 \\
\hline E350 & 11932 & 20 -juil & 15 & 23457 & 20-juil & 15 & 10755 & 02-oct & 8 & 32502 & 20-juil & 15 \\
\hline E360 & 12863 & 20-juil & 15 & 31981 & 24-avr & 16 & 8859 & 03-sept & 17 & 38322 & 02-oct & 10 \\
\hline
\end{tabular}

\begin{tabular}{|c|c|c|c|c|c|c|c|c|c|c|c|c|}
\hline \multirow{3}{*}{ Cases } & \multicolumn{12}{|c|}{ Annual Hourly Integrated Maxima Consumptions and Loads } \\
\hline & \multicolumn{3}{|c|}{$\begin{array}{c}\text { Energy Consumption } \\
\text { Compr + Both Fans }\end{array}$} & \multicolumn{3}{|c|}{ Sensible ${ }^{E}$} & \multicolumn{3}{|c|}{$\begin{array}{c}\text { r Coil Loads } \\
\text { Latent }\end{array}$} & \multicolumn{2}{|c|}{ Sensible + Latent } & \multirow[b]{2}{*}{ Hour } \\
\hline & Wh & Date & Hour & Wh & Date & Hour & Wh & Date & Hour & Wh & Date & \\
\hline E500 & 10177 & 20 -juil & 15 & 18776 & 04-juin & 15 & 7805 & 29-juin & 16 & 26567 & 29-juin & 16 \\
\hline E510 & 11186 & 20 -juil & 15 & 21121 & 04-juin & 13 & 8850 & 17-juin & 14 & 29948 & 17-juin & 14 \\
\hline E520 & 11044 & 20-juil & 15 & 18969 & 20-juil & 16 & 7726 & 30-juin & 16 & 26675 & 20-juil & 16 \\
\hline E522 & 10639 & 20 -juil & 15 & 18785 & 04-juin & 15 & 7743 & 29-juin & 16 & 26514 & 29-juin & 16 \\
\hline E525 & 9419 & 20-juil & 15 & 18759 & 04-juin & 15 & 7938 & 29-juin & 16 & 26683 & 29-juin & 16 \\
\hline E530 & 7992 & 20-juil & 15 & 18776 & 04-juin & 15 & 179 & 11-mars & 11 & 18776 & 04-juin & 15 \\
\hline E540 & 8846 & 20-juil & 15 & 18794 & 04-juin & 15 & 845 & 11-mars & 10 & 18794 & 04-juin & 15 \\
\hline E545 & 7351 & 20-juil & 15 & 18759 & 04-juin & 15 & 4 & 20 -juil & 15 & 18764 & 20-juil & 15 \\
\hline
\end{tabular}

\begin{tabular}{|c|c|c|c|c|c|c|c|c|c|c|c|c|}
\hline \multirow{4}{*}{ Cases } & \multicolumn{12}{|c|}{ Annual Hourly Integrated Maxima and Minima-COP2 and Zone } \\
\hline & \multicolumn{6}{|c|}{$\mathrm{COP} 2$} & \multicolumn{6}{|c|}{ Indoor Drybulb Temperature } \\
\hline & \multicolumn{3}{|c|}{ Maximum } & \multicolumn{3}{|c|}{ Minimum } & \multicolumn{3}{|c|}{ Maximum } & \multicolumn{3}{|c|}{ Minimum* } \\
\hline & COP2 & Date & Hour & COP2 & Date & Hour & ${ }^{\circ} \mathrm{C}$ & Date & Hour & ${ }^{\circ} \mathrm{C}$ & Date & Hour \\
\hline E300 & 3.870611 & 30-avr & 16 & 2.785629 & 13-juin & 17 & 25.05 & 21-févr & 17 & 8 & 06-janv & 5 \\
\hline E310 & 4.12764 & 30-avr & 15 & 2.872645 & 01-déc & 15 & 26.62 & 20-juil & 15 & 8 & 06-janv & 5 \\
\hline E320 & 3.943305 & 16-sept & 15 & 2.814522 & 31-mars & 15 & 32.32 & 20-juil & 15 & 8 & 06-janv & 5 \\
\hline E330 & 4.121946 & 17-juin & 16 & 2.823325 & 31-mars & 15 & 31.9 & 20-juil & 15 & 8 & 06-janv & 5 \\
\hline E340 & 4.017161 & 16-sept & 16 & 2.823325 & 31-mars & 15 & 32.15 & 20-juil & 15 & 8 & 06-janv & 5 \\
\hline E350 & 3.932099 & 04-oct & 24 & 2.785909 & 13-juin & 17 & 35 & 21-avr & 1 & 8 & 06-janv & 5 \\
\hline E360 & 4.43201 & 04-oct & 24 & 2.823325 & 31-mars & 15 & 33 & 20-juil & 15 & 8 & 06-janv & 5 \\
\hline
\end{tabular}




\begin{tabular}{|c|c|c|c|c|c|c|c|c|c|c|c|c|}
\hline \multirow{3}{*}{ Cases } & \multicolumn{6}{|c|}{ Humidity Ratio } & \multicolumn{5}{|c|}{ Relative Humidity } & \\
\hline & \multicolumn{3}{|c|}{ Maximum } & \multicolumn{3}{|c|}{ Minimum* } & \multicolumn{3}{|c|}{ Maximum ${ }^{*}$} & \multicolumn{3}{|c|}{ Minimum* } \\
\hline & $\mathrm{kg} / \mathrm{kg}$ & Date & Hour & $\mathrm{kg} / \mathrm{kg}$ & Date & Hour & $\%$ & Date & Hour & $\%$ & Date & Hour \\
\hline E300 & 0.013457 & 16-nov & \begin{tabular}{l|l}
16 \\
\end{tabular} & 0.001968 & 11-janv & 3 & 68.00 & $16-$ nov & 16 & 15 & 06-nov & 5 \\
\hline E310 & 0.015432 & 02-oct & 8 & 0.002019 & 05-janv & 7 & 77.00 & 12-juin & 8 & 16 & 06-nov & 8 \\
\hline E320 & 0.017547 & 10-juil & 12 & 0.001968 & 11-janv & 3 & 83.00 & 03-sept & 17 & 15 & 06-nov & 5 \\
\hline E330 & 0.017045 & 10-juil & 13 & 0.001968 & 11-janv & 3 & 76.00 & 10-juin & 18 & 15 & 06-nov & 5 \\
\hline E340 & 0.017272 & 10-juil & 13 & 0.001968 & 11-janv & 3 & 80.00 & 03-sept & 17 & 15 & 06-nov & 5 \\
\hline E350 & 0.016479 & 02-oct & 2 & 0.001968 & 11-janv & 3 & 70.00 & 02-oct & 8 & 15 & 06-nov & 5 \\
\hline E360 & 0.013457 & 16-nov & 16 & 0.001968 & 11-janv & 3 & 68.00 & 16-nov & 16 & 15 & 06-nov & 5 \\
\hline
\end{tabular}

\begin{tabular}{|c|c|c|c|c|c|c|c|c|c|c|c|c|}
\hline \multirow{4}{*}{ Cases } & \multicolumn{12}{|c|}{ Annual Hourly Integrated Maxima and Minima-COP2 and Zone } \\
\hline & \multicolumn{6}{|c|}{ COP2 } & \multicolumn{6}{|c|}{ Indoor Drybulb Temperature } \\
\hline & \multicolumn{3}{|c|}{ Maximum } & \multicolumn{3}{|c|}{ Minimum } & \multicolumn{3}{|c|}{ Maximum } & \multicolumn{3}{|c|}{ Minimum* } \\
\hline & COP2 & Date & Hour & COP2 & Date & Hour & ${ }^{\circ} \mathrm{C}$ & Date & Hour & ${ }^{\circ} \mathrm{C}$ & Date & Hour \\
\hline E500 & 4.184622 & 16-mars & 10 & 2.666464 & 30-juil & 12 & 25.02 & 30 -mars & 17 & 8.54 & 20-déc & 8 \\
\hline E510 & 4.689584 & 04-oct & 24 & 2.881736 & 31-mars & 15 & 25.02 & 30-mars & 17 & 8.54 & 20-déc & 2 \\
\hline E520 & 3.801729 & $30-a v r$ & 16 & 2.333333 & 29-janv & 10 & 15.98 & 20-juil & 15 & 8.51 & 20-déc & 2 \\
\hline E522 & 3.985798 & 30-avr & 16 & 2.428571 & 30-mars & 17 & 20.05 & 13-mars & 22 & 8.54 & 20-déc & 20 \\
\hline E525 & 4.638054 & 16-mars & 10 & 2.894073 & 29-juil & 12 & 35 & 11-mars & 10 & 8.54 & 20-déc & 20 \\
\hline E530 & 3.840045 & 16-mars & 10 & 2.473282 & 29-juil & 12 & 25.02 & 30-mars & 17 & 8.54 & 20-déc & 2 \\
\hline E540 & 3.666667 & 11-mars & 22 & 2.142857 & 05-avr & 20 & 15.05 & 28-janv & 20 & 8.51 & 20-déc & 20 \\
\hline E545 & 4.156489 & 16-mars & 10 & 2.692021 & 29-juil & 12 & 35 & 11-mars & 10 & 8.54 & 20-déc & 20 \\
\hline
\end{tabular}

\begin{tabular}{|c|c|c|c|c|c|c|c|c|c|c|c|c|}
\hline \multirow{3}{*}{ Cases } & \multicolumn{6}{|c|}{ Humidity Ratio } & \multicolumn{5}{|c|}{ Relative Humidity } & \\
\hline & \multicolumn{3}{|c|}{ Maximum } & \multicolumn{3}{|c|}{ Minimum } & \multicolumn{3}{|c|}{ Maximum* } & \multicolumn{3}{|c|}{ Minimum* } \\
\hline & $\mathrm{kg} / \mathrm{kg}$ & Date & Hour & $\mathrm{kg} / \mathrm{kg}$ & Date & Hour & $\%$ & Date & Hour & $\%$ & Date & Hour \\
\hline E500 & 0.011713 & 20 -juil & 15 & 0.006908 & 20-déc & 20 & 100.00 & 14-nov & 5 & 54 & 04-oct & 24 \\
\hline E510 & 0.011716 & 20-juil & 15 & 0.006908 & 20-déc & 20 & 100.00 & 14-nov & 5 & 54 & 04-oct & 23 \\
\hline E520 & 0.007566 & 20-juil & 15 & 0.006525 & 27-nov & 23 & 95.00 & 20-déc & 17 & 61 & 27-nov & 22 \\
\hline E522 & 0.009398 & 20-juil & 15 & 0.006908 & 20-déc & 20 & 100.00 & 15-déc & 1 & 60 & 04-oct & 23 \\
\hline E525 & 0.017626 & 20-juil & 15 & 0.006909 & 20-déc & 20 & 100.00 & 11-nov & 23 & 44 & 04-mai & 4 \\
\hline E530 & 0.005491 & 01-avr & 1 & 0.005454 & $01-n o v$ & 21 & 79.00 & 20-déc & 8 & 28 & 01-avr & 10 \\
\hline E540 & 0.003256 & 01-avr & 1 & 0.003253 & 29 -avr & 23 & 47.00 & 20-déc & 6 & 31 & 01-avr & 1 \\
\hline E545 & 0.006689 & 01-avr & 1 & 0.006685 & 20-juil & 15 & 97.00 & 20-déc & 4 & 19 & 01-avr & 10 \\
\hline
\end{tabular}




\section{Program name (please include version number}

CODYRUN

Your name, organisation, and country

Thierry MARA, Eric FOCK, François GARDE and Harry BOYER

Laboratory of Industrial Engineering, University of La Reunion, FRANCE

\section{Program status}

\begin{tabular}{|l|l|}
\hline & Public domain \\
\hline & Commercial \\
\hline $\mathbf{X}$ & Research \\
\hline & Other (please specify) \\
\hline
\end{tabular}

\section{Solution method for unitary space cooling equipment}

\begin{tabular}{|c|l|}
\hline $\mathbf{X}$ & Overall Performance Maps \\
\hline & Individual Component Models \\
\hline & Constant Performance (no possible variation with entering or ambient conditions) \\
\hline $\mathbf{a}$ & Other: First order model for dynamic modeling and performance mapping for steady-state modeling \\
\hline
\end{tabular}

\section{Interaction between loads and systems calculations}

\begin{tabular}{|l|l|}
\hline $\mathbf{X}$ & Both are calculated during the same time step \\
\hline & $\begin{array}{l}\text { First, loads are calculated for the entire simulation period, then equipment performance is calculated } \\
\text { separately }\end{array}$ \\
\hline & Other (please specify) \\
\hline
\end{tabular}

\section{Time step}

$\mathbf{X}$ Fixed within code: the same as the meteorological data sampling interval

User-specified (please specify time step)

Other (please specify)

\section{Timing convention for meteorological data: sampling interval}

\begin{tabular}{|l|l|}
\hline $\mathbf{X}$ & Fixed within code: it is fixed in the meteorological data file \\
\hline & User-specified \\
\hline
\end{tabular}

\section{Timing convention for meteorological data: period covered by first record}

$\mathbf{X}$ Fixed within code (please specify period or time which meteorological record covers): 0:00-1:00 User-specified

\section{Meteorological data reconstitution scheme}

\begin{tabular}{|l|l|}
\hline $\mathbf{X}$ & Climate assumed stepwise constant over sampling interval \\
\hline & Linear interpolation used over climate sampling interval \\
\hline & Other (please specify) \\
\hline
\end{tabular}




\section{Output timing conventions}

Produces spot predictions at the end of each time step

Produces spot output at end of each hour

$\mathbf{X}$ Produces average outputs for each hour (please specify period to which value relates): same as time step

\section{Treatment of zone air}

$\mathbf{X}$ Single temperature (i.e., good mixing assumed)

Stratified model

Simplified distribution model

Full CFD model

Other (please specify)

\section{Zone air initial conditions}

$\mathbf{X}$ Same as outside air

a Other (please specify): user specified

\section{Internal gains output characteristics}

\begin{tabular}{|l|l|}
\hline & Purely convective \\
\hline & Radiative/Convective split fixed within code \\
\hline $\mathbf{X}$ & Radiative/Convective split specified by user \\
\hline & Detailed modeling of source output \\
\hline
\end{tabular}

\section{Mechanical systems output characteristics}

X $\quad$ Purely convective

Radiative/Convective split fixed within code

Radiative/Convective split specified by user

Detailed modeling of source output

\section{Control temperature}

\begin{tabular}{|l|l|}
\hline $\mathbf{X}$ & Air temperature \\
\hline & Combination of air and radiant temperatures fixed within the code \\
\hline & User-specified combination of air and radiant temperatures \\
\hline & User-specified construction surface temperatures \\
\hline & User-specified temperatures within construction \\
\hline & Other (please specify) \\
\hline
\end{tabular}




\section{Control properties}

\begin{tabular}{|l|l|}
\hline & Ideal control as specified in the user's manual \\
\hline $\mathbf{a}$ & On/Off thermostat control \\
\hline $\mathbf{X}$ & $\begin{array}{l}\text { On/Off thermostat control with hysteresis: and a first order model. The hysteresis control band was fixed to } \\
+-0.05^{\circ} \mathrm{C} \text { and the time constant to } 0.8 \mathrm{sec} \text { so that } \mathrm{Cd}=0.229(\mathrm{CDF}=1-\mathrm{Cd}(1-\mathrm{PLR})) .\end{array}$ \\
\hline & On/Off thermostat control with minimum equipment on and/or off durations \\
\hline & Proportional control \\
\hline & More comprehensive controls (please specify) \\
\hline
\end{tabular}

\section{Performance Map: characteristics}

\begin{tabular}{|l|l|}
\hline $\mathbf{a}$ & Default curves \\
\hline $\mathbf{X}$ & Custom curve fitting \\
\hline & Detailed mapping not available \\
\hline & Other (please specify) \\
\hline
\end{tabular}

\section{Performance Map: independent variables}

\begin{tabular}{|l|l|}
\hline $\mathbf{X}$ & Entering Dry-Bulb Temperature \\
\hline $\mathbf{X}$ & Entering Wet-Bulb Temperature \\
\hline $\mathbf{X}$ & Outdoor Dry-Bulb Temperature \\
\hline & Part-Load Ratio \\
\hline & Indoor Fan Airflow Rate \\
\hline & Other (please specify) \\
\hline
\end{tabular}

\section{Performance Map: dependent variables}

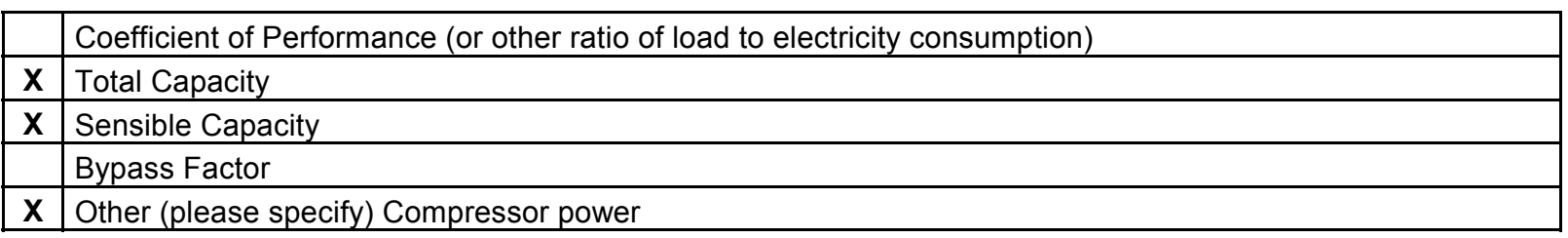

\section{Performance Map: available curve fit techniques}

\begin{tabular}{|l|l|}
\hline & Linear, f(one independent variable) \\
\hline & Quadratic, f(one independent variable) \\
\hline & Cubic, f(one independent variable) \\
\hline & Bi-Linear, f(two independent variables) \\
\hline & Bi-Quadratic, f(two independent variables) \\
\hline $\mathbf{X}$ & Other (please specify) Non Linear: neural networks or multivariate polynomial \\
\hline
\end{tabular}




\section{Performance Map: extrapolation limits}

\begin{tabular}{|l|l|}
\hline & Limits independent variables \\
\hline & Limits dependent variables \\
\hline $\mathbf{X}$ & No extrapolation limits \\
\hline & Extrapolation not allowed \\
\hline & Other (please specify) \\
\hline
\end{tabular}

\section{Cooling coil and supply air conditions model}

Supply air temperature = apparatus dew point (ADP); supply air humidity ratio = humidity ratio of saturated air at ADP

Bypass factor model using listed ADP data

Bypass factor model with ADP calculated from extending condition line

Fan heat included

X More comprehensive model: only the capacities (sensible and latent) supplied by the system are considered.

\section{Disaggregation of fans' electricity use directly in the simulation and output}

\begin{tabular}{|l|l|}
\hline & Indoor fan only \\
\hline & Outdoor fan only \\
\hline $\mathbf{X}$ & Both indoor and outdoor fans disaggregated in the output \\
\hline & None - disaggregation of fan outputs with separate calculations by the user \\
\hline
\end{tabular}

\section{Economizer settings available (for E400 series)}

Temperature, outdoor dry-bulb temperature versus return air temperature (E400, E410)

Temperature, outdoor dry-bulb temperature high limit setting (E420)

Enthalpy, outdoor air enthalpy versus return air enthalpy (E430)

Enthalpy, outdoor air enthalpy high limit setting (E440)

Compressor Lockout (E410)

$\mathbf{X}$ Other (please specify) no object 


\title{
Appendix II-C
}

\section{TRNSYS-TUD Modeler Report for HVAC BESTEST E300-545}

\author{
by \\ Gottfried Knabe and Huu-Thoi Le \\ Institute for Thermodynamics and Technical Building Services \\ Dresden University of Technology \\ February 2003
}

\section{Introduction}

TRNSYS (A Transient System Simulation Program) [1] is a program for solar simulation written by the University of Wisconsin, USA. Since applying for a license of this program the Dresden University of Technology has changed the program codes, especially the building module TYPE 56. Additional modules have also been written, therefore, the TUD has developed a new program for the simulation of heating systems and air conditioning. It is designated TRNSYS-TUD. Physical and empirical models for each component of a system are available at the TU Dresden. The loads and the system can be simultaneously calculated. Since program code has been changed by the TU Dresden it is now possible to run the simulation with a time step of a thousandth of an hour.

It is necessary to prepare a dek-file for running a simulation with TRNSYS-TUD. This dek-file contains all information the TRNSYS-TUD needs to run a particular simulation; that is, the time step, run time, tolerances, user specified equations, declared types, etc. Therefore, this file is named input-file or management-file for the TRNSYS simulation. As mentioned above, the TRNSYS-TUD consists of a main program and several modules (types). A type is represented as a component of the HVAC system with defined inputs and outputs as well as parameters. A type describes the behaviors of a certain component of the HVAC system.

The IEA SHC Task 22 offers different methods to test the whole program system for energy building simulation. There are analytical validation, comparison test and empirical verification. Therefore, the Task 22 is a good opportunity to improve the modules available in the program package TRNSYS-TUD. This report is to document the HVAC BESTEST [2] made by TU Dresden.

\section{Modeling}

In order to run a simulation with TRNSYS-TUD the building as well as the HVAC system has to be modeled. As known, the more precise the modeling the more simulation results are reached in good agreement with precise measurements. Consequently, the modeling is made under consideration of the behaviors at full load as well as at part-load operation and the possible frame conditions. As shown in [3] a HVAC system operates for over $80 \%$ of the total operating hours in part-load field. Therefore, the modeling of a system with only the characteristic curves given by manufacturers at full-load operation is not precise enough to determine the energy consumptions and to diagnose the zone parameters (temperature, humidity, etc.). An analysis of the system behavior at part-load operation is always necessary to fulfill the requirements mentioned above [3]. 
In the current HVAC BESTEST [2] there is a coupled simulation of a zone (building) with a HVAC split system. In contrast to the HVAC BESTEST E100 series [4] the system is tested now under real boundary conditions. That means the real building fabrics and the real weather data are used to test the ability of the whole system for energy building simulation. Therefore, the transient processes of the building envelope the thermal storages in the walls and in the zone air are also taken into consideration. The modeling of each component is described in detail as follows.

\subsection{Modeling: Building}

A detailed description of the building fabrics as well as the weather data are available in [2]. All this information (wall materials, heat transfer coefficients, thermal and moisture storages in the walls and in the zone air, etc.) is exactly taken into account to model the applied zone for running the HVAC BESTEST Task 22 cases E300-E545.

This model assumes that the zone air temperature is homogenous within the zone. In the program TRNSYS-TUD the CFD model is available. That makes it possible to evaluate the distribution of the zone air temperature. The reasons for not applying this CFD model are the long computing time and the dependence on the location of the supply air, etc.

\subsection{Modeling: HVAC Split System}

Compared to HVAC BESTEST cases E100-E200 the split system with higher capacity is here utilized for the cases E300-E545 because the cooling zone loads are larger now. Similar to the preparation for the E100 series $[5,6]$ the analysis of the split system behavior is carried out at first. For that the given measurements data from manufacturers at full-load operation [2] are applied. As shown in [5, 6], the different behavior of the split system at wet-coil conditions and at dry-coil conditions are taken into account as well. 


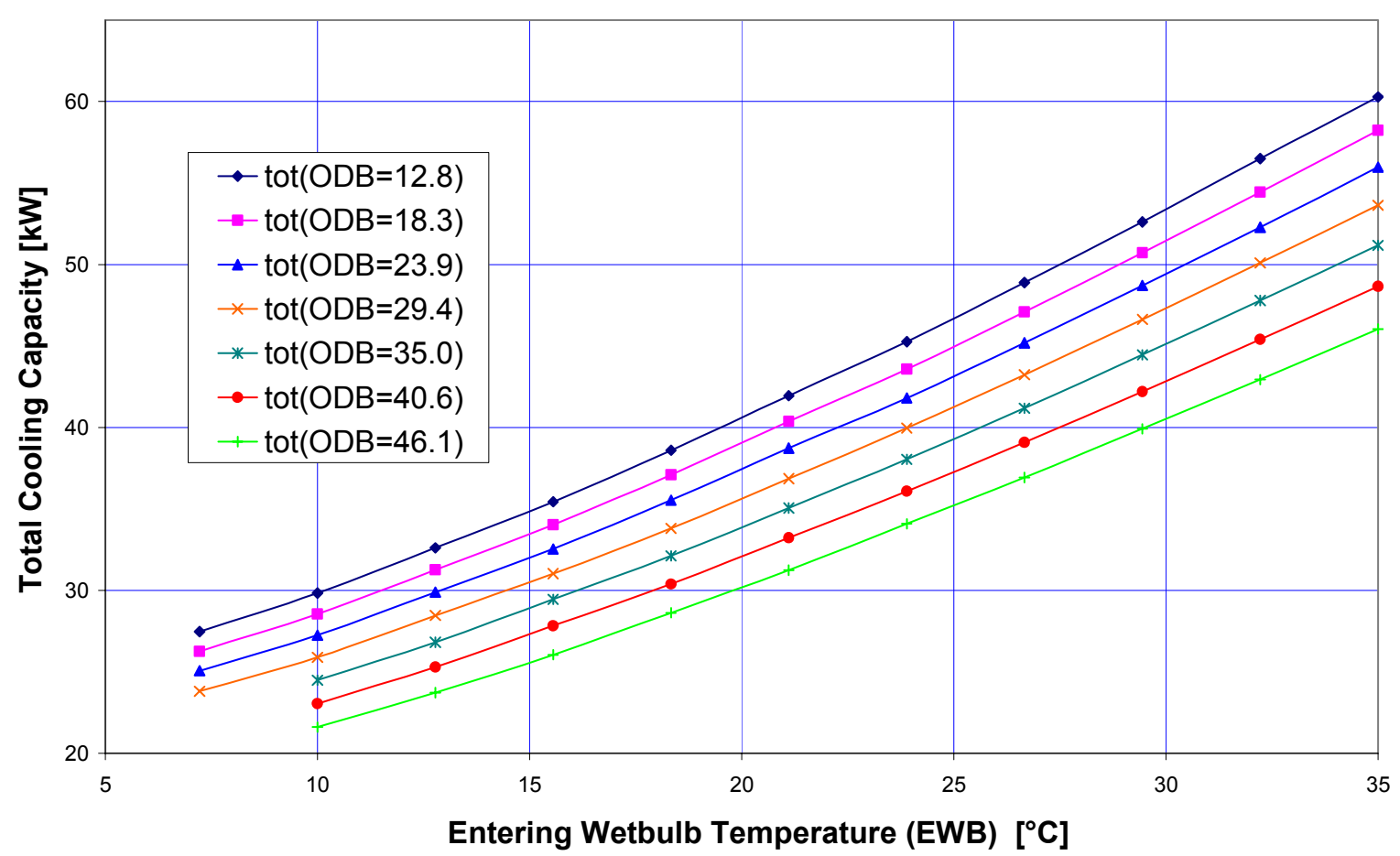

Figure 2C-1. Total cooling capacity at full-load operation with different ODB as a function of EWB

Figure 2C-1 shows the total cooling capacity of the applied split system at different ODB as a function of EWB. Compared to HVAC BESTEST series E100 the characteristics curves of the total cooling capacity do not behave linearly to the entering wet-bulb temperature (EWB) but quadratically to the EWB. The characteristics curves for the sensible cooling capacity are shown in Figure $2 \mathrm{C}-2$. There are similar behaviors to the BESTEST cases E100-E200. In Figure 2C-3 the system behaviors at dry-coil and at wet -coil condition are represented for $\mathrm{ODB}=35^{\circ} \mathrm{C}$. The characteristic curves of the sensible and total cooling capacity crosses in a point that is named transition cooling point (TCP). On the right of this TCP $(\mathrm{EWB}>\mathrm{TCP})$ the split system operates with wet coil. That means that the latent cooling capacity is higher than zero and a part of the water content of the zone air is taken away. Otherwise, the dry-coil conditions will occur. In this case the total cooling capacity as well as the sensible cooling capacity are constant and independent of the EWB. Their values are equal to the values at the TCP. 


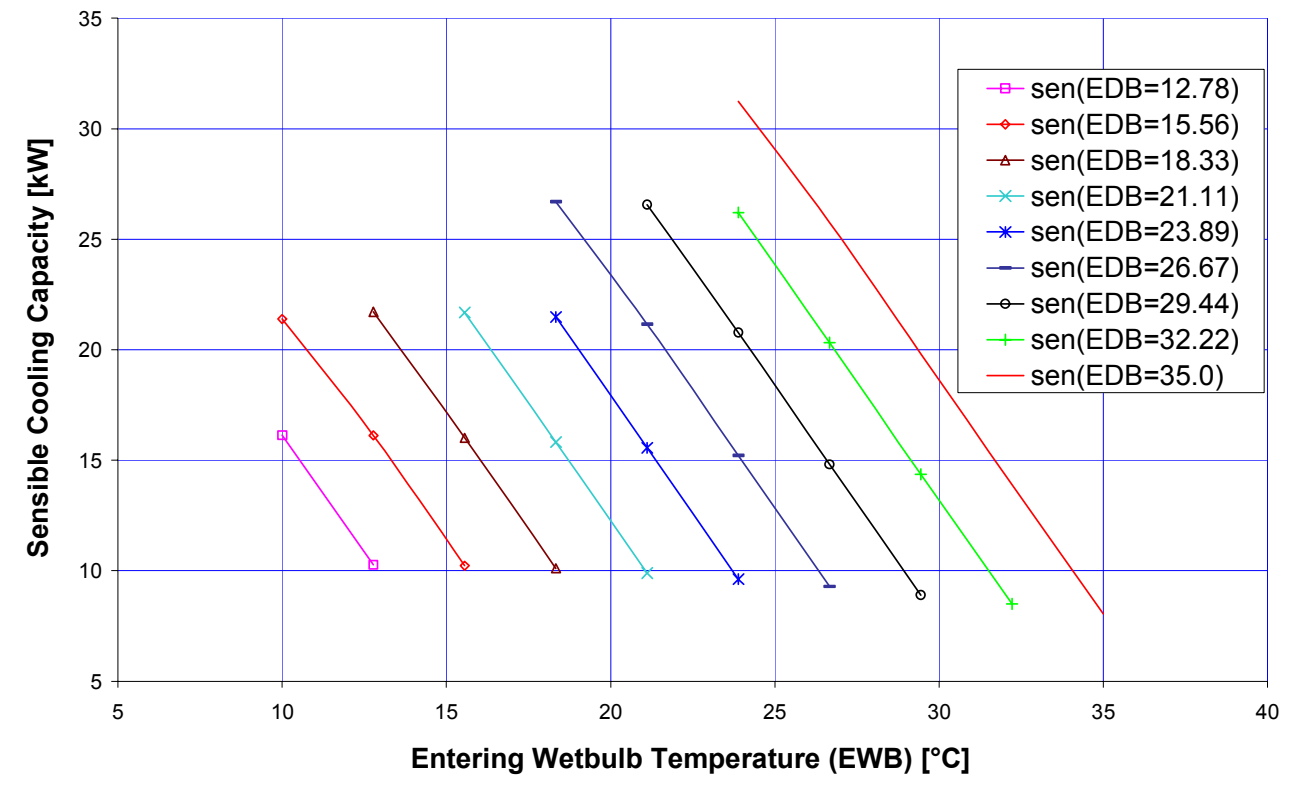

Figure 2C-2. Sensible cooling capacity at full-load operation with different EDB; $O D B=46.1^{\circ} \mathrm{C}$ as a function of EWB

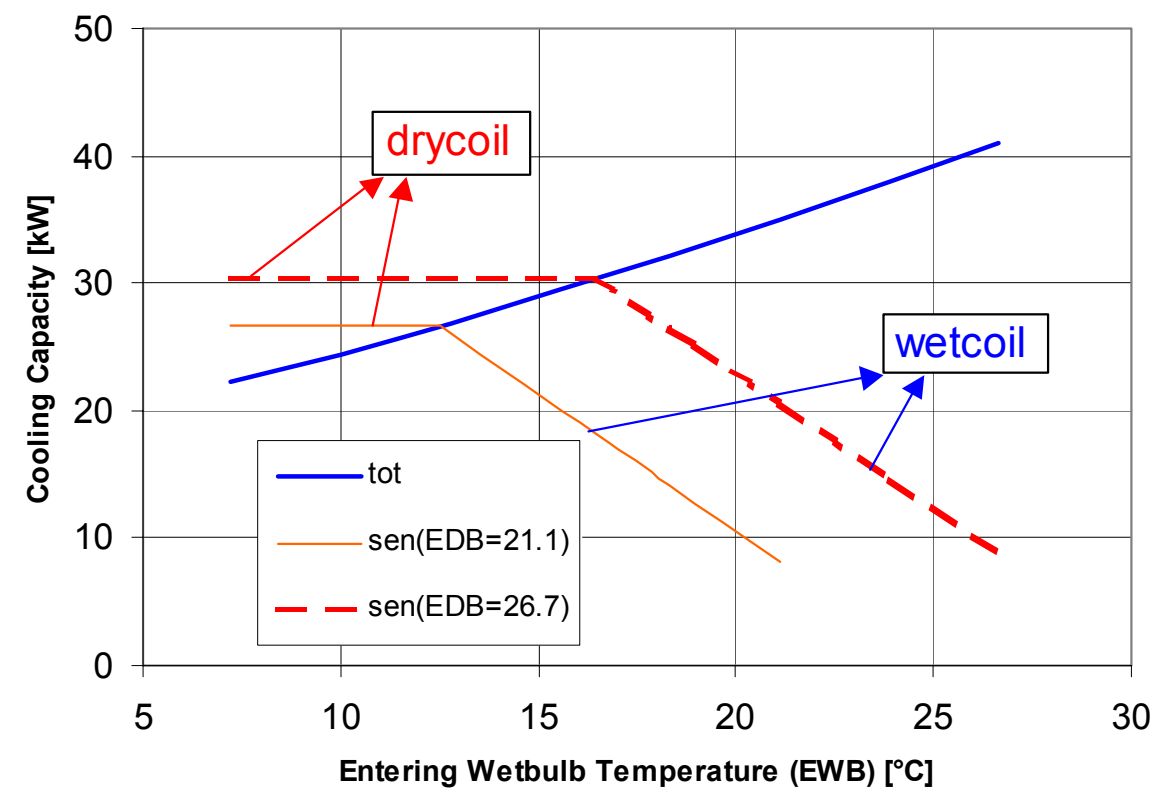

Figure 2C-3. Dry-coil and wet-coil behavior of the used split system at full-load operation with different $\mathrm{EDB}\left(21.1^{\circ} \mathrm{C} ; 26.7^{\circ} \mathrm{C}\right)$ and $O D B=35^{\circ} \mathrm{C}$ as a function of EWB 
As shown in Figures $2 \mathrm{C}-1$ to $2 \mathrm{C}-3$, the characteristics curves are approximated with the equations shown below.

$$
\begin{aligned}
& \dot{\mathrm{Q}}_{\mathrm{N}, \text { tot }}=\left(\mathrm{A}_{1} \cdot \mathrm{ODB}+\mathrm{A}_{2}\right)\left(\mathrm{A}_{3} \cdot \mathrm{EWB}^{2}+\mathrm{A}_{4} \cdot \mathrm{EWB}+\mathrm{A}_{5}\right)+\left(\mathrm{A}_{6} \cdot \mathrm{ODB}+\mathrm{A}_{7}\right) \\
& \dot{\mathrm{Q}}_{\mathrm{N}, \text { sen }}=\left(\mathrm{B}_{1} \cdot \mathrm{ODB}+\mathrm{B}_{2} \cdot \mathrm{EDB}+\mathrm{B}_{3}\right) \cdot \mathrm{EWB}+\left(\mathrm{B}_{4} \cdot \mathrm{ODB}+\mathrm{B}_{5} \cdot \mathrm{EDB}+\mathrm{B}_{6}\right) \\
& \dot{\mathrm{Q}}_{\mathrm{N}, \text { lat }}=\dot{\mathrm{Q}}_{\mathrm{N}, \text { tot }}-\dot{\mathrm{Q}}_{\mathrm{N}, \text { sen }}
\end{aligned}
$$

The behavior of the compressor power is similar to the one of the total cooling capacity. Therefore, one can calculate the compressor power with the following equation.

$$
\mathrm{P}_{\text {comp }}=\left(\mathrm{C}_{1} \cdot \mathrm{ODB}+\mathrm{C}_{2}\right)\left(\mathrm{C}_{3} \cdot \mathrm{EWB}^{2}+\mathrm{C}_{4} \cdot \mathrm{EWB}+\mathrm{C}_{5}\right)+\left(\mathrm{C}_{6} \cdot \mathrm{ODB}+\mathrm{C}_{7}\right)
$$

To control the cooling capacity to maintain the temperature set point, a two-point-controller is taken into operation. At part-load operation an extent of run time of the compressor as well as the outdoor fan is required. This behavior is illustrated in detail in the test description [2]. The CDF factor is applied for these components to calculate the energy consumptions. This behavior is not valid for the indoor fan in case this fan runs continuously.

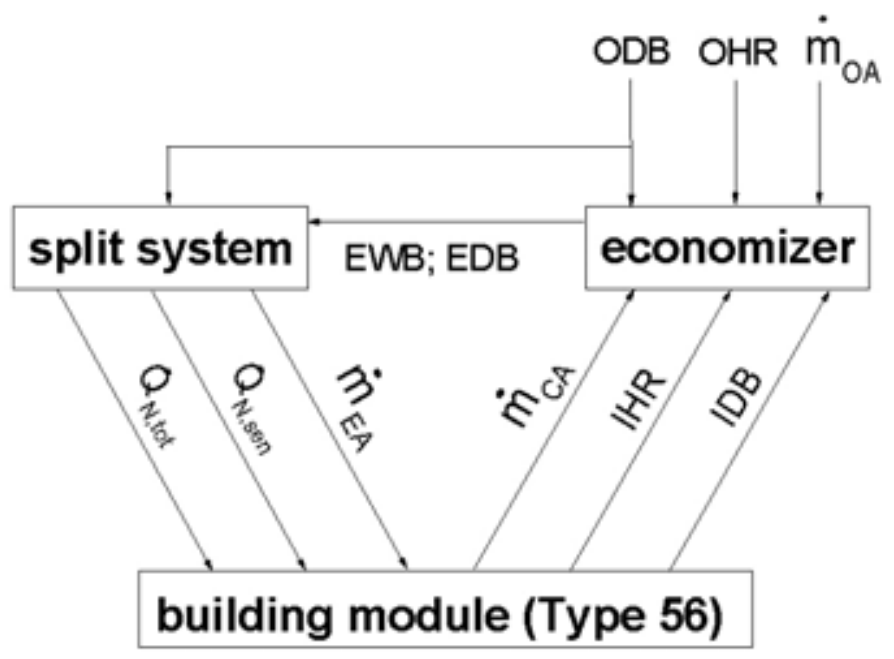

Figure 2C-4: Coupling of the split system with the building module (Type 56) in TRNSYS-TUD

\subsection{Coupling of building with HVAC split system}

At first, Figure 2C-4 shows the scheme how the split system is coupled into the program TRNSYS-TUD. The economizer is applied. The economizer is controlled by a given strategy to fulfill the hygienic requirements as well as the energy saving during the operating time at low outdoor dry-bulb temperatures. The mixed air conditions (entering air) are determined by the zone air and the outdoor air as well as by their mass flow rates. Depending on the ODB, EDB, and EWB, the split system supplies its cooling capacities to the building module (Type 56). In Type 56, heat and moisture are balanced. Of course, this Type 56 considers the heat and moisture transfers through the walls and the windows, the radiations of the sun, the infiltration, etc. It results in the zone air conditions that are used to calculate the 
entering air by the economizer. Therefore, iteration is necessary for the calculating procedures in Figure $2 \mathrm{C}-4$. As a result, this calculation takes a long time. To avoid this iteration, the results of the previous time step (zone air conditions) are introduced into the calculation for the current time step. This is equivalent to a digital controller used for the control of HVAC systems in practice. The time step chosen for the simulation should be very short to reduce the deviation caused by this consideration.

To determine the cooling capacities, the characteristic curves at full-load operation described in Eq. 1 to Eq. 3 are used. As mentioned above, the total cooling capacity consists of a sensible and a latent part. The sensible cooling capacity is responsible for the maintenance of the set point temperature, whereas part of the water content of the zone air condenses due to the latent cooling capacity. After a short run time, the steady-state operating point adjusts and the latent cooling capacity exactly matches the latent cooling zone loads.

Because of a direct input of latent cooling capacity or latent cooling zone loads into the program TRNSYS-TUD is not allowed, so a conversion from latent capacity into mass flow rate of water vapor needs to be done. This input is available in this program. The vapor rate is calculated with the following equation.

$$
\dot{\mathrm{m}}_{\text {vapour }}=\frac{\dot{\mathrm{Q}}_{\text {lat }}}{2501+1.86 \cdot \mathrm{EDB}}
$$

\subsection{Control Strategy}

The current series E300 of BESTEST consists of a total of 20 cases with different frame conditions to test the whole program system. The control strategy varies from case to case as described in [2]. In addition to the description in [2], a real controller is adapted into operation in the program TRNSYSTUD to model the system behavior as realistically as possible. As shown in [6], the differential gap has a large influence on the state parameters, especially at small part-load ratio. To avoid this effect and to enable a comparison of TRNSYS-TUD results with other programs, the differential gap is set to zero.

On the one hand, there is a simulation period of 1 year for the test series E300. That means that the run time and the results data are essentially higher compared to the test series E100. On the other hand, as mentioned above, the time step chosen for the simulation should be short to reduce the deviation due to the calculation algorithm described above. As a compromise for that, a time step of 90 seconds is utilized for all simulation cases in the test series.

\section{Results}

Experiences from the HVAC BESTEST series E100 show that the careful preparations for the simulation - handling of the frame conditions, the input files, the output files, and especially the dekfile - are much recommended. In case errors occur in the simulation or remarkable disagreements among the simulation programs are obtained by comparison to each other or big differences between the simulation results and analytical solution appear, the simulation program used has to be checked from one component to the others until the errors are found. The whole procedure would take a lot of time. Due to very careful preparations and some errors that were already discovered in the program TRNSYSTUD in the test series E100, no errors have been found in this round.

It should be noted in the test series E300 that first the program TRNSYS-TUD gives simulation results in files. Because the result files are very large and contain a lot of values due to applying of the real controller with a time step of 90 seconds, a manual compiling of these results would take a very long 
time. Consequently, a module was written in Excel to determine the values required in [2] from the result files of TRNSYS-TUD. Unfortunately, the prior (untested) version of this module in Excel containing an error was used for the determination of updated results in the meantime. Therefore, these updated results contained an error. This error is fixed now.

Further, the compiled results presented in the 15th meeting of the Task 22 showed a difference between annual $\mathrm{COP}_{2}$ and seasonal $\mathrm{COP}_{2}$. The pure definition of $\mathrm{COP}_{2}$ is available in the test description [2]. The annual $\mathrm{COP}_{2}$ is calculated as arithmetic average value of the hourly $\mathrm{COP}_{2}$ over the year, whereas the seasonal $\mathrm{COP}_{2}$ is the ratio of the sum of the hourly total cooling capacity in a season to the total energy consumption of the given season.

In the end, the results were submitted to the project coordinator to be compared with other simulation programs. It shows very good agreement with other simulation programs.

\section{Conclusion}

In the HVAC BESTEST a model of the split system was developed and integrated in the program package TRNSYS-TUD. The BESTEST series E100 and E300 enable testing of the model of the split system applied as well as other models of the whole program for the energy building simulation.

In the cases of the first test series E100 some errors were found in the program TRNSYS-TUD, which have now been fixed. In the second series, the program shows good agreements with other programs tested.

The HVAC BESTEST is very useful to improve the program package TRNSYS-TUD.

\section{Nomenclature}

CDF Coefficient of Performance Degradation Factor

CFD Computing Fluid Dynamics

COP Coefficient of Performance

EDB Entering Dry-Bulb Temperature

EWB Entering Wet-Bulb Temperature

TCP Transition Cooling Point

IDB Indoor Dry-Bulb Temperature

IHR Indoor Humidity Ratio

ODB Outdoor Dry-Bulb Temperature

OHR Outdoor Humidity Ratio

$\dot{\mathrm{Q}}_{\mathrm{N}, \text { lat }} \quad$ Latent Cooling Capacity

$\dot{\mathrm{Q}}_{\mathrm{N}, \text { sen }} \quad$ Sensible Cooling Capacity

$\dot{\mathrm{Q}}_{\mathrm{N}, \text { tot }} \quad$ Total Cooling Capacity

$\mathrm{P}_{\text {comp }} \quad$ Compressor Power

$\dot{\mathrm{m}}_{\mathrm{CA}} \quad$ Mass Flow Rate of Recirculation Air

$\dot{\mathrm{m}}_{\mathrm{EA}} \quad$ Mass Flow Rate of Entering Air

$\dot{\mathrm{m}}_{\mathrm{OA}} \quad$ Mass Flow Rate of Outside Air

$\dot{\mathrm{m}}_{\text {vapor }}$ Mass Flow Rate of Vapor 


\section{References}

[1] TRNSYS: A Transient System Simulation Program, Solar Energy Laboratory, University of Wisconsin, Madison, USA 1983; Internet: http://sel.me.wisc.edu/trnsys/default.html

[2] Neymark, J.; Judkoff, R.: International Energy Agency Building Energy Simulation Test and Diagnostic Method for Heating, Ventilation and Air-Conditioning Equipment Models (HVAC BESTEST), Volume 2: Cases E300-E545, National Renewable Energy Laboratory, Golden, Colorado, USA, March 2002.

[3] Steimle, F.: Integrierte Planung - Vorraussetzung für gute Klimatechnik, KI Luft- und Kältetechnik, February 2003, S. 47.

[4] Neymark, J.; Judkoff, R.: International Energy Agency Building Energy Simulation Test and Diagnostic Method for Heating, Ventilation and Air-Conditioning Equipment Models (HVAC

BESTEST), Volume 1: Cases E100-E200, National Renewable Energy Laboratory, Golden, Colorado, USA, November 2000.

[5] Le, H.-T.; Knabe, G.: HVAC BESTEST Modeler Report analytical solutions for cases E100-E200, Dresden, September 2000.

[6] Le, H.-T.; Knabe, G.: HVAC BESTEST Modeler Report simulation model with TRNSYS TUD for cases E100-E200, Dresden, September 2000. 


\section{Program name (please include version number) \\ TRNSYS-TUD \\ Your name, organisation, and country \\ Gottfried Knabe, Huu-Thoi Le, Dresden University of Technology, Germany}

TRNSYS-TUD Pro-Forma Model description is included with Volume 1, Appendix III-B. The information below was not included previously.

\section{Economizer settings available (for E400 series)}

\begin{tabular}{|l|l}
$\mathrm{x}$ & Temperature, outdoor dry-bulb temperature versus return air temperature $(\mathrm{E} 400, \mathrm{E} 410)$ \\
\hline $\mathrm{x}$ &
\end{tabular}

$\mathrm{x}$ Temperature, outdoor dry-bulb temperature high limit setting (E420)

$\mathrm{x} \quad$ Enthalpy, outdoor air enthalpy versus return air enthalpy (E430)

$\mathrm{x}$ Enthalpy, outdoor air enthalpy high limit setting (E440)

$\mathrm{x}$ Compressor Lockout (E410)

Other (please specify) 


\title{
Appendix II-D
}

\section{APPLICATION OF IEA COOLING TEST CASES SERIES 300-500 TO THE HOT3000 BUILDING ENERGY SIMULATION COMPUTER PROGRAM}

\author{
Prepared by \\ Kamel Haddad, Ph.D. \\ Building Energy Simulation Researcher \\ SIMULATION GROUP \\ CANMET ENERGY TECHNOLOGY CENTRE \\ OTTAWA, ONTARIO K1A 0E4
}

\author{
September 9, 2003
}

\section{Summary}

The IEA Cooling Test Cases E300-E545 are applied to the HOT3000 building energy simulation program. The zone description is modified from the test specifications so that the boundary condition on the outside of the building envelope is adiabatic. This is needed to overcome convergence issues associated with using low thermal mass. The HOT3000 cooling model is capable of handling all the situations described in the test specification, which include effects of outdoor air and economizer control. One of the limitations with HOT3000 is that only one day type can be defined for internal gains and infiltration. To overcome this, these two simulation inputs are read for each time step from an ASCII file.

The simulation results from HOT3000 agree well with those from other programs. The largest differences are observed in the predicted values of zone air temperature, humidity ratios, and relative humidity for cases E500-E545. This can be attributed to the fact that in the HOT3000 simulations the zone is modeled with adiabatic boundary conditions. Other differences between the HOT3000 results and those from the other programs are due to the fact that the current model performs a successive rather than a simultaneous solution of the loads and HVAC systems.

Initially it is found that there is a discrepancy between the relative difference between the results for case E330 and cases E320 and E340 predicted by HOT3000 and the other simulation programs included with the kit. A modification is made to the way the effect of outdoor air is accounted for in the HOT3000 model and a better agreement is obtained. The simulation results also indicate the need to upgrade the HOT3000 model so that a simultaneous solution of the loads and HVAC domains is performed instead of the successive solution method currently employed.

\section{Modeling Assumptions}

\section{Description of HOT3000 Air-Conditioning Model}

The model is based on the use of performance curves to predict the energy consumption of the equipment. One of the major inputs to the model is the space sensible load, which is predicted by the HOT3000 load module. When the indoor circulation fan is in the continuous mode, the fan power is 
included as part of the sensible internal gains to the space. In the case where the fan is in the auto or intermittent mode, its effect is accounted for by reducing the capacity of the equipment when computing the part-load ratio for the time step. After the sensible loads of the zones served by the cooling equipment are predicted by the HOT3000 load module, the air-conditioning model subroutine is called and the following main steps are then performed:

- If economizer control exists, determine proper outdoor airflow and updated sensible cooling load to be supplied by compressor-based system.

- Determine cooling coil inlet air conditions. This accounts for any outdoor air effects.

- For the inlet dry-bulb temperature, determine the maximum wet-bulb temperature for dry-coil conditions.

- Set the gross capacity and the sensible heat ratio of the equipment based on the inlet air conditions to the coil and the maximum wet-bulb temperature for dry-coil operation.

- Determine equipment part-load ratio and part-load factor. The space latent load is determined in the process.

- Determine coefficient of performance.

- Predict energy consumption of compressor, outdoor fan, and indoor fan.

- Set airflow and moisture content to include in the zone moisture balance.

- Determine conductance of outdoor air to include as part of space infiltration.

- Set proper sensible capacity for ideal temperature controller.

In the last step listed above, the indoor and outdoor conditions for the current time step are used to find the sensible cooling capacity of the air-conditioner. This sensible cooling capacity is set equal to the controller capacity for the next time step. In other words, the sensible loads and conditions of the space for a certain time step are determined using a controller capacity from the previous time step. The model currently does not include an iterative procedure within each time step, to update the controller capacity once the current conditions within the space are found, until convergence of the solution.

\section{Weather Data}

The TMY2 weather files provided with the test suite are used to generate binary weather files for HOT3000. Hourly weather data required for HOT3000 are:

- Outdoor dry-bulb temperature

- Direct normal radiation

- Diffuse solar radiation on horizontal surface

- Wind speed

- Wind direction

- Relative humidity.

All of these variables are given directly in the TMY2 weather files. 


\section{Building Zone Description}

The building zone description is as specified in section 1.3.1.3 [Part I] except for the material specifications in Table 1-3a [Part I]. Initially the material specifications in the table are used, but this results in a convergence problem due to the very low specific heat, density, and conductivity specified when the envelope elements are declared as exposed to ambient conditions. To resolve the convergence problems, an adiabatic boundary condition for the envelope is used instead. In this case it is possible to specify a very low material density and specific heat to eliminate any thermal mass effects. This modification will impact the predicted values of temperature, relative humidity, and humidity ratio when the cooling load within the zone is zero (absence of internal gains) for an extended period of time, as is the case for test cases E500-E545. For these cases, an adiabatic boundary condition will result in constant zone air conditions in the absence of sensible and latent gains to the space.

\section{Internal Gains and Infiltration}

One of the limitations of HOT3000 for specifying sensible gains, latent gains, and infiltration is that the user is able to specify only one day type for the whole simulation. Given this limitation, the time step sensible gains, latent gains, and infiltration are stored in an ASCII file and then read during the simulation. This ASCII file contained information for the full year as well as the start-up period of the month of December.

\section{Equipment Performance Curves}

The HOT3000 cooling model uses correlations for the gross equipment capacity and the power input to the compressor. The equipment data in Table 1-7b [Part I] of the report are used to develop the correlations used.

The gross cooling capacity of the air-conditioner under wet conditions is correlated to the outdoor drybulb temperature and the coil entering wet-bulb temperature:

$$
\begin{aligned}
& \text { Total Cooling Capacity }(\mathrm{kW})=a 1+a 2 \times T o d b+a 3 \times T o d b^{2}+a 4 \times T e w b+a 5 \times T e w b^{2}+ \\
& a 6 \times T o d b \times T e w b
\end{aligned}
$$

$\mathrm{a} 1=23.49707981$

$\mathrm{a} 2=-0.1076915531$

a3 $=-0.001612289548$

$\mathrm{a} 4=0.8052200912$

a5 $=0.008864708391$

$\mathrm{a} 6=-0.004824135037$

The power input to the compressor under wet conditions is also correlated to the outdoor dry-bulb temperature and the coil inlet wet-bulb temperature:

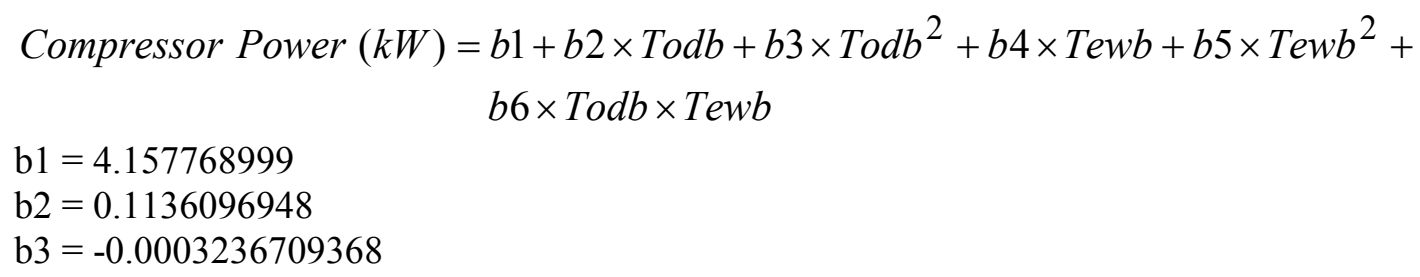


$\mathrm{b} 4=0.01115838853$

b5 $=0.002180347593$

b6 $=0.001799048516$

The HOT3000 cooling model includes a method for calculating the coil sensible heat ratio under wet conditions. Therefore the sensible capacity equipment data in Table 1-7b [Part I] are not used to generate the simulation results. The sensible heat ratio is determined based on the coil bypass factor at rating conditions. The model also includes a method for determining whether the coil is dry or wet. Given the entering dry-bulb temperature to the coil, the maximum coil inlet wet-bulb temperature associated with dry conditions is determined. If the actual inlet wet-bulb temperature to the coil is greater than this cutoff wet-bulb temperature, it is assumed the coil is wet; otherwise it is dry.

\section{Part-Load Performance}

The part-load performance is based on the equation given in the test specification:

$C D F=1-0.229 \times(1-P L R)$

This part-load factor is also used to find the energy consumption of the outdoor and indoor fan when used in the intermittent mode.

\section{Ideal Controller}

An ideal controller with no throttling range is used. The controller cools the space back to the set point temperature when air temperature inside the space rises above the set point. For cases E300-E360, the maximum sensible cooling capacity of the controller for the time step is set to the gross sensible cooling capacity of the equipment for the previous time step. In this case the fan power is included as part of the sensible internal gains to the space.

For cases E400-E440, when the air-conditioner and the economizer can operate together to meet the load, the maximum controller capacity is set to the gross sensible cooling capacity for the previous time step plus any sensible cooling capacity associated with the operation of the economizer. If the airconditioner and the economizer can not operate together to meet the load, then the controller maximum cooling capacity is set to the gross equipment sensible cooling capacity for the previous time step. Also in this case the fan power is included as part of the sensible internal gains to the space.

For cases E500-E545 the maximum sensible capacity of the controller is set to the sensible gross cooling capacity of the equipment for the previous time step minus the fan power. In this case the fan power is not included as an internal gain to the space, but its effect will show up in higher part-load ratios due to the lower equipment capacity.

\section{Effect of Indoor Circulation Fan}

When the indoor circulation fan is in continuous mode, it is specified as a sensible internal gain to the space. Its effect is then accounted for through the effect on the sensible cooling load of the space and an increased part-load ratio of the air-conditioner.

When the indoor circulation fan is in auto mode, the capacity of the equipment is degraded by the fan power. As a result, the predicted part-load ratio is higher due to the effect of the indoor fan. In this case the fan power is not included as internal gain to the space. 


\section{Start-up Simulation Period}

A start-up period of 31 days is used corresponding to the full month of December.

\section{Simulation of Infiltration and Outdoor Air Effects}

Given that HOT3000 does not allow for more than one day type of infiltration during the simulation, the conductance associated with infiltration for cases E320 and E340 is read from an ASCII file. For each time step, this conductance is set equal to the product of the outdoor air density, volume flow rate, and specific heat:

$C_{\mathrm{inf}}=\rho_{o a} \dot{V}_{o a} C p_{o a}$

This conductance is then automatically used in HOT3000 as part of the air-point energy balance.

HOT3000 performs a zone moisture balance for each time step. This moisture balance accounts for vapor addition or removal within the space due to infiltration and/or ventilation air, and the operation of any mechanical system such as an air conditioner. Any moisture generation within the space is also accounted for. In case there is control of the humidity level within the space, then the action of the controller is also modeled.

Initially, the sensible gain/loss from the introduction of outdoor air through the HVAC system is accounted for as part of the sensible internal gains of the space. In this case the sensible effect of outdoor air for the time step is treated like a sensible gain from lights or any other source of internal gain. The space air-point moisture balance is modified to include an extra moist air supply term at the actual exit air conditions from the coil. The model accounts for the effect of outdoor air on the inlet conditions to the coil. These inlet conditions are needed to predict the correct steady-state total capacity and COP of the air-conditioner. Using this approach and the previous approach for infiltration, the annual sums predicted for cases E320-E340 are shown in the following table:

Table 2D-1: HOT3000 Predictions of Annual Sums for Cases E320-E340 with Original Modeling Approach of Outdoor Air Effects

\begin{tabular}{|l|l|l|l|l|l|l|l|}
\hline \multirow{2}{*}{ Cases } & \multicolumn{6}{|l|}{ Energy Consumption (kWh) } & \multicolumn{3}{l|}{ Coil Loads (kWh) } \\
\cline { 2 - 8 } & Total & Compressor & $\begin{array}{l}\text { Compressor } \\
\text { Fan }\end{array}$ & $\begin{array}{l}\text { Indoor } \\
\text { Fan }\end{array}$ & Total & $\begin{array}{l}\text { Sensible } \\
\text { Load }\end{array}$ & $\begin{array}{l}\text { Latent } \\
\text { Load }\end{array}$ \\
\hline E320 & 39475 & 25928 & 2683 & 10880 & 97036 & 62720 & 34315 \\
\hline E330 & 38770 & 25338 & 2568 & 10880 & 94992 & 58428 & 36562 \\
\hline E340 & 39892 & 26349 & 2680 & 10880 & 99404 & 61509 & 37895 \\
\hline
\end{tabular}

These results indicate a decrease in the total and sensible evaporator coil loads for case E330 relative to cases E320 and E340. This is in contradiction to all the results from the other simulation programs, which predict an increase in the total and sensible coil loads for case E330 relative to E320 and E340. It can therefore be concluded that the original modeling approach in HOT3000 does not effectively predict the relative differences between simulation results when both outdoor air and infiltration are present. 
The initial approach for modeling the outdoor air through the HVAC system is then modified. Its effect on the air-point energy and moisture balance is now accounted for in the same way infiltration is accounted for within the HOT3000 loads module. In this case then outside air is included as another airflow into the conditioned space within the HOT3000 numerical solution scheme. The moisture removal at the cooling coil is still accounted for in the space moisture balance. When there is outdoor air through the HVAC system, it is accounted for to find the proper inlet conditions to the cooling coil. Infiltration also affects inlet conditions to the coil through its effect on the space energy and moisture balances. With this modification, the results for case E330 show the same kind of relative differences with cases E320 and E340 as that predicted by the other simulation programs as shown in the following table. This approach for treating outdoor air is then used to generate the results for all the test cases involving the introduction of outdoor air through the HVAC system.

Table 2D-2: HOT3000 Predictions of Annual Sums for Cases E320-E340 with Modified Modeling Approach of Outdoor Air Effects

\begin{tabular}{|l|l|l|l|l|l|l|l|}
\hline \multirow{3}{*}{ Cases } & \multicolumn{2}{|l|}{ Energy Consumption (kWh) } & \multicolumn{2}{l|}{ Coil Loads (kWh) } \\
\cline { 2 - 8 } & Total & Compressor & $\begin{array}{l}\text { Compressor } \\
\text { Fan }\end{array}$ & $\begin{array}{l}\text { Indoor } \\
\text { Fan }\end{array}$ & Total & $\begin{array}{l}\text { Sensible } \\
\text { Load }\end{array}$ & $\begin{array}{l}\text { Latent } \\
\text { Load }\end{array}$ \\
\hline E320 & 39457 & 25912 & 2681 & 10880 & 96957 & 62734 & 34224 \\
\hline E330 & 40330 & 26775 & 2693 & 10880 & 102008 & 61822 & 40186 \\
\hline E340 & 39947 & 26400 & 2684 & 10880 & 99753 & 61406 & 38346 \\
\hline
\end{tabular}

\section{Discussion of Remaining Differences in Results Between HOT3000 and Other Programs}

The following discussion addresses several differences between the HOT3000 results and those from the other programs that were highlighted (Neymark 2003).

For cases E310 and E520, the peak-hour total electricity consumption from HOT3000 is slightly lower than in the case of the other programs. For these two cases, there are instances when the total space sensible + latent loads for the time step are very close to the total equipment capacity. The HOT3000 model sets the maximum controller capacity for the time step equal to the sensible equipment capacity from the previous time step. The model does not include at this time an iterative process within the time step to update the controller capacity once new space conditions are found for the time step. It is then possible with the current model to have a sensible space load for the time step that is slightly higher than the present sensible equipment capacity. When this happens, the model reduces the sensible load and sets it equal to the equipment sensible capacity for the time step, which explains the lower peak consumptions observed in these cases.

For cases E400 and E440, the peak hourly consumption is slightly lower than for case E300. The other programs show the same peak hourly consumption for all these cases. For these two cases (E400 and E440) also, there are instances when the space sensible load is very close to the equipment sensible capacity. As explained in the previous paragraph this can cause slight reductions in the peak consumption.

The total sensible cooling load and peak hourly COP for case E330 are lower than those for case E320 for HOT3000, whereas for the other simulation programs they are higher. For many time steps the sensible cooling load for cases E320 and E330 are also very close to the sensible equipment capacity. Therefore, as described in the previous paragraph, for these cases also there are some minor uncertainties in the results associated with setting the present controller capacity equal to the sensible equipment 
capacity from the previous time step. This can be corrected by including an iterative process within each time step so that the controller capacity is updated after each solution of the space conditions until there is convergence. This model upgrade is planned for the future.

For cases E520 and E522 HOT3000 predicts higher peak zone temperatures and humidity ratios than most of the other programs. For these cases also, there are instances when the sensible space load is very close to the sensible equipment capacity. As mentioned previously, the maximum controller sensible capacity is not updated within the time step simulation to reflect the exact equipment capacity. As a result, the space temperature and humidity ratios can be higher than they actually are.

\section{Conclusions}

Overall, a good agreement is obtained between the simulation results from HOT3000 and the other computer programs included in the kit. The largest differences are observed in the predicted values of the temperature, humidity ratio, and relative humidity for cases E500-E545. This can be attributed to the use of adiabatic boundary conditions instead of the material construction given in Table 1-3a [Part I]. Cases E500-E545 have an extended period of time where there are no internal gains with the air temperature free floating inside the space. It is expected that the assumed adiabatic boundary conditions will have an impact on the predicted results for these cases. Other differences are found to be attributed to the fact that the HOT3000 model performs a successive solution of the loads and systems parts rather than a simultaneous solution.

The application of the test cases illustrated their algorithm validation benefits. In the present case, the relative differences between the predicted annual sums for case E330 relative to cases E320 and E340 were not in agreement with the predictions from the other simulation programs. Originally the sensible effect of the introduction of outdoor air through the HVAC system on the space load was accounted for by including it as part of the space sensible internal gains. This was then modified so that the sensible effect on the space load of the HVAC outdoor air was treated the same way as infiltration is treated in the HOT3000 numerical simulation scheme. In both cases though, the HOT3000 air-conditioning model accounts properly for the effect of condensation at the coil on the space moisture balance and for the effect of outdoor air on the inlet conditions to the coil. With this change, a better agreement was obtained with the other simulation programs for cases E320-E340.

The simulation results also show the need to upgrade the HOT3000 model so that the loads and HVAC domains are solved simultaneously. Currently, the space loads and conditions for a given time step are determined using a controller capacity equal to the sensible equipment capacity from the previous time step. The model can be improved by taking the space conditions for the time step to update the equipment sensible capacity and then determining the space loads and conditions again. Such an upgrade to the HOT3000 model is planned for the future.

\section{Reference}

Neymark, J. (2003). Email communication, 25 July 2003. 


\title{
Appendix II-E
}

\author{
DOE-2.1E \\ National Renewable Energy Laboratory/J. Neymark \& Associates \\ United States \\ June 17, 2004
}

\section{Introduction}

Software: DOE-2.1E ESTSC version 120 (Pre-release version; the output file designation indicating "version 2.1E-119" will be corrected by the code authors.)

Authoring Organization: Lawrence Berkeley National Laboratory, Los Alamos National Laboratory, and James J. Hirsch \& Associates

Authoring Country: USA

\section{Referencing of DOE-2.1E Modeler Report Included with Volume 1 of HVAC BESTEST and Input Decks Included with Accompanying CD}

HVAC BESTEST Volume 1 (Neymark and Judkoff 2002), Appendix III-A includes a modeler report for an earlier version of DOE-2.1E that was distributed by James J. Hirsch \& Associates rather than by the U.S. government's Energy Science and Technology Software Center (ESTSC). Because there are numerous similarities between the DOE-2.1E programs issued by these sources, only additions and modifications to the DOE-2.1E modeler report of HVAC BESTEST Volume 1 are included herein. The most complete source regarding current modeling details are the input decks included with the accompanying electronic media. Input decks for cases E300-E545 were developed from the input decks for cases E100-E200; they contain some commentary notes from that earlier work as well as comments added for running the current set of test cases.

\section{Modeling Methodology}

Recall from the Volume 1 modeler report that DOE2 assumes that total coil capacity and compressor power do not vary with EDB.

Extrapolation of curve fits can be limited in DOE2, using either a limit on the dependent variable results, or limit cap on ODB and EWB. The lower-end limit on EWB for versions 119 and earlier was hard-wired at $\mathrm{EWB}=60^{\circ} \mathrm{F}\left(15.6^{\circ} \mathrm{C}\right)$; that was changed (per the testing for this project) to $\mathrm{EWB}=\mathrm{ODB}-10\left({ }^{\circ} \mathrm{F}\right)$.

DOE-2.1E automatically identifies when a dry-coil condition has occurred and does calculations accordingly. $\mathrm{f}(\mathrm{EWB}, \mathrm{ODB})$ curve fit data used in DOE-2 are meant for wet coils only. Where possible $\mathrm{f}(\mathrm{T})$ data points assume $\mathrm{EDB}=80^{\circ} \mathrm{F}$; however, at lower $\mathrm{EWB}$, it was necessary to use data for $\mathrm{EDB}<80^{\circ} \mathrm{F}$ (and normalize those data to be consistent with $\mathrm{EDB}-80^{\circ} \mathrm{F}$ data) to give proper information to curve fit routines. The methodology is described in the input decks included with the accompanying CD; the spreadsheet used to implement this methodology (e300MAP-doe2-1102.XLS) is also included. For HVAC BESTEST volume 2 cases, $55^{\circ} \mathrm{F} \leq \mathrm{ODB} \leq 95^{\circ} \mathrm{F}$. Maximum ODB for New Orleans $\mathrm{TMY} 2$ is $95^{\circ} \mathrm{F}$, and by design of the cases system operation below $\mathrm{ODB}=55^{\circ} \mathrm{F}$ should not occur. Also $55^{\circ} \mathrm{F}<\mathrm{EWB}<75^{\circ} \mathrm{F}$ is the most common range 
of operation for the cases, although some operation occurs outside of that range, especially in specific cases with specified higher or lower EDB (set point).

The COIL-BF-FT curve fit was set so that bypass factor remains constant throughout the simulations. Bypass factor was allowed to vary as $\mathrm{f}(\mathrm{ODB}, \mathrm{EWB})$ in cases E100-E200.

\section{Modeling Assumptions}

Modeling assumptions that vary from those for cases E100-E200 are listed below. Fullest detail is included with the input decks.

- FLOOR-WEIGHT $=0.74\left(\mathrm{lb} / \mathrm{ft}^{2}\right)$ : This accounts for the mass of air in the zone. Custom weighting factors (set by entering " 0 ") will not run with zero-mass construction. $0.1 \mathrm{lb} / \mathrm{ft}^{2}$ - the lowest value allowed per the DOE-2 Reference Manual Version 2.1A (1981), p. III-51—was used in runs with ESTSC version 119 and initial runs with version 120 , and then corrected to $0.74 \mathrm{lb} / \mathrm{ft}^{2}$ to account for the mass of zone air in a second set of runs using version 120.

- MIN-SUPPLY-T = 35: lowest allowed value. Per test specification, Appendix D, $34.6<\mathrm{MST}<$ $35.1^{\circ} \mathrm{F}$; depending on air properties, $35.1^{\circ} \mathrm{F}$ may be a more precise value.

- $\quad$ SUPPLY-DELTA-T $=0.960$ (temperature difference from fan heat): This value is based on Qfan $=$ $\mathrm{m}(\mathrm{cp})($ deltaT), $1242 \mathrm{~W}, 4000 \mathrm{cfm}$. This value was calculated to match the assumptions of DOE-2 documented on p. IV.28 of the DOE-2 Engineers Manual (1982), and utilizes the following air properties: density $=0.075 \mathrm{lb} / \mathrm{ft}^{3}$ and $\mathrm{cp}=0.244 \mathrm{Btu} /\left(\mathrm{lb}^{\circ} \mathrm{F}\right)$ for humidity ratio $=0.01 \mathrm{lb} / \mathrm{lb}$.

- $\quad$ COOL-FT-MIN = 50 ( ${ }^{\circ} \mathrm{F}$; used for calculations defining lower limit temperatures for performance calculations using curve-fit data [e.g. as COOL-FT-MIN - 10], if not hard-wired elsewhere in the software): This value allows performance calculations down to $\mathrm{ODB}=50^{\circ} \mathrm{F}$ and $\mathrm{EWB}=40^{\circ} \mathrm{F}$ in ESTSC version 120; version 119 had hard-wired lower limit of $\mathrm{EWB}=60^{\circ} \mathrm{F}\left(15.6^{\circ} \mathrm{C}\right)$ for performance calculations.

- OUTDOOR-FAN-T $=24\left({ }^{\circ} \mathrm{F}\right)$ : limit below which fans do not run. The minimum hour ODB for New Orleans TMY2 annual weather data is $24^{\circ} \mathrm{F}$.

\section{Modeling Options}

\section{SYSTEM-TYPE: PSZ model}

A number of SYSTEM-TYPEs are possible and reasonable for modeling the HVAC BESTEST DX system, including RESYS2, RESYS, PSZ, and PTAC. Choice of system type affects default performance curves and features available with the system. Of these, according to a DOE-2 documentation supplement (James J. Hirsch \& Associates 1996), neither PTAC nor RESYS had the improved part-load (cycling) model for packaged systems incorporated (the improved model uses the COOL-CLOSS-FPLR curve rather than the COOL-EIR-FPLR curve). Either the PSZ or RESYS2 models could have worked since custom performance curves are applied. PSZ was chosen because the system used in the test cases is larger than what would normally be used in a single-family detached residence. 


\section{Modeling Difficulties}

COIL-BF-FPLR was originally specified such that bypass factor would not vary with part-load ratio. However, this caused erroneous results in cases with continuously operating fans as noted further below. Based on advice of one of the code authors (Buhl 2003), input for this curve fit was set to default (i.e., the final input decks are silent regarding this input).

DOE-2.1E does not provide hourly output of zone humidity ratio. An output for return air humidity ratio (which is equivalent to zone humidity ratio for a single zone case with no duct leakage) is available, but this value is only enabled when the air distribution fan is operating. Zone relative humidity was calculated with a post-processor based on hourly outputs for zone temperature, return air humidity ratio, and atmospheric pressure. For cases with intermittent fan operation (E500-E545) it was not possible to obtain annual average zone humidity ratio and relative humidity, maximum relative humidity, and minimum humidity ratios and relative humidity. It was possible to obtain average humidity ratios and post-processed relative humidity for results taken for the period from May 1-Sep 30 for cases E500 and E510 because the cooling system is required to operate during all hours of that time period for those cases.

\section{Software Errors Discovered}

In the process of testing DOE-2.1E ESTSC version, we found two documentation problems, one bug that resulted in a new version, and three other disagreements that the code authors are not planning to fix in DOE-2.1E because these disagreements do not occur in their next-generation software EnergyPlus. These are all discussed below.

\section{Documentation Problems}

There is a problem with misleading documentation related to use of the COIL-BF-FPLR curve that adjusts bypass factor (BF) as a function of part-load ratio. This caused $30 \%-115 \%$ overestimation of annual latent coil loads resulting in a 7\%-22\% overestimation of total annual consumption for cases with continuous fan operation (E300-E440). Detailed discussion of this problem is included in the main body of the report, Part II, Section 2.4.4.1.

Another documentation problem relates to that DOE-2.1E provides two possibilities for zone temperature output (DOE-2 Supplement 1994):

TNOW: "Current hour zone temperature ( $\left.{ }^{\circ} \mathrm{F}\right)$ "

TAVE: "The average zone air temperature during the hour $\left({ }^{\circ} \mathrm{F}\right)$. This is the value used for the energy calculation."

For the Volume 1 steady-state cases (E100-E200), there was no difference in results for TNOW versus TAVE, and TNOW was used in the input decks for those cases. For the Volume 2 cases TNOW and TAVE give the same annual average results, but different hourly results. Per discussions with one of the DOE-2 authors, TAVE is representative of the average zone conditions over the hour and should be used; TNOW may not be representative of average zone conditions for certain hours (Hirsch 2003). Revising from TNOW to TAVE caused mostly minor variations to the maximum and minimum IDB results and maximum and minimum relative humidity results (because the relative humidity results are developed using a separate post processor outside of DOE-2); by far the biggest change was a $4^{\circ} \mathrm{C}$ decrease in maximum IDB for Case E330. 


\section{Fixed Bug Resulting from this Work}

After addressing the above documentation problem a number of other disagreements remained, and were transmitted to the code authors. Figure 2E-1 illustrates the remaining fan electric consumption disagreement for cases E520 and E540 using DOE-2.1E ESTSC version 119 (Neymark 2003).

\section{HVAC BESTEST: E300 - E545 Indoor Fan Electricity Consumption}

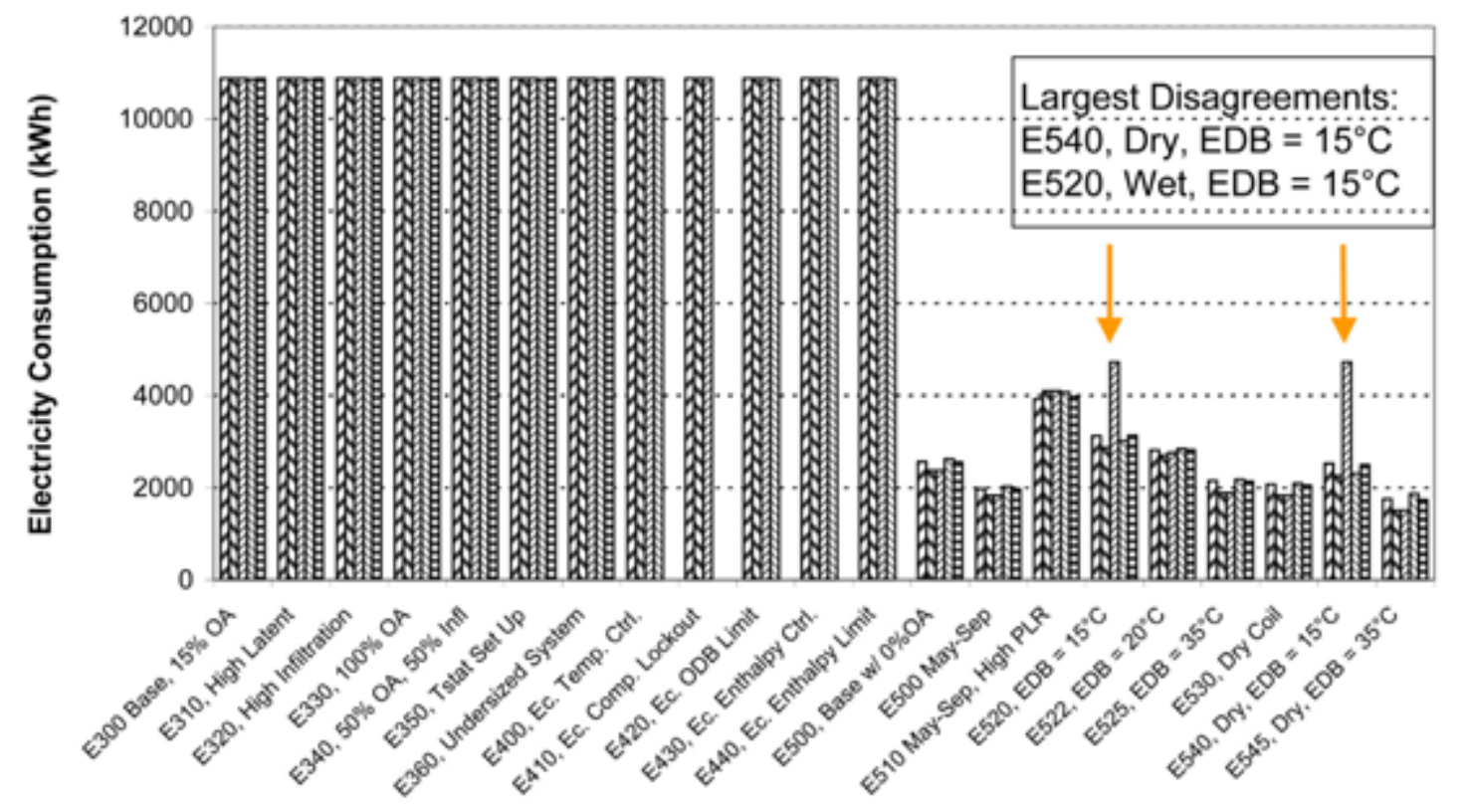

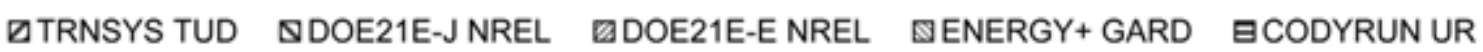

Figure 2E-1. DOE-2.1E ESTSC 119, indoor fan electricity disagreements for E520 and E540

Based on the observation that these disagreements were occurring only for cases with low EDB, some sort of performance data limiting issue was suspected as the cause. Upon further analysis by one of the code authors, he responded with the following (Buhl 2003):

"The reason for this difference is a hard lower limit of $60 \mathrm{~F}$ on the coil entering wet-bulb temperature. Changing

$$
\mathrm{EWB}=\mathrm{AMAX} 1(<\text { PASTMIXW.,60. })
$$

to

$$
\mathrm{EWB}=\operatorname{AMAX1}(<\text { PASTMIXW }>,<\text { COOL-FT-MIN }>-10 .)
$$

causes the difference to go away and the ESTSC and Hirsch versions [of DOE-2.1E] to get [an agreeing] result. 
Note: $<$ COOL-FT-MIN $>$ is the minimum outside air or entering air temperature for the capacity and EIR modification curves; $<$ PASTMIXW $>$ is the previous hour's value for mixed air wet-bulb temperature.

This change will be incorporated in the next ESTSC version of DOE-2.1E.”

For cases E520 and E540 only, for ESTSC version 119 versus version 120 results, modification of the EWB lower limit caused a 39\%-52\% decrease in indoor fan electricity, a $7 \%-15 \%$ increase in outdoor fan electricity, and a $1 \%-5 \%$ increase in compressor electricity, resulting in a $6 \%-7 \%$ decrease in total energy consumption; also there was a $6^{\circ}-7^{\circ} \mathrm{C}$ decrease in maximum IDB (using TNOW). The DOE-2.1E ESTSC version 120 results are included in Part III.

\section{Other Disagreements Transmitted to Code Authors}

The disagreements noted for DOE-2.1E ESTSC version 119 in Figures 2E-2, 2E-3, 2E-4, and 2E-5 were also transmitted to the code authors along with other figures and comments not included here (Neymark 2003).

HVAC BESTEST: E300 - E545

Peak Hour Latent Coil Load

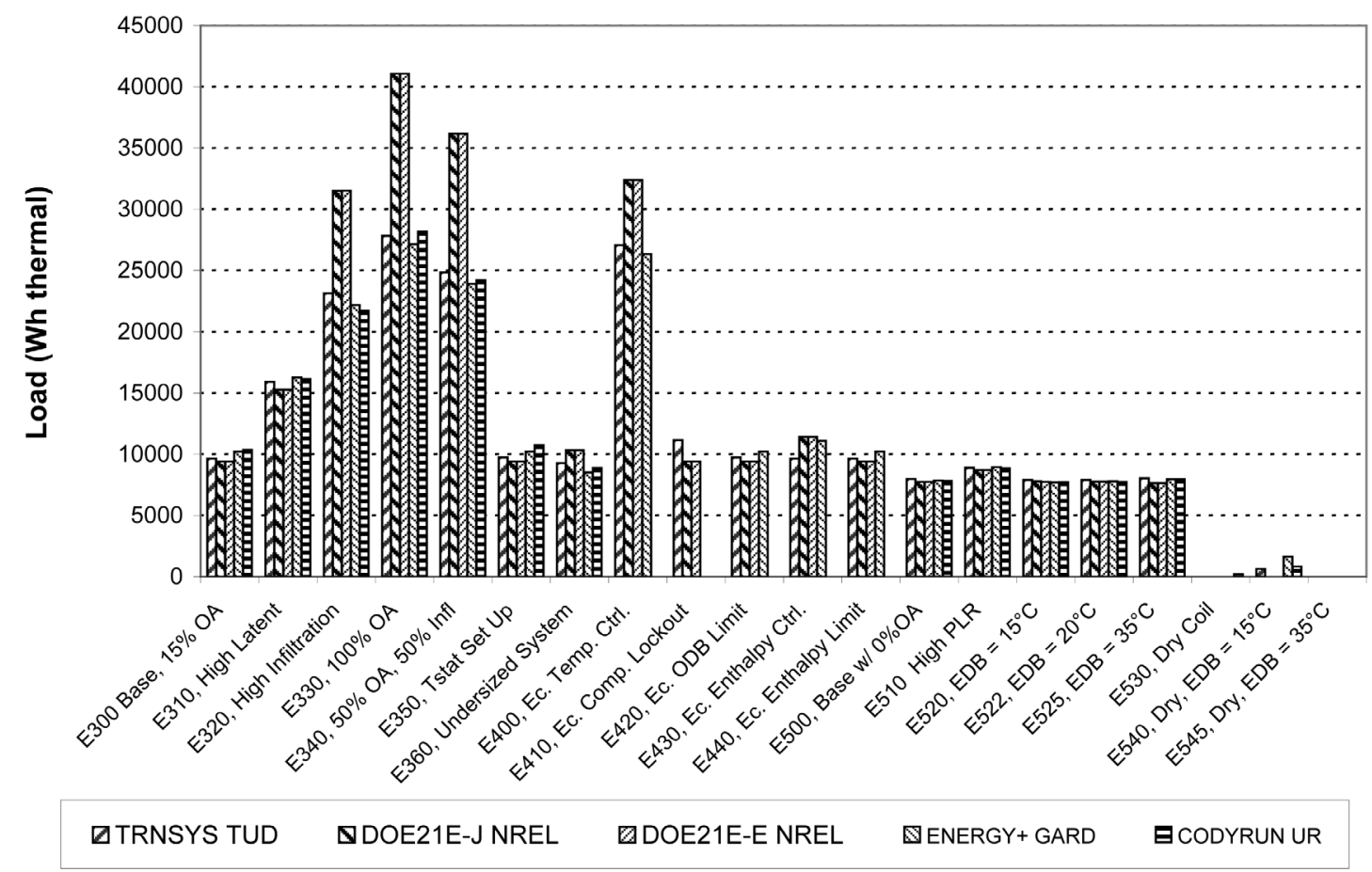

Figure 2E-2. DOE-2.1E ESTSC 119, peak-hour latent coil load disagreement for cases E320, E330, E340, and E400 
HVAC BESTEST: E300 - E545

Maximum COP2

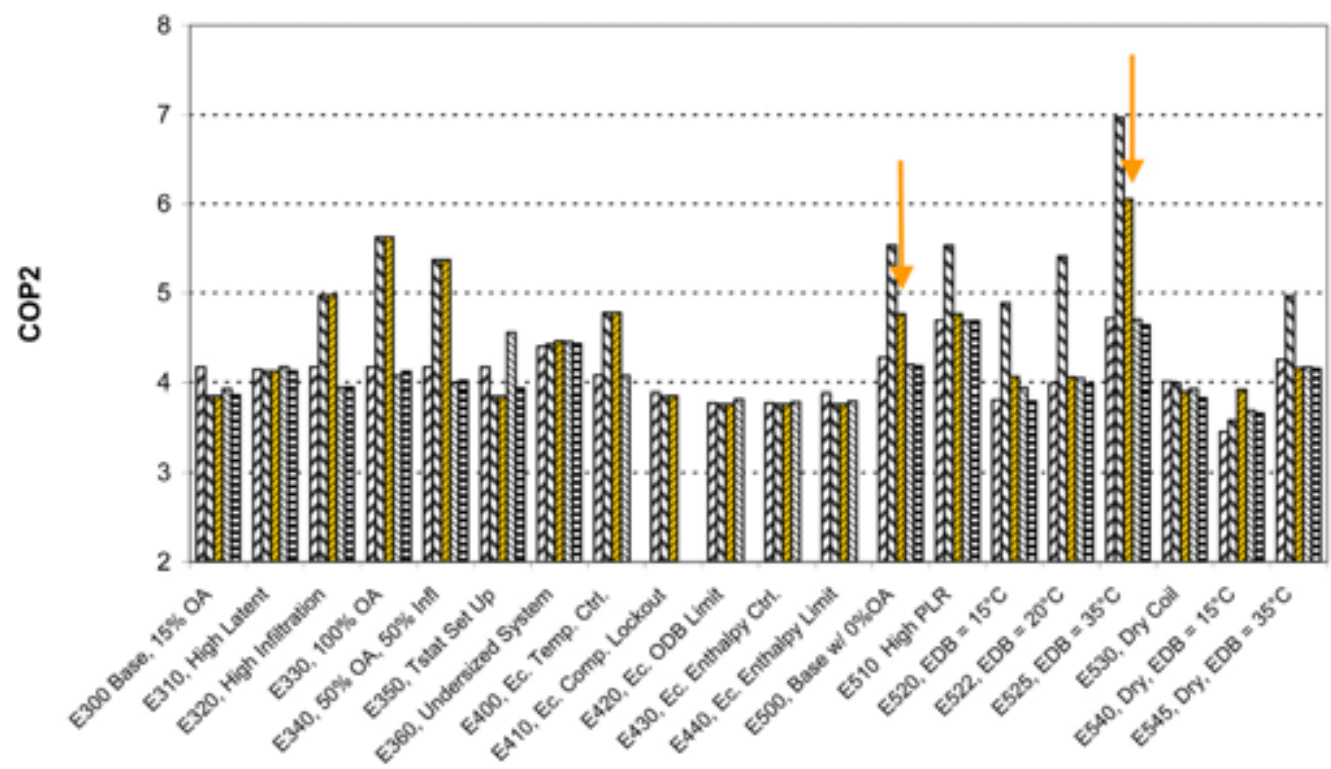

\TRNSYS TUD QDOE21E-J NREL EDOE21E-E NREL DENERGY+GARD ECOOYRUNUR

Figure 2E-3. DOE-2.1E ESTSC 119, maximum COP2 disagreements

HVAC BESTEST: E300 - E545

Maximum Zone Humidity Ratio

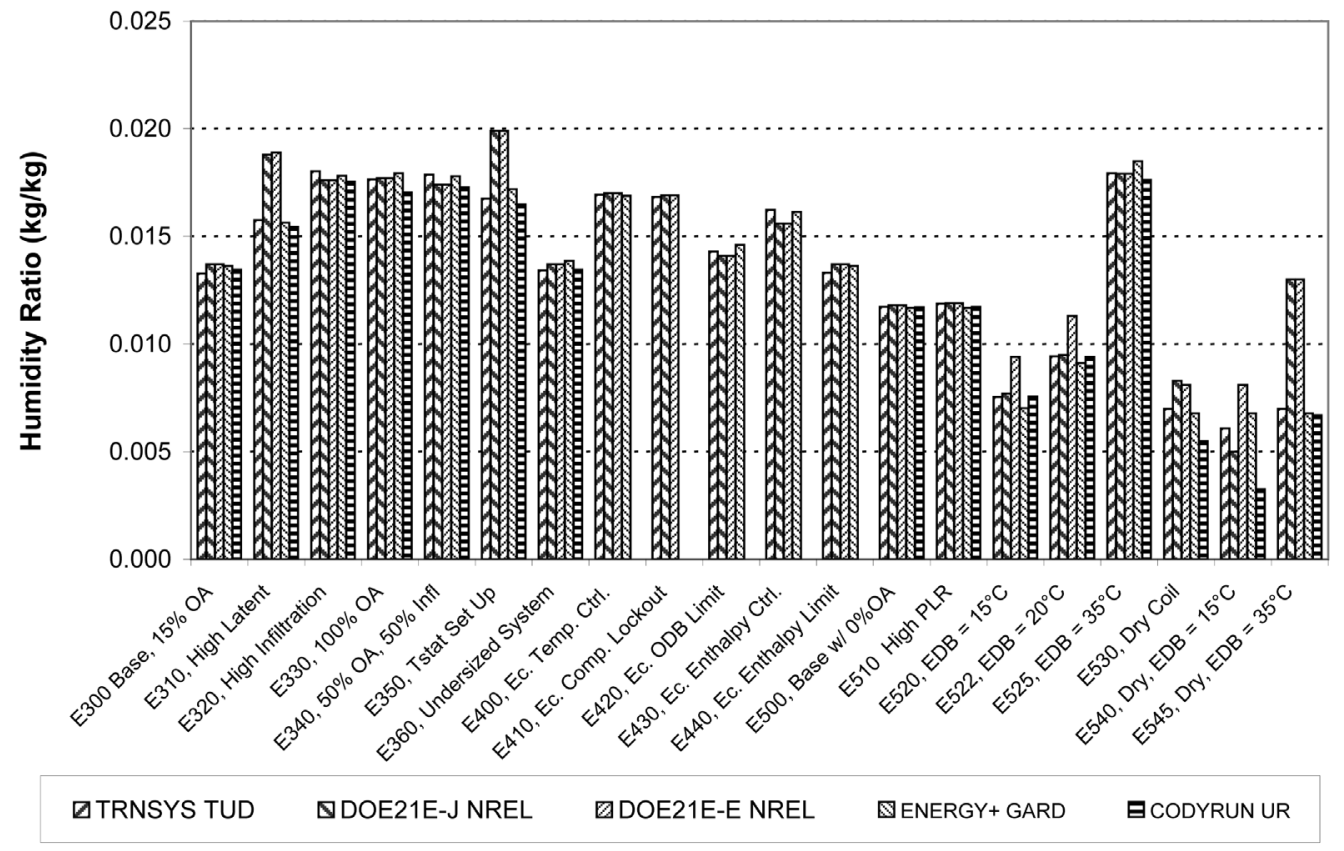

Figure 2E-4. DOE-2.1E ESTSC 119, peak-hour humidity ratio disagreements for cases E310, E350, and E545 


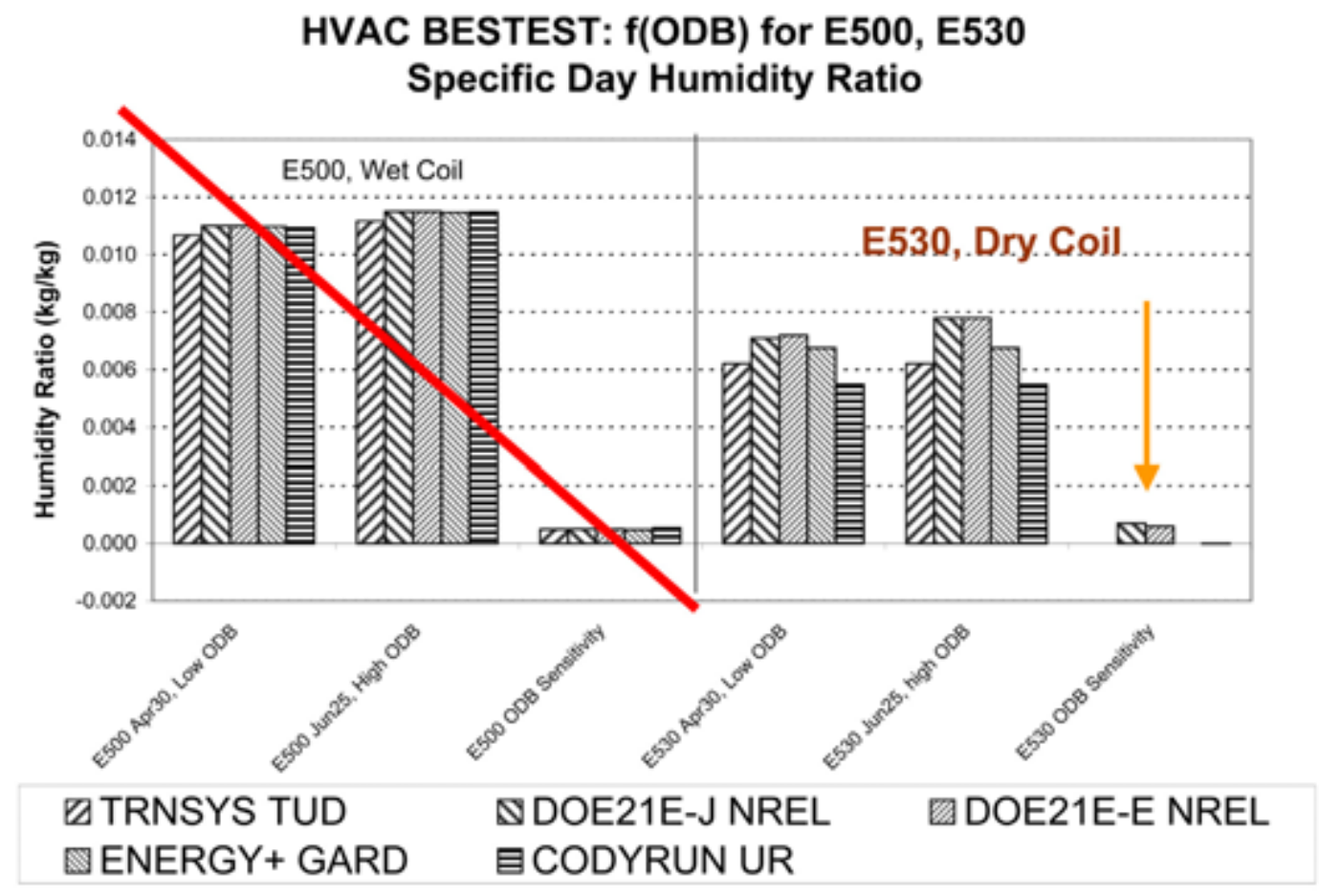

Figure 2E-5. Is DOE-2 “inhaling moisture” in dry-coil Case E530?

Responses from one of the code authors may be categorized according to the above figures (Buhl 2003). Regarding Figure 2E-2, which indicates a $20 \%-50 \%$ overestimation of peak-hour latent coil loads for cases E320, E330, E340, and E400:

“... High peak-hour coil load for cases E330, E340, E350, E400.

This difference between DOE-2 and the other programs is due to DOE-2's use of the previous hour's mixed air wet-bulb temperature in the COOL-SH-FT sensible capacity modification curve. When entering humidity jumps abruptly in one hour this results in a misestimate of the sensible capacity, which gives a misestimate of the minimum supply temperature leading finally to a misestimate of the moisture removal capability.

DOE-2 employs a single-pass HVAC calculation with a 1-hour time step. Entering conditions are estimated from the previous time step values. As a consequence the program does not do well in the time step after an abrupt change in load or conditions. Note that this has nothing to do with the coupling of the envelope and the HVAC calculation; it is strictly a consequence of the HVAC solution method which was chosen years ago for execution speed with good annual energy numbers, not for detailed equipment performance calculations in rapidly varying conditions. In steady-state conditions the program will of course do well. If the HVAC calculation were iterated or run at a smaller time step, the problem would go away. However, no change to the program 
is contemplated to resolve this issue: it would involve rewriting the DOE-2 HVAC calculation."

Regarding Figure 2E-3:

“... High COP2, cases E320, E330, E340, E500, E525.

The difference between DOE-2 and the other programs (E320, E330, E340)

is due to [the issue discussed with Figure 2E-2]. The difference between the 2 versions of

DOE-2 (E500, E520) is probably due to [the issue discussed with Figure 2E-1]."

Regarding Figure 2E-4, which indicates $20 \%, 18 \%$, and $80 \%$ overestimations of peak-hour zone humidity ratio for cases E310, E350, and E545, respectively:

“... High maximum humidity ratio for cases E310, E350, E545.

Only case E310 was examined. For E310 the peak "zone" humidity ratio occurs on October 15, hour 9. For this hour the cooling is off, but the latent heat gain has started. The fan is running and there is no infiltration. For this simple case we can calculate the humidity balance by hand. The outside air fraction is 0.15 , outside humidity ratio is 0.0104 , latent load is $24008(\mathrm{Btu} / \mathrm{h}), \mathrm{CFM}$ is 4000 . The hand calculation gives a return humidity ratio of 0.0189 , the same as reported by DOE-2.

Why is the cooling off? In EnergyPlus it is on for this hour. The answer is that DOE-2 uses a 1-hour time step and the average zone temperature for the hour is well below the cooling set point: the thermostat is in the deadband and cooling is off. In EnergyPlus the HVAC calculation time step drops to 1 minute as the load ramps up; the cooling switches on during the hour and there is significant moisture removal. Thus the difference in zone max humidity is just a result of comparing a program with a fixed 1-hour time step to a program with a varying time step. With a 1-hour time step, on/off decisions have to be made for the whole hour at the start of the hour. Lack of iteration means that the decision cannot be changed.

No code change is planned to deal with this issue. Fixing it would require rewriting DOE-2 HVAC."

Regarding Figure 2E-5:

“... DOE-2 'inhaling’ moisture? E530, April 30 versus June 25.

As far as I can tell, this case has no source for moisture during the entire year. In this case there is no "correct" answer for the humidity ratio anywhere in the system. I suppose it would be nice if whatever humidity ratio is chosen would remain fixed. DOE-2's varies a bit: it is set to WSURF, the presumed coil surface humidity ratio - actually 
the humidity ratio obtained assuming $100 \%$ relative humidity at the coil surface temperature. The coil surface temperature varies with the load, thus so does WSURF. DOE-2 expels as well as inhales moisture in this zero source of moisture case.

No code change is planned to deal with this issue."

\section{Results}

Unlike the analytical verification tests of cases E100-E200, cases E300-E545 do not have analytical solutions and therefore provide no mathematical truth standard for comparison of results. Therefore, simulation results are assumed to be in agreement with other simulation results unless a disagreement is obviously noticeable. In cases where the range of results is relatively wide with noticeable relative disagreement among all the results, the criteria for disagreement are looser. Additionally where all results are reasonably agreeing, there is no certainty that a result in the center of a range of results is any better than a result that defines the extreme of a range of results.

In general DOE-2.1E exhibits a good level of agreement with the other programs for annual energy use, loads, and other annual average results. There are some notable disagreements for peak-hour results, however, as discussed above. A compilation of what appear to be obviously disagreeing results based on Part III is included below; these disagreements should all be related to the problems discussed above, although there is no way to be certain because the code authors do not plan to rewrite the HVAC calculations for DOE-2.1E.

Remaining disagreements:

Peak-hour total coil load: E320, E330, E340, E400

Peak-hour total coil load sensitivity: E320-E300, E330-E300, E330-E320, E340-E300, E400-E300

Peak-hour latent coil load: E320, E330, E340, E400

Peak-hour latent coil load sensitivity: E320-E300, E330-E300, E330-E320, E340-E300, E400-E300

Maximum COP2: E320, E330, E340, E350, E400, E500 through E525

Maximum COP2 sensitivity: many cases

Minimum COP2 sensitivity: E400-E300, E430-E300, E440-E300, E510-E500

Minimum IDB: E320

Maximum humidity ratio: E310, E350, E522, E545

Maximum humidity ratio sensitivity: E310-E300, E350-E300

Maximum relative humidity: E310, E350

Maximum relative humidity sensitivity: E310-E300

Humidity ratio f(ODB): E530. 


\section{Other}

There is some disagreement regarding hourly latent coil load for Case E300, June 28, hours 7, 8, 11, and 13 (see Figure 2F-7 of Appendix II-F). This is related to differences in handling of weather data in DOE2 versus the other programs as shown in Figure 2F-8 of Appendix II-F. Here DOE-2 is applying original raw weather data values for the entire hour, while other programs appear to be performing some type of averaging. Justification for interpreting weather data differently is given in Section 1.3.1.1 of Part I.

\section{Conclusions and Recommendations}

\section{Regarding the DOE-2.1E Results}

Working with DOE-2.1E during the development of HVAC BESTEST Volume 2, cases E300-E545, allowed additional examination of the DOE-2 results and identified the following issues relating to accuracy of the software. The list includes the significance of the problem and related actions.

- COIL-BF-FPLR documentation problem (7\%-22\% overestimation of total consumption for cases with continuous fan operation [E300-E440]), authors notified and input revised.

- Minimum EWB was $60^{\circ} \mathrm{F}$ (low EDB cases E520 and E540 only: $65 \%-109 \%$ overestimation of indoor fan electricity, $6 \%-8 \%$ overestimation of total energy consumption), fixed in ESTSC version 120.

- Single-pass HVAC calculation with 1-hour time step using previous hour's EWB $(20 \%-50 \%$ overestimation of peak-hour latent coil loads for cases E320, E330, E340, and E400; 20\%, 18\%, and $80 \%$ overestimation of peak-hour zone humidity ratio for cases E310, E350, and E545, respectively). Authors do not plan to fix in DOE-2.1E; these issues are addressed in their nextgeneration software EnergyPlus, which can iterate between loads and systems calculations within subhourly time steps.

- Zone humidity ratio for dry-coils assumes $100 \%$ relative-humidity air at the coil surface temperature resulting in unexpected variations of zone humidity ratio $(10 \%-25 \%$ overestimation of humidity ratio for dry-coil case E530). Authors do not plan to fix DOE-2.1E; this problem does not exist in their next-generation software EnergyPlus.

For DOE-2.1E the annual summed or averaged results for system performance and zone conditions appear satisfactory when compared with other programs. See Part III for detailed results. The inability of DOE-2.1E to iterate systems and loads calculations within a time step, and the inability to apply subhourly time steps appear to be related to a number of disagreements versus the other programs for hourly extreme values and perhaps some hourly estimates in general (see Sections 5 and 6 above).

\section{Regarding HVAC BESTEST}

After improvements to earlier versions of DOE-2.1E documented in Volume 1, the James J. Hirsch \& Associates version of DOE-2.1E (version 133) showed good agreement for the Volume 1 steady-state cases E100-E200; this was before that program was applied to the Volume 2 cases that have more realistic dynamics and apply additional mechanical equipment features. For the Volume 2 test cases, both the Hirsch and ESTSC versions of DOE-2.1E exhibit similar overall results and similar disagreements versus the other programs. The disagreements are related to use of calculation techniques that were originally developed to save execution time. This discovery of further disagreements for both versions of DOE-2.1E, after testing one of the versions with Volume 1, indicates the importance of also having tested the programs over a wider range of varying conditions and applying additional mechanical features in the test cases. 


\section{References}

Buhl, W.F. (2003). Email communications, May 25, 2003, October 7, 2003. Lawrence Berkeley National Laboratory, Berkeley, California, US. Discussion related to COIL-BF-FPLR documentation problem is from May 15, 2003; discussion related to Figures 2E-1 through 2E-5 is from October 7, 2003.

DOE-2 Reference Manual (Version 2.1A) Part 1. (May 1981). D. York, C. Cappiello, eds. Berkeley, California, US: Lawrence Berkeley Laboratory.

DOE-2 Engineer's Manual (Version 2.1A). (November 1982). D. York, C. Cappiello, eds. Berkeley, California, US: Lawrence Berkeley Laboratory.

DOE-2 Supplement (Version 2.1E). (January 1994). Berkeley, California, US: Lawrence Berkeley Laboratory.

Hirsch, J. (June 2003). Personal telephone communication. June 2003. Camarillo, California, US: James J. Hirsch \& Associates.

JJHirsch DOE-2.1E Documentation ERRATA and ADDITIONS. Part III: ADDITIONS to the JJ Hirsch DOE-2.1E Program. (January 1996). Included with DOE-2.1E as "C: $\mid D O E 21 E \backslash D O C \backslash 21 E D O C . D O C . "$ Camarillo, California, US: James J. Hirsch \& Associates,.

Neymark, J. (2003). Email communication with W.F. Buhl, sent May 19, 2003. J. Neymark \& Associates, Golden, Colorado, US. Results shown in Figures 2E-1 through 2E-5 are from spreadsheet:

E300results0503.xls (HVAC BESTEST Vol. 2 results summary May 2003, with revisions to charts afterward.)

Neymark, J.; Judkoff, R. (2002). International Energy Agency Building Energy Simulation Test and Diagnostic Method for Mechanical Equipment (HVAC BESTEST), Volume 1: Cases E100-E200.

NREL/TP-550-30152. Golden, Colorado, US: National Renewable Energy Laboratory. 
Program name (please include version number)

DOE-2.1E ESTSC version 120

Your name, organisation, and country

Joel Neymark, National Renewable Energy Laboratory/J. Neymark \& Associates, United States

In tables below:

$\mathrm{x}=$ method used

$\mathrm{a}=$ method available, but not used

\section{Program status}

\begin{tabular}{l|l}
\hline & Public domain \\
\hline$x$ & Commercial: \\
\hline
\end{tabular}

x $\quad$ Commercial: purchased from Energy Science and Technology Software Center, Oak Ridge TN, USA.

Research

Other (please specify)

\section{Solution method for unitary space cooling equipment}

\begin{tabular}{|l|l}
$\mathrm{x}$ & Overall Performance Maps \\
\hline
\end{tabular}

Individual Component Models

Constant Performance (no possible variation with entering or ambient conditions)

Other (please specify)

\section{Interaction between loads and systems calculations}

\begin{tabular}{|l|l|}
\hline & Both are calculated during the same time step \\
\hline$x$ & $\begin{array}{l}\text { First, loads are calculated for the entire simulation period, then equipment performance is calculated } \\
\text { separately }\end{array}$ \\
\hline & Other (please specify) \\
\hline
\end{tabular}

\section{Time step}

\begin{tabular}{|l|l}
$\mathrm{x}$ & Fixed within code (please specify time step): one hour \\
\hline
\end{tabular}

User-specified (please specify time step)

Other (please specify)

Timing convention for meteorological data: sampling interval

\begin{tabular}{|l|l}
$\mathrm{x}$ & Fixed within code (please specify interval): one hour \\
\hline
\end{tabular}

User-specified

Timing convention for meteorological data: period covered by first record

$\mathrm{x} \quad$ Fixed within code (please specify period or time which meteorological record covers): 0:00 - 1:00

User-specified

\section{Meteorological data reconstitution scheme}

\begin{tabular}{|l|l|}
\hline$x$ & Climate assumed stepwise constant over sampling interval \\
\hline & Linear interpolation used over climate sampling interval \\
\hline & Other (please specify) \\
\hline
\end{tabular}




\section{Output timing conventions}

Produces spot predictions at the end of each time step

Produces spot output at end of each hour

$\mathrm{x}$ Produces average outputs for each hour (please specify period to which value relates): same as time step

\section{Treatment of zone air}

$\mathrm{x} \quad$ Single temperature (i.e., good mixing assumed)

Stratified model

Simplified distribution model

Full CFD model

Other (please specify)

\section{Zone air initial conditions}

$\mathrm{x} \quad$ Same as outside air

Other (please specify)

\section{Internal gains output characteristics}

Purely convective

Radiative/Convective split fixed within code

$\mathrm{x} \quad$ Radiative/Convective split specified by user

Detailed modeling of source output

\section{Mechanical systems output characteristics}

\begin{tabular}{|l|l|}
\hline$x$ & Purely convective \\
\hline
\end{tabular}

Radiative/Convective split fixed within code

Radiative/Convective split specified by user

Detailed modeling of source output

\section{Control temperature}

$\mathrm{x} \quad$ Air temperature

Combination of air and radiant temperatures fixed within the code

User-specified combination of air and radiant temperatures

User-specified construction surface temperatures

User-specified temperatures within construction

Other (please specify) 


\section{Control properties}

\begin{tabular}{|l|l|}
\hline & Ideal control as specified in the user's manual \\
\hline & On/Off thermostat control \\
\hline & On/Off thermostat control with hysteresis \\
\hline & On/Off thermostat control with minimum equipment on and/or off durations \\
\hline $\mathrm{x}$ & $\begin{array}{l}\text { Proportional control: a throttling range setting of } 0.1^{\circ} \mathrm{F} \text { was input along with a "TWO-POSITION" thermostat } \\
\text { type. }\end{array}$ \\
\hline & More comprehensive controls (please specify) \\
\hline
\end{tabular}

\section{Performance Map: characteristics}

\begin{tabular}{|l|l|}
\hline $\mathrm{a}$ & Default curves \\
\hline $\mathrm{x}$ & Custom curve fitting \\
\hline & Detailed mapping not available \\
\hline & Other (please specify) \\
\hline
\end{tabular}

\section{Performance Map: independent variables}

\begin{tabular}{|l|l|}
\hline $\mathrm{x}$ & $\begin{array}{l}\text { Entering Dry-bulb Temperature: The effect of EDB is "hardwired" in DOE-2, and only affects sensible } \\
\text { capacity. }\end{array}$ \\
\hline $\mathrm{x}$ & Entering Wet-bulb Temperature \\
\hline $\mathrm{x}$ & Outdoor Dry-bulb Temperature \\
\hline $\mathrm{x}$ & Part-Load Ratio \\
\hline $\mathrm{a}$ & Indoor Fan Airflow Rate: did not use; fan air-flow was always at rated conditions when the fan was operating. \\
\hline & Other (please specify) \\
\hline
\end{tabular}

\section{Performance Map: dependent variables}

\begin{tabular}{|l|l|}
\hline$x$ & Coefficient of Performance (or other ratio of load to electricity consumption) \\
\hline$x$ & Total Capacity \\
\hline$x$ & Sensible Capacity \\
\hline$x$ & Bypass Factor \\
\hline & Other (please specify) \\
\hline
\end{tabular}

\section{Performance Map: available curve fit techniques}

\begin{tabular}{|l|l|}
\hline $\mathrm{x}$ & Linear, $\mathrm{f}($ one independent variable): COIL-BF-FPLR using default linear curve \\
\hline $\mathrm{a}$ & Quadratic, $\mathrm{f}($ one independent variable) \\
\hline $\mathrm{x}$ & Cubic, $\mathrm{f}($ one independent variable): CLOSS-FPLR \\
\hline $\mathrm{x}$ & Bi-Linear, $\mathrm{f}($ two independent variables): COIL-BF-FT input as constant (multiplier always = 1) \\
\hline $\mathrm{x}$ & $\mathrm{Bi}-\mathrm{Quadratic}, \mathrm{f}(\mathrm{two}$ independent variables): SCAP-FT, CAP-FT, BF-FT, EIR-FT \\
\hline $\mathrm{x}$ & Other (please specify) \\
\hline
\end{tabular}




\section{Performance Map: extrapolation limits}

$\mathrm{x} \quad$ Limits independent variables: $O D B$ (input setting $=50^{\circ} \mathrm{F}$ ); EWBmin = ODBmin - 10; before work with $\mathrm{HVAC}$ BESTEST EWB lower limit was $60^{\circ} \mathrm{F}$, which caused problems

a Limits dependent variables: available for all curves

$\mathrm{x} \quad$ No extrapolation limits: available dependent variable limits were not applied

Extrapolation not allowed

Other (please specify)

\section{Cooling coil and supply air conditions model}

Supply air temperature = apparatus dew point (ADP); supply air humidity ratio = humidity ratio of saturated air at ADP

a $\quad$ Bypass factor model using listed ADP data

$\mathrm{x} \quad$ Bypass factor model with ADP calculated from extending condition line

$\mathrm{x}$ Fan heat included

More comprehensive model (please specify)

\section{Disaggregation of fans' electricity use directly in the simulation and output}

\begin{tabular}{|l|l|}
\hline$a$ & Indoor fan only \\
\hline$a$ & Outdoor fan only \\
\hline$x$ & Both indoor and outdoor fans disaggregated in the output \\
\hline$a$ & None - disaggregation of fan outputs with separate calculations by the user \\
\hline
\end{tabular}

\section{Economizer settings available (for E400 series)}

\begin{tabular}{|l|l|}
\hline $\mathbf{x}$ & Temperature \\
\hline $\mathrm{x}$ & Enthalpy \\
\hline $\mathrm{x}$ & Compressor Lockout \\
\hline & Other (please specify) \\
\hline
\end{tabular}




\title{
Appendix II-F
}

\author{
DOE-2.2 \\ National Renewable Energy Laboratory/J. Neymark \& Associates \\ United States \\ June 17, 2004
}

\section{Introduction}

Software: DOE-2.2 version NT42j

Authoring Organization: Lawrence Berkeley National Laboratory/University of California, and James J. Hirsch \& Associates (distributed by James J. Hirsch \& Associates)

Authoring Country: United States

\section{Referencing of DOE-2.1E Modeler Report Included with Volume 1 of HVAC BESTEST and Input Decks Included with Accompanying CD}

HVAC BESTEST Volume 1 (Neymark and Judkoff 2002), Appendix III-A includes a modeler report for an earlier version of DOE-2.1E that was distributed by James J. Hirsch \& Associates. DOE-2.2 is the Hirsch update of their version of DOE-2.1E. Because many similarities remain between DOE-2.1E and DOE-2.2, only additions and modifications to the DOE-2.1E modeler report of HVAC BESTEST Volume 1 are included herein. The most complete source regarding current modeling details are the input decks included with the accompanying electronic media. Input decks for cases E300-E545 were developed from the input decks for cases E100-E200; they contain some commentary notes from that earlier work as well as comments added for running the current set of test cases. DOE-2 simulations for this project originally began with both the Hirsch and ESTSC versions of DOE-2.1E. James J. Hirsch \& Associates assisted with conversion of input decks from DOE-2.1E to DOE-2.2 (Hirsch 2003a).

\section{Modeling Methodology}

Recall from the Volume 1 modeler report that DOE-2 assumes that total coil capacity and compressor power do not vary with EDB. Extrapolation of curve fits can be limited in DOE-2, using either a limit on the dependent variable results, or a limit cap on ODB and EWB.

DOE-2.1E automatically identifies when a dry-coil condition has occurred and does calculations accordingly. $\mathrm{f}(\mathrm{EWB}, \mathrm{ODB})$ curve fit data used in DOE-2 are meant for wet coils only. Where possible $\mathrm{f}(\mathrm{T})$ data points assume $\mathrm{EDB}=80^{\circ} \mathrm{F}$; however, at lower $\mathrm{EWB}$, it was necessary to use data for $\mathrm{EDB}<80^{\circ} \mathrm{F}$ (and normalize those data to be consistent with $\mathrm{EDB}-80^{\circ} \mathrm{F}$ data) to give proper information to curve fit routines. The methodology is described in the input decks included with the accompanying CD; the spreadsheet used to implement this methodology (e300MAP-doe2-1102.XLS) is also included. For HVAC BESTEST Volume 2 cases, $55^{\circ} \mathrm{F} \leq \mathrm{ODB} \leq 95^{\circ} \mathrm{F}$. The maximum ODB for New Orleans $\mathrm{TMY} 2$ is $95^{\circ} \mathrm{F}$, and by design of the cases, system operation below $\mathrm{ODB}=55^{\circ} \mathrm{F}$ should not occur. Also $55^{\circ} \mathrm{F}<\mathrm{EWB}<75^{\circ} \mathrm{F}$ is the most common range of operation for the cases, although some operation occurs outside of that range, especially in specific cases with specified higher or lower EDB (set point). 
The COIL-BF-FT curve fit was set so that bypass factor remains constant throughout the simulations. Bypass factor was allowed to vary as $\mathrm{f}(\mathrm{ODB}, \mathrm{EWB})$ in cases E100-E200.

\section{Modeling Assumptions}

Modeling assumptions that vary from those for cases E100-E200 are listed below. Fullest detail is included with the input decks.

- FLOOR-WEIGHT $=0.74\left(\mathrm{lb} / \mathrm{ft}^{2}\right)$ : This accounts for the mass of air in the zone. Custom weighting factors (set by entering " 0 ") will not run with zero-mass construction. $0.1 \mathrm{lb} / \mathrm{ft}^{2}$ - the lowest value allowed per the DOE-2 Reference Manual Version 2.1A (1981), p. III-51-was used in runs with version NT41n and initial runs with version NT42j, and then corrected to $0.74 \mathrm{lb} / \mathrm{ft}^{2}$ in a second set of runs using version NT42j.

- MIN-SUPPLY-T = 35: lowest allowed value. Per test specification, Appendix D, $34.6<\mathrm{MST}<$ $35.1^{\circ} \mathrm{F}$; depending on air properties, $35.1^{\circ} \mathrm{F}$ may be a more precise value.

- $\quad$ SUPPLY-DELTA-T $=0.960$ (temperature difference from fan heat): This value is based on Qfan $=$ $\mathrm{m}(\mathrm{cp})($ deltaT), $1242 \mathrm{~W}, 4000 \mathrm{cfm}$. This value calculated to match the assumptions of DOE-2 documented on p. IV.28 of the DOE-2 Engineers Manual (1982), and utilizes the following air properties: density $=0.075 \mathrm{lb} / \mathrm{ft}^{3}$ and $\mathrm{cp}=0.244 \mathrm{Btu} /\left(\mathrm{lb}^{\circ} \mathrm{F}\right)$ for humidity ratio $=0.01 \mathrm{lb} / \mathrm{lb}$.

- $\quad$ COOL-FT-MIN $=50\left({ }^{\circ} \mathrm{F}\right.$; used for calculations defining lower limit temperatures for performance calculations using curve-fit data [e.g., as COOL-FT-MIN - 10]): This value allows performance calculations down to $\mathrm{ODB}=50^{\circ} \mathrm{F}$ and $\mathrm{EWB}=40^{\circ} \mathrm{F}$.

- OUTDOOR-FAN-T $=24\left({ }^{\circ} \mathrm{F}\right)$ : limit below which fans do not run. The minimum hour ODB for New Orleans TMY2 annual weather data is $24^{\circ} \mathrm{F}$.

\section{Modeling Options}

\section{SYSTEM-TYPE: PSZ model}

A number of SYSTEM-TYPEs are possible and reasonable for modeling the HVAC BESTEST DX system, including RESYS2, RESYS, PSZ, and PTAC. Choice of system type affects default performance curves and features available with the system. Of these, according to a DOE-2 documentation supplement (J.J. Hirsch and Associates 1996), neither PTAC nor RESYS had the improved part-load (cycling) model for packaged systems incorporated (the improved model uses the COOL-CLOSS-FPLR curve rather than the COOL-EIRFPLR curve) into DOE-2.1E. Either the PSZ or RESYS2 models could have worked since custom performance curves are applied. PSZ was chosen because the system used in the test cases is larger than what would normally be used in a single-family detached residence.

\section{Modeling Difficulties}

Neither DOE-2.1E nor DOE-2.2 provide hourly output of zone humidity ratio. An output for return air humidity ratio (which is equivalent to zone humidity ratio for a single zone case with no duct leakage) is available, but this value is enabled only when the air distribution fan is operating. Zone relative humidity was calculated with a post-processor based on hourly outputs for zone temperature, return air humidity ratio, and atmospheric pressure. For cases with intermittent fan operation (E500-E545) it was not possible to obtain annual average zone humidity ratio and relative humidity, maximum relative humidity, and minimum humidity ratios and relative humidity. It was possible to obtain average humidity ratios and post-processed relative humidity for results taken for the period from May 1-Sep 30 for cases E500 and E510 because the cooling system is required to operate during all hours of that time period for those cases. 


\section{Software Errors Discovered}

In the process of testing James J. Hirsch \& Associates DOE-2.1E and DOE-2.2 we found one documentation problem, one fixed bug, and other results disagreements that have been transmitted to the code authors. These are discussed below.

\section{Documentation Problem}

DOE-2.2 provides 2 possibilities for zone temperature (DOE-2.2 Volume 4 2002)

TNOW: "Current hour zone temperature $\left({ }^{\circ} \mathrm{F}\right)$ "

TAVE: "The average zone air temperature during the hour $\left({ }^{\circ} \mathrm{F}\right)$. This is the value used for the energy calculation."

For the Volume 1 steady-state cases (E100-E200), there was no difference in results for TNOW versus TAVE, and TNOW was used in the input decks for those cases. For the Volume 2 cases, TNOW and TAVE give the same annual average results, but different hourly results. Per discussions with one of the DOE-2 authors, TAVE is representative of the average zone conditions over the hour and should be used; TNOW may not be representative of average zone conditions for certain hours (Hirsch 2003b). Revising from TNOW to TAVE caused mostly minor variations to the maximum and minimum IDB results in the DOE-2.1E ESTSC version as documented in Appendix II-E.

\section{Disagreements Transmitted to Code Authors November 13, 2003 (Includes 1 Fixed Bug)}

The disagreements noted for DOE-2.2 NT41n in Figures 2F-1 through 2F-4 are similar to those documented in Appendix II-E for DOE-2.1E ESTSC version 120. These disagreements were transmitted to the DOE-2.2 code authors (Neymark 2003a). 


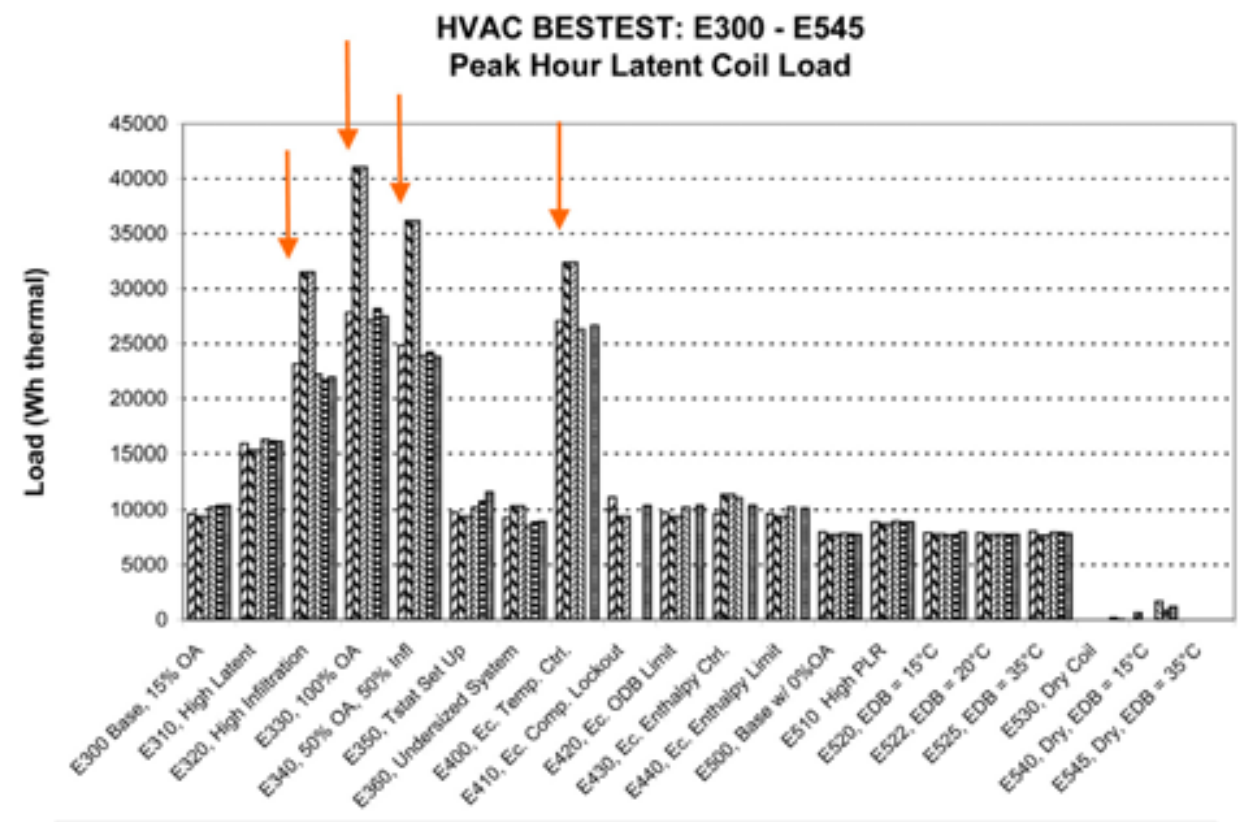

\TRNSYS TUD SDOE21E-J NREL IDOE21E-E NREL. DENERGY+GARD ECOOYRUN UR םHOT3000 NRCan

Figure 2F-1. DOE-2.2 NT41n, peak-hour latent coil load disagreements: cases E320, E330, E340, and E400

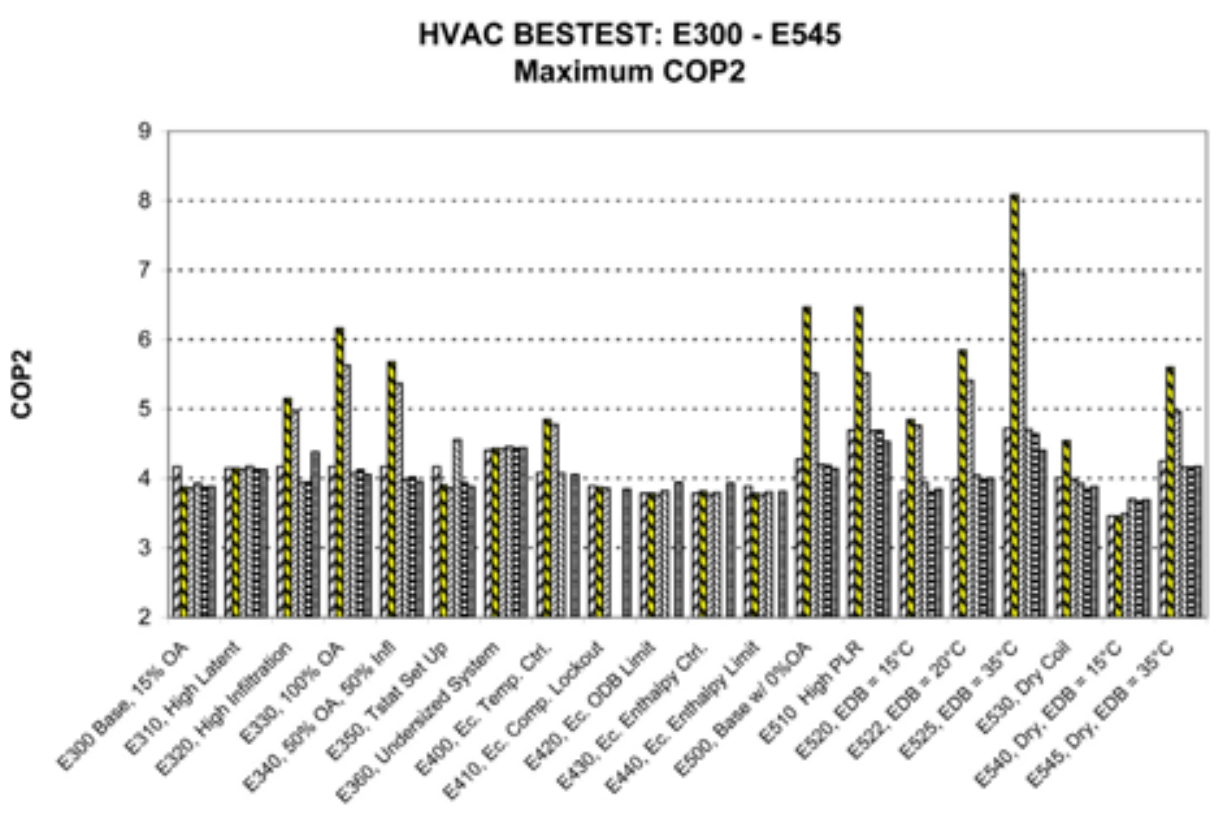

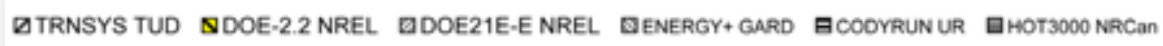

Figure 2F-2. DOE-2.2 NT41n, maximum COP2 disagreements 
HVAC BESTEST: E300 - E545

Maximum Zone Humidity Ratio

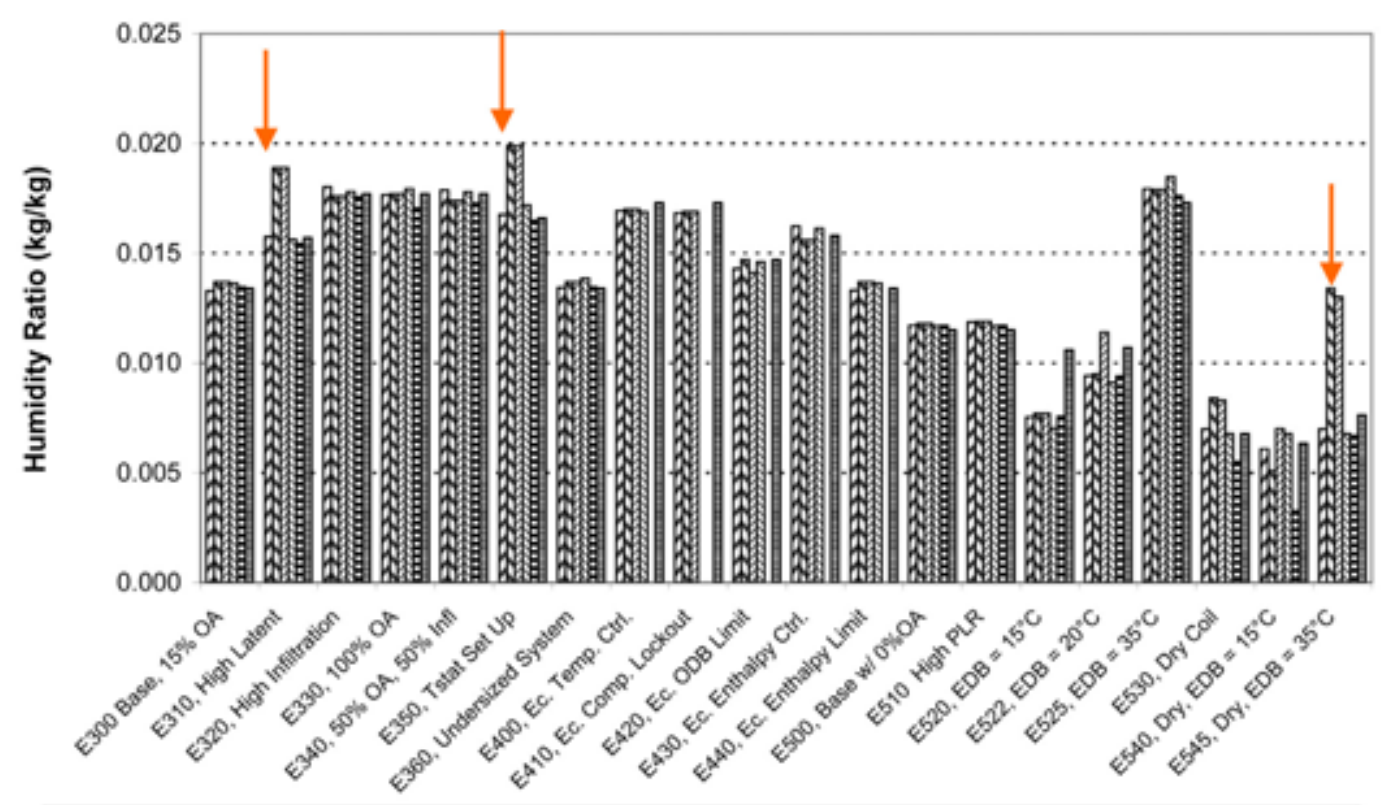

DTRNSYS TUD QDOE-2.2 NREL DDOE21E-E NREL DENERGY+GARD ECOOYRUNUR 日HOT3000 NRCan

Figure 2F-3. DOE-2.2 NT41n, peak-hour humidity ratio disagreements for cases E310, E350, and E545

HVAC BESTEST: $f(O D B)$ for E530

Specific Day Humidity Ratio

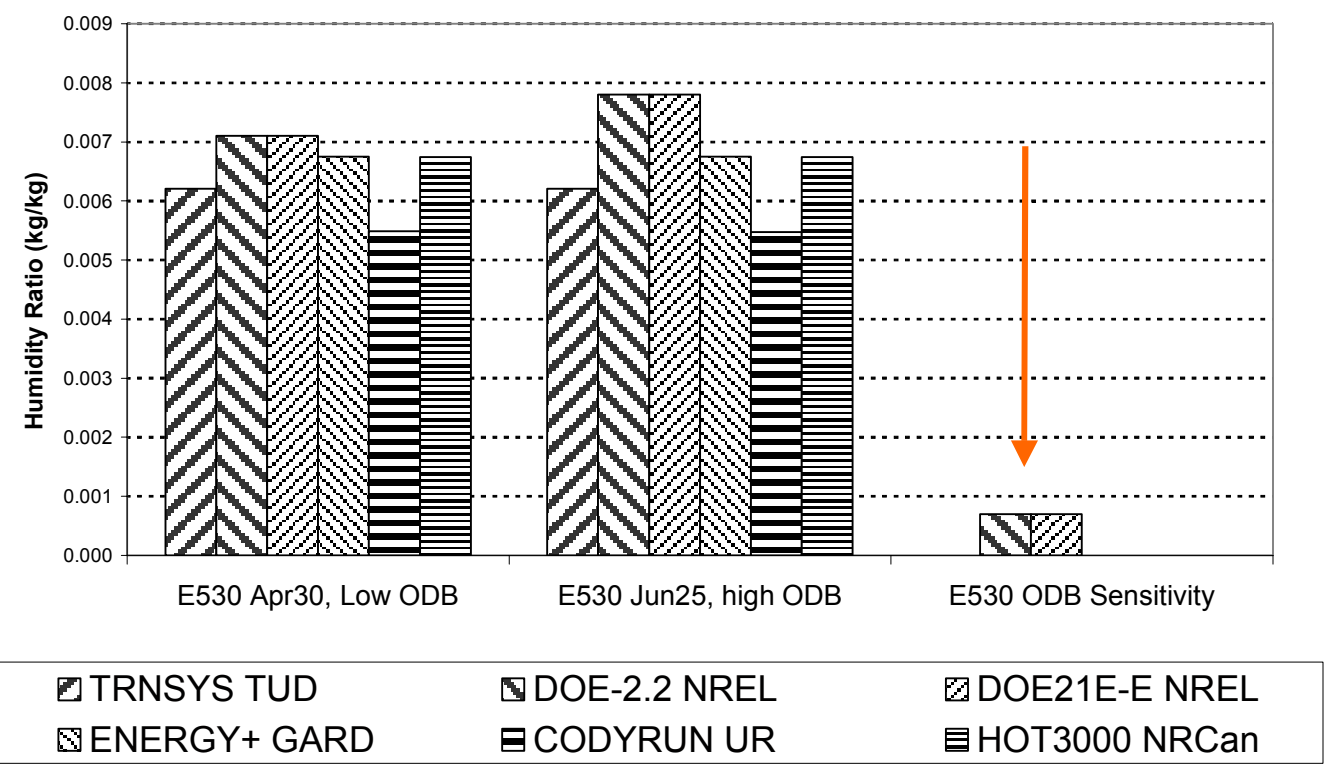

Figure 2F-4. DOE-2.2 NT41n, Is DOE-2 “inhaling” moisture in dry-coil Case E530? 
One of the code authors responded by first addressing the problem in Case E330 (see Figures 2F-1 and 2F2), which has 100\% outside air and no infiltration. His response is included below (Hirsch 2003c):

"The problem was a single hour anomaly where the total and particularly the latent cooling removal for the unit was way over the unit actual capacity. This happened in the hour (using $100 \%$ OA in New Orleans LA) when the OA fraction was changed to $100 \%$ at the same time a latent and sensible load appeared in the space. This hour highlighted a incorrect line of logic in the code ... where for the case of fans being on in the previous hour the wet-bulb temperature used in the first iteration (really the first estimation as DOE-2 does not do 'true' iterations) for the estimation of unit capacity and supply temperature incorrectly used the previous hour[']s unit entering wet-bulb with no correction for the current hour[']s conditions. At this point of the code it had correctly updated the estimated dry-bulb entering condition but skipped around the entering wet-bulb correction only if the fans were on the previous hour. I removed that skip to cause the unit entering wet-bulb to always be updated using current conditions. This problem would only have a bad effect in the case where both the internal and external conditions (load and wet-/dry-bulb) change abruptly during two consecutive hours when the unit fans were operating."

Correction of the coding error that caused the use of the previous hour EWB as the current hour EWB results in a 34\% decrease in peak-hour latent coil load for Case E340. Cases E330 and E400 show a decrease in peak-hour latent coil load of $16 \%$ and 21\%, respectively; for Case E300 the decrease is only 1\%, and there is no effect on the E500 series cases (which have no outside air). The greatest effect on annual energy consumption is a $1.0 \%$ increase going from versions NT41n to NT42j that occurs for Case E330. Regarding the disagreements noted above, after this correction good agreement was achieved only for the peak latent coil load and maximum COP2 for Case E330. Figure 2F-5 indicates remaining latent coil load disagreements for cases E320 and E340 where infiltration is also occurring. Figure 2F-6 indicates remaining maximum COP2 disagreements for cases E320 and E340, as well as for many of the E500 series cases.

HVAC BESTEST: E300 - E545

Peak Hour Latent Coil Load

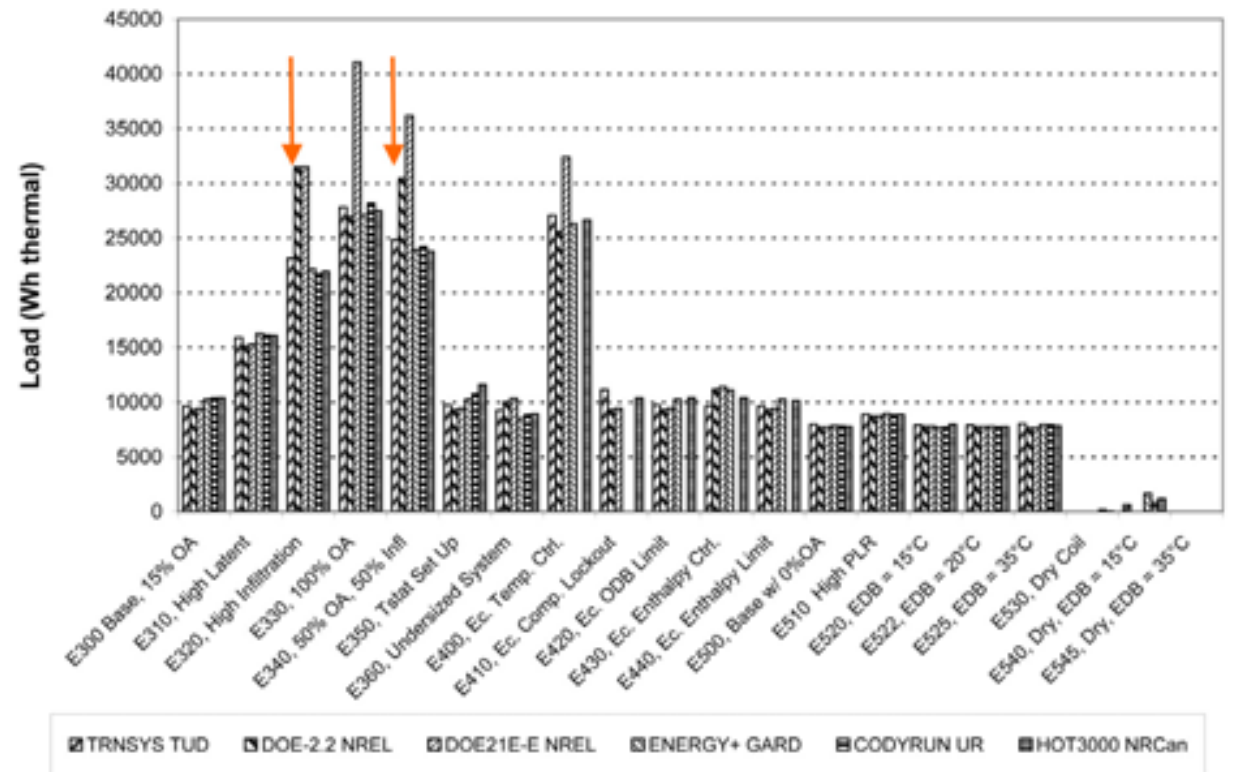

Figure 2F-5. DOE-2.2NT42j, peak-hour latent coil load disagreements: E320 and E340 


\section{HVAC BESTEST: E300 - E545 \\ Maximum COP2}

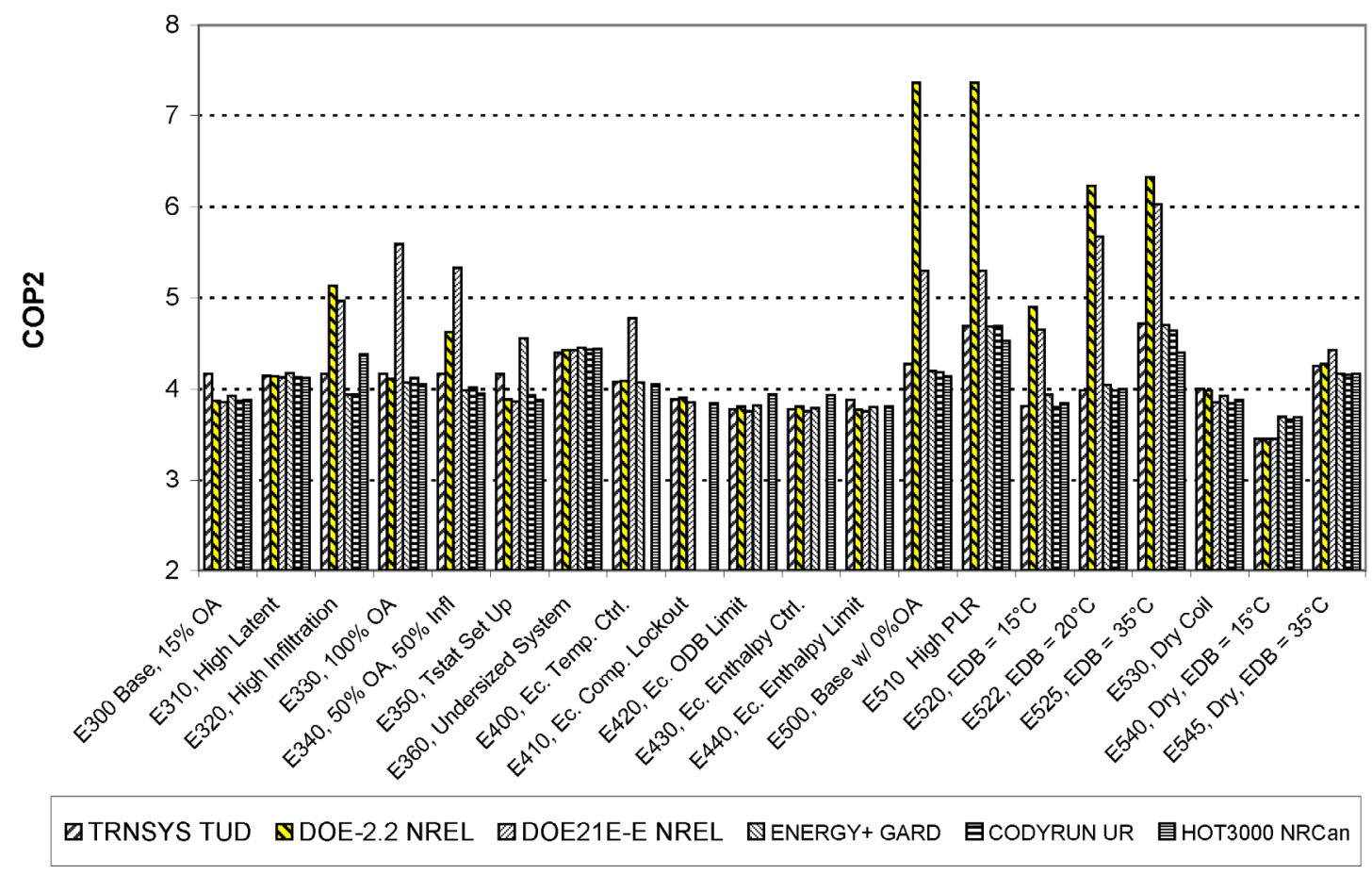

Figure 2F-6. DOE-2.2NT42j, maximum COP2 disagreements: E320, E340, and E500-E525

\section{Remaining Disagreements Transmitted to Code Authors}

Disagreements documented above for DOE-2.2 NT41n in Figures 2F-3 and 2F-4 remain in NT42j. The disagreements noted in Figures $2 \mathrm{~F}-3$ through $2 \mathrm{~F}-6$ were transmitted to the code authors (Neymark 2003a). Based on the current results sets, the code authors are planning to examine remaining disagreements and revise their software if necessary, but were not able to address the remaining disagreements in time for publication of this report.

\section{Results}

Unlike the analytical verification tests of cases E100-E200, cases E300-E545 do not have analytical solutions and therefore provide no mathematical truth standard for comparison of results. Therefore, simulation results are assumed to be in agreement with other simulation results unless a disagreement is obviously noticeable. In cases where the range of results is relatively wide with noticeable relative disagreement among all the results, the criteria for disagreement are looser. Additionally, where all results are reasonably agreeing, there is no certainty that a result in the center of a range of results is any better than a result that defines the extreme of a range of results.

In general DOE-2.2 exhibits a good level of agreement with the other programs for annual energy use, loads, and other annual average results. There are some notable disagreements for peak-hour results, however, as discussed above. A compilation of what appear to be disagreeing results based on Part III is included below. 
Remaining disagreements:

Peak-hour total coil load: E320, E340

Peak-hour total coil load sensitivity: E320-E300, E330-E320, E340-E300, E330-E340

Peak-hour latent coil load: E320, E340

Peak-hour latent coil load sensitivity: E320-E300, E330-E320, E340-E300, E330-E340

Maximum COP2: E320, E340; E500 through E525

Maximum COP2 sensitivity: E330-E320, E340-E300, E330-E340, E500-E300, E510-E500, E530-E500

Minimum COP2 sensitivity: E400-E300, E430-E300, E440-E300

Minimum IDB: E320

Maximum humidity ratio: E310, E350, E545

Maximum humidity ratio sensitivity: E310-E300, E350-E300

Maximum relative humidity: E310, E350

Maximum relative humidity sensitivity: E310-E300

Humidity ratio f(ODB): E530.

\section{Other}

There is some disagreement regarding hourly latent coil load for Case E300, June 28 hours 7, 8, 11, 13 (see Figure 2F-7 [Neymark 2003b]). This is related to differences in handling of weather data in DOE-2 versus the other programs as shown in Figure 2F-8. Here DOE-2 is applying original raw weather data values for the entire hour, while other programs appear to be performing some type of averaging. Justification for interpreting weather data differently is given in Section 1.3.1.1 of Part I.

\section{HVAC BESTEST: E300 \\ June 28 Hourly Latent Coil Loads}

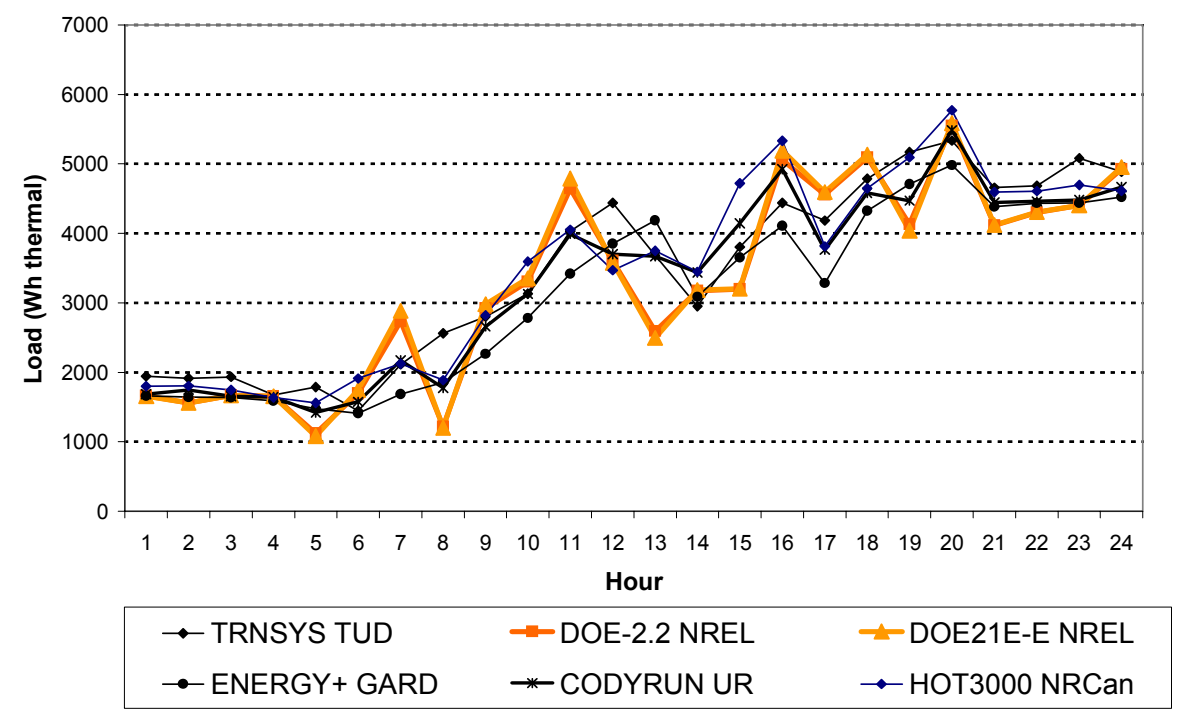

Figure 2F-7. DOE-2 latent coil load disagreements for hours 7, 8, 11, and 13 
HVAC BESTEST: E300

June 28 Hourly OHR

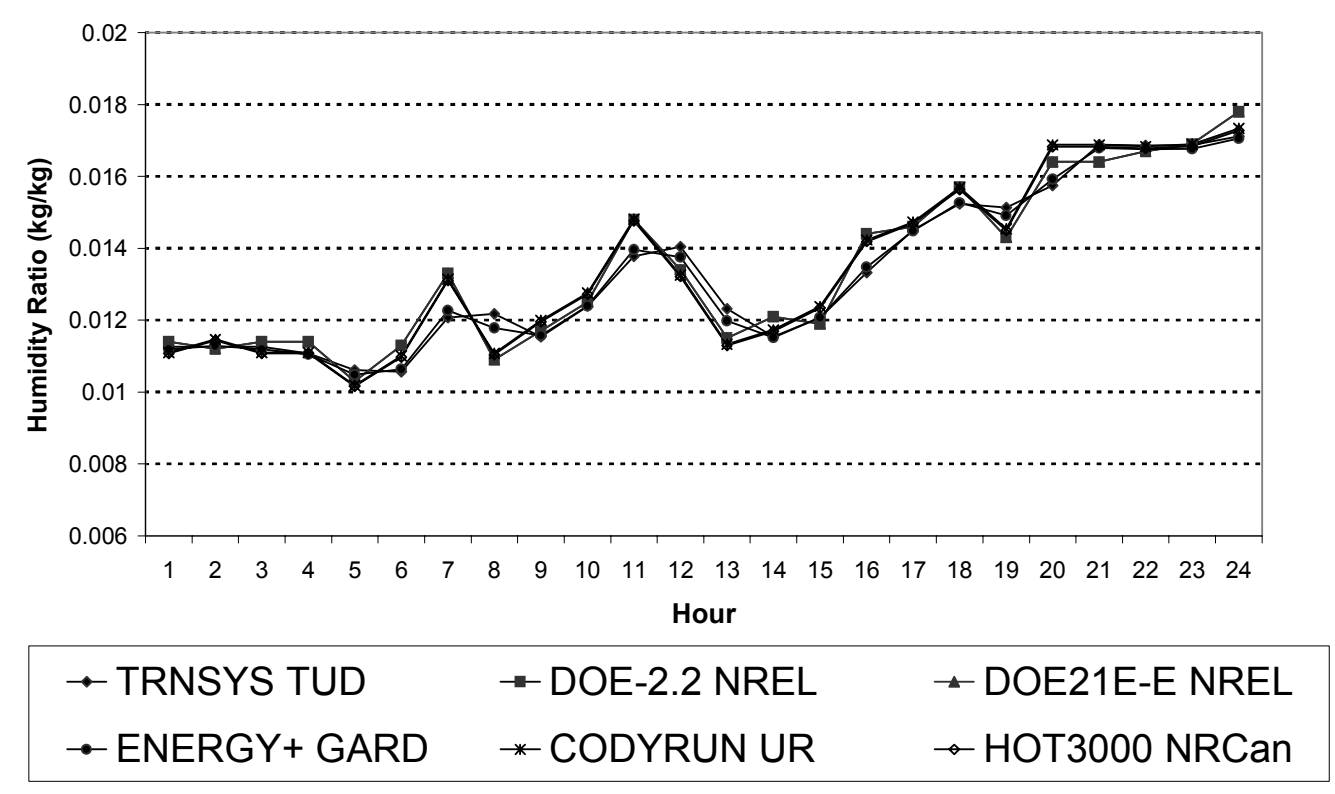

Figure 2F-8. June 28 outdoor humidity ratio, all simulations

\section{Conclusions and Recommendations}

\section{Regarding the DOE-2.2 Results}

Working with DOE-2.1E and DOE-2.2 during the development of HVAC BESTEST Volume 2, cases E300-E545, allowed additional examination of the DOE-2 results and identified the following fixed bug.

- Correction of the coding error that caused the use of the previous hour EWB as the current hour EWB $(34 \%, 16 \%$, and $21 \%$ decreases in peak-hour latent coil load for cases E330, E340, and E400, respectively; $1.4 \%$ increase in annual energy consumption for E340.)

For DOE-2.2 the annual summed or averaged results for system performance and zone conditions appear satisfactory when compared with other programs. Disagreements relating to specific maximum-hour values that were transmitted to the code authors were described in Section 5 of this modeler report and cover:

- Maximum-hour latent coil loads for high zone-air infiltration rates (E320, E340)

- Maximum-hour COP2 calculations when there are no outside air and no infiltration (E500 series wet-coil cases [E500 through E525])

- Maximum-hour zone humidity ratio calculation for cases with very high latent loads (E310), thermostat set up (E350), and dry coil with high EDB (E545). 
Based on the current results sets, the code authors are planning to examine remaining disagreements and revise their software if necessary, but were not able to address the remaining disagreements in time for publication of this report.

\section{Regarding HVAC BESTEST}

After improvements to earlier versions of DOE-2.1E documented in Volume 1, the James J. Hirsch \& Associates version of DOE-2.1E (version 133) showed good agreement for the Volume 1 steady-state cases E100-E200; this was before DOE-2.2 (which evolved from DOE-2.1E) was applied to the Volume 2 cases that have more realistic dynamics and also apply additional mechanical equipment features. For the Volume 2 test cases, fixing of a bug and discovery of further disagreements for DOE-2.2 after testing of DOE-2.1E with Volume 1 indicates the importance of also having tested the programs over a wider range of varying conditions and applying additional mechanical features in the test cases.

\section{References}

DOE-2 Reference Manual (Version 2.1A) Part 1. (May 1981). D. York, C. Cappiello, eds. Berkeley, California, US: Lawrence Berkeley Laboratory.

DOE-2 Engineer's Manual (Version 2.1A). (November 1982). D. York, C. Cappiello, eds. Berkeley, California, US: Lawrence Berkeley Laboratory.

DOE-2.2 Building Energy Use and Cost Analysis Program, Volume 4: Libraries and Reports. (March 2002). Camarillo, California, US: James J. Hirsch \& Associates.

JJHirsch DOE-2.1E Documentation ERRATA and ADDITIONS. Part III: ADDITIONS to the JJ Hirsch DOE-2.1E Program. (January 1996). Included with DOE-2.1E as "C: $\backslash D O E 21 E \backslash D O C \backslash 21 E D O C . D O C . "$ Camarillo, California, US: James J. Hirsch \& Associates.

Hirsch, J. (2003a). E-mail communications, May 21-22, 2003. Camarillo, California, US: James J. Hirsch \& Associates.

Hirsch, J. (2003b). Personal telephone communication, June 2003. Camarillo, California, US: James J. Hirsch \& Associates.

Hirsch, J. (2003c). E-mail communication, 14 November 2003. Camarillo, California, US: James J. Hirsch \& Associates.

Neymark, J. (2003a). E-mail communications with J. Hirsch, November 17, 2003. J. Neymark \& Associates, Golden, Colorado, US. Results shown in Figures 2F-1 through 2F-4 are from spreadsheet E300results 111203.xls (HVAC BESTEST Vol. 2 results summary, November 12, 2003). Results shown in Figures 2F-5 through 2F-6 are from spreadsheet: E300results 111703.xls (HVAC BESTEST Vol. 2 results summary, November 17, 2003).

Neymark, J. (2003b). E300results 111703.xls. (HVAC BESTEST Vol. 2 results summary, November 2003.)

Neymark, J.; Judkoff, R. (2002). International Energy Agency Building Energy Simulation Test and Diagnostic Method for Mechanical Equipment (HVAC BESTEST), Volume 1: Cases E100-E200.

NREL/TP-550-30152. Golden, Colorado, US: National Renewable Energy Laboratory. 
Program name (please include version number)

DOE-2.2 version NT42j

Your name, organisation, and country

Joel Neymark, National Renewable Energy Laboratory/J. Neymark \& Associates, United States

In tables below:

$\mathrm{x}=$ method used

$\mathrm{a}=$ method available, but not used

\section{Program status}

\begin{tabular}{l|l}
\hline & Public domain \\
\hline$x$ & Commercial: obt
\end{tabular}

x Commercial: obtained from James J. Hirsch \& Associates, Camarillo, Callifornia, US.

Research

Other (please specify)

\section{Solution method for unitary space cooling equipment}

\begin{tabular}{|l|l}
$\mathrm{x}$ & Overall Performance Maps \\
\hline
\end{tabular}

Individual Component Models

Constant Performance (no possible variation with entering or ambient conditions)

Other (please specify)

\section{Interaction between loads and systems calculations}

\begin{tabular}{|l|l|}
\hline & Both are calculated during the same time step \\
\hline $\mathrm{x}$ & $\begin{array}{l}\text { First, loads are calculated for the entire simulation period, then equipment performance is calculated } \\
\text { separately }\end{array}$ \\
\hline & Other (please specify) \\
\hline
\end{tabular}

\section{Time step}

$\mathrm{x} \quad$ Fixed within code (please specify time step): one hour

User-specified (please specify time step)

Other (please specify)

Timing convention for meteorological data: sampling interval

\begin{tabular}{|l|l}
$\mathrm{x}$ & Fixed within code (please specify interval): one hour \\
\hline
\end{tabular}

User-specified

Timing convention for meteorological data: period covered by first record

$x \quad$ Fixed within code (please specify period or time which meteorological record covers): 0:00 - 1:00

User-specified

\section{Meteorological data reconstitution scheme}

\begin{tabular}{|l|l|}
\hline $\mathrm{x}$ & Climate assumed stepwise constant over sampling interval \\
\hline & Linear interpolation used over climate sampling interval \\
\hline & Other (please specify) \\
\hline
\end{tabular}




\section{Output timing conventions}

Produces spot predictions at the end of each time step

Produces spot output at end of each hour

$\mathrm{x}$ Produces average outputs for each hour (please specify period to which value relates): same as time step

\section{Treatment of zone air}

$\mathrm{x} \quad$ Single temperature (i.e., good mixing assumed)

Stratified model

Simplified distribution model

Full CFD model

Other (please specify)

\section{Zone air initial conditions}

$\mathrm{x} \quad$ Same as outside air

Other (please specify)

\section{Internal gains output characteristics}

Purely convective

Radiative/Convective split fixed within code

$\mathrm{x} \quad$ Radiative/Convective split specified by user

Detailed modeling of source output

\section{Mechanical systems output characteristics}

\begin{tabular}{|l|l|}
\hline$x$ & Purely convective \\
\hline & Radiative/Convective split fixed within code \\
\hline & Radiative/Convective split specified by user \\
\hline & Detailed modeling of source output \\
\hline
\end{tabular}

\section{Control temperature}

$\mathrm{x} \quad$ Air temperature

Combination of air and radiant temperatures fixed within the code

User-specified combination of air and radiant temperatures

User-specified construction surface temperatures

User-specified temperatures within construction

Other (please specify) 


\section{Control properties}

\begin{tabular}{|l|l|}
\hline & Ideal control as specified in the user's manual \\
\hline & On/Off thermostat control \\
\hline & On/Off thermostat control with hysteresis \\
\hline & On/Off thermostat control with minimum equipment on and/or off durations \\
\hline $\mathrm{x}$ & $\begin{array}{l}\text { Proportional control: a throttling range setting of } 0.1^{\circ} \mathrm{F} \text { was input along with a "TWO-POSITION" thermostat } \\
\text { type }\end{array}$ \\
\hline & More comprehensive controls (please specify) \\
\hline
\end{tabular}

\section{Performance Map: characteristics}

\begin{tabular}{|l|l|}
\hline $\mathrm{a}$ & Default curves \\
\hline $\mathrm{x}$ & Custom curve fitting \\
\hline & Detailed mapping not available \\
\hline & Other (please specify) \\
\hline
\end{tabular}

\section{Performance Map: independent variables}

\begin{tabular}{|l|l|}
\hline $\mathrm{x}$ & $\begin{array}{l}\text { Entering Dry-bulb Temperature: The effect of EDB is "hard-wired" in DOE-2, and only affects sensible } \\
\text { capacity. }\end{array}$ \\
\hline $\mathrm{x}$ & Entering Wet-bulb Temperature \\
\hline $\mathrm{x}$ & Outdoor Dry-bulb Temperature \\
\hline $\mathrm{x}$ & Part-Load Ratio \\
\hline $\mathrm{a}$ & Indoor Fan Airflow Rate: did not use; fan airflow was always at rated conditions when the fan was operating \\
\hline & Other (please specify) \\
\hline
\end{tabular}

\section{Performance Map: dependent variables}

\begin{tabular}{|l|l|}
\hline$x$ & Coefficient of Performance (or other ratio of load to electricity consumption) \\
\hline$x$ & Total Capacity \\
\hline$x$ & Sensible Capacity \\
\hline$x$ & Bypass Factor \\
\hline & Other (please specify) \\
\hline
\end{tabular}

\section{Performance Map: available curve fit techniques}

\begin{tabular}{|l|l|}
\hline $\mathrm{x}$ & Linear, $\mathrm{f}($ one independent variable): COIL-BF-FPLR using default linear curve \\
\hline $\mathrm{a}$ & Quadratic, $\mathrm{f}($ one independent variable) \\
\hline $\mathrm{x}$ & Cubic, $\mathrm{f}($ one independent variable): CLOSS-FPLR \\
\hline $\mathrm{x}$ & Bi-Linear, $\mathrm{f}($ two independent variables): COIL-BF-FT input as constant (multiplier always = 1) \\
\hline $\mathrm{x}$ & $\mathrm{Bi}-\mathrm{Quadratic}, \mathrm{f}(\mathrm{two}$ independent variables): SCAP-FT, CAP-FT, BF-FT, EIR-FT \\
\hline $\mathrm{x}$ & Other (please specify) \\
\hline
\end{tabular}




\section{Performance Map: extrapolation limits}

$\mathrm{x} \quad$ Limits independent variables: $O D B$ (input setting $=50^{\circ} \mathrm{F}$ ); EWBmin $=$ ODBmin -10

a $\quad$ Limits dependent variables: available for all curves

$\mathrm{x}$ No extrapolation limits: available dependent variable limits were not applied

Extrapolation not allowed

Other (please specify)

\section{Cooling coil and supply air conditions model}

Supply air temperature = apparatus dew point (ADP); supply air humidity ratio = humidity ratio of saturated air at ADP

a $\quad$ Bypass factor model using listed ADP data

$x \quad$ Bypass factor model with ADP calculated from extending condition line

$\mathrm{x}$ Fan heat included

More comprehensive model (please specify)

\section{Disaggregation of fans' electricity use directly in the simulation and output}

\begin{tabular}{|l|l|}
\hline$a$ & Indoor fan only \\
\hline $\mathrm{a}$ & Outdoor fan only \\
\hline $\mathrm{x}$ & Both indoor and outdoor fans disaggregated in the output \\
\hline $\mathrm{a}$ & None - disaggregation of fan outputs with separate calculations by the user \\
\hline
\end{tabular}

\section{Economizer settings available (for E400 series)}

\begin{tabular}{|l|l|}
\hline$x$ & Temperature \\
\hline$x$ & Enthalpy \\
\hline$x$ & Compressor Lockout \\
\hline & Other (please specify) \\
\hline
\end{tabular}


This page is intentionally blank. 


\subsection{Part III: Simulation Field Trial Results}

Here we present the simulation results for the field trials of cases E300-E545. These are results after numerous iterations to incorporate clarifications to the test specification, simulation input deck corrections, and simulation software improvements. Where improvements to simulation programs or simulation inputs were made as a result of running the tests, such improvements must have mathematical and physical bases and must be applied consistently across tests. Also, all improvements were required to be documented in modeler reports. Arbitrary modification of a simulation program's input or internal code just for the purpose of more closely matching a given set of results is not allowed. The diagnostic process of trapping bugs discussed in Section 2.4 of Part II also isolated input errors that were corrected, as noted there and in the modeler reports (Part II, Section 2.9).

An electronic version of these results is included on the accompanying CD in the file E300RESULTS.XLS, with its navigation instructions included in E300RESULTS.DOC. This section presents graphs of the results first, followed by tables of the results.

We have attempted to give a brief description of the cases in the x-axis labels of the accompanying graphs. See Section 2.7 of Part II for definitions of the abbreviations and acronyms. Case descriptions are summarized in Table 1-1 in Part I. The results tables include dates and hours of occurrences for hourly maxima and minima; times of occurrence are not indicated in the graphs depicting hourly maxima and minima.

Table 3-1 summarizes the following information for the six models that were implemented by the five organizations that participated in this project: model-authoring organization, model testing organization ("Implemented by"), and abbreviation labels used in the results graphs and tables. 
Table 3-1. Participating Organizations and Computer Programs

\begin{tabular}{|c|c|c|c|}
\hline $\begin{array}{l}\text { Simulation } \\
\text { Program }\end{array}$ & Authoring Organization & Implemented by & Abbreviation \\
\hline CODYRUN/LGIMAT & Université de la Reunion Island, France & $\begin{array}{l}\text { Université de la Reunion } \\
\text { Island, France }\end{array}$ & CODYRUN/UR \\
\hline $\begin{array}{l}\text { DOE-2.1E-ESTSC } \\
\text { version }\end{array}$ & $\begin{array}{l}\text { LANL/LBNL/ESTSC/JJH, a,b,c,d United } \\
\text { States }\end{array}$ & $\begin{array}{l}\text { NREL/JNA, }{ }^{e} \text { United } \\
\text { States }\end{array}$ & $\begin{array}{l}\text { DOE-2.1E-E/NREL } \\
\text { DOE21E-E }\end{array}$ \\
\hline DOE-2.2 NT & LBNL/JJH, ${ }^{\mathrm{b}, \mathrm{d}}$ United States & $\begin{array}{l}\text { NREL/JNA, }{ }^{e} \text { United } \\
\text { States }\end{array}$ & DOE-2.2/NREL \\
\hline ENERGYPLUS & $\begin{array}{l}\text { LBNL/UIUC/CERL/OSU/GARD } \\
\text { Analytics/FSEC/DOE-BT, }, \text { b,f,g,h,i,j United } \\
\text { States }\end{array}$ & $\begin{array}{l}\text { GARD Analytics, United } \\
\text { States }\end{array}$ & ENERGY+/GARD \\
\hline НОТ3000 & CETC/ESRU, ${ }^{\mathrm{k}, \mathrm{l}}$ Canada/United Kingdom & CETC, ${ }^{\mathrm{k}}$ Canada & HOT3000/NRCan \\
\hline $\begin{array}{l}\text { TRNSYS 14.2-TUD } \\
\text { with real controller } \\
\text { model }\end{array}$ & $\begin{array}{l}\text { University of Wisconsin, United States; } \\
\text { Technische Universität Dresden, } \\
\text { Germany }\end{array}$ & $\begin{array}{l}\text { Technische Universität } \\
\text { Dresden, Germany }\end{array}$ & TRNSYS-TUD/TUD \\
\hline
\end{tabular}

${ }^{a}$ LANL: Los Alamos National Laboratory, United States

${ }^{b}$ LBNL: Lawrence Berkeley National Laboratory, United States

${ }^{c}$ ESTSC: Energy Science and Technology Software Center (at Oak Ridge National Laboratory, United States)

${ }^{\mathrm{d} J J H}$ : James J. Hirsch \& Associates, United States

${ }^{\mathrm{e}}$ NREL/JNA: National Renewable Energy Laboratory/J. Neymark \& Associates, United Sates

${ }^{f}$ UIUC: University of Illinois Urbana/Champaign, United States

${ }^{\mathrm{g}}$ CERL: U.S. Army Corps of Engineers, Construction Engineering Research Laboratories, United States

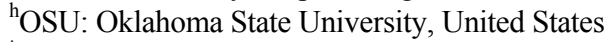

${ }^{\mathrm{i}}$ FSEC: University of Central Florida, Florida Solar Energy Center, United States

${ }^{j}$ DOE-BT: U.S. Department of Energy, Office of Building Technologies, Energy Efficiency and Renewable Energy, United States

${ }^{k}$ CETC: CANMET Energy Technology Centre, Natural Resources Canada, Canada

${ }^{\mathrm{l}}$ ESRU: Energy Systems Research Unit, University of Strathclyde, Scotland, United Kingdom 
HVAC BESTEST: E300 - E545

Total Electricity Consumption

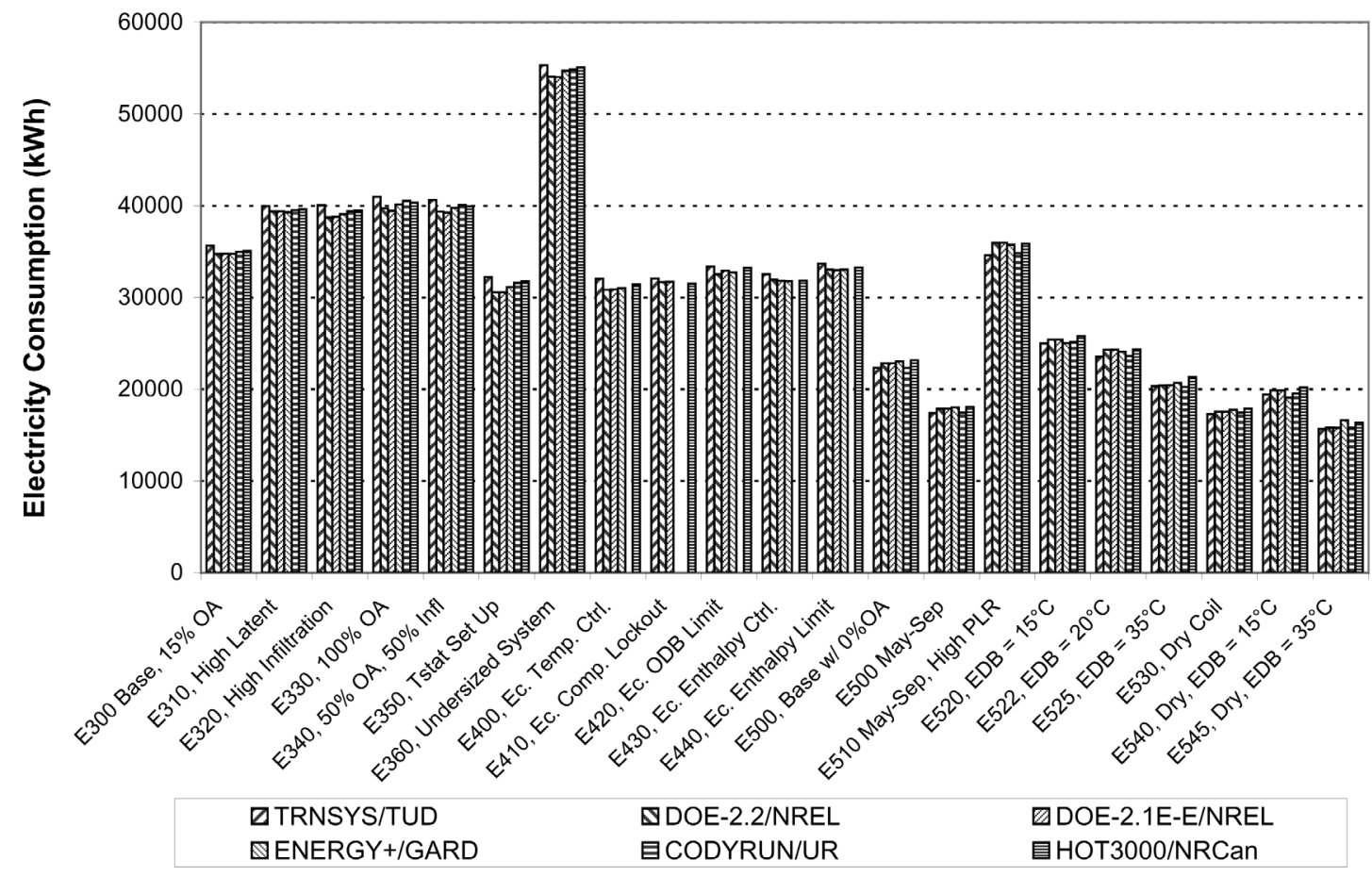

HVAC BESTEST: E300 - E545

Total Space Cooling Electricity Consumption Sensitivities

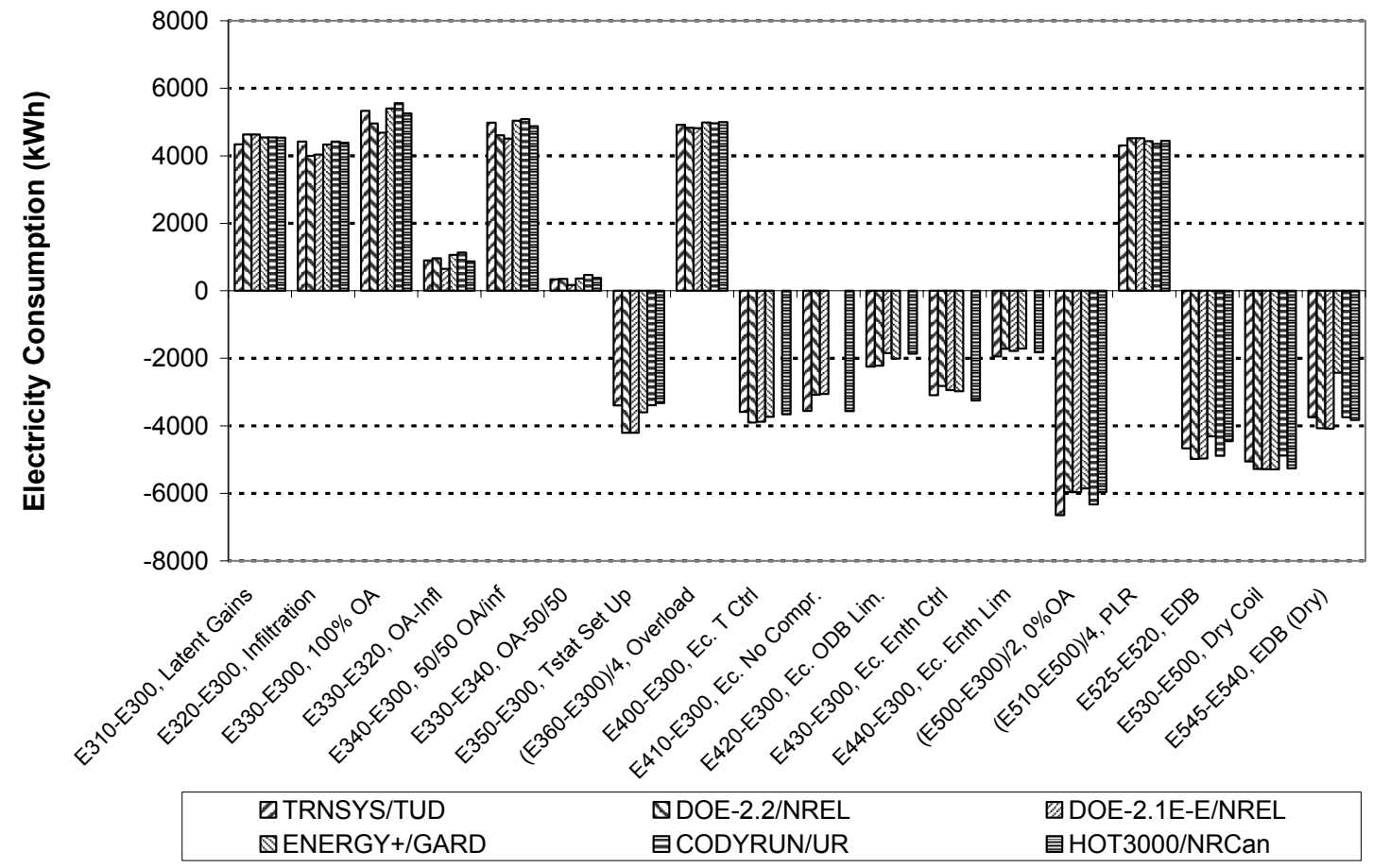


HVAC BESTEST: E300 - E545

Peak Hour Total Electricity Consumption

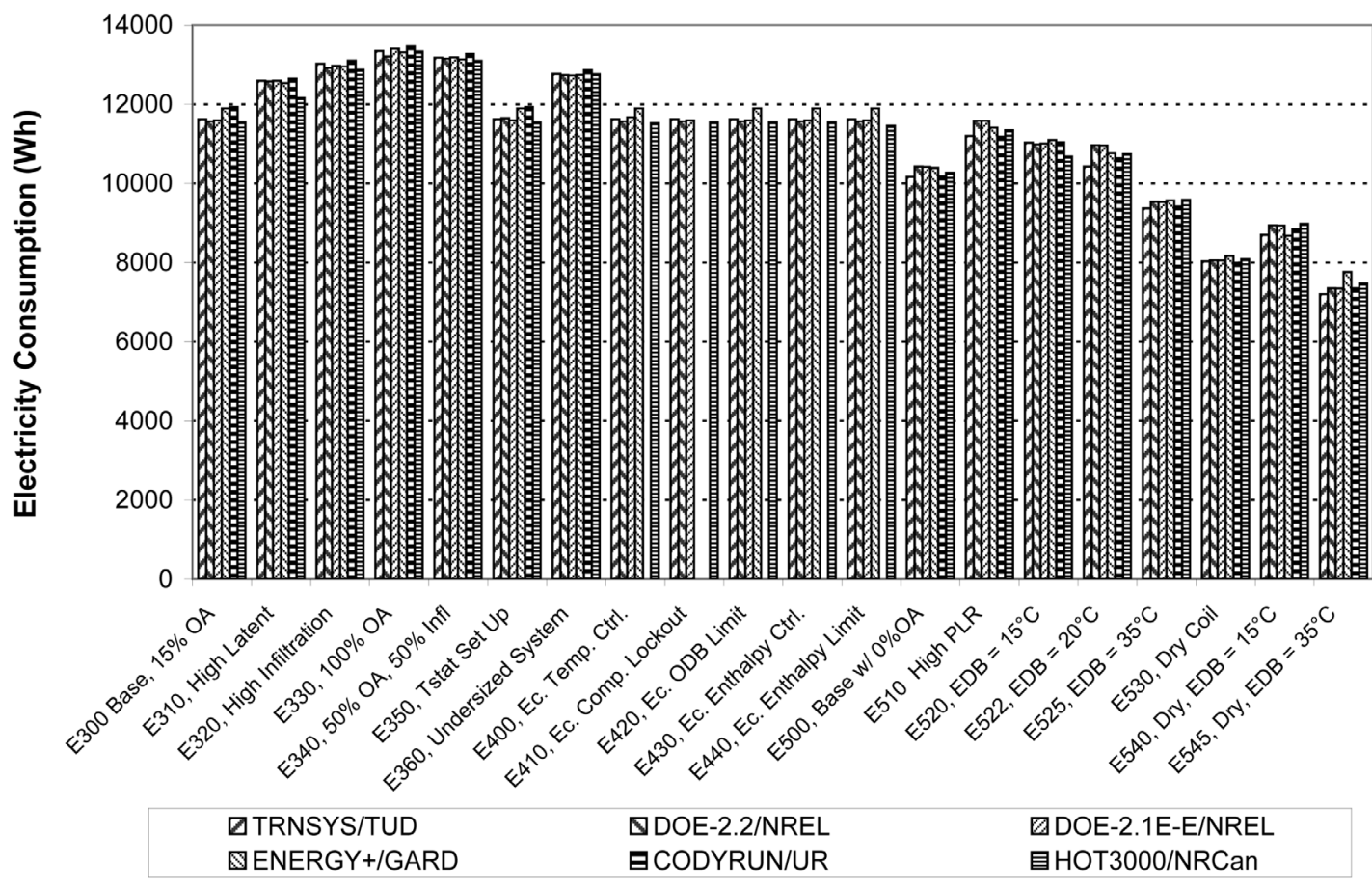

HVAC BESTEST: E300 - E545

Hourly Maximum Total Space Cooling Consumption Sensitivities

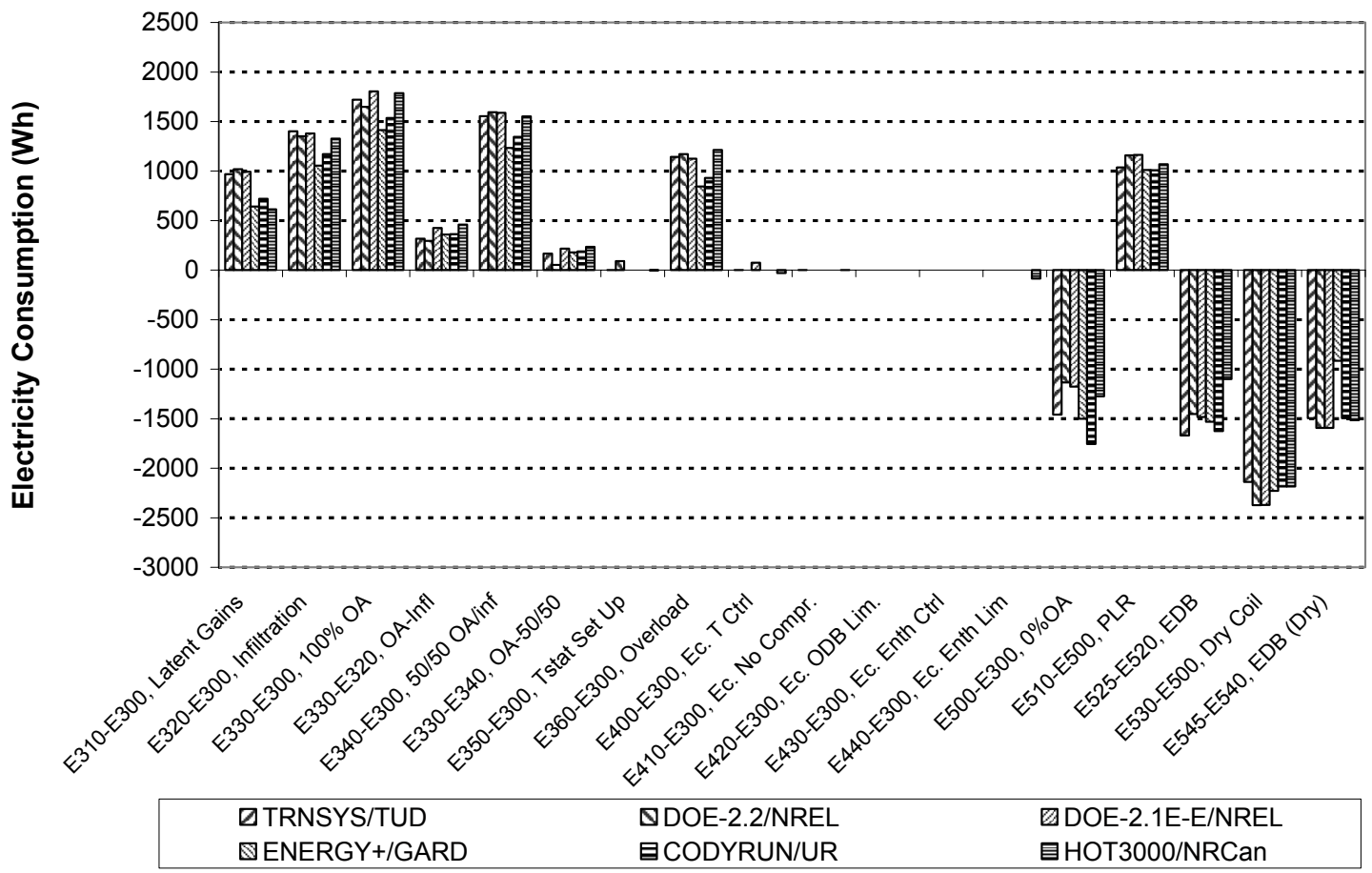


HVAC BESTEST: E300 - E545

Compressor Electricity Consumption

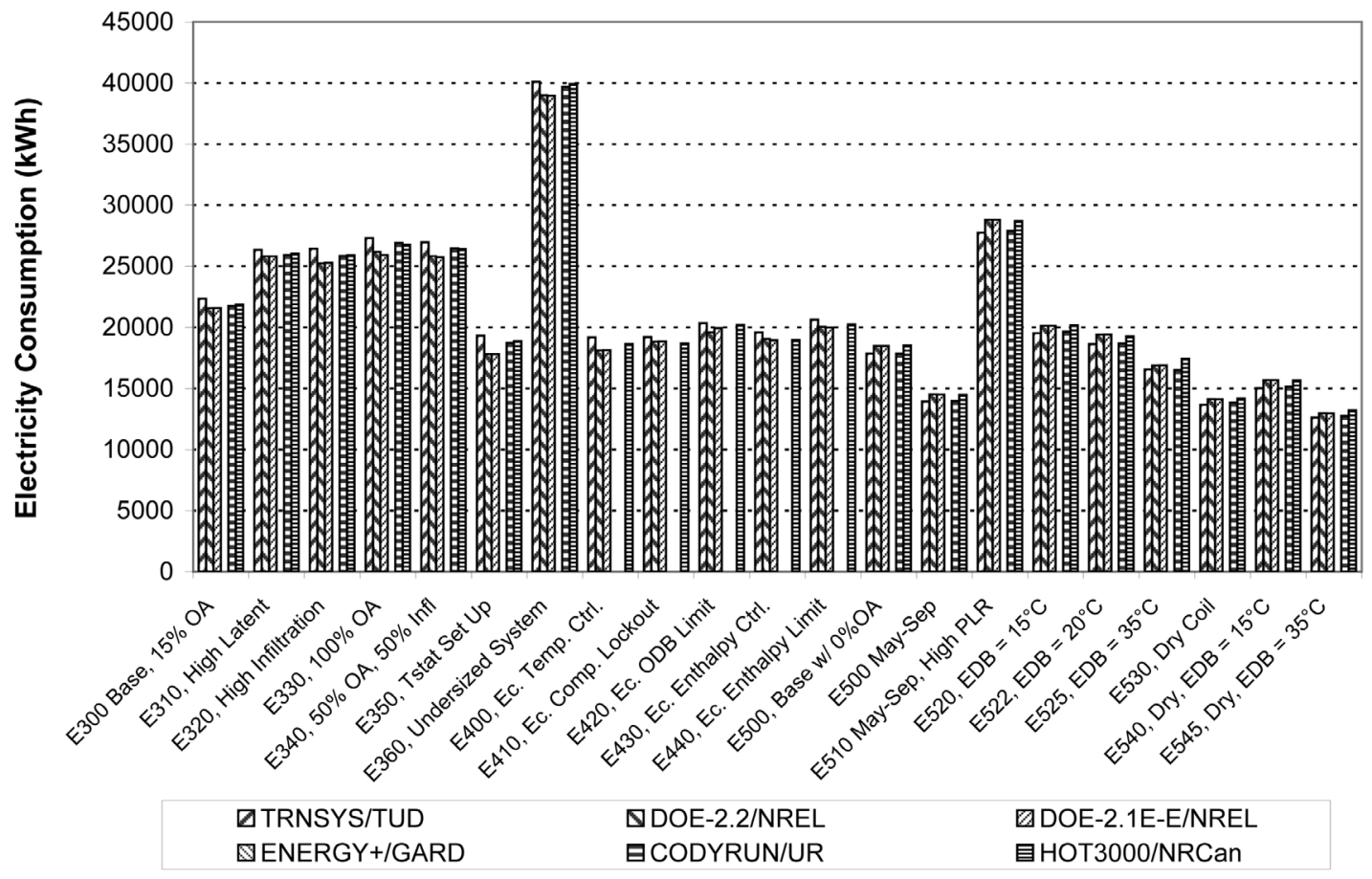

HVAC BESTEST: E300 - E545

Compressor Electricity Consumption Sensitivities

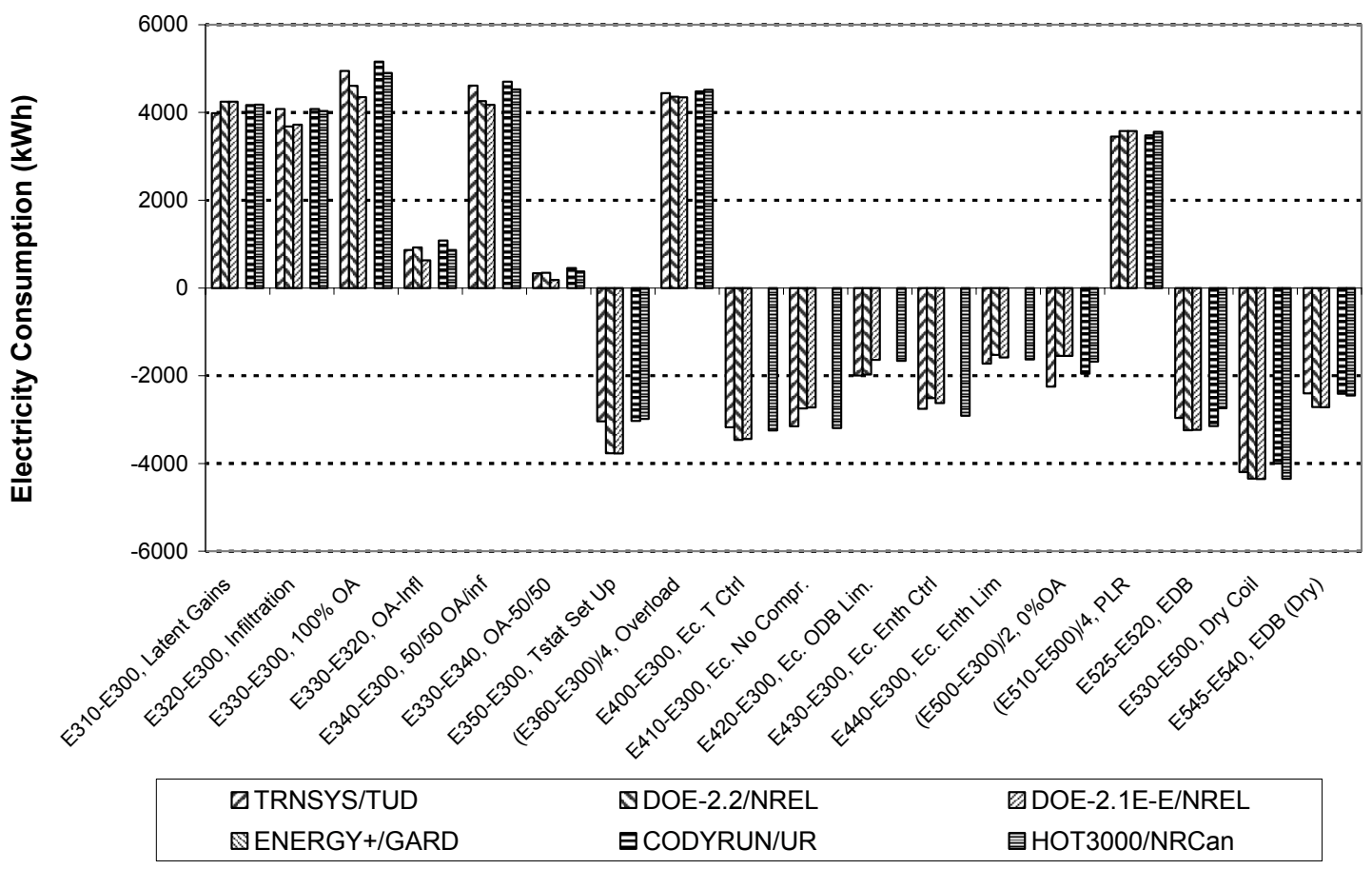



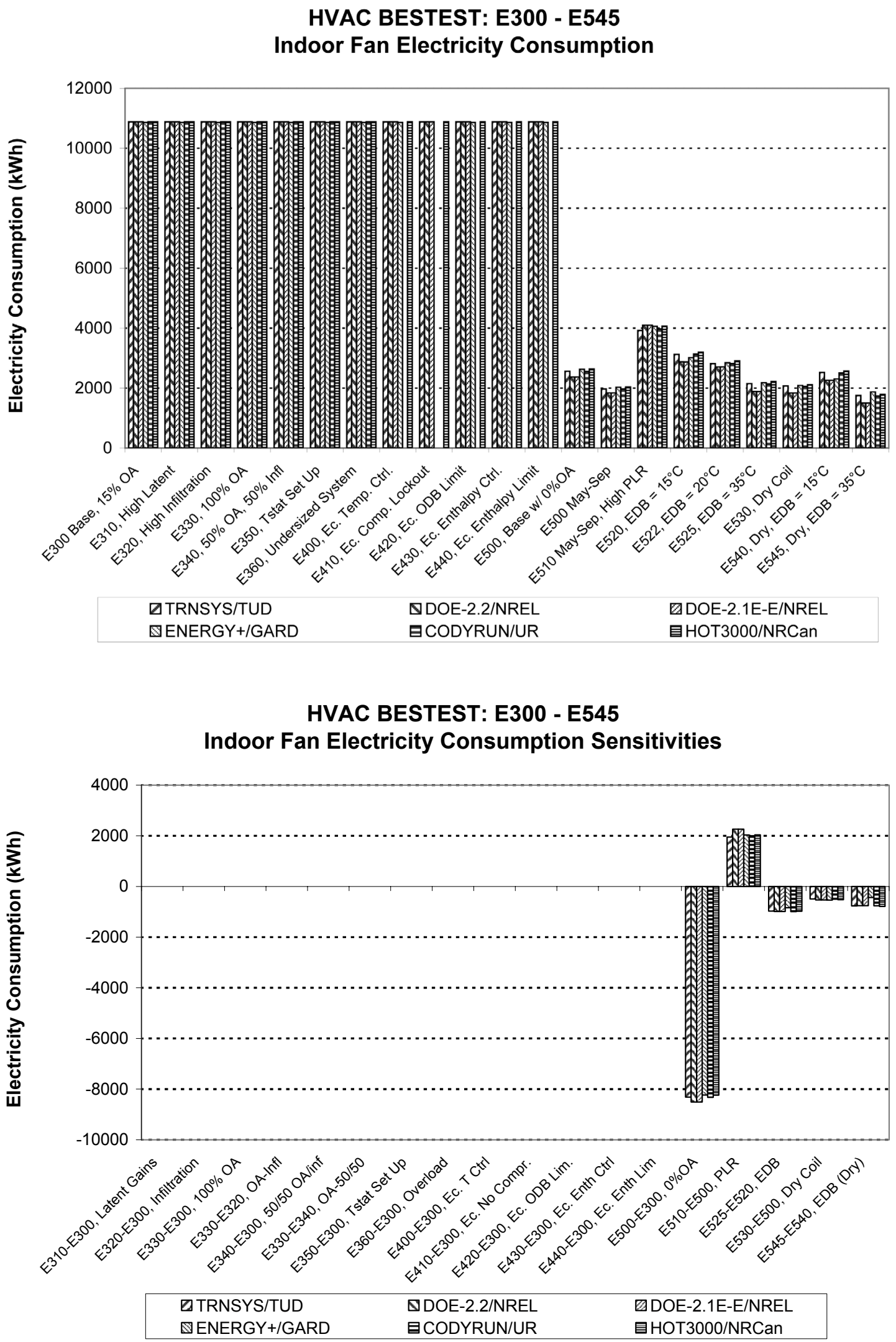
HVAC BESTEST: E300 - E545 Outdoor Fan Electricity Consumption

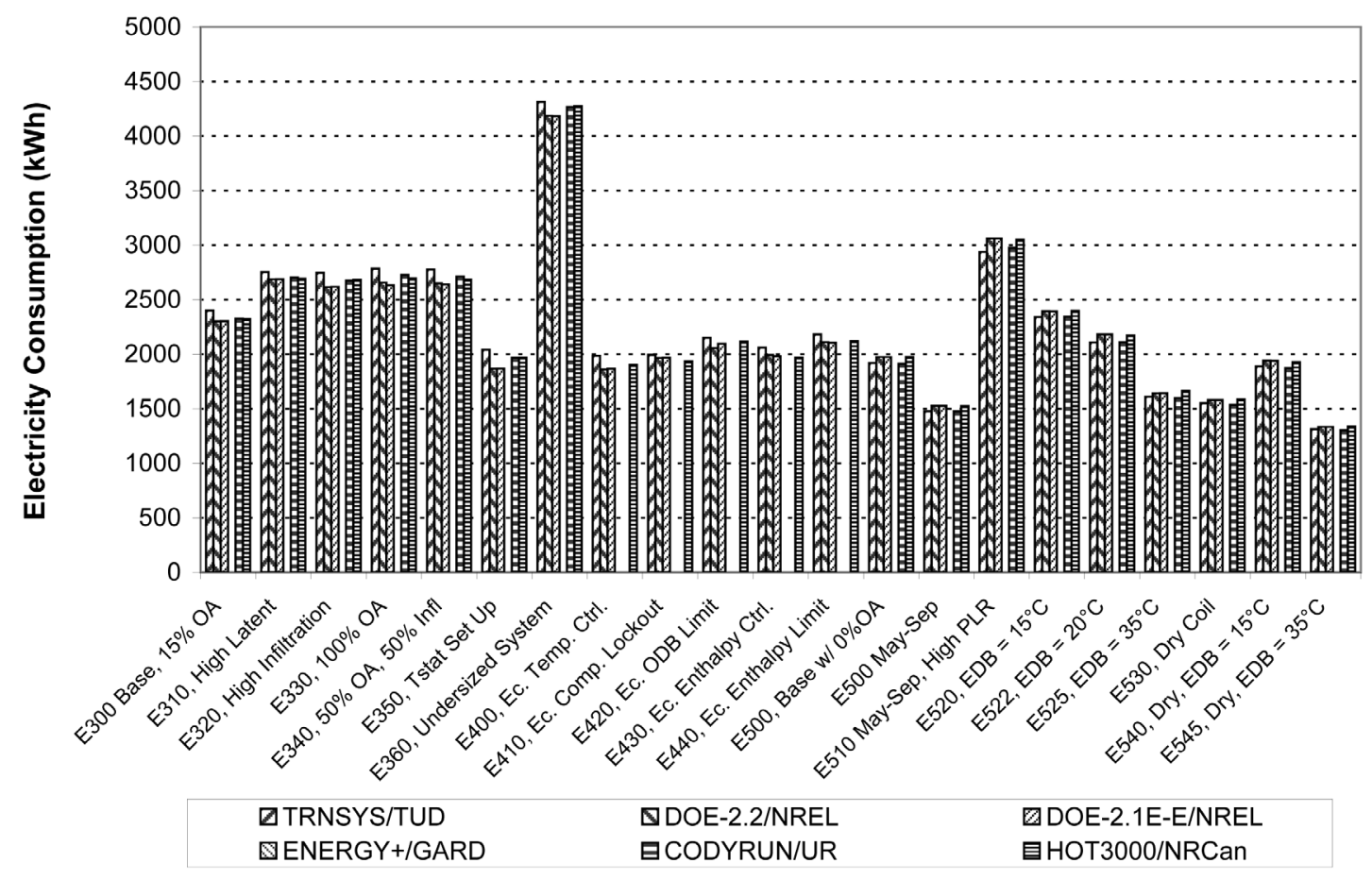

HVAC BESTEST: E300 - E545

Condenser Fan Electricity Consumption Sensitivities

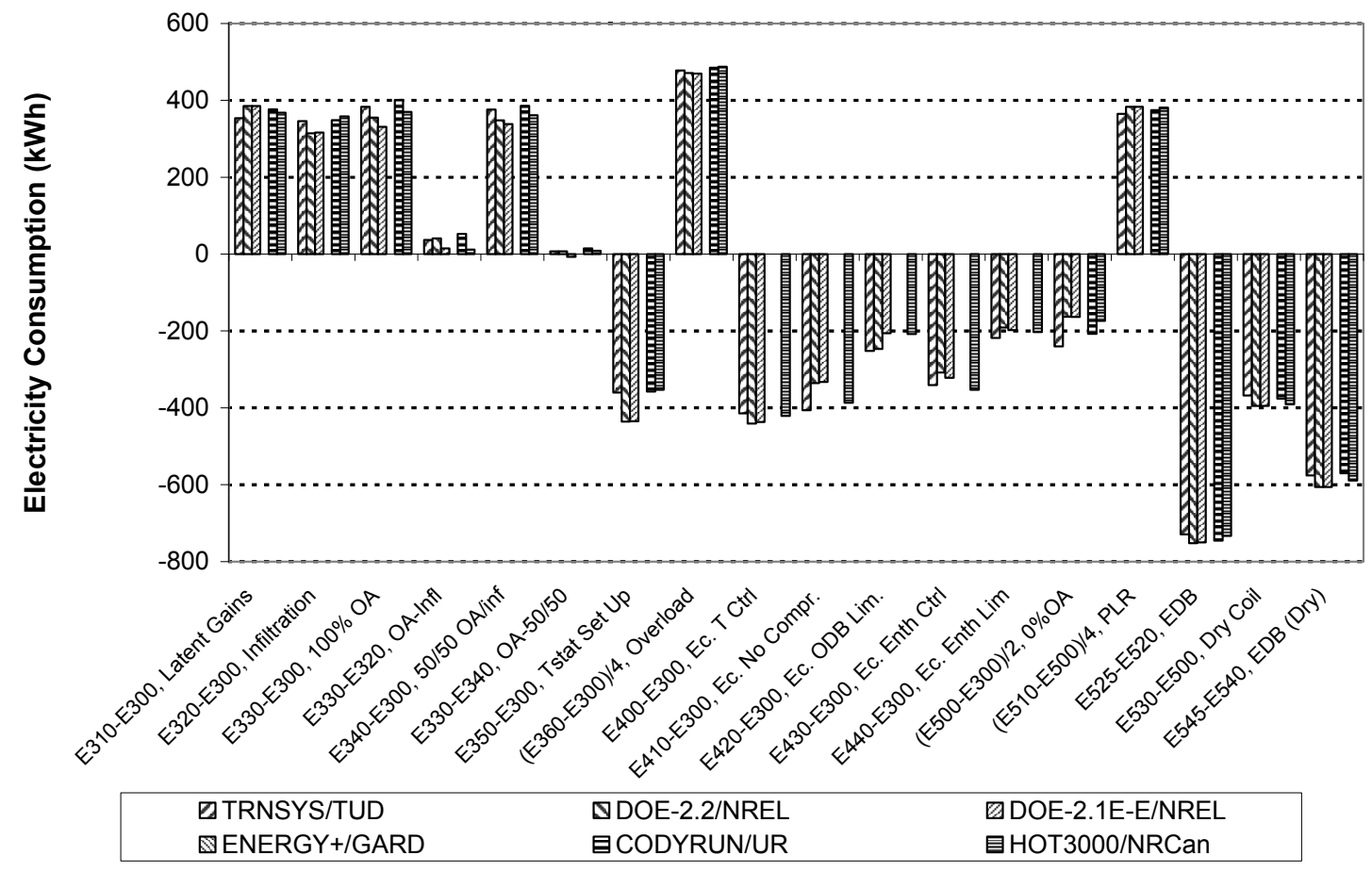


HVAC BESTEST: E300 - E545

Total Coil Load
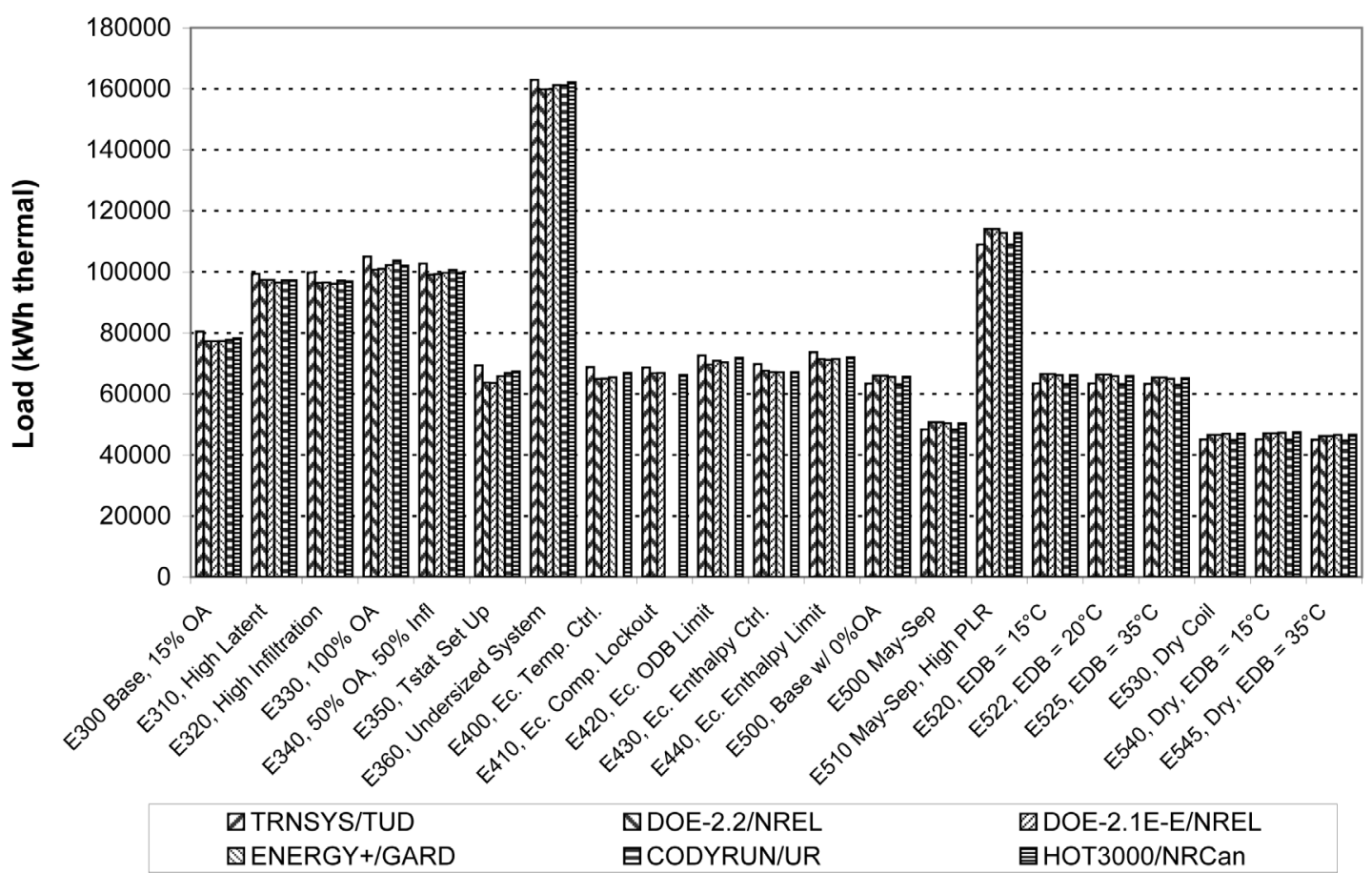


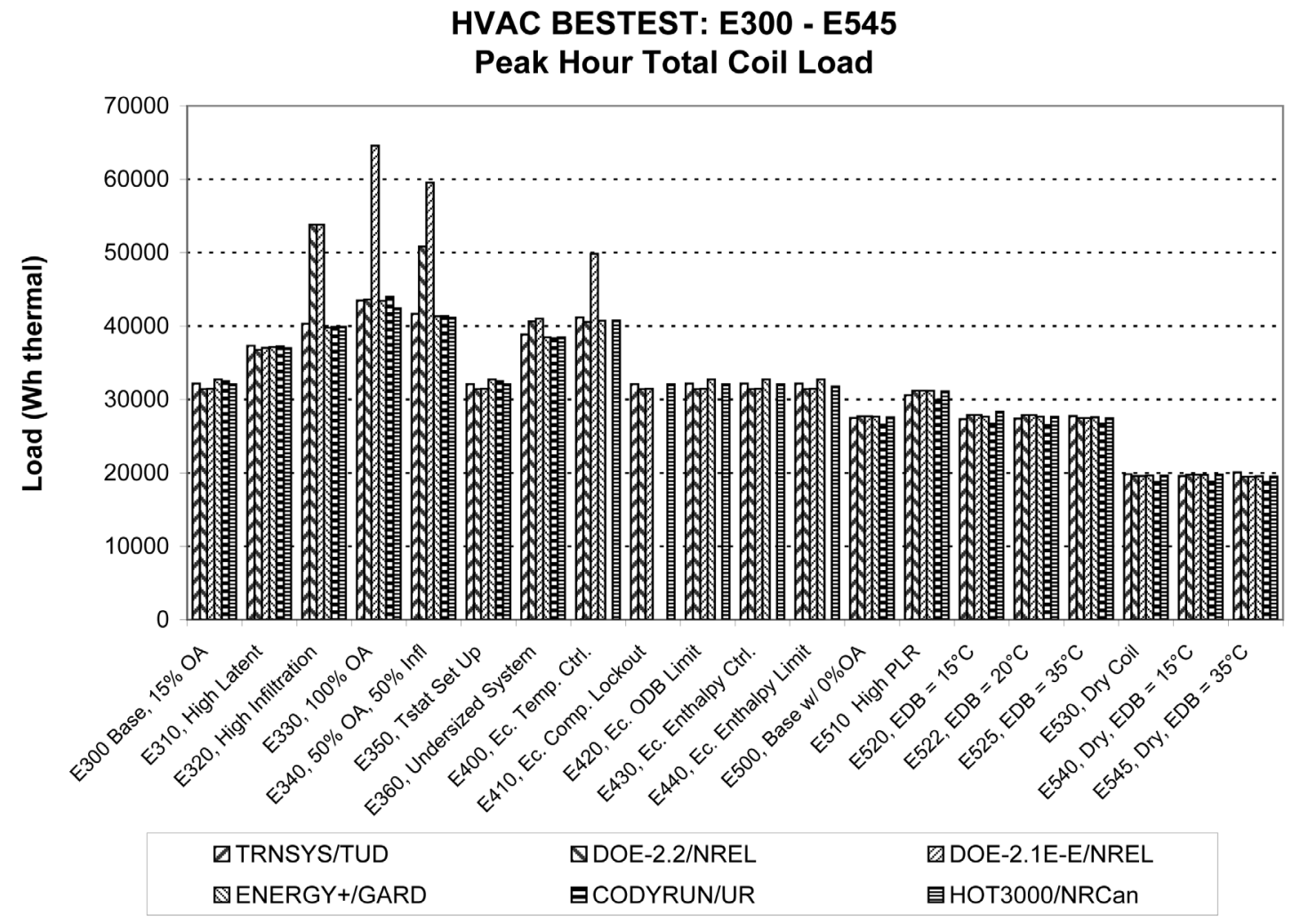

HVAC BESTEST: E300 - E545

Hourly Maximum Total Coil Load Sensitivities

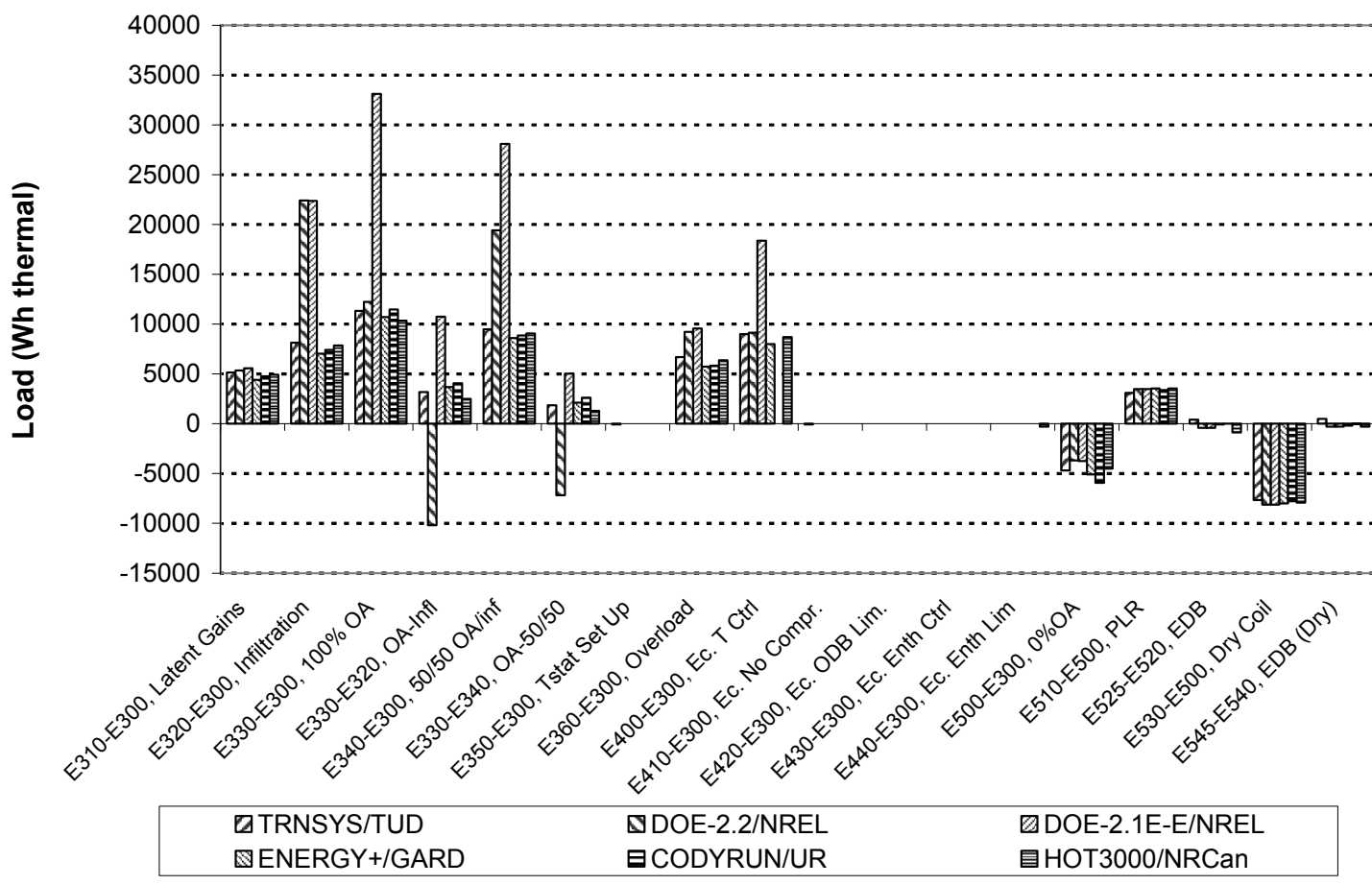


HVAC BESTEST: E300 - E545

Sensible Coil Load

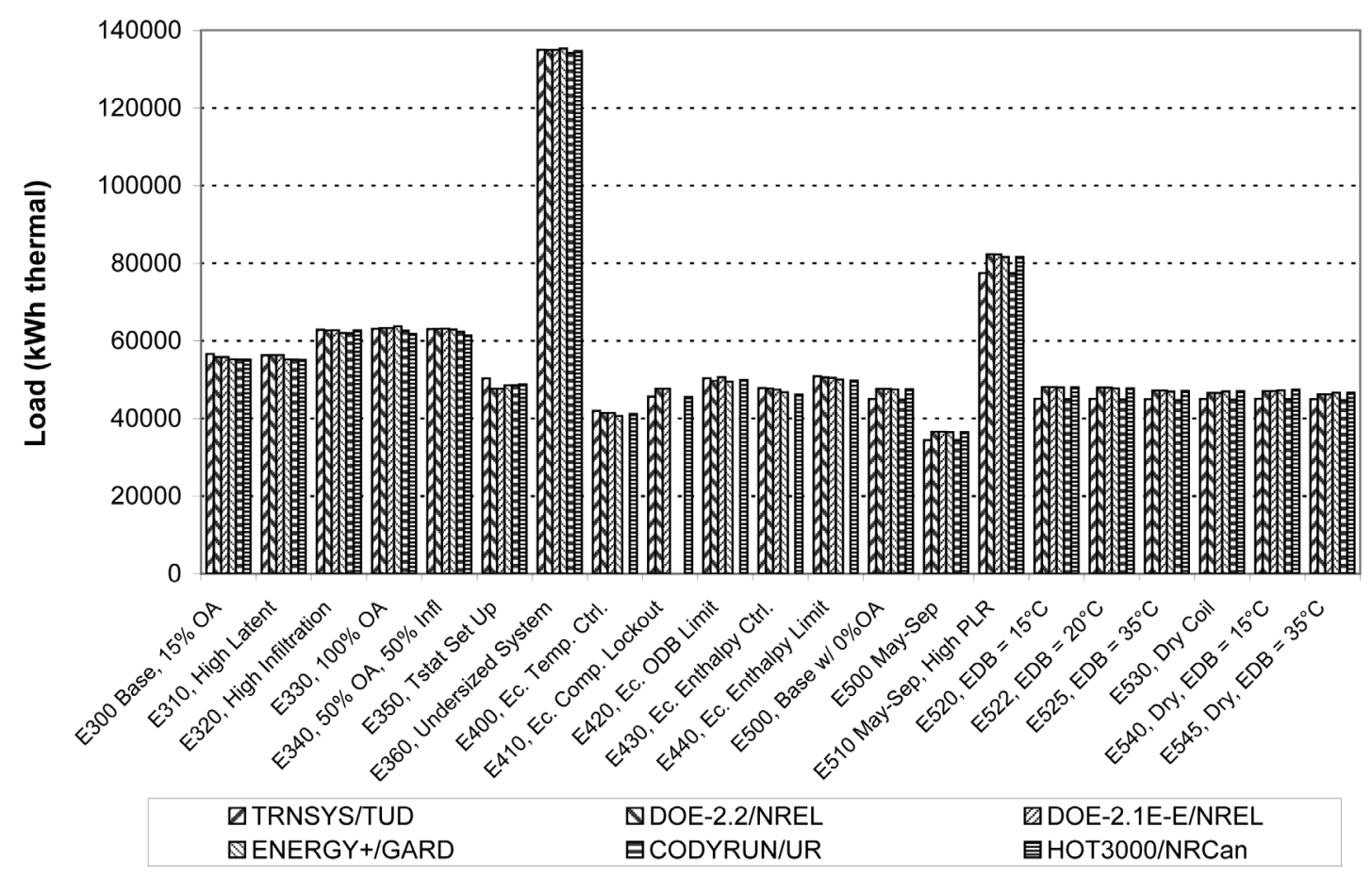

HVAC BESTEST: E300 - E545

Sensible Cooling Load Sensitivities

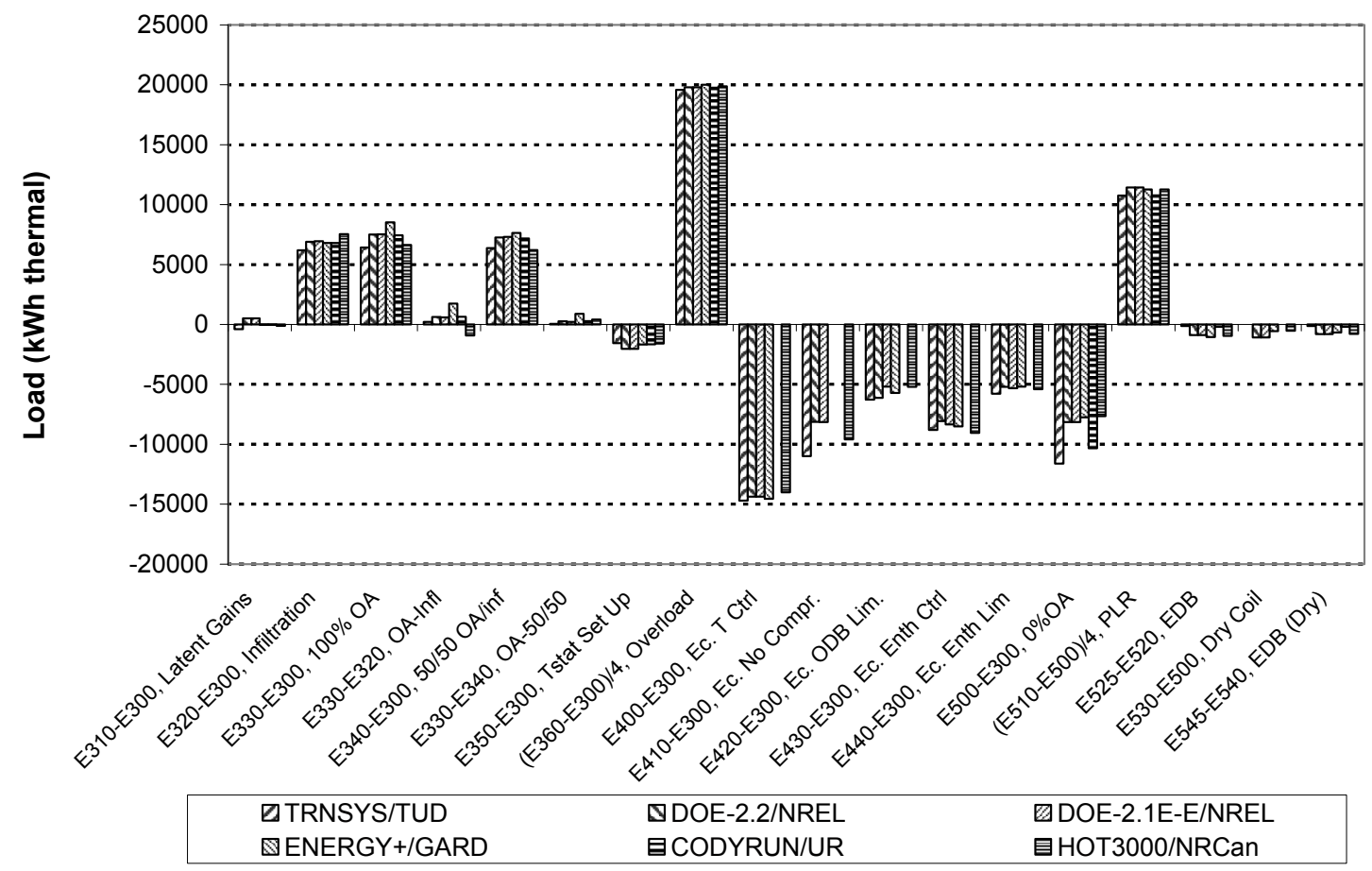




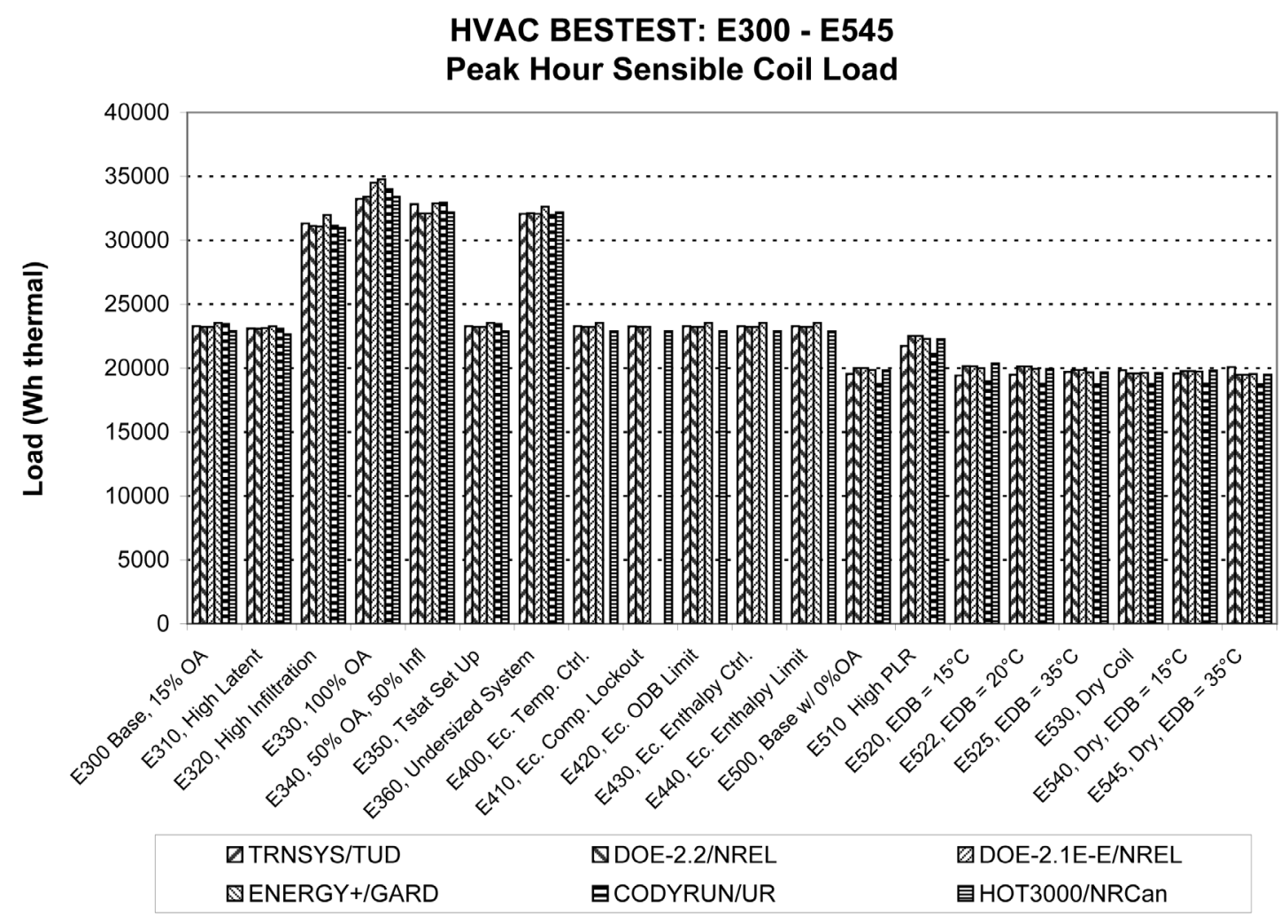


HVAC BESTEST: E300 - E545

Latent Coil Load

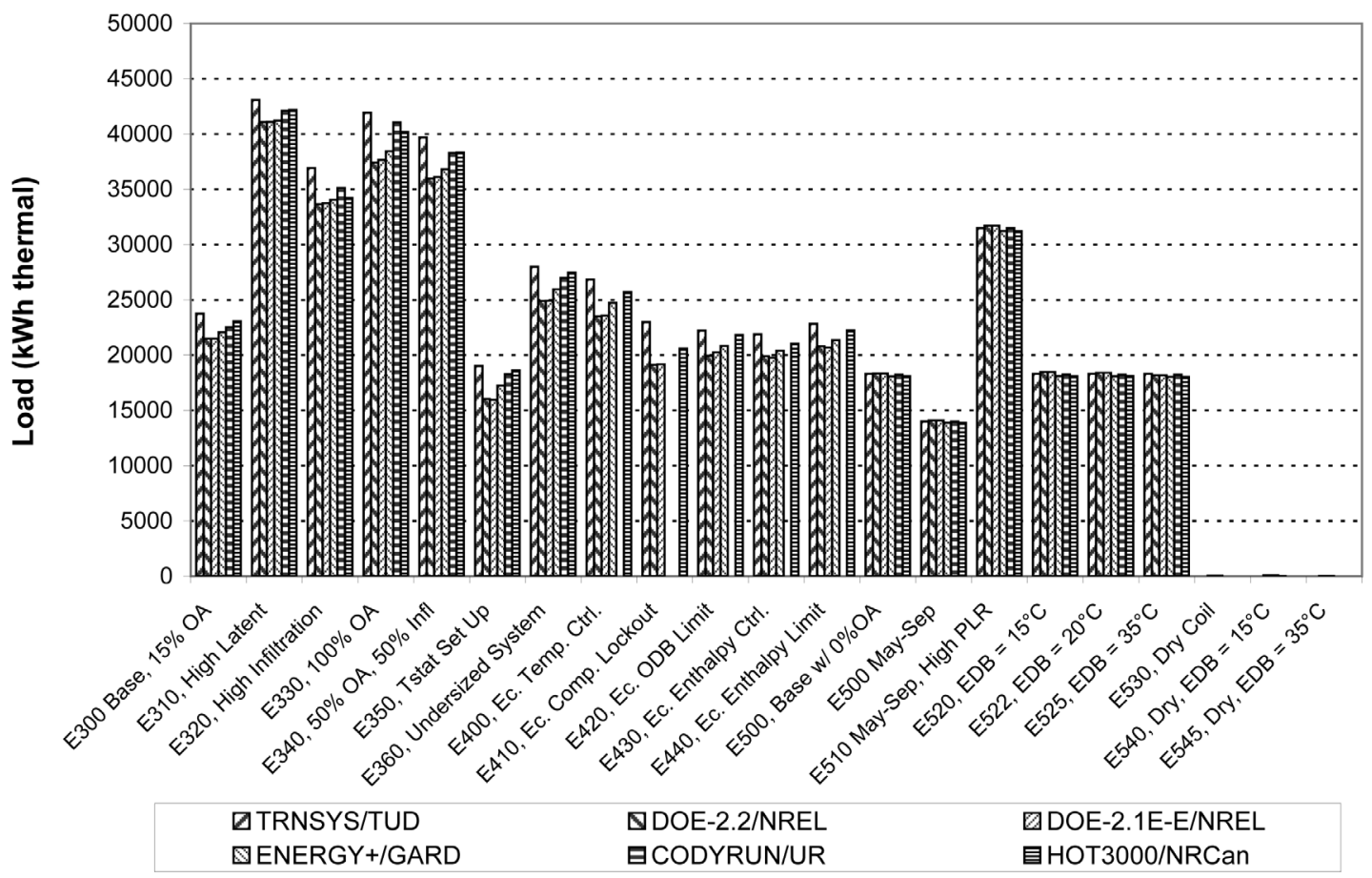

HVAC BESTEST: E300 - E545

Latent Cooling Load Sensitivities

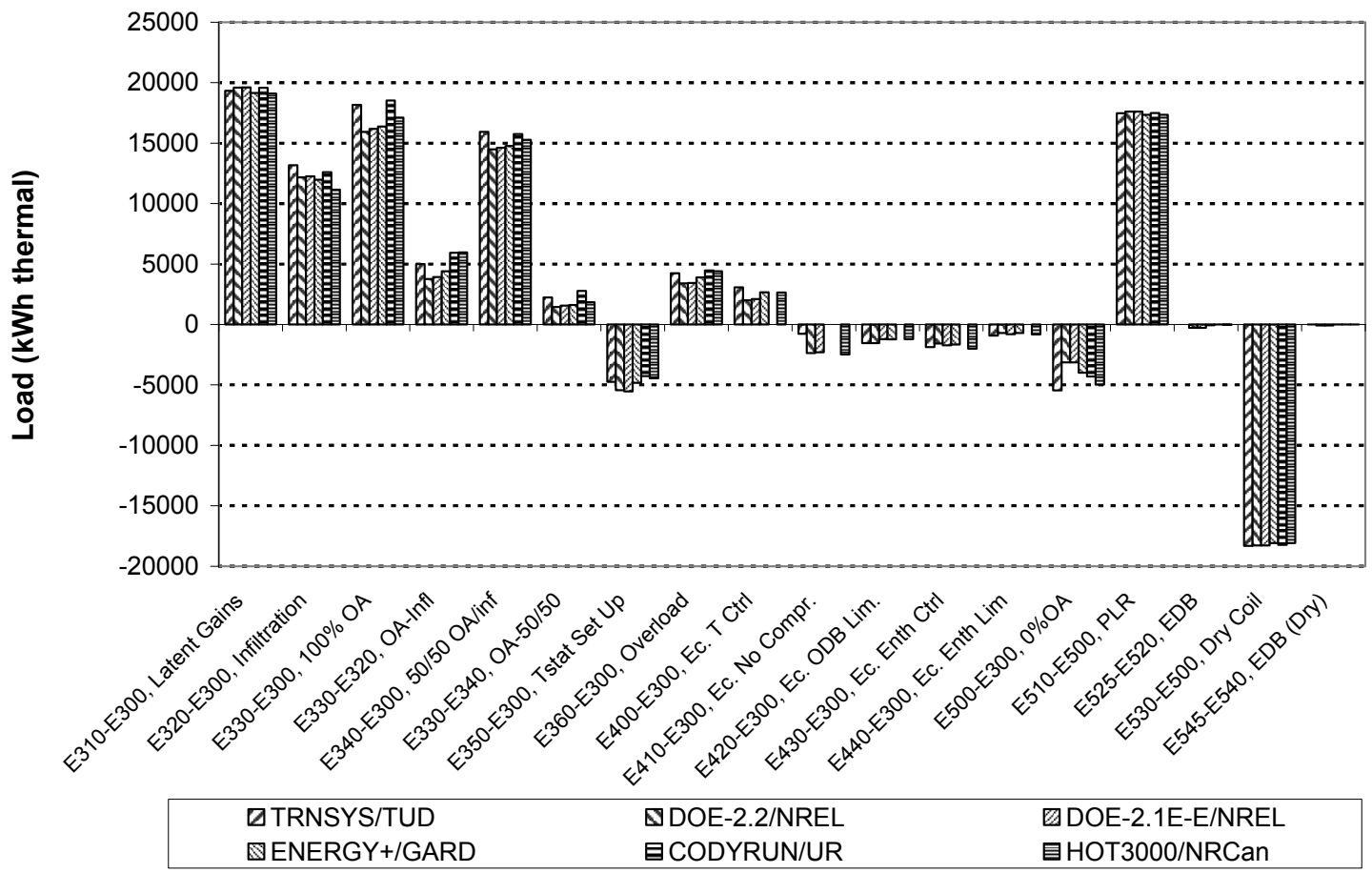




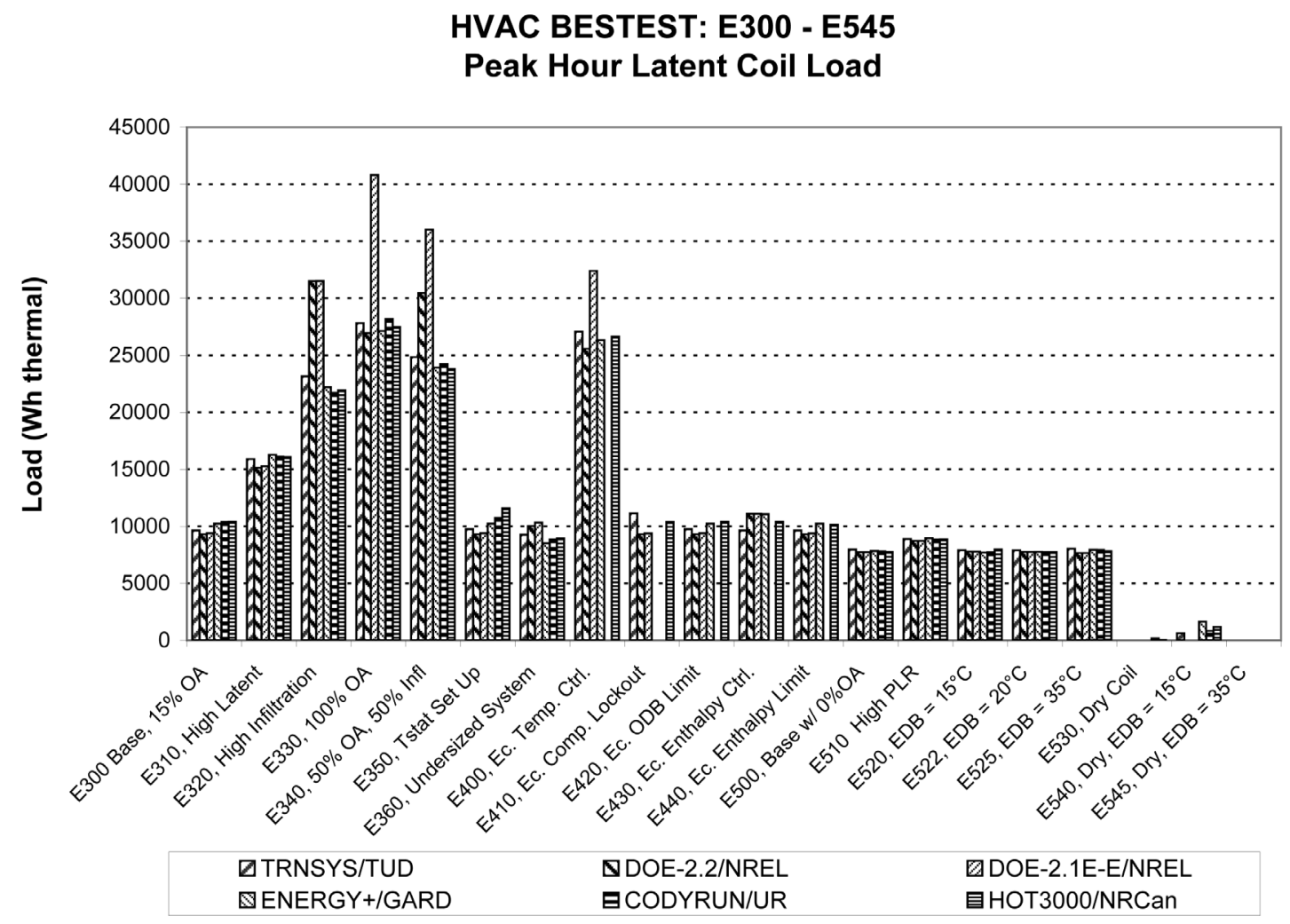

HVAC BESTEST: E300 - E545

Hourly Maximum Latent Coil Load Sensitivities

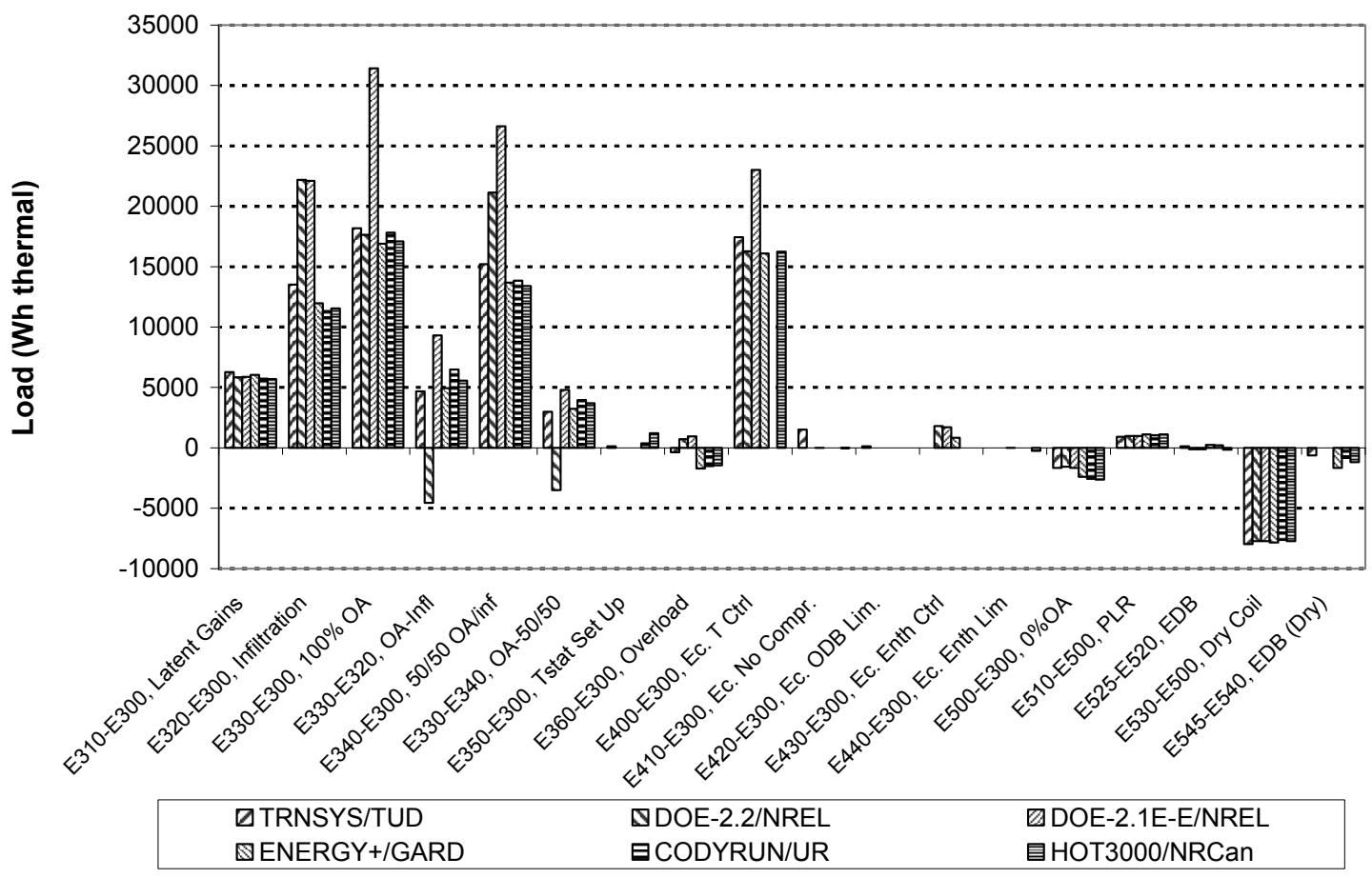


HVAC BESTEST: E300 - E545

COP2

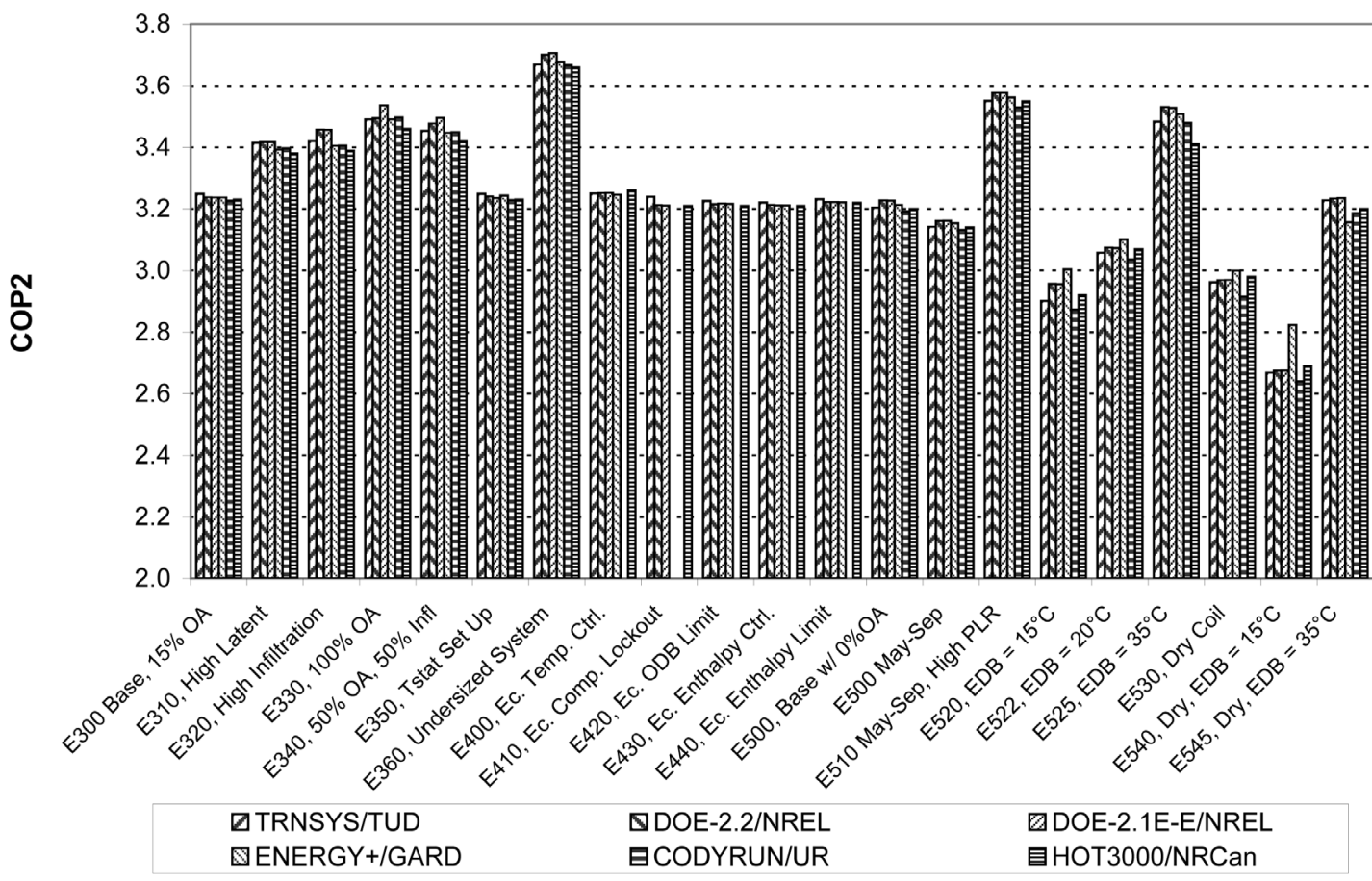

HVAC BESTEST: E300 - E545

COP2 Sensitivities

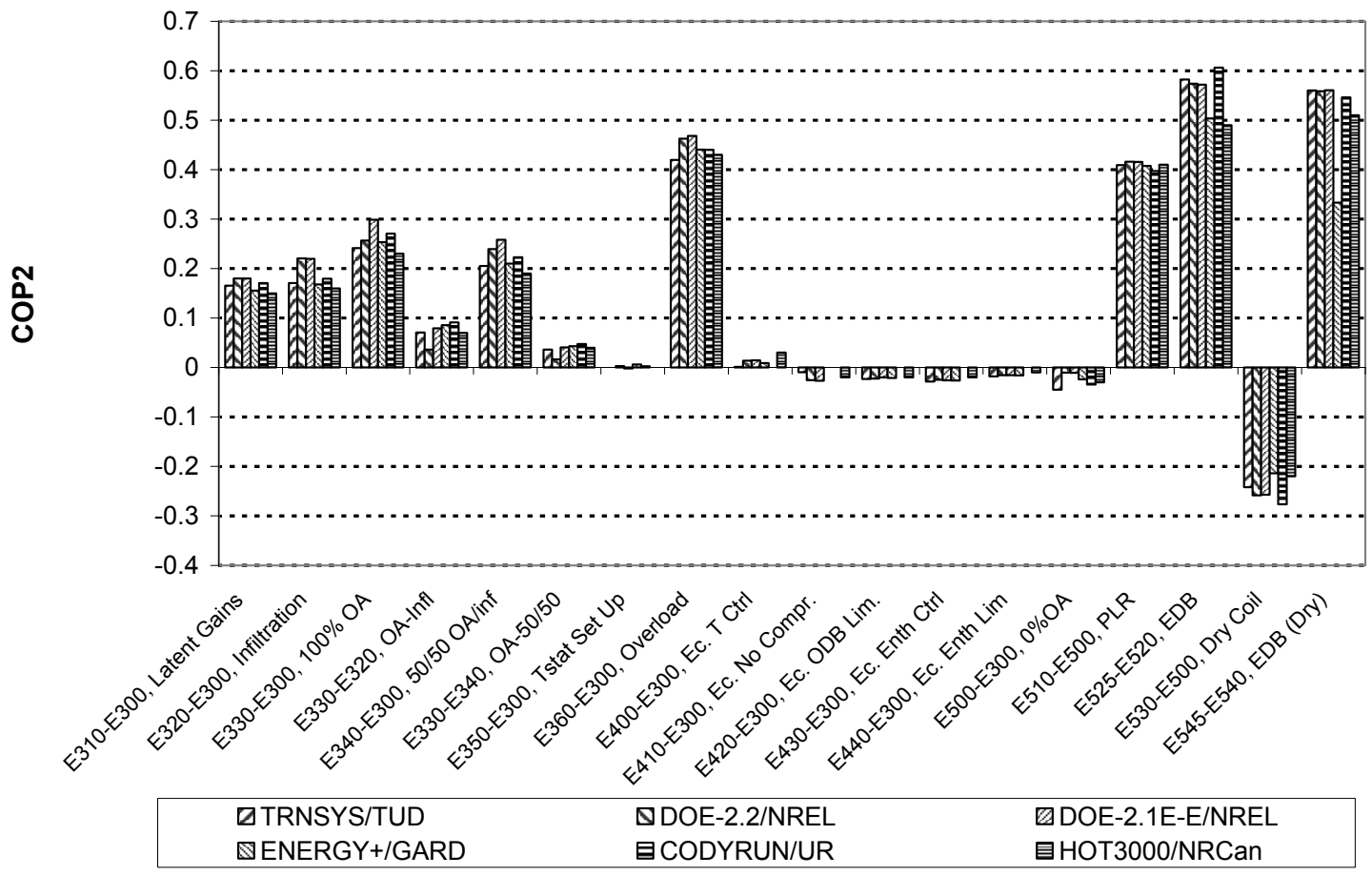


HVAC BESTEST: E300 - E545

Maximum COP2
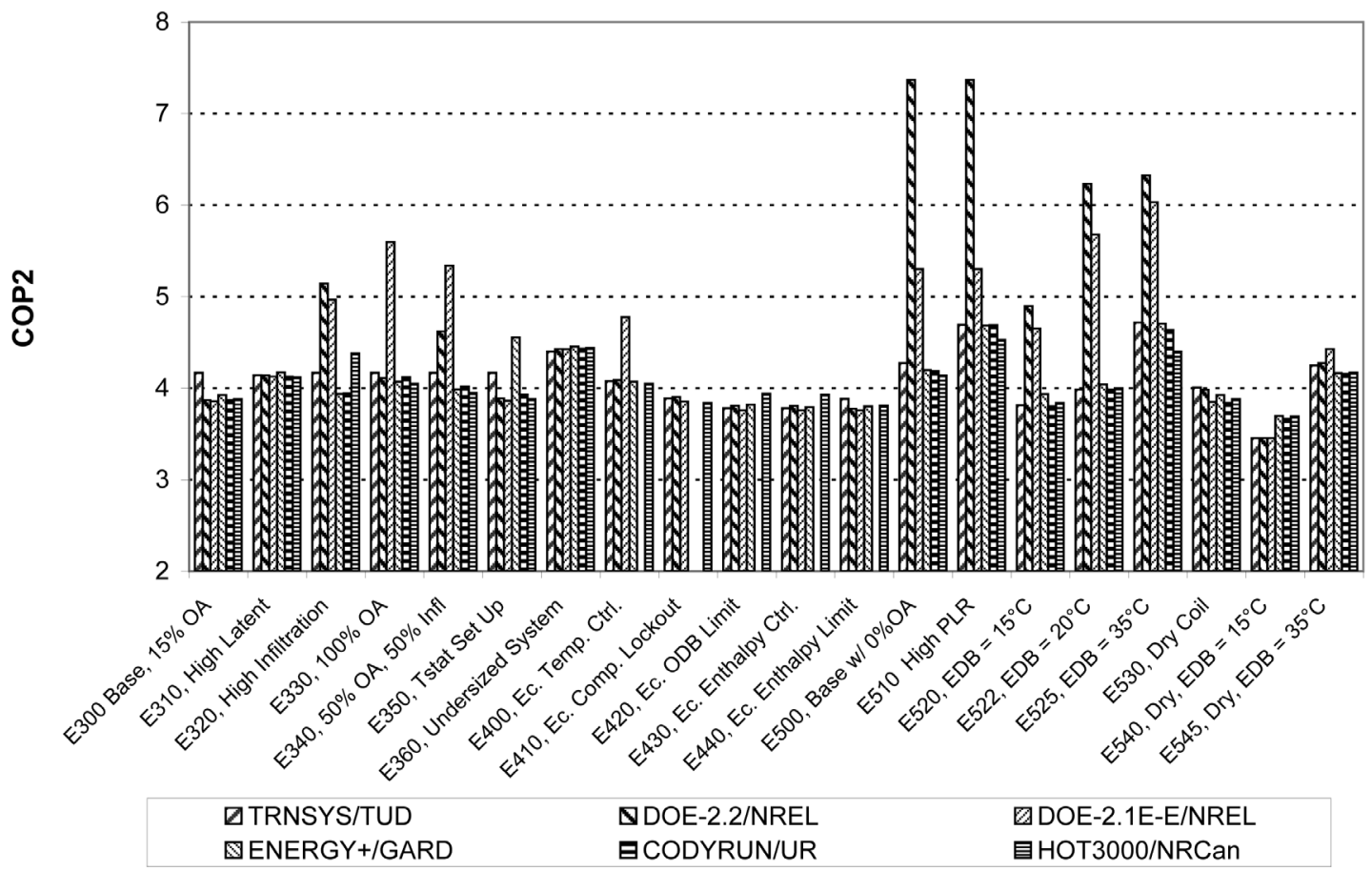

HVAC BESTEST: E300 - E545

Hourly Maximum COP2 Sensitivities

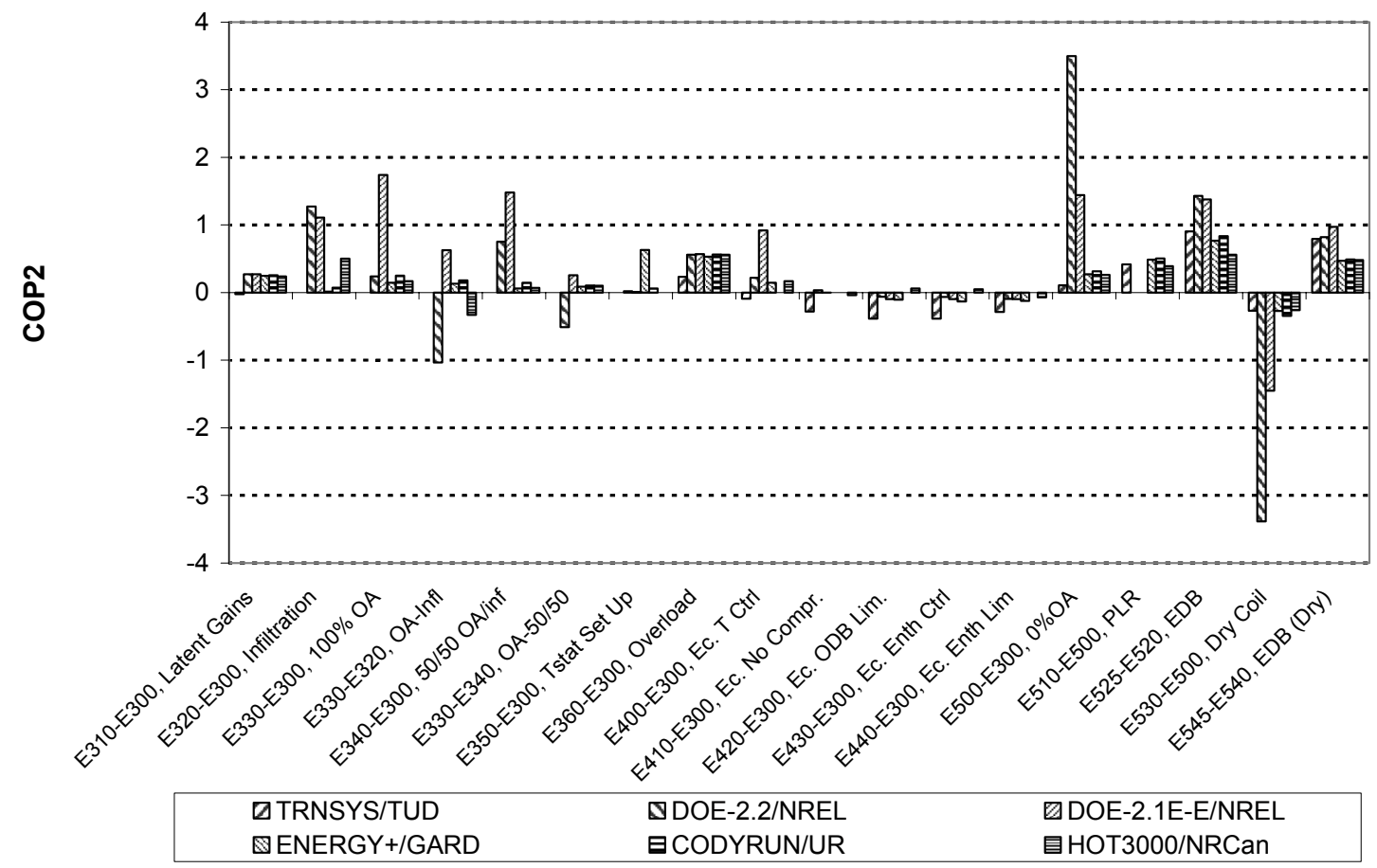


HVAC BESTEST: E300 - E545

Minimum COP2

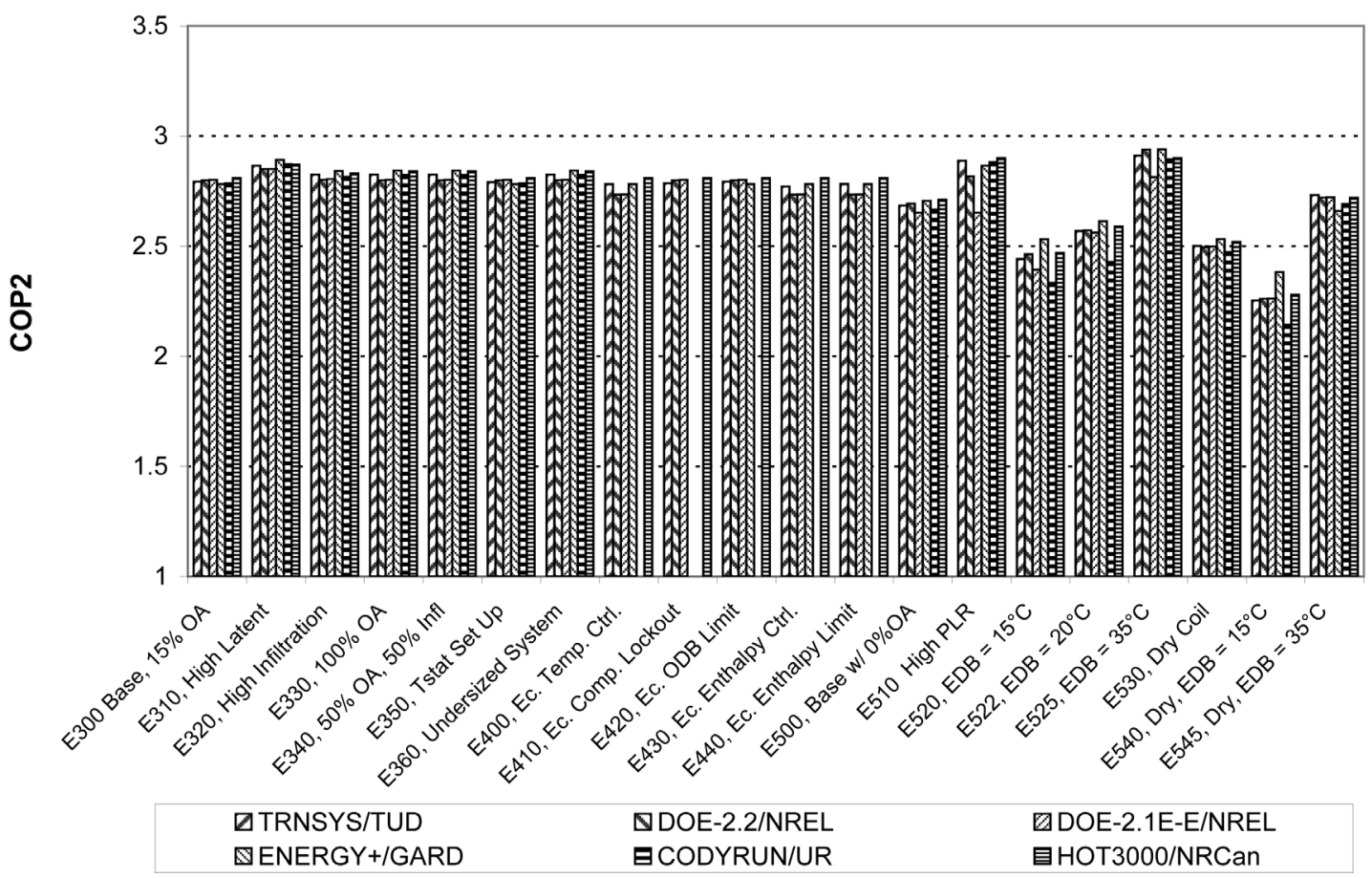

HVAC BESTEST: E300 - E545

Hourly Minimum COP2 Sensitivities

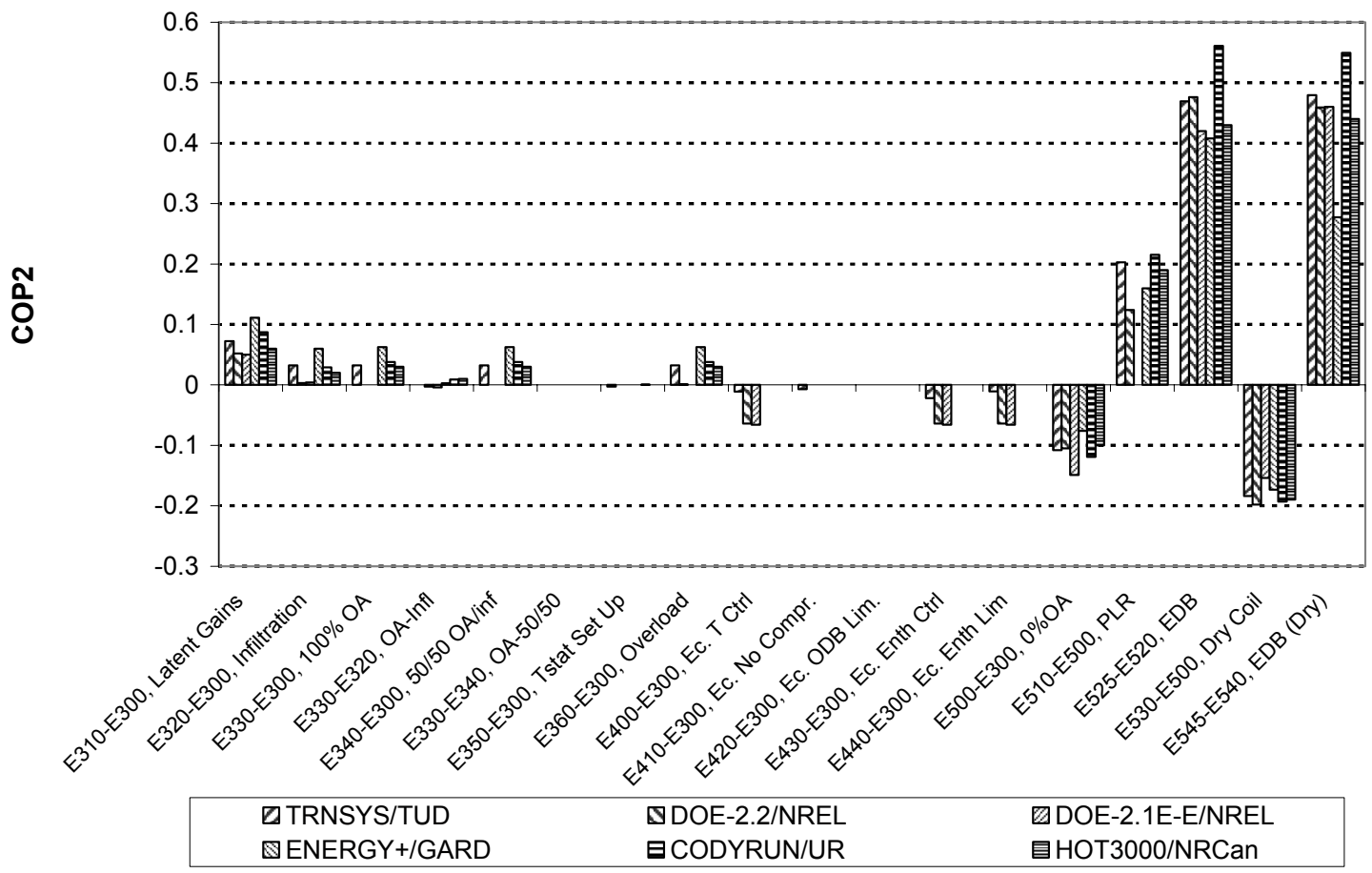




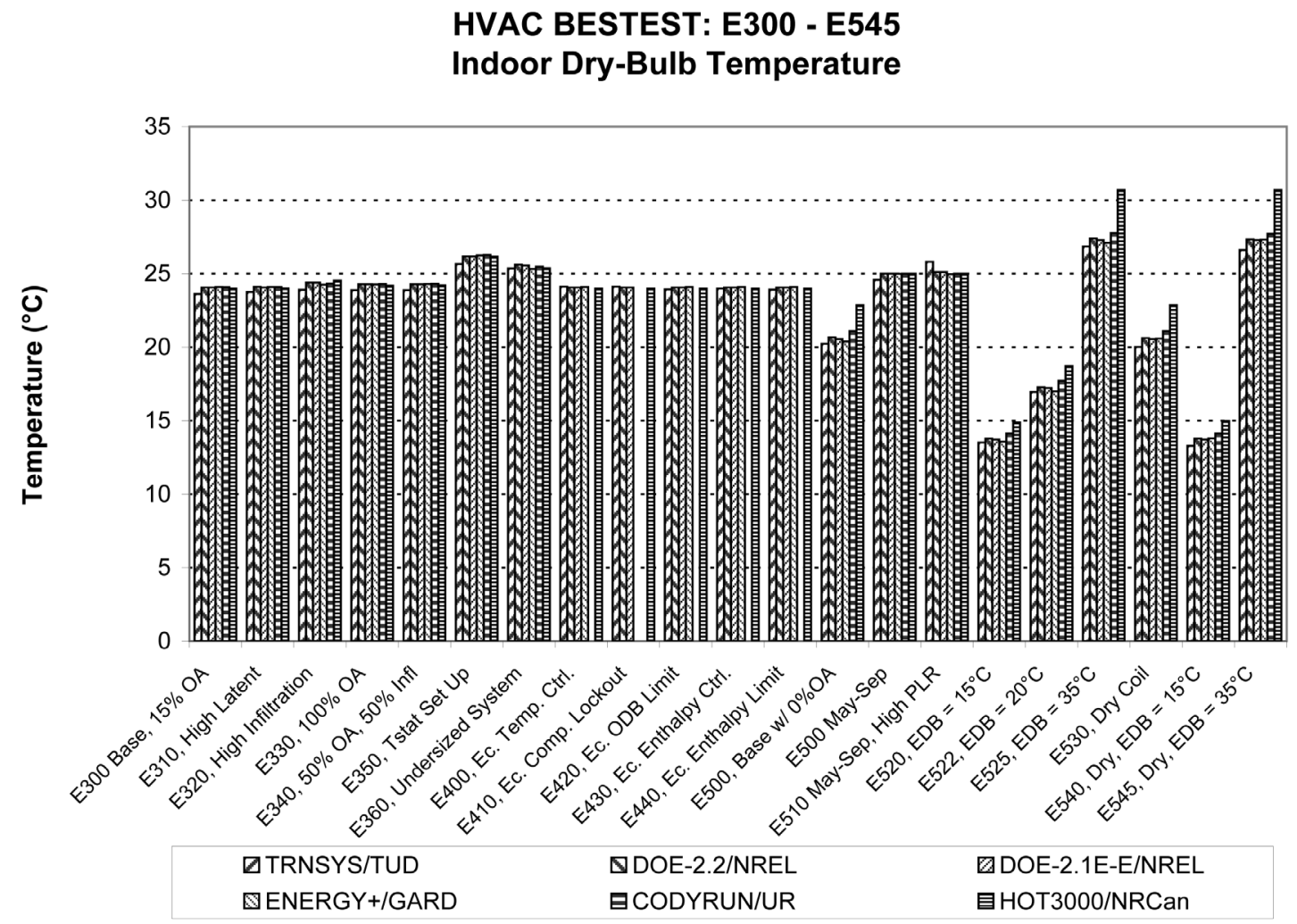

HVAC BESTEST: E300 - E545

IDB Sensitivities

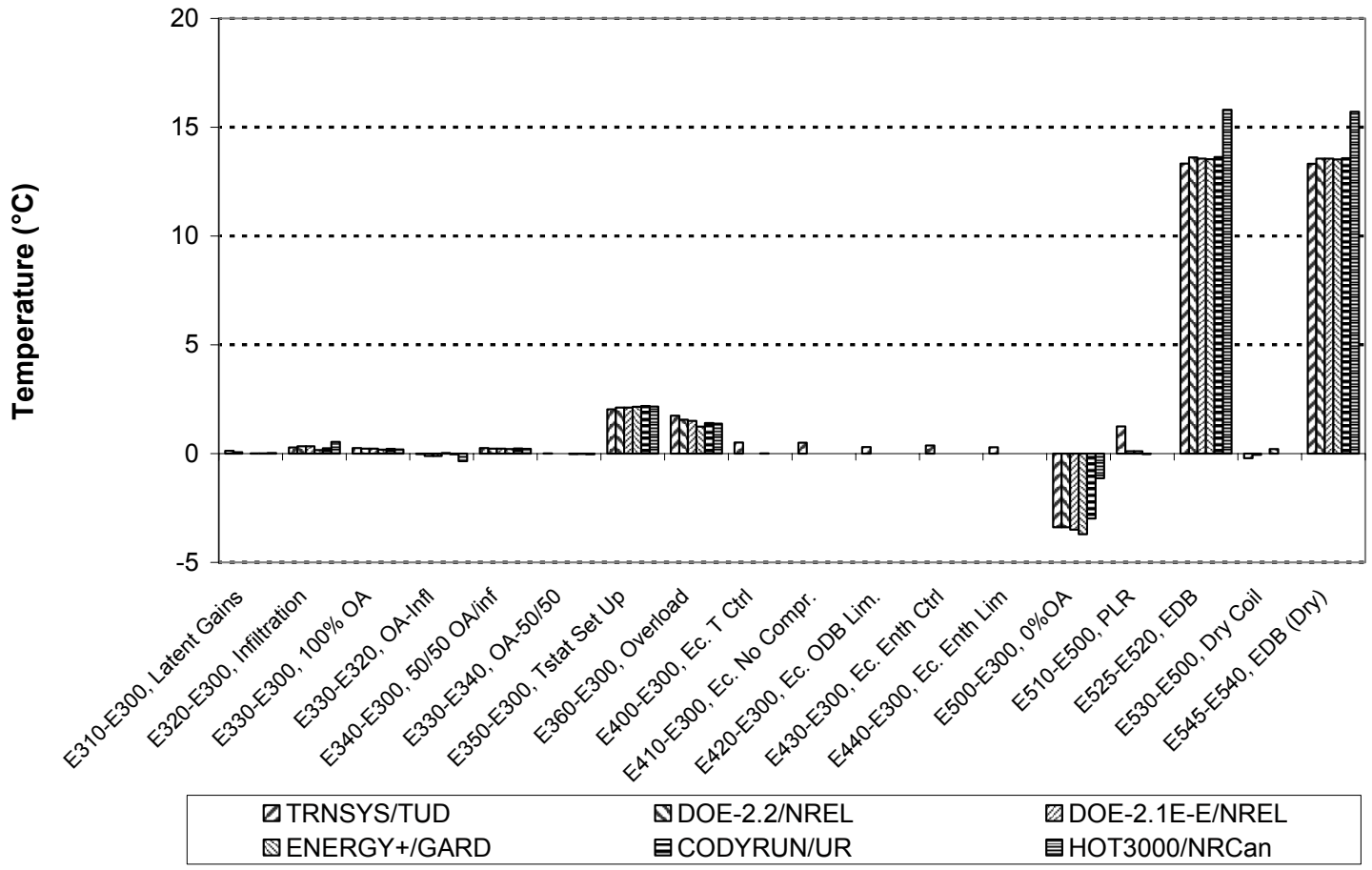


HVAC BESTEST: E300 - E545

Maximum Indoor Dry-Bulb Temperature

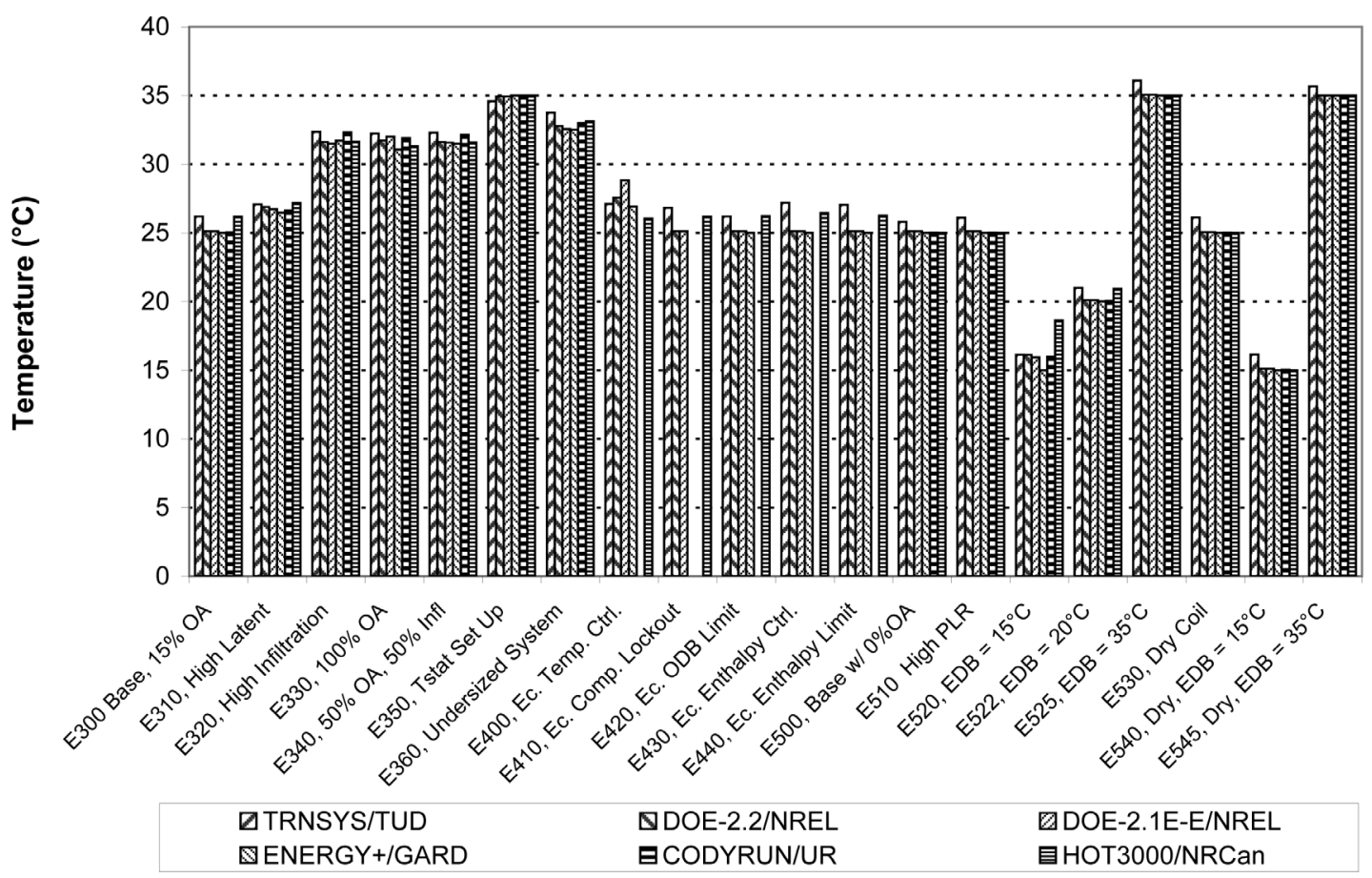

HVAC BESTEST: E300 - E545

Hourly Maximum IDB Sensitivities

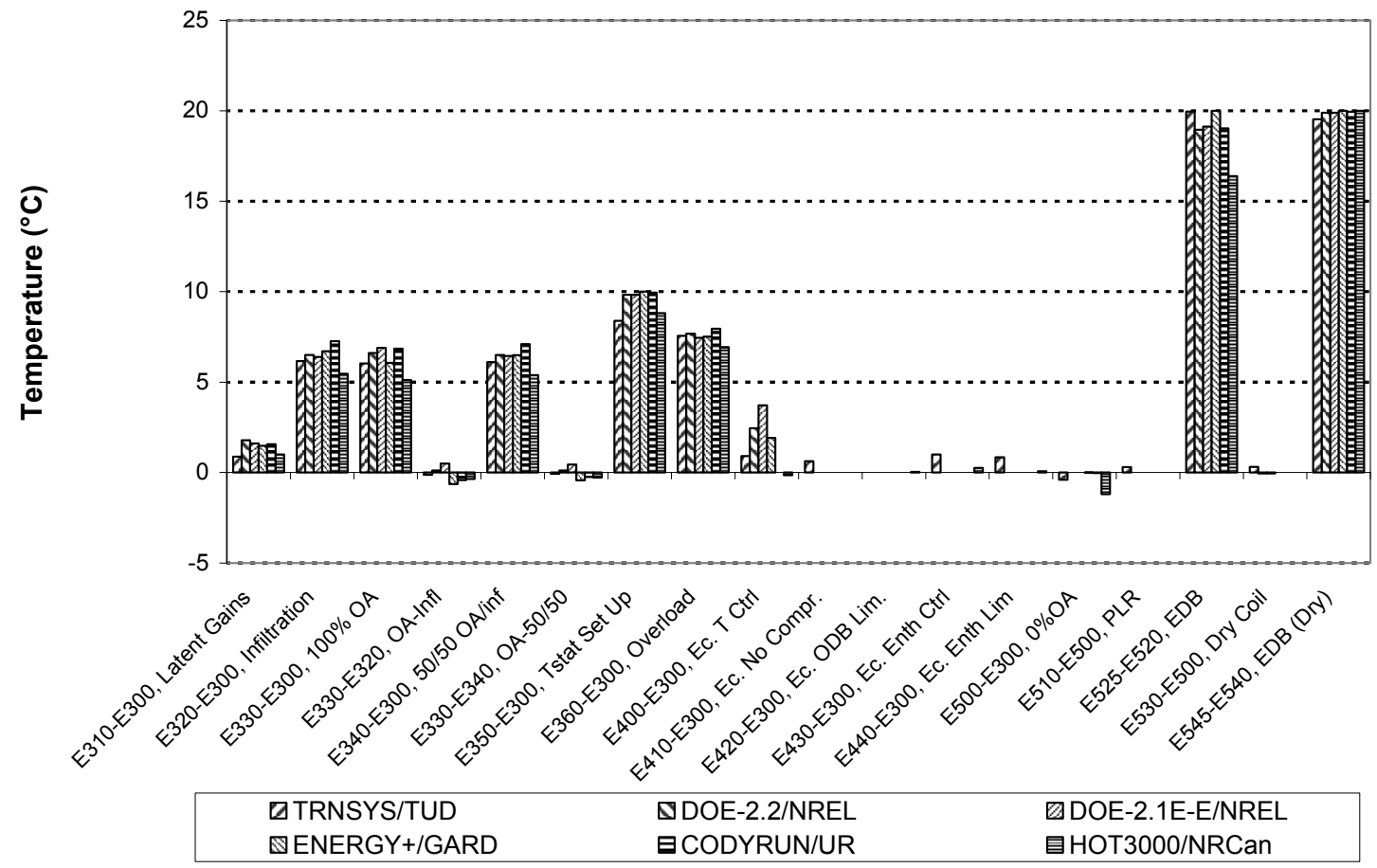


HVAC BESTEST: E300 - E545

Minimum Indoor Dry-Bulb Temperature

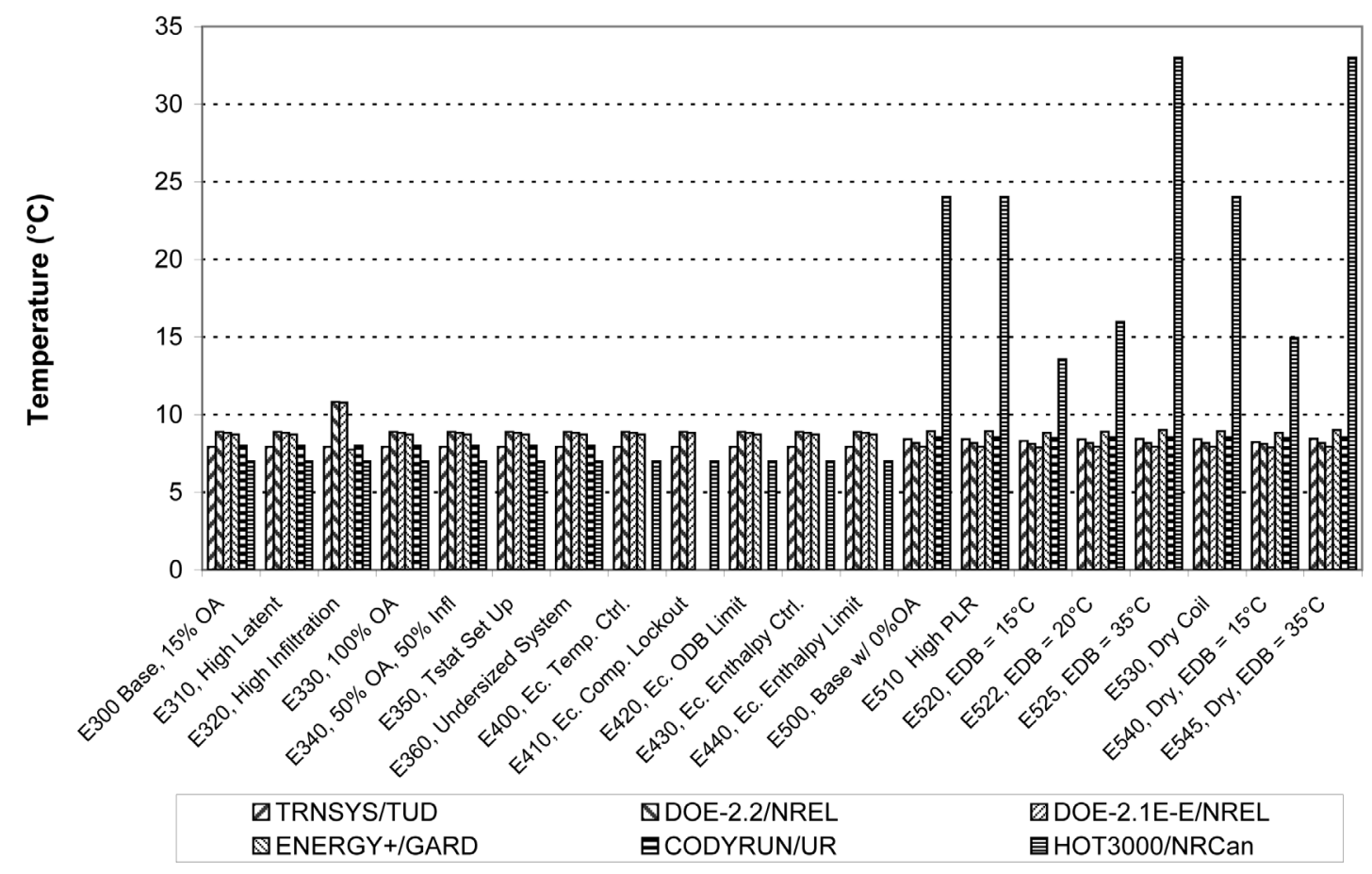




\section{HVAC BESTEST: E300 - E545}

Zone Humidity Ratio

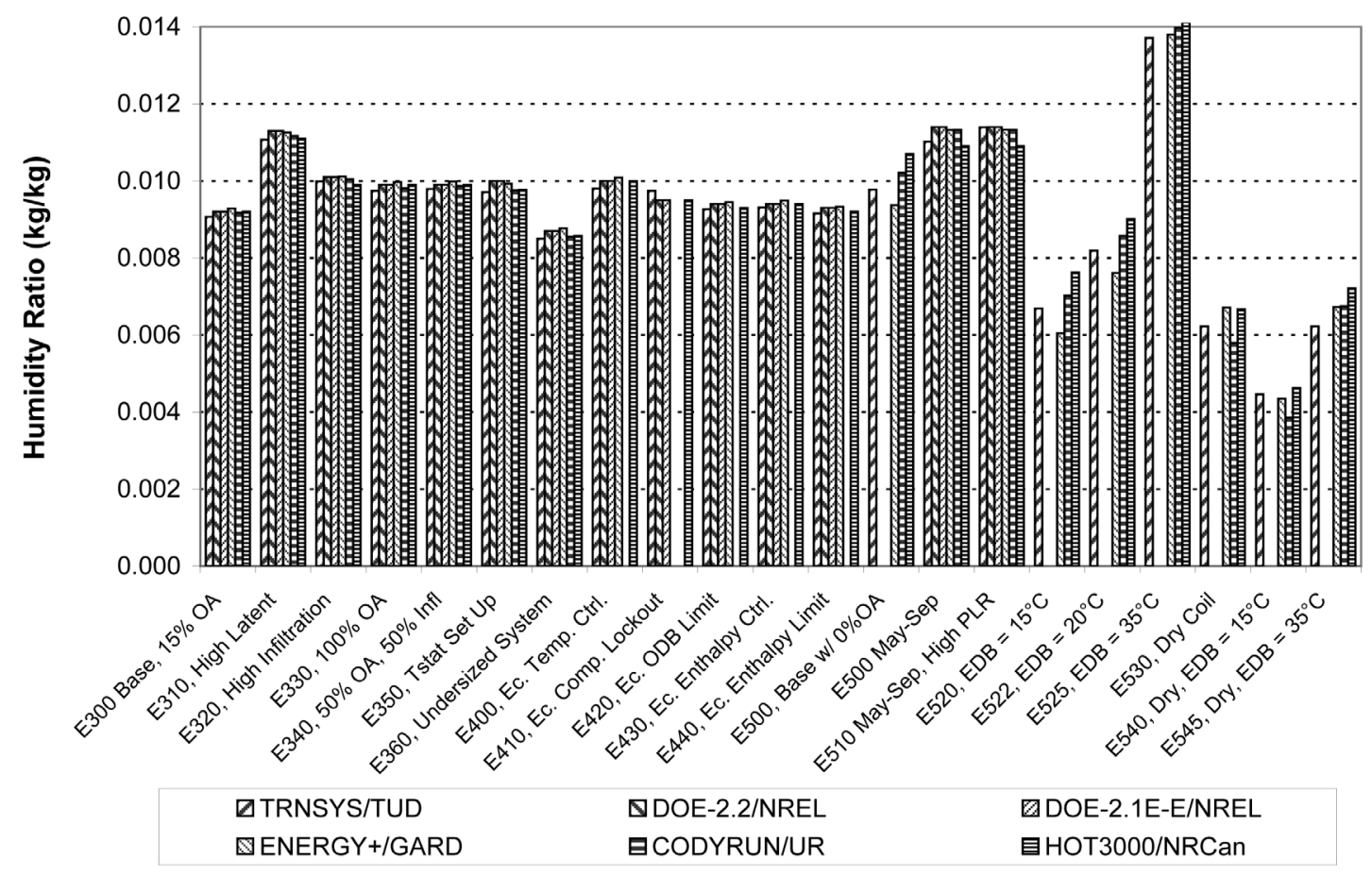

HVAC BESTEST: E300 - E545

Humidity Ratio Sensitivities

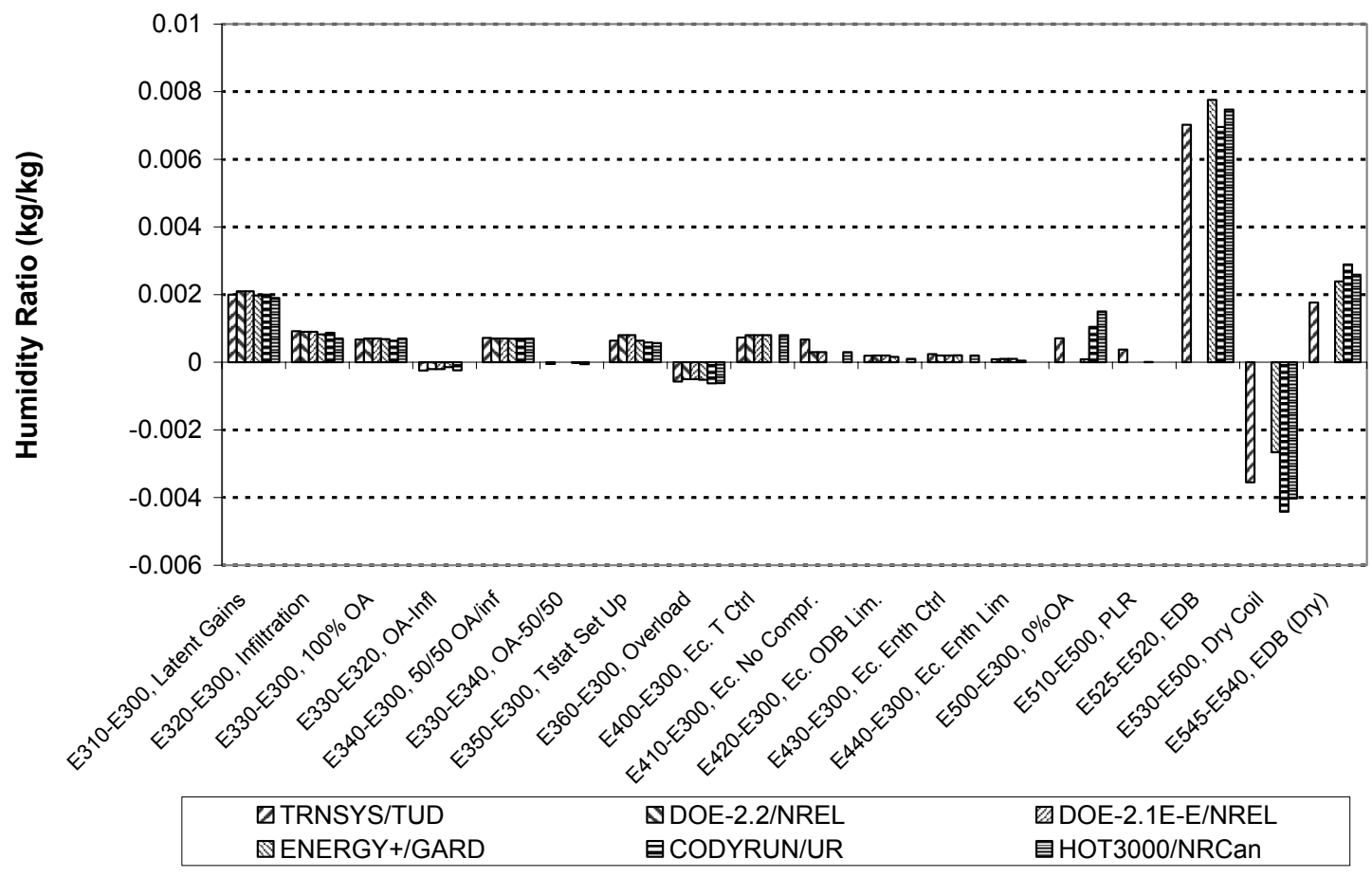


HVAC BESTEST: E300 - E545

Maximum Zone Humidity Ratio

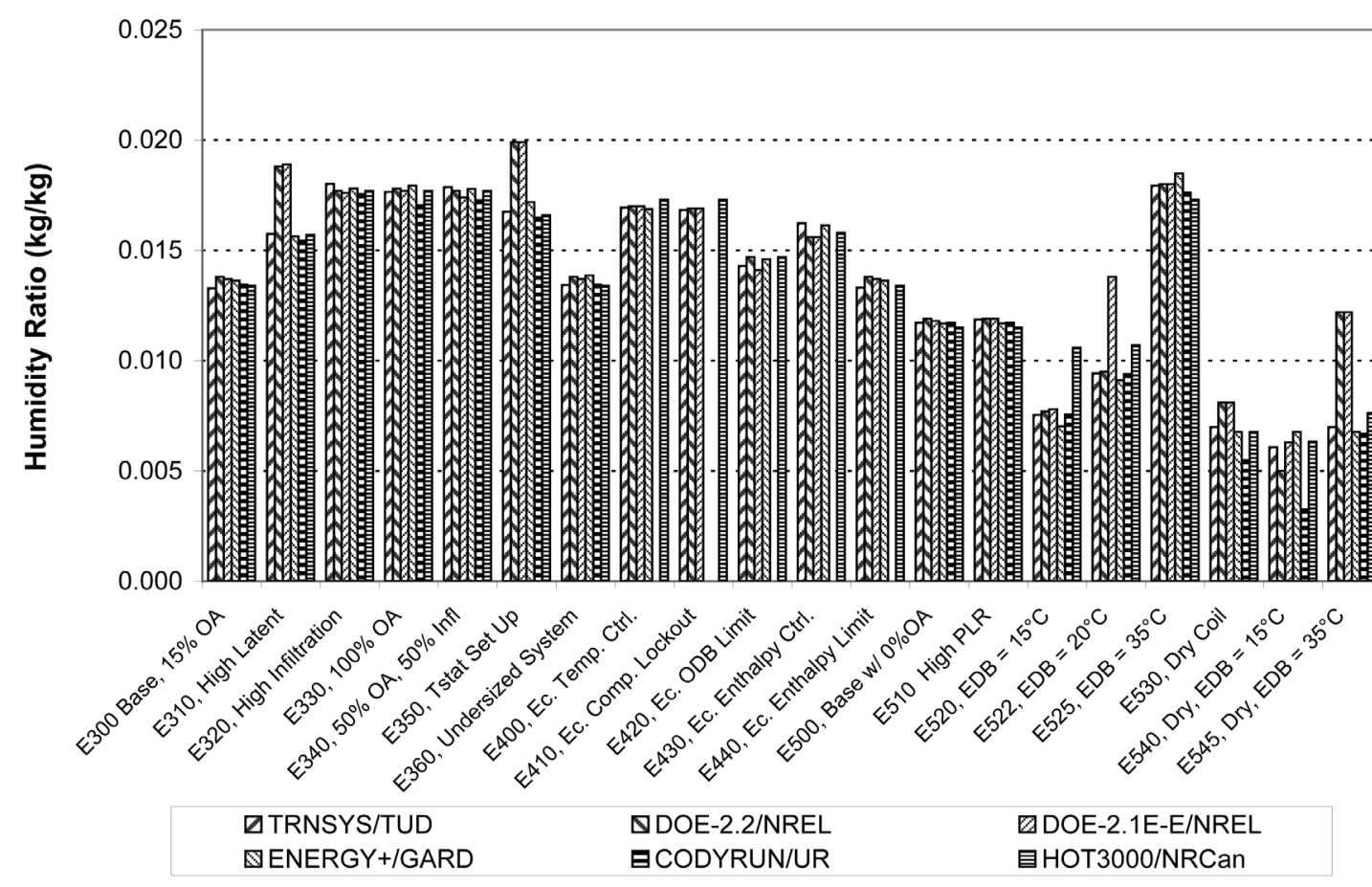

HVAC BESTEST: E300 - E545

Hourly Maximum Humidity Ratio Sensitivities

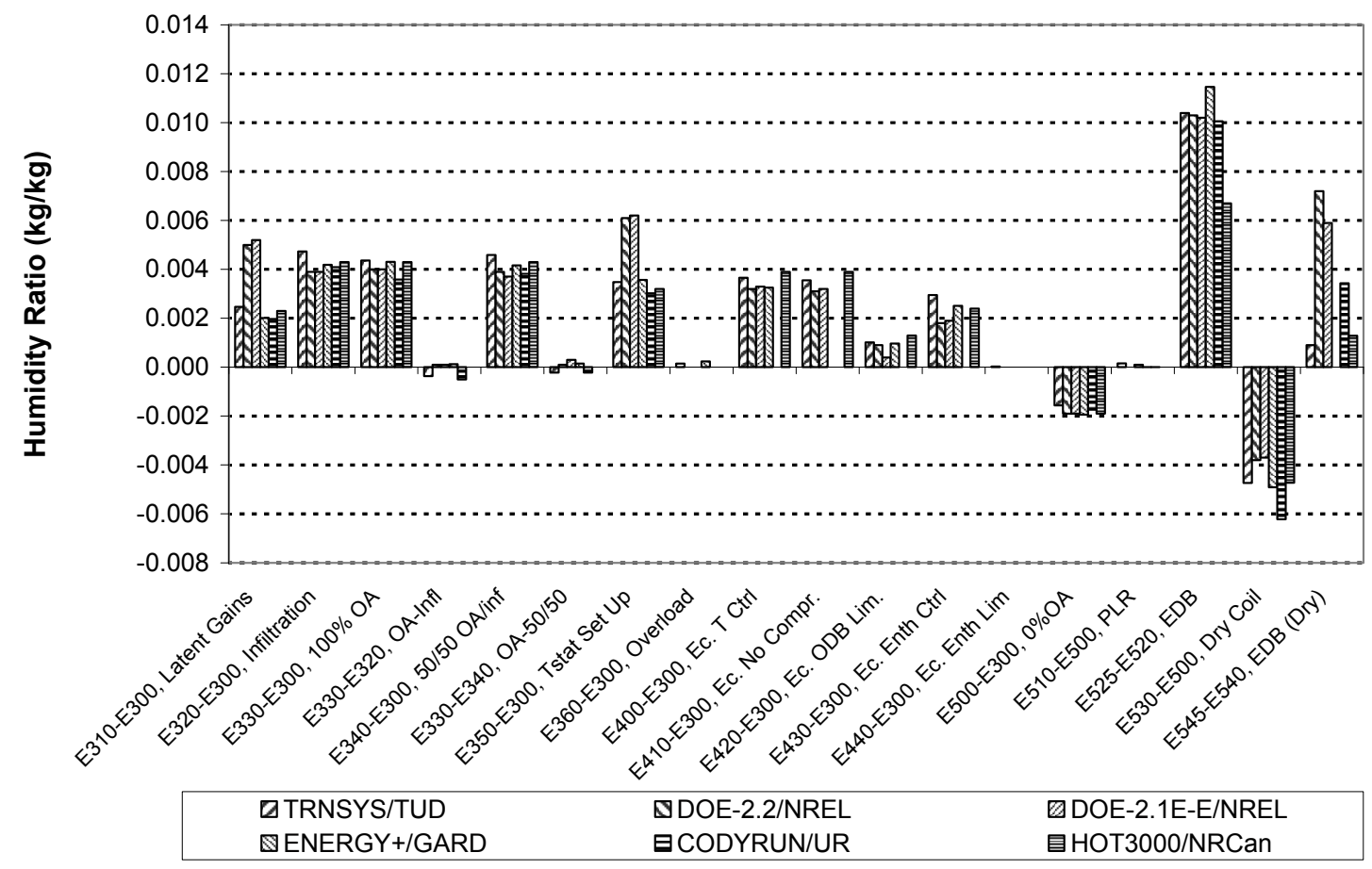


HVAC BESTEST: E300 - E545

Minimum Zone Humidity Ratio

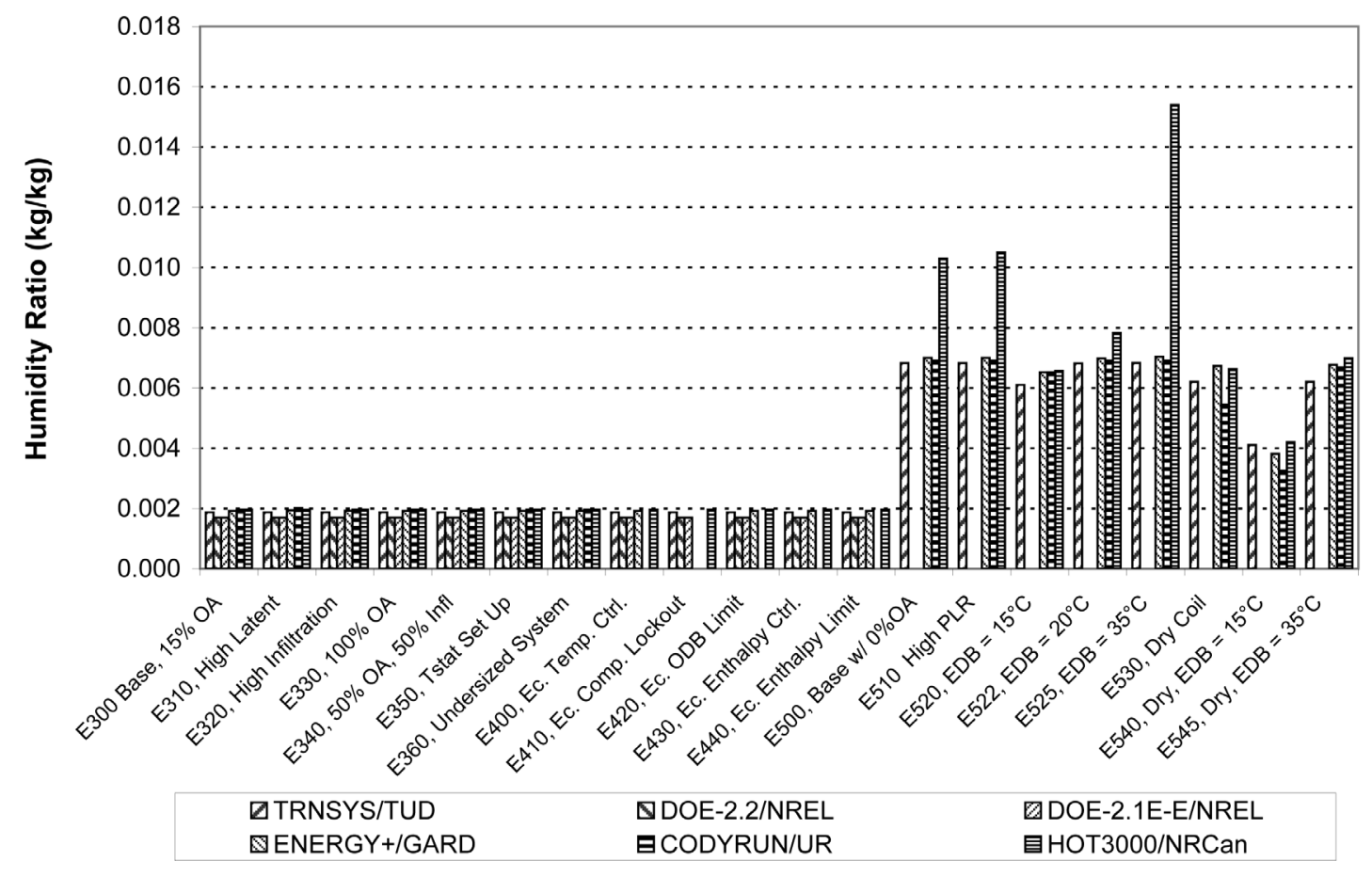


HVAC BESTEST: E300 - E545

Relative Humidity

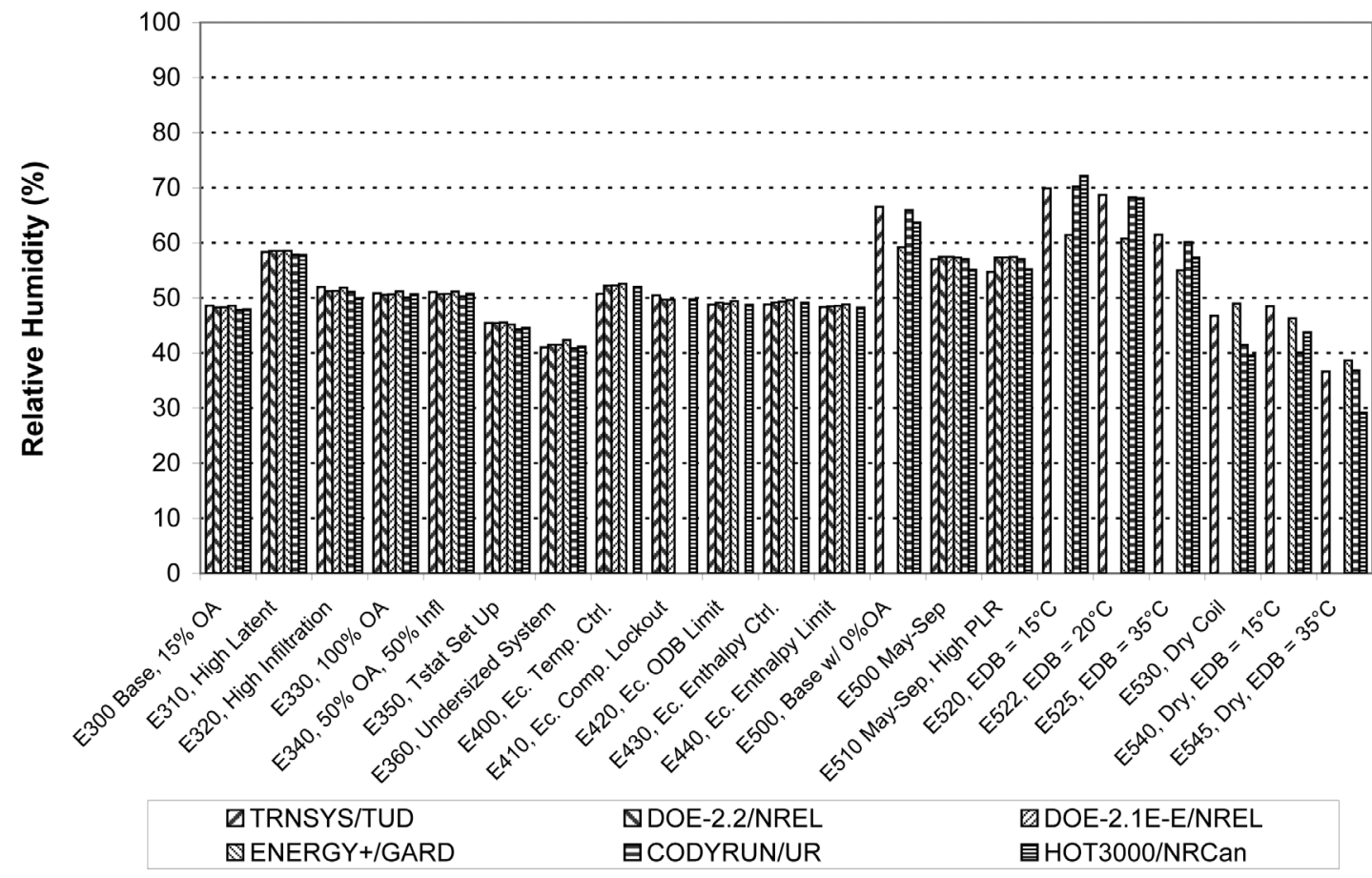

HVAC BESTEST: E300 - E545

Relative Humidity Sensitivities

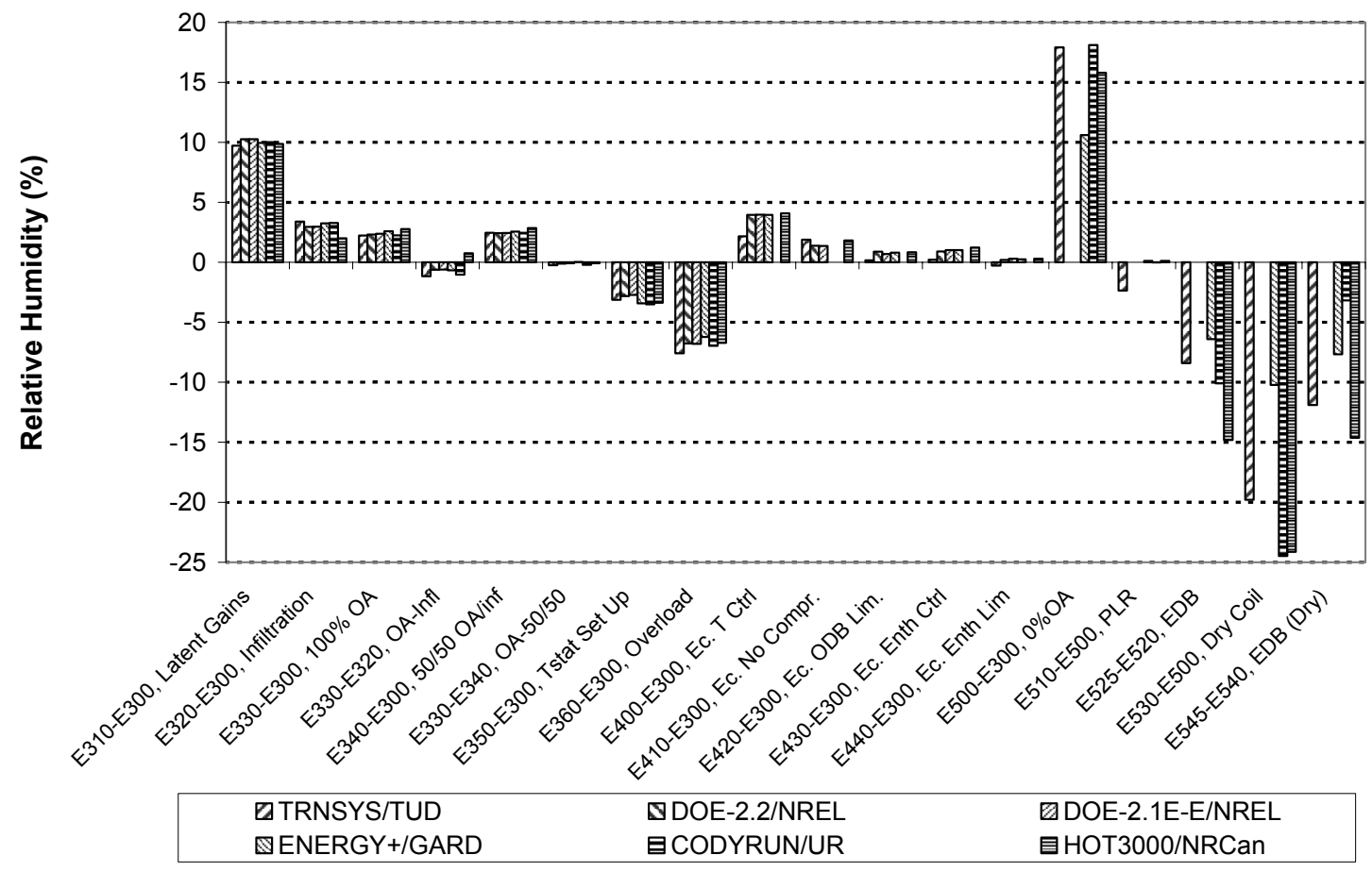




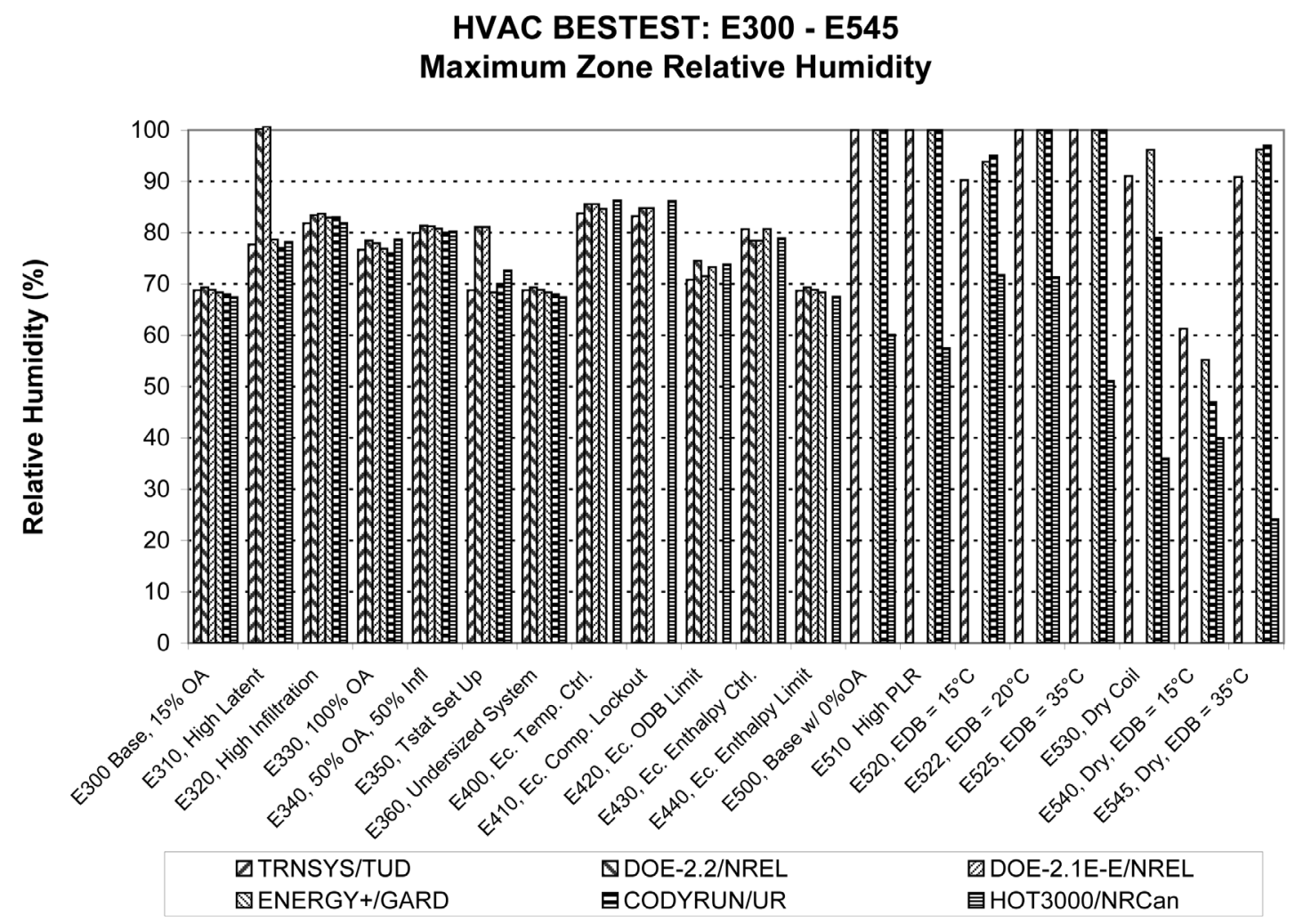

HVAC BESTEST: E300 - E545

Hourly Maximum Relative Humidity Sensitivities

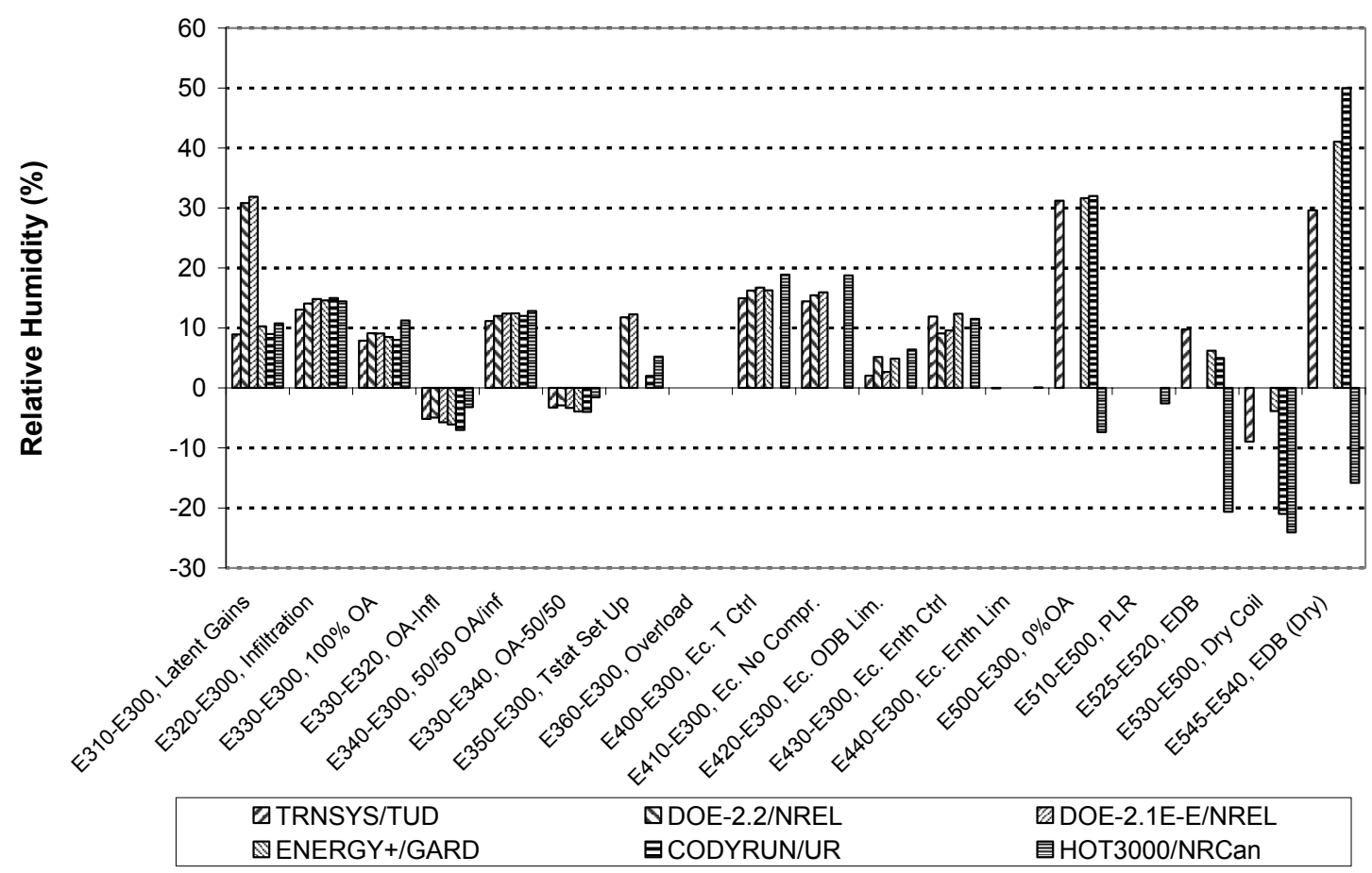


HVAC BESTEST: E300 - E545

Minimum Zone Relative Humidity

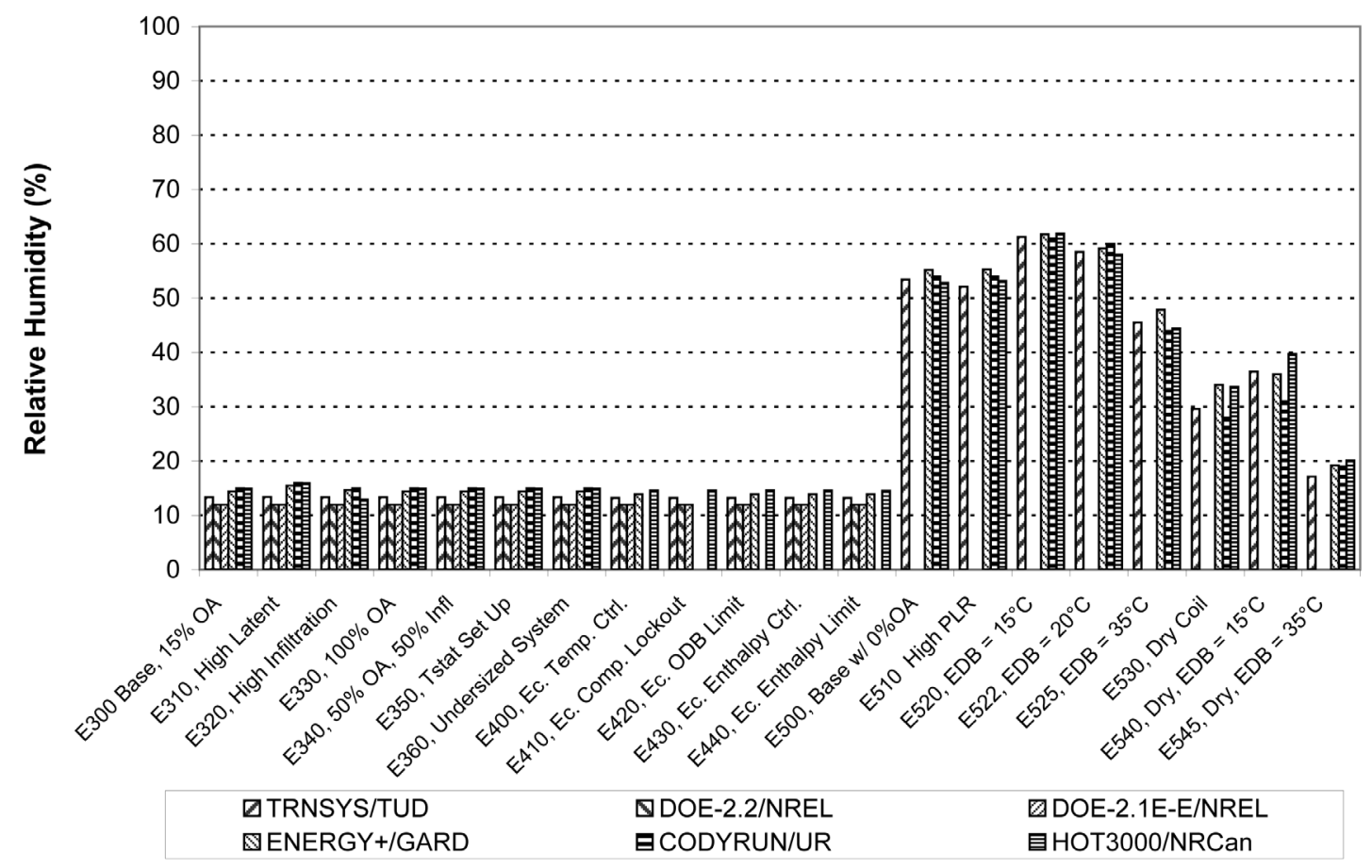


HVAC BESTEST: $f(O D B)$ for E500, E530

Specific Day Electricity Consumptions

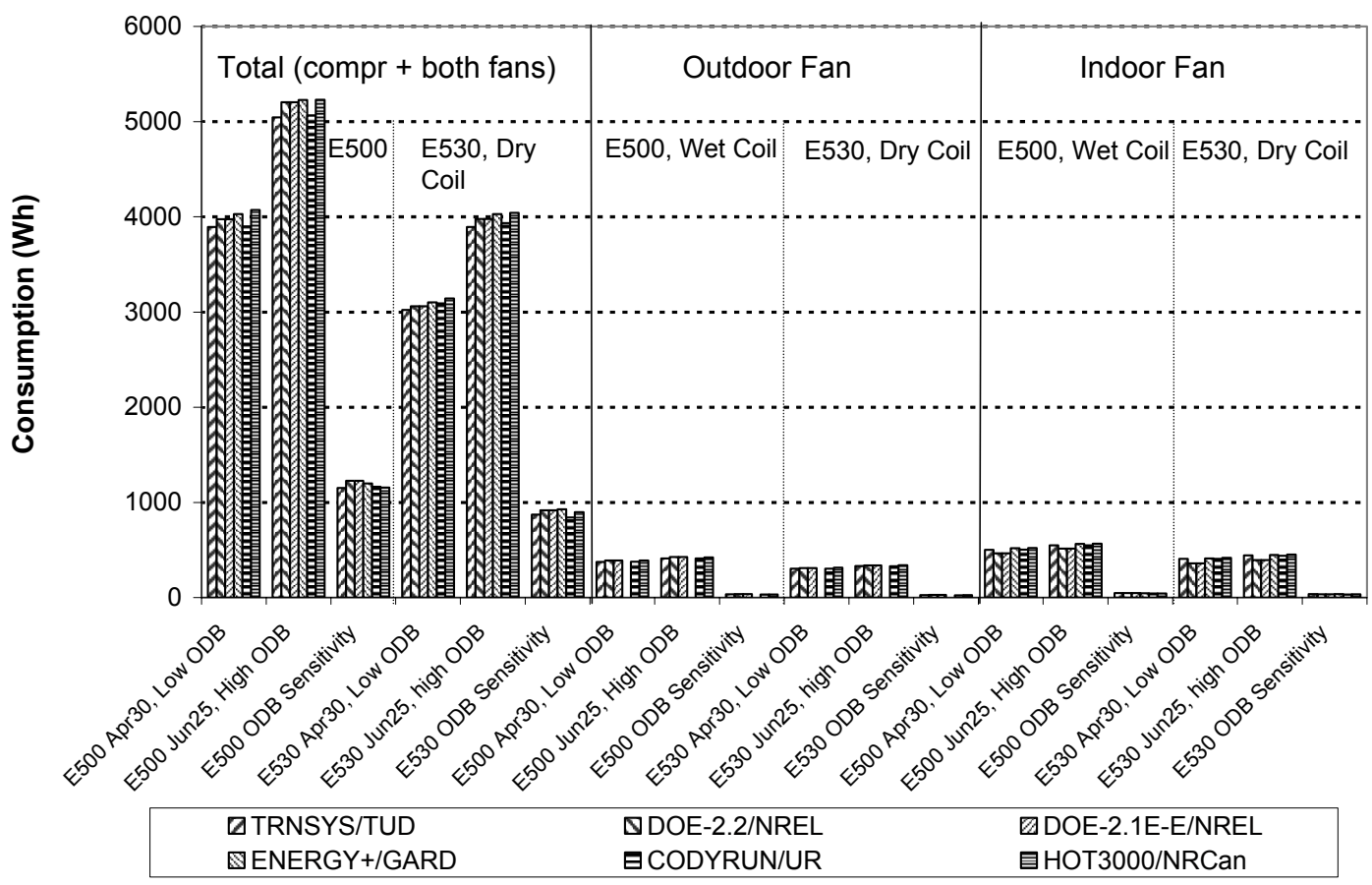

HVAC BESTEST: $f(O D B)$ for E500, E530

Specific Day Coil Loads

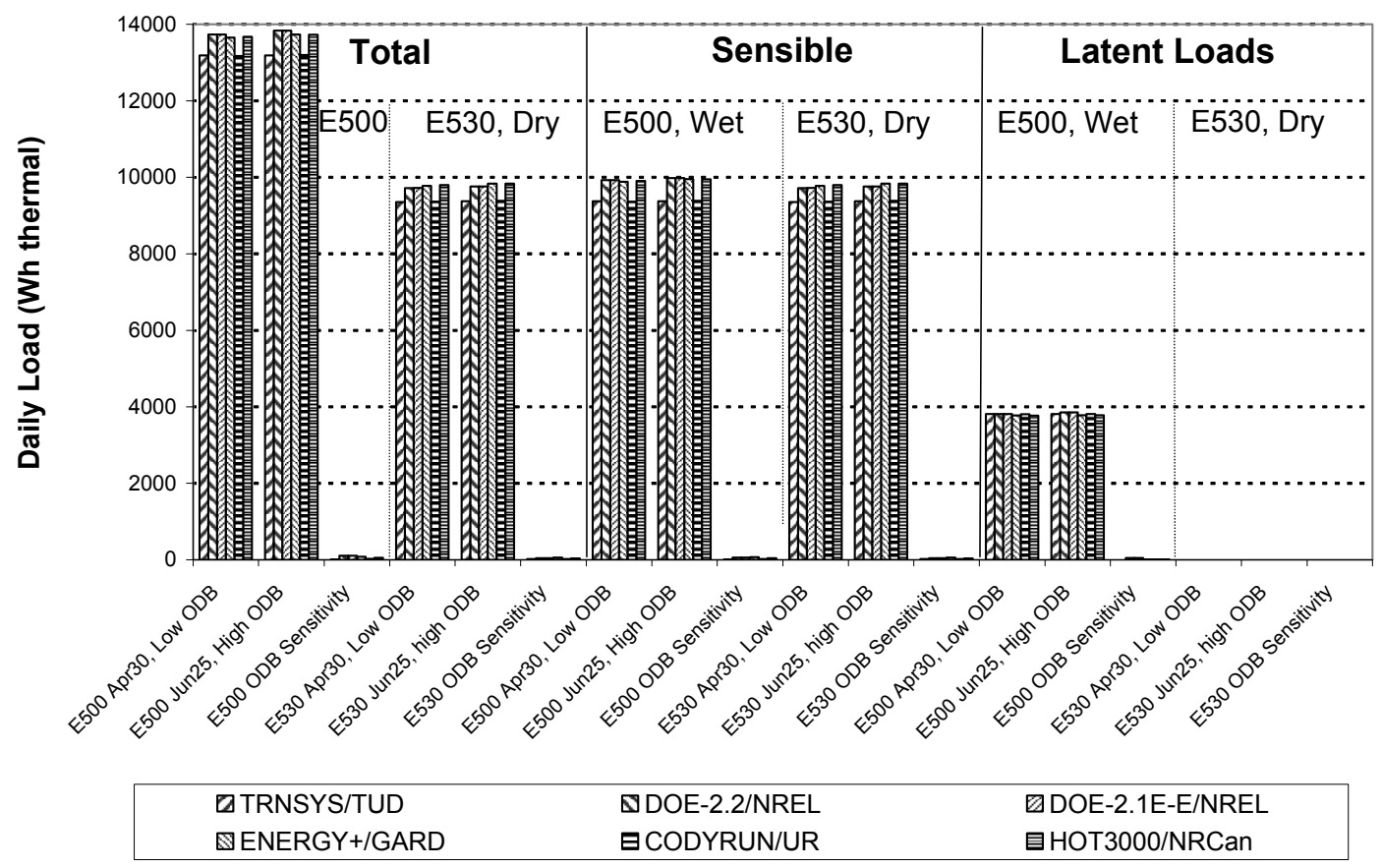


HVAC BESTEST: $f(O D B)$ for E500, E530

Specific Day COP2

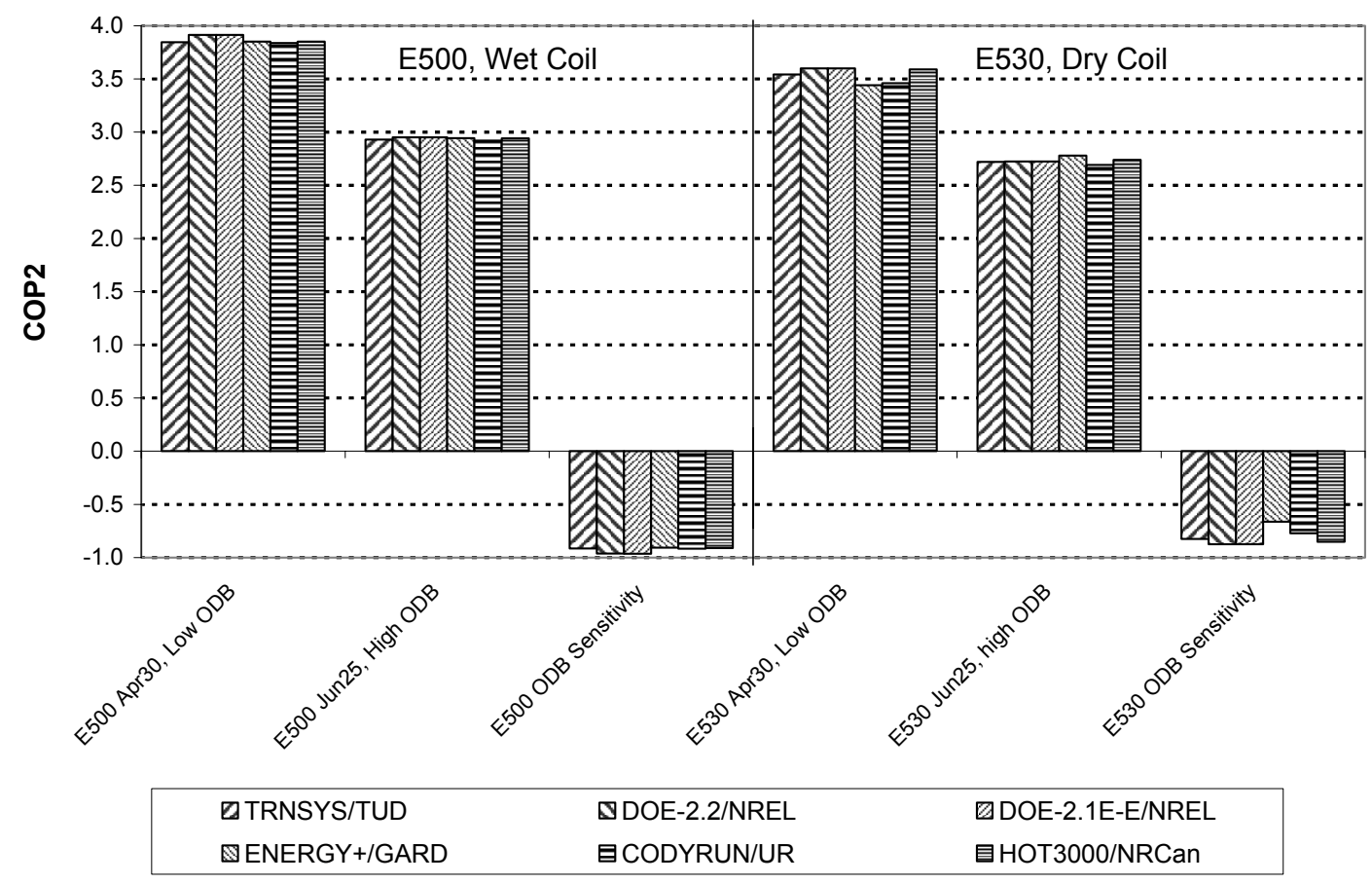

HVAC BESTEST: $f(O D B)$ for E500, E530

Specific Day Humidity Ratio

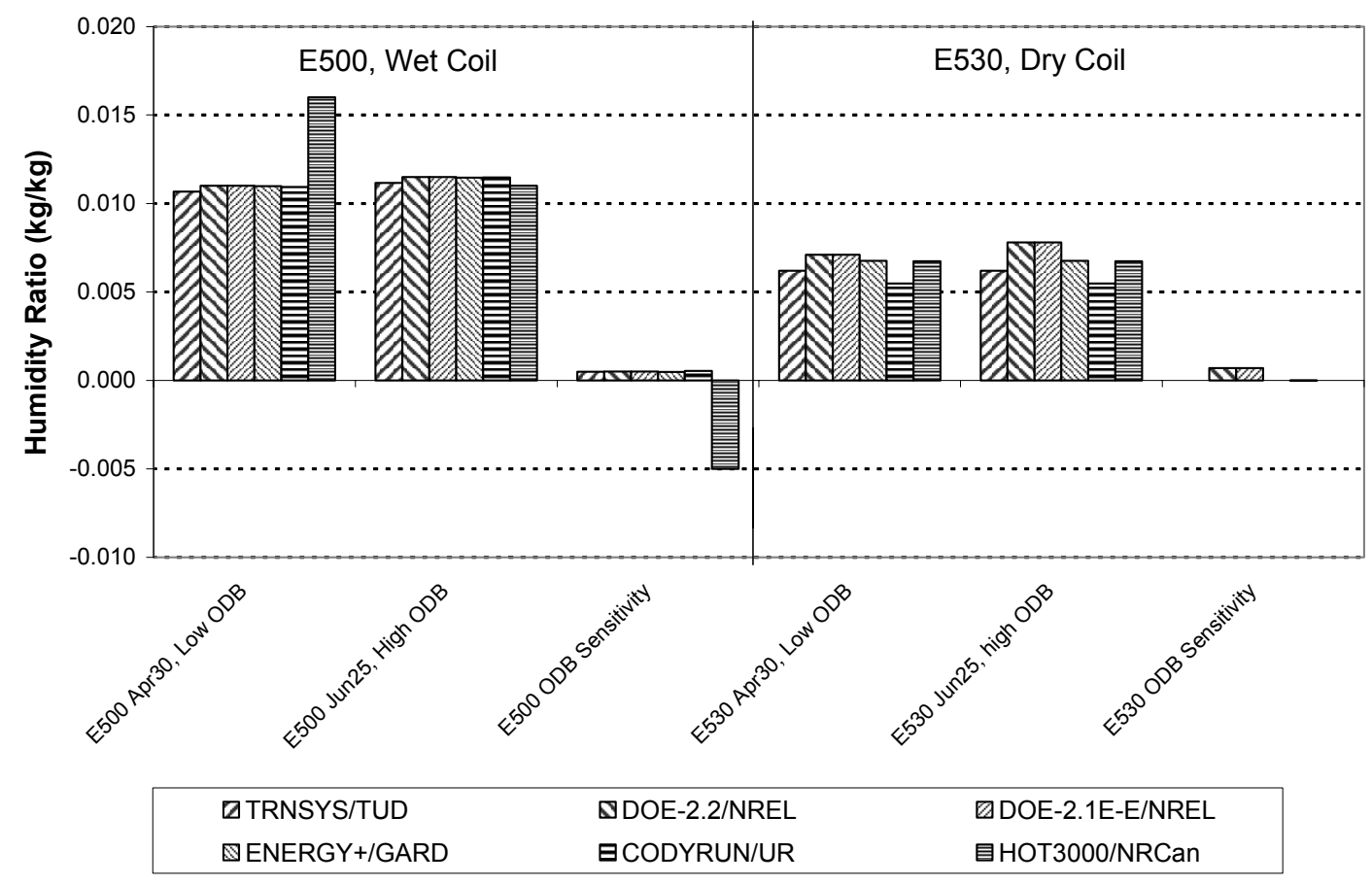


HVAC BESTEST: E300

June 28 Hourly Electricity Consumption

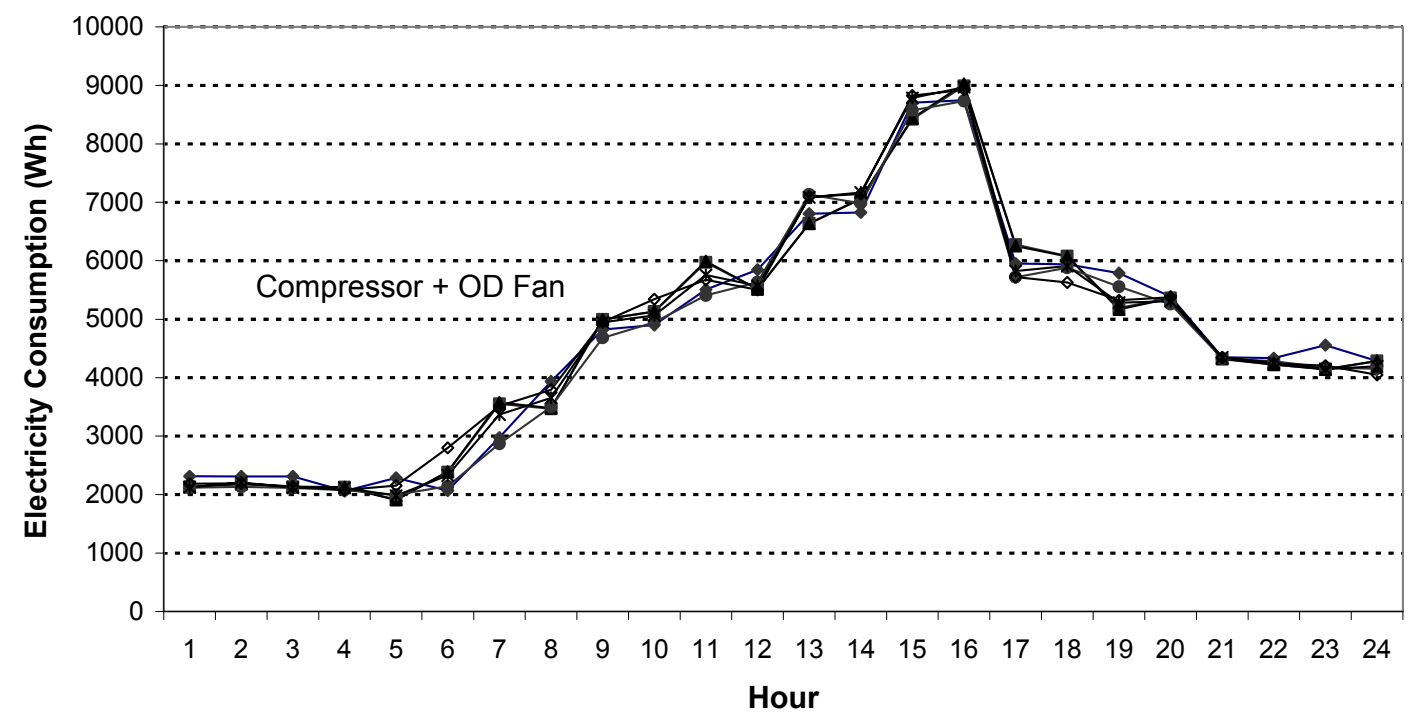

$\begin{array}{lll}\rightarrow-\text { TRNSYS/TUD } & \rightarrow \text { DOE-2.2/NREL } & \rightarrow \text { DOE-2.1E-E/NREL } \\ \rightarrow-\text { ENERGY+/GARD } & * \text {-CODYRUN/UR } & \rightarrow \text {-HOT3000/NRCan }\end{array}$

HVAC BESTEST: E300

June 28 Hourly Coil Loads

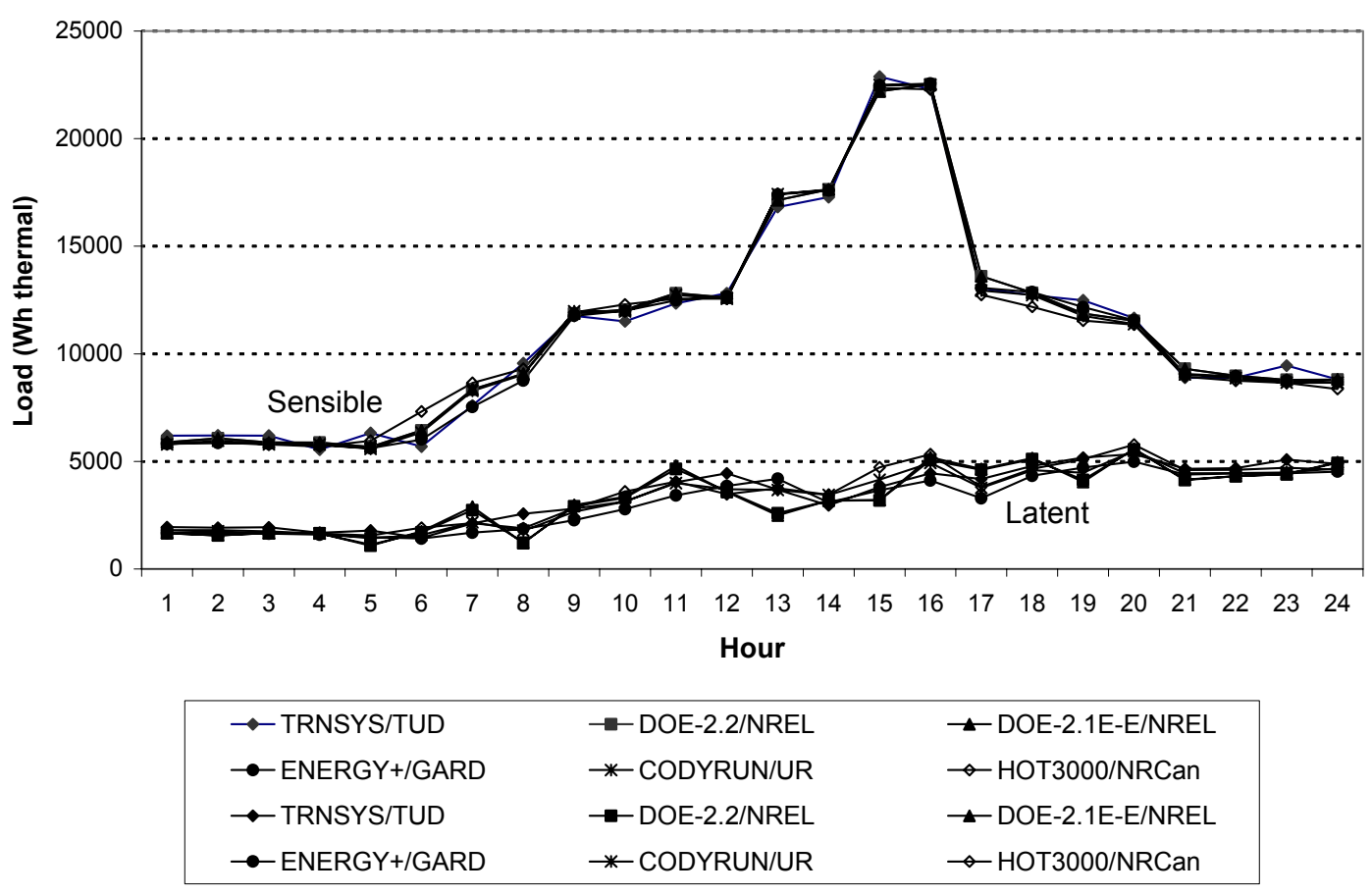


HVAC BESTEST: E300

June 28 Hourly COP2

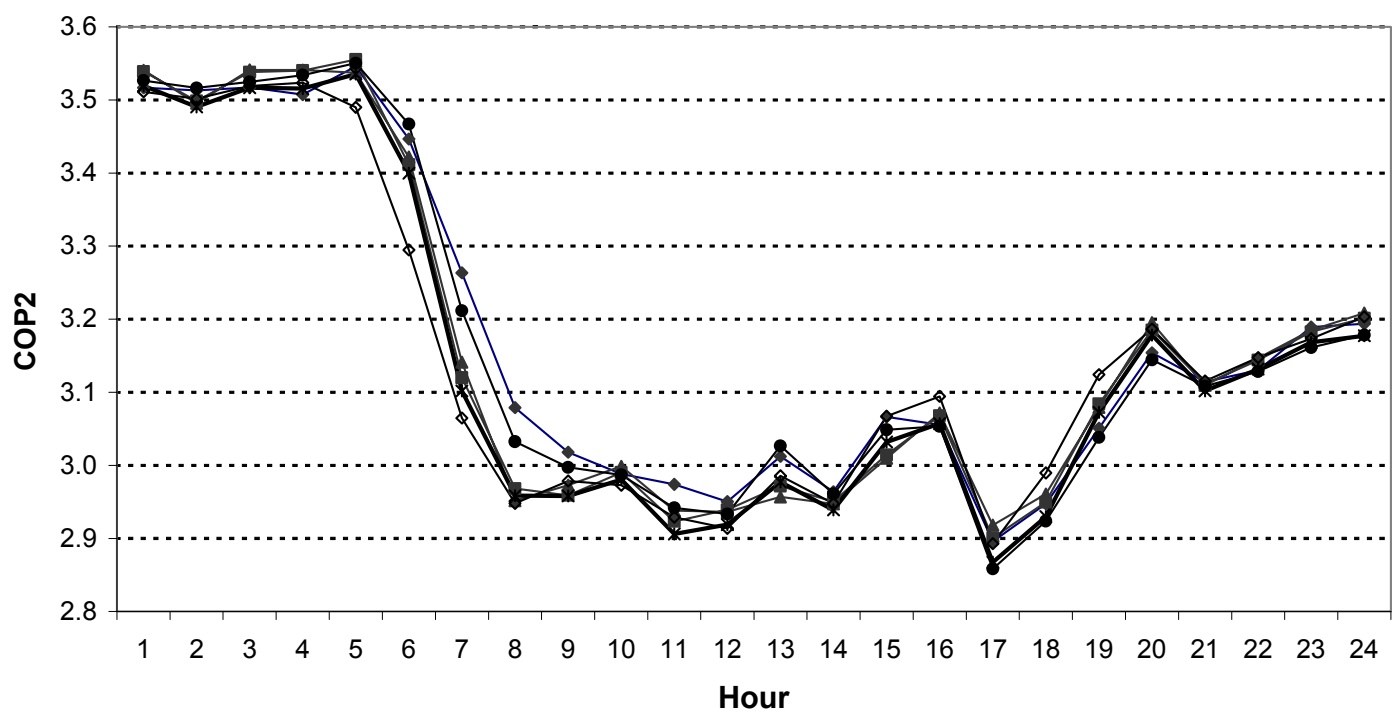

$\begin{array}{lll}\rightarrow \rightarrow \text { TRNSYS/TUD } & \rightarrow \text { DOE-2.2/NREL } & \rightarrow \text { DOE-2.1E-E/NREL } \\ \rightarrow-\text { ENERGY+/GARD } & * \text { CODYRUN/UR } & \rightarrow \text { HOT3000/NRCan }\end{array}$


HVAC BESTEST: E300

June 28 Hourly Zone Humidity Ratio

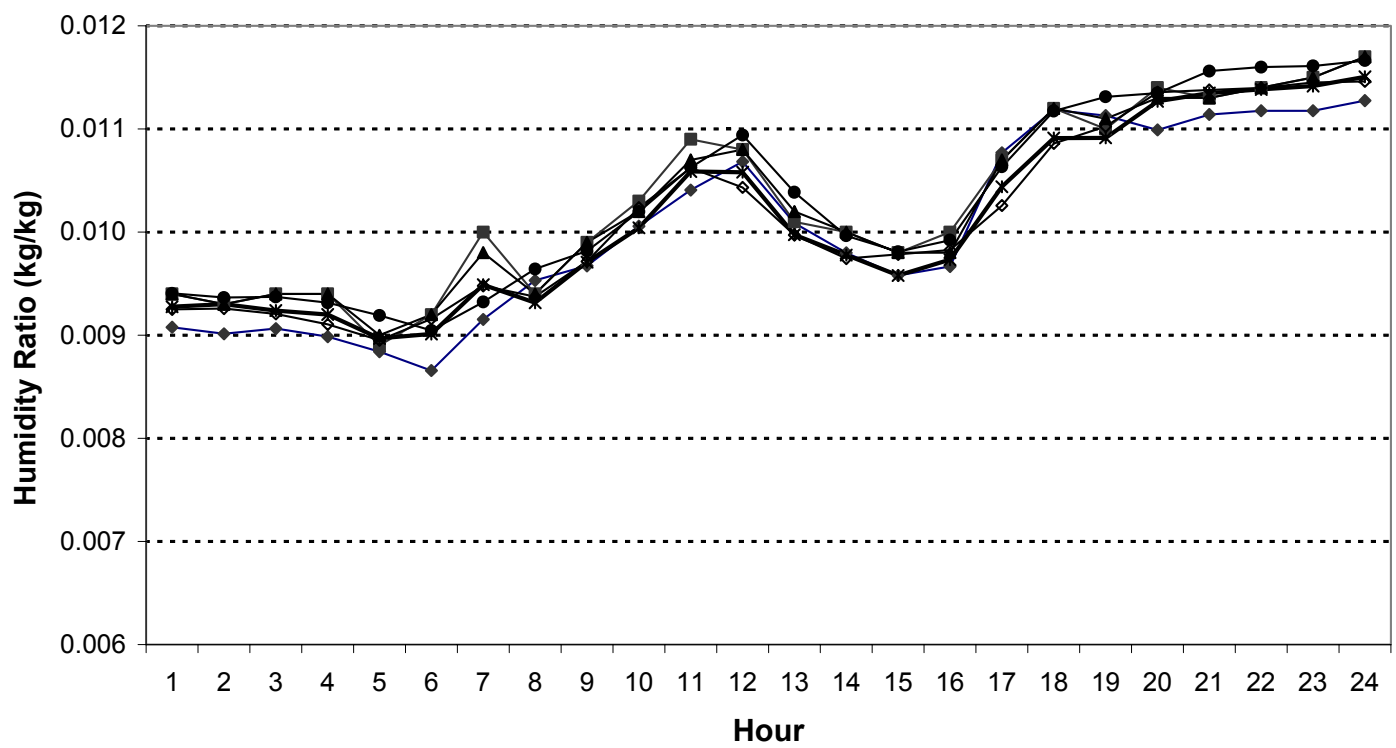

$\begin{array}{lll}\rightarrow \rightarrow \text { TRNSYS/TUD } & \rightarrow \text { DOE-2.2/NREL } & \rightarrow \text { DOE-2.1E-E/NREL } \\ \rightarrow-\text { ENERGY+/GARD } & \rightarrow \text { CODYRUN/UR } & \rightarrow \text { HOT3000/NRCan }\end{array}$

HVAC BESTEST: E300

June 28 Hourly EDB \& EWB

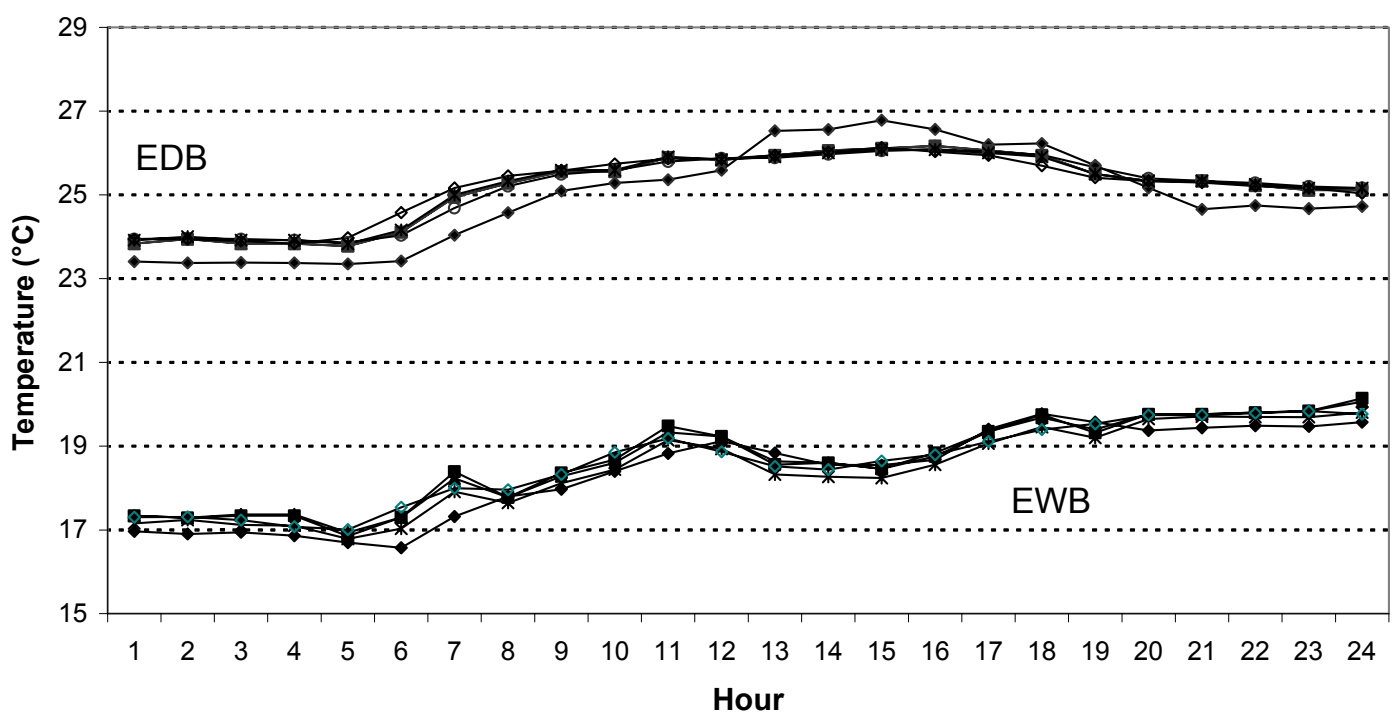

\begin{tabular}{lll}
\hline$\rightarrow-$ TRNSYS/TUD & $\rightarrow-$ DOE-2.2/NREL & $\rightarrow$ DOE-2.1E-E/NREL \\
$\rightarrow-$ ENERGY+/GARD & $\rightarrow$ CODYRUN/UR & $\rightarrow-$ HOT3000/NRCan \\
$\rightarrow-$ TRNSYS/TUD & $\rightarrow-$ DOE-2.2/NREL & $\rightarrow$ DOE-2.1E-E/NREL \\
$\rightarrow-$ ENERGY+/GARD & $\rightarrow$ CODYRUN/UR & $\rightarrow-$ HOT3000/NRCan \\
\hline
\end{tabular}


HVAC BESTEST: E300

June 28 Hourly ODB

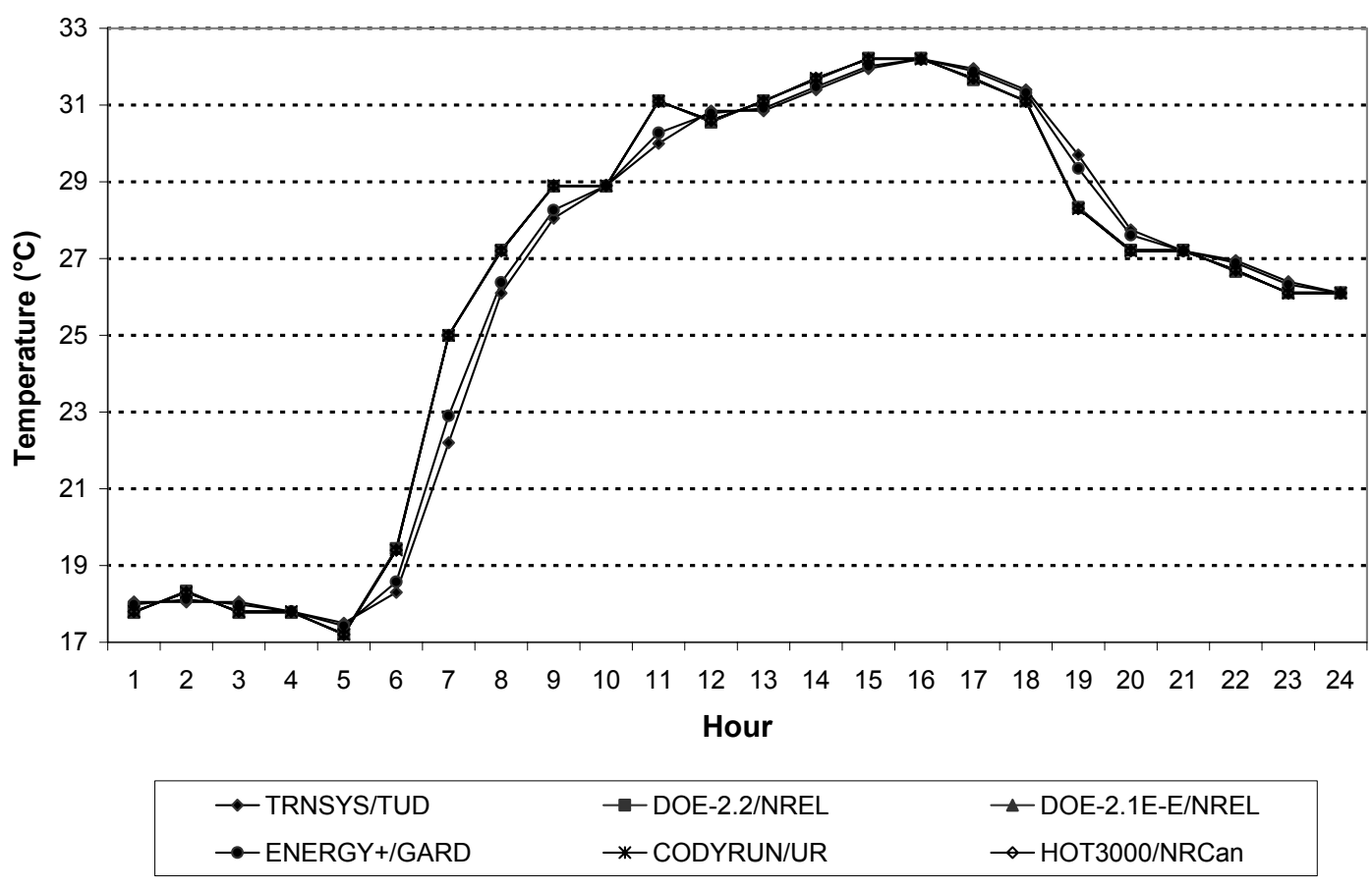

HVAC BESTEST: E300

June 28 Hourly OHR

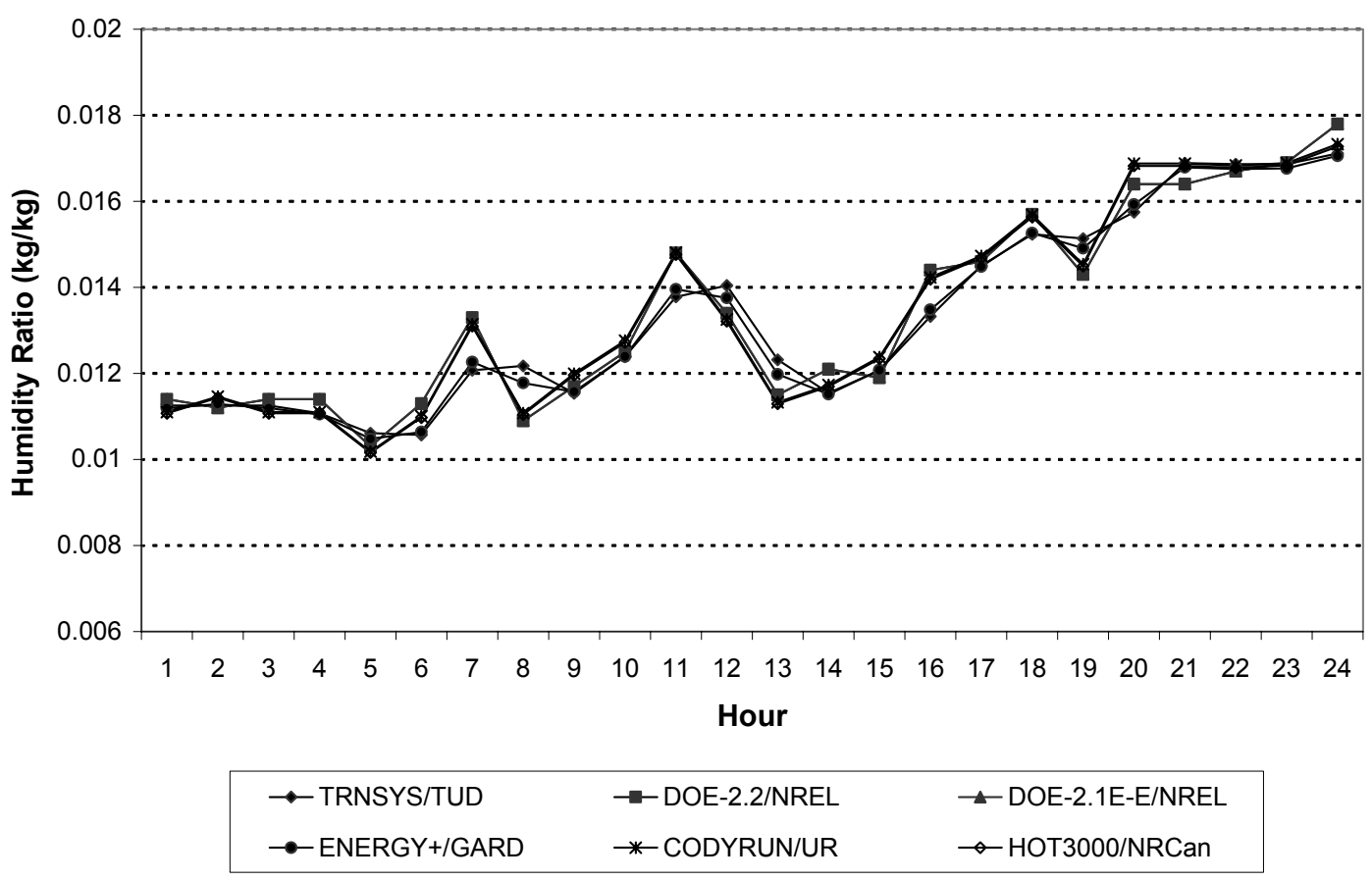


Space Cooling Electricity Consumption

\begin{tabular}{|c|c|c|c|c|c|c|c|c|c|}
\hline \multicolumn{7}{|c|}{ Energy Consumption, Total (kWh,e) } & \multicolumn{3}{|c|}{ Statistics, All Results } \\
\hline & TRNSYS & DOE-2.2 & DOE21E-E & Energy+ & CODYRUN & НОТ3000 & & & (Max-Min) \\
\hline & TUD & NREL & NREL & GARD & UR & NRCan & Min & Max & /Mean \\
\hline E300 & 35634 & 34750 & 34755 & 34746 & 34976 & 35070 & 34746 & 35634 & $2.5 \%$ \\
\hline E310 & 39973 & 39379 & 39384 & 39290 & 39520 & 39608 & 39290 & 39973 & $1.7 \%$ \\
\hline E320 & 40060 & 38745 & 38792 & 39079 & 39401 & 39457 & 38745 & 40060 & $3.3 \%$ \\
\hline E330 & 40963 & 39708 & 39438 & 40143 & 40535 & 40330 & 39438 & 40963 & $3.8 \%$ \\
\hline E340 & 40619 & 39358 & 39265 & 39783 & 40065 & 39947 & 39265 & 40619 & $3.4 \%$ \\
\hline E350 & 32237 & 30547 & 30548 & 31145 & 31587 & 31742 & 30547 & 32237 & $5.4 \%$ \\
\hline E360 & 55299 & 54064 & 54016 & 54705 & 54843 & 55068 & 54016 & 55299 & $2.3 \%$ \\
\hline E400 & 32045 & 30846 & 30876 & 31013 & & 31413 & 30846 & 32045 & $3.8 \%$ \\
\hline E410 & 32078 & 31668 & 31699 & & & 31503 & 31503 & 32078 & $1.8 \%$ \\
\hline E420 & 33387 & 32530 & 32910 & 32736 & & 33208 & 32530 & 33387 & $2.6 \%$ \\
\hline E430 & 32538 & 31932 & 31811 & 31772 & & 31818 & 31772 & 32538 & $2.4 \%$ \\
\hline E440 & 33691 & 33032 & 32973 & 33032 & & 33248 & 32973 & 33691 & $2.2 \%$ \\
\hline E500 & 22338 & 22817 & 22822 & 23035 & 22323 & 23138 & 22323 & 23138 & $3.6 \%$ \\
\hline E500 May-Sep & 17391 & 17872 & 17870 & 17996 & 17435 & 18051 & 17391 & 18051 & $3.7 \%$ \\
\hline E510 May-Sep & 34609 & 35971 & 35970 & 35732 & 34849 & 35845 & 34609 & 35971 & $3.8 \%$ \\
\hline E520 & 24987 & 25389 & 25390 & 25017 & 25131 & 25781 & 24987 & 25781 & $3.1 \%$ \\
\hline E522 & 23544 & 24293 & 24307 & 24078 & 23620 & 24360 & 23544 & 24360 & $3.4 \%$ \\
\hline E525 & 20321 & 20408 & 20421 & 20702 & 20242 & 21323 & 20242 & 21323 & $5.3 \%$ \\
\hline E530 & 17281 & 17540 & 17537 & 17742 & 17442 & 17875 & 17281 & 17875 & $3.4 \%$ \\
\hline E540 & 19430 & 19878 & 19874 & 19061 & 19537 & 20164 & 19061 & 20164 & $5.6 \%$ \\
\hline E545 & 15687 & 15802 & 15791 & 16636 & 15791 & 16339 & 15687 & 16636 & $5.9 \%$ \\
\hline Energy Consur & iption, Col & npressor (l) & kWh,e) & & & & Statistic & All Resu & \\
\hline & TRNSYS & DOE-2.2 & DOE21E-E & Energy+ & CODYRUN & НОТ3000 & & & (Max-Min) \\
\hline & TUD & NREL & NREL & GARD & UR & NRCan & Min & Max & /Mean \\
\hline E300 & 22354 & 21569 & 21573 & & 21770 & 21876 & 21569 & 22354 & $3.6 \%$ \\
\hline E310 & 26340 & 25813 & 25817 & & 25937 & 26053 & 25813 & 26340 & $2.0 \%$ \\
\hline E320 & 26433 & 25250 & 25294 & & 25846 & 25912 & 25250 & 26433 & $4.6 \%$ \\
\hline E330 & 27300 & 26172 & 25925 & & 26928 & 26775 & 25925 & 27300 & $5.2 \%$ \\
\hline E340 & 26963 & 25829 & 25745 & & 26473 & 26400 & 25745 & 26963 & $4.6 \%$ \\
\hline E350 & 19317 & 17802 & 17801 & & 18738 & 18891 & 17801 & 19317 & $8.2 \%$ \\
\hline E360 & 40106 & 38999 & 38955 & & 39697 & 39941 & 38955 & 40106 & $2.9 \%$ \\
\hline E400 & 19179 & 18106 & 18131 & & & 18629 & 18106 & 19179 & $5.8 \%$ \\
\hline E410 & 19204 & 18823 & 18850 & & & 18685 & 18685 & 19204 & $2.8 \%$ \\
\hline E420 & 20359 & 19596 & 19934 & & & 20214 & 19596 & 20359 & $3.8 \%$ \\
\hline E430 & 19599 & 19059 & 18951 & & & 18966 & 18951 & 19599 & $3.4 \%$ \\
\hline E440 & 20629 & 20042 & 19989 & & & 20249 & 19989 & 20629 & $3.2 \%$ \\
\hline E500 & 17854 & 18473 & 18478 & & 17858 & 18522 & 17854 & 18522 & $3.7 \%$ \\
\hline E500 May-Sep & 13942 & 14508 & 14506 & & 13989 & 14491 & 13942 & 14508 & $4.0 \%$ \\
\hline E510 May-Sep & 27748 & 28811 & 28810 & & 27902 & 28721 & 27748 & 28811 & $3.7 \%$ \\
\hline |E520 & 19521 & 20121 & 20126 & & 19655 & 20185 & 19521 & 20185 & $3.3 \%$ \\
\hline E522 & 18620 & 19407 & 19418 & & 18690 & 19281 & 18620 & 19418 & $4.2 \%$ \\
\hline E525 & 16558 & 16880 & 16893 & & 16507 & 17443 & 16507 & 17443 & $5.6 \%$ \\
\hline E530 & 13657 & 14127 & 14124 & & 13856 & 14172 & 13657 & 14172 & $3.7 \%$ \\
\hline E540 & 15021 & 15680 & 15677 & & 15164 & 15664 & 15021 & 15680 & $4.3 \%$ \\
\hline E545 & 12622 & 12967 & 12957 & & 12751 & 13215 & 12622 & 13215 & $4.6 \%$ \\
\hline
\end{tabular}

e300results.xIs q:a06..m55; 07/19/04 
Space Cooling Electricity Consumption

\begin{tabular}{|c|c|c|c|c|c|c|c|c|c|}
\hline \multicolumn{7}{|c|}{ Energy Consumption, Supply Fan (kWh,e) } & \multicolumn{3}{|c|}{ S Statistics, All Results } \\
\hline & TRNSYS & DOE-2.2 & DOE21E-E & Energy+ & CODYRUN & НОТ3000 & \multirow[b]{2}{*}{ Min } & \multicolumn{2}{|c|}{ (Max-Min) } \\
\hline & TUD & NREL & NREL & GARD & UR & NRCan & & Max & /Mean \\
\hline E300 & 10880 & 10880 & 10880 & 10862 & 10880 & 10880 & 10862 & 10880 & $0.2 \%$ \\
\hline E310 & 10880 & 10880 & 10880 & 10862 & 10880 & 10880 & 10862 & 10880 & $0.2 \%$ \\
\hline E320 & 10880 & 10880 & 10880 & 10862 & 10880 & 10880 & 10862 & 10880 & $0.2 \%$ \\
\hline E330 & 10880 & 10880 & 10880 & 10862 & 10880 & 10880 & 10862 & 10880 & $0.2 \%$ \\
\hline E340 & 10880 & 10880 & 10880 & 10862 & 10880 & 10880 & 10862 & 10880 & $0.2 \%$ \\
\hline E350 & 10880 & 10880 & 10880 & 10862 & 10880 & 10880 & 10862 & 10880 & $0.2 \%$ \\
\hline E360 & 10880 & 10880 & 10880 & 10862 & 10880 & 10880 & 10862 & 10880 & $0.2 \%$ \\
\hline E400 & 10880 & 10880 & 10880 & 10862 & & 10880 & 10862 & 10880 & $0.2 \%$ \\
\hline E410 & 10880 & 10880 & 10880 & & & 10880 & 10880 & 10880 & $0.0 \%$ \\
\hline E420 & 10880 & 10880 & 10880 & 10862 & & 10880 & 10862 & 10880 & $0.2 \%$ \\
\hline E430 & 10880 & 10880 & 10880 & 10862 & & 10880 & 10862 & 10880 & $0.2 \%$ \\
\hline E440 & 10880 & 10880 & 10880 & 10862 & & 10880 & 10862 & 10880 & $0.2 \%$ \\
\hline E500 & 2564 & 2369 & 2369 & 2628 & 2553 & 2639 & 2369 & 2639 & $10.7 \%$ \\
\hline E500 May-Sep & 1972 & 1837 & 1837 & 2029 & 1970 & 2035 & 1837 & 2035 & $10.2 \%$ \\
\hline E510 May-Sep & 3923 & 4099 & 4099 & 4063 & 3972 & 4073 & 3923 & 4099 & $4.4 \%$ \\
\hline E520 & 3125 & 2874 & 2871 & 3019 & 3131 & 3200 & 2871 & 3200 & $10.8 \%$ \\
\hline E522 & 2816 & 2704 & 2707 & 2843 & 2819 & 2904 & 2704 & 2904 & $7.1 \%$ \\
\hline E525 & 2152 & 1886 & 1885 & 2180 & 2136 & 2221 & 1885 & 2221 & $16.2 \%$ \\
\hline E530 & 2072 & 1833 & 1833 & 2090 & 2051 & 2117 & 1833 & 2117 & $14.2 \%$ \\
\hline E540 & 2522 & 2258 & 2258 & 2309 & 2500 & 2573 & 2258 & 2573 & $13.1 \%$ \\
\hline E545 & 1753 & 1501 & 1501 & 1871 & 1739 & 1786 & 1501 & 1871 & $21.9 \%$ \\
\hline \multicolumn{7}{|c|}{ Energy Consumption, Condenser Fan (kWh,e) } & \multicolumn{3}{|c|}{ Statistics, All Results } \\
\hline & TRNSYS & DOE-2.2 & DOE21E-E & Energy+ & CODYRUN & НОТ3000 & & & ax-Min) \\
\hline & TUD & NREL & NREL & GARD & UR & NRCan & Min & $\operatorname{Max}$ & /Mean \\
\hline E300 & 2400 & 2301 & 2302 & & 2326 & 2323 & 2301 & 2400 & $4.3 \%$ \\
\hline E310 & 2754 & 2686 & 2687 & & 2703 & 2691 & 2686 & 2754 & $2.5 \%$ \\
\hline E320 & 2747 & 2615 & 2618 & & 2675 & 2681 & 2615 & 2747 & $4.9 \%$ \\
\hline E330 & 2784 & 2656 & 2633 & & 2727 & 2693 & 2633 & 2784 & $5.6 \%$ \\
\hline E340 & 2776 & 2649 & 2640 & & 2713 & 2684 & 2640 & 2776 & $5.1 \%$ \\
\hline E350 & 2040 & 1865 & 1867 & & 1969 & 1970 & 1865 & 2040 & $9.0 \%$ \\
\hline E360 & 4313 & 4185 & 4181 & & 4266 & 4272 & 4181 & 4313 & $3.1 \%$ \\
\hline E400 & 1986 & 1860 & 1865 & & & 1902 & 1860 & 1986 & $6.6 \%$ \\
\hline E410 & 1994 & 1965 & 1969 & & & 1936 & 1936 & 1994 & $3.0 \%$ \\
\hline E420 & 2149 & 2054 & 2096 & & & 2115 & 2054 & 2149 & $4.5 \%$ \\
\hline E430 & 2059 & 1993 & 1980 & & & 1970 & 1970 & 2059 & $4.5 \%$ \\
\hline E440 & 2182 & 2110 & 2104 & & & 2120 & 2104 & 2182 & $3.7 \%$ \\
\hline E500 & 1920 & 1975 & 1975 & & 1912 & 1976 & 1912 & 1976 & $3.3 \%$ \\
\hline E500 May-Sep & 1477 & 1527 & 1527 & & 1476 & 1524 & 1476 & 1527 & $3.4 \%$ \\
\hline E510 May-Sep & 2938 & 3061 & 3061 & & 2974 & 3050 & 2938 & 3061 & $4.1 \%$ \\
\hline E520 & 2340 & 2394 & 2393 & & 2345 & 2396 & 2340 & 2396 & $2.4 \%$ \\
\hline E522 & 2108 & 2182 & 2182 & & 2111 & 2174 & 2108 & 2182 & $3.4 \%$ \\
\hline E525 & 1611 & 1642 & 1643 & & 1599 & 1663 & 1599 & 1663 & $3.9 \%$ \\
\hline E530 & 1552 & 1580 & 1580 & & 1536 & 1585 & 1536 & 1585 & $3.1 \%$ \\
\hline E540 & 1888 & 1940 & 1939 & & 1872 & 1926 & 1872 & 1940 & $3.5 \%$ \\
\hline E545 & 1312 & 1334 & 1333 & & 1302 & 1337 & 1302 & 1337 & $2.7 \%$ \\
\hline
\end{tabular}

e300results.xls q:a56..m105; 07/19/04

Weather Data Checks, E300 Only

\begin{tabular}{|c|c|c|c|c|c|c|c|c|c|}
\hline & $\begin{array}{r}\text { TRNSYS } \\
\text { TUD }\end{array}$ & $\begin{array}{c}\text { DOE-2.2 } \\
\text { NREL }\end{array}$ & $\begin{array}{r}\text { DOE21E-E } \\
\text { NREL }\end{array}$ & $\begin{array}{r}\text { Energy+ } \\
\text { GARD }\end{array}$ & $\begin{array}{r}\text { CODYRUN } \\
\text { UR }\end{array}$ & $\begin{array}{r}\text { HOT3000 } \\
\text { NRCan }\end{array}$ & $\begin{array}{r}\text { Statistic } \\
\text { Min }\end{array}$ & $\begin{array}{r}\text {, All Resu } \\
\text { Max }\end{array}$ & $\begin{aligned} \text { ts } \\
\text { (Max-Min) } \\
\text { /Mean }\end{aligned}$ \\
\hline \multicolumn{10}{|c|}{ Annual Mean Output } \\
\hline ODB & 19.91 & 19.89 & 19.89 & 19.91 & 19.91 & 19.91 & 20 & 20 & $0.1 \%$ \\
\hline $\mathrm{OHR}$ & 0.01164 & 0.01160 & 0.01160 & 0.01159 & 0.01165 & 0.01160 & 0.01159 & 0.01165 & $0.5 \%$ \\
\hline \multicolumn{10}{|c|}{ Annual Hourly Integrated Maxima } \\
\hline ODB & 34.70 & 35.00 & 35.00 & 34.78 & 35.00 & 35.00 & 35 & 35 & $0.9 \%$ \\
\hline $\mathrm{OHR}$ & 0.02188 & 0.02250 & 0.02250 & 0.02184 & 0.02241 & 0.02230 & 0.02184 & 0.02250 & $3.0 \%$ \\
\hline
\end{tabular}


Space Cooling Coil Loads

\begin{tabular}{|c|c|c|c|c|c|c|c|c|c|}
\hline \multicolumn{7}{|c|}{$\mid$ Total Sensible + Latent (kWh,th) } & \multicolumn{3}{|c|}{ Statistics, All Results } \\
\hline & TRNSYS & DOE-2.2 & DOE21E-E & Energy+ & CODYRUN & НОТ3000 & \multicolumn{3}{|c|}{ (Max-Min) } \\
\hline & TUD & NREL & NREL & GARD & UR & NRCan & Min & Max & /Mean \\
\hline E300 & 80427 & 77283 & 77292 & 77318 & 77745 & 78257 & 77283 & 80427 & $4.0 \%$ \\
\hline E310 & 99342 & 97395 & 97412 & 96448 & 97296 & 97261 & 96448 & 99342 & $3.0 \%$ \\
\hline E320 & 99792 & 96356 & 96493 & 96084 & 97141 & 96957 & 96084 & 99792 & $3.8 \%$ \\
\hline E330 & 105013 & 100730 & 100993 & 102211 & 103713 & 102008 & 100730 & 105013 & $4.2 \%$ \\
\hline E340 & 102728 & 99028 & 99223 & 99709 & 100676 & 99753 & 99028 & 102728 & $3.7 \%$ \\
\hline E350 & 69388 & 63736 & 63635 & 65790 & 66860 & 67389 & 63635 & 69388 & $8.7 \%$ \\
\hline E360 & 162974 & 159807 & 159854 & 161248 & 161200 & 162168 & 159807 & 162974 & $2.0 \%$ \\
\hline E400 & 68793 & 64918 & 65025 & 65414 & & 66898 & 64918 & 68793 & $5.9 \%$ \\
\hline E410 & 68673 & 66780 & 66844 & & & 66175 & 66175 & 68673 & $3.7 \%$ \\
\hline E420 & 72609 & 69611 & 70882 & 70349 & & 71803 & 69611 & 72609 & $4.2 \%$ \\
\hline E430 & 69756 & 67641 & 67219 & 67141 & & 67200 & 67141 & 69756 & $3.9 \%$ \\
\hline E440 & 73711 & 71380 & 71181 & 71417 & & 72029 & 71181 & 73711 & $3.5 \%$ \\
\hline E500 & 63357 & 65996 & 65992 & 65571 & 63105 & 65614 & 63105 & 65996 & $4.5 \%$ \\
\hline E500 May-Sep & 48443 & 50693 & 50690 & 50354 & 48440 & 50357 & 48440 & 50693 & $4.5 \%$ \\
\hline E510 May-Sep & 108974 & 114018 & 114015 & 112793 & 108979 & 112781 & 108974 & 114018 & $4.5 \%$ \\
\hline E520 & 63422 & 66571 & 66565 & 66088 & 63212 & 66146 & 63212 & 66571 & $5.1 \%$ \\
\hline E522 & 63389 & 66373 & 66372 & 65851 & 63157 & 65900 & 63157 & 66373 & $4.9 \%$ \\
\hline E525 & 63293 & 65399 & 65395 & 64973 & 63002 & 65155 & 63002 & 65399 & $3.7 \%$ \\
\hline E530 & 45046 & 46634 & 46631 & 46944 & 44875 & 47002 & 44875 & 47002 & $4.6 \%$ \\
\hline E540 & 45113 & 47130 & 47126 & 47297 & 44980 & 47462 & 44980 & 47462 & $5.3 \%$ \\
\hline E545 & 44981 & 46240 & 46236 & 46612 & 44775 & 46668 & 44775 & 46668 & $4.1 \%$ \\
\hline \multicolumn{7}{|c|}{ Sensible Coil Load (kWh,th) } & \multicolumn{3}{|c|}{ "Statistics, All Results } \\
\hline & TRNSYS & DOE-2.2 & DOE21E-E & Energy+ & CODYRUN & НОТ3000 & & & (Max-Min) \\
\hline & TUD & NREL & NREL & GARD & UR & NRCan & Min & Max & /Mean \\
\hline E300 & 56662 & 55797 & 55805 & 55252 & 55209 & 55191 & 55191 & 56662 & $2.6 \%$ \\
\hline E310 & 56256 & 56301 & 56313 & 55225 & 55185 & 55083 & 55083 & 56313 & $2.2 \%$ \\
\hline E320 & 62859 & 62697 & 62747 & 62043 & 62009 & 62734 & 62009 & 62859 & $1.4 \%$ \\
\hline E330 & 63083 & 63311 & 63328 & 63779 & 62649 & 61822 & 61822 & 63779 & $3.1 \%$ \\
\hline E340 & 63033 & 63053 & 63111 & 62886 & 62381 & 61406 & 61406 & 63111 & $2.7 \%$ \\
\hline E350 & 50371 & 47684 & 47677 & 48545 & 48589 & 48768 & 47677 & 50371 & $5.5 \%$ \\
\hline E360 & 134977 & 134920 & 134940 & 135287 & 134206 & 134697 & 134206 & 135287 & $0.8 \%$ \\
\hline E400 & 41952 & 41419 & 41437 & 40688 & & 41181 & 40688 & 41952 & $3.1 \%$ \\
\hline E410 & 45677 & 47659 & 47660 & & & 45585 & 45585 & 47660 & $4.4 \%$ \\
\hline E420 & 50390 & 49666 & 50612 & 49524 & & 49984 & 49524 & 50612 & $2.2 \%$ \\
\hline E430 & 47863 & 47731 & 47454 & 46739 & & 46143 & 46143 & 47863 & $3.6 \%$ \\
\hline E440 & 50876 & 50593 & 50492 & 50060 & & 49785 & 49785 & 50876 & $2.2 \%$ \\
\hline E500 & 45044 & 47650 & 47646 & 47491 & 44874 & 47530 & 44874 & 47650 & $5.9 \%$ \\
\hline E500 May-Sep & 34443 & 36596 & 36593 & 36476 & 34448 & 36480 & 34443 & 36596 & $6.0 \%$ \\
\hline E510 May-Sep & 77489 & 82306 & 82303 & 81566 & 77499 & 81563 & 77489 & 82306 & $6.0 \%$ \\
\hline E520 & 45110 & 48102 & 48096 & 47986 & 44977 & 48059 & 44977 & 48102 & $6.6 \%$ \\
\hline E522 & 45076 & 47962 & 47961 & 47758 & 44924 & 47795 & 44924 & 47962 & $6.5 \%$ \\
\hline E525 & 44979 & 47218 & 47213 & 46930 & 44775 & 47110 & 44775 & 47218 & $5.3 \%$ \\
\hline E530 & 45046 & 46574 & 46570 & 46944 & 44874 & 47002 & 44874 & 47002 & $4.6 \%$ \\
\hline E540 & 45112 & 47023 & 47019 & 47288 & 44977 & 47460 & 44977 & 47460 & $5.3 \%$ \\
\hline E545 & 44981 & 46214 & 46210 & 46612 & 44775 & 46668 & 44775 & 46668 & $4.1 \%$ \\
\hline \multicolumn{7}{|c|}{ Latent Coil Load(kWh,th) } & \multicolumn{3}{|c|}{ Statistics, All Results } \\
\hline & TRNSYS & DOE-2.2 & DOE21E-E & Energy+ & CODYRUN & НОТ3000 & & & (Max-Min) \\
\hline & TUD & NREL & NREL & GARD & UR & NRCan & Min & Max & /Mean \\
\hline E300 & 23765 & 21487 & 21487 & 22066 & 22535 & 23067 & 21487 & 23765 & $10.2 \%$ \\
\hline E310 & 43086 & 41094 & 41099 & 41222 & 42111 & 42178 & 41094 & 43086 & $4.8 \%$ \\
\hline E320 & 36932 & 33659 & 33746 & 34040 & 35133 & 34224 & 33659 & 36932 & $9.5 \%$ \\
\hline E330 & 41929 & 37419 & 37666 & 38433 & 41063 & 40186 & 37419 & 41929 & $11.4 \%$ \\
\hline E340 & 39695 & 35974 & 36113 & 36823 & 38296 & 38346 & 35974 & 39695 & $9.9 \%$ \\
\hline E350 & 19017 & 16052 & 15958 & 17245 & 18271 & 18621 & 15958 & 19017 & $17.5 \%$ \\
\hline E360 & 27997 & 24887 & 24914 & 25961 & 26994 & 27470 & 24887 & 27997 & $11.8 \%$ \\
\hline E400 & 26840 & 23498 & 23588 & 24726 & & 25717 & 23498 & 26840 & $13.4 \%$ \\
\hline E410 & 22996 & 19121 & 19184 & & & 20590 & 19121 & 22996 & $18.9 \%$ \\
\hline E420 & 22219 & 19945 & 20270 & 20826 & & 21855 & 19945 & 22219 & $10.8 \%$ \\
\hline E430 & 21893 & 19909 & 19765 & 20403 & & 21057 & 19765 & 21893 & $10.3 \%$ \\
\hline E440 & 22835 & 20788 & 20689 & 21357 & & 22244 & 20689 & 22835 & $9.9 \%$ \\
\hline E500 & 18313 & 18346 & 18346 & 18080 & 18231 & 18084 & 18080 & 18346 & $1.5 \%$ \\
\hline E500 May-Sep & 14000 & 14097 & 14097 & 13879 & 13991 & 13877 & 13877 & 14097 & $1.6 \%$ \\
\hline E510 May-Sep & 31485 & 31712 & 31712 & 31226 & 31480 & 31217 & 31217 & 31712 & $1.6 \%$ \\
\hline E520 & 18312 & 18470 & 18470 & 18101 & 18235 & 18087 & 18087 & 18470 & $2.1 \%$ \\
\hline E522 & 18313 & 18411 & 18410 & 18093 & 18233 & 18104 & 18093 & 18411 & $1.7 \%$ \\
\hline E525 & 18314 & 18182 & 18182 & 18044 & 18227 & 18045 & 18044 & 18314 & $1.5 \%$ \\
\hline E530 & 0 & 61 & 61 & 0 & 1 & 0 & 0 & 61 & $297.1 \%$ \\
\hline E540 & 1 & 107 & 107 & 9 & 3 & 2 & 1 & 107 & $278.2 \%$ \\
\hline E545 & 0 & 25 & 25 & 0 & 0 & 0 & 0 & 25 & $300.0 \%$ \\
\hline
\end{tabular}


Various Annual Means (COP2, IDB)

\begin{tabular}{|c|c|c|c|c|c|c|c|c|c|}
\hline \multirow[t]{3}{*}{ COP2 } & & & & & & & \multicolumn{3}{|c|}{ Statistics, All Results } \\
\hline & TRNSYS & DOE-2.2 & DOE21E-E & Energy+ & CODYRUN & НОТ3000 & & & ax-Min) \\
\hline & TUD & NREL & NREL & GARD & UR & NRCan & Min & Max & /Mean \\
\hline E300 & 3.249 & 3.238 & 3.237 & 3.237 & 3.226 & 3.230 & 3.226 & 3.249 & $0.7 \%$ \\
\hline E310 & 3.415 & 3.417 & 3.417 & 3.393 & 3.397 & 3.380 & 3.380 & 3.417 & $1.1 \%$ \\
\hline E320 & 3.420 & 3.458 & 3.457 & 3.405 & 3.406 & 3.390 & 3.390 & 3.458 & $2.0 \%$ \\
\hline E330 & 3.491 & 3.494 & 3.536 & 3.491 & 3.497 & 3.460 & 3.460 & 3.536 & $2.2 \%$ \\
\hline E340 & 3.454 & 3.477 & 3.496 & 3.448 & 3.450 & 3.420 & 3.420 & 3.496 & $2.2 \%$ \\
\hline E350 & 3.249 & 3.241 & 3.235 & 3.244 & 3.229 & 3.230 & 3.229 & 3.249 & $0.6 \%$ \\
\hline E360 & 3.669 & 3.701 & 3.706 & 3.678 & 3.667 & 3.660 & 3.660 & 3.706 & $1.2 \%$ \\
\hline E400 & 3.250 & 3.251 & 3.252 & 3.246 & & 3.260 & 3.246 & 3.260 & $0.4 \%$ \\
\hline E410 & 3.240 & 3.212 & 3.211 & & & 3.210 & 3.210 & 3.240 & $0.9 \%$ \\
\hline E420 & 3.226 & 3.215 & 3.218 & 3.216 & & 3.210 & 3.210 & 3.226 & $0.5 \%$ \\
\hline E430 & 3.221 & 3.213 & 3.211 & 3.211 & & 3.210 & 3.210 & 3.221 & $0.3 \%$ \\
\hline E440 & 3.231 & 3.222 & 3.222 & 3.221 & & 3.220 & 3.220 & 3.231 & $0.4 \%$ \\
\hline E500 & 3.204 & 3.227 & 3.227 & 3.213 & 3.192 & 3.200 & 3.192 & 3.227 & $1.1 \%$ \\
\hline E500 May-Sep & 3.142 & 3.161 & 3.162 & 3.154 & 3.132 & 3.140 & 3.132 & 3.162 & $0.9 \%$ \\
\hline E510 May-Sep & 3.551 & 3.577 & 3.577 & 3.562 & 3.530 & 3.550 & 3.530 & 3.577 & $1.3 \%$ \\
\hline E520 & 2.901 & 2.957 & 2.956 & 3.004 & 2.873 & 2.920 & 2.873 & 3.004 & $4.5 \%$ \\
\hline E522 & 3.058 & 3.074 & 3.073 & 3.101 & 3.036 & 3.070 & 3.036 & 3.101 & $2.1 \%$ \\
\hline E525 & 3.484 & 3.531 & 3.528 & 3.508 & 3.480 & 3.410 & 3.410 & 3.531 & $3.5 \%$ \\
\hline E530 & 2.962 & 2.969 & 2.969 & 2.999 & 2.916 & 2.980 & 2.916 & 2.999 & $2.8 \%$ \\
\hline E540 & 2.668 & 2.675 & 2.675 & 2.823 & 2.640 & 2.690 & 2.640 & 2.823 & $6.8 \%$ \\
\hline E545 & 3.228 & 3.233 & 3.236 & 3.157 & 3.186 & 3.200 & 3.157 & 3.236 & $2.5 \%$ \\
\hline \multirow[t]{3}{*}{ IDB $\left({ }^{\circ} \mathrm{C}\right)$} & & & & & & & \multicolumn{3}{|c|}{ Statistics, All Results } \\
\hline & TRNSYS & DOE-2.2 & DOE21E-E & Energy+ & CODYRUN & НОТ3000 & & & ax-Min) \\
\hline & TUD & NREL & NREL & GARD & UR & NRCan & Min & Max & /Mean \\
\hline E300 & 23.62 & 24.06 & 24.06 & 24.09 & 24.08 & 23.99 & 23.62 & 24.09 & $1.9 \%$ \\
\hline E310 & 23.76 & 24.11 & 24.06 & 24.09 & 24.09 & 24.01 & 23.76 & 24.11 & $1.5 \%$ \\
\hline E320 & 23.90 & 24.39 & 24.39 & 24.25 & 24.33 & 24.53 & 23.90 & 24.53 & $2.6 \%$ \\
\hline E330 & 23.88 & 24.28 & 24.28 & 24.27 & 24.30 & 24.18 & 23.88 & 24.30 & $1.7 \%$ \\
\hline E340 & 23.88 & 24.28 & 24.28 & 24.30 & 24.31 & 24.21 & 23.88 & 24.31 & $1.8 \%$ \\
\hline E350 & 25.66 & 26.17 & 26.17 & 26.24 & 26.27 & 26.15 & 25.66 & 26.27 & $2.3 \%$ \\
\hline E360 & 25.36 & 25.61 & 25.56 & 25.32 & 25.48 & 25.37 & 25.32 & 25.61 & $1.1 \%$ \\
\hline E400 & 24.13 & 24.06 & 24.06 & 24.09 & & 23.99 & 23.99 & 24.13 & $0.6 \%$ \\
\hline E410 & 24.12 & 24.06 & 24.06 & & & 23.99 & 23.99 & 24.12 & $0.5 \%$ \\
\hline E420 & 23.93 & 24.06 & 24.06 & 24.09 & & 23.99 & 23.93 & 24.09 & $0.7 \%$ \\
\hline E430 & 23.99 & 24.06 & 24.06 & 24.09 & & 23.99 & 23.99 & 24.09 & $0.4 \%$ \\
\hline E440 & 23.91 & 24.06 & 24.06 & 24.09 & & 23.99 & 23.91 & 24.09 & $0.7 \%$ \\
\hline E500 & 20.23 & 20.67 & 20.56 & 20.38 & 21.10 & 22.86 & 20.23 & 22.86 & $12.5 \%$ \\
\hline E500 May-Sep & 24.57 & 25.00 & 25.00 & 24.98 & 25.00 & 25.00 & 24.57 & 25.00 & $1.7 \%$ \\
\hline E510 May-Sep & 25.82 & 25.11 & 25.11 & 24.96 & 25.00 & 25.00 & 24.96 & 25.82 & $3.4 \%$ \\
\hline E520 & 13.52 & 13.78 & 13.72 & 13.58 & 14.14 & 14.89 & 13.52 & 14.89 & $9.9 \%$ \\
\hline |E522 & 16.95 & 17.28 & 17.22 & 17.00 & 17.73 & 18.70 & 16.95 & 18.70 & $10.0 \%$ \\
\hline E525 & 26.84 & 27.39 & 27.28 & 27.10 & 27.77 & 30.69 & 26.84 & 30.69 & $13.8 \%$ \\
\hline E530 & 20.03 & 20.61 & 20.56 & 20.59 & 21.10 & 22.86 & 20.03 & 22.86 & $13.5 \%$ \\
\hline E540 & 13.29 & 13.78 & 13.72 & 13.79 & 14.14 & 14.98 & 13.29 & 14.98 & $12.1 \%$ \\
\hline E545 & 26.61 & 27.33 & 27.28 & 27.31 & 27.72 & 30.69 & 26.61 & 30.69 & $14.7 \%$ \\
\hline
\end{tabular}

e300results.xls q:a205..m254; 07/19/04 
Various Annual Means (Humidity Ratio, Zone Relative Humidity)

\begin{tabular}{|c|c|c|c|c|c|c|c|c|c|}
\hline \multicolumn{7}{|c|}{$\mid$ Humidity Ratio (kg/kg) } & \multicolumn{3}{|c|}{ "Statistics, All Results } \\
\hline & TRNSYS & DOE-2.2 & DOE21E-E & Energy+ & CODYRUN & НОТ3000 & \multicolumn{3}{|c|}{ (Max-Min) } \\
\hline & TUD & NREL & NREL & GARD & UR & NRCan & Min & Max & /Mean \\
\hline E300 & 0.0091 & 0.0092 & 0.0092 & 0.0093 & 0.0092 & 0.0092 & 0.0091 & 0.0093 & $2.4 \%$ \\
\hline E310 & 0.0111 & 0.0113 & 0.0113 & 0.0113 & 0.0112 & 0.0111 & 0.0111 & 0.0113 & $2.0 \%$ \\
\hline |E320 & 0.0100 & 0.0101 & 0.0101 & 0.0101 & 0.0100 & 0.0099 & 0.0099 & 0.0101 & $2.1 \%$ \\
\hline E330 & 0.0097 & 0.0099 & 0.0099 & 0.0100 & 0.0098 & 0.0099 & 0.0097 & 0.0100 & $2.3 \%$ \\
\hline E340 & 0.0098 & 0.0099 & 0.0099 & 0.0100 & 0.0099 & 0.0099 & 0.0098 & 0.0100 & $1.9 \%$ \\
\hline E350 & 0.0097 & 0.0100 & 0.0100 & 0.0099 & 0.0098 & 0.0098 & 0.0097 & 0.0100 & $3.0 \%$ \\
\hline E360 & 0.0085 & 0.0087 & 0.0087 & 0.0088 & 0.0086 & 0.0086 & 0.0085 & 0.0088 & $3.1 \%$ \\
\hline |E400 & 0.0098 & 0.0100 & 0.0100 & 0.0101 & & 0.0100 & 0.0098 & 0.0101 & $2.9 \%$ \\
\hline E410 & 0.0097 & 0.0095 & 0.0095 & & & 0.0095 & 0.0095 & 0.0097 & $2.5 \%$ \\
\hline E420 & 0.0093 & 0.0094 & 0.0094 & 0.0094 & & 0.0093 & 0.0093 & 0.0094 & $2.0 \%$ \\
\hline |E430 & 0.0093 & 0.0094 & 0.0094 & 0.0095 & & 0.0094 & 0.0093 & 0.0095 & $1.9 \%$ \\
\hline E440 & 0.0092 & 0.0093 & 0.0093 & 0.0093 & & 0.0092 & 0.0092 & 0.0093 & $1.9 \%$ \\
\hline |E500 & 0.0098 & & & 0.0094 & 0.0102 & 0.0107 & 0.0094 & 0.0107 & $13.2 \%$ \\
\hline E500 May-Sep & 0.0110 & 0.0114 & 0.0114 & 0.0113 & 0.0113 & 0.0109 & 0.0109 & 0.0114 & $4.5 \%$ \\
\hline E510 May-Sep & 0.0114 & 0.0114 & 0.0114 & 0.0113 & 0.0113 & 0.0109 & 0.0109 & 0.0114 & $4.4 \%$ \\
\hline E520 & 0.0067 & & & 0.0060 & 0.0070 & 0.0076 & 0.0060 & 0.0076 & $23.1 \%$ \\
\hline |E522 & 0.0082 & & & 0.0076 & 0.0086 & 0.0090 & 0.0076 & 0.0090 & $16.8 \%$ \\
\hline E525 & 0.0137 & & & 0.0138 & 0.0140 & 0.0151 & 0.0137 & 0.0151 & $9.8 \%$ \\
\hline E530 & 0.0062 & & & 0.0067 & 0.0058 & 0.0067 & 0.0058 & 0.0067 & $14.4 \%$ \\
\hline E540 & 0.0045 & & & 0.0043 & 0.0039 & 0.0046 & 0.0039 & 0.0046 & $17.9 \%$ \\
\hline E545 & 0.0062 & & & 0.0067 & 0.0067 & 0.0072 & 0.0062 & 0.0072 & $14.8 \%$ \\
\hline \multicolumn{7}{|c|}{ Relative Humidity (\%) } & \multicolumn{3}{|c|}{ Statistics, All Results } \\
\hline & TRNSYS & DOE-2.2 & DOE21E-E & Energy+ & CODYRUN & НОТ3000 & & & ax-Min) \\
\hline & TUD & NREL & NREL & GARD & UR & NRCan & Min & Max & /Mean \\
\hline E300 & 48.61 & 48.26 & 48.28 & 48.59 & 47.83 & 47.93 & 47.83 & 48.61 & $1.6 \%$ \\
\hline E310 & 58.33 & 58.51 & 58.53 & 58.55 & 57.84 & 57.80 & 57.80 & 58.55 & $1.3 \%$ \\
\hline E320 & 52.01 & 51.21 & 51.25 & 51.84 & 51.10 & 49.94 & 49.94 & 52.01 & $4.0 \%$ \\
\hline E330 & 50.84 & 50.58 & 50.65 & 51.18 & 50.08 & 50.70 & 50.08 & 51.18 & 2.2 \\
\hline E340 & 51.09 & 50.69 & 50.73 & 51.15 & 50.30 & 50.78 & 50.30 & 51.15 & $1.7 \%$ \\
\hline E350 & 45.48 & 45.45 & 45.55 & 45.17 & 44.32 & 44.56 & 44.32 & 45.55 & $2.7 \%$ \\
\hline E360 & 41.03 & 41.49 & 41.49 & 42.37 & 40.87 & 41.21 & 40.87 & 42.37 & $3.6 \%$ \\
\hline E400 & 50.77 & 52.21 & 52.25 & 52.55 & & 52.01 & 50.77 & 52.55 & $3.4 \%$ \\
\hline E410 & 50.50 & 49.65 & 49.63 & & & 49.75 & 49.63 & 50.50 & $1.7 \%$ \\
\hline E420 & 48.78 & 49.14 & 48.97 & 49.40 & & 48.76 & 48.76 & 49.40 & $1.3^{\circ}$ \\
\hline E430 & 48.82 & 49.17 & 49.30 & 49.60 & & 49.17 & 48.82 & 49.60 & $1.6 \%$ \\
\hline E440 & 48.33 & 48.46 & 48.57 & 48.83 & & 48.23 & 48.23 & 48.83 & $1.2 \%$ \\
\hline E500 & 66.53 & & & 59.20 & 65.94 & 63.73 & 59.20 & 66.53 & $11.5 \%$ \\
\hline E500 May-Sep & 57.05 & 57.47 & 57.47 & 57.32 & 57.07 & 55.13 & 55.13 & 57.47 & $4.1 \%$ \\
\hline E510 May-Sep & 54.70 & 57.36 & 57.36 & 57.44 & 57.06 & 55.24 & 54.70 & 57.44 & $4.8 \%$ \\
\hline E520 & 69.87 & & & 61.40 & 70.23 & 72.17 & 61.40 & 72.17 & $15.7 \%$ \\
\hline |E522 & 68.68 & & & 60.75 & 68.23 & 68.11 & 60.75 & 68.68 & $11.9 \%$ \\
\hline E525 & 61.47 & & & 54.99 & 60.14 & 57.37 & 54.99 & 61.47 & $11.1 \%$ \\
\hline E530 & 46.73 & & & 48.97 & 41.45 & 39.60 & 39.60 & 48.97 & $21.2 \%$ \\
\hline E540 & 48.52 & & & 46.31 & 40.05 & 43.82 & 40.05 & 48.52 & $19.0 \%$ \\
\hline E545 & 36.62 & & & 38.63 & 36.87 & 29.20 & 29.20 & 38.63 & $26.7 \%$ \\
\hline
\end{tabular}

e300results.xIs q:a255..m304; 07/19/04 
f(ODB) Sensitivity E500 and E530, April 30 and June 25

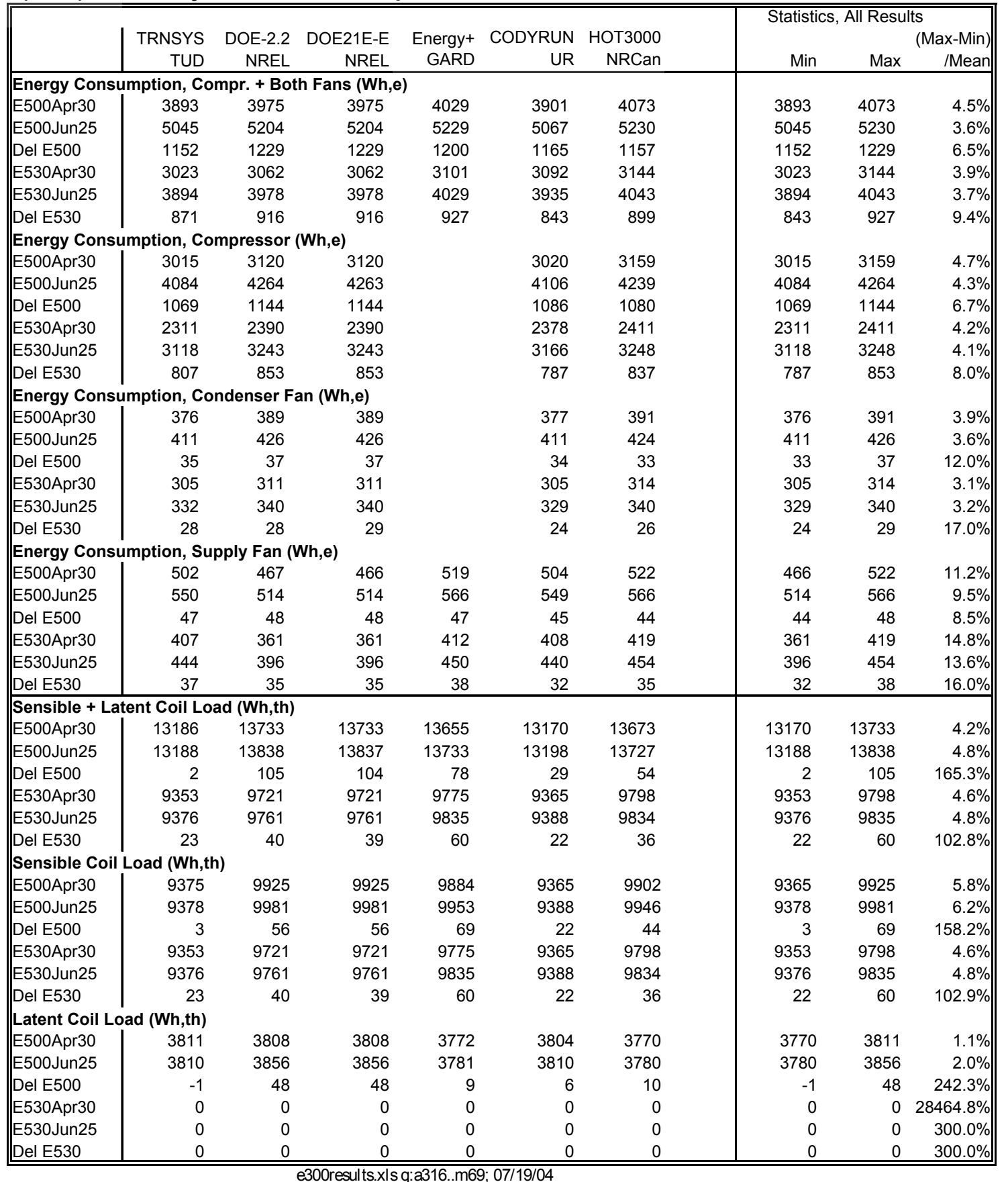

300results.xls q:a316..m69; 07/19/04 
f(ODB) Sensitivity E500 and E530, April 30 and June 25

\begin{tabular}{|c|c|c|c|c|c|c|c|c|c|}
\hline & $\begin{array}{r}\text { TRNSYS } \\
\text { TUD }\end{array}$ & $\begin{array}{r}\text { DOE-2.2 } \\
\text { NREL }\end{array}$ & $\begin{array}{r}\text { DOE21E-E } \\
\text { NREL }\end{array}$ & $\begin{array}{r}\text { Energy+ } \\
\text { GARD }\end{array}$ & $\begin{array}{r}\text { CODYRUN } \\
\text { UR }\end{array}$ & $\begin{array}{r}\text { HOT3000 } \\
\text { NRCan }\end{array}$ & $\begin{array}{r}\text { Statistic } \\
\text { Min }\end{array}$ & All Resul & $\begin{array}{r}\text { (Max-Min) } \\
\text { /Mean } \\
\end{array}$ \\
\hline \multicolumn{10}{|c|}{ Humidity Ratio (kg/kg) } \\
\hline E500Apr30 & 0.0107 & 0.0110 & 0.0110 & 0.0110 & 0.0109 & 0.0160 & 0.011 & 0.016 & $45.3 \%$ \\
\hline E500Jun25 & 0.0112 & 0.0115 & 0.0115 & 0.0115 & 0.0115 & 0.0110 & 0.011 & 0.012 & $4.4 \%$ \\
\hline Del E500 & 0.0005 & 0.0005 & 0.0005 & 0.0005 & 0.0005 & -0.0050 & -0.005 & 0.001 & $-1334.8 \%$ \\
\hline E530Apr30 & 0.0062 & 0.0071 & 0.0071 & 0.0068 & 0.0055 & 0.0067 & 0.005 & 0.007 & $24.6 \%$ \\
\hline E530Jun25 & 0.0062 & 0.0078 & 0.0078 & 0.0068 & 0.0055 & 0.0067 & 0.005 & 0.008 & $34.2 \%$ \\
\hline Del E530 & 0.0000 & 0.0007 & 0.0007 & 0.0000 & 0.0000 & 0.0000 & 0.000 & 0.001 & $304.5 \%$ \\
\hline \multicolumn{10}{|l|}{ COP2 } \\
\hline E500Apr30 & 3.845 & 3.914 & 3.914 & 3.850 & 3.837 & 3.850 & 3.837 & 3.914 & $2.0 \%$ \\
\hline E500Jun25 & 2.931 & 2.951 & 2.951 & 2.943 & 2.921 & 2.940 & 2.921 & 2.951 & $1.0 \%$ \\
\hline Del E500 & -0.914 & -0.963 & -0.963 & -0.907 & -0.916 & -0.910 & -0.963 & -0.907 & $-6.1 \%$ \\
\hline E530Apr30 & 3.543 & 3.599 & 3.599 & 3.441 & 3.460 & 3.590 & 3.441 & 3.599 & $4.5 \%$ \\
\hline E530Jun25 & 2.720 & 2.724 & 2.724 & 2.780 & 2.690 & 2.740 & 2.690 & 2.780 & $3.3 \%$ \\
\hline Del E530 & -0.823 & -0.874 & -0.875 & -0.662 & -0.770 & -0.850 & -0.875 & -0.662 & $-26.3 \%$ \\
\hline \multicolumn{10}{|l|}{ ODB $\left({ }^{\circ} \mathrm{C}\right)$} \\
\hline E500Apr30 & 16.79 & 16.83 & 16.83 & 16.81 & 16.88 & 16.96 & 16.79 & 16.96 & $1.0 \%$ \\
\hline E500Jun25 & 29.52 & 29.50 & 29.50 & 29.52 & 29.52 & 29.50 & 29.50 & 29.52 & $0.1 \%$ \\
\hline Del E500 & 12.73 & 12.67 & 12.67 & 12.70 & 12.63 & 12.54 & 12.54 & 12.73 & $1.5 \%$ \\
\hline E530Apr30 & 16.79 & 16.83 & 16.83 & 16.81 & 16.88 & 16.96 & 16.79 & 16.96 & $1.0 \%$ \\
\hline E530Jun25 & 29.52 & 29.50 & 29.50 & 29.52 & 29.52 & 29.50 & 29.50 & 29.52 & $0.1 \%$ \\
\hline Del E530 & 12.73 & 12.67 & 12.67 & 12.70 & 12.63 & 12.54 & 12.54 & 12.73 & $1.5 \%$ \\
\hline \multicolumn{10}{|l|}{ EDB $\left({ }^{\circ} \mathrm{C}\right)$} \\
\hline E500Apr30 & 24.64 & 24.94 & 24.94 & 24.98 & 25.00 & 25.00 & 24.64 & 25.00 & $1.4 \%$ \\
\hline E500Jun25 & 24.55 & 25.00 & 25.00 & 24.98 & 25.00 & 25.00 & 24.55 & 25.00 & $1.8 \%$ \\
\hline Del E500 & -0.09 & 0.06 & 0.06 & 0.00 & 0.00 & 0.00 & -0.09 & 0.06 & $4740.8 \%$ \\
\hline E530Apr30 & 24.37 & 24.94 & 24.67 & 25.00 & 25.00 & 25.00 & 24.37 & 25.00 & $2.6 \%$ \\
\hline E530Jun25 & 24.35 & 24.94 & 24.94 & 25.00 & 25.00 & 25.00 & 24.35 & 25.00 & $2.6 \%$ \\
\hline Del E530 & -0.01 & 0.00 & 0.28 & 0.00 & 0.00 & 0.00 & -0.01 & 0.28 & $651.2 \%$ \\
\hline
\end{tabular}

e300results.xls q:a370..m402; 07/19/04 
Hourly Integrated Maxima (Total Cooling System Energy Consumption and Total Coil Load)

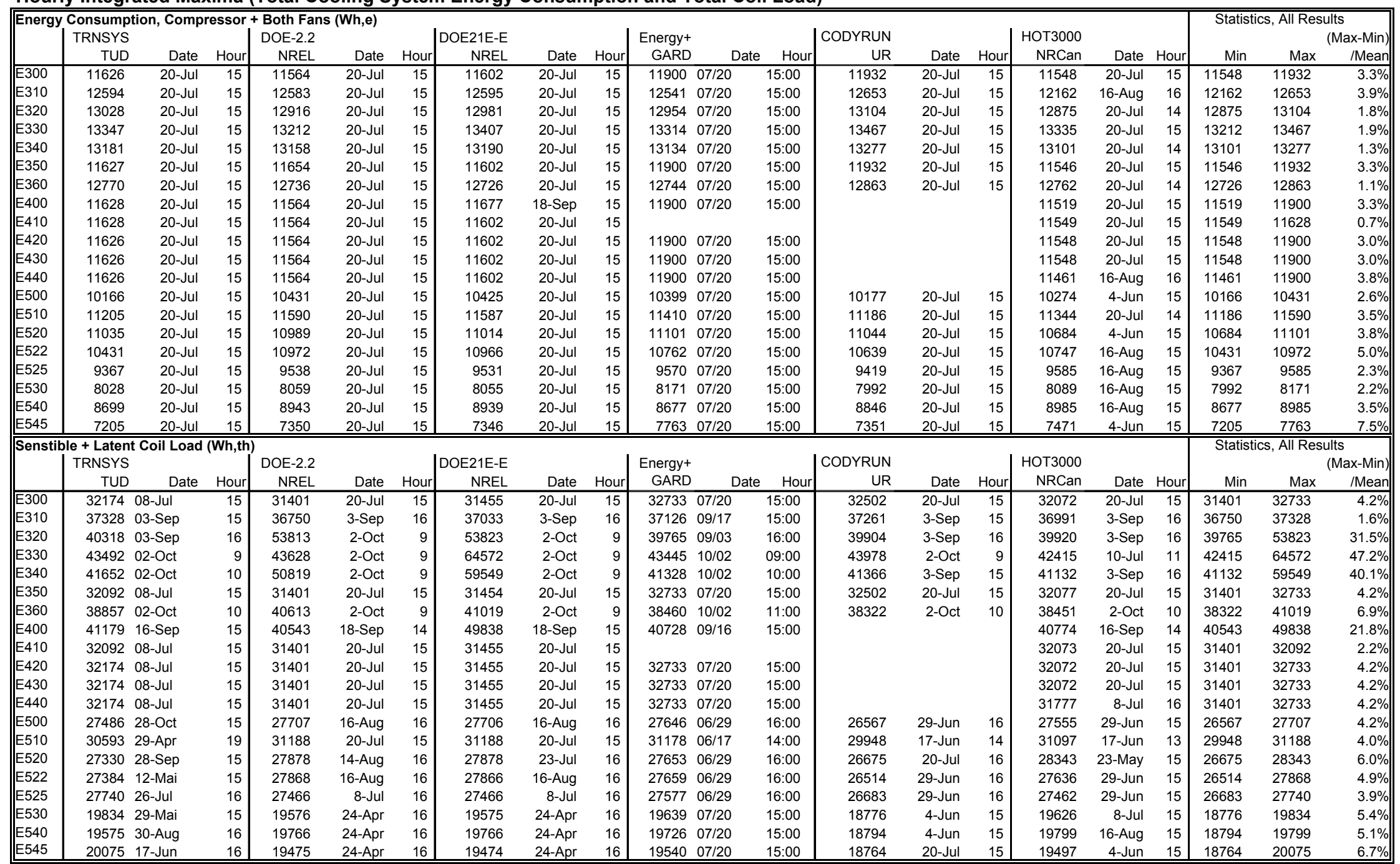


Hourly Integrated Maxima (Sensible Coil Load and Latent Coil Load)

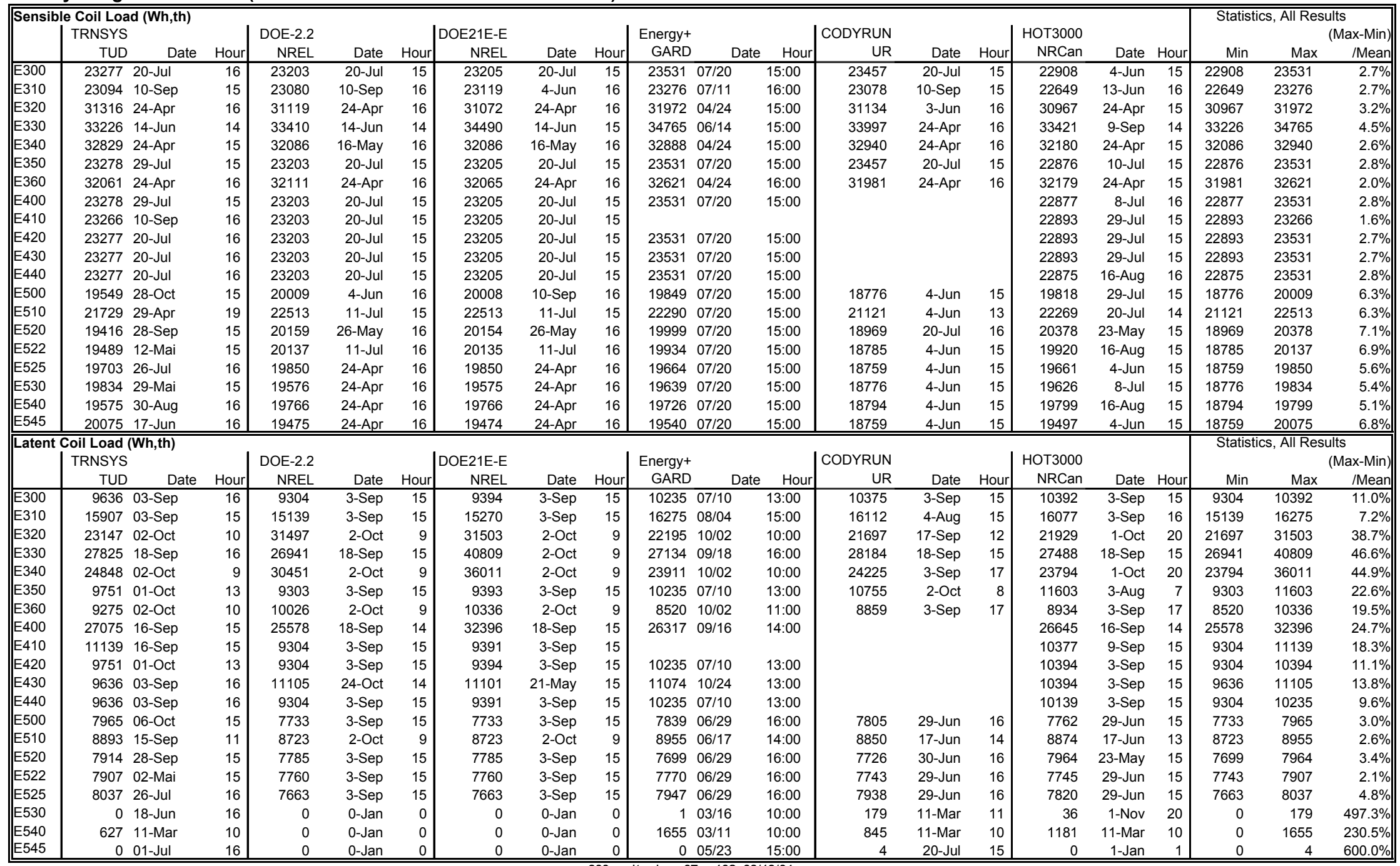

e300results.xls r:a07..w102; 08/19/04 
Hourly Integrated Maxima and Minima (COP2)

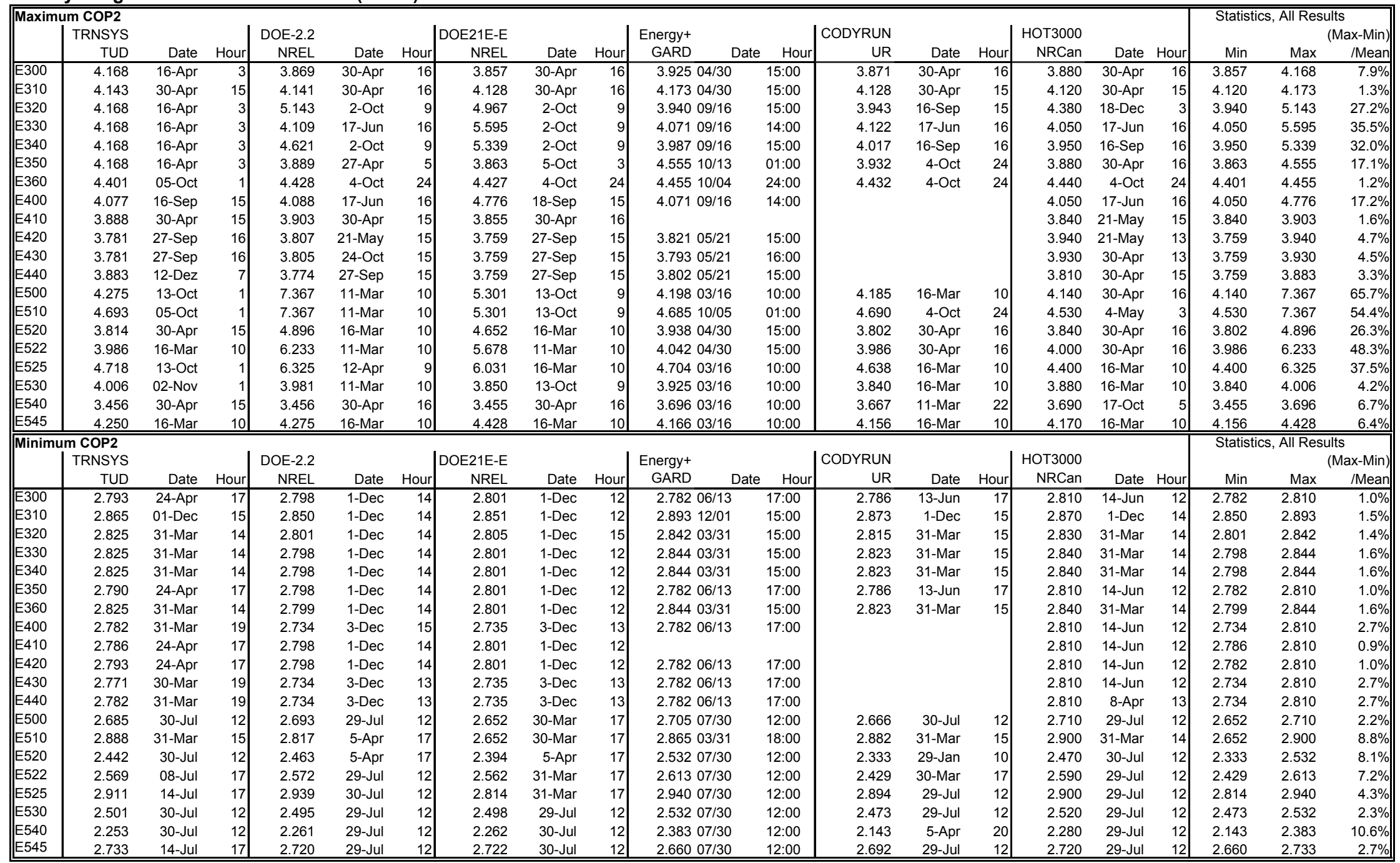


Hourly Integrated Maxima and Minima (IDB)

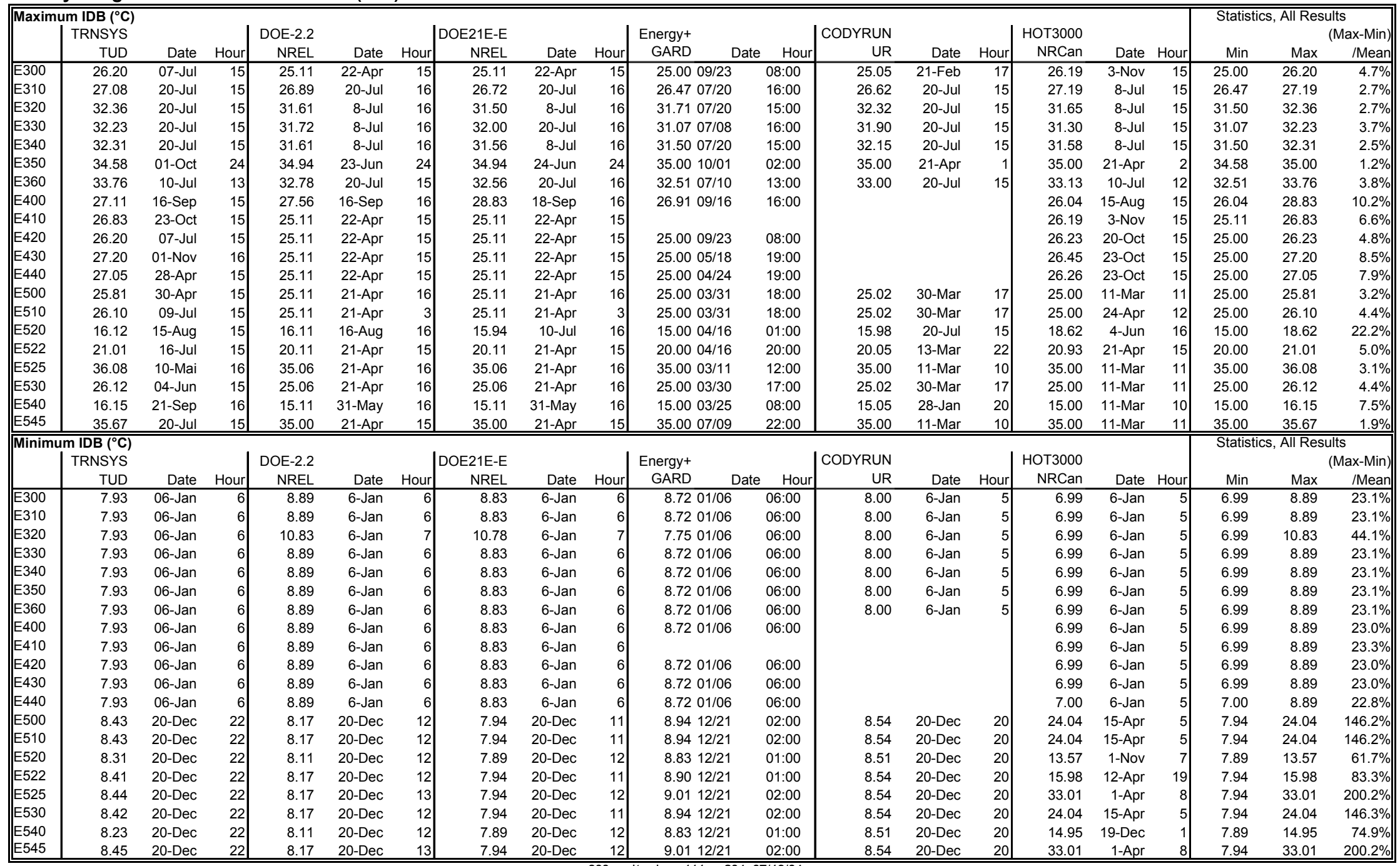

e300results.x.ls s:a111..2a204; 07/19/04 
Hourly Integrated Maxima and Minima (Zone Humidity Ratio)

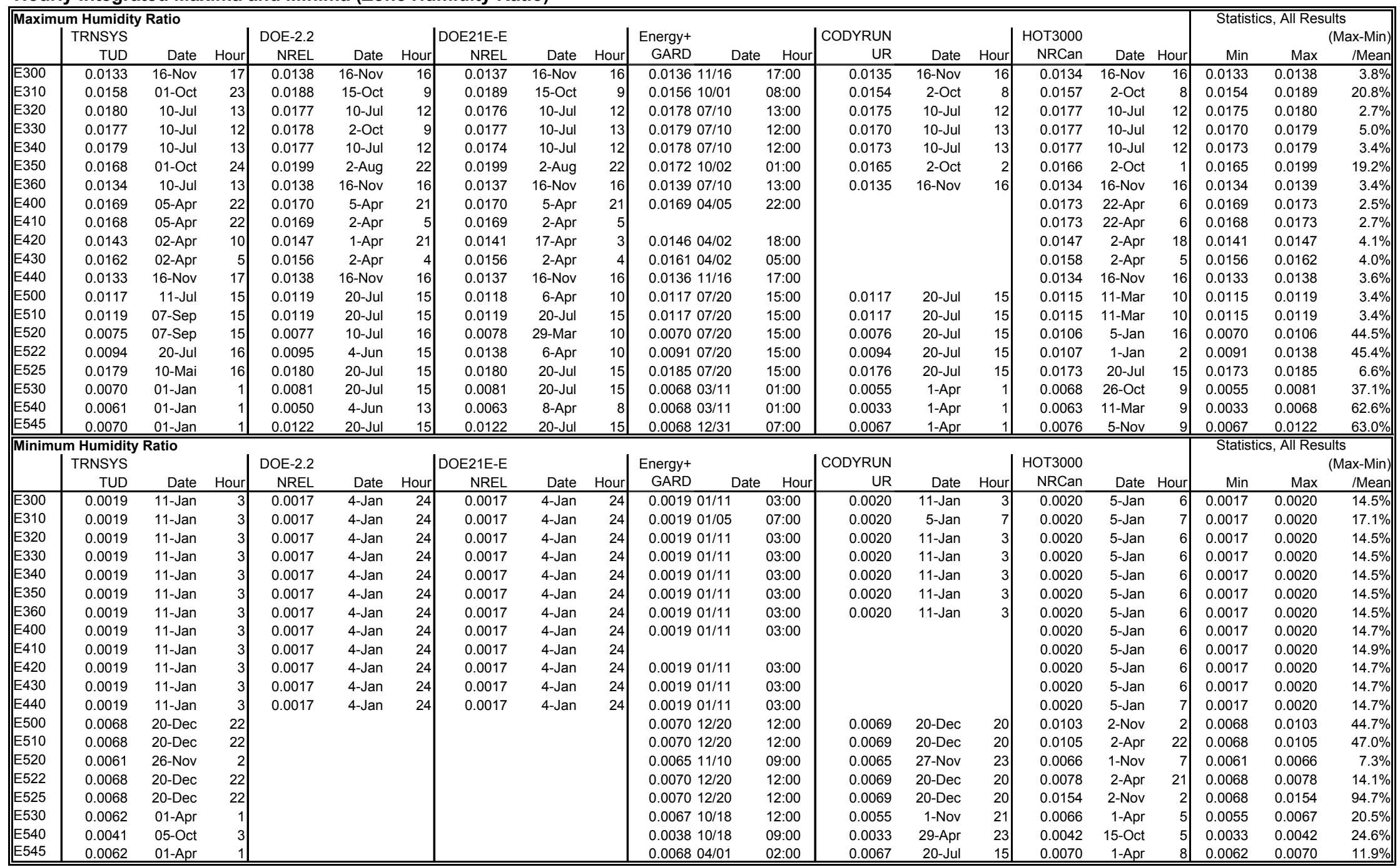


Hourly Integrated Maxima and Minima (Relative Humidity)

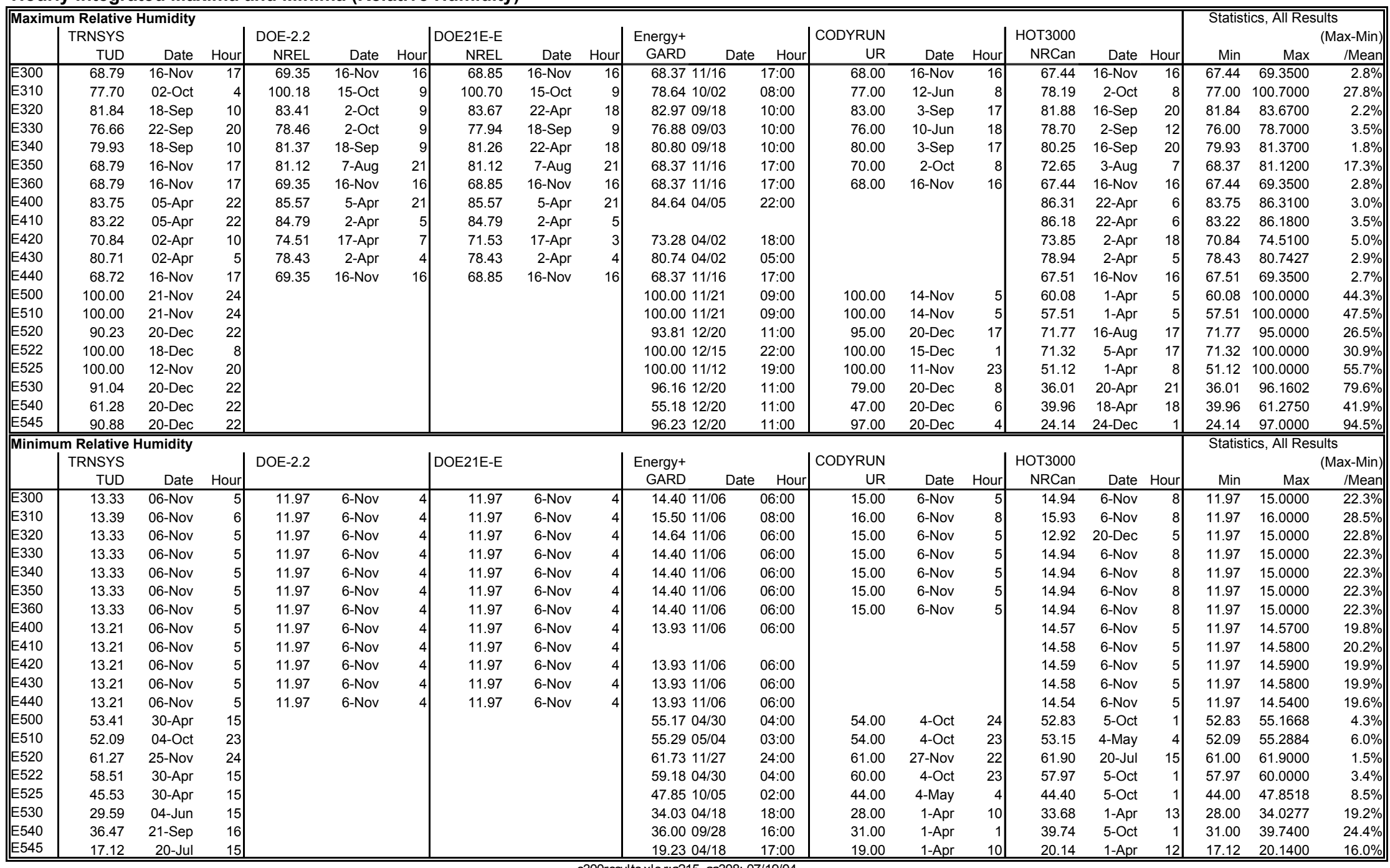

ins $19.2304 / 18$. $17: 00$ 
June 28 Hourly Output - Case E300

\begin{tabular}{|c|c|c|c|c|c|c|c|c|c|c|c|}
\hline $\mid$\begin{tabular}{|l} 
TRNSYS-TUD \\
\end{tabular} & Energy Cons & sumption & Eva & orator Coil & & ne Hum. & & & & & \\
\hline Hour & $\begin{array}{r}\text { Compressor } \\
(\mathrm{Wh})\end{array}$ & $\begin{array}{r}\text { Cond Fan } \\
(\mathrm{Wh})\end{array}$ & $\begin{array}{l}\text { Total } \\
\text { (Wh) }\end{array}$ & $\begin{array}{r}\text { Sensible } \\
(\mathrm{Wh})\end{array}$ & $\begin{array}{r}\text { Latent } \\
(\mathrm{Wh})\end{array}$ & $\begin{array}{r}\text { Ratio } \\
(\mathrm{kg} / \mathrm{kg})\end{array}$ & COP2 & $\begin{array}{l}\text { ODB } \\
\left({ }^{\circ} \mathrm{C}\right)\end{array}$ & $\begin{array}{l}\text { EDB } \\
\left({ }^{\circ} \mathrm{C}\right)\end{array}$ & $\begin{array}{r}\text { EWB } \\
\left({ }^{\circ} \mathrm{C}\right)\end{array}$ & $\begin{array}{r}\text { OHR } \\
(\mathrm{kg} / \mathrm{kg})\end{array}$ \\
\hline 1 & 2056 & 257 & 8132 & 6189 & 1942 & 0.0091 & 3.517 & 18.05 & 23.41 & 16.96 & 0.0113 \\
\hline 2 & 2054 & 257 & 8116 & 6202 & 1914 & 0.0090 & 3.513 & 18.05 & 23.37 & 16.90 & 0.0113 \\
\hline 3 & 2054 & 257 & 8128 & 6194 & 1934 & 0.0091 & 3.517 & 18.05 & 23.38 & 16.94 & 0.0113 \\
\hline 4 & 1830 & 230 & 7224 & 5549 & 1676 & 0.0090 & 3.507 & 17.80 & 23.37 & 16.86 & 0.0111 \\
\hline 5 & 2029 & 256 & 8105 & 6319 & 1786 & 0.0088 & 3.546 & 17.50 & 23.35 & 16.70 & 0.0106 \\
\hline 6 & 1839 & 230 & 7131 & 5686 & 1445 & 0.0087 & 3.447 & 18.30 & 23.42 & 16.57 & 0.0106 \\
\hline$\| 7$ & 2667 & 309 & 9711 & 7597 & 2115 & 0.0092 & 3.263 & 22.20 & 24.04 & 17.32 & 0.0121 \\
\hline 8 & 3553 & 384 & 12121 & 9558 & 2563 & 0.0095 & 3.079 & 26.10 & 24.57 & 17.79 & 0.0122 \\
\hline 9 & 4365 & 458 & 14556 & 11758 & 2798 & 0.0097 & 3.018 & 28.05 & 25.09 & 17.97 & 0.0115 \\
\hline $\mid 10$ & 4441 & 458 & 14639 & 11506 & 3133 & 0.0101 & 2.988 & 28.90 & 25.28 & 18.40 & 0.0124 \\
\hline|| 11 & 5000 & 506 & 16374 & 12342 & 4032 & 0.0104 & 2.974 & 30.00 & 25.36 & 18.82 & 0.0138 \\
\hline $\mid 12$ & 5317 & 529 & 17248 & 12810 & 4438 & 0.0107 & 2.950 & 30.85 & 25.59 & 19.12 & 0.0140 \\
\hline $\mid 13$ & 6189 & 617 & 20498 & 16816 & 3682 & 0.0101 & 3.012 & 30.85 & 26.53 & 18.84 & 0.0123 \\
\hline|| 14 & 6211 & 616 & 20234 & 17284 & 2951 & 0.0098 & 2.964 & 31.40 & 26.56 & 18.55 & 0.0115 \\
\hline $\mid 15$ & 7922 & 781 & 26687 & 22882 & 3805 & 0.0096 & 3.066 & 31.95 & 26.78 & 18.55 & 0.0121 \\
\hline || 16 & 7965 & 781 & 26723 & 22285 & 4438 & 0.0097 & 3.055 & 32.20 & 26.56 & 18.67 & 0.0133 \\
\hline $\mid 17$ & 5421 & 529 & 17231 & 13048 & 4183 & 0.0108 & 2.896 & 31.95 & 26.20 & 19.40 & 0.0145 \\
\hline $\mid 18$ & 5410 & 529 & 17506 & 12721 & 4785 & 0.0112 & 2.947 & 31.40 & 26.23 & 19.77 & 0.0152 \\
\hline $\mid 19$ & 5260 & 529 & 17662 & 12491 & 5171 & 0.0111 & 3.051 & 29.70 & 25.70 & 19.58 & 0.0151 \\
\hline $\mid 20$ & 4880 & 506 & 16990 & 11655 & 5335 & 0.0110 & 3.154 & 27.75 & 25.17 & 19.37 & 0.0157 \\
\hline $\mid 21$ & 3939 & 409 & 13540 & 8882 & 4658 & 0.0111 & 3.114 & 27.20 & 24.65 & 19.44 & 0.0169 \\
\hline || 22 & 3924 & 410 & 13565 & 8880 & 4684 & 0.0112 & 3.130 & 26.95 & 24.74 & 19.48 & 0.0169 \\
\hline |23 & 4123 & 434 & 14531 & 9449 & 5082 & 0.0112 & 3.189 & 26.40 & 24.67 & 19.47 & 0.0169 \\
\hline 24 & 3877 & 410 & 13692 & 8807 & 4885 & 0.0113 & 3.194 & 26.10 & 24.73 & 19.57 & 0.0171 \\
\hline
\end{tabular}

\begin{tabular}{|c|c|c|c|c|c|c|c|c|c|c|c|}
\hline \multirow{2}{*}{$\begin{array}{l}\text { DOE-2.2 } \\
\text { Hour }\end{array}$} & \multicolumn{2}{|c|}{ Energy Consumption } & \multicolumn{3}{|c|}{ Evaporator Coil Load } & Zone Hum. & \multirow[b]{2}{*}{ COP2 } & \multirow[b]{2}{*}{$\begin{array}{r}\text { ODB } \\
\left({ }^{\circ} \mathrm{C}\right)\end{array}$} & \multirow[b]{2}{*}{$\begin{array}{r}\text { EDB } \\
\left({ }^{\circ} \mathrm{C}\right)\end{array}$} & \multirow[b]{2}{*}{$\begin{array}{r}\mathrm{EWB} \\
\left({ }^{\circ} \mathrm{C}\right)\end{array}$} & \multirow[b]{2}{*}{$\begin{array}{r}\mathrm{OHR} \\
(\mathrm{kg} / \mathrm{kg})\end{array}$} \\
\hline & $\begin{array}{r}\text { Compressor } \\
(\mathrm{Wh})\end{array}$ & $\begin{array}{r}\text { Cond Fan } \\
(\mathrm{Wh})\end{array}$ & $\begin{array}{l}\text { Total } \\
(\mathrm{Wh})\end{array}$ & $\begin{array}{r}\text { Sensible } \\
(\mathrm{Wh})\end{array}$ & $\begin{array}{r}\text { Latent } \\
(\mathrm{Wh})\end{array}$ & $\begin{array}{r}\text { Ratio } \\
(\mathrm{kg} / \mathrm{kg})\end{array}$ & & & & & \\
\hline 1 & 1897 & 237 & 7552 & 5889 & 1663 & 0.0094 & 3.539 & 17.78 & 23.83 & 17.34 & 0.0114 \\
\hline 2 & 1941 & 240 & 7630 & 6070 & 1560 & 0.0093 & 3.499 & 18.33 & 23.94 & 17.29 & 0.0112 \\
\hline 3 & 1897 & 237 & 7550 & 5881 & 1669 & 0.0094 & 3.538 & 17.78 & 23.83 & 17.34 & 0.0114 \\
\hline 4 & 1891 & 237 & 7534 & 5878 & 1656 & 0.0094 & 3.540 & 17.78 & 23.83 & 17.34 & 0.0114 \\
\hline 5 & 1697 & 215 & 6798 & 5675 & 1123 & 0.0089 & 3.555 & 17.22 & 23.78 & 16.85 & 0.0103 \\
\hline 6 & 2126 & 259 & 8136 & 6439 & 1698 & 0.0092 & 3.411 & 19.44 & 24.11 & 17.30 & 0.0113 \\
\hline 7 & 3198 & 352 & 11076 & 8342 & 2734 & 0.0100 & 3.120 & 25.00 & 24.94 & 18.39 & 0.0133 \\
\hline 8 & 3135 & 332 & 10291 & 9070 & 1221 & 0.0094 & 2.968 & 27.22 & 25.28 & 17.78 & 0.0109 \\
\hline 9 & 4528 & 469 & 14786 & 11873 & 2913 & 0.0099 & 2.959 & 28.89 & 25.56 & 18.36 & 0.0117 \\
\hline 10 & 4651 & 479 & 15340 & 12039 & 3301 & 0.0103 & 2.990 & 28.89 & 25.56 & 18.68 & 0.0125 \\
\hline 11 & 5434 & 537 & 17455 & 12812 & 4643 & 0.0109 & 2.923 & 31.11 & 25.89 & 19.48 & 0.0148 \\
\hline 12 & 5019 & 498 & 16215 & 12612 & 3603 & 0.0108 & 2.939 & 30.56 & 25.83 & 19.23 & 0.0134 \\
\hline 13 & 6040 & 597 & 19723 & 17139 & 2584 & 0.0101 & 2.972 & 31.11 & 25.94 & 18.56 & 0.0115 \\
\hline 14 & 6420 & 633 & 20808 & 17638 & 3170 & 0.0100 & 2.950 & 31.67 & 26.06 & 18.60 & 0.0121 \\
\hline 15 & 7671 & 751 & 25387 & 22196 & 3191 & 0.0098 & 3.014 & 32.22 & 26.11 & 18.46 & 0.0119 \\
\hline 16 & 8190 & 800 & 27581 & 22528 & 5053 & 0.0100 & 3.068 & 32.22 & 26.17 & 18.84 & 0.0144 \\
\hline 17 & 5715 & 561 & 18205 & 13599 & 4605 & 0.0107 & 2.901 & 31.67 & 26.06 & 19.35 & 0.0146 \\
\hline 18 & 5536 & 544 & 17933 & 12830 & 5103 & 0.0112 & 2.950 & 31.11 & 25.94 & 19.75 & 0.0157 \\
\hline 19 & 4711 & 481 & 16012 & 11876 & 4137 & 0.0110 & 3.084 & 28.33 & 25.50 & 19.32 & 0.0143 \\
\hline 20 & 4859 & 504 & 17082 & 11532 & 5550 & 0.0114 & 3.185 & 27.22 & 25.33 & 19.76 & 0.0164 \\
\hline 21 & 3913 & 405 & 13435 & 9302 & 4133 & 0.0113 & 3.111 & 27.22 & 25.33 & 19.76 & 0.0164 \\
\hline 22 & 3825 & 399 & 13280 & 8974 & 4307 & 0.0114 & 3.144 & 26.67 & 25.22 & 19.80 & 0.0167 \\
\hline 23 & 3750 & 395 & 13192 & 8787 & 4404 & 0.0115 & 3.183 & 26.11 & 25.11 & 19.84 & 0.0169 \\
\hline 24 & 3880 & 407 & 13724 & 8799 & 4925 & 0.0117 & 3.201 & 26.11 & 25.11 & 20.14 & 0.0178 \\
\hline
\end{tabular}


June 28 Hourly Output(Ctd.) - Case E300

\begin{tabular}{|c|c|c|c|c|c|c|c|c|c|c|c|}
\hline \multirow{2}{*}{$\begin{array}{l}\text { DOE-2.1E-E } \\
\text { Hour }\end{array}$} & \multicolumn{2}{|c|}{ Energy Consumption } & \multicolumn{3}{|c|}{ Evaporator Coil Load } & Zone Hum. & \multirow[b]{2}{*}{ COP2 } & \multirow[b]{2}{*}{$\begin{array}{r}\text { ODB } \\
\left({ }^{\circ} \mathrm{C}\right)\end{array}$} & \multirow[b]{2}{*}{$\begin{array}{l}\text { EDB } \\
\left({ }^{\circ} \mathrm{C}\right)\end{array}$} & \multirow[b]{2}{*}{$\begin{array}{r}\text { EWB } \\
\left({ }^{\circ} \mathrm{C}\right)\end{array}$} & \multirow[b]{2}{*}{$\begin{array}{r}\mathrm{OHR} \\
(\mathrm{kg} / \mathrm{kg})\end{array}$} \\
\hline & $\begin{array}{r}\text { Compressor } \\
(\mathrm{Wh})\end{array}$ & $\begin{array}{r}\text { Cond Fan } \\
(\mathrm{Wh})\end{array}$ & $\begin{array}{l}\text { Total } \\
\text { (Wh) }\end{array}$ & $\begin{array}{r}\text { Sensible } \\
(\mathrm{Wh})\end{array}$ & $\begin{array}{r}\text { Latent } \\
(\mathrm{Wh})\end{array}$ & $\begin{array}{r}\text { Ratio } \\
(\mathrm{kg} / \mathrm{kg})\end{array}$ & & & & & \\
\hline 1 & 1894 & 237 & 7545 & 5887 & 1658 & 0.0094 & 3.541 & 17.78 & 23.83 & 17.34 & 0.0114 \\
\hline 2 & 1941 & 241 & 7627 & 6067 & 1560 & 0.0093 & 3.495 & 18.33 & 23.94 & 17.29 & 0.0112 \\
\hline 3 & 1894 & 237 & 7546 & 5878 & 1668 & 0.0094 & 3.541 & 17.78 & 23.83 & 17.37 & 0.0114 \\
\hline 4 & 1890 & 236 & 7528 & 5873 & 1655 & 0.0094 & 3.541 & 17.78 & 23.83 & 17.37 & 0.0114 \\
\hline 5 & 1694 & 215 & 6753 & 5672 & 1081 & 0.0090 & 3.537 & 17.22 & 23.78 & 16.94 & 0.0103 \\
\hline 6 & 2133 & 259 & 8185 & 6439 & 1747 & 0.0092 & 3.422 & 19.44 & 24.11 & 17.30 & 0.0113 \\
\hline 7 & 3223 & 353 & 11233 & 8348 & 2885 & 0.0098 & 3.141 & 25.00 & 24.94 & 18.23 & 0.0133 \\
\hline 8 & 3145 & 335 & 10272 & 9069 & 1203 & 0.0094 & 2.952 & 27.22 & 25.28 & 17.78 & 0.0109 \\
\hline 9 & 4526 & 467 & 14844 & 11875 & 2969 & 0.0099 & 2.973 & 28.89 & 25.56 & 18.28 & 0.0117 \\
\hline 10 & 4655 & 478 & 15393 & 12041 & 3352 & 0.0102 & 2.999 & 28.89 & 25.56 & 18.60 & 0.0125 \\
\hline 11 & 5456 & 536 & 17605 & 12818 & 4787 & 0.0107 & 2.938 & 31.11 & 25.89 & 19.33 & 0.0148 \\
\hline 12 & 5015 & 498 & 16188 & 12611 & 3577 & 0.0108 & 2.936 & 30.56 & 25.83 & 19.23 & 0.0134 \\
\hline 13 & 6036 & 600 & 19621 & 17135 & 2486 & 0.0102 & 2.957 & 31.11 & 25.94 & 18.64 & 0.0115 \\
\hline 14 & 6429 & 635 & 20819 & 17639 & 3180 & 0.0100 & 2.947 & 31.67 & 26.06 & 18.60 & 0.0121 \\
\hline 15 & 7683 & 754 & 25393 & 22197 & 3196 & 0.0098 & 3.010 & 32.22 & 26.11 & 18.46 & 0.0119 \\
\hline 16 & 8222 & 803 & 27721 & 22533 & 5188 & 0.0098 & 3.072 & 32.22 & 26.17 & 18.76 & 0.0144 \\
\hline 17 & 5696 & 556 & 18245 & 13600 & 4644 & 0.0107 & 2.918 & 31.67 & 26.06 & 19.35 & 0.0146 \\
\hline 18 & 5531 & 541 & 17978 & 12832 & 5146 & 0.0112 & 2.961 & 31.11 & 25.94 & 19.68 & 0.0157 \\
\hline 19 & 4689 & 479 & 15914 & 11871 & 4043 & 0.0111 & 3.079 & 28.33 & 25.50 & 19.40 & 0.0143 \\
\hline 20 & 4855 & 503 & 17120 & 11534 & 5586 & 0.0113 & 3.195 & 27.22 & 25.33 & 19.76 & 0.0164 \\
\hline 21 & 3918 & 406 & 13445 & 9303 & 4142 & 0.0113 & 3.109 & 27.22 & 25.33 & 19.76 & 0.0164 \\
\hline 22 & 3823 & 399 & 13285 & 8974 & 4311 & 0.0114 & 3.147 & 26.67 & 25.22 & 19.80 & 0.0167 \\
\hline 23 & 3748 & 394 & 13192 & 8787 & 4405 & 0.0115 & 3.185 & 26.11 & 25.11 & 19.84 & 0.0169 \\
\hline 24 & 3880 & 407 & 13754 & 8800 & 4955 & 0.0117 & 3.208 & 26.11 & 25.11 & 20.06 & 0.0178 \\
\hline
\end{tabular}

\begin{tabular}{|c|c|c|c|c|c|c|c|c|c|c|}
\hline \multirow{2}{*}{$\begin{array}{l}\text { EnergyPlus } \\
\text { Hour }\end{array}$} & Energy Consumption & \multicolumn{3}{|c|}{ Evaporator Coil Load } & one Hum. & \multirow[b]{2}{*}{ COP2 } & \multirow[b]{2}{*}{$\begin{array}{r}\text { ODB } \\
\left({ }^{\circ} \mathrm{C}\right)\end{array}$} & \multirow[b]{2}{*}{$\begin{array}{r}\mathrm{EDB} \\
\left({ }^{\circ} \mathrm{C}\right)\end{array}$} & \multirow[b]{2}{*}{$\begin{array}{r}\text { EWB } \\
\left({ }^{\circ} \mathrm{C}\right)\end{array}$} & \multirow[b]{2}{*}{$\begin{array}{r}\mathrm{OHR} \\
(\mathrm{kg} / \mathrm{kg})\end{array}$} \\
\hline & $\begin{array}{rr}\text { Compressor } & \text { Cond Fan } \\
(\mathrm{Wh}) & (\mathrm{Wh})\end{array}$ & $\begin{array}{l}\text { Total } \\
\text { (Wh) }\end{array}$ & $\begin{array}{r}\text { Sensible } \\
(\mathrm{Wh})\end{array}$ & $\begin{array}{r}\text { Latent } \\
(\mathrm{Wh})\end{array}$ & $\begin{array}{r}\text { Ratio } \\
(\mathrm{kg} / \mathrm{kg})\end{array}$ & & & & & \\
\hline 1 & 2119 Note 1 & 7472 & 5811 & 1661 & 0.0094 & 3.527 & 17.99 & 23.95 & 0.00 & 0.0112 \\
\hline 2 & 2131 Note 1 & 7494 & 5853 & 1641 & 0.0094 & 3.516 & 18.11 & 23.96 & 0.00 & 0.0113 \\
\hline 3 & 2113 Note 1 & 7447 & 5809 & 1637 & 0.0094 & 3.525 & 17.99 & 23.95 & 0.00 & 0.0112 \\
\hline 4 & 2075 Note 1 & 7332 & 5744 & 1588 & 0.0093 & 3.534 & 17.80 & 23.92 & 0.00 & 0.0111 \\
\hline 5 & 1997 Note 1 & 7091 & 5614 & 1477 & 0.0092 & 3.550 & 17.43 & 23.86 & 0.00 & 0.0105 \\
\hline 6 & 2142 Note 1 & 7425 & 6015 & 1410 & 0.0090 & 3.467 & 18.58 & 24.03 & 0.00 & 0.0106 \\
\hline 7 & 2870 Note 1 & 9216 & 7532 & 1684 & 0.0093 & 3.212 & 22.90 & 24.68 & 0.00 & 0.0123 \\
\hline 8 & 3499 Note 1 & 10609 & 8757 & 1853 & 0.0096 & 3.033 & 26.38 & 25.21 & 0.00 & 0.0118 \\
\hline 9 & 4682 Note 1 & 14032 & 11767 & 2265 & 0.0098 & 2.997 & 28.26 & 25.49 & 0.00 & 0.0116 \\
\hline 10 & 4948 Note 1 & 14778 & 11996 & 2781 & 0.0102 & 2.987 & 28.90 & 25.59 & 0.00 & 0.0124 \\
\hline 11 & 5407 Note 1 & 15905 & 12488 & 3417 & 0.0106 & 2.942 & 30.28 & 25.79 & 0.00 & 0.0140 \\
\hline 12 & 5632 Note 1 & 16522 & 12671 & 3851 & 0.0109 & 2.933 & 30.79 & 25.87 & 0.00 & 0.0138 \\
\hline 13 & 7133 Note 1 & 21588 & 17401 & 4187 & 0.0104 & 3.027 & 30.91 & 25.88 & 0.00 & 0.0120 \\
\hline 14 & 6983 Note 1 & 20678 & 17592 & 3086 & 0.0100 & 2.961 & 31.48 & 25.97 & 0.00 & 0.0115 \\
\hline 15 & 8572 Note 1 & 26133 & 22481 & 3652 & 0.0098 & 3.049 & 32.01 & 26.05 & 0.00 & 0.0121 \\
\hline 16 & 8733 Note 1 & 26665 & 22557 & 4107 & 0.0099 & 3.053 & 32.20 & 26.08 & 0.00 & 0.0135 \\
\hline 17 & 5718 Note 1 & 16345 & 13061 & 3283 & 0.0106 & 2.858 & 31.89 & 26.04 & 0.00 & 0.0145 \\
\hline 18 & 5881 Note 1 & 17193 & 12870 & 4324 & 0.0112 & 2.924 & 31.33 & 25.95 & 0.00 & 0.0153 \\
\hline 19 & 5555 Note 1 & 16878 & 12170 & 4708 & 0.0113 & 3.038 & 29.35 & 25.65 & 0.00 & 0.0149 \\
\hline 20 & 5259 Note 1 & 16536 & 11556 & 4981 & 0.0113 & 3.144 & 27.61 & 25.39 & 0.00 & 0.0159 \\
\hline 21 & 4326 Note 1 & 13445 & 9063 & 4383 & 0.0116 & 3.108 & 27.20 & 25.33 & 0.00 & 0.0168 \\
\hline 22 & 4279 Note 1 & 13387 & 8953 & 4434 & 0.0116 & 3.129 & 26.89 & 25.29 & 0.00 & 0.0168 \\
\hline 23 & 4173 Note 1 & 13191 & 8753 & 4437 & 0.0116 & 3.161 & 26.33 & 25.20 & 0.00 & 0.0168 \\
\hline 24 & 4152 Note 1 & 13196 & 8674 & 4522 & 0.0117 & 3.178 & 26.10 & 25.17 & 0.00 & 0.0171 \\
\hline
\end{tabular}


June 28 Hourly Output(Ctd.) - Case E 300

\begin{tabular}{|c|c|c|c|c|c|c|c|c|c|c|c|}
\hline 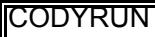 & "Energy Cor & sumption & $\overline{\text { Evap }}$ & Jrator Coil & & " ne Hum. & & & & & \\
\hline Hour & $\begin{array}{r}\text { Compressor } \\
(\mathrm{Wh})\end{array}$ & $\begin{array}{r}\text { Cond Fan } \\
(\mathrm{Wh}) \\
\end{array}$ & $\begin{array}{l}\text { Total } \\
(\mathrm{Wh}) \\
\end{array}$ & $\begin{array}{r}\text { Sensible } \\
(\mathrm{Wh})\end{array}$ & $\begin{array}{r}\text { Latent } \\
(\mathrm{Wh})\end{array}$ & $\begin{array}{r}\text { Ratio } \\
(\mathrm{kg} / \mathrm{kg})\end{array}$ & COP2 & $\begin{array}{r}\text { ODB } \\
\left({ }^{\circ} \mathrm{C}\right) \\
\end{array}$ & $\begin{array}{r}\text { EDB } \\
\left({ }^{\circ} \mathrm{C}\right) \\
\end{array}$ & $\begin{array}{r}\mathrm{EWB} \\
\left({ }^{\circ} \mathrm{C}\right) \\
\end{array}$ & $\begin{array}{r}\text { OHR } \\
(\mathrm{kg} / \mathrm{kg}) \\
\end{array}$ \\
\hline 1 & 1886 & 237 & 7472 & 5788 & 1684 & 0.0093 & 3.520 & 17.80 & 23.92 & 17.16 & 0.0111 \\
\hline $\mid 2$ & 1964 & 244 & 7707 & 5961 & 1747 & 0.0093 & 3.490 & 18.30 & 24.00 & 17.24 & 0.0115 \\
\hline $\mid 3$ & 1881 & 236 & 7445 & 5788 & 1657 & 0.0092 & 3.517 & 17.80 & 23.92 & 17.12 & 0.0111 \\
\hline 4 & 1878 & 236 & 7432 & 5788 & 1644 & 0.0092 & 3.516 & 17.80 & 23.92 & 17.10 & 0.0111 \\
\hline 5 & 1756 & 224 & 7000 & 5580 & 1420 & 0.0090 & 3.535 & 17.20 & 23.83 & 16.79 & 0.0102 \\
\hline 6 & 2075 & 253 & 7915 & 6341 & 1574 & 0.0090 & 3.400 & 19.40 & 24.16 & 17.03 & 0.0110 \\
\hline$\| 7$ & 3035 & 334 & 10450 & 8277 & 2173 & 0.0095 & 3.102 & 25.00 & 25.00 & 17.91 & 0.0131 \\
\hline 8 & 3303 & 352 & 10813 & 9038 & 1775 & 0.0093 & 2.958 & 27.20 & 25.33 & 17.65 & 0.0111 \\
\hline 9 & 4483 & 463 & 14631 & 11971 & 2660 & 0.0097 & 2.958 & 28.90 & 25.59 & 18.12 & 0.0120 \\
\hline $\mid 10$ & 4594 & 472 & 15099 & 11971 & 3128 & 0.0100 & 2.980 & 28.90 & 25.59 & 18.44 & 0.0128 \\
\hline $\mid 11$ & 5238 & 516 & 16722 & 12731 & 3991 & 0.0106 & 2.906 & 31.10 & 25.91 & 19.14 & 0.0148 \\
\hline $\mid 12$ & 5066 & 504 & 16258 & 12559 & 3699 & 0.0106 & 2.919 & 30.60 & 25.84 & 18.94 & 0.0133 \\
\hline $\mid 13$ & 6442 & 642 & 21090 & 17422 & 3669 & 0.0100 & 2.977 & 31.10 & 25.91 & 18.33 & 0.0113 \\
\hline $\mid 14$ & 6523 & 645 & 21067 & 17629 & 3438 & 0.0098 & 2.939 & 31.70 & 26.00 & 18.27 & 0.0117 \\
\hline $\mid 15$ & 8000 & 785 & 26636 & 22491 & 4145 & 0.0096 & 3.032 & 32.20 & 26.08 & 18.24 & 0.0124 \\
\hline $\mid 16$ & 8169 & 799 & 27416 & 22491 & 4925 & 0.0097 & 3.057 & 32.20 & 26.08 & 18.56 & 0.0142 \\
\hline|| 17 & 5306 & 519 & 16702 & 12939 & 3763 & 0.0104 & 2.867 & 31.70 & 26.00 & 19.06 & 0.0147 \\
\hline $\mid 18$ & 5381 & 528 & 17312 & 12729 & 4582 & 0.0109 & 2.930 & 31.10 & 25.91 & 19.46 & 0.0157 \\
\hline $\mid 19$ & 4791 & 492 & 16232 & 11761 & 4470 & 0.0109 & 3.072 & 28.30 & 25.50 & 19.20 & 0.0145 \\
\hline 20 & 4809 & 498 & 16867 & 11381 & 5486 & 0.0113 & 3.178 & 27.20 & 25.33 & 19.65 & 0.0169 \\
\hline 21 & 3939 & 408 & 13484 & 9036 & 4447 & 0.0113 & 3.102 & 27.20 & 25.33 & 19.71 & 0.0169 \\
\hline |22 & 3852 & 402 & 13322 & 8864 & 4459 & 0.0114 & 3.132 & 26.70 & 25.25 & 19.70 & 0.0168 \\
\hline 23 & 3752 & 395 & 13139 & 8656 & 4482 & 0.0114 & 3.168 & 26.10 & 25.16 & 19.69 & 0.0169 \\
\hline 24 & 3794 & 399 & 13323 & 8656 & 4666 & 0.0115 & 3.177 & 26.10 & 25.16 & 19.81 & 0.0173 \\
\hline
\end{tabular}

\begin{tabular}{|c|c|c|c|c|c|c|c|c|c|c|c|}
\hline \multirow{2}{*}{$\begin{array}{l}\text { HOT3000 } \\
\text { Hour }\end{array}$} & \multicolumn{2}{|c|}{ Energy Consumption } & \multicolumn{4}{|c|}{ Evaporator Coil Load $\quad$ Zone Hum. } & \multirow[b]{2}{*}{ COP2 } & \multirow[b]{2}{*}{$\begin{array}{r}\text { ODB } \\
\left({ }^{\circ} \mathrm{C}\right)\end{array}$} & \multirow[b]{2}{*}{$\begin{array}{r}\text { EDB } \\
\left({ }^{\circ} \mathrm{C}\right)\end{array}$} & \multirow[b]{2}{*}{$\begin{array}{r}\mathrm{EWB} \\
\left({ }^{\circ} \mathrm{C}\right)\end{array}$} & \multirow[b]{2}{*}{$\begin{array}{r}\text { OHR } \\
(\mathrm{kg} / \mathrm{kg})\end{array}$} \\
\hline & $\begin{array}{r}\text { Compressor } \\
(\mathrm{Wh})\end{array}$ & $\begin{array}{r}\text { Cond Fan } \\
(\mathrm{Wh})\end{array}$ & $\begin{array}{l}\text { Total } \\
(\mathrm{Wh})\end{array}$ & $\begin{array}{r}\text { Sensible } \\
(\mathrm{Wh})\end{array}$ & $\begin{array}{r}\text { Latent } \\
(\mathrm{Wh})\end{array}$ & $\begin{array}{r}\text { Ratio } \\
(\mathrm{kg} / \mathrm{kg})\end{array}$ & & & & & \\
\hline 1 & 1943 & 241 & 7668 & 5870 & 1798 & 0.0093 & 3.511 & 17.80 & 23.94 & 17.30 & 0.0111 \\
\hline 2 & 1951 & 241 & 7674 & 5872 & 1803 & 0.0093 & 3.502 & 18.30 & 23.94 & 17.31 & 0.0114 \\
\hline 3 & 1902 & 237 & 7528 & 5783 & 1745 & 0.0092 & 3.519 & 17.80 & 23.90 & 17.24 & 0.0111 \\
\hline 4 & 1845 & 231 & 7317 & 5683 & 1634 & 0.0091 & 3.524 & 17.80 & 23.84 & 17.08 & 0.0111 \\
\hline 5 & 1914 & 239 & 7514 & 5955 & 1559 & 0.0090 & 3.490 & 17.20 & 23.98 & 17.01 & 0.0102 \\
\hline 6 & 2507 & 293 & 9223 & 7312 & 1911 & 0.0092 & 3.295 & 19.40 & 24.58 & 17.54 & 0.0110 \\
\hline 7 & 3171 & 343 & 10770 & 8647 & 2123 & 0.0095 & 3.065 & 25.00 & 25.16 & 17.99 & 0.0131 \\
\hline 8 & 3434 & 361 & 11186 & 9299 & 1888 & 0.0094 & 2.948 & 27.20 & 25.45 & 17.96 & 0.0110 \\
\hline 9 & 4489 & 461 & 14744 & 11923 & 2821 & 0.0097 & 2.979 & 28.90 & 25.58 & 18.33 & 0.0120 \\
\hline $\mid 10$ & 4853 & 489 & 15882 & 12287 & 3595 & 0.0102 & 2.973 & 28.90 & 25.74 & 18.85 & 0.0127 \\
\hline $\mid 11$ & 5164 & 508 & 16615 & 12562 & 4053 & 0.0106 & 2.929 & 31.10 & 25.86 & 19.19 & 0.0148 \\
\hline $\mid 12$ & 5005 & 497 & 16030 & 12561 & 3468 & 0.0104 & 2.914 & 30.60 & 25.86 & 18.87 & 0.0132 \\
\hline $\mid 13$ & 6455 & 639 & 21180 & 17431 & 3749 & 0.0100 & 2.986 & 31.10 & 25.94 & 18.52 & 0.0113 \\
\hline || 14 & 6503 & 640 & 21055 & 17609 & 3447 & 0.0097 & 2.948 & 31.70 & 26.02 & 18.44 & 0.0117 \\
\hline $\mid 15$ & 8041 & 785 & 27070 & 22350 & 4719 & 0.0098 & 3.067 & 32.20 & 26.13 & 18.65 & 0.0123 \\
\hline $\mid 16$ & 8134 & 794 & 27623 & 22292 & 5331 & 0.0098 & 3.094 & 32.20 & 26.03 & 18.80 & 0.0142 \\
\hline $\mid 17$ & 5212 & 510 & 16551 & 12739 & 3812 & 0.0103 & 2.893 & 31.70 & 25.94 & 19.11 & 0.0147 \\
\hline $\mid 18$ & 5122 & 507 & 16830 & 12181 & 4649 & 0.0109 & 2.990 & 31.10 & 25.70 & 19.39 & 0.0156 \\
\hline $\mid 19$ & 4832 & 493 & 16635 & 11541 & 5095 & 0.0110 & 3.124 & 28.30 & 25.41 & 19.53 & 0.0145 \\
\hline 20 & 4875 & 501 & 17131 & 11359 & 5772 & 0.0114 & 3.187 & 27.20 & 25.33 & 19.74 & 0.0168 \\
\hline 21 & 3936 & 406 & 13525 & 8931 & 4593 & 0.0114 & 3.115 & 27.20 & 25.29 & 19.74 & 0.0168 \\
\hline 22 & 3844 & 399 & 13356 & 8747 & 4609 & 0.0114 & 3.148 & 26.70 & 25.21 & 19.79 & 0.0168 \\
\hline 23 & 3807 & 397 & 13343 & 8647 & 4697 & 0.0114 & 3.173 & 26.10 & 25.16 & 19.84 & 0.0168 \\
\hline 24 & 3664 & 386 & 12973 & 8360 & 4613 & 0.0115 & 3.203 & 26.10 & 25.04 & 19.77 & 0.0173 \\
\hline
\end{tabular}


Delta Annual Space Cooling Electricity Consumptions

\begin{tabular}{|c|c|c|c|c|c|c|c|c|c|}
\hline \multirow[t]{3}{*}{$\sqrt{\text { Total }(\mathrm{kWh}, \mathrm{e})}$} & \multirow{3}{*}{$\begin{array}{r}\text { TRNSYS } \\
\text { TUD }\end{array}$} & \multirow{2}{*}{\multicolumn{2}{|c|}{ DOE-2.2 DOE21E-E }} & \multirow{3}{*}{$\begin{array}{r}\text { Energy+ } \\
\text { GARD }\end{array}$} & \multirow{3}{*}{$\begin{array}{r}\text { CODYRUN } \\
\text { UR }\end{array}$} & \multirow{3}{*}{$\begin{array}{r}\text { HOT3000 } \\
\text { NRCan }\end{array}$} & \multirow{2}{*}{\multicolumn{3}{|c|}{$\begin{array}{l}\text { Statistics, All Results } \\
\text { (Max-Min) }\end{array}$}} \\
\hline & & & & & & & & & \\
\hline & & NREL & NREL & & & & Min & Max & /Mean \\
\hline E310-E300 & 4340 & 4629 & 4629 & 4545 & 4543 & 4538 & 4340 & 4629 & $6.4 \%$ \\
\hline E320-E300 & 4426 & 3995 & 4037 & 4333 & 4424 & 4387 & 3995 & 4426 & $10.1 \%$ \\
\hline E330-E300 & 5330 & 4958 & 4683 & 5398 & 5559 & 5260 & 4683 & 5559 & $16.8 \%$ \\
\hline E330-E320 & 904 & 963 & 646 & 1064 & 1134 & 873 & 646 & 1134 & $52.5 \%$ \\
\hline E340-E300 & 4986 & 4608 & 4510 & 5037 & 5089 & 4877 & 4510 & 5089 & $11.9 \%$ \\
\hline E330-E340 & 344 & 350 & 173 & 360 & 470 & 383 & 173 & 470 & $85.6 \%$ \\
\hline E350-E300 & -3397 & -4203 & -4207 & -3601 & -3390 & -3328 & -4207 & -3328 & $-23.8 \%$ \\
\hline E360-E300 & 19665 & 19314 & 19261 & 19959 & 19867 & 19998 & 19261 & 19998 & $3.7 \%$ \\
\hline E400-E300 & -3589 & -3904 & -3879 & -3733 & & -3657 & -3904 & -3589 & $-8.4 \%$ \\
\hline E410-E300 & -3555 & -3082 & -3056 & & & -3567 & -3567 & -3056 & $-15.4 \%$ \\
\hline E420-E300 & -2247 & -2220 & -1845 & -2010 & & -1862 & -2247 & -1845 & $-19.7 \%$ \\
\hline E430-E300 & -3096 & -2818 & -2944 & -2973 & & -3252 & -3252 & -2818 & $-14.4 \%$ \\
\hline E440-E300 & -1942 & -1718 & -1782 & -1714 & & -1822 & -1942 & -1714 & $-12.7 \%$ \\
\hline E500-E300 & -13296 & -11933 & -11933 & -11711 & -12653 & -11932 & -13296 & -11711 & $-12.9 \%$ \\
\hline E510-E500 & 17218 & 18099 & 18100 & 17736 & 17414 & 17794 & 17218 & 18100 & $5.0 \%$ \\
\hline E525-E520 & -4666 & -4981 & -4969 & -4316 & -4889 & -4458 & -4981 & -4316 & $-14.1 \%$ \\
\hline E530-E500 & -5057 & -5277 & -5285 & -5293 & -4880 & -5263 & -5293 & -4880 & $-8.0 \%$ \\
\hline E545-E540 & -3743 & -4076 & -4083 & -2425 & -3745 & -3825 & -4083 & -2425 & $-45.4 \%$ \\
\hline \multicolumn{7}{|c|}{ Compressor (kWh,e) } & \multicolumn{3}{|c|}{ "Statistics, All Results } \\
\hline & TRNSYS & \multicolumn{2}{|c|}{ DOE-2.2 DOE21E-E } & Energy+ & CODYRUN & НОТ3000 & \multicolumn{3}{|c|}{ (Max-Min) } \\
\hline & TUD & NREL & NREL & GARD & UR & NRCan & Min & Max & /Mean \\
\hline E310-E300 & 3986 & 4244 & 4244 & & 4167 & 4177 & 3986 & 4244 & $6.2 \%$ \\
\hline E320-E300 & 4080 & 3681 & 3721 & & 4076 & 4036 & 3681 & 4080 & $10.2 \%$ \\
\hline E330-E300 & 4946 & 4603 & 4352 & & 5158 & 4899 & 4352 & 5158 & $16.8 \%$ \\
\hline E330-E320 & 867 & 922 & 631 & & 1082 & 863 & 631 & 1082 & $51.6 \%$ \\
\hline E340-E300 & 4609 & 4260 & 4172 & & 4703 & 4524 & 4172 & 4703 & $11.9 \%$ \\
\hline E330-E340 & 337 & 343 & 180 & & 455 & 375 & 180 & 455 & $81.4 \%$ \\
\hline E350-E300 & -3037 & -3767 & -3772 & & -3032 & -2985 & -3772 & -2985 & $-23.7 \%$ \\
\hline E360-E300 & 17752 & 17430 & 17382 & & 17927 & 18065 & 17382 & 18065 & $3.9 \%$ \\
\hline E400-E300 & -3175 & -3463 & -3442 & & & -3247 & -3463 & -3175 & $-8.7 \%$ \\
\hline E410-E300 & -3149 & -2746 & -2723 & & & -3191 & -3191 & -2723 & $-15.9 \%$ \\
\hline E420-E300 & -1995 & -1973 & -1639 & & & -1662 & -1995 & -1639 & $-19.6 \%$ \\
\hline E430-E300 & -2755 & -2510 & -2622 & & & -2910 & -2910 & -2510 & $-14.8 \%$ \\
\hline E440-E300 & -1724 & -1527 & -1584 & & & -1627 & -1724 & -1527 & $-12.2 \%$ \\
\hline E500-E300 & -4499 & -3096 & -3095 & & -3912 & -3354 & -4499 & -3095 & $-39.1 \%$ \\
\hline E510-E500 & 13806 & 14303 & 14304 & & 13913 & 14230 & 13806 & 14304 & $3.5 \%$ \\
\hline E525-E520 & -2963 & -3241 & -3233 & & -3148 & -2742 & -3241 & -2742 & $-16.3 \%$ \\
\hline E530-E500 & -4197 & -4346 & -4354 & & -4002 & -4350 & -4354 & -4002 & $-8.3 \%$ \\
\hline E545-E540 & -2399 & -2713 & -2720 & & -2413 & -2449 & -2720 & -2399 & $-12.6 \%$ \\
\hline
\end{tabular}

e300results.xls t:a06..m49; 07/19/04 
Delta Annual Space Cooling Electricity Consumptions (ctd.)

\begin{tabular}{|c|c|c|c|c|c|c|c|c|c|}
\hline \multicolumn{7}{|c|}{ Supply Fan (kWh,e) } & \multicolumn{3}{|c|}{ "Statistics, All Results } \\
\hline & TRNSYS & \multicolumn{2}{|c|}{ DOE-2.2 DOE21E-E } & \multirow{2}{*}{$\begin{array}{r}\text { Energy+ } \\
\text { GARD }\end{array}$} & \multirow{2}{*}{$\begin{array}{r}\text { CODYRUN } \\
\text { UR }\end{array}$} & \multirow{2}{*}{$\begin{array}{r}\text { HOT3000 } \\
\text { NRCan }\end{array}$} & \multicolumn{3}{|c|}{ (Max-Min) } \\
\hline & TUD & NREL & NREL & & & & Min & Max & /Mean \\
\hline E310-E300 & 0 & 0 & 0 & 0 & 0 & 0 & 0 & 0 & \#DIV/O! \\
\hline E320-E300 & 0 & 0 & 0 & 0 & 0 & 0 & 0 & 0 & \#DIV/0! \\
\hline E330-E300 & 0 & 0 & 0 & 0 & 0 & 0 & 0 & 0 & \#DIV/0! \\
\hline E330-E320 & 0 & 0 & 0 & 0 & 0 & 0 & 0 & 0 & \#DIV/O! \\
\hline E340-E300 & 0 & 0 & 0 & 0 & 0 & 0 & 0 & 0 & \#DIV/O! \\
\hline E330-E340 & 0 & 0 & 0 & 0 & 0 & 0 & 0 & 0 & \#DIV/0! \\
\hline E350-E300 & 0 & 0 & 0 & 0 & 0 & 0 & 0 & 0 & \#DIV/0! \\
\hline E360-E300 & 0 & 0 & 0 & 0 & 0 & 0 & 0 & 0 & \#DIV/O! \\
\hline E400-E300 & 0 & 0 & 0 & 0 & & 0 & 0 & 0 & \#DIV/O! \\
\hline E410-E300 & 0 & 0 & 0 & & & 0 & 0 & 0 & \#DIV/0! \\
\hline E420-E300 & 0 & 0 & 0 & 0 & & 0 & 0 & 0 & \#DIV/0! \\
\hline E430-E300 & 0 & 0 & 0 & 0 & & 0 & 0 & 0 & \#DIV/O! \\
\hline E440-E300 & 0 & 0 & 0 & 0 & & 0 & 0 & 0 & \#DIV/O! \\
\hline E500-E300 & -8316 & -8511 & -8511 & -8234 & -8327 & -8241 & -8511 & -8234 & $-3.3 \%$ \\
\hline E510-E500 & 1951 & 2262 & 2262 & 2034 & 2002 & 2038 & 1951 & 2262 & $14.9 \%$ \\
\hline E525-E520 & -973 & -988 & -986 & -839 & -996 & -979 & -996 & -839 & $-16.3 \%$ \\
\hline E530-E500 & -491 & -536 & -536 & -538 & -502 & -522 & -538 & -491 & $-9.0 \%$ \\
\hline E545-E540 & -769 & -757 & -757 & -438 & -762 & -787 & -787 & -438 & $-49.0 \%$ \\
\hline \multicolumn{4}{|c|}{ Condenser Fan (kWh,e) } & & & & \multicolumn{3}{|c|}{ Statistics, All Results } \\
\hline & TRNSYS & DOE-2.2D & E21E-E & Energy+ & CODYRUN & НОТ3000 & & & (Max-Min) \\
\hline & TUD & NREL & NREL & GARD & UR & NRCan & Min & Max & /Mean \\
\hline E310-E300 & 354 & 385 & 385 & & 376 & 368 & 354 & 385 & $8.4 \%$ \\
\hline E320-E300 & 346 & 314 & 316 & & 348 & 358 & 314 & 358 & $13.1 \%$ \\
\hline E330-E300 & 383 & 355 & 331 & & 401 & 370 & 331 & 401 & $19.0 \%$ \\
\hline E330-E320 & 37 & 41 & 15 & & 53 & 12 & 12 & 53 & $128.8 \%$ \\
\hline E340-E300 & 376 & 348 & 338 & & 386 & 361 & 338 & 386 & $13.3 \%$ \\
\hline E330-E340 & 7 & 7 & -7 & & 15 & 9 & -7 & 15 & $352.1 \%$ \\
\hline E350-E300 & -360 & -436 & -435 & & -358 & -353 & -436 & -353 & $-21.4 \%$ \\
\hline E360-E300 & 1913 & 1884 & 1879 & & 1940 & 1949 & 1879 & 1949 & $3.7 \%$ \\
\hline E400-E300 & -414 & -441 & -437 & & & -421 & -441 & -414 & $-6.3 \%$ \\
\hline E410-E300 & -406 & -336 & -333 & & & -387 & -406 & -333 & $-20.1 \%$ \\
\hline E420-E300 & -252 & -247 & -206 & & & -208 & -252 & -206 & $-20.1 \%$ \\
\hline E430-E300 & -341 & -308 & -322 & & & -353 & -353 & -308 & $-13.6 \%$ \\
\hline E440-E300 & -218 & -191 & -198 & & & -203 & -218 & -191 & $-13.4 \%$ \\
\hline E500-E300 & -481 & -326 & -327 & & -415 & -347 & -481 & -326 & $-40.8 \%$ \\
\hline E510-E500 & 1461 & 1534 & 1534 & & 1499 & 1526 & 1461 & 1534 & $4.8 \%$ \\
\hline E525-E520 & -729 & -752 & -750 & & -746 & -733 & -752 & -729 & $-3.1 \%$ \\
\hline E530-E500 & -368 & -395 & -395 & & -376 & -391 & -395 & -368 & $-7.0 \%$ \\
\hline E545-E540 & -576 & -606 & -606 & & -571 & -589 & -606 & -571 & $-6.0 \%$ \\
\hline
\end{tabular}

e300results.xls t:a51..m94; 07/19/04 
Delta Cooling Coil Loads

\begin{tabular}{|c|c|c|c|c|c|c|c|c|c|}
\hline \multicolumn{7}{|c|}{ Sensible Coil Load (kWh,th) } & \multirow{2}{*}{\multicolumn{3}{|c|}{$\begin{array}{l}\text { Statistics, All Results } \\
\text { (Max-Min) }\end{array}$}} \\
\hline & \multirow{2}{*}{$\begin{array}{r}\text { TRNSYS } \\
\text { TUD }\end{array}$} & \multicolumn{2}{|c|}{ DOE-2.2 DOE21E-E } & \multirow{2}{*}{$\begin{array}{r}\text { Energy+ } \\
\text { GARD }\end{array}$} & \multirow{2}{*}{$\begin{array}{r}\text { CODYRUN } \\
\text { UR }\end{array}$} & \multirow{2}{*}{$\begin{array}{r}\text { HOT3000 } \\
\text { NRCan }\end{array}$} & & & \\
\hline & & NREL & NREL & & & & Min & Max & /Mean \\
\hline E310-E300 & -405 & 504 & 508 & -27 & -24 & -108 & -405 & 508 & $1224.5 \%$ \\
\hline E320-E300 & 6197 & 6900 & 6942 & 6791 & 6799 & 7543 & 6197 & 7543 & $19.6 \%$ \\
\hline E330-E300 & 6422 & 7514 & 7523 & 8527 & 7440 & 6631 & 6422 & 8527 & $28.7 \%$ \\
\hline E330-E320 & 224 & 614 & 581 & 1735 & 641 & -912 & -912 & 1735 & $550.9 \%$ \\
\hline E340-E300 & 6371 & 7257 & 7306 & 7634 & 7171 & 6215 & 6215 & 7634 & $20.3 \%$ \\
\hline E330-E340 & 51 & 258 & 217 & 893 & 269 & 416 & 51 & 893 & $240.2 \%$ \\
\hline E350-E300 & -6291 & -8112 & -8128 & -6707 & -6621 & -6423 & -8128 & -6291 & $-26.1 \%$ \\
\hline E360-E300 & 78315 & 79123 & 79135 & 80035 & 78996 & 79506 & 78315 & 80035 & $2.2 \%$ \\
\hline E400-E300 & -14709 & -14378 & -14368 & -14564 & & -14010 & -14709 & -14010 & $-4.9 \%$ \\
\hline E410-E300 & -10985 & -8138 & -8145 & & & -9606 & -10985 & -8138 & $-30.9 \%$ \\
\hline E420-E300 & -6272 & -6131 & -5193 & -5728 & & -5207 & -6272 & -5193 & $-18.9 \%$ \\
\hline E430-E300 & -8798 & -8066 & -8351 & -8513 & & -9048 & -9048 & -8066 & $-11.5 \%$ \\
\hline E440-E300 & -5786 & -5204 & -5313 & -5192 & & -5406 & -5786 & -5192 & $-11.0 \%$ \\
\hline E500-E300 & -11618 & -8147 & -8159 & -7761 & -10335 & -7661 & -11618 & -7661 & $-44.2 \%$ \\
\hline E510-E500 & 43046 & 45710 & 45710 & 45091 & 43051 & 45083 & 43046 & 45710 & $6.0 \%$ \\
\hline E525-E520 & -131 & -884 & -882 & -1057 & -202 & -949 & -1057 & -131 & $-135.4 \%$ \\
\hline E530-E500 & 2 & -1076 & -1076 & -547 & 0 & -528 & -1076 & 2 & $-200.6 \%$ \\
\hline E545-E540 & -130 & -809 & -809 & -676 & -202 & -792 & -809 & -130 & $-119.1 \%$ \\
\hline \multicolumn{7}{|c|}{ Latent Coil Load(kWh,th) } & \multicolumn{3}{|c|}{ "Statistics, All Results } \\
\hline & TRNSYS & \multicolumn{2}{|c|}{ DOE-2.2 DOE21E-E } & Energy+ & CODYRUN & \multirow{2}{*}{$\begin{array}{r}\text { HOT3000 } \\
\text { NRCan }\end{array}$} & \multirow{2}{*}{\multicolumn{3}{|c|}{$\operatorname{Max} \begin{array}{r}(\text { Max-Min }) \\
/ \text { Mean }\end{array}$}} \\
\hline & TUD & NREL & NREL & GARD & UR & & & & \\
\hline E310-E300 & 19321 & 19607 & 19612 & 19156 & 19576 & 19111 & 19111 & 19612 & $2.6 \%$ \\
\hline E320-E300 & 13167 & 12173 & 12259 & 11974 & 12597 & 11157 & 11157 & 13167 & $16.4 \%$ \\
\hline E330-E300 & 18164 & 15932 & 16179 & 16367 & 18528 & 17119 & 15932 & 18528 & $15.2 \%$ \\
\hline E330-E320 & 4997 & 3760 & 3919 & 4393 & 5931 & 5962 & 3760 & 5962 & $45.6 \%$ \\
\hline E340-E300 & 15930 & 14488 & 14625 & 14757 & 15760 & 15279 & 14488 & 15930 & $9.5 \%$ \\
\hline E330-E340 & 2234 & 1445 & 1553 & 1610 & 2768 & 1840 & 1445 & 2768 & $69.3 \%$ \\
\hline E350-E300 & -4748 & -5435 & -5529 & -4821 & -4264 & -4446 & -5529 & -4264 & $-26.0 \%$ \\
\hline E360-E300 & 4232 & 3401 & 3427 & 3895 & 4459 & 4403 & 3401 & 4459 & $26.7 \%$ \\
\hline E400-E300 & 3075 & 2012 & 2101 & 2660 & & 2650 & 2012 & 3075 & $42.5 \%$ \\
\hline E410-E300 & -769 & -2366 & -2303 & & & -2477 & -2477 & -769 & $-86.3 \%$ \\
\hline E420-E300 & -1546 & -1542 & -1217 & -1240 & & -1212 & -1546 & -1212 & $-24.7 \%$ \\
\hline E430-E300 & -1872 & -1577 & -1722 & -1663 & & -2010 & -2010 & -1577 & $-24.5 \%$ \\
\hline E440-E300 & -930 & -699 & -798 & -709 & & -823 & -930 & -699 & $-29.1 \%$ \\
\hline E500-E300 & -5452 & -3141 & -3141 & -3986 & -4304 & -4983 & -5452 & -3141 & $-55.5 \%$ \\
\hline E510-E500 & 17485 & 17615 & 17615 & 17348 & 17488 & 17340 & 17340 & 17615 & $1.6 \%$ \\
\hline E525-E520 & 2 & -288 & -288 & -58 & -9 & -42 & -288 & 2 & $-255.0 \%$ \\
\hline E530-E500 & -18313 & -18285 & -18286 & -18080 & -18230 & -18084 & -18313 & -18080 & $-1.3 \%$ \\
\hline E545-E540 & -1 & -81 & -81 & -9 & -3 & -2 & -81 & -1 & $-272.0 \%$ \\
\hline
\end{tabular}

e300resul ts.xIs t:a99..m142; 07/19/04 
Delta Various Annual Means (COP2, IDB)

\begin{tabular}{|c|c|c|c|c|c|c|c|c|c|}
\hline \multirow[t]{2}{*}{ COP2 } & \multirow{2}{*}{$\begin{array}{r}\text { TRNSYS } \\
\text { TUD }\end{array}$} & \multicolumn{2}{|c|}{ DOE-2.2 DOE21E-E } & \multirow{2}{*}{$\begin{array}{r}\text { Energy+ } \\
\text { GARD }\end{array}$} & \multirow{2}{*}{$\begin{array}{r}\text { CODYRUN } \\
\text { UR }\end{array}$} & \multirow{2}{*}{$\begin{array}{r}\text { HOT3000 } \\
\text { NRCan }\end{array}$} & \multicolumn{3}{|c|}{$\begin{array}{l}\text { Statistics, All Results } \\
\text { (Max-Min) }\end{array}$} \\
\hline & & NREL & NREL & & & & Min & Max & /Mean \\
\hline |E310-E300 & 0.166 & 0.180 & 0.180 & 0.155 & 0.171 & 0.150 & 0.150 & 0.180 & $18.0 \%$ \\
\hline ||E320-E300 & 0.171 & 0.220 & 0.220 & 0.168 & 0.180 & 0.160 & 0.160 & 0.220 & $32.3 \%$ \\
\hline E330-E300 & 0.242 & 0.256 & 0.299 & 0.253 & 0.271 & 0.230 & 0.230 & 0.299 & $26.7 \%$ \\
\hline ||E330-E320 & 0.071 & 0.036 & 0.079 & 0.086 & 0.091 & 0.070 & 0.036 & 0.091 & $76.3 \%$ \\
\hline E340-E300 & 0.205 & 0.240 & 0.258 & 0.210 & 0.223 & 0.190 & 0.190 & 0.258 & $30.9 \%$ \\
\hline |E330-E340 & 0.036 & 0.017 & 0.041 & 0.043 & 0.048 & 0.040 & 0.017 & 0.048 & $82.5 \%$ \\
\hline E350-E300 & 0.000 & 0.003 & -0.002 & 0.006 & 0.003 & 0.000 & -0.002 & 0.006 & $498.6 \%$ \\
\hline E360-E300 & 0.420 & 0.463 & 0.468 & 0.441 & 0.440 & 0.430 & 0.420 & 0.468 & $10.9 \%$ \\
\hline E400-E300 & 0.001 & 0.014 & 0.015 & 0.009 & & 0.030 & 0.001 & 0.030 & $210.3 \%$ \\
\hline E410-E300 & -0.010 & -0.025 & -0.027 & & & -0.020 & -0.027 & -0.010 & $-84.0 \%$ \\
\hline |E420-E300 & -0.023 & -0.022 & -0.020 & -0.021 & & -0.020 & -0.023 & -0.020 & $-14.9 \%$ \\
\hline E430-E300 & -0.028 & -0.025 & -0.026 & -0.026 & & -0.020 & -0.028 & -0.020 & $-33.0 \%$ \\
\hline E440-E300 & -0.018 & -0.015 & -0.015 & -0.016 & & -0.010 & -0.018 & -0.010 & $-51.9 \%$ \\
\hline E500-E300 & -0.045 & -0.010 & -0.011 & -0.024 & -0.034 & -0.030 & -0.045 & -0.010 & $-135.4 \%$ \\
\hline |E510-E500 & 0.409 & 0.416 & 0.416 & 0.408 & 0.397 & 0.410 & 0.397 & 0.416 & $4.6 \%$ \\
\hline E525-E520 & 0.582 & 0.574 & 0.572 & 0.504 & 0.606 & 0.490 & 0.490 & 0.606 & $21.0 \%$ \\
\hline |E530-E500 & -0.242 & -0.258 & -0.257 & -0.214 & -0.276 & -0.220 & -0.276 & -0.214 & $-25.5 \%$ \\
\hline E545-E540 & 0.560 & 0.559 & 0.560 & 0.334 & 0.546 & 0.510 & 0.334 & 0.560 & $44.3 \%$ \\
\hline \multirow[t]{3}{*}{ IDB $\left({ }^{\circ} \mathrm{C}\right)$} & & & & & & & \multirow{2}{*}{\multicolumn{3}{|c|}{$\begin{array}{l}\text { Statistics, All Results } \\
\text { (Max-Min) }\end{array}$}} \\
\hline & TRNSYS & DOE-2.2 & E21E-E & Energy+ & CODYRUN & НОT3000 & & & \\
\hline & TUD & NREL & NREL & GARD & UR & NRCan & Min & Max & /Mean \\
\hline E310-E300 & 0.13 & 0.06 & 0.00 & 0.00 & 0.01 & 0.02 & 0.00 & 0.13 & $364.3 \%$ \\
\hline |E320-E300 & 0.28 & 0.33 & 0.33 & 0.16 & 0.25 & 0.54 & 0.16 & 0.54 & $119.3 \%$ \\
\hline E330-E300 & 0.26 & 0.22 & 0.22 & 0.18 & 0.21 & 0.19 & 0.18 & 0.26 & $34.0 \%$ \\
\hline |E330-E320 & -0.02 & -0.11 & -0.11 & 0.02 & -0.03 & -0.35 & -0.35 & 0.02 & $-365.4 \%$ \\
\hline |E340-E300 & 0.25 & 0.22 & 0.22 & 0.21 & 0.23 & 0.22 & 0.21 & 0.25 & $19.5 \%$ \\
\hline |E330-E340 & 0.00 & 0.00 & 0.00 & -0.02 & -0.01 & -0.03 & -0.03 & 0.00 & $-319.0 \%$ \\
\hline |E350-E300 & 2.04 & 2.11 & 2.11 & 2.15 & 2.19 & 2.16 & 2.04 & 2.19 & $7.1 \%$ \\
\hline |E360-E300 & 1.74 & 1.56 & 1.50 & 1.23 & 1.40 & 1.38 & 1.23 & 1.74 & $34.6 \%$ \\
\hline E400-E300 & 0.50 & 0.00 & 0.00 & 0.00 & & 0.00 & 0.00 & 0.50 & $498.8 \%$ \\
\hline |E410-E300 & 0.50 & 0.00 & 0.00 & & & 0.00 & 0.00 & 0.50 & $400.0 \%$ \\
\hline |E420-E300 & 0.30 & 0.00 & 0.00 & 0.00 & & 0.00 & 0.00 & 0.30 & $500.3 \%$ \\
\hline |E430-E300 & 0.37 & 0.00 & 0.00 & 0.00 & & 0.00 & 0.00 & 0.37 & $500.3 \%$ \\
\hline E440-E300 & 0.29 & 0.00 & 0.00 & 0.00 & & 0.00 & 0.00 & 0.29 & $500.2 \%$ \\
\hline |E500-E300 & -3.39 & -3.39 & -3.50 & -3.71 & -2.98 & -1.13 & -3.71 & -1.13 & $-85.5 \%$ \\
\hline |E510-E500 & 1.24 & 0.11 & 0.11 & -0.02 & 0.00 & 0.00 & -0.02 & 1.24 & $526.6 \%$ \\
\hline |E525-E520 & 13.33 & 13.61 & 13.56 & 13.53 & 13.63 & 15.80 & 13.33 & 15.80 & $17.8 \%$ \\
\hline |E530-E500 & -0.21 & -0.06 & 0.00 & 0.21 & 0.00 & 0.00 & -0.21 & 0.21 & $-4302.5 \%$ \\
\hline E545-E540 & 13.32 & 13.56 & 13.56 & 13.52 & 13.58 & 15.71 & 13.32 & 15.71 & $17.3 \%$ \\
\hline
\end{tabular}

e300results.xls t:a145..m188; 07/19/04 
Delta Various Annual Means (Zone Humidity)

\begin{tabular}{|c|c|c|c|c|c|c|c|c|c|}
\hline \multicolumn{7}{|c|}{ Humidity Ratio (kg/kg) } & \multicolumn{3}{|c|}{ Statistics, All Results } \\
\hline & TRNSYS & \multicolumn{2}{|c|}{ DOE-2.2 DOE21E-E } & Energy+ & CODYRUN & НОТ3000 & \multirow[b]{2}{*}{ Min } & \multicolumn{2}{|c|}{ (Max-Min) } \\
\hline & TUD & NREL & NREL & GARD & UR & NRCan & & Max & /Mean \\
\hline E310-E300 & 0.0020 & 0.0021 & 0.0021 & 0.0020 & 0.0020 & 0.0019 & 0.0019 & 0.0021 & $9.9 \%$ \\
\hline E320-E300 & 0.0009 & 0.0009 & 0.0009 & 0.0008 & 0.0009 & 0.0007 & 0.0007 & 0.0009 & $25.7 \%$ \\
\hline E330-E300 & 0.0007 & 0.0007 & 0.0007 & 0.0007 & 0.0006 & 0.0007 & 0.0006 & 0.0007 & $9.3 \%$ \\
\hline E330-E320 & -0.0002 & -0.0002 & -0.0002 & -0.0001 & -0.0002 & 0.0000 & -0.0002 & 0.0000 & $-143.9 \%$ \\
\hline E340-E300 & 0.0007 & 0.0007 & 0.0007 & 0.0007 & 0.0007 & 0.0007 & 0.0007 & 0.0007 & $4.1 \%$ \\
\hline E330-E340 & -0.0001 & 0.0000 & 0.0000 & 0.0000 & -0.0001 & 0.0000 & -0.0001 & 0.0000 & $-277.9 \%$ \\
\hline E350-E300 & 0.0006 & 0.0008 & 0.0008 & 0.0006 & 0.0006 & 0.0006 & 0.0006 & 0.0008 & $34.2 \%$ \\
\hline E360-E300 & -0.0006 & -0.0005 & -0.0005 & -0.0005 & -0.0006 & -0.0006 & -0.0006 & -0.0005 & $-22.0 \%$ \\
\hline E400-E300 & 0.0007 & 0.0008 & 0.0008 & 0.0008 & & 0.0008 & 0.0007 & 0.0008 & $8.7 \%$ \\
\hline E410-E300 & 0.0007 & 0.0003 & 0.0003 & & & 0.0003 & 0.0003 & 0.0007 & $94.5 \%$ \\
\hline E420-E300 & 0.0002 & 0.0002 & 0.0002 & 0.0002 & & 0.0001 & 0.0001 & 0.0002 & $58.3 \%$ \\
\hline E430-E300 & 0.0002 & 0.0002 & 0.0002 & 0.0002 & & 0.0002 & 0.0002 & 0.0002 & $19.7 \%$ \\
\hline E440-E300 & 0.0001 & 0.0001 & 0.0001 & 0.0000 & & 0.0000 & 0.0000 & 0.0001 & $148.5 \%$ \\
\hline E500-E300 & 0.0007 & & & 0.0001 & 0.0010 & 0.0015 & 0.0001 & 0.0015 & $169.4 \%$ \\
\hline E510-E500 & 0.0004 & & & 0.0000 & 0.0000 & 0.0000 & 0.0000 & 0.0004 & $394.2 \%$ \\
\hline E525-E520 & 0.0070 & & & 0.0078 & 0.0070 & 0.0075 & 0.0070 & 0.0078 & $10.9 \%$ \\
\hline E530-E500 & -0.0035 & & & -0.0027 & -0.0044 & -0.0040 & -0.0044 & -0.0027 & $-48.0 \%$ \\
\hline E545-E540 & 0.0018 & & & 0.0024 & 0.0029 & 0.0026 & 0.0018 & 0.0029 & $46.8 \%$ \\
\hline \multicolumn{4}{|c|}{ Relative Humidity (\%) } & & & & \multicolumn{3}{|c|}{ Statistics, All Results } \\
\hline & TRNSYS & \multicolumn{2}{|c|}{ DOE-2.2 DOE21E-E } & Energy+ & CODYRUN & НОТ3000 & \multicolumn{3}{|c|}{ (Max-Min) } \\
\hline & TUD & NREL & NREL & GARD & UR & NRCan & Min & Max & /Mean \\
\hline E310-E300 & 9.72 & 10.25 & 10.25 & 9.96 & 10.01 & 9.87 & 9.72 & 10.25 & $5.3 \%$ \\
\hline E320-E300 & 3.39 & 2.95 & 2.97 & 3.25 & 3.28 & 2.01 & 2.01 & 3.39 & $46.4 \%$ \\
\hline E330-E300 & 2.23 & 2.32 & 2.37 & 2.59 & 2.26 & 2.77 & 2.23 & 2.77 & $22.3 \%$ \\
\hline E330-E320 & -1.16 & -0.63 & -0.60 & -0.66 & -1.02 & 0.76 & -1.16 & 0.76 & $-347.8 \%$ \\
\hline E340-E300 & 2.47 & 2.43 & 2.45 & 2.56 & 2.47 & 2.85 & 2.43 & 2.85 & $16.5 \%$ \\
\hline E330-E340 & -0.24 & -0.11 & -0.08 & 0.03 & -0.21 & -0.08 & -0.24 & 0.03 & $-232.7 \%$ \\
\hline E350-E300 & -3.13 & -2.81 & -2.73 & -3.42 & -3.51 & -3.37 & -3.51 & -2.73 & $-24.7 \%$ \\
\hline E360-E300 & -7.58 & -6.77 & -6.79 & -6.22 & -6.96 & -6.72 & -7.58 & -6.22 & $-19.9 \%$ \\
\hline E400-E300 & 2.16 & 3.95 & 3.97 & 3.96 & & 4.08 & 2.16 & 4.08 & $53.1 \%$ \\
\hline E410-E300 & 1.88 & 1.39 & 1.35 & & & 1.82 & 1.35 & 1.88 & $33.0 \%$ \\
\hline E420-E300 & 0.16 & 0.88 & 0.69 & 0.81 & & 0.83 & 0.16 & 0.88 & $106.1 \%$ \\
\hline E430-E300 & 0.21 & 0.91 & 1.02 & 1.01 & & 1.24 & 0.21 & 1.24 & $117.8 \%$ \\
\hline E440-E300 & -0.29 & 0.20 & 0.29 & 0.24 & & 0.30 & -0.29 & 0.30 & $394.1 \%$ \\
\hline E500-E300 & 17.91 & & & 10.61 & 18.12 & 15.80 & 10.61 & 18.12 & $48.1 \%$ \\
\hline E510-E500 & -2.35 & & & 0.11 & -0.01 & 0.11 & -2.35 & 0.11 & $-461.4 \%$ \\
\hline E525-E520 & -8.41 & & & -6.41 & -10.09 & -14.80 & -14.80 & -6.41 & $-84.5 \%$ \\
\hline E530-E500 & -19.80 & & & -10.22 & -24.49 & -24.13 & -24.49 & -10.22 & $-72.6 \%$ \\
\hline E545-E540 & -11.90 & & & -7.68 & -3.18 & -14.62 & -14.62 & -3.18 & $-122.5 \%$ \\
\hline
\end{tabular}

e300results.xlst:a191..m234; 07/19/04 
Delta Hourly Integrated Maximum Total Consumptions

\begin{tabular}{|c|c|c|c|c|c|c|c|c|c|}
\hline & \multirow{2}{*}{\multicolumn{3}{|c|}{$\begin{array}{r}\text { Statistics, All Results } \\
\text { (Max-Min) }\end{array}$}} \\
\hline \multicolumn{4}{|c|}{$\begin{array}{l}\text { Total Consumption (Wh,e) } \\
\qquad \text { TRNSYS DOE-2.2DOE21E-E }\end{array}$} & \multirow{2}{*}{$\begin{array}{r}\text { Energy+ } \\
\text { GARD }\end{array}$} & \multirow{2}{*}{$\begin{array}{r}\text { CODYRUN } \\
\text { UR }\end{array}$} & \multirow{2}{*}{$\begin{array}{r}\text { HOT3000 } \\
\text { NRCan } \\
\end{array}$} & & & \\
\hline & TUD & NREL & NREL & & & & Min & Max & /Mean \\
\hline E310-E300 & 968 & 1019 & 993 & 641 & 721 & 614 & 614 & 1019 & $49.0 \%$ \\
\hline |E320-E300 & 1402 & 1352 & 1379 & 1055 & 1172 & 1327 & 1055 & 1402 & $27.1 \%$ \\
\hline E330-E300 & 1721 & 1648 & 1805 & 1414 & 1535 & 1787 & 1414 & 1805 & $23.7 \%$ \\
\hline |E330-E320 & 319 & 296 & 426 & 360 & 363 & 460 & 296 & 460 & $44.3 \%$ \\
\hline |E340-E300 & 1555 & 1594 & 1588 & 1234 & 1345 & 1553 & 1234 & 1594 & $24.3 \%$ \\
\hline |E330-E340 & 166 & 54 & 217 & 180 & 190 & 234 & 54 & 234 & $103.8 \%$ \\
\hline |E350-E300 & 1 & 90 & 0 & 0 & 0 & -2 & -2 & 90 & $621.2 \%$ \\
\hline E360-E300 & 1143 & 1172 & 1124 & 844 & 931 & 1214 & 844 & 1214 & $34.5 \%$ \\
\hline E400-E300 & 2 & 0 & 75 & 0 & & -29 & -29 & 75 & $1087.2 \%$ \\
\hline E410-E300 & 2 & 0 & 0 & & & 1 & 0 & 2 & $258.7 \%$ \\
\hline ||E420-E300 & 0 & 0 & 0 & 0 & & 0 & 0 & 0 & \#DIV/O! \\
\hline E430-E300 & 0 & 0 & 0 & 0 & & 0 & 0 & 0 & $-500.0 \%$ \\
\hline E440-E300 & 0 & 0 & 0 & 0 & & -87 & -87 & 0 & $-500.0 \%$ \\
\hline |E500-E300 & -1460 & -1133 & -1177 & -1501 & -1755 & -1274 & -1755 & -1133 & $-45.0 \%$ \\
\hline E510-E500 & 1038 & 1159 & 1162 & 1011 & 1009 & 1070 & 1009 & 1162 & $14.2 \%$ \\
\hline |E525-E520 & -1669 & -1451 & -1483 & -1531 & -1625 & -1099 & -1669 & -1099 & $-38.6 \%$ \\
\hline E530-E500 & -2138 & -2372 & -2370 & -2228 & -2185 & -2185 & -2372 & -2138 & $-10.4 \%$ \\
\hline E545-E540 & -1494 & -1593 & -1593 & -915 & -1495 & -1514 & -1593 & -915 & $-47.3 \%$ \\
\hline
\end{tabular}


Delta Hourly Integrated Maximum Coil Loads

\begin{tabular}{|c|c|c|c|c|c|c|c|c|c|}
\hline \multicolumn{7}{|c|}{ |Sensible + Latent Coil Load (Wh,th) } & \multicolumn{3}{|c|}{ "Statistics, All Results } \\
\hline & TRNSYS & DOE-2.2 & E21E-E & Energy+ & CODYRUN & НОТ3000 & \multirow[b]{2}{*}{ Min } & \multicolumn{2}{|r|}{ (Max-Min) } \\
\hline & TUD & NREL & NREL & GARD & UR & NRCan & & Max & /Mean \\
\hline E310-E300 & 5154 & 5349 & 5578 & 4393 & 4759 & 4919 & 4393 & 5578 & $23.6 \%$ \\
\hline E320-E300 & 8144 & 22412 & 22368 & 7032 & 7402 & 7848 & 7032 & 22412 & $122.7 \%$ \\
\hline E330-E300 & 11318 & 12227 & 33117 & 10712 & 11476 & 10343 & 10343 & 33117 & $153.2 \%$ \\
\hline E330-E320 & 3174 & -10185 & 10749 & 3680 & 4074 & 2495 & -10185 & 10749 & $898.0 \%$ \\
\hline E340-E300 & 9478 & 19418 & 28094 & 8595 & 8864 & 9060 & 8595 & 28094 & $140.1 \%$ \\
\hline E330-E340 & 1840 & -7191 & 5023 & 2117 & 2612 & 1283 & -7191 & 5023 & $1289.3 \%$ \\
\hline E350-E300 & -82 & 0 & -1 & 0 & 0 & 5 & -82 & 5 & $-669.0 \%$ \\
\hline E360-E300 & 6683 & 9212 & 9564 & 5726 & 5820 & 6379 & 5726 & 9564 & $53.1 \%$ \\
\hline E400-E300 & 9005 & 9142 & 18383 & 7995 & & 8702 & 7995 & 18383 & $97.6 \%$ \\
\hline E410-E300 & -82 & 0 & 0 & & & 1 & -82 & 1 & $-409.8 \%$ \\
\hline E420-E300 & 0 & 0 & 0 & 0 & & 0 & 0 & 0 & \#DIV/0! \\
\hline E430-E300 & 0 & 0 & 0 & 0 & & 0 & 0 & 0 & $-500.0 \%$ \\
\hline E440-E300 & 0 & 0 & 0 & 0 & & -295 & -295 & 0 & $-500.0 \%$ \\
\hline E500-E300 & -4689 & -3694 & -3749 & -5087 & -5935 & -4517 & -5935 & -3694 & $-48.6 \%$ \\
\hline E510-E500 & 3108 & 3481 & 3482 & 3531 & 3381 & 3542 & 3108 & 3542 & $12.7 \%$ \\
\hline E525-E520 & 410 & -412 & -412 & -76 & 8 & -881 & -881 & 410 & $-568.4 \%$ \\
\hline E530-E500 & -7651 & -8131 & -8131 & -8008 & -7791 & -7929 & -8131 & -7651 & $-6.0 \%$ \\
\hline E545-E540 & 500 & -291 & -292 & -187 & -30 & -302 & -302 & 500 & $-800.3 \%$ \\
\hline \multicolumn{7}{|c|}{ Sensible Coil Load (Wh,th) } & \multicolumn{3}{|c|}{ Statistics, All Results } \\
\hline & TRNSYS & \multicolumn{2}{|c|}{ DOE-2.2 DOE21E-E } & Energy+ & CODYRUN & НОТ3000 & \multicolumn{3}{|r|}{ (Max-Min) } \\
\hline & TUD & NREL & NREL & GARD & UR & NRCan & Min & Max & /Mean \\
\hline E310-E300 & -183 & -123 & -86 & -254 & -379 & -259 & -379 & -86 & $-136.9 \%$ \\
\hline E320-E300 & 8038 & 7916 & 7867 & 8441 & 7677 & 8059 & 7677 & 8441 & $9.6 \%$ \\
\hline E330-E300 & 9949 & 10207 & 11285 & 11234 & 10540 & 10513 & 9949 & 11285 & $12.6 \%$ \\
\hline E330-E320 & 1911 & 2291 & 3418 & 2793 & 2863 & 2454 & 1911 & 3418 & $57.5 \%$ \\
\hline E340-E300 & 9552 & 8883 & 8881 & 9357 & 9483 & 9272 & 8881 & 9552 & $7.3 \%$ \\
\hline E330-E340 & 397 & 1324 & 2404 & 1877 & 1057 & 1241 & 397 & 2404 & $145.1 \%$ \\
\hline E350-E300 & 0 & 0 & 0 & 0 & 0 & -32 & -32 & 0 & $-603.8 \%$ \\
\hline E360-E300 & 8783 & 8908 & 8860 & 9090 & 8524 & 9271 & 8524 & 9271 & $8.4 \%$ \\
\hline E400-E300 & 0 & 0 & 0 & 0 & & -31 & -31 & 0 & $-503.2 \%$ \\
\hline E410-E300 & -12 & 0 & 0 & & & -15 & -15 & 0 & $-224.7 \%$ \\
\hline E420-E300 & 0 & 0 & 0 & 0 & & -15 & -15 & 0 & $-500.0 \%$ \\
\hline E430-E300 & 0 & 0 & 0 & 0 & & -15 & -15 & 0 & $-500.0 \%$ \\
\hline E440-E300 & 0 & 0 & 0 & 0 & & -33 & -33 & 0 & $-500.0 \%$ \\
\hline E500-E300 & -3728 & -3194 & -3197 & -3682 & -4681 & -3090 & -4681 & -3090 & $-44.3 \%$ \\
\hline E510-E500 & 2180 & 2504 & 2505 & 2441 & 2345 & 2451 & 2180 & 2505 & $13.5 \%$ \\
\hline E525-E520 & 287 & -309 & -304 & -336 & -210 & -717 & -717 & 287 & $-379.1 \%$ \\
\hline E530-E500 & 285 & -433 & -433 & -211 & 0 & -192 & -433 & 285 & $-437.9 \%$ \\
\hline E545-E540 & 500 & -291 & -292 & -187 & -35 & -302 & -302 & 500 & $-793.7 \%$ \\
\hline \multicolumn{7}{|c|}{ | Latent Coil Load (Wh,th) } & \multicolumn{3}{|c|}{ Statistics, All Results } \\
\hline & TRNSYS & \multicolumn{2}{|c|}{ DOE-2.2 DOE21E-E } & Energy+ & CODYRUN & НОТ3000 & \multicolumn{3}{|r|}{ (Max-Min) } \\
\hline & TUD & NREL & NREL & GARD & UR & NRCan & Min & Max & /Mean \\
\hline E310-E300 & 6271 & 5835 & 5876 & 6040 & 5737 & 5685 & 5685 & 6271 & $9.9 \%$ \\
\hline E320-E300 & 13512 & 22193 & 22109 & 11961 & 11322 & 11537 & 11322 & 22193 & $70.4 \%$ \\
\hline E330-E300 & 18190 & 17637 & 31415 & 16899 & 17809 & 17096 & 16899 & 31415 & $73.2 \%$ \\
\hline E330-E320 & 4678 & -4556 & 9306 & 4939 & 6487 & 5559 & -4556 & 9306 & $314.9 \%$ \\
\hline E340-E300 & 15213 & 21147 & 26617 & 13676 & 13850 & 13402 & 13402 & 26617 & $76.3 \%$ \\
\hline E330-E340 & 2977 & -3510 & 4798 & 3223 & 3959 & 3694 & -3510 & 4798 & $329.2 \%$ \\
\hline E350-E300 & 116 & -1 & -1 & 1 & 380 & 1211 & -1 & 1211 & $426.5 \%$ \\
\hline E360-E300 & -361 & 722 & 942 & -1715 & -1516 & -1458 & -1715 & 942 & $-470.9 \%$ \\
\hline E400-E300 & 17440 & 16274 & 23002 & 16082 & & 16253 & 16082 & 23002 & $38.9 \%$ \\
\hline E410-E300 & 1503 & 0 & -3 & & & -15 & -15 & 1503 & $408.9 \%$ \\
\hline E420-E300 & 115 & 0 & 0 & 0 & & 2 & 0 & 115 & $491.5 \%$ \\
\hline E430-E300 & 0 & 1801 & 1707 & 839 & & 2 & 0 & 1801 & $207.1 \%$ \\
\hline E440-E300 & 0 & 0 & -3 & 0 & & -253 & -253 & 0 & $-494.1 \%$ \\
\hline E500-E300 & -1670 & -1571 & -1661 & -2396 & -2570 & -2630 & -2630 & -1571 & $-50.8 \%$ \\
\hline E510-E500 & 927 & 990 & 990 & 1116 & 1045 & 1112 & 927 & 1116 & $18.3 \%$ \\
\hline E525-E520 & 123 & -122 & -122 & 249 & 212 & -144 & -144 & 249 & $1201.2 \%$ \\
\hline E530-E500 & -7965 & -7733 & -7733 & -7838 & -7626 & -7726 & -7965 & -7626 & $-4.4 \%$ \\
\hline E545-E540 & -627 & 0 & 0 & -1655 & -841 & -1181 & -1655 & 0 & $-230.7 \%$ \\
\hline
\end{tabular}


Delta Hourly Integrated Maximum and Minimum COP2

\begin{tabular}{|c|c|c|c|c|c|c|c|c|c|}
\hline \multicolumn{7}{|c|}{\begin{tabular}{|l|} 
Maximum COP2 \\
\end{tabular}} & \multirow{2}{*}{\multicolumn{3}{|c|}{$\begin{array}{l}\text { Statistics, All Results } \\
\text { (Max-Min) }\end{array}$}} \\
\hline & TRNSYS & \multicolumn{2}{|c|}{ DOE-2.2 DOE21E-E } & \multirow{2}{*}{$\begin{array}{r}\text { Energy+ } \\
\text { GARD }\end{array}$} & \multirow{2}{*}{$\begin{array}{r}\text { CODYRUN } \\
\text { UR }\end{array}$} & \multirow{2}{*}{$\begin{array}{r}\text { HOT3000 } \\
\text { NRCan }\end{array}$} & & & \\
\hline & TUD & NREL & NREL & & & & Min & Max & /Mean \\
\hline E310-E300 & -0.025 & 0.272 & 0.271 & 0.248 & 0.257 & 0.240 & -0.025 & 0.272 & $141.1 \%$ \\
\hline |E320-E300 & 0.000 & 1.274 & 1.110 & 0.014 & 0.073 & 0.500 & 0.000 & 1.274 & $257.3 \%$ \\
\hline |E330-E300 & 0.000 & 0.240 & 1.738 & 0.146 & 0.251 & 0.170 & 0.000 & 1.738 & $409.6 \%$ \\
\hline |E330-E320 & 0.000 & -1.034 & 0.628 & 0.132 & 0.179 & -0.330 & -1.034 & 0.628 & $-2344.2 \%$ \\
\hline |E340-E300 & 0.000 & 0.752 & 1.482 & 0.061 & 0.147 & 0.070 & 0.000 & 1.482 & $354.0 \%$ \\
\hline |E330-E340 & 0.000 & -0.512 & 0.256 & 0.085 & 0.105 & 0.100 & -0.512 & 0.256 & $13685.7 \%$ \\
\hline |E350-E300 & 0.000 & 0.020 & 0.006 & 0.630 & 0.061 & 0.000 & 0.000 & 0.630 & $526.8 \%$ \\
\hline |E360-E300 & 0.233 & 0.559 & 0.570 & 0.530 & 0.561 & 0.560 & 0.233 & 0.570 & $67.2 \%$ \\
\hline |E400-E300 & -0.091 & 0.219 & 0.919 & 0.146 & & 0.170 & -0.091 & 0.919 & $370.7 \%$ \\
\hline E410-E300 & -0.280 & 0.034 & -0.002 & & & -0.040 & -0.280 & 0.034 & $-436.1 \%$ \\
\hline |E420-E300 & -0.387 & -0.062 & -0.098 & -0.104 & & 0.060 & -0.387 & 0.060 & $-378.3 \%$ \\
\hline E430-E300 & -0.387 & -0.064 & -0.098 & -0.133 & & 0.050 & -0.387 & 0.050 & $-346.0 \%$ \\
\hline |E440-E300 & -0.285 & -0.095 & -0.098 & -0.123 & & -0.070 & -0.285 & -0.070 & $-160.0 \%$ \\
\hline |E500-E300 & 0.107 & 3.498 & 1.444 & 0.273 & 0.314 & 0.260 & 0.107 & 3.498 & $345.1 \%$ \\
\hline |E510-E500 & 0.417 & 0.000 & 0.000 & 0.487 & 0.505 & 0.390 & 0.000 & 0.505 & $168.4 \%$ \\
\hline |E525-E520 & 0.904 & 1.429 & 1.379 & 0.766 & 0.836 & 0.560 & 0.560 & 1.429 & $88.8 \%$ \\
\hline |E530-E500 & -0.269 & -3.386 & -1.451 & -0.273 & -0.345 & -0.260 & -3.386 & -0.260 & $-313.5 \%$ \\
\hline E545-E540 & 0.794 & 0.819 & 0.973 & 0.470 & 0.490 & 0.480 & 0.470 & 0.973 & $74.9 \%$ \\
\hline \multirow{2}{*}{\multicolumn{4}{|c|}{ Minimum COP2 }} & & & & \multicolumn{3}{|c|}{ "Statistics, All Results } \\
\hline & TRNSYS & & & Energy+ & CODYRUN & НОТ3000 & & & (Max-Min) \\
\hline & TUD & NREL & NREL & GARD & UR & NRCan & Min & Max & /Mean \\
\hline E310-E300 & 0.072 & 0.052 & 0.050 & 0.111 & 0.087 & 0.060 & 0.050 & 0.111 & $84.8 \%$ \\
\hline |E320-E300 & 0.032 & 0.003 & 0.004 & 0.060 & 0.029 & 0.020 & 0.003 & 0.060 & $231.0 \%$ \\
\hline |E330-E300 & 0.032 & 0.000 & 0.000 & 0.063 & 0.038 & 0.030 & 0.000 & 0.063 & $231.1 \%$ \\
\hline |E330-E320 & 0.000 & -0.003 & -0.004 & 0.003 & 0.009 & 0.010 & -0.004 & 0.010 & $584.2 \%$ \\
\hline |E340-E300 & 0.032 & 0.000 & 0.000 & 0.063 & 0.038 & 0.030 & 0.000 & 0.063 & $231.1 \%$ \\
\hline |E330-E340 & 0.000 & 0.000 & 0.000 & 0.000 & 0.000 & 0.000 & 0.000 & 0.000 & \#DIV/0! \\
\hline |E350-E300 & -0.003 & 0.000 & 0.000 & 0.000 & 0.000 & 0.000 & -0.003 & 0.000 & $-742.2 \%$ \\
\hline |E360-E300 & 0.032 & 0.001 & 0.000 & 0.063 & 0.038 & 0.030 & 0.000 & 0.063 & $229.7 \%$ \\
\hline |E400-E300 & -0.011 & -0.064 & -0.066 & 0.000 & & 0.000 & -0.066 & 0.000 & $-233.8 \%$ \\
\hline |E410-E300 & -0.007 & 0.000 & 0.000 & & & 0.000 & -0.007 & 0.000 & $-400.0 \%$ \\
\hline |E420-E300 & 0.000 & 0.000 & 0.000 & 0.000 & & 0.000 & 0.000 & 0.000 & \#DIV/0! \\
\hline |E430-E300 & -0.022 & -0.064 & -0.066 & 0.000 & & 0.000 & -0.066 & 0.000 & $-217.2 \%$ \\
\hline |E440-E300 & -0.011 & -0.064 & -0.066 & 0.000 & & 0.000 & -0.066 & 0.000 & $-234.7 \%$ \\
\hline |E500-E300 & -0.108 & -0.105 & -0.149 & -0.076 & -0.119 & -0.100 & -0.149 & -0.076 & $-66.6 \%$ \\
\hline ||E510-E500 & 0.203 & 0.124 & 0.000 & 0.160 & 0.215 & 0.190 & 0.000 & 0.215 & $144.8 \%$ \\
\hline ||E525-E520 & 0.469 & 0.476 & 0.420 & 0.408 & 0.561 & 0.430 & 0.408 & 0.561 & $33.2 \%$ \\
\hline |E530-E500 & -0.184 & -0.198 & -0.154 & -0.173 & -0.193 & -0.190 & -0.198 & -0.154 & $-24.2 \%$ \\
\hline E545-E540 & 0.479 & 0.459 & 0.460 & 0.277 & 0.549 & 0.440 & 0.277 & 0.549 & $61.2 \%$ \\
\hline
\end{tabular}

e300results.xls t:a341..m384; 07/19/04 
Delta Hourly Integrated Maximum and Minimum IDB

\begin{tabular}{|c|c|c|c|c|c|c|c|c|c|}
\hline \multicolumn{7}{|c|}{ 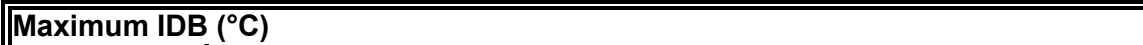 } & \multirow{2}{*}{\multicolumn{3}{|c|}{$\begin{array}{l}\text { Statistics, All Results } \\
\text { (Max-Min) }\end{array}$}} \\
\hline & TRNSYS & \multicolumn{2}{|c|}{ DOE-2.2 DOE21E-E } & \multirow{2}{*}{$\begin{array}{r}\text { Energy+ } \\
\text { GARD }\end{array}$} & \multirow{2}{*}{$\begin{array}{r}\text { CODYRUN } \\
\text { UR }\end{array}$} & \multirow{2}{*}{$\begin{array}{r}\text { HOT3000 } \\
\text { NRCan }\end{array}$} & & & \\
\hline & TUD & NREL & NREL & & & & Min & Max & /Mean \\
\hline E310-E300 & 0.88 & 1.78 & 1.61 & 1.47 & 1.57 & 1.00 & 0.88 & 1.78 & $65.1 \%$ \\
\hline E320-E300 & 6.16 & 6.50 & 6.39 & 6.71 & 7.27 & 5.46 & 5.46 & 7.27 & $28.2 \%$ \\
\hline |E330-E300 & 6.03 & 6.61 & 6.89 & 6.07 & 6.85 & 5.11 & 5.11 & 6.89 & $28.4 \%$ \\
\hline |E330-E320 & -0.13 & 0.11 & 0.50 & -0.64 & -0.42 & -0.35 & -0.64 & 0.50 & $-736.8 \%$ \\
\hline |E340-E300 & 6.11 & 6.50 & 6.45 & 6.50 & 7.10 & 5.39 & 5.39 & 7.10 & $27.0 \%$ \\
\hline E330-E340 & -0.07 & 0.11 & 0.44 & -0.43 & -0.25 & -0.28 & -0.43 & 0.44 & $-1078.3 \%$ \\
\hline |E350-E300 & 8.38 & 9.83 & 9.83 & 10.00 & 9.95 & 8.81 & 8.38 & 10.00 & $17.1 \%$ \\
\hline E360-E300 & 7.56 & 7.67 & 7.45 & 7.51 & 7.95 & 6.94 & 6.94 & 7.95 & $13.4 \%$ \\
\hline E400-E300 & 0.91 & 2.45 & 3.72 & 1.91 & & -0.15 & -0.15 & 3.72 & $218.8 \%$ \\
\hline E410-E300 & 0.63 & 0.00 & 0.00 & & & 0.00 & 0.00 & 0.63 & $400.0 \%$ \\
\hline |E420-E300 & 0.00 & 0.00 & 0.00 & 0.00 & & 0.04 & 0.00 & 0.04 & $500.0 \%$ \\
\hline E430-E300 & 1.00 & 0.00 & 0.00 & 0.00 & & 0.26 & 0.00 & 1.00 & $396.6 \%$ \\
\hline |E440-E300 & 0.85 & 0.00 & 0.00 & 0.00 & & 0.07 & 0.00 & 0.85 & $461.5 \%$ \\
\hline E500-E300 & -0.39 & 0.00 & 0.00 & 0.00 & -0.03 & -1.19 & -1.19 & 0.00 & $-441.5 \%$ \\
\hline |E510-E500 & 0.29 & 0.00 & 0.00 & 0.00 & 0.00 & 0.00 & 0.00 & 0.29 & $600.0 \%$ \\
\hline |E525-E520 & 19.96 & 18.95 & 19.12 & 20.00 & 19.02 & 16.38 & 16.38 & 20.00 & $19.1 \%$ \\
\hline E530-E500 & 0.31 & -0.05 & -0.05 & 0.00 & 0.00 & 0.00 & -0.05 & 0.31 & $1025.2 \%$ \\
\hline E545-E540 & 19.53 & 19.89 & 19.89 & 20.00 & 19.95 & 20.00 & 19.53 & 20.00 & $2.4 \%$ \\
\hline \multicolumn{4}{|c|}{ Minimum IDB $\left({ }^{\circ} \mathrm{C}\right)$} & & & & \multicolumn{3}{|c|}{ Statistics, All Results } \\
\hline & TRNSYS & \multicolumn{2}{|c|}{ DOE-2.2 DOE21E-E } & Energy+ & CODYRUN & НОТ3000 & \multicolumn{3}{|c|}{ (Max-Min) } \\
\hline & TUD & NREL & NREL & GARD & UR & NRCan & Min & Max & /Mean \\
\hline E310-E300 & 0.00 & 0.00 & 0.00 & 0.00 & 0.00 & 0.00 & 0.00 & 0.00 & $-600.0 \%$ \\
\hline |E320-E300 & 0.00 & 1.94 & 1.95 & -0.96 & 0.00 & 0.00 & -0.96 & 1.95 & $597.5 \%$ \\
\hline E330-E300 & 0.00 & 0.00 & 0.00 & 0.00 & 0.00 & 0.00 & 0.00 & 0.00 & $-600.0 \%$ \\
\hline |E330-E320 & 0.00 & -1.94 & -1.95 & 0.96 & 0.00 & 0.00 & -1.95 & 0.96 & $-596.8 \%$ \\
\hline |E340-E300 & 0.00 & 0.00 & 0.00 & 0.00 & 0.00 & 0.00 & 0.00 & 0.00 & $-600.0 \%$ \\
\hline |E330-E340 & 0.00 & 0.00 & 0.00 & 0.00 & 0.00 & 0.00 & 0.00 & 0.00 & \#DIV/O! \\
\hline |E350-E300 & 0.00 & 0.00 & 0.00 & 0.00 & 0.00 & 0.00 & 0.00 & 0.00 & \#DIV/O! \\
\hline |E360-E300 & 0.00 & 0.00 & 0.00 & 0.00 & 0.00 & 0.00 & 0.00 & 0.00 & $600.0 \%$ \\
\hline E400-E300 & 0.00 & 0.00 & 0.00 & 0.00 & & 0.00 & 0.00 & 0.00 & $-500.0 \%$ \\
\hline |E410-E300 & 0.00 & 0.00 & 0.00 & & & 0.00 & 0.00 & 0.00 & \#DIV/O! \\
\hline |E420-E300 & 0.00 & 0.00 & 0.00 & 0.00 & & 0.00 & 0.00 & 0.00 & $-500.0 \%$ \\
\hline E430-E300 & 0.00 & 0.00 & 0.00 & 0.00 & & 0.00 & 0.00 & 0.00 & $-500.0 \%$ \\
\hline E440-E300 & 0.00 & 0.00 & 0.00 & 0.00 & & 0.01 & 0.00 & 0.01 & $500.0 \%$ \\
\hline |E500-E300 & 0.50 & -0.72 & -0.89 & 0.22 & 0.54 & 17.05 & -0.89 & 17.05 & $644.6 \%$ \\
\hline |E510-E500 & 0.00 & 0.00 & 0.00 & 0.00 & 0.00 & 0.00 & 0.00 & 0.00 & $600.0 \%$ \\
\hline |E525-E520 & 0.14 & 0.06 & 0.05 & 0.18 & 0.03 & 19.44 & 0.03 & 19.44 & $585.3 \%$ \\
\hline E530-E500 & -0.01 & 0.00 & 0.00 & 0.00 & 0.00 & 0.00 & -0.01 & 0.00 & $-533.6 \%$ \\
\hline E545-E540 & 0.22 & 0.06 & 0.05 & 0.18 & 0.03 & 18.06 & 0.03 & 18.06 & $581.6 \%$ \\
\hline
\end{tabular}

e300results.xls t:a386..m429; 07/19/04 
Delta Hourly Integrated Maximum and Minimum Zone Humidity Ratio

\begin{tabular}{|c|c|c|c|c|c|c|c|c|c|}
\hline \multicolumn{7}{|c|}{$\mid$\begin{tabular}{|l} 
Maximum Humidity Ratio (kg/kg) \\
\end{tabular}} & \multirow{2}{*}{\multicolumn{3}{|c|}{$\begin{array}{l}\text { Statistics, All Results } \\
\text { (Max-Min) }\end{array}$}} \\
\hline & \multirow{2}{*}{$\begin{array}{r}\text { TRNSYS } \\
\text { TUD }\end{array}$} & \multicolumn{2}{|c|}{ DOE-2.2 DOE21E-E } & \multirow{2}{*}{$\begin{array}{r}\text { Energy+ } \\
\text { GARD }\end{array}$} & \multirow{2}{*}{$\begin{array}{r}\text { CODYRUN } \\
\text { UR }\end{array}$} & \multirow{2}{*}{$\begin{array}{r}\text { HOT3000 } \\
\text { NRCan }\end{array}$} & & & \\
\hline & & NREL & NREL & & & & Min & Max & /Mean \\
\hline E310-E300 & 0.0025 & 0.0050 & 0.0052 & 0.0020 & 0.0020 & 0.0023 & 0.0020 & 0.0052 & $102.1 \%$ \\
\hline E320-E300 & 0.0047 & 0.0039 & 0.0039 & 0.0042 & 0.0041 & 0.0043 & 0.0039 & 0.0047 & $19.9 \%$ \\
\hline E330-E300 & 0.0044 & 0.0040 & 0.0040 & 0.0043 & 0.0036 & 0.0043 & 0.0036 & 0.0044 & $19.0 \%$ \\
\hline E330-E320 & -0.0004 & 0.0001 & 0.0001 & 0.0001 & -0.0005 & 0.0000 & -0.0005 & 0.0001 & $-696.5 \%$ \\
\hline E340-E300 & 0.0046 & 0.0039 & 0.0037 & 0.0042 & 0.0038 & 0.0043 & 0.0037 & 0.0046 & $21.8 \%$ \\
\hline E330-E340 & -0.0002 & 0.0001 & 0.0003 & 0.0001 & -0.0002 & 0.0000 & -0.0002 & 0.0003 & $3174.2 \%$ \\
\hline E350-E300 & 0.0035 & 0.0061 & 0.0062 & 0.0036 & 0.0030 & 0.0032 & 0.0030 & 0.0062 & $74.6 \%$ \\
\hline E360-E300 & 0.0001 & 0.0000 & 0.0000 & 0.0002 & 0.0000 & 0.0000 & 0.0000 & 0.0002 & $366.5 \%$ \\
\hline E400-E300 & 0.0037 & 0.0032 & 0.0033 & 0.0033 & & 0.0039 & 0.0032 & 0.0039 & $20.2 \%$ \\
\hline E410-E300 & 0.0036 & 0.0031 & 0.0032 & & & 0.0039 & 0.0031 & 0.0039 & $23.3 \%$ \\
\hline E420-E300 & 0.0010 & 0.0009 & 0.0004 & 0.0010 & & 0.0013 & 0.0004 & 0.0013 & $98.3 \%$ \\
\hline E430-E300 & 0.0029 & 0.0018 & 0.0019 & 0.0025 & & 0.0024 & 0.0018 & 0.0029 & $49.6 \%$ \\
\hline E440-E300 & 0.0000 & 0.0000 & 0.0000 & 0.0000 & & 0.0000 & 0.0000 & 0.0000 & $500.0 \%$ \\
\hline E500-E300 & -0.0016 & -0.0019 & -0.0019 & -0.0019 & -0.0017 & -0.0019 & -0.0019 & -0.0016 & $-20.6 \%$ \\
\hline E510-E500 & 0.0002 & 0.0000 & 0.0001 & 0.0000 & 0.0000 & 0.0000 & 0.0000 & 0.0002 & $352.6 \%$ \\
\hline E525-E520 & 0.0104 & 0.0103 & 0.0102 & 0.0115 & 0.0101 & 0.0067 & 0.0067 & 0.0115 & $48.3 \%$ \\
\hline E530-E500 & -0.0047 & -0.0038 & -0.0037 & -0.0049 & -0.0062 & -0.0047 & -0.0062 & -0.0037 & $-53.9 \%$ \\
\hline E545-E540 & 0.0009 & 0.0072 & 0.0059 & 0.0000 & 0.0034 & 0.0013 & 0.0000 & 0.0072 & $230.7 \%$ \\
\hline \multicolumn{7}{|c|}{ Minimum Humidity Ratio (kg/kg) } & \multicolumn{3}{|c|}{ Statistics, All Results } \\
\hline & TRNSYS & \multicolumn{2}{|c|}{ DOE-2.2 DOE21E-E } & Energy+ & CODYRUN & \multirow{2}{*}{$\begin{array}{r}\text { HOT3000 } \\
\text { NRCan } \\
\end{array}$} & \multirow{2}{*}{\multicolumn{3}{|c|}{$\begin{array}{rr} & (\text { Max-Min }) \\
\text { ax } & / \text { Mean }\end{array}$}} \\
\hline & TUD & NREL & NREL & GARD & UR & & & & \\
\hline E310-E300 & 0.0000 & 0.0000 & 0.0000 & 0.0000 & 0.0001 & 0.0000 & 0.0000 & 0.0001 & $646.4 \%$ \\
\hline E320-E300 & 0.0000 & 0.0000 & 0.0000 & 0.0000 & 0.0000 & 0.0000 & 0.0000 & 0.0000 & $600.0 \%$ \\
\hline E330-E300 & 0.0000 & 0.0000 & 0.0000 & 0.0000 & 0.0000 & 0.0000 & 0.0000 & 0.0000 & $-600.0 \%$ \\
\hline E330-E320 & 0.0000 & 0.0000 & 0.0000 & 0.0000 & 0.0000 & 0.0000 & 0.0000 & 0.0000 & $-600.0 \%$ \\
\hline E340-E300 & 0.0000 & 0.0000 & 0.0000 & 0.0000 & 0.0000 & 0.0000 & 0.0000 & 0.0000 & $-600.0 \%$ \\
\hline E330-E340 & 0.0000 & 0.0000 & 0.0000 & 0.0000 & 0.0000 & 0.0000 & 0.0000 & 0.0000 & \#DIV/0! \\
\hline E350-E300 & 0.0000 & 0.0000 & 0.0000 & 0.0000 & 0.0000 & 0.0000 & 0.0000 & 0.0000 & \#DIV/0! \\
\hline E360-E300 & 0.0000 & 0.0000 & 0.0000 & 0.0000 & 0.0000 & 0.0000 & 0.0000 & 0.0000 & $-600.0 \%$ \\
\hline E400-E300 & 0.0000 & 0.0000 & 0.0000 & 0.0000 & & 0.0000 & 0.0000 & 0.0000 & $500.0 \%$ \\
\hline E410-E300 & 0.0000 & 0.0000 & 0.0000 & & & 0.0000 & 0.0000 & 0.0000 & \#DIV/0! \\
\hline E420-E300 & 0.0000 & 0.0000 & 0.0000 & 0.0000 & & 0.0000 & 0.0000 & 0.0000 & $-500.0 \%$ \\
\hline E430-E300 & 0.0000 & 0.0000 & 0.0000 & 0.0000 & & 0.0000 & 0.0000 & 0.0000 & $500.0 \%$ \\
\hline E440-E300 & 0.0000 & 0.0000 & 0.0000 & 0.0000 & & 0.0000 & 0.0000 & 0.0000 & $-500.0 \%$ \\
\hline E500-E300 & 0.0050 & & & 0.0051 & 0.0049 & 0.0083 & 0.0049 & 0.0083 & $58.2 \%$ \\
\hline E510-E500 & 0.0000 & & & 0.0000 & 0.0000 & 0.0002 & 0.0000 & 0.0002 & $400.0 \%$ \\
\hline E525-E520 & 0.0007 & & & 0.0005 & 0.0004 & 0.0088 & 0.0004 & 0.0088 & $322.8 \%$ \\
\hline E530-E500 & -0.0006 & & & -0.0003 & -0.0015 & -0.0037 & -0.0037 & -0.0003 & $-226.1 \%$ \\
\hline E545-E540 & 0.0021 & & & 0.0030 & 0.0034 & 0.0028 & 0.0021 & 0.0034 & $47.3 \%$ \\
\hline
\end{tabular}

e300results.xls t:a431..m474; 07/19/04 
Delta Hourly Integrated Maximum and Minimum Zone Relative Humidity

\begin{tabular}{|c|c|c|c|c|c|c|c|c|c|}
\hline \multicolumn{7}{|c|}{\begin{tabular}{||l} 
Maximum Relative Humidity (\%) \\
\end{tabular}} & \multirow{2}{*}{\multicolumn{3}{|c|}{$\begin{array}{l}\text { Statistics, All Results } \\
\text { (Max-Min) }\end{array}$}} \\
\hline & TRNSYS & \multicolumn{2}{|c|}{ DOE-2.2 DOE21E-E } & Energy+ & CODYRUN & НОT3000 & & & \\
\hline & TUD & NREL & NREL & GARD & UR & NRCan & Min & Max & /Mean \\
\hline E310-E300 & 8.91 & 30.83 & 31.85 & 10.28 & 9.00 & 10.75 & 8.91 & 31.85 & $135.4 \%$ \\
\hline |E320-E300 & 13.05 & 14.06 & 14.82 & 14.60 & 15.00 & 14.44 & 13.05 & 15.00 & $13.6 \%$ \\
\hline |E330-E300 & 7.87 & 9.11 & 9.09 & 8.51 & 8.00 & 11.26 & 7.87 & 11.26 & $37.8 \%$ \\
\hline |E330-E320 & -5.18 & -4.95 & -5.73 & -6.09 & -7.00 & -3.18 & -7 & -3 & $-71.3 \%$ \\
\hline |E340-E300 & 11.14 & 12.02 & 12.41 & 12.43 & 12.00 & 12.81 & 11 & 13 & $13.8 \%$ \\
\hline |E330-E340 & -3.27 & -2.91 & -3.32 & -3.92 & -4.00 & -1.55 & -4 & -2 & $-77.5 \%$ \\
\hline |E350-E300 & 0.00 & 11.77 & 12.27 & 0.00 & 2.00 & 5.21 & 0.00 & 12.27 & $235.6 \%$ \\
\hline |E360-E300 & 0.00 & 0.00 & 0.00 & 0.00 & 0.00 & 0.00 & 0.00 & 0.00 & $-600.0 \%$ \\
\hline E400-E300 & 14.96 & 16.22 & 16.72 & 16.27 & & 18.87 & 14.96 & 18.87 & $23.5 \%$ \\
\hline |E410-E300 & 14.44 & 15.44 & 15.94 & & & 18.74 & 14.44 & 18.74 & $26.7 \%$ \\
\hline |E420-E300 & 2.05 & 5.16 & 2.68 & 4.92 & & 6.41 & 2.05 & 6.41 & $102.7 \%$ \\
\hline E430-E300 & 11.92 & 9.08 & 9.58 & 12.38 & & 11.50 & 9.08 & 12.38 & $30.3 \%$ \\
\hline E440-E300 & -0.06 & 0.00 & 0.00 & 0.00 & & 0.07 & -0.06 & 0.07 & $13500.0 \%$ \\
\hline |E500-E300 & 31.21 & & & 31.63 & 32.00 & -7.36 & -7.36 & 32.00 & $180.0 \%$ \\
\hline |E510-E500 & 0.00 & & & 0.00 & 0.00 & -2.57 & -2.57 & 0.00 & $-400.0 \%$ \\
\hline |E525-E520 & 9.77 & & & 6.19 & 5.00 & -20.65 & -20.65 & 9.77 & $39706.5 \%$ \\
\hline |E530-E500 & -8.96 & & & -3.84 & -21.00 & -24.07 & -24.07 & -3.84 & $-139.8 \%$ \\
\hline E545-E540 & 29.60 & & & 41.06 & 50.00 & -15.82 & -15.82 & 50.00 & $251.1 \%$ \\
\hline \multicolumn{7}{|c|}{ Minimum Relative Humidity (\%) } & \multicolumn{3}{|c|}{ Statistics, All Results } \\
\hline & TRNSYS & \multicolumn{2}{|c|}{ DOE-2.2 DOE21E-E } & Energy+ & CODYRUN & НОТ3000 & \multicolumn{3}{|r|}{ (Max-Min) } \\
\hline & TUD & NREL & NREL & GARD & UR & NRCan & Min & Max & /Mean \\
\hline E310-E300 & 0.06 & 0.00 & 0.00 & 1.10 & 1.00 & 0.99 & 0.00 & 1.10 & $209.6 \%$ \\
\hline |E320-E300 & 0.00 & 0.00 & 0.00 & 0.24 & 0.00 & -2.02 & -2.02 & 0.24 & $-761.2 \%$ \\
\hline E330-E300 & 0.00 & 0.00 & 0.00 & 0.00 & 0.00 & 0.00 & 0.00 & 0.00 & $600.0 \%$ \\
\hline |E330-E320 & 0.00 & 0.00 & 0.00 & -0.24 & 0.00 & 2.02 & -0.24 & 2.02 & $761.1 \%$ \\
\hline |E340-E300 & 0.00 & 0.00 & 0.00 & 0.00 & 0.00 & 0.00 & 0.00 & 0.00 & $600.0 \%$ \\
\hline |E330-E340 & 0.00 & 0.00 & 0.00 & 0.00 & 0.00 & 0.00 & 0.00 & 0.00 & \#DIV/0! \\
\hline |E350-E300 & 0.00 & 0.00 & 0.00 & 0.00 & 0.00 & 0.00 & 0.00 & 0.00 & \#DIV/0! \\
\hline |E360-E300 & 0.00 & 0.00 & 0.00 & 0.00 & 0.00 & 0.00 & 0.00 & 0.00 & $-600.0 \%$ \\
\hline E400-E300 & -0.12 & 0.00 & 0.00 & -0.48 & & -0.37 & -0.48 & 0.00 & $-246.0 \%$ \\
\hline |E410-E300 & -0.12 & 0.00 & 0.00 & & & -0.36 & -0.36 & 0.00 & $-298.7 \%$ \\
\hline E420-E300 & -0.12 & 0.00 & 0.00 & -0.48 & & -0.35 & -0.48 & 0.00 & $-251.4 \%$ \\
\hline |E430-E300 & -0.12 & 0.00 & 0.00 & -0.48 & & -0.36 & -0.48 & 0.00 & $-248.3 \%$ \\
\hline E440-E300 & -0.12 & 0.00 & 0.00 & -0.48 & & -0.40 & -0.48 & 0.00 & $-238.1 \%$ \\
\hline |E500-E300 & 40.07 & & & 40.76 & 39.00 & 37.89 & 37.89 & 40.76 & $7.3 \%$ \\
\hline |E510-E500 & -1.32 & & & 0.12 & 0.00 & 0.32 & -1.32 & 0.32 & $-747.8 \%$ \\
\hline |E525-E520 & -15.74 & & & -13.87 & -17.00 & -17.50 & -17.50 & -13.87 & $-22.6 \%$ \\
\hline |E530-E500 & -23.81 & & & -21.14 & -26.00 & -19.15 & -26.00 & -19.15 & $-30.4 \%$ \\
\hline |E545-E540 & -19.35 & & & -16.77 & -12.00 & -19.60 & -19.60 & -12.00 & $-44.9 \%$ \\
\hline
\end{tabular}

e300results.xls t:a476..m519; 07/19/04 


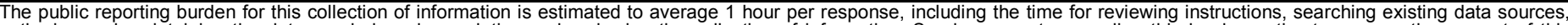

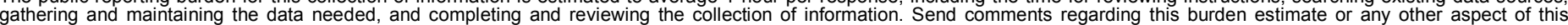

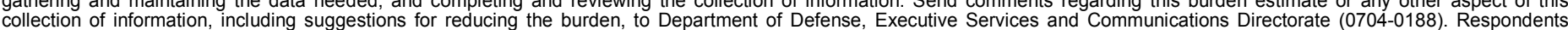

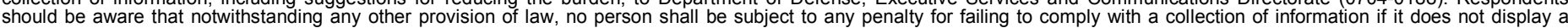

should be awa that notwithstanding

PLEASE DO NOT RETURN YOUR FORM TO THE ABOVE ORGANIZATION.

\begin{tabular}{l|l|l|} 
1. REPORT DATE $(D D-M M-Y Y Y Y)$ & 2. REPORT TYPE & 3. DATES COVERED (FrOm - TO)
\end{tabular}

December 2004

4. TITLE AND SUBTITLE

International Energy Agency Building Energy Simulation Test and

Diagnostic Method for Heating, Ventilating, and Air-Conditioning

Equipment Models (HVAC BESTEST). Volume 2. Cases E300-

E545.

6. AUTHOR(S)

Joel Neymark and Ron Judkoff 5a. CONTRACT NUMBER

DE-AC36-99-GO10337

5b. GRANT NUMBER

5c. PROGRAM ELEMENT NUMBER

5d. PROJECT NUMBER

NREL/TP-550-36754

5e. TASK NUMBER

5500.5000

5f. WORK UNIT NUMBER
7. PERFORMING ORGANIZATION NAME(S) AND ADDRESS(ES)

National Renewable Energy Laboratory

1617 Cole Blvd.

Golden, CO 80401-3393
8. PERFORMING ORGANIZATION REPORT NUMBER

NREL/TP-550-36754

9. SPONSORING/MONITORING AGENCY NAME(S) AND ADDRESS(ES)

10. SPONSOR/MONITOR'S ACRONYM(S) NREL

11. SPONSORING/MONITORING AGENCY REPORT NUMBER

12. DISTRIBUTION AVAILABILITY STATEMENT

National Technical Information Service

U.S. Department of Commerce

5285 Port Royal Road

Springfield, VA 22161

13. SUPPLEMENTARY NOTES

14. ABSTRACT (Maximum 200 Words)

This report documents an additional set of mechanical system test cases that are planned for inclusion in

ANSI/ASHRAE STANDARD 140. The cases test a program's modeling capabilities on the working-fluid side of the coil, but in an hourly dynamic context over an expanded range of performance conditions. These cases help to scale the significance of disagreements that are less obvious in the steady-state cases. The report is Vol. 2 of HVAC BESTEST Volume 1. Volume 1 was limited to steady-state test cases that could be solved with analytical solutions. Volume 2 includes hourly dynamic effects, and other cases that cannot be solved analytically. NREL conducted this work in collaboration with the Tool Evaluation and Improvement Experts Group under the International Energy Agency (IEA) Solar Heating and Cooling Programme Task 22.

15. SUBJECT TERMS

Heating, Ventilating, and Air-Conditioning equipment models; HVAC; BESTEST; IEA; Building Energy Simulation; testing and diagnostics.

\begin{tabular}{|c|c|c|}
\hline 16. SECURITY & CLASSIFICATI & N OF: \\
\hline $\begin{array}{l}\text { a. REPORT } \\
\text { Unclassified }\end{array}$ & $\begin{array}{l}\text { b. ABSTRACT } \\
\text { Unclassified }\end{array}$ & $\begin{array}{l}\text { c. THIS PAGE } \\
\text { Unclassified }\end{array}$ \\
\hline
\end{tabular}

\begin{tabular}{|c|c|}
\hline $\begin{array}{l}\text { 17. LIMITATION } \\
\text { OF ABSTRACT }\end{array}$ & $\begin{array}{l}\text { 18. NUMBER } \\
\text { OF PAGES }\end{array}$ \\
\hline UL & \\
\hline
\end{tabular}

19a. NAME OF RESPONSIBLE PERSON

19b. TELEPHONE NUMBER (Include area code) 